Izaskun Elorza Amorós

\title{
ASPECTOS DE LA DIDÁCTICA DEL INGLÉS PARA FINES ESPECÍFICOS. LA TRADUCCIÓN ESPECIALIZADA COMO MÉTODO DE EVALUACIÓN FORMATIVA Y DE AUTOEVALUACIÓN
}

EDICIONES UNIVERSIDAD DE SALAMANCA 


\section{COLECCIÓN VÍTOR}

169

(C)

Ediciones Universidad de Salamanca

e Izaskun Elorza Amorós

$1^{a}$ edición: Noviembre, 2005

I.S.B.N.: 84-7800-506-4

Depósito Legal: S. 1361-2005

Ediciones Universidad de Salamanca

Plaza de San Benito, s/n

37002 Salamanca (España)

Página en Internet: http://webeus.usal.es

Correo-e: eus@usal.es

\section{Realización: Nemática S.L.}

Impreso en España - Printed in Spain

Todos los derechos reservados.

Ni la totalidad ni parte de este libro puede reproducirse ni transmitirse

sin permiso escrito de

Ediciones Universidad de Salamanca

CEP. Servicio de Bibliotecas 


\section{Resumen}

Este trabajo trata la utilidad de las actividades de traducción en la enseñanza y el aprendizaje del Inglés para Fines Específicos. Aunque podemos encontrar entre los especialistas de este campo posiciones enfrentadas con respecto de esta cuestión, la realidad es que no parece que ninguna esté sustentada en argumentos de tipo teórico. Por esta razón, la investigación realizada tiene un doble propósito. De un lado, se busca establecer un marco teórico comprehensivo capaz de apoyar los distintos argumentos sobre la utilidad didáctica de la traducción. De otro, se pretende aplicar este marco para investigar la funcionalidad didáctica de la traducción para alcanzar objetivos educacionales de tipo actitudinal cuando las actividades de traducción son utilizadas para la autoevaluación de la actuación y para la evaluación formativa.

Para conseguir el primer objetivo, se analizan en profundidad los marcos teóricos desarrollados por la lingüística aplicada, por los estudios de traducción y por la didáctica general. De este modo, y a partir de un enfoque interdisciplinar, se propone una taxonomía comprehensiva de las funciones didácticas de la traducción.

Seguidamente, dado que la viabilidad del uso didáctico de las actividades de traducción depende de las nociones utilizadas de enseñanza y aprendizaje de una lengua no materna, del grado de especificidad de los contenidos lingüísticos a impartir y de los modelos aplicados de lenguaje y de mediación intercultural, el primer paso para conseguir el segundo objetivo es dar cuenta detallada de todos estos aspectos. De este planteamiento derivan, entre otros, dos inconvenientes: la gran complejidad del análisis textual de las traducciones, debido al gran número de factores implicados, y la ausencia de un criterio normalizado que pueda aplicarse a la comparación entre los textos traducidos y sus correspondientes originales. Además de esto, la traducción es tratada en relación con su utilidad como herramienta de recogida de datos en la evaluación formativa, lo que revela que, cuando los objetivos educacionales evaluados son distintos de la competencia 
traductora, las traducciones sólo pueden proporcionar información de forma indirecta.

Para superar estas dificultades metodológicas, se ha diseñado un constructo pedagógico con una doble función. Consta de un cuestionario abierto de autoevaluación (llamado 'informe de la traducción') y de un recopilatorio abierto de variaciones de efecto que pueden ser identificadas entre el texto traducido y su correspondiente texto original (llamado 'repertorio de variaciones'). El informe de la traducción es una herramienta centrada en el aprendiz, cuyo propósito es informar de las reflexiones y estrategias utilizadas por éste al producir el texto traducido. Por medio de esta herramienta, el profesor y los aprendices pueden discutir y analizar no sólo las estrategias empleadas por ellos, sino también sus actitudes, opiniones y valores relacionados con los factores textuales y contextuales asociados típicamente con la comunicación en un campo específico. Por el contrario, el repertorio de variaciones es una herramienta centrada en el analista, cuyo propósito es poner en evidencia las discrepancias que éste detecta al comparar el texto traducido con el texto original. Esta herramienta permite al analista hacer explícito el criterio comparativo aplicado, facilitando por tanto al profesor y a los aprendices el establecimiento de un punto común de debate. Como el constructo ha sido utilizado de forma experimental, se aportan ejemplos reales de la información obtenida mediante esta herramienta.

Por lo que se refiere a la taxonomía de funciones didácticas de la traducción, se concluye que las actividades de traducción muestran una variada serie de funciones didácticas potenciales para el aprendizaje de lenguas. En relación con la funcionalidad teórica de la traducción para alcanzar objetivos educacionales de tipo actitudinal cuando las actividades de traducción son utilizadas para la autoevaluación y la evaluación formativa, se concluye que las actividades de traducción pueden facilitar la consecución de este propósito al menos en relación con los objetivos actitudinales de nivel más bajo, aunque es aún necesaria más investigación experimental. 


\begin{abstract}
This dissertation deals with the question of the use of translation activities in the learning of English for Specific Purposes. Attitudes for and against have been identified in the literature but no theoretical underpinning seems to support them. Therefore, the purpose of this research is twofold. Firstly, we seek to establish a comprehensive theoretical framework capable of supporting arguments for (or against) the pedagogic use of translation in learning domains. Secondly, we seek to apply this framework to examine the theoretical functionality of translation for fulfilling educational objectives of the attitudinal type when translation activities are used for performance self-assessment and for formative evaluation.

In order to achieve our first goal, the theoretical domains of applied linguistics, translation studies and general pedagogy are considered. Using this interdisciplinary approach a comprehensive taxonomy of pedagogic functions of translation is proposed.

After that, as the feasibility of using translation activities to learn is dependent upon the notions of teaching and learning a non-native language, on the degree of specificity of the linguistic contents to be taught and on the models of language and intercultural mediation applied, our first step to reach our second goal is to give a detailed account of all these issues. Among others, two drawbacks are inherent in this account, namely the great complexity of textual analysis of translations, due to the number of factors involved, and also the lack of a standardised comparative criterion to be applied between translations and their corresponding originals. In addition to this, translation is discussed in relation to its feasibility as an evaluating tool in formative evaluation. These considerations reveal that, when the educational objectives evaluated are different from translating competence, translations can only supply information in an indirect fashion.

In order to overcome these methodological difficulties, a construct has been designed as a pedagogic tool operating in two ways. It consists of an open
\end{abstract}


questionnaire for learners' performance self-assessment (termed the 'translation report') along with an open list of variations of effect which can be identified between a translated text and its corresponding original (termed the "variation index'). The translation report is a learner-centred tool, the purpose of which is to reveal information concerning the learners' strategies and reflections in relation to the production of the translated text. By means of this tool, both teacher and learners can discuss and analyse not only the strategies applied but also the learners' attitudes, beliefs and values relating to those textual and contextual factors involved in communicating in a specific domain. The variation index, on the other hand, is an analyst-centred tool, the purpose of which is to reveal those discrepancies detected by the analyst when comparing the translated text with its original. This tool allows the analyst to make explicit the comparative criterion applied, thus helping both teacher and learners establish common ground for discussion. The construct has been applied in practice and evidence of the type of information gathered by means of this tool is provided.

As far as the taxonomy of pedagogic functions of translation is concerned, we conclude that translation activities show a potential usefulness for language learning within a varied range of pedagogic functions. In reference to the theoretical functionality of translation for fulfilling educational objectives of the attitudinal type when translation activities are used for performance self-assessment and for formative evaluation, we conclude that translation activities may help achieve this goal at least with respect to low-level attitudinal objectives, although more experimental research is still needed. 


\section{Índice general}

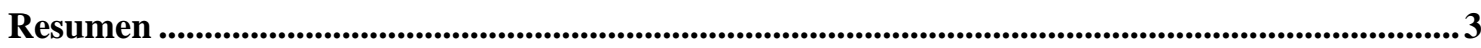

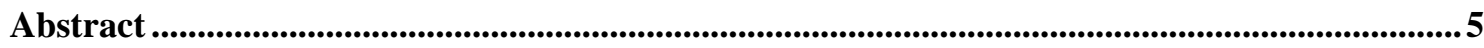

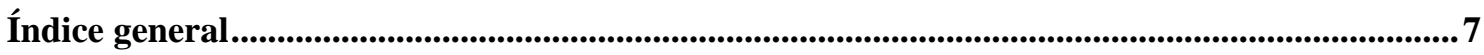

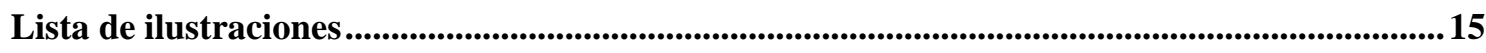

Lista de tablas ...................................................................................................................................................... 16

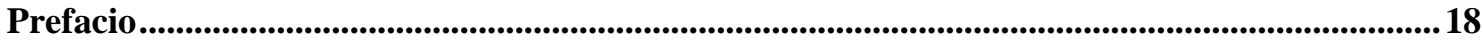

1. Lingüística, traducción y didáctica: algunas cuestiones previas ..............................................24

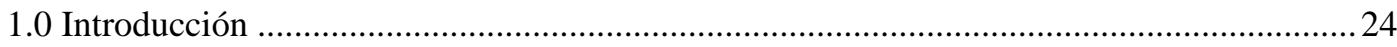

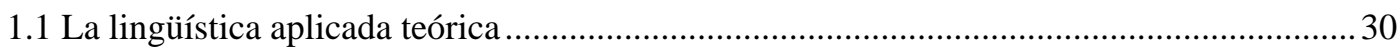

1.2 Didáctica de la traducción y didáctica de las lenguas extranjeras: breve repaso

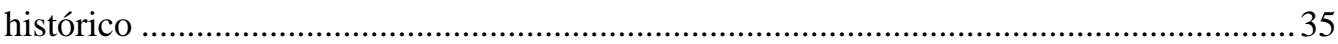

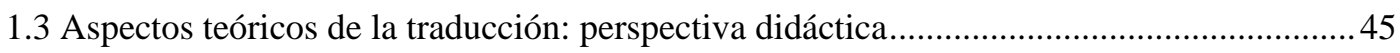

2. Las funciones didácticas de la traducción ........................................................................50

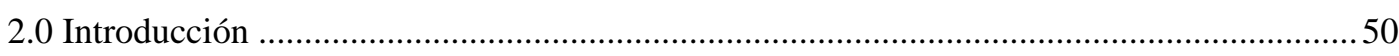

2.1 Las funciones didácticas tradicionales de la traducción ......................................................51 
2.1.1 La traducción como un medio para la enseñanza.......................................................52

2.1.2 La traducción como un fin de la enseñanza .....................................................................57

2.2 El Inglés para Fines Específicos en relación con el Inglés General: aproximación didáctica

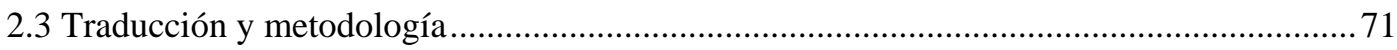

2.4 Nueva propuesta de las funciones didácticas de la traducción a partir de un enfoque comprehensivo 79

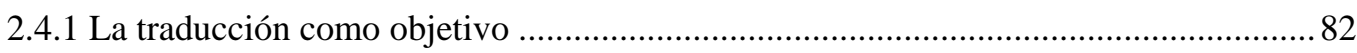

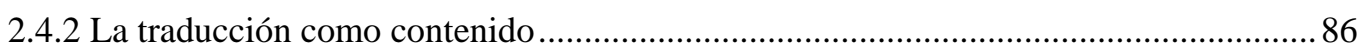

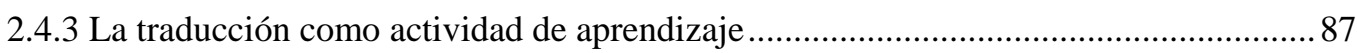

2.4.4 La traducción como procedimiento de evaluación del aprendizaje ...............................89

2.4.4.1 La traducción como método de evaluación para el aprendizaje .............................90

\section{La traducción como medio de facilitación del aprendizaje del Inglés para Fines}

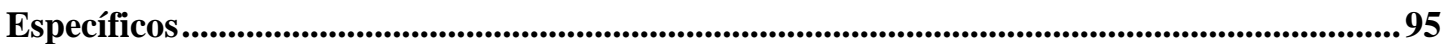

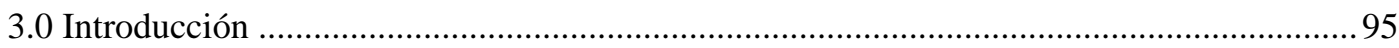

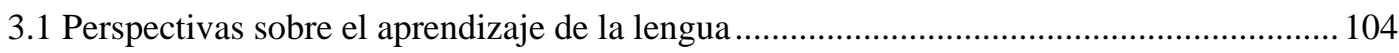

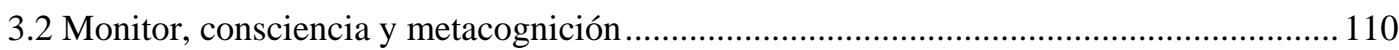

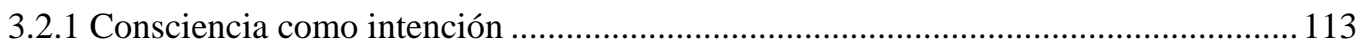

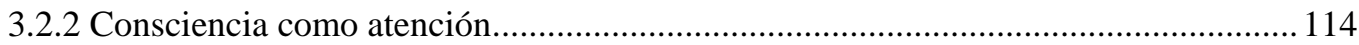

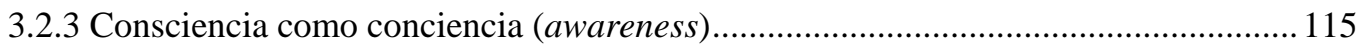

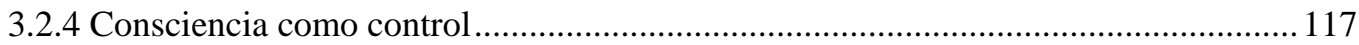

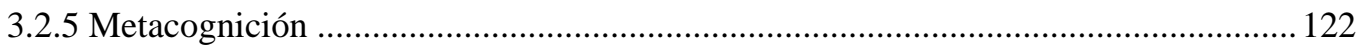

3.3 Traducción, competencia comunicativa y capacidad ...................................................... 128

3.3.1 Traducción y aprendizaje de la gramática............................................................... 130

3.3.2 Traducción y competencia sociolingüística ............................................................ 135

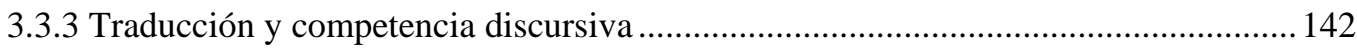

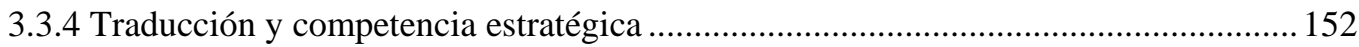


3.4 El contexto de aprendizaje del Inglés para Fines Específicos

3.4.1 La Unión Europea como contexto educativo supranacional para la enseñanza y el aprendizaje de lenguas

3.4.2 El Marco de Referencia Europeo y sus antecedentes en relación con el Inglés para Fines Específicos y con la traducción

4. La lengua de especialización: concepto y análisis

4.0 Introducción

4.1 Concepto y descripción de la lengua de especialización

4.1.1 Divergencias conceptuales: aproximación didáctica, aproximación terminológica y aproximación lingüística

4.1.2 La lengua de especialización como restricción de la lengua general

4.1.3 Divergencias descriptivas: enfoque terminológico, enfoque estilístico, enfoque educativo y enfoque sociolingüístico

4.2 Parámetros de descripción del uso del lenguaje

4.2.1 Texto 217

4.2.2 Situación 219

4.2.3 Registro 222

4.2.4 Código .223

4.2.5 Sistema lingüístico 224

4.2.6 Estructura social .225

4.3 Las unidades analíticas del texto 227

4.3.1 Análisis del género y análisis del registro 229

4.3.2 Texto y discurso

4.3.3 Perspectiva global sobre la traducción en relación con el texto como unidad analítica 


\section{La comunicación especializada: entorno socio-semiótico, entorno textual y entorno}

cognitivo 266

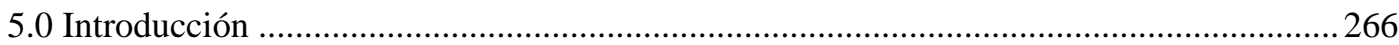

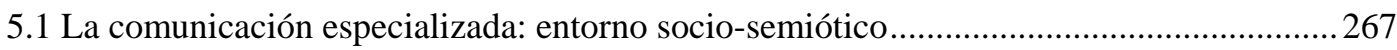

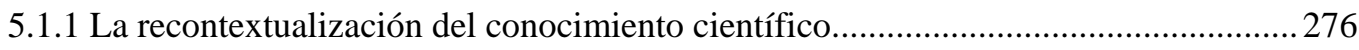

5.1.1.1 Emergencia o especialización de un nuevo campo científico............................. 278

5.1.1.2 Configuración de nuevas relaciones sociales ................................................... 280

5.1.1.3 Aparición de nuevos modos de representación y (re)producción del

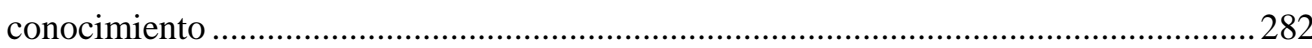

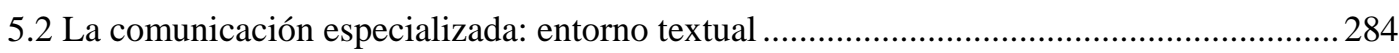

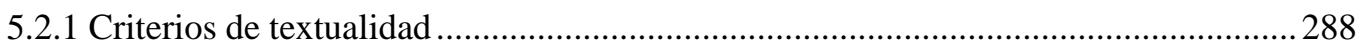

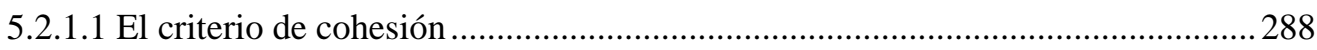

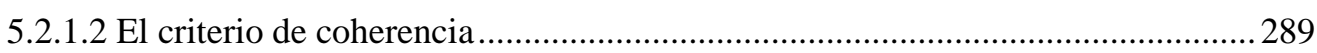

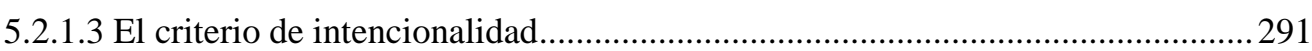

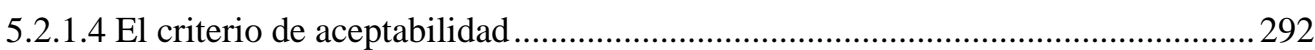

5.2.1.4.1 El texto como conjunto de instrucciones para el receptor........................... 292

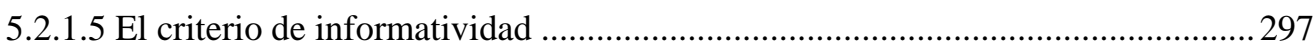

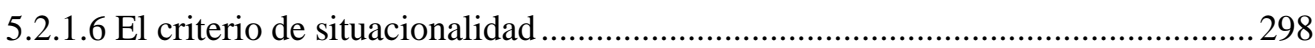

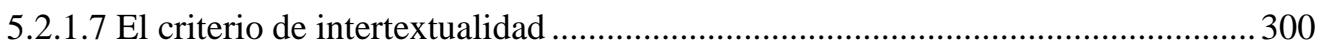

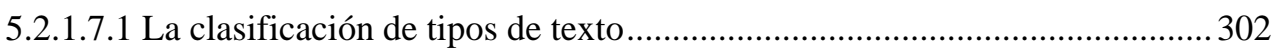

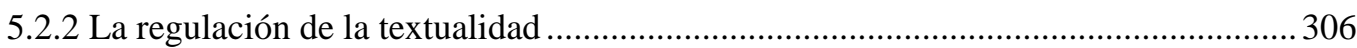

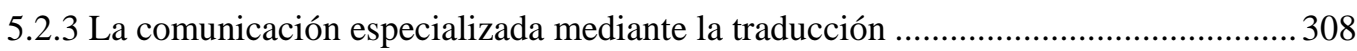

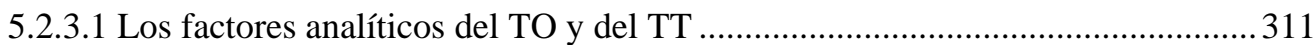

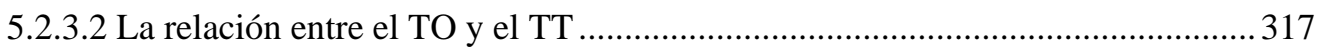

5.2.3.2.1 La adecuación como criterio evaluativo del TT............................................ 323

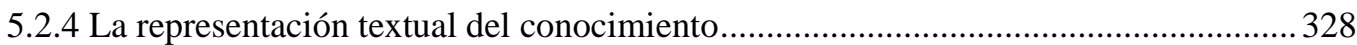

5.2.4.1 La metáfora gramatical del discurso científico inglés ..........................................340

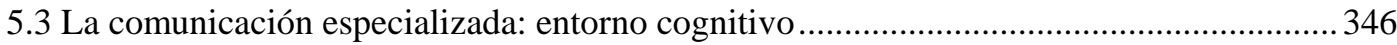




\section{La evaluación y la traducción especializada como método de evaluación para el aprendizaje}

355

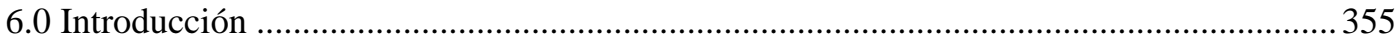

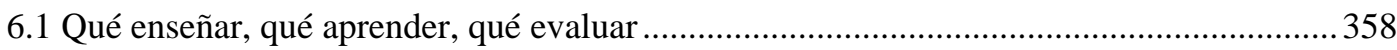

6.1.1 Taxonomía de objetivos de la educación: ámbito del conocimiento...........................369

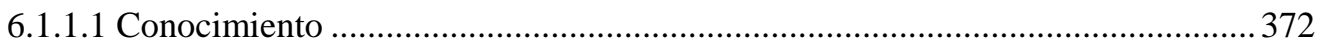

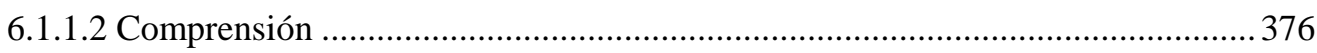

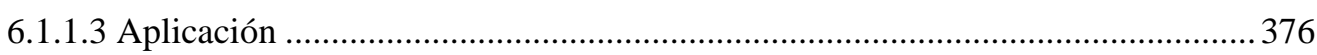

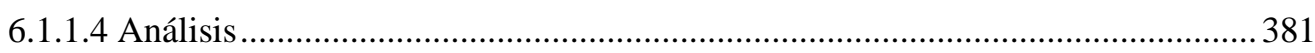

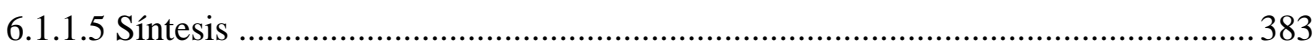

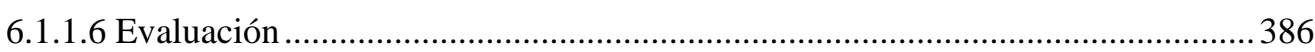

6.1.2 Taxonomía de objetivos de la educación: ámbito de la afectividad.............................389

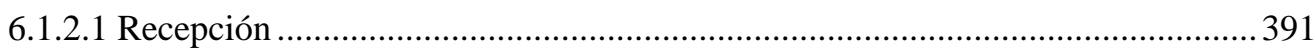

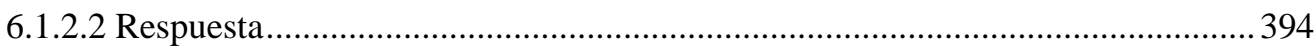

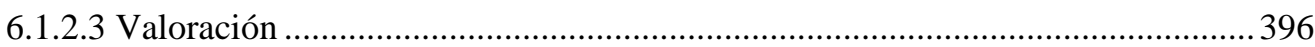

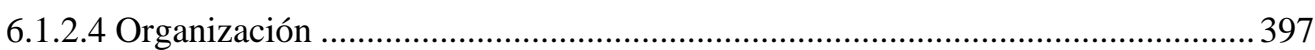

6.1.2.5 Caracterización por un valor o un conjunto de valores ...................................... 398

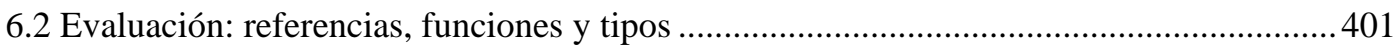

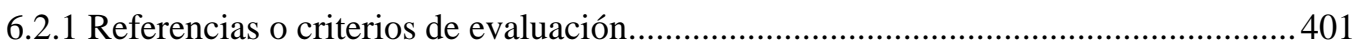

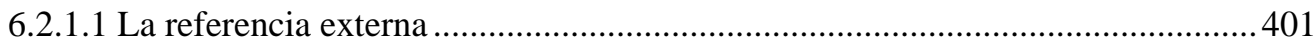

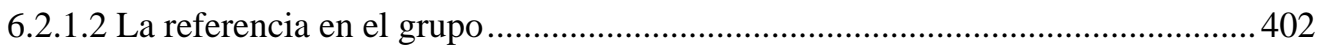

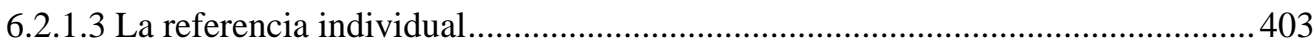

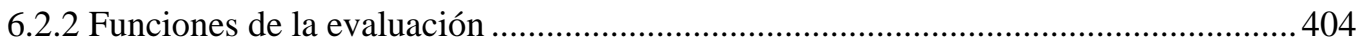

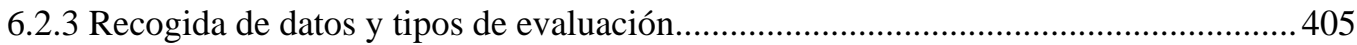

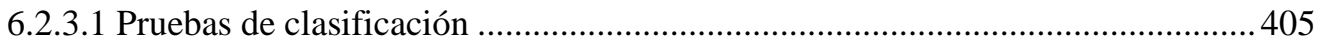

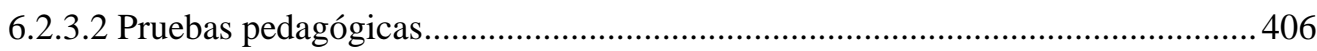

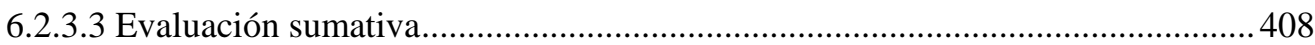

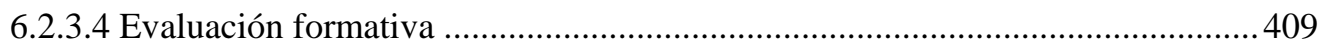

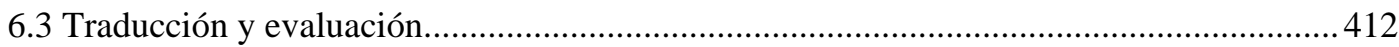


6.3.1 La evaluación de las traducciones.

6.3.1.1 Las condiciones de validez de la traducción como prueba de evaluación

6.3.2 La traducción como evaluación en la enseñanza y el aprendizaje del Inglés para

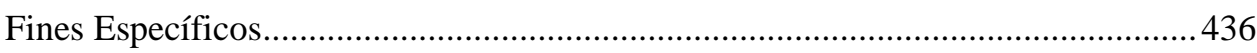

6.3.2.1 La traducción especializada como autoevaluación...............................................443

6.3.2.2 La traducción especializada como evaluación formativa ................................... 450

6.4 Análisis didáctico de la traducción: un repertorio de variaciones entre los efectos

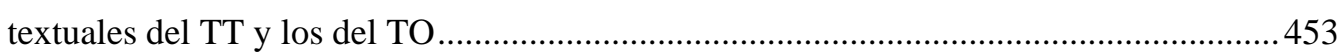

6.4.1 Variaciones de efecto que afectan al nivel macrotextual .......................................... 454

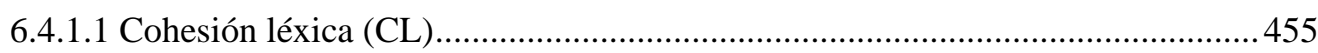

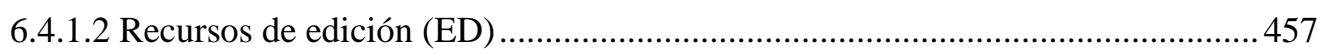

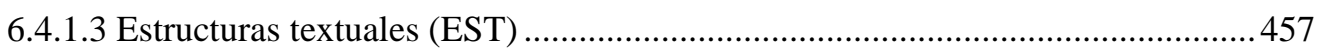

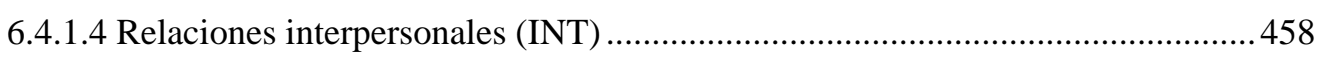

6.4.1.5 Uso excesivo de estructuras pasivas (PAS) ..................................................... 460

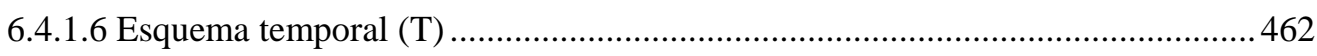

6.4.2 Variaciones de efecto que afectan al nivel microtextual........................................463

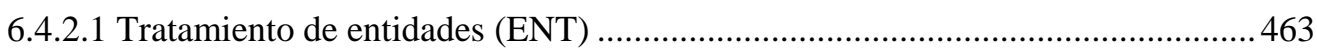

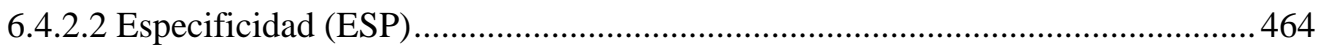

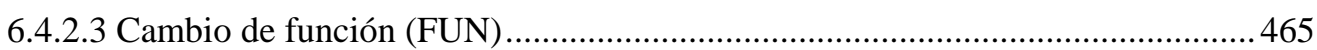

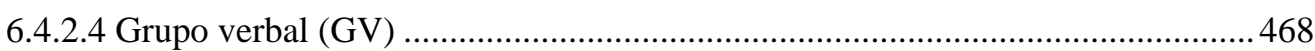

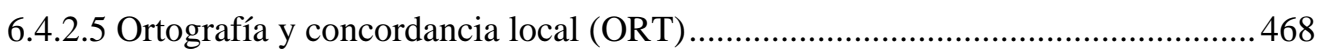

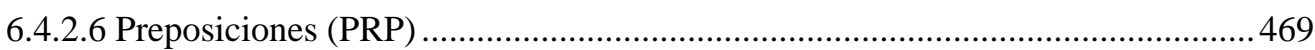

6.4.3 Variaciones de efecto que pueden afectar al nivel macrotextual o al nivel

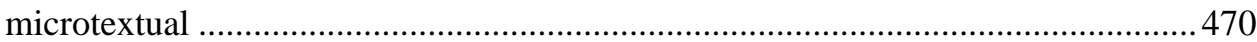

6.4.3.1 Información absurda o incomprensible (ABS) ................................................... 471

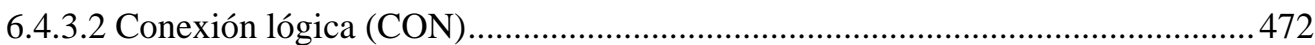

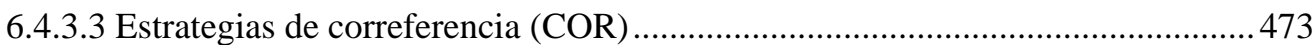

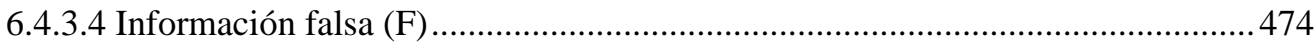

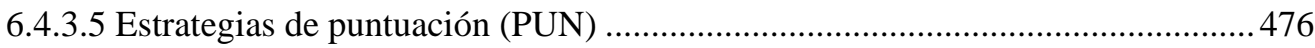

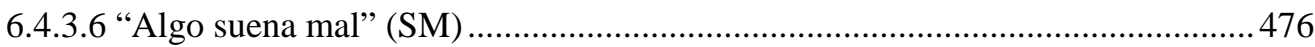




\section{Sobre la funcionalidad de la traducción para la didáctica del Inglés para Fines}

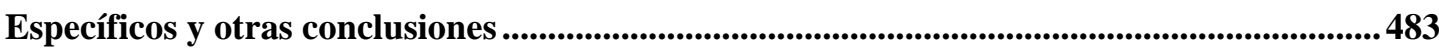

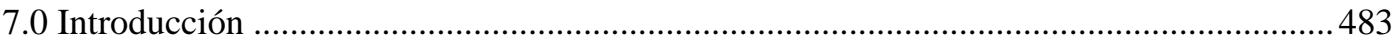

7.1 Límites del establecimiento de objetivos educacionales en relación con la distinción entre Inglés General e Inglés para Fines Específicos ..........................................................4 484

7.1.1 Diferencias en la relevancia de los objetivos educacionales de tipo actitudinal .........484

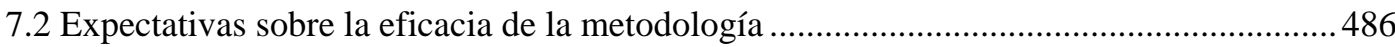

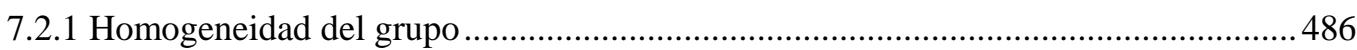

7.2.2 Eficiencia de la enseñanza y nivel de precisión del aprendizaje................................ 487

7.2.3 Aprendizaje autónomo, objetivos actitudinales y traducción....................................... 489

7.3 Traducción, competencia de lectura y metacognición: like a rabbit facing a snake, like a rabbit eating a carrot.

7.4 Pautas para aclarar los límites difusos de la funcionalidad didáctica de la traducción.

7.5 Conclusiones sobre la traducción especializada como método de evaluación formativa y de autoevaluación para la consecución de objetivos actitudinales .500

Referencias 502

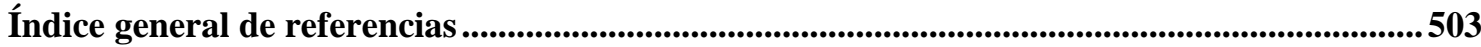

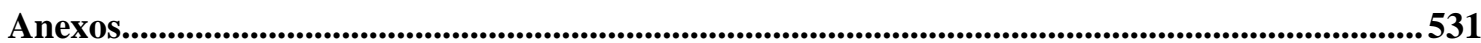

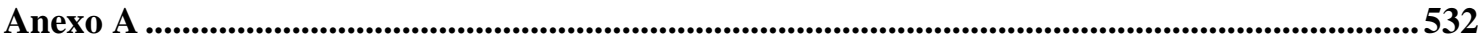

Anexo B 533

Anexo C 
Anexo D

.540

Anexo E

542

Anexo F...

546

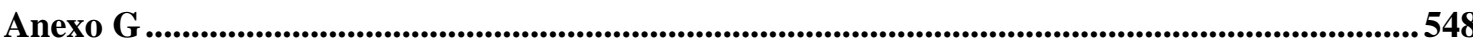




\section{Lista de ilustraciones}

FIGURA 1. INTERRELACIÓN DE LOS DOMINIOS QUE CONTEXTUALIZAN LAS ACTIVIDADES LINGÜÍST ICAS (ADAPTADA DE COUNCIL FOR CULTURAL COOPERATION 1996).

FiguRA 2. MODELIZACIÓN TEÓRICA DEL LENGUAJE COMO SISTEMA SOCIOSEMIÓTICO (MATTHIESSEN 2001)

FigURA 3. LA COMUNICACIÓN Y LA EVALUACIÓN DE LA INVESTIGACIÓN (BARNES 1985)

Figura 4. ASPECTOS INVOLUCRAdOS EN El CONCEPTO DE EVALUACIÓN (HERRERA GARCÍA Y RODRÍGUEZ CONDE 2001) .369

FIGURA 5. ETAPAS DE UN PROCESO DE RESOLUCIÓN DE PROBLEMAS DE APLICACIÓN (BLOOM ET AL. 1956). .378

FiguRA 6. TIPOS DE FEEDBACK Y OBJETIVOS DE LA EVALUACIÓN (REA-DiCKINS 1989) .408 


\section{Lista de tablas}

TABLA 1. TIPOS DE CURSOS A LO LARGO DE LA LÍNEA CONTINUA DE LA DIDÁCTICA DE LA LENGUA INGLESA (DUdLEY-EvANS Y ST. JoHN 1998)......64

TABLA 2. RELACIÓN ENTRE LOS OBJETIVOS Y LA METODOLOGÍA DIDÁCTICA

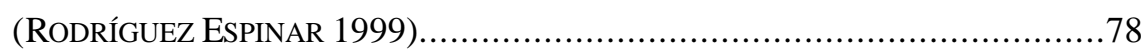

TABLA 3. CONTENIDOS Y FASES DE LA PLANIFICACIÓN DE LA ENSEÑANZA

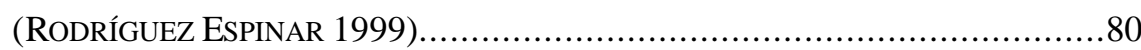

TABla 4. COMPONENTES DEl Plan Docente (RodRíGUEZ EsPinAR 1999) .........81

TABLA 5. LAS FUNCIONES DIDÁCTICAS DE LA TRADUCCIÓN DESDE UN

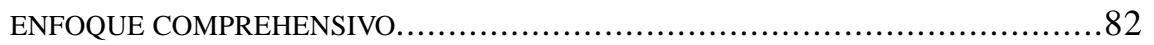

TABla 6. DesCriptores de las aCtiVIDAdes COMUNICATIVAS DE RECEPCIÓN (COUNCIL FOR CULTURAL CO-OPERATION 1996)....................181

TABLA 7. MODO TRADUCTOR Y PRINCIPALES MODALIDADES DE TRADUCCIÓN (HURTADO Albir 1999)

TABla 8. DESCRIPTORES DE LAS ACTIVIDADES COMUNICATIVAS DE MEDIACIÓN (COUNCIL FOR CULTURAL CO-OPERATION 1996) ....

TABLA 9. ESTRUCTURA DEL GUPO NOMINAL EN INGLÉS (HALLIDAY Y HASAN 1976:40)

TABLA 10. TAXONOMÍA DE LOS OBJETIVOS DE LA EDUCACIÓN: ÁMBITO DEL CONOCIMIENTO (ADAPTADA DE BLOOM ET AL. 1956)

TABla 11. TAXONOMÍA DE LOS OBJETIVOS DE LA EDUCACIÓN: ÁMBITO DE LA AFECTIVIDAD (ADAPTADA DE KRATHWOHL, BLOOM Y MASIA 1964).

TABLA 12. MODOS DE MEJORA DEL PROCESO DE EVALUACIÓN (HERRERA GARCÍA Y RODRÍGUEZ CONDE 2001) 
TABLA 13. NIVELES DE DIFICULTAD DE RESOLUCIÓN DE PROBLEMAS EN ORDEN CRECIENTE (GREENE 1975:23-24) ....................................440

TABLA 14. REPERTORIO DE VARIACIONES DE EFECTO ENTRE EL TT Y EL TO (VERSIÓN REVISADA DE ELORZA 1999; 2001; 2002). .479 


\section{Prefacio}

El origen de este trabajo de investigación parte de una pregunta que ha pasado en algún momento por la cabeza de la mayoría de los profesores de inglés como lengua extranjera: ¿es útil la traducción para aprender inglés?

Se trata de una pregunta sencilla, aparentemente fácil. Otras preguntas igualmente sencillas habrían obtenido como respuesta un lacónico 'sí' o un simple 'no'. El hecho de que para poder elaborar lo más aproximado a una respuesta hayan sido necesarios los años de esfuerzo y dedicación que se plasman en este trabajo de investigación nos lleva a pensar que, al igual que sucede con otras preguntas aparentemente simples, en realidad encierra un elevado grado de complejidad. No se trata, por tanto, de una pregunta sencilla ni fácil, pero sí de una pregunta interesante.

Se trata de una pregunta que despierta interés porque, hasta la fecha, no tiene respuesta. Al menos en el sentido de una respuesta aceptada de forma convencional o generalizada entre los profesores de inglés como lengua extranjera. Este hecho puede resultar sorprendente si tenemos en cuenta el sofisticado grado de desarrollo de la didáctica del inglés en comparación con la didáctica de otras lenguas modernas, o incluso con las didácticas de otros tipos de conocimientos. Se trata, por consiguiente, de una pregunta que no sólo es interesante, sino que además tiene relevancia desde el punto de vista de la investigación.

Por otra parte, se trata de una pregunta demasiado amplia porque a su vez genera otras preguntas: ¿qué quiere decir que sea útil?, ¿qué queremos decir con traducción?, ¿útil para aprender inglés en cualquier situación?, ¿útil para aprender cualquier lengua extranjera? La primera cuestión nos conduce al ámbito de la didáctica, la segunda nos remite a la conceptualización de los fenómenos involucrados típicamente en la mediación intercultural, mientras que las dos últimas preguntas nos remiten a su vez a las restricciones que necesariamente debemos imponer en el alcance de nuestra investigación. Con el fin de limitar en principio parte de la complejidad de la tarea, vamos a considerar el ámbito de la didáctica de 
lenguas para fines específicos, y dentro de éste la didáctica del Inglés para Fines Específicos, como el entorno relevante en el que contestar esta pregunta. Se trata de un acotamiento conveniente puesto que podemos utilizar este entorno como banco de pruebas donde experimentar de forma práctica con estudiantes reales. Se trata también de una restricción relevante porque podemos documentar la utilización práctica de la traducción en muchos cursos de Inglés para Fines Específicos en España en la actualidad.

Asumimos como objetivo general de la investigación ofrecer una respuesta a la pregunta formulada y, si esto no es posible, al menos aclarar los términos en los que se podría llegar a responder esta pregunta. Para ello, y considerando que el objeto de investigación que proponemos y desarrollamos no puede ser tratado desde un único campo de estudio, advertimos que el lector se verá inmerso en tres campos disciplinares, lingüística, didáctica y traducción.

La lingüística constituye el campo disciplinar al que se adscribe nuestra investigación, ya que el marco general en el que se plantea nuestra tesis y en el que nuestras conclusiones tienen validez es un marco lingüístico. En esta investigación se han incorporado tanto las teorías desarrolladas por la rama teórica de la lingüística en los últimos años, como los avances descriptivos alcanzados hasta el momento en esta disciplina, para desarrollar lo que definimos como un trabajo de investigación en lingüística aplicada teórica, tal como se expone en el Capítulo 1.

Las aportaciones fundamentales de la disciplina de la traducción a nuestra investigación consisten, por una parte, en las idealizaciones del fenómeno de la traducción desarrolladas por la rama teórica de esta disciplina y, por otra, en la concepción y el desarrollo de la didáctica de la traducción. No obstante, tal como expondremos en el Capítulo 2, la didáctica de la traducción tal como se ha desarrollado en esta disciplina no es suficiente para dar cuenta del objeto de estudio que tratamos en este trabajo de un modo comprehensivo. Así pues, dado que nuestro campo de aplicación no corresponde con futuros traductores sino con futuros profesionales de campos científicos y/o técnicos (biólogos, matemáticos, ingenieros, etc.), será necesaria la incorporación de un marco teórico de la didáctica diferente al marco de la didáctica de la traducción. No obstante, como quiera que el marco de la didáctica de las lenguas para fines específicos se mostrará insuficiente para tal fin, deberemos incorporar el marco teórico más amplio de la didáctica general.

La didáctica general no sólo no tiene una aportación testimonial en este trabajo, sino que entendemos que el desarrollo de las didácticas especiales de los distintos campos de conocimiento no sucede (o al menos no debe hacerlo) al margen 
de la didáctica general, sino que ésta constituye una disciplina que proporciona una perspectiva más amplia de los aspectos relevantes involucrados en la enseñanza y el aprendizaje de cualquier materia que las didácticas especiales de cada campo de conocimiento, incluyendo marcos teóricos tan desarrollados como el de la didáctica del inglés como lengua extranjera y como segunda lengua, y también el de la didáctica del Inglés para Fines Específicos.

Si bien estos tres campos disciplinares guardan una estrecha relación entre sí, muy a menudo son tratados de forma independiente, especialmente en la investigación. No obstante, tenemos la convicción de que únicamente adoptando una perspectiva interdisciplinar es posible defender las tesis que se plantean en este trabajo de investigación, para lo cual será necesario tratar los tres campos disciplinares de un modo integrado. Por esta razón, la transición de un marco disciplinar a otro puede resultar en ocasiones confusa, por lo cual se ha intentado señalar convenientemente qué marco se está utilizando en cada caso. No obstante, se mantiene a lo largo de todo el trabajo una visión de conjunto sobre el objeto de estudio, de tal modo que los enfoques provenientes de cada campo de investigación son tratados de forma integrada y organizados del modo que se detalla a continuación.

En primer lugar, el Capítulo 1, titulado «Lingüística, traducción y didáctica: algunas cuestiones previas», pretende hacer explícitos aquellos aspectos que afectan a la concepción de nuestro trabajo desde una perspectiva global. Este capítulo de introducción persigue mostrar una visión integradora de los campos disciplinares de la lingüística (teórica, descriptiva y aplicada, particularmente en relación con la didáctica especial de las lenguas extranjeras y, particularmente, la didáctica de las lenguas para fines específicos), de la traducción (teórica y aplicada a la didáctica, particularmente lo que concierne a la didáctica de la traducción y, dentro de ésta, aquellos aspectos más directamente asociados a la traducción especializada) y por último, aunque no menos importante, de la didáctica general (teórica).

A continuación, bajo el título «Las funciones didácticas de la traducción», el Capítulo 2 establece cuál es el repertorio relevante de funciones didácticas de la traducción en el entorno del Inglés para Fines Específicos. Por lo que concierne a este entorno de la didáctica, en este capítulo se detallan las características que se asocian a la enseñanza del Inglés para Fines Específicos.

En el Capítulo 3, titulado «La traducción como medio de facilitación del aprendizaje del Inglés para Fines Específicos», se lleva a cabo un análisis de las cuestiones relativas a la investigación sobre el aprendizaje de la segunda lengua o de 
las lenguas extranjeras que sean relevantes para tratar las funciones didácticas de la traducción en relación con el aprendizaje de las lenguas extranjeras y, particularmente, de la lengua inglesa. Así pues, en este capítulo se detallan cuáles son los aspectos característicos del aprendizaje del Inglés para Fines Específicos.

El Capítulo 4 está dedicado, bajo el título «La lengua de especialización: concepto y análisis», a describir qué entendemos por lengua de especialización, para lo cual hacemos explícito qué entendemos por lenguaje en un sentido global. Posteriormente, el Capítulo 5, titulado «La comunicación especializada: entorno socio-semiótico, entorno textual y entorno cognitivo», persigue describir qué entendemos por uso del lenguaje en cuanto a su dimensión social, a su dimensión textual y a su dimensión cognitiva en el entorno relevante para este trabajo de investigación. Si bien tratamos estas cuestiones desde una perspectiva global, en este capítulo nos interesan especialmente los aspectos más relevantes en relación con la descripción de los textos que utilizaremos en el aula. La justificación para incluir estos dos capítulos se basa en la recomendación de Widdowson (1983) acerca de la necesidad de considerar la naturaleza del uso del lenguaje antes de establecer cómo de específicos deben ser los objetivos educacionales cuando se persigue diseñar proyectos eficaces de enseñanza-aprendizaje de Inglés para Fines Específicos. Así pues, en el Capítulo 4 abordamos la descripción de lenguaje en uso que utilizamos en este trabajo, mientras que en el Capítulo 5 describimos las características del contexto de situación relevante.

En el Capítulo 6, con el título «La evaluación y la traducción especializada como método de evaluación para el aprendizaje», el objetivo general es analizar el concepto de evaluación en relación con la traducción como medio de facilitación del aprendizaje desde la perspectiva de la didáctica general. En este análisis, comenzamos por situar la evaluación como un concepto intrínsecamente asociado a los objetivos y a los contenidos educacionales, por lo que es necesario establecer un repertorio de objetivos y contenidos relevantes como paso previo. A continuación se definen los diferentes tipos de evaluación de acuerdo con la tipología clásica utilizada por la didáctica general con el fin de delimitar los aspectos más relevantes que afectan a las tareas de traducción cuando son utilizadas en la evaluación formativa y como instrumento de autoevaluación. Por último, incluimos la descripción detallada de un constructo pedagógico que ha sido diseñado para su aplicación práctica al llevar a cabo actividades de traducción en el aula de Inglés para Fines Específicos, y que consta de dos instrumentos complementarios de recogida de información. 
Por último, en el Capítulo 7, titulado «Sobre la funcionalidad didáctica de la traducción para el aprendizaje del Inglés para Fines Específicos y otras conclusiones», presentamos las conclusiones a las que hemos llegado con nuestra investigación. Estas conclusiones no sólo consisten en un pronunciamiento afirmativo o negativo acerca de la funcionalidad potencial de la traducción para la didáctica del Inglés para Fines Específicos, sino que se refieren también a algunos aspectos más puntuales que han sido expuestos y tratados a lo largo del trabajo y que, por lo general, se relacionan con las expectativas que podemos albergar acerca de la eficacia de la metodología que adoptamos, así como con los límites que podemos establecer para la funcionalidad didáctica de la traducción.

Son muchas las personas a quienes expresar nuestro agradecimiento por su contribución a que este trabajo finalmente vea la luz. La flexibilidad y accesibilidad que ha mostrado en todo momento el director del mismo, el Dr. Jon Robert Hyde, así como sus innumerables sugerencias, han sido una gran ayuda y un apoyo constantes, sin olvidar su paciencia en la concienzuda corrección de las diferentes versiones del trabajo. Asimismo, debemos mencionar el interés constante de la tutora de este trabajo, la Dra. Pilar Alonso y agradecer su esfuerzo en la revisión final del mismo. También debemos mencionar la decisiva ayuda de Eduardo González en las tediosas tareas de la corrección ortotipográfica y en las cuestiones tratadas en relación con la filosofía de la ciencia. Debemos agradecer a la Dra. $\mathrm{M}^{\mathrm{a}}$ José Rodríguez Conde su asesoramiento en la parte de evaluación, especialmente al llamar nuestra atención sobre el trabajo de Cunningham, al Dr. Craig Chaudron (University of Hawai'i) su ayuda en relación con el trabajo de Richard Schmidt y la adquisición de segundas lenguas y a Clara de Vega (BULATS, Ecole National du Génie Rural des Eaux et des Forêts (ENGREF) e Institut National Agronomique Paris et Grignon (INAPG)) su generosidad proporcionando la información relativa a los sistemas de evaluación de ALTE y BULATS. Queremos mencionar expresamente la accesibilidad y buena disposición mostradas por el Dr. Robert De Beaugrande (Universidade Federal de Paríba, Brasil) para aclarar algunas dudas puntuales, la generosidad del Dr. Gilbert Strang (Massachusetts Institute of Technology) al ceder tan amablemente sus derechos para utilizar sin restricciones sus textos de matemática aplicada, así como el interés expresado por la Dra. Christiane Nord (Fachhochschule Magdeburg, Alemania) por este trabajo. Por último, también debemos agradecer a la Universidad de Salamanca la ayuda económica concedida para realizar una estancia de investigación en la Universidad de Edimburgo. 
No queremos terminar este prefacio sin señalar que emprendimos esta investigación con un afán por esclarecer las razones que pudieran explicar la paradoja de que actualmente la traducción esté ausente de las metodologías de la enseñanza de las lenguas extranjeras, cuando la realidad muestra que está presente en muchos de estos cursos. Confiamos en que nuestro trabajo sirva para contribuir a que la decisión particular de incluir o no tareas de traducción en los cursos de lenguas extranjeras, y particularmente en los cursos de Inglés para Fines Específicos, pueda ser tomada en adelante con más elementos de juicio que la mera adhesión a los embates de las modas en metodología. 


\section{Lingüística, traducción y didáctica: algunas cuestiones previas}

\subsection{Introducción}

En este capítulo nuestro objetivo principal consiste en hacer explícitos aquellos aspectos que afectan a la concepción de nuestro trabajo desde una perspectiva global, y que son necesarios para situar convenientemente los argumentos que vamos a desarrollar alrededor de las cuestiones que trataremos en los capítulos posteriores.

Dado que nuestro trabajo de investigación tiene una marcada vocación interdisciplinar, en esta introducción queremos comenzar por referirnos a ciertos aspectos relacionados con la adscripción disciplinar de esta obra. Su mismo título permite inferir que son tres los campos de investigación a los que nos referiremos principalmente. Desde un enfoque abierto, identificamos estos campos con la lingüística, la traducción y la didáctica. Estas tres disciplinas tienen una importancia fundamental para que podamos alcanzar el objetivo de nuestra investigación, que consiste en tratar desde una perspectiva teórica la validez (o la falta de ella) de las tareas de traducción como medios de facilitación del aprendizaje en el entorno del Inglés para Fines Específicos tal como se lleva a cabo en los estudios universitarios en España.

No obstante, debemos precisar que nuestra aproximación a esta cuestión sigue una línea trazada esencialmente por la lingüística, incluyendo la perspectiva que adoptamos acerca de los fenómenos involucrados en la traducción. Consideramos que la traducción es una forma de comunicación lingüística, y que 
esta forma de comunicación cuenta con un potencial didáctico que aún queda por esclarecer.

Si nos atenemos a las discusiones producidas en el ámbito de la didáctica de las lenguas extranjeras y también en el de la didáctica de la traducción sobre esta cuestión, podemos pensar que el potencial didáctico de las tareas de traducción es ciertamente exiguo. No obstante, la didáctica general nos proporciona un repertorio de opciones mucho más amplio y versátil que las que se suelen tratar en relación con la enseñanza y el aprendizaje de las lenguas extranjeras y de la traducción. La aportación de la didáctica general a este trabajo es justamente la que nos permitirá llevar a cabo una aproximación mucho más comprehensiva que la que se limita a los trabajos producidos en el ámbito de la didáctica de las lenguas extranjeras y en el de la didáctica de la traducción.

De acuerdo con nuestra aproximación a la cuestión planteada, la investigación que vamos a exponer se inscribe en el campo de la lingüística aplicada, si bien se trata de un trabajo cuyos objetivos, contenidos y resultados son de tipo teórico. Como quiera que pudiera parecer un contrasentido situar una obra de tipo teórico dentro de un campo aplicado, en la siguiente sección (v. 1.1) trataremos justamente esta aparente paradoja. No obstante, queremos detenernos previamente en algunas cuestiones teóricas de carácter general que afectan a h relación existente entre la linguística y la traducción de acuerdo con el debate desarrollado en el ámbito de la traducción, y que nos servirán para poner de manifiesto nuestra perspectiva general acerca de la investigación que tenemos entre manos.

Desde el punto de vista disciplinar, la heterogénea producción escrita sobre traducción hace referencia en numerosas ocasiones a la situación de la traducción respecto de la lingüística, particularmente en relación con el grado de independencia que la primera ha alcanzado o debería alcanzar de la segunda. Así, nos encontramos con dos posturas enfrentadas, que resumimos a continuación.

Muchos académicos conciben la traducción como una disciplina significativamente diferente de la lingüística. El argumento utilizado por aquellos que adoptan esta perspectiva se basa en que la peculiaridad y complejidad de este fenómeno justifican la necesidad de tratar la traducción como un objeto de estudio que presenta unos problemas específicos y que precisa unos métodos de investigación y enseñanza propios. Así, la cuestión crucial estribará en identificar cuáles son los problemas específicos que afectan a la traducción, en elaborar y 
validar sus propios métodos $\mathrm{y}$, obviamente, en delimitar qué comprende exactamente el objeto de estudio.

Baker es un ejemplo de esta postura cuando defiende la peculiaridad y complejidad del fenómeno de la traducción frente a otras formas de comportamiento lingüístico, basándose en las diferencias de actuación al traducir entre un sujeto capaz de hablar varias lenguas y un traductor profesional (Baker 1996).

Otros muchos académicos contemplan, por el contrario, la traducción como un fenómeno (o un conjunto complejo de fenómenos) que no es significativamente distinto de otros fenómenos lingüísticos. Aquellos que adoptan esta interpretación tienden a pensar que la lingüística puede proporcionar un marco teórico suficiente para dar cuenta de los fenómenos involucrados en la actividad de traducir. Podemos decir que esta postura es en cierto modo heredera del desarrollo inicial de los estudios de la traducción como disciplina. Según Munday se ha producido, especialmente a partir de la segunda mitad del siglo XX, una aplicación sistemática de sucesivos modelos lingüísticos al estudio de la traducción: «the continued application of a linguistic approach in general, and specific linguistic models such as generative grammar or functional grammar [...] has demonstrated an inherent gut link with translation» (Munday 2001:9).

Como un caso extremo de esta postura, podemos citar el trabajo de ErnstAugust Gutt, que ha aplicado la teoría de la relevancia de Sperber y Wilson (1986) a la traducción (Gutt 1989;1990;1991;1996). Sin embargo, Tirkkonen-Condit (1992) critica el trabajo de Gutt (1991) al cuestionar el poder explicativo de la aplicación de la teoría de la relevancia a la traducción basándose en que ésta no refleja adecuadamente los procesos reales que siguen los sujetos que traducen. En este sentido, el trabajo de Gutt tiene poca utilidad para nuestra investigación, ya que no puede dar cuenta de aspectos que son relevantes desde un punto de vista didáctico. Esta crítica expresada por Tirkkonen-Condit es consistente con los resultados del trabajo de Laukkanen (1996) acerca de la influencia de los factores afectivos y actitudinales del sujeto hacia la tarea de traducir.

Otra de las cuestiones generales que queremos mencionar se refiere a los problemas con los que se enfrenta la traducción para consolidarse como una disciplina con entidad propia, en cierta medida causados por la falta de relación entre la teoría y la práctica de la traducción, tal como mencionan diversos autores (véase, por ejemplo, Baker 1996:42). De Beaugrande explica esta falta de relación como un desfase: 
Like 'discourse for special purposes', translation is an eminent discourse domain in which practice has long run far ahead of theory [...]. People have been translating since the earliest contacts among cultures, but theoretical models or accounts of how they do so have until recently been rare or rudimentary. Apparently, the practitioners believed they could do their work well enough without such accounts, while the theoreticians have widely viewed each language as an abstract system in its own right and defined by internal criteria alone. (De Beaugrande 1997:370)

Por otra parte, en una postura radical, algunos investigadores del campo de la traducción niegan la utilidad de los modelos lingüísticos para dar cuenta de los fenómenos involucrados en la traducción (v. Munday 2001:190). No obstante, resulta muy revelador el hecho de que algunos aspectos que han sido incorporados a los modelos utilizados por la lingüística para la descripción del funcionamiento del lenguaje en uso (el contexto social y cultural en que se produce el lenguaje, los procesos cognitivos asociados a la actuación de los usuarios reales en la comunicación, etc.) son utilizados por algunos investigadores de la traducción para defender la necesidad de que dicha disciplina desarrolle su propia metodología. Por ejemplo, tanto Baker (1996) como Tirkkonen-Condit (1992) apelan a cuestiones de tipo cognitivo para justificar la necesidad de que la traducción adquiera una entidad sólida como disciplina.

Creemos que la preocupación de los investigadores por cuestiones que caen fuera de los aspectos formales del lenguaje son un reflejo de un cambio en el enfoque necesario para abordar la descripción del lenguaje tal como se da en la realidad, lo cual incluye asimismo la descripción de los fenómenos involucrados en la actividad de traducir. Por consiguiente, no creemos que la traducción deba constituirse en disciplina basándose en el argumento de que la lingüística no es capaz de proporcionar un marco teórico lo suficientemente comprehensivo como para dar cuenta de los fenómenos involucrados en la mediación intercultural. Aunque creemos que puede resultar muy productivo que se desarrolle una metodología específica para investigar fenómenos involucrados típicamente en la traducción, no pensamos que este desarrollo deba transcurrir de espaldas oal margen de la investigación lingüística, ni mucho menos que la traducción pueda ser considerada en ningún caso como un objeto de estudio ajeno al lenguaje.

El desarrollo experimentado por la investigación descriptiva, tanto en la linguística como en la traducción, últimamente se puede asociar con un afán por considerar la investigación desde perspectivas interdisciplinares, más capaces de contribuir a explicaciones complejas de los fenómenos estudiados en cada caso. No 
obstante, se trata de un enfoque que no se halla exento de problemas, tal como señala Munday:

Much research in translation studies makes use of techniques and concepts from a range of backgrounds. Yet the construction of an interdisciplinary methodology is not straightforward, since few researchers possess the necessary expertise in a wide range of subject areas, and the original academic background of the individual researcher inevitably conditions the focus of their approach. (Munday 2001:189)

$\mathrm{Si}$, tal como afirma Munday, el bagaje académico de un investigador marca inevitablemente el enfoque de su investigación, entonces debemos decir que nuestra investigación está claramente marcada por un enfoque lingüístico. Pero, en el fondo, esta afirmación no aclara en absoluto qué implicaciones se pueden derivar de ella. $\mathrm{Si}$ acaso, tanto esta afirmación como las anteriores consideraciones de esta introducción no constituyen más que un mínimo esbozo de la perspectiva que adoptamos en este trabajo de investigación. A lo largo de los capítulos siguientes iremos desgranando con mayor profundidad y exactitud cuáles son los componentes de este enfoque, si bien podemos anticipar que incluye algunas características que mencionamos a continuación.

Con el fin de no restringir nuestro objeto de estudio de forma excesiva, ya que queremos llevar a cabo nuestro análisis sin caer en las limitaciones derivadas de una concepción estanca de las disciplinas que se ocupan de la actividad de traducir, el estudio que nos proponemos hacer tiene en cuenta las contribuciones de la investigación desarrollada (cuando menos) en tres campos de investigación: la lingüística, la traducción y la didáctica.

Por otra parte, nos interesan en general todos los aspectos involucrados en la actividad de traducir con el objetivo de facilitar a los alumnos el aprendizaje, es decir, con una finalidad esencialmente didáctica, y especialmente en relación con la enseñanza y el aprendizaje del Inglés para Fines Específicos.

Partimos de los siguientes supuestos en relación con la condición teórica de nuestro trabajo:

1. La investigación didáctica debe sustentarse principalmente en los avances alcanzados por la investigación teórica (sea ésta desarrollada por la traducción, la lingüística, la psicología cognitiva, la didáctica o cualquier otra disciplina que se ocupe de alguno de los aspectos que afectan al objeto de estudio), a partir de las investigaciones de tipo empírico y los resultados obtenidos de tipo descriptivo. Asumimos que la relación ideal entre estos tres tipos de investigación (descriptiva, teórica y didáctica) es de tipo 
dialéctico, nutriéndose cada uno de ellos de los logros alcanzados en los demás campos de la investigación en un feedback continuo.

2. Corresponde a la didáctica teórica construir hipótesis acerca de las aplicaciones práctic as para la enseñanza, a partir de los logros obtenidos en los campos disciplinares involucrados, con el fin de poder elaborar metodologías cuya eficacia pueda ser comprobada.

Además de esto, partimos de los siguientes supuestos en relación con la concepción de lenguaje utilizada en este trabajo:

1. El texto es entendido como una unidad de lenguaje en uso significativa e intencional. Es decir, no se establece ninguna discriminación previa en cuanto a la consideración del contexto entre texto y discurso, como hacen otros autores (véase, por ejemplo, Cook 1989), de tal modo que, por defecto, el contexto se contempla como un aspecto inherente del texto. Tampoco utilizaremos estos términos para referirnos a distinciones entre lengua hablada y lengua escrita. La diferencia que se establece entre texto y discurso únicamente afectará a que, cuando nos refiramos al texto, estaremos hablando de un objeto específico con unas características determinadas (extensión, lengua, relación de los elementos concretos que contiene, etc.) y, cuando nos refiramos al discurso, estaremos hablando del lenguaje en uso sin importar la forma específica que éste adopte.

2. Siguiendo a Nord (1991), las características textuales y contextuales se refieren en nuestro trabajo a los aspectos intratextuales y extratextuales del texto original (en adelante TO) y del texto traducido (en adelante TT), junto con lo que esta autora denomina el «factor global-integral» refiriéndose al efecto que el texto produce en sus receptores.

Por último, al considerar de forma específica aquellos aspectos que se relacionan más estrechamente con el aprendizaje de la traducción, partimos de dos supuestos de tipo teórico en cuanto a los aspectos involucrados en la actuación del sujeto que traduce y en relación con la didáctica:

1. Independientemente del modelo teórico utilizado, una teoría acerca de la traducción (no sólo las que se refieren al proceso de traducir, sino también al producto del mismo) sólo tendrá utilidad para la didáctica de la traducción si contempla la influencia de los factores relacionados con el sujeto que traduce, tanto los de tipo cognitivo como los relacionados con el contexto situacional en el que el sujeto desarrolla la actividad.

2. No sólo las características del TO y las que derivan de los contextos de la situación del TO y del TT son determinantes para la configuración específica que adoptará el TT, sino que los factores que dependen del sujeto 
que traduce y que afectan a las decisiones que toma, tales como sus creencias acerca de lo que es una buena traducción, sus valoraciones sobre el texto y la situación contextual o sus motivaciones para realizar la traducción, ejercen asimismo una gran influencia en la especificidad de la configuración del TT.

A continuación vamos a ahondar con mayor profundidad en algunas de las cuestiones que acabamos de esbozar, comenzando por el aparentemente paradójico concepto de la investigación teórica dentro de la rama aplicada de la lingüística. Más adelante (v. 1.2), nos centraremos con mayor detalle en el tratamiento que se ha venido haciendo de la traducción desde una perspectiva didáctica para pasar, en la sección siguiente (v. 1.3), a exponer con mayor precisión los problemas que nos encontramos al tratar la traducción desde la perspectiva de la didáctica teórica.

\subsection{La lingüística aplicada teórica}

El desarrollo de la lingüística a lo largo del siglo Xx tiene que ver, entre otras cosas, con la identificación de rasgos distintivos de diferentes fenómenos relacionados con el lenguaje, así como con diferencias en la relevancia que se ha concedido a cada uno de estos fenómenos. Esto ha dado pie a la constitución de diferentes disciplinas teóricas, cuyo objetivo es la construcción de modelos que sirvan para dar cuenta de estos fenómenos, y de otras disciplinas que se han identificado con la aplicación de los logros obtenidos en el campo teórico a la resolución de los problemas planteados por las disciplinas teóricas. El ejemplo clásico de disciplina aplicada que se ha desarrollado al amparo de la lingüística es la Enseñanza de Lenguas Extranjeras. De hecho, para muchos lingüistas, hablar de lingüística aplicada es sinónimo de enseñanza de lenguas (Marcos Marín y Sánchez Lobato 1991:18).

Sin embargo, la tradicional imagen de que la lingüística aplicada se reduce al objetivo general de la enseñanza del lenguaje, o al objetivo específico de la adquisición de una lengua determinada o de ciertos aspectos de un lenguaje especializado, significa minimizar su complejidad y alcance. La importancia que los logros alcanzados en esta disciplina tienen y han tenido para la concepción global del funcionamiento del lenguaje, como la teoría de la interlengua de Selinker, el análisis de errores de Corder, o los modelos de adquisición de lenguas de Krashen, Canale y Swain, Bialystok o Tarone, por citar unos ejemplos bien extendidos, pone 
de manifiesto que la aplicación práctica de modelos teóricos no proviene exclusivamente de los avances de las disciplinas puramente teóricas y, por tanto, que las disciplinas aplicadas no constituyen meramente la sección práctica de las denominadas disciplinas puras.

En este sentido, Marcos Marín y Sánchez Lobato afirman que, al igual que ocurre dentro de la lingüística teórica, también se van desarrollando dentro de la lingüística aplicada «estudios teóricos, no sólo heurísticos, más ambiciosos que los metodológicos, hasta poderse hablar, sin paradoja, de una Lingüística Aplicada Teórica» (Marcos Marín y Sánchez Lobato 1991:11). Según estos autores, esto no sólo es lícito, sino también beneficioso para la rama aplicada, ya que los modelos abstractos permiten una mejor comprensión de las aplicaciones lingüísticas que las propias aplicaciones al estar configurados por una cantidad manejable de componentes abstractos sujetos a principios generalmente bien definidos.

En el caso de la traducción, el reduccionismo tradicional aludido ha afectado también a la consideración de la legitimidad de pertenencia de la traducción a la esfera de las disciplinas aplicadas de la lingüística y a su situación dentro de este campo. Tal como Bühler pone de relieve: «translation has been discussed within applied linguistics traditionally as a didactic method in foreign language teaching and testing rather than as a mediating process between foreign languages and cultures carried out by professionals» (Bühler 1987:106).

Para paliar estas diferencias existentes entre la utilización de la traducción como una herramienta más o menos conveniente para el aprendizaje de lenguas extranjeras y la traducción como objetivo del aprendizaje, Bihler establece una línea divisoria considerando que la traducción como herramienta y la traducción como fin son dos tipos distintos de fenómeno, lo cual es consistente con la visión de otros autores. Aunque detecta áreas de contacto entre ambos tipos de fenómeno, el interés de Bühler se centra en la traducción como objetivo del aprendizaje, y no como herramienta, desde el punto de vista de la traducción profesional, incluyendo la formación de futuros traductores. En general, cuando los autores tratan la traducción como disciplina, lo hacen en este sentido, tanto desde el punto de vista teórico como del práctico y del didáctico. Esto supone un problema a la hora de considerar el valor didáctico de la traducción en campos que no pertenecen estrictamente a la disciplina de la traducción, ya que el desarrollo de la investigación sobre la didáctica de la traducción se enmarca en el ámbito de los Estudios de Traducción pero los trabajos que se llevan a cabo no suelen ser abordados de un modo interdisciplinar. 
Así, siguiendo el planteamiento de Bühler desde una perspectiva global de la traducción como la que adoptamos en nuestro trabajo, las diferencias entre una y otra utilización de la traducción en el entorno de instrucción tienen asimismo repercusiones en el nivel teórico de la didáctica, que a su vez se reflejarán en las opciones metodológicas disponibles. Es decir, consideramos que al abordar la didáctica de la traducción se debe disponer de una taxonomía que albergue las distintas manifestaciones de la traducción en los entornos propios de la didáctica, y que esta taxonomía esté elaborada a partir de los principios de la didáctica teórica.

Por otra parte, la influencia que algunos de los avances obtenidos en unas disciplinas aplicadas tienen en otras, como la teoría de la interlengua en la traducción (Toury 1980:71-78), demuestra no sólo que existe una afinidad global que subyace a todas ellas, y que consiste en identificar el lenguaje natural en cualquiera de sus manifestaciones como objeto de estudio, sino que el desarrollo de teorías en las disciplinas aplicadas forma parte de la propia constitución de las mismas.

Esto, además de representar una visión interdisciplinar de facto entre las disciplinas aplicadas del campo de la lingüística, es decir, la Lingüística Aplicada entendida como un campo interdisciplinar, se complementa con el enfoque interdisciplinar vigente entre disciplinas de campos tradicionalmente no relacionados, es decir, la Lingüística Aplicada se configura como una 'ciencia de intersección’ (Marcos Marín y Sánchez Lobato 1991:19). Asimismo, para Steiner «the study of the theory and practice of translation has become a point of contact between established and newly evolving disciplines» (Steiner 1992:250).

Si tomamos la traducción como una forma de comportamiento lingüístico y, a su vez, el comportamiento lingüístico como una forma de comportamiento humano, el lenguaje como objeto de estudio rebasa las fronteras (actualmente obsoletas) de la lingüística tradicional, que limitaba el objeto de estudio a los aspectos relativos a las reglas subyacentes del lenguaje, y consideraba la oración como unidad máxima del objeto de estudio de la semántica, la sintaxis y la morfología. En ese punto, el estudio del lenguaje pasa a adentrarse en el campo de las ciencias cognoscitivas.

Este planteamiento, que para muchos lingüistas puede ser interpretado como un alejamiento del objeto legítimo de la lingüística, ha empezado a mostrar vestigios de ser fructífero para la explicación de los procesos humanos que afectan al funcionamiento del lenguaje desde el punto de vista del usuario y, por lo tanto, a la traducción como proceso, frente a otras líneas de investigación más tradicionales 
y despreocupadas de tales cuestiones. Si bien es cierto que el escaso desarrollo de la aplicación de los avances del campo cognoscitivo a la traducción hace prematuro que existan muchas conclusiones definitivas en forma de evidencias, su repercusión es indudable en los aspectos teóricos de la didáctica que afectan al sujeto desde el punto de vista de la toma de decisiones y del comportamiento estratégico, como apunta Tirkkonen-Condit:

\begin{abstract}
Recent decision theories [...] have seriously challenged the assumption that human decision-making is predominantly rational. Affective factors are often decisive in radically delineating the domain within which rational choices are possible. Empirical research on managerial decision-making [...] has also pinpointed subjective biases as major components in strategic planning. (Tirkkonen-Condit 1992:244)
\end{abstract}

Otro tanto puede afirmarse de la consideración de la traducción como una forma de comunicación entre comunidades, sociedades o culturas diferentes, cuyas características han sido estudiadas tradicionalmente por la antropología y la sociología. Bajo este enfoque se han elaborado modelos socioculturales que contemplan la traducción como «un acto de comunicación intercultural que va más allá de las fronteras lingüísticas y/o literarias y que se encuadra en el contexto global de la cultura» (Rabadán 1991a:49).

Desde un punto de vista interdisciplinar, la incorporación de estos planteamientos, ignorados por la lingüística tradicional, tiene su propio reflejo en la constitución y evolución de otras disciplinas aplicadas del campo de la lingüística (en el caso de los aspectos cognoscitivos, en la Psicolingüística, y en el caso de los aspectos socioculturales en la Etnolingüística y la Sociolingüística), así como en la propia evolución de la linguística, especialmente con el cambio de enfoque que ha supuesto para esta dsciplina contemplar el lenguaje como acción social. En otras palabras, la lingüística actual se caracteriza por incorporar al estudio del lenguaje aquellos aspectos pragmáticos que afectan al lenguaje en uso, tal y como lo utiliza la gente en la interacción social.

Por otra parte, la lingüística moderna se diferencia de la lingüística tradicional en que, para poder ofrecer una descripción adecuada del lenguaje real en uso, ha tenido que desechar los planteamientos clásicos acerca de la oración y tomar el texto como unidad de estudio. Y el cambio no ha consistido simplemente en ampliar el tamaño de las muestras de lenguaje bajo observación, sino que ha afectado al propio concepto de texto, que hasta entonces era considerado como una mera yuxtaposición de oraciones. Por ejemplo, se ha comprobado que existen relaciones entre elementos lingüísticos que actúan en un entorno más amplio que la 
oración, como es el caso de la correferencia, y que son representadas de forma más precisa por modelos hipertextuales o reticulares que por modelos lineales. Además, se ha comprobado que estas relaciones textuales no son casos aislados, infrecuentes o típicos únicamente en ciertas lenguas, sino que constituyen un rasgo característico del lenguaje escrito, independientemente de los recursos técnicos específicos que utilice cada lengua particular para establecerlas ${ }^{1}$.

Esto ha supuesto también un cambio cualitativo en la consideración y el estudio del lenguaje, que se ha plasmado en el vertiginoso desarrollo de la lingüística textual (análisis del discurso, o cualquier otra denominación adscrita a este enfoque), y que ha influido notablemente en una parte de las teorías actuales acerca de la traducción. Para la didáctica teórica de la traducción, la linguiística textual repercute particularmente en los aspectos relacionados con el análisis de los TOs y de los TTs. Para la metodología, la lingüística textual no puede ser ignorada al seleccionar los materiales que se utilizarán en el curso, ni al plantear las estrategias de tratamiento de estos materiales.

Como resumen, la interdisciplinariedad a gran escala de los últimos años, más que una mera opción a seguir en la investigación en traducción, es una necesidad real para no perder de vista la dimensión global del objeto de estudio. Desde esta perspectiva, la relación entre la traducción y la lingüística debe interpretarse en un sentido muy amplio que concierne a todas las disciplinas que, de una forma $\mathrm{u}$ otra, están relacionadas con los aspectos del lenguaje y del comportamiento humano que afectan a la comunicación intercultural, independientemente de que tradicionalmente se hayan clasificado como legítimamente pertenecientes a la lingüística o no. En última instancia, como ya hemos visto, se trata de una relación que se enmarca dentro de los límites de la Lingüística Aplicada.

En este sentido, cualquier planteamiento que intente dar cuenta del fenómeno de la traducción a partir de una visión parcial del mismo es reduccionista,

\footnotetext{
${ }^{1}$ En realidad, las relaciones textuales como la correferencia no son únicamente características del lenguaje escrito, sino del lenguaje humano en general. No obstante, desde el punto de vista de la traducción, nos interesan especialmente aquellas relaciones que afectan al discurso, entendiendo éste como «stretches of language perceived to be meaningful, unified, and purposive» (Cook 1989:156), en la interacción escrita más que en la interacción oral, por lo que tenemos en cuenta principalmente los elementos y relaciones de cohesión y de coherencia de los textos. Por otra parte, limitar nuestro interés a la interacción escrita es pertinente para nuestro propósito dado que algunos autores, como McCarthy (1991), presentan diferentes modelos de análisis en función del tipo de interacción.
} 
ya que su manifiesta complejidad sólo podrá ser abordada teniendo en cuenta los diferentes aspectos que lo constituyen desde un punto de vista global, por mucho que el objeto de la investigación sea únicamente un aspecto determinado. Este reduccionismo se manifiesta cuando el fenómeno sólo se aborda desde lo que se suele denominar el 'enfoque lingüístico', es decir, cuando la traducción se considera meramente como una forma de comportamiento lingüístico que puede ser explicada desde la lingüística contrastiva. No obstante, el reduccionismo se manifiesta igualmente cuando la traducción es considerada como un fenómeno radicalmente distinto del comportamiento lingüístico, es decir, cuando se pretende que la traducción sea estudiada totalmente al margen del aparato de la lingüística. Este tipo de reduccionismo suele darse con frecuencia cuando el estudio se aborda desde la literatura comparada.

En realidad, el propio planteamiento de un debate acerca de la dependencia/independencia de la traducción respecto de la lingüística es reduccionista, tanto en cuanto la cuestión relevante no consiste en el reparto de los objetos de estudio entre diferentes disciplinas, sino en la consideración conceptual del objeto a pesar de la clasificación disciplinar existente. En última instancia, el debate es comprensible si lo entendemos como una cuestión de identidad, es decir, como el intento necesario de deslindar los problemas y los objetivos de la traducción de la esfera de las disciplinas tradicionales de la lingüística para así constituirse como una nueva disciplina, a partir de la convicción de que un fenómeno tan extremadamente complejo precisa un aparato teórico propio para poder resolver sus problemas convenientemente, lo cual no implica necesariamente una segregación disciplinar radical. Esta visión se refleja en lo que Toury (1991:45) denomina «the rapid growth of translation studies [...] towards semi-independence». En cualquier caso, esta semi-independencia implica para nuestro trabajo que, tal como veremos en la siguiente sección, la traducción desde una perspectiva didáctica sólo puede ser tratada en profundidad apelando al tratamiento que ha recibido tanto por parte de la lingüística como por parte de los estudios de traducción.

\subsection{Didáctica de la traducción y didáctica de las lenguas extranjeras: breve repaso histórico}

A pesar de las disquisiciones acerca de la pertenencia y la situación de la traducción respecto de la lingüística presentes en el acervo textual de esta disciplina, 
parece que las posturas radicales no constituyen la tendencia general entre los especialistas. Según Bühler (1987), la AILA (Association Internationale de Linguistique Appliquée) reconoció los estudios de traducción como disciplina de pleno derecho en el campo de la lingüística aplicada en su congreso de 1978 en Montreal $^{2}$. En este sentido, Holmes puede ser considerado el padre de la disciplina, tanto por la contribución que la difusión de sus postulados hizo al nacimiento de ésta, como por sugerir la utilización del término 'Translation Studies' para denominarla (Gentzler 1993:74; Toury 1980:76). Siguiendo esta perspectiva, en el presente trabajo emplearemos la forma 'Estudios de Traducción' para referirnos a la disciplina. A esto hay que sumar el amplio desarrollo de la traducción como actividad profesional de los años cincuenta (v. Newmark 1987:20-21), junto con su reconocimiento a escala internacional, fundamentalmente a partir del nacimiento de la FIT (Fédération Internationale des Traducteurs) y de la AIIC (Association Internationale des Interprètes de Conférence), ambas en 1953. En realidad, de acuerdo con Holmes (1988), hasta esta fecha no se puede hablar de ningún intento serio en Occidente para formar una teoría en sentido estricto del fenómeno de la traducción ${ }^{3}$. Por último, el hecho de que muchos países empezaran a ofrecer preparación académica y titulación a los futuros traductores (Bühler 1987) también se relaciona con el reconocimiento internacional de la traducción como profesión, y con el gran valor social actual de la traducción (Lörscher 1991).

\footnotetext{
${ }^{2}$ Rabadán apunta como causa del nacimiento de la disciplina la difusión de los postulados básicos de Holmes (1988) a diversos grupos de investigación. Sin embargo, no afirma explícitamente que el reconocimiento de la traducción como disciplina dentro del campo de la lingüística aplicada haya sido mutuo, es decir, avalado por los propios investigadores de la traducción, sino que más bien parece sugerir lo contrario. Por otra parte, la autora explica qué opción terminológica empieza a destacar en un sentido más comprehensivo: «en medio de la confusión terminológica respecto a la denominación de la nueva disciplina comienza a afianzarse la expresión Translation Studies para designar de la forma más neutra posible los distintos enfoques de las investigaciones». (Rabadán 1991a:46)

3 La exclusiva referencia a Occidente se debe a que Holmes (1988) ignora, como él mismo reconoce, cuál es el estado de la investigación de la traducción en Rusia y los demás países del Este. Es cierto que la difusión de la investigación entre los países del Este y los del Oeste no se ha producido en sentido de ida y vuelta, ya que habitualmente la investigación occidental ha llegado más o menos puntualmente a Rusia, pero no al contrario. En este sentido, es muy útil el trabajo de Fernández Vernet (1995), que ofrece un panorama de la traducción en Rusia en el que muestra que la investigación ha seguido un desarrollo distinto al occidental. Por otra parte, el prestigio social que tradicionalmente ha tenido la traducción no ha sido el mismo debido a que, según Zlateva (1993:1), h traducción en Rusia «has always enjoyed greater respect [than in other European countries]».
} 
A pesar de esto, el desarrollo de la didáctica de la traducción ha sido el más relegado de la disciplina, probablemente porque, así como en sus orígenes la dependencia directa de las teorías de traducción respecto de las teorías vigentes de la lingüística era un hecho manifiesto (Rabadán 1991a), a lo largo de estos años no se ha producido una relación análoga entre la enseñanza de la traducción y la enseñanza de lenguas extranjeras. Las diferencias notorias entre la traducción como herramienta didáctica en el aprendizaje de lenguas extranjeras y la traducción como fin mismo del aprendizaje han hecho que la relación se haya producido más bien en sentido inverso a la de la teoría.

Por otra parte, la lentitud del desarrollo de la didáctica, por comparación con la evolución vertiginosa que han sufrido las teorías acerca de la traducción, puede ser un síntoma de la disociación entre la teoría y la práctica de la traducción. Esto significa que las diferencias de evolución de ambos aspectos de la disciplina pueden estar producidas por el hecho de que la práctica de la traducción tiene una antigüedad largamente superior a las teorías acerca del fenómeno. Es decir, esta falta de urgencia por desarrollar los aspectos didácticos podría descansar sobre el hecho de que, a pesar de la ausencia de siglos de teorías mínimamente rigurosas sobre la traducción, durante todo este tiempo han existido traductores con mayor o menor éxito que, de una forma u otra, se han formado como tales y han ejercido su actividad profesionalmente.

En este sentido, Hatim y Mason sugieren, al igual que otros autores, que la falta de correlación en el desarrollo de la traducción teórica y la didáctica puede deberse a la lenta permeabilidad entre la lingüística, la traducción teórica, y la didáctica de la traducción:

[...] there appears to be a time-lag between the currency of ideas in general linguistic theory, their subsequent passage into works on translation theory and their eventual pedagogical application in manuals of translating, so that more recent trends within linguistics are not yet reflected in manuals of translating while the structuralist approach is still influential here and there. (Hatim y Mason 1990:31)

En cualquier caso, el resultado ha sido que la didáctica de la traducción no se ha visto muy beneficiada por los avances del campo teórico y, por lo tanto, su desarrollo no se ha caracterizado históricamente por la consolidación de diferentes líneas o escuelas metodológicas, sino por la proliferación desordenada de trabajos que reflejan la visión puntual de sus autores acerca de los problemas que afectan a la práctica de la traducción, y de las soluciones propuestas para paliarlos. Las 
diferencias metodológicas se ponen de manifiesto en un paradigma que incluye tres aspectos fundamentales.

Desde el punto de vista de un diagnóstico global, se identifican las fuentes de los problemas que se consideran más acuciantes, por ejemplo, la carencia de conocimientos adecuados en la lengua materna (véase, por ejemplo, Hervey y Higgins 1992:1,18). Partiendo del supuesto de la imposibilidad intrínseca de contar con un repertorio completo que cubra todos los problemas traslativos existentes para cualquier texto y usuario, se identifica la restricción del número y alcance de los problemas concretos que abordan. Por último, desde la ignorancia acerca de cómo surge y se desarrolla en el individuo la capacidad de mediación intercultural, se establece una asociación directa entre la cantidad de conocimientos lingüísticos que el individuo posee en dos lenguas y su capacidad para traducir. Esto último conlleva a su vez una despreocupación por ahondar en la naturaleza de esa capacidad presente en el ser humano.

Existe, sin embargo, un doble nexo de unión en los diferentes trabajos con afán didáctico que se han producido a lo largo de la historia de la actividad traslativa. En primer lugar, la preocupación subyacente a todas las obras clásicas es conseguir alcanzar el conocimiento necesario para identificar la excelencia de las traducciones, es decir, encontrar la respuesta a la pregunta ¿qué hace que una traducción sea buena?. En segundo lugar, el afán didáctico se plasma en el espíritu prescriptivo de la obra, se dice lo que se debe hacer para poder traducir correctamente. El alcance de la prescripción es variable, ya que se encuentra en obras de diversa índole en cuanto a la variedad de aspectos acerca de los cuales los autores reflexionan, por ejemplo, el autor o la obra que se traduce (particularmente al traducir obras clásicas de autores griegos y latinos), o bien las lenguas implicadas en la traducción, como hace, por ejemplo, A. Capmany en su Arte de traducir el idioma francés al castellano de 1777 (reproducido en Vega 1994:66).

Sin embargo, donde más claramente se plasma la conjunción entre la preocupación general por la calidad de las traducciones y el afán prescriptivo del autor es en los tratados acerca de la traducción desde un punto de vista que podríamos denominar abstracto e idealista: a partir de un autor, una obra o un par de lenguas determinados, el autor del tratado realiza un proceso de abstracción para teorizar acerca del fenómeno de la traducción, haciendo generalizaciones acerca del genio y la naturaleza de las distintas lenguas con el fin último de aprehender el ideal de excelencia de toda traducción. Estos dos aspectos llevan a los autores a formular 
un cúmulo de opiniones que, por lo general, se recogen alrededor de la clásica dicotomía de Cicerón 'traducción literal-traducción libre'.

Este breve esbozo histórico nos permite llamar la atención sobre dos constantes históricas acerca de la didáctica de la traducción:

a) que el prescriptivismo ha estado históricamente más ligado al afán por elaborar teorías acerca de la traducción que a la preocupación explícita por enseñar a traducir, y

b) que el prescriptivismo se ha manifestado tradicionalmente en la formulación de reglas o 'leyes' acerca de cómo hay que traducir.

Esta segunda constante suele ser ilustrada con ejemplos del tipo de las 'leyes de la traducción' que promulgó A.F. Tytler (Lord Woodhouselee) en su Essay on the Principles of Translation de 1791 (reproducido en Bell 1991:11; Hatim y Mason 1990:16; Vega 1994:211-216):

I. That the Translation should give a complete transcript of the ideas of the original work.

II. That the style and manner of writing should be of the same character with that of the original.

III. That the Translation should have all the ease of original composition.

La importancia de este aspecto prescriptivo, junto con el hecho de que las leyes de Tytler sean un ejemplo clásico en la disciplina, son comprensibles si, como afirma Bell, no podemos decir que haya habido grandes avances en este sentido:

It is no exaggeration to say that the programme followed by most translation theorists, in the English-speaking world at least (with a small number of exceptions; Nida and Catford in the mid-1960s in particular), has been, and still is, dominated by the thinking put forward in an essay written two centuries ago in 1791. (Bell 1991:10)

Desde el punto de vista histórico, situar el prescriptivismo en la esfera de la traducción teórica parece sugerir que la teoría y la didáctica de la traducción han seguido el mismo rumbo evolutivo y que, por lo tanto, hablar de la teoría o de la didáctica supone abordar un desarrollo único desde dos aspectos distintos. Esto podría explicar por qué, hasta el momento, no se ha desarrollado mucho en este campo el concepto de didáctica de la traducción, y por qué la historia de la traducción está repleta de tratados teóricos acerca del fenómeno de la traducción mientras que, paralelamente, ha habido una notoria ausencia hasta los últimos años de obras diseñadas explícitamente para el aprendizaje de la traducción fuera de la metodología de la enseñanza de lenguas extranjeras. 
Sin embargo, resulta problemática la utilización en la enseñanza de la traducción de las recopilaciones normativas consideradas por la teoría. Los repertorios tradicionales de prescripciones o preceptos, como el de Tytler, se asientan sobre cómo ha de ser una buena traducción, pero la ambigüedad de este concepto lo hace demasiado proclive a la falta de unanimidad. Si el propio significado de lo que se considera una buena traducción es relativo y dependiente, entre otras cosas, de la cultura y del periodo en los que se produce el TT (Rabadán 1991a:48), ya no se trata sólo de que el alcance de la prescripción sea variable, sino de que su validez se convierte en dudosa o en tan sumamente pequeña que el poder prescriptivo real del repertorio será prácticamente nulo.

En este sentido, toda prescripción podrá ser rebatida presentando casos concretos para los que se muestre inútil y eso la hará inválida, aunque sea parcialmente. La razón de que esto sea así es, probablemente, que la generación de preceptos se ha venido realizando a partir de la valoración subjetiva de lo que es una buena traducción (Bell 1991:11). Según Tytler (v. Vega 1994:211-212) ${ }^{4}$,

Si fuera posible definir de manera exacta o -quizás mejor- describir lo que se considera una buena traducción, es obvio que se habría avanzado lo suficiente para poder establecer las reglas del Arte [de la traducción], ya que estas reglas emanarían por naturaleza de dicha definición o descripción.

[...] yo describiría una buena traducción como: Aquella en la que el mérito de la obra original se ha trasladado hasta tal punto a otra lengua, que se comprende claramente y percibe con fuerza tanto por el nativo del país al que dicha lengua pertenece como por aquellos que hablan la lengua de la obra original.

Ahora, partiendo de que esta suposición sea exacta -lo que estimo-, pasemos a considerar cuáles son las leyes de la traducción que se pueden deducir de ella.

Aquí, el problema más relevante para la didáctica de la traducción es que Tytler, y como él muchos otros teóricos, hayan producido sus repertorios preceptivos deduciéndolos a partir de supuestos descriptivos hipotéticos, es decir, cuya validez no está demostrada. En este caso concreto, tal como apuntan Hatim y Mason (1990:16), Tytler elabora sus leyes partiendo del supuesto de que las finalidades que éstas persiguen no sólo son alcanzables, sino además compatibles entre sí, pero, si nos atenemos a que el contenido y la manera de expresarlo son aspectos diferenciables, entonces las tres leyes, aunque sólo sea en parte, se excluyen mutuamente porque están formuladas como normas que tienen el mismo ámbito de aplicación.

\footnotetext{
${ }^{4}$ La traducción del fragmento, tal y como aparece en la recopilación de Vega, está realizada por Lidia Taillefer.
} 
Por otra parte, la identificación que hemos utilizado entre didactismo y prescriptivismo no es casual. Cuando Holmes (1988) plantea los requisitos necesarios para desarrollar una teoría global de la traducción, afirma que ésta debería estar compuesta por teorías parciales de, al menos, cuatro tipos:

a) Una teoría del proceso de la traducción: «the theory of what happens when people decide to translate something» (Holmes 1988:95)

b) Una teoría del producto de la traducción, es decir, de lo que es específico del TT en cuanto a texto: «in what ways is it similar to and in what ways is it different from other kinds of texts, literary or other» (Holmes 1988:95) ${ }^{5}$

c) Una teoría de la función de la traducción que dé cuenta de la recepción del TT en la cultura de llegada: «how the translation works in the recipient society» (Holmes 1988:95)

d) Una teoría de la didáctica de la traducción

En esta consideración global acerca de las diferentes tendencias o posibilidades para abordar el objeto de estudio desde el punto de vista teórico, el prescriptivismo, que históricamente estaba ligado a toda consideración teórica acerca de la traducción, pasa a ocupar una posición mucho más clara y restringida, ya que, en opinión de Holmes, corresponde únicamente a la didáctica de la traducción:

The first three of these partial theories, I feel, should be non-normative. They should be attempts to provide models by which we could analyse existing situations, describing not what the situation should be but what it is. The fourth, on the other hand, the theory of translation didactics, is necessarily normative. (Holmes 1988:95)

Sin embargo, hasta los años cincuenta, la mayor parte de las teorías desarrolladas en Occidente acerca del fenómeno de la traducción eran de carácter claramente normativo, ya que el énfasis de los modelos desarrollados recaía fundamentalmente en especificar qué pasos se debían seguir para producir una buena traducción, en lugar de intentar describir cómo traduce la gente realmente (Bell 1991:10-12; Holmes 1988:94; Lörscher 1991:2), a pesar de que su afán no era explícitamente didáctico. Es decir, las teorías desarrolladas afectaban fundamentalmente a algunos aspectos didácticos de la traducción, desde el punto de vista de que indirectamente proporcionaban el material que se utilizaba en la

\footnotetext{
${ }_{5}^{5}$ Muchos autores, como Bell (1991), utilizan diferentes términos para referirse al proceso (translating) y al producto de dicho proceso (a translation).
} 
formación de los traductores (van den Broeck 1992:112; Holmes 1988:95), aunque no fuera ése el fin perseguido.

Aunque esta época fue la que marcó el inicio de los intentos de desarrollar una teoría de la traducción en sentido estricto, lo cierto es que, más que deshacerse del lastre normativo, muchas de las teorías que se han elaborado hasta la fecha son implícitamente normativas sin pretenderlo, particularmente las que atañen a la traducción como proceso. La elaboración de teorías acerca del proceso se ha solido basar en las inferencias que se hacían sobre él mediante la descripción y evaluación del producto (Bell 1991:13). Tradicionalmente, la descripción del TT se ha llevado a cabo mediante el análisis comparativo de éste con el TO, empleando para ello criterios de equivalencia poco productivos, bien porque se han construido a partir de las relaciones entre los sistemas virtuales de las lenguas (por lo que su aplicabilidad para las relaciones existentes entre sistemas actualizados es muy discutible), o bien porque se han establecido de forma local entre los textos analizados y su capacidad de generalización como abstracción teórica no es muy evidente ${ }^{6}$.

Según van Leuven-Zwart (1991), el carácter prescriptivo de estas teorías implícitamente normativas se debe a que, durante siglos, fueron fundamentalmente los propios traductores los que reflexionaron sobre el fenómeno de la traducción y, como resultado,

[...] the concept of norm as a synonym of rule entered the theory and description of translation. And since norms for good translations changed with periods and literary traditions, there have been contradicting and conflicting «theories» of translation since time immemorial: a true Babel of the requirements for good translations. (van Leuven-Zwart 1991:37) ${ }^{7}$

Esto nos lleva a considerar que, para establecer una teoría de la didáctica de la traducción, ésta deberá situar adecuadamente el papel del criterio de excelencia

\footnotetext{
${ }^{6}$ Seguimos la distinción que establece De Beaugrande (1980a:16), basándose en Hartmann, así como en Gülich y Raible, entre sistemas virtuales y sistemas actuales:

The intersystem of a natural language such as English is composed of virtual systems: functional unities of elements whose potential is not yet put to use, e.g. the repertories of sounds, grammatical forms, sentence patterns, concept names, etc. which a particular language offers its users; in contrast to these repertories, a text is an actual system: a functional unity created through processes of decision and selection among options of virtual systems.
}

${ }^{7}$ Haghighi (1994) opina que, en Occidente, esto ocurre desde el Renacimiento: «European values, norms, attitudes and perceptions are rooted many centuries back, specifically in the Renaissance, and today these are blended into the texture of Western society and taken for granted» (pág.47). 
de las traducciones, teniendo en cuenta lo temporales y en ocasiones poco definidos que son los valores que adopta. Habrá que definir para ello un concepto de norma dinámico, es decir, que no esté basado en un criterio absoluto, sino relativo, de la excelencia de las traducciones.

Por su parte, Toury también critica muchas de las teorías de traducción existentes precisamente porque, en realidad, muestran una concepción del fenómeno excesivamente simplista dado que se limitan a discriminar lo que es traducción de lo que no lo es, reduciendo, de este modo,

\begin{abstract}
«translation» to «translatability», while failing to take into account other factors which have a role to play both in the information and formulation of actual translated texts and in their acceptance as translations in specific cultural and linguistic contexts.

Moreover, their notions are only restricted versions of a general concept of translatability because they always have some specified adequacy conditions which are postulated as the only proper ones, if not distinguished as the only possible ones. (Toury 1980:26)
\end{abstract}

Nos encontramos entonces con que buena parte de los textos teóricos sobre traducción consiste en realidad en un repertorio de pseudo-teorías de la didáctica de la traducción, ya que muchas de ellas no fueron elaboradas con un objetivo didáctico preestablecido aunque sí se utilizaron con tal fin. Esto implica que las bases didácticas de la enseñanza de la traducción se han venido asentando tradicionalmente sobre una serie de criterios propuestos al margen de la propia enseñanza en sí. Y, si tenemos en cuenta que la elaboración de los preceptos se hacía únicamente a partir de la concepción de la traducción preconfigurada por el propio autor, lo cual carece de validez científica desde nuestra concepción moderna de la disciplina, podemos afirmar que estas bases didácticas se han asentado incluso sobre criterios propuestos al margen de las características del propio fenómeno.

Desde nuestra perspectiva actual, y a la vista del panorama ofrecido, parece que la didáctica de la traducción está siendo irremediablemente arrastrada a la especulación subjetiva y asistemática, es decir, meramente intuitiva $\mathrm{y}$, por consiguiente, condenada a la relatividad de su eficacia. Después de todo, como dice Holmes (1988:95), «we have to make decisions about how to train translators whether we know the answers or not, simply because translators have to be trained». Aunque la metodología básica que se siga en un curso de traducción se limite a la práctica intensiva y/o extensiva de la tarea de traducir, quedarán aún por resolver muchos otros aspectos didácticos, como por ejemplo, cuál será el criterio que se seguirá en la evaluación y corrección de los textos producidos. Y lo peor de la 
cuestión es que ni siquiera intentando desterrar la especulación se puede tener la garantía de que $\mathbf{b}$ efectividad de la metodología sea un hecho, a menos que esa especulación vaya de la mano de la aplicación de métodos empíricos acerca del aprendizaje y sea respaldada por los avances producidos en la investigación didáctica ${ }^{8}$.

Actualmente parece existir un acuerdo general de que la investigación del proceso de traducir es abordable únicamente desde el análisis de lo que la gente hace realmente cuando traduce, a pesar de que aún quedan por solventar muchos problemas derivados de la, para muchos dudosa, validez de los instrumentos metodológicos aplicados. Este cambio de tendencia puede ser contemplado como una evolución del prescriptivismo tradicional hacia un afán descriptivo del objeto de estudio, que hoy en día afecta particularmente a los aspectos relacionados con la actividad de traducir.

Con un talante optimista, se podría afirmar que se trata de un salto cualitativo en la consideración del objeto de estudio, ya que, si la incipiente investigación sobre el proceso interno de traducir resulta ser exitosa, es de suponer que sus logros influirán radicalmente en otras áreas de la investigación en traducción, particularmente en la traducción como resultado del proceso de traducir y en la didáctica.

Lo que entendemos como un cambio cualitativo ha consistido hasta el momento en asumir la necesidad de describir el objeto de estudio desde paradigmas más generalizables que los construidos ad interim por cada autor, y en basarse para ello en el proceso que se desencadena al traducir, entendiendo que este proceso es susceptible de ser abordado como un fenómeno común a cualquier realización concreta de la actividad de traducir. De ahí la necesidad de establecer vínculos estables con los profesionales de la traducción y la interpretación aludida por Baker. Desde nuestro punto de vista, ésta es probablemente la actitud más fructífera (si no la única posible) para poder construir un marco teórico acerca del proceso que sea suficientemente riguroso. Esta actitud es, además, necesaria para poder plantear

\footnotetext{
${ }^{8}$ Entendemos aquí la especulación como algo negativo, en el sentido de falta de rigor científico y, por lo tanto, como una actitud en conflicto con el empirismo. Esta actitud proviene de la concepción de los Estudios de Traducción como una disciplina empírica (van Leuven-Zwart 1991:36); de hecho, para Toury (1991:45), «the introduction of empirical methods [in translation studies] proved to be a true landmark in the evolution of the discipline». Para una visión más positiva y conciliadora entre la especulación y el empirismo en el campo de la lingüística aplicada, véase Davies (1993).
} 
hipótesis que puedan ser corroboradas o rechazadas empíricamente con el fin de poder avanzar en la investigación científica acerca del proceso.

\title{
1.3 Aspectos teóricos de la traducción: perspectiva didáctica
}

Desde el punto de vista de la didáctica de la traducción, al contemplar la evolución en la investigación desde el prescriptivismo tradicional al afán por describir el objeto de estudio, la perspectiva es diferente e, inevitablemente, más pesimista. Los estudios y experimentos llevados a cabo acerca del proceso de traducir se realizan con sujetos expertos, o bien mediante la comparación entre sujetos noveles y expertos. Probablemente debido a que las variables que afectan a la taxonomía y caracterización de los diferentes estados del aprendizaje de la traducción no están definidas, en los experimentos llevados a cabo no se caracteriza a cada grupo de sujetos de acuerdo con su estado en el proceso de aprendizaje, sino que se toman como sujetos expertos a traductores profesionales o a estudiantes de traducción de último curso, y como sujetos noveles a estudiantes de los primeros cursos. Por consiguiente, el énfasis de los experimentos acerca del proceso suele recaer sobre la actividad de los traductores expertos, obviando las cuestiones relacionadas con el proceso de aprendizaje.

A este respecto, Hewson y Martin apuntan la falta de claridad y de unanimidad que muestran los trabajos sobre los procesos involucrados en la traducción al tratar el concepto de 'proceso':

\begin{abstract}
It has never been made quite clear whether the word [process] refers to the actual cognitive operations involved in the production of a Translated Text proposed as the translation of a Source Text (ST), or to some instrumental process meant to achieve the same result, or to a combination of both; and, furthermore, whether the two operations are comparable, complementary, or radically different from each other. Besides, it is not certain that this process can be studied in isolation from the cross-cultural relationships in which it is inscribed. Most of the previous approaches, in various degrees of conceptual perceptiveness, describe one activity while at the same time referring to another, treat all at the same time or resort to a unifying concept that obscures the above-mentioned distinctions. (Hewson y Martin 1991:1-2)
\end{abstract}

En el presente trabajo consideramos el proceso de traducir desde tres ángulos diferentes: 
a) la actividad interna que lleva a cabo cualquier sujeto que traduce desde el punto de vista de los procesos cognitivos intrínsecos a la propia actividad. Aquí partimos de la hipótesis de que la actividad es cualitativamente invariable, pero se cuenta con la dificultad de que la actividad no es fácilmente abstraíble ni teorizable debido a que el fenómeno no es directamente observable (el proceso o los procesos como actividad cognoscitiva independiente del resultado)

b) la actividad interna que lleva a cabo un sujeto concreto que traduce desde el punto de vista de los procesos cognitivos peculiares del sujeto. Se parte de la hipótesis de que es una actividad variable y que esa variabilidad está directamente relacionada con la variabilidad del resultado de la actividad, si bien esa relación es, asimismo, hipotética (el proceso o los procesos como actividad cognoscitiva desarrollada en un macroproceso en el que se relacionan el objetivo de traducir un texto como desencadenante de la actividad y otro texto como resultado final de la actividad y de la tarea)

c) el proceso de evolución del sujeto en el modo de realización de la actividad a lo largo del tiempo. La hipótesis de la que partimos es que se puede modificar ese proceso de evolución mediante la intervención y modelarlo con un objetivo predeterminado (el proceso de aprendizaje, con independencia de que la evolución sea el resultado de la elaboración de estrategias de aprendizaje de forma autodidacta o de la instrucción que reciba)

Pero establecer los elementos necesarios para elaborar una metodología de la enseñanza conlleva, a su vez, tener en cuenta los aspectos que afectan propiamente al aprendizaje en sí. En este sentido, la didáctica teórica carece hasta la fecha de un modelo de representación del aprendizaje de la traducción (no sólo de la adquisición de la capacidad de mediación, sino de la adquisición de lo que se denomina vagamente el 'nivel experto'). Sin conocimientos fehacientes acerca del proceso de traducir es muy difícil elaborar una teoría de la adquisición de la capacidad de mediación que sea sólida y fiable, es decir, que tenga un potencial explicativo aceptable. Y, sin embargo, esta teoría es necesaria para poder empezar a plantearse la eficacia o ineficacia de las diferentes metodologías que se aplican hoy en día en la enseñanza de la traducción.

No podemos tampoco establecer unas bases sólidas de la didáctica de la traducción sin tratar los aspectos que se refieren al cambio que se produce en el aprendiz desde el punto de partida del aprendizaje, hasta el estado que alcanza cuando es un traductor profesional. En este caso nos encontramos de nuevo con que la investigación del campo no se ha ocupado mucho de estas cuestiones; sin embargo, esto no significa que debamos obviarlas. Desde un punto de vista general, el aprendizaje de la traducción tiene aspectos comunes con el aprendizaje de otros 
procesos de tipo cognitivo. En última instancia, comparte cierta descripción del proceso con cualquier tipo de aprendizaje, ya que en el concepto de aprendizaje está implícita la idea de una transformación de un estado inicial a otro estado final diferente, de tal modo que dicha transformación implica la adquisición de experiencia y de conocimientos de varios tipos, tal como se señala en la introducción del Capítulo 3. Teniendo en cuenta estas afinidades, no esperamos que la descripción general del proceso de aprendizaje de la traducción responda a un esquema diferente al de, pongamos por caso, el proceso de aprendizaje de la comprensión lectora o el proceso de resolución de problemas matemáticos.

Si volvemos a las diferencias que Baker ponía de relieve entre la actuación de un traductor profesional y la de un sujeto políglota, podemos esperar que el estado experto presente características diferentes en ambos casos y, por consiguiente, parece más razonable abordar la didáctica de forma diferente cuando se plantea la traducción como fin del aprendizaje y cuando ésta se contempla como medio del aprendizaje de lenguas extranjeras. Es decir, el hecho de que la definición del estado experto resulte diferente en ambos casos justifica aparentemente que se adopten taxonomías discriminatorias como la de Bühler en el nivel teórico de la didáctica, tal como defendíamos anteriormente (v. 1.1).

Con la excepción apuntada acerca de los estudios sobre el traductor experto, los trabajos sobre la enseñanza de la traducción omiten el tratamiento de cualquiera de estos aspectos. Esta carencia es extensiva al resto de áreas de la disciplina. Por el contrario, en el campo de la enseñanza de lenguas extranjeras parece haber despertado más interés el estado de conocimientos del sujeto en relación con la traducción como herramienta en el aprendizaje de lenguas extranjeras y, particularmente, la relación que existe entre la traducción y la competencia lingüística (en la L1 y la L2) del sujeto que traduce. Desde el punto de vista de la didáctica tal y como se plantea en el presente trabajo, esta omisión es injustificada dado que esta relación entre la traducción y el estado de conocimientos lingüísticos del sujeto es tan relevante cuando la traducción es el fin del aprendizaje como cuando es instrumental.

En el siguiente capítulo continuaremos ahondando en la relación entre traducción y lingüística aplicada con el propósito de establecer, en un sentido amplio, cuáles son las funciones de la traducción en el ámbito de la didáctica, con independencia del tipo de entorno de instrucción. Además de esto, relacionaremos de forma restrictiva estas funciones didácticas con el entorno de instrucción del 
Inglés para Fines Específicos, con la finalidad de estudiar de forma más detallada las manifestaciones de la traducción en el entorno relevante para nuestro trabajo.

Börsch (1986), al considerar la aplicación de diferentes métodos de recogida de datos a la investigación sobre la traducción y la comunicación intercultural, utiliza una clasificación de dos tipos de traducción según la función de ésta:

[...] we have to distinguish between different kinds of translation depending on [its function]: it is important to differentiate at least between 'translation as an intermediating process' mainly conducted by professional translators translating from the target language into the mother-tongue and 'translation as a didactic method in foreign language learning and teaching' undertaken by pupils from the mother-tongue into the foreign language and vice versa. (Börsch 1986:205-206)

Aparentemente, el criterio de comparación es la función de la traducción según (a) quién la lleva a cabo: «conducted by professional translators», o bien «undertaken by pupils», y (b) en qué dirección se traduce: «from the target language into the mother-tongue», o «from the mother-tongue into the foreign language and vice versa». Lo que además se asume con estas palabras es que la traducción profesional se produce en una dirección, de la L2 a la L1, bien porque es más natural, bien porque se considera que así se garantiza más calidad en el resultado. Por el contrario, la traducción en el aula se produce en ambas direcciones y cabe preguntarse la razón: ¿porque hay que practicar de todo?, ¿porque en el aula no importa tanto la calidad del resultado, lo cual conllevaría interpretar el resultado en relación con la precisión y el control, como la práctica en sí para adquirir experiencia (lo que supone interpretar el resultado en relación con la fluidez)?, ¿porque hay diferencias direccionales que son relevantes para la didáctica?

Si enfocamos esta cuestión desde la didáctica debemos hablar de, al menos, dos tipos específicos de didáctica: la didáctica de la traducción y la didáctica de las lenguas extranjeras. De las palabras de Börsch se desprende que asume que en la didáctica de la traducción la función que se le asigna a la traducción tiende a ser la misma que la descrita para la traducción profesional, porque ésa es la meta del aprendizaje, ya que para esta autora la direccionalidad de la traducción únicamente es irrelevante cuando ésta es utilizada como método didáctico para enseñar una lengua extranjera. ¿Por qué? ¿Existen realmente razones teóricas o prácticas para utilizar diferentes conceptos de traducción en cada caso? Por otra parte, Börsch señala al menos dos funciones para la traducción pero ¿podría haber otras funciones?; además, ¿es posible establecer un repertorio comprehensivo de 
funciones didácticas de la traducción desde una perspectiva teórica? y, en caso afirmativo, ¿cuáles son la funciones que lo componen? Estas son las cuestiones específicas sobre las que nos vamos a centrar en el capítulo siguiente. 


\section{Las funciones didácticas de la traducción}

\subsection{Introducción}

La traducción es una actividad presente en muchos cursos de Inglés para Fines Específicos. Sin embargo, su papel no está suficientemente analizado desde el punto de vista de la didáctica en este entorno (Valero Garcés 1992).

El objetivo general del presente capítulo consiste en establecer cuáles son las funciones didácticas de la traducción en el entorno del Inglés para Fines Específicos. Analizaremos estas posibles funciones didácticas en relación con una clasificación taxonómica dada, para lo cual partimos de la tipología clásica de Holmes (1988) en la que se basa Börsch (v. 1.3). Subsidiariamente, este análisis nos llevará a tratar la relación entre el Inglés para Fines Específicos y el Inglés General desde el punto de vista de la didáctica especial de las lenguas extranjeras, así como la concepción subyacente de la didáctica del Inglés para Fines Específicos, al tiempo que serán mencionados algunos aspectos relacionados con las diferentes manifestaciones del fenómeno de la traducción.

Desde el punto de vista de la traducción como disciplina, en su ya clásica descripción de los Estudios de Traducción, Holmes (1988) discrimina dos tipos distintos de enseñanza de la traducción: la traducción en el aula de lenguas extranjeras y la traducción en el aula de traducción profesional. Al menos desde Holmes, esta distinción es comúnmente aceptada y utilizada, de tal modo que podemos encontrar características representativas de cada uno de ambos tipos en trabajos como el de Bühler (1987). No obstante, desde el punto de vista 
epistemológico de la didáctica, la naturaleza de esta división merece una reflexión crítica.

A tal efecto, y con el fin de alcanzar nuestro objetivo, comenzaremos en la sección 2.1 por considerar los aspectos relacionados con la pregunta ¿es la traducción en el aula de traducción profesional un fenómeno didáctico inherentemente distinto de la traducción en el aula de lenguas extranjeras?

A continuación (v. 2.2), pasaremos a analizar qué tipo de relación se da entre la didáctica del denominado Inglés General y la del Inglés para Fines Específicos.

Finalmente, a la vista de la ineficacia que la actual clasificación vigente muestra para dar cuenta de todos los casos posibles de funciones didácticas de la traducción, formularemos una propuesta (v. 2.3) que es consistente con la didáctica general, y que supone un marco más comprehensivo que el utilizado en la actualidad. Creemos que esta propuesta ofrece claras ventajas sobre el modelo tradicional, ya que nos permite tratar el fenómeno de la traducción desde una perspectiva didáctica con el rigor necesario para poder describir las características de sus distintas funciones.

\subsection{Las funciones didácticas tradicionales de la traducción}

Para analizar desde el prisma de la didáctica la primera cuestión planteada, vamos a utilizar un criterio de comparación que refleje la concepción general del proceso educativo como un proceso eminentemente humano e intencional (Escribano González 1998:62). En este marco de referencia la enseñanza se contempla como una acción desarrollada con la intención de llevar a alguien al aprendizaje, y es definida como el 'conjunto de decisiones, actividades y medios que se organizan sistemáticamente para facilitar el aprendizaje al estudiante' por De la Cruz ${ }^{1}$. Este proceso puede ser observado y analizado de forma más precisa desde dos perspectivas diferentes: la del aprendiz y la del profesor. A lo largo de este trabajo aludiremos con frecuencia a este proceso de diversas formas. En aquellos casos en que la perspectiva adoptada sea la del profesor, utilizaremos la

\footnotetext{
${ }^{1}$ Taller titulado «Elaboración del Proyecto Docente», impartido por la Dra. A. De la Cruz los días 19 y 20 de Febrero de 2001 en la Universidad de Salamanca.
} 
denominación de 'enseñanza' para referirnos a dicho proceso, mientras que cuando el punto de vista corresponda con el aprendiz emplearemos el término 'aprendizaje'. Así, preferimos emplear la denominación 'proceso de enseñanza-aprendizaje', desde un punto de vista general, para referirnos al proceso educativo en el que se desarrolla el curso de Inglés para Fines Específicos.

\subsubsection{La traducción como un medio para la enseñanza}

De acuerdo con la división de Holmes (1988) de los Estudios de Traducción dentro de la rama aplicada, llamamos 'traducción como medio' a la traducción utilizada con el propósito último de enseñar una lengua extranjera. $\mathrm{Su}$ entorno de aplicación es, por lo tanto, el aula de lenguas extranjeras en particular. En este contexto, la traducción es empleada como una técnica o un método que se aplica para lograr diversos fines, tales como reforzar el aprendizaje de la lengua extranjera por contraste con la materna, evaluar la comprensión escrita, o evaluar la adquisición de la lengua extranjera (véase, por ejemplo, Zohrevandi 1994). En todos estos casos, la traducción no es considerada tanto en relación con el tipo de fenómeno lingüístico que supone, sino más bien desde la perspectiva de la función didáctica que va a ejercer dentro de la planificación de la enseñanza de la lengua extranjera. Así, Bühler (1987) describe este tipo de traducción como un proceso más bien mecánico que habitualmente consiste en la trascodificación más o menos automática de ciertos elementos linguísticos, como palabras y frases, de una lengua de origen a una lengua de llegada, con la ocasional paráfrasis (a menudo $a$ posteriori) destinada a ajustarse a las restricciones de la lengua de llegada (véase también Parkinson 1995:78).

En este tipo de traducción, la atención se suele centrar en los aspectos estructurales y léxicos del lenguaje desde un punto de vista contrastivo, al tiempo que el significado se contempla como una entidad objetiva cuyo alcance afecta a los términos del tradicional tertium comparationis. El énfasis de este enfoque recae en la producción de formas lingüísticas correctas en la lengua extranjera a partir de un input en la lengua materna (o viceversa) que suele aparecer descontextualizado.

Como apunta Bühler, la traducción en este entorno no está al servicio de ningún propósito comunicativo. Sin embargo, la traducción en la realidad siempre se produce en un entorno de tipo social. Como fenómeno lingüístico, la traducción comparte con otras manifestaciones del lenguaje el hecho de que nunca se produce en el vacío, sino que se manifiesta como un acto de comunicación entre 
interlocutores de distintos tipos. No en vano se considera que la traducción surge como respuesta a la necesidad de relacionarse con grupos sociales diferentes al menos lingüísticamente. Torre opina que «mucho antes de la invención de la escritura, el contacto entre grupos pertenecientes a comunidades lingüísticas diferentes hubo de exigir el concurso de un intérprete o traductor oral» (Torre 1994:16). La traducción es inherentemente, por tanto, un fenómeno de interacción social.

En este sentido, como plantean Reiss y Vermeer, esta interacción está determinada «por la realidad cultural ya dada, por las circunstancias exteriores del momento, por las condiciones sociales y personales de los interlocutores y por su relación mutua. Por tanto, un modelo de interacción debe incluir factores tanto individuales como supraindividuales (sociales)» (Reiss y Vermeer 1991:13-14).

A la vista de estas consideraciones, la traducción como medio de la enseñanza no responde a un modelo de interacción social y, por tanto, es insuficiente para dar cuenta de las distintas traducciones producidas en el aula si el input ofrecido para traducir no está contextualizado. En el siguiente ejemplo una parte de la variación potencial de las distintas traducciones de los estudiantes reside en la ausencia de información sobre el input. ¿Se trata de un texto o es una acumulación de oraciones sin textura? ${ }^{2}$ ¿Quiénes son los interlocutores en cada caso? No se trata de curiosidad gratuita, sino de tener información disponible que sea suficiente para poder comprender la secuencia y así poder decidir qué elementos aparecerán en la traducción. Por ejemplo, si se utilizarán pronombres masculinos o femeninos al traducir «le miro», «me gusta», «le telefoneé», o «no quiso venir»; es decir, necesitamos saber en este caso si la información se refiere a un hombre o a una mujer.

Translation into English:

Da la casualidad que lo conocí en uno de mis viajes a Inglaterra. Parecía que le gustaba la vida en Londres. Cuanto más le miro tanto más me gusta. ¿Qué habrías hecho tú si él te hubiera invitado? Yo le telefoneé para que viniera pero no quiso venir. ¿Desde cuándo trabajas en este hospital? Desde hace dos meses. Parece que tenemos horarios diferentes porque no te he visto durante este tiempo. (Alcaraz y Moody 1978:54)

\footnotetext{
${ }^{2}$ Halliday y Hasan definen la 'textura' como lo que distigue a un texto de lo que no es texto. La textura se deriva del hecho de que el texto funciona como una unidad con respecto de su entorno (Halliday \& Hasan 1976:2). En este ejemplo, la ausencia de información sobre el entorno de la comunicación, es decir, la falta de información contextual, así como las características cotextuales presentes, es decir, el entorno local en el propio texto, hacen que la interpretación de «Cuanto más le miro más me gusta» sea difícil para el receptor, que en este caso es el estudiante de Inglés.
} 
En este sentido, no es de extrañar que la traducción como medio de la enseñanza no goce de gran acogida. La lingüística aplicada a la enseñanza de lenguas extranjeras ha aceptado la traducción como un instrumento para aprender la lengua, tradicionalmente mediante el papel que ha tenido en el denominado 'grammar translation method' (Schmidt 1994:11; Zaro 2001). Esta aceptación ha sido desigual a lo largo de la historia pero lo que es sumamente interesante es que, de acuerdo con Davies (1993), la aceptación o el rechazo de la traducción en este entorno no ha respondido a planteamientos de tipo didáctico ${ }^{3}$. A su vez, Holmes (1988) objeta que, antes de proceder al diseño curricular, se debería dar prioridad a una investigación extensiva y rigurosa para valorar la eficacia de la traducción como técnica y como método de evaluación en el proceso de enseñanza-aprendizaje de lenguas extranjeras, dado que las posibilidades de que esta técnica resulte ineficaz son bastante elevadas. No parece que hasta la fecha se haya avanzado mucho en esa dirección, por lo que nuestro conocimiento acerca de la eficacia de la traducción en ese entorno continúa siendo muy exiguo.

Tal como señala Holmes, tampoco parece estar muy clara la eficacia de la traducción como instrumento de evaluación del aprendizaje. Especialmente la falta de claridad acerca de qué conocimientos, destrezas o actitudes estamos evaluando exactamente, hacen que la tarea de evaluar se complique extraordinariamente, o bien que exija al profesor mucha más dedicación que cuando utiliza otros métodos de recogida de datos ${ }^{4}$. Esto puede servir para explicar por qué la traducción parece

\footnotetext{
${ }^{3}$ «In language teaching as in education generally, what determines change is the roundabout in fashion which seems recently to be moving back towards a modified grammar-translation method after a number of years in which such an approach to language teaching was anathema to many people» (Davies 1993:14).

${ }^{4}$ Zaro (2001) detecta aquí una contradicción en el ámbito de la didáctica de las lenguas extranjeras entre lo que indican las obras sobre evaluación y el uso que se da a las actividades de traducción en la práctica docente:
}

Puede decirse como hipótesis, a falta de informaciones fiables, que los profesores españoles de lenguas extranjeras que enseñan a alumnos monolingües siguen recurriendo a la traducción como ejercicio de evaluación, sobre todo de la L1 a la L2, a veces sin excesiva coherencia ni claridad de objetivos. En consecuencia, podemos suponer que los alumnos posiblemente también preparan sus pruebas de evaluación traduciendo, sobre todo como manera de comprobar sus conocimientos, a sabiendas de que la traducción es un componente esencial del test. Todo ello cuando la literatura sobre evaluación de lenguas extranjeras, que a partir de los años sesenta desarrolla un carácter ante todo cuantitativo en su afán por alcanzar condiciones mínimas de fiabilidad y objetividad, haya rechazado de plano la traducción a la L2 como elemento de evaluación por su intríseca complejidad, que la gran mayoría de las veces sitúa por encima de la competencia real del alumno. 
no gozar de gran aceptación como instrumento de recogida de información en el entorno de la didáctica especial de las lenguas extranjeras. Interpretamos como un indicio de esta falta de aceptación el hecho de que, al menos en lo que concierne a la didáctica del Inglés para Fines Específicos, ningún autor de los que hemos consultado trata de forma detallada cómo evaluar las traducciones en este entorno a pesar de que las tareas de traducción suelen ser utilizadas en muchos cursos de lenguas para fines específicos.

Zaro (2001) señala tres problemas que se le achacan al uso de la traducción en el aula de lengua extranjera, y que podemos resumir así:

1. La traducción no es una 'actividad natural' porque es radicalmente distinta de las cuatro destrezas. Por consiguiente, es un mal ejercicio para evaluar el aprendizaje de dichas destrezas.

2. La traducción produce confusión en los alumnos porque «pueden creer que unidades de una y otra lengua tienen una correspondencia unívoca y, por tanto, impide que los alumnos piensen en la lengua extranjera y produce interferencias».

3. La traducción hace «perder un tiempo valioso» que puede emplearse en enseñar las cuatro destrezas, por lo que «sólo debería contemplarse en el caso de alumnos de Traducción».

En el primer caso, la objeción se refiere a la incapacidad de la traducción para evaluar el aprendizaje de la lengua extranjera. Aquí nos encontramos con una doble falacia en el argumento, ya que, en primer lugar, es la separación del lenguaje en cuatro destrezas la que constituye una clasificación no natural, en el sentido de que no es una propiedad del lenguaje, sino simplemente un criterio de clasificación útil para la metodología. Por el contrario, la traducción sí es una actividad natural dado que se trata de una capacidad que se manifiesta en el individuo en cuanto aprende más de una lengua, independientemente del método de aprendizaje o del momento o del par o el grupo de lenguas de que se trate. Es decir, se trata de una capacidad característica de aquellos sujetos que conocen más de una lengua y, por lo tanto, no podemos afirmar que se trate de una 'actividad no natural' puesto que surge espontáneamente en el individuo.

La segunda parte de la falacia consiste en creer que el único método para comprobar el aprendizaje de la escritura es pedir al sujeto que escriba, de la comprensión auditiva es pedirle que escuche, de la comprensión lectora es pedirle que lea, y de la competencia verbal, pedirle que hable. En esta línea argumental, Zaro, basándose en otros autores, señala los supuestos peligros de utilizar la 
traducción para evaluar la competencia en la lengua extranjera: «a translation test is not valid as a test of mastery of a foreign language. If properly constructed, a translation test can be a valid test of the ability to translate. In addition, the problem of scoring translation tests is a very serious one» (Zaro 2001). Sin embargo, como podemos comprobar revisando el repertorio de métodos de recogida de información que Bloom y sus colaboradores mencionan para cada uno de los objetivos educacionales (Bloom et al. 1956; Krathwohl, Bloom y Masia 1964), existen múltiples métodos de recogida de información que no implican más que indirectamente alguna de las cuatro destrezas.

Es evidente que podemos comprobar la capacidad de comprensión lectora pidiendo al alumno que ejecute las instrucciones que aparecen en un texto. Si esas instrucciones consisten en dibujar un cilindro de unas medidas determinadas, por poner un caso, y el alumno las lleva a cabo de acuerdo con las indicaciones del texto, asumiremos que ha comprendido el texto porque la comprensión de éste es un prerrequisito para que pueda dibujar la figura de acuerdo con las condiciones señaladas en el texto. Así pues, esta objeción no es suficiente para invalidar la potencial utilidad de la traducción como método de evaluación del aprendizaje porque se basa en argumentos falsos tanto desde una perspectiva cognitiva como desde el punto de vista de la didáctica general.

La objeción que Zaro menciona a continuación, considerar que la traducción es una fuente de confusión para los estudiantes porque les puede inducir a pensar que el significado entre lenguas tiene una relación de univocidad, sólo es plausible en el caso de que la traducción sea utilizada con el objetivo de aprender léxico o reglas gramaticales. Esto implica un concepto de la traducción que no representa adecuadamente el tipo de fenómeno complejo de que se trata. Como quiera que es el profesor el responsable del tipo de actividad y del concepto de traducción que se utilizará en la metodología del curso, así como de la adopción de una metodología en particular u otra, podemos afirmar que esta objeción no invalida la utilidad de la traducción en sí misma, sino que más bien pone en tela de juicio al profesor que elige adoptar una metodología con un enfoque así. Por otra parte, podemos esperar razonablemente, por nuestra experiencia docente y por la de otros colegas, que los estudiantes del entorno que estamos considerando en este trabajo ya tengan antes de comenzar el curso ideas preconcebidas acerca del lenguaje que coincidan con las que supuestamente la traducción puede inducir a forjar, por lo que la objeción no es aplicable en ese caso. Más bien al contrario, desde nuestra perspectiva, pensamos que existe la posibilidad de que sea precisamente la 
traducción, al implicar necesariamente la puesta en contacto de dos sistemas lingüísticos, sociales y culturales diferentes, una de las actividades con mayor potencial para mostrar a los estudiantes cómo una visión unívoca sobre el significado es errónea.

El último problema señalado por Zaro considera el uso de la traducción en términos de su baja rentabilidad: exige demasiado tiempo para los beneficios que reporta, al menos, en comparación con la enseñanza de las (otras) cuatro destrezas. Y bien, es cierto que las tareas de traducción son costosas de evaluar, del mismo modo que la evaluación de resúmenes lo es. Se trata de destrezas complejas por la cantidad de factores involucrados y su análisis es asimismo complejo, de modo que la preparación del método y el análisis de los datos obtenidos mediante una prueba de estas características exige tiempo y esfuerzo por parte del profesor. Pero en esto, como señala Cunningham, tampoco presentan grandes diferencias con otros métodos complejos de evaluación:

The construction of an effective, valid assessment instrument requires extensive planning and preparation. When teachers are unwilling to devote sufficient amount of time to the test construction process, unplanned tests are often the result. Teachers are usually overburdened with responsibilities and they may feel that they don't have enough time to plan and create valid assessment tools, while continuing to accomplish everything expected of them. Unfortunately, there is no way to create a good test in a limited amount of time. There are shortcuts, but they should be approached with caution. (Cunningham 1998:46)

Teniendo en cuenta todas estas consideraciones, podemos decir que no existen objeciones sólidas para la utilización de la traducción como método de recogida de información en la evaluación del aprendizaje ni como tarea para mejorar el aprendizaje de lenguas extranjeras más allá de la propia complejidad de este fenómeno.

\subsubsection{La traducción como un fin de la enseñanza}

Por su parte, llamamos 'traducción como fin' al proceso educativo en el que la traducción se enseña con el objeto de formar a futuros traductores profesionales; proceso mucho más reciente que el de la enseñanza de las lenguas extranjeras. Nos referimos aquí a la traducción tal como se manifiesta cuando es el propio fin del proceso de enseñanza-aprendizaje. Su entorno de aplicación es, en este caso, el aula de traducción profesional y Bühler (1987) describe este tipo de traducción como una operación esencialmente comunicativa. En este contexto, la traducción es concebida 
como un proceso de mediación entre diferentes culturas y civilizaciones que requiere del traductor una gran profesionalidad y fiabilidad para garantizar la transferencia deseada de la información. Esta concepción de la traducción responde al objetivo fundamental de preparar profesionalmente a futuros traductores. Gallardo San Salvador explica, a grandes rasgos, en qué consiste esta profesionalización:

[...] traductores capaces de integrarse en el mercado de trabajo profesional, con unos conocimientos básicos y suficientes de los mecanismos de la traducción, de sus técnicas y estrategias, de las características de los diferentes tipos de texto, nociones básicas de documentación, terminología, etc. (Gallardo San Salvador 1999:63).

Desde el punto de vista de la intencionalidad del proceso educativo en cada caso, parece que nos estamos refiriendo a fenómenos de distinta índole. La traducción como medio y la traducción como fin muestran varios rasgos contrastivos, que podemos resumir del siguiente modo:

- El entorno de enseñanza: la traducción como medio se asocia con el aula de lenguas extranjeras, mientras que la traducción como fin se asocia con el aula de traducción profesional

- El objetivo de la enseñanza: cuando la traducción es un medio, el fin de la enseñanza es lograr que el aprendiz mejore su competencia lingüística o bien su competencia comunicativa en la lengua extranjera; en el segundo caso, el fin es mejorar su competencia traslativa o traductora

- El tiempo dedicado a la actividad de traducir y su importancia relativa dentro de la metodología utilizada son exiguos, secundarios, irrelevantes o inexistentes en el aula de lenguas extranjeras, mientras que son muy prominentes en el aula de traducción profesional

- La concepción subyacente del fenómeno: la traducción es concebida en el aula de lenguas extranjeras a partir de la cualidad de objeto tangible que tiene el TO, y dentro de ésta, en su calidad de muestra visual de las manifestaciones de los sistemas lingüísticos implicados. Así, en el aula de lenguas extranjeras, el texto tiende a ser contemplado y analizado como un conjunto de palabras y expresiones lingüísticas, y la traducción como la vía de unión y contraste con otros sistemas lingüísticos ${ }^{5}$. Podemos decir que la

\footnotetext{
${ }^{5}$ En el aula de lenguas extranjeras, el texto que pasa a ser tomado como un TO, es decir, el texto que va a ser utilizado para practicar la traducción, tiende a ser contemplado como un conjunto de estructuras sintácticas, palabras y expresiones lingüísticas. Esto ocurre aun a pesar de que el enfoque acerca del lenguaje que se suele adoptar en los actuales métodos de enseñanza de lenguas extranjeras como el inglés o el español sea comunicativo, es decir, un enfoque en el que
} 
traducción es contemplada aquí como un método de análisis contrastivo entre dos lenguas, llevado a cabo con el fin de identificar diferencias entre ambos sistemas lingüísticos (Munday 2001:9)

Por su parte, en el aula de traducción profesional, además de considerar la traducción como un producto que es el resultado del proceso de traducir, el concepto de traducción adoptado suele comprender, asimismo, sus complejas manifestaciones como proceso comunicativo desde un enfoque menos restrictivo. Es decir, en el aula de traducción profesional, el texto y la traducción (y, de forma subyacente, el lenguaje) suelen ser considerados, observados y analizados como un complejo vehículo de comunicación. Se suele seguir una concepción más integradora de la traducción, que Hurtado Albir define como aquella en la que «la traducción es texto, acto de comunicación y proceso mental» (Hurtado Albir 1999:40).

Desde una perspectiva global, no obstante, no debemos olvidar que la traducción como medio y la traducción como fin son aspectos particulares del mismo complejo fenómeno, que se manifiesta de un modo u otro en función del objetivo educacional establecido en cada caso. En este sentido, resulta obvio que la traducción en el aula de lenguas extranjeras, tal y como la describe Bühler, representa una concepción excesivamente simplificada del fenómeno. La razón de esto probablemente sea que en este entorno la traducción es contemplada como un instrumento de eficacia dudosa como facilitador del aprendizaje de la lengua, por lo cual se considera innecesario explicar en qué consiste o reflexionar acerca del fenómeno en sí. En esta línea, la opinión de Zaro (2001) es muy ilustrativa del desfase existente entre la investigación y la práctica docente en muchos casos:

[...] la conspicua ausencia de la traducción en los materiales didácticos, recomendaciones oficiales y, en general, en la formación del profesorado de lenguas extranjeras durante tantos años ha sido probablemente uno de los «pactos de silencio» mejor observados de la profesión, que contrasta con la realidad de su uso en la práctica docente, fácilmente observable tanto en actividades de clase como en pruebas de evaluación. (Zaro 2001)

A pesar de que la traducción es un fenómeno único con múltiples y diversas manifestaciones (lo cual explica en parte las dificultades existentes para establecer taxonomías de este fenómeno), la traducción como medio y la traducción como fin suelen ser tratadas como manifestaciones de fenómenos inherentemente distintos en

predomina el aspecto comunicativo del lenguaje sobre otros aspectos que tradicionalmente han ostentado un estatus preponderante, como ocurría con la gramática clásica hace unos años, frente a la gramática comunicativa o funcional actual. 
el entorno de la didáctica de la traducción por razones prácticas, a pesar de no existir razones teóricas para ello.

En este sentido, la tipología didáctica tradicional de la traducción se sustenta sobre bases ajenas a los fundamentos epistemológicos de la didáctica, y no refleja adecuadamente el hecho de que se trate de un fenómeno complejo único con independencia de sus diversas manifestaciones. Esto es más fácilmente observable al analizar la función didáctica de la traducción en el aula de Inglés para Fines Específicos. Dado que se suele tratar de forma discriminada la didáctica de las lenguas extranjeras en general y la didáctica de las lenguas para fines específicos, no podemos identificar de manera automática la función didáctica de la traducción en uno de estos entornos con su función didáctica en el otro entorno.

Por último, nuestras conclusiones señalan que la tipología didáctica tradicional de la traducción, tal y como la describen Holmes y Bühler, no es lo suficientemente flexible para clasificar las posibles funciones de la traducción en el entorno del Inglés para Fines Específicos. Puede que esta falta de flexibilidad provenga de la identificación entre la didáctica de las lenguas extranjeras y la didáctica del Inglés para Fines Específicos, en cuyo caso habríamos de considerar si, tal como estos autores apuntan, la única función de la traducción en el aula de Inglés para Fines Específicos es lo que hemos descrito como 'traducción como medio'. Por esta razón, en la sección siguiente analizaremos en más detalle la relación entre la didáctica del denominado Inglés General y la didáctica del Inglés para Fines Específicos.

\subsection{El Inglés para Fines Específicos en relación con el Inglés General: aproximación didáctica}

Nuestro punto de partida en esta sección es que, si bien la traducción se manifiesta de distintos modos en el aula de acuerdo con el enfoque didáctico planteado para el proceso de enseñanza-aprendizaje, la función didáctica de la traducción en el entorno del Inglés para Fines Específicos no ha sido tratada de forma explícita por la didáctica especial de las lenguas extranjeras.

Cualquier enfoque didáctico especifica los contenidos del curso, los objetivos, los métodos para alcanzar esos objetivos y la evaluación como método de comprobación de los resultados obtenidos, así como otros factores necesarios para determinar en el tiempo y el espacio el proceso de enseñanza-aprendizaje (la 
temporalización, la secuenciación, etc.). Estos fundamentos pedagógicos se hacen explícitos y adoptan unos valores determinados u otros en función de las características particulares de los contenidos que se vayan a tratar en el curso, en lo que se denomina 'didáctica especial' por oposición a la 'didáctica general' (Escribano González 1998). Es decir, se trata de la didáctica que recoge las particularidades propias de la materia que se imparte (qué se enseña y qué se aprende), incluyendo las peculiaridades en el modo de impartirla (cómo se enseña y cómo se aprende).

Por lo que respecta a la didáctica del Inglés para Fines Específicos, que es en muchas ocasiones tratada por los especialistas de este campo de forma independiente de la didáctica de las lenguas extranjeras (véase, por ejemplo, Pajares Infante y Romero Armentia 1992), el mayor hincapié de la investigación ha recaído hasta la fecha en el análisis de necesidades previo al diseño del curso, así como en la producción de materiales de apoyo a la docencia. De hecho, el análisis de necesidades ha sido el aspecto más controvertido en los cuarenta años de reflexión e investigación que se llevan desarrollando en este campo.

Por su parte, los cambios en los materiales producidos a lo largo de este tiempo pueden ser interpretados como un reflejo de los cambios progresivos en la conceptualización del Inglés para Fines Específicos. Estos cambios no son necesariamente excluyentes ni incompatibles entre sí, pero presentan características que se pueden organizar alrededor de dos bloques, a saber, uno que aglutina cuestiones relacionadas directamente con la didáctica, y otro dedicado al tratamiento del concepto de lenguaje que subyace a la caracterización del proceso educativo (v. Widdowson 1983:32) ${ }^{6}$. Por lo que respecta a esta tesis doctoral, una buena parte está dedicada a poner de manifiesto cuál es nuestra concepción del Inglés para Fines Específicos y nuestra forma de proceder consiste en la descripción, entre otros aspectos involucrados, de las características que se asocian con ambos bloques temáticos. Así, a lo largo de este capítulo y del siguiente nos centraremos en el primer bloque, atendiendo en primer lugar a los aspectos que caracterizan el Inglés

\footnotetext{
${ }^{6}$ Es importante disociar la concepción del enfoque metodológico y la concepción de lenguaje que se utiliza en el proyecto de enseñanza-aprendizaje. Podemos ilustrar este punto aludiendo a Widdowson cuando critica el enfoque estructural:
}

The basic flaw in the structural approach is not that it fails to teach communication directly, but that it represents language in a way which dissociates the learner from his own experience of language, prevents real participation, and so makes the acquisition of communicative abilities particularly (and needlessly) difficult. (Widdowson 1979:246) 
para Fines Específicos desde la perspectiva de la enseñanza. Trataremos a continuación (en el Capítulo 3) los aspectos relevantes para la didáctica del Inglés para Fines Específicos desde la perspectiva del aprendiz y del aprendizaje, mientras que los aspectos relativos a la concepción del lenguaje que subyace en nuestra apoximación se desarrollarán a lo largo de los Capítulos 4 y 5 .

Hutchinson y Waters conciben lo que denominamos Inglés para Fines Específicos (o cualquier otra expresión de las que se utilizan) como un modo de enseñar la lengua, más que como un tipo de lenguaje específico: «ESP should properly be seen not as any particular language product but as an approach to language teaching which is directed by specific and apparent reasons for learning» (Hutchinson y Waters 1987:19). Partimos, por tanto, de una concepción general de la didáctica especial de las lenguas extranjeras en la que están incluidos tanto el Inglés para Fines Específicos como el Inglés General.

Desde esta perspectiva, el Inglés para Fines Específicos y el Inglés General forman un todo inseparable. Así, se interpreta que los conceptos de 'lengua general' y 'lengua especializada' no reflejan divisiones reales, sino que se utilizan por razones de tipo práctico (Varantola 1986). No obstante, para algunos autores, la razón subyacente de esta división es que los contenidos deben ser muy específicos en relación con el campo de aplicación, como explica García Mayo (2000:43): «traditionally the linguistic features of the target situation have formed the basis of the ESP syllabus (e.g. asking mechanical engineers to study mechanical engineering texts)».

Por otra parte, el conjunto de opciones metodológicas disponibles es común a cualquier modalidad de didáctica de las lenguas extranjeras y sigue una misma trayectoria de desarrollo en el Inglés para Fines Específicos y en el Inglés General (Revilla Vicente 1995; Robinson 1991) ${ }^{7}$.

Por lo que se refiere a los materiales disponibles en el mercado para apoyar la docencia de los cursos de lenguas extranjeras, tanto los que se utilizan en los cursos de Inglés para Fines Específicos como en los de Inglés General, son producidos tras un cuidadoso análisis de necesidades (por ejemplo, los materiales se destinarán a adultos japoneses, para un curso de 50 horas, y la variedad predominante de inglés será la denominada 'received pronunciation' o RP, o quizá se van a destinar a bioquímicos españoles, para un curso de 200 horas, y la variedad

\footnotetext{
${ }^{7}$ Para una revisión histórica de la trayectoria de las metodologías y de los distintos enfoque didácticos en el Inglés para Fines Específicos, véase la obra de García Mayo (2000) o la de Revilla Vicente (2003).
} 
predominante será la denominada General English) y están orientados a alcanzar unas metas determinadas previamente (por ejemplo, la meta consiste en obtener los conocimientos necesarios para superar el examen First Certificate de la Universidad de Cambridge, o quizá los conocimientos necesarios para presentar y discutir los resultados de una investigación mediante una presentación multimedia en un congreso internacional).

Por último, los métodos de evaluación que se utilizan para comprobar si los objetivos del curso han sido alcanzados o para valorar los progresos de los aprendices son también los mismos. No obstante, algunos autores, como Montañes Brunet y Bosch Abarca piensan que, en el caso del Inglés para Fines Específicos, se deben añadir elementos que evalúen los progresos en cuanto al contenido específico del curso ${ }^{8}$ :

Tests usually measure general proficiency but, things may vary slightly when we tackle the issue of English for Specific Purposes (ESP). ESP testing descriptions may be similar to those of General English but they are modified to fit the needs of our students and the special register(s) required [...].

In the required register, we focus on subject matters or subject specific materials, thus we have to add to the features of integrative test a further important element in our specific area: Knowledge-based statements (which test the specific content of the course designed to meet the needs of our students). (Montañes Brunet y Bosch Abarca 1992:158)

Probablemente a partir de cómo es tratada por Widdowson (1983) la cuestión sobre el grado de generalidad o especificidad que deben tener los cursos en el ámbito de la didáctica del Inglés para Fines Específicos (v. 3.3.5), Dudley-Evans y St. John (1998) consideran que resulta más productivo contemplar la didáctica de la lengua inglesa como una línea continua que va desde cursos claramente definibles como cursos de Inglés General hasta cursos de Inglés para Fines realmente Específicos. Estos autores establecen cinco posiciones relativas a lo largo de la hipotética línea continua de la didáctica de la lengua inglesa, en función del grado de especificidad que tenga cada curso en particular, y que reproducimos esquemáticamente en la Tabla 1.

\footnotetext{
${ }^{8}$ Estas autoras definen el 'integrative test' como «[that which] attempts to assess the learner's capacity to use many bits (of language) all at the same time» (Montañes Brunet y Bosch Abarca 1992:157).
} 


\begin{tabular}{|c|c|c|c|c|}
\hline \multicolumn{2}{|c|}{ GENERAL } & \multirow[b]{2}{*}{3} & \multicolumn{2}{|r|}{ SPECIFIC } \\
\hline $\mid 1$ & 2 & & 4 & 5 \\
\hline Position 1 & Position 2 & Position 3 & Position 4 & Position 5 \\
\hline $\begin{array}{l}\text { English for } \\
\text { Beginners }\end{array}$ & $\begin{array}{l}\text { Intermediate to } \\
\text { advanced EGP } \\
\text { courses with a } \\
\text { focus on } \\
\text { particular skills }\end{array}$ & $\begin{array}{l}\text { EGAP/EGBP } \\
\text { courses based } \\
\text { on common- } \\
\text { core language } \\
\text { and skills not } \\
\text { related to } \\
\text { specific } \\
\text { disciplines or } \\
\text { professions }\end{array}$ & $\begin{array}{l}\text { Courses for } \\
\text { broad } \\
\text { disciplinary or } \\
\text { professional } \\
\text { areas, for } \\
\text { example Report } \\
\text { Writing for } \\
\text { Scientists and } \\
\text { Engineers, } \\
\text { Medical } \\
\text { English, Legal } \\
\text { English, } \\
\text { Negotiation/Me } \\
\text { eting Skills for } \\
\text { Business } \\
\text { People }\end{array}$ & $\begin{array}{l}\text { 1) An } \\
\text { 'academic } \\
\text { support' course } \\
\text { related to a } \\
\text { particular } \\
\text { academic } \\
\text { course. } \\
\text { 2) One-to-one } \\
\text { work with } \\
\text { business people }\end{array}$ \\
\hline
\end{tabular}

Tabla 1. Tipos de cursos a lo largo de la línea continua de la didáctica de la lengua inglesa (Dudley-Evans y St. John 1998) ${ }^{9}$

En el presente trabajo, nos parece que la posición más razonable para tratar de un modo necesariamente general y suficientemente específico nuestra aproximación a los cursos de Inglés para Fines Específicos será la que DudleyEvans y St. John (1998) sitúan en la tercera y la cuarta posición, con especial referencia a los cursos diseñados para la variedad denominada 'Inglés Académico', dada su relevancia para el entorno que estamos analizando. Dudley-Evans y St. John explican qué tipo de cursos se incluyen la cuarta posición, más específica que la tercera, de modo que nos remitiremos a la descripción que hacen estos autores para ilustrar de forma económica los cursos y destrezas que consideramos relevantes en este trabajo:

\footnotetext{
${ }^{9}$ Las siglas EGP, EGAP y EGBP corresponden respectivamente con 'English for General Purposes', 'English for General Academic Purposes' (que incluye las destrezas asociadas típicamente con las actividades académicas que son comunes a todas las disciplinas) y, por último, 'English for General Business Purposes' (que se refiere a aquellos cursos destinados a «preexperience learners or those at the very early stages of their career» (Dudley-Evans y St. John 1998:55)).
} 
At position 4 , the work is very specific in terms of the skills taught, but the groups themselves are not homogeneous groups from one discipline or profession. When we talk of engineers, scientists or doctors, we are talking about broad groups: individual members may have quite different needs and backgrounds. So, on the one hand, detailed attention will be paid to a skill such as report writing, or particular features of language and/or discourse of, say, a business meeting, but, on the other hand, great care has to be taken in choosing the actual skill or skills to focus on and the contexts in which to do so. For example, some doctors will need to read and write medical journal articles, others will need oral skills for talking to patients. A group of engineers from a variety of branches such as civil, highways, electronic, chemical and mechanical will probably not take kindly to materials that use contexts from just one branch of engineering. Teaching material prepared for such groups needs contexts that are acceptable and understandable to all branches. (Dudley-Evans y St. John 1998:8-9)

En otro orden de cosas, Widdowson (1983) también parte de una concepción general de la didáctica del inglés como lengua extranjera para analizar qué es lo que justifica desde la didáctica la existencia del Inglés para Fines Específicos como entidad propia, y comienza por poner de relieve diferencias en el modo de definición de los objetivos, así como en la manera de llegar a su consecución:

Perhaps the first observation to make is that, in spite of the implied claim, an ESP course is in one sense really no more specific in its purposes than is one designed for general purpose English teaching (GPE for short). Syllabus designers and textbook writers have customarily worked to quite exact specifications, drawn up with reference to inventories of language items of one sort or another and directed at purposes represented by different stages of achievement, themselves defined by reference to some notion of eventual aims. In this respect, GPE is no less specific and purposeful than ESP. What distinguishes them is the way in which purpose is defined, and the manner of its implementation. (Widdowson 1983:5)

En general, los cursos de cualquier lengua extranjera suelen presentar ciertas peculiaridades, según se contemple como objeto de la enseñanza la lengua general o bien la lengua con fines específicos. Cuando se trata de enseñar la lengua general, el objetivo último del proceso educativo suele ser que los estudiantes alcancen el nivel máximo de competencia comunicativa. Por su parte, los objetivos específicos del curso se definen en relación con el nivel de competencia que el grupo de estudiantes ya posee. Es decir, el curso se planifica de modo que los estudiantes progresen a partir de la consolidación de los conocimientos adquiridos con anterioridad al comienzo del curso. Así, la homogeneidad del grupo suele estribar en un punto de partida común en el aprendizaje, de ahí las pruebas iniciales de ubicación por niveles. La lengua se desglosa en niveles de competencia 
comunicativa y los cursos se articulan en secuencias graduales por niveles. El estudiante sigue las etapas de aprendizaje de forma escalonada de tal modo que el techo alcanzado en un nivel sirve de punto de partida en el nivel siguiente.

Por el contrario, cuando se trata de enseñar una lengua con fines específicos, suelen confluir una serie de peculiaridades entre las que Giménez destaca la duración específica, la orientación instrumental del curso como motivación para los estudiantes, y las propias expectativas de éstos:

First, ESP courses are usually of short duration (usually from 6-8 months), seriously limiting the time available for remedial work. This time constraint seems even greater when we consider that, unlike General English students, ESP students usually work within a rigid timetable. Secondly, ESP students are instrumentally motivated and they «are likely to be more goal oriented and to expect success» (Ellis \& Johnson 1994: p.11). Thus, the perception of what the course should prepare them to do is different from that of students in General English courses. Finally, ESP students, especially those who need English at work, are more likely to put into practice what they have learnt as soon as they leave their classrooms, reinforcing language errors through frequent practice. (Giménez 1996:234)

En el entorno del Inglés para Fines Específicos, el objetivo último de la enseñanza suele ser que los estudiantes alcancen el grado de competencia necesario en las tareas que precisan llevar a cabo profesionalmente o en un entorno académico. Ejemplos de estas tareas son la producción de artículos científicos, la comunicación oral o escrita con clientes extranjeros, la comprensión de los manuales de instalación de maquinaria sofisticada, así como otras tareas especializadas que se dan en entornos restringidos, en los que sólo participan ciertos grupos sociales. Por esta razón, los objetivos específicos del curso se definen en relación con las necesidades comunicativas específicas que el grupo de estudiantes presenta. Así, el curso se planifica de tal modo que los estudiantes puedan llegar a cubrir sus carencias y superar sus limitaciones comunicativas en unos contextos determinados. En este sentido, la homogeneidad del grupo se encuentra en las metas que se pretenden alcanzar, es decir, en el punto de llegada común en el aprendizaje. El objetivo no es, como en el caso de los cursos sin finalidad específica, la competencia comunicativa en conjunto, sino lo que podríamos denominar una 'competencia comunicativa especializada' o restringida.

La diferencia más notoria entre los cursos de Inglés General y los de Inglés para Fines Específicos radica en la definición de la competencia que se desea adquirir y en la concepción de los objetivos del curso. En ambos casos se apela al 
análisis de las necesidades de los estudiantes para establecer un tipo de objetivos u otro, pero Widdowson opina que esta expresión es ambigua.

Este autor establece una diferencia en la formulación de objetivos entre el Inglés para Fines Específicos y el Inglés General. En el primer caso, el objetivo se interpreta como una 'cualificación', mientras que en el segundo, se asocia con el concepto de 'educación':

In ESP, 'purpose' [...] is essentially [...] a training concept: having established as precisely as possible what learners need language for, one then designs a course which converges on that need. The course is successful to the extent that it provides learners with the restricted competence they need to meet their requirements. In GPE it is of course not possible to define purpose in this way. Instead it has to be conceived of in educational terms, as a formulation of objectives which will achieve a potential for later practical use. (Widdowson 1983:6)

El objetivo tiene una finalidad inmediata para el estudiante de Inglés para Fines Específicos, mientras que la aplicación práctica en el caso del Inglés General es únicamente prospectiva. Por estas razones, Widdowson utiliza dos términos distintos para lo que se suele denominar genéricamente 'objetivo', objectives y aims (a los que denominaremos respectivamente 'objetivos' y 'metas'):

By objectives I mean the pedagogic intentions of a particular course of study to be achieved within the period of that course and in principle measurable by some assessment device at the end of the course. By aims I mean the purposes to which learning will be put after the end of the course. (Widdowson 1983:67)

La ambigüedad de la expresión 'necesidades del estudiante' se produce precisamente por no discriminar entre objetivos y metas del curso. Estas necesidades se pueden referir a dos aspectos bien distintos. Podemos centrarnos en las necesidades que tienen los estudiantes desde el punto de vista de sus carencias antes de comenzar el curso, por lo que estas necesidades están relacionadas con las metas que se aspira alcanzar: «what the learner has to do with language once he has learned it»(Widdowson 1983:20), o bien podemos referirnos a las necesidades marcadas por el propio proceso de aprendizaje y que, por tanto, están relacionadas con los objetivos educacionales: «what the learner has to do in order to learn» (Widdowson 1983:20).

Por su parte, en el ámbito de la didáctica general no se suele distinguir entre ambos tipos de objetivos. En este entorno, los objetivos se interpretan como los resultados que se producen en los alumnos a causa de nuestra actividad docente, por 
lo que se definen como «los cambios esperados en los alumnos» (Morales Vallejo 1995b:15). Se trata, por tanto, de una noción muy difusa porque, aun situándonos en el punto de vista del aprendiz, no discrimina entre las metas que se marcan para paliar carencias, de las que el aprendiz es consciente, y los objetivos que hay que alcanzar para poder llegar a cumplir esas metas, de los que el aprendiz no tiene por qué ser consciente. Al situarnos en el punto de vista del aprendiz, no podemos olvidar, tal como señalaba Giménez (1996), la importancia de las expectativas de los estudiantes en el propio proceso de aprendizaje, sobre las que nos detendremos en el capítulo siguiente.

En el ámbito de la didáctica general, Morales Vallejo (1995b:16) incluye una diferenciación equiparable a la de Widdowson, a la que se suman los objetivos propuestos por otros niveles superiores del entorno educativo (como el Ministerio de Educación, el Consejo de Europa, o la propia filosofía de la educación), todos ellos en calidad de 'criterios de selección de objetivos' en el proceso previo a la formulación explícita de estos:

(a) objetivos formulados a un nivel superior

(b) análisis de los alumnos (aquí situamos las necesidades de los estudiantes, lo que Widdowson denomina learners' needs, y que nos proporciona información acerca de las metas del curso)

(c) análisis de la asignatura o de la materia (aquí situamos las necesidades propias del aprendizaje, lo que Widdowson denomina learning needs, y que nos proporciona información acerca de los objetivos educacionales del curso)

Widdowson (1983) plantea que, en el ámbito del Inglés para Fines Específicos, las metas han traspasado su calidad de criterio de selección para identificarse con los propios objetivos del curso, confundiéndose con éstos. De este modo, los objetivos educacionales quedan relegados a un segundo plano. Esto se interpreta como una consecuencia de que la enseñanza del Inglés para Fines Específicos se haya disgregado de la didáctica de las lenguas extranjeras. Para Widdowson esto es un error, ya que los objetivos educacionales deberían ocupar una posición central en el proceso educativo.

Esta diferenciación entre objetivos educacionales y metas del curso tiene repercusiones para establecer el papel de la traducción en la didáctica del Inglés para Fines Específicos. En primer lugar, según la descripción tradicional, no se establece ninguna diferencia cuando la traducción es la meta del curso de cuando es uno de los objetivos educacionales. Ambos casos se pueden clasificar como 'traducción como fin', si nos atenemos a la descripción dada. 
Como consecuencia de esto, debemos desligar lo que se establece como meta o como objetivo del curso del propio entorno del curso. Por consiguiente, tanto la traducción como cualquier otro proceso, actividad o campo de conocimientos es susceptible de adoptar diferentes funciones dentro del proceso educativo, sin que estas funciones estén asociadas únicamente con un entorno académico en particular. En este sentido, la clasificación de la traducción de acuerdo con el entorno académico es menos productiva que una taxonomía basada en un repertorio de diferentes funciones didácticas posibles.

En el entorno de la didáctica especial de las lenguas extranjeras, se puede pensar que la traducción no ha gozado últimamente de muy buena acogida precisamente porque no se suele considerar una de las metas del aprendizaje. Por otra parte, en el entorno del Inglés para Fines Específicos, se suele aceptar que la traducción forme parte del curso siempre y cuando ésta sea una de las tareas que los estudiantes tendrán que realizar dentro de su campo de especialización (véase, por ejemplo, Revilla Vicente 1995:472). Es decir, la traducción se admite en los cursos de Inglés para Fines Específicos si ésta se define como una de las metas del curso.

Aludiendo a la tipología de Holmes, la descripción de la función de la traducción en un curso de Inglés para Fines Específicos correspondería a una manifestación de la ya descrita 'traducción como fin', más que a la que Holmes y Bühler asocian con la enseñanza de las lenguas extranjeras.

No obstante, aplicando la diferenciación de Widdowson entre metas y objetivos, la traducción es susceptible de ser considerada como objetivo educacional aunque no constituya una meta del curso. Un ejemplo de esta diferencia de función puede verse si comparamos la función predominante de la traducción en la licenciatura de Traducción e Interpretación, donde constituye una meta del aprendizaje, frente a su función predominante en la licenciatura de Filología Inglesa, por ejemplo, donde suele ser un objetivo educacional en algunas asignaturas de lengua inglesa ${ }^{10}$. Asimismo, la traducción suele ser utilizada para evaluar los conocimientos de los aprendices, es decir, se suele emplear como método de evaluación en ambos entornos didácticos (aunque no se emplee para evaluar lo mismo).

Desde esta perspectiva, la tipología de Holmes no es suficiente para establecer las funciones didácticas de la traducción porque no discrimina aspectos que son relevantes para la clasificación. Esta incapacidad se origina al identificar el

\footnotetext{
${ }^{10}$ A menos que especifiquemos lo contrario, las menciones al entorno educativo que se hacen en todo el trabajo se refieren a los estudios universitarios en España.
} 
uso de la traducción con el entorno donde ésta se utiliza. Holmes y Bühler utilizan como criterio de clasificación el entorno de uso (dónde se utiliza la traducción) en lugar de la función didáctica (cómo y para qué se utiliza). A la vista de las consideraciones apuntadas, parece que una clasificación basada en las funciones de la traducción puede albergar más casos diferentes en una taxonomía de la didáctica de la traducción, y por tanto será más comprehensiva, que una tipología basada en los entornos de uso. En este sentido, preferimos adoptar la función de la traducción como criterio pertinente de clasificación para la didáctica, en lugar del tipo de entorno didáctico, ya que la funcionalidad del fenómeno es una propiedad del mismo, mientras que la variabilidad del entorno no lo es.

En cualquier caso, la traducción no tiene por qué ajustarse únicamente a los dos tipos tratados en la tipología de Holmes, ya que es potencialmente más versátil para la didáctica de lo que esta clasificación sugiere. De todos modos, para ceñirnos a los inevitables límites del presente trabajo, únicamente vamos a considerar este potencial en relación con la didáctica del Inglés para Fines Específicos, aunque sin perder de vista que nuestra concepción de la didáctica de las lenguas para fines específicos (de la que la didáctica del Inglés para Fines Específicos es una de sus posibles realizaciones) se inscribe necesariamente en una didáctica general de las lenguas extranjeras. Entendemos que ésta, a su vez, participa tanto de los fundamentos epistemológicos de la Didáctica como de los de la Lingüística Aplicada. Buena parte de estos fundamentos son, al mismo tiempo, compartidos por la didáctica de la traducción, lo cual puede verse en trabajos como el de Hurtado Albir (1999).

En esta sección hemos considerado los componentes comunes a todo diseño didáctico, a partir de los cuales hemos concluido que la taxonomía de Holmes es insuficiente para definir con precisión la funcionalidad didáctica de la traducción. En la siguiente sección, procederemos a formular una propuesta especificando cuáles son potencialmente las funciones de la traducción en relación con la didáctica del Inglés para Fines Específicos, desde una perspectiva más abierta que la de Holmes. 


\subsection{Traducción y metodología}

García Mayo (2000) ofrece un panorama de la evolución del Inglés para Fines Específicos, mediante la descripción de lo que identifica como sus principios esenciales, y señala cuáles son las últimas tendencias de la didáctica en este entorno.

Las tendencias identificadas por esta autora corresponden al 'enfoque centrado en el aprendizaje' propuesto por Hutchinson y Waters (1987) y al 'análisis de los géneros' según la concepción de Swales. Éste último será tratado más adelante en relación con las unidades de análisis textual, por lo que ahora nos dedicaremos con mayor detenimiento al enfoque centrado en el aprendizaje.

Hutchinson y Waters (1987) reflexionan sobre qué es lo determinante para un curso de Inglés con Fines Específicos, concluyendo que la respuesta depende precisamente del enfoque didáctico que se siga. Si el centro de atención es la lengua, entonces lo que determinará el curso será la naturaleza de la competencia comunicativa en la situación meta. Pero plantean una objeción: la mera descripción de la lengua que se utiliza en la situación meta no conlleva necesariamente su aprendizaje. Siguiendo esta línea argumental, si además consideramos el estado de conocimientos de los estudiantes, como hace James (1984), no parece que exista una relación intrínseca entre la frecuencia en el uso de ciertas expresiones en un entorno determinado y la necesidad de su enseñanza en el curso de Inglés para Fines Específicos (a pesar de que tradicionalmente haya sido así):

\footnotetext{
It would be unwise, for example, to teach something simply because it commonly occurs in the language that botanists and zoologists most frequently employ. The frequency and importance of such language elements may ensure that they are precisely those which the student handles most accurately and easily. (James 1984:60)
}

Para Hutchinson y Waters, el enfoque centrado en la lengua es insuficiente, ya que debemos ir más allá para descubrir qué procesos hacen posible la actuación. Es decir, no basta con tener conocimientos acerca de qué elementos componen la lengua, sino que debemos adquirir también conocimientos acerca del funcionamiento de ésta. No obstante, estos autores opinan que esto tampoco es suficiente porque si nos centramos en el propio aprendizaje, como sugería Widdowson, lo determinante no son las características peculiares de la competencia que se desea adquirir, sino el cómo se adquiere esa competencia.

Si consideramos el diseño del curso de Inglés para Fines Específicos desde este ángulo, los objetivos del curso estarán relacionados en su mayoría con los procesos que permitirán al aprendiz una actuación lingüística eficaz y exitosa. De 
todos modos, desde nuestra perspectiva, los distintos enfoques descritos por Hutchinson y Waters deben ser complementarios, nunca excluyentes. El uso del lenguaje es una actividad muy compleja en la que están involucrados tanto conocimientos de tipo declarativo o factual (saber qué) como conocimientos de tipo procedimental, es decir, de los procesos que participan (saber cómo), así como el conjunto de valores y creencias que nos identifican en nuestras actuaciones. Si nos centramos en el aprendizaje de estos conocimientos con el propósito de estructurar su enseñanza, debemos contar además con información suficiente acerca del propio proceso de aprendizaje (cómo saber).

En este orden de cosas, al intentar desvelar el papel de la traducción en la didáctica del Inglés para Fines Específicos, no encontramos información sobre si la traducción es considerada como un tipo de conocimiento (saber qué o cómo) o qué relación tiene con el proceso de aprendizaje de la lengua extranjera. Lo que encontramos, más que resultados de investigaciones que nos puedan ayudar a situar su función o que nos guíen en la práctica de la enseñanza, son opiniones subjetivas e imprecisas, bien a favor o bien en contra de su utilización.

Los autores que se muestran a favor de la utilización de la traducción en los cursos de Inglés para Fines Específicos apelan a su utilidad (Álvarez de Mon y Lerchundi 1992; Álvarez Rodríguez, Corchado y Oncins 1992) pero no suelen precisar cómo o para qué es útil exactamente. En el otro extremo, los autores que se declaran en contra de su utilización suelen argumentar que la traducción no es conveniente para el aprendizaje porque produce interferencias en la interlengua, tal como opinan Moreno Moreno y Rodríguez Mederos, para quienes la traducción es una tentación que hay que evitar a toda costa (Moreno Moreno y Rodríguez Mederos 1992:147). Esa vehemencia parece sugerir que la traducción es algo espontáneo y natural en el proceso de aprendizaje que hay que reprimir porque, aunque es perjudicial para el aprendizaje de la lengua extranjera, de algún modo pugna por salir. Esto puede explicar la ausencia de la traducción de los enfoques didácticos utilizados en la enseñanza y el aprendizaje de las lenguas extranjeras pero deja sin respuesta las cuestiones acerca de qué papel tiene exactamente en el proceso de aprendizaje y, más importante por lo que nos concierne aquí, cómo aprovechar su funcionalidad didáctica en beneficio de la enseñanza y el aprendizaje de la lengua.

Pérez González (1999) nos recuerda, muy acertadamente, que el papel de la traducción ha evolucionado considerablemente en la didáctica de las lenguas extranjeras, pasando de ser prácticamente el único método utilizado para la 
enseñanza de la lengua, a haber desaparecido totalmente de la metodología, e incluso a ser una actividad menospreciada por la didáctica (Escobar 1999).

En realidad, podemos decir que la traducción ha desaparecido de los enfoques didácticos en cuanto a su tratamiento o consideración teórica, pero no de la práctica cotidiana que se utiliza en las aulas de Inglés para Fines Específicos en el entorno universitario en España. En las I Jornadas Internacionales del Inglés Académico, Técnico y Profesional que organizó la Universidad de Alcalá hace poco más de una década, el diez por ciento de las contribuciones allí presentadas trataban la traducción o algún aspecto de ella como tema central (Barrueco, Sánchez y Sierra 1992). Posteriormente, en las VI Jornadas, este porcentaje continuaba siendo el mismo (Barrueco, Hernández y Sierra 1999) aun sin existir bloques temáticos en la estructura organizativa de estas jornadas ${ }^{11}$. Esto parece indicar que el interés por la traducción en la investigación y la enseñanza de las lenguas para fines específicos en España se encuentra en un plano secundario pero no desaparece. Sin embargo, lo preocupante es que su papel concreto en el proceso educativo continúa sin estar determinado.

Desde el punto de vista de su utilización práctica, la traducción suele ser tratada como una quinta destreza en el aula de lenguas extranjeras ${ }^{12}$. Es cierto que no tenemos mucha información acerca de cómo surge y se desarrolla en el individuo esta capacidad de mediación entre lenguas, pero parece estar inherentemente relacionada con la adquisición de la segunda lengua. No obstante, se considera que el desarrollo conjunto de las habituales cuatro destrezas lingüísticas lleva al aprendiz a la competencia lingüística o bien a la competencia comunicativa, mientras que la traducción surge como un efecto colateral que muchos autores consideran perjudicial, particularmente para alcanzar la competencia comunicativa.

En el entorno de las lenguas para fines específicos, sin embargo, se considera habitual centrarse en el desarrollo de una única destreza. En el caso del Inglés para Fines Específicos tal como se enseña en España (véase, por ejemplo, Álvarez de Mon y Lerchundi 1992:136), la destreza que tiene mayor peso en la programación didáctica suele ser la comprensión de textos escritos especializados (García Mayo 2000:40; Pajares Infante y Romero Armentia 1992:134).

\footnotetext{
${ }^{11}$ Se han contabilizado las contribuciones que contenían el término 'traducción' en el título pero ésta aparece tratada de forma secundaria en muchos más casos.

${ }^{12}$ Así la denomina Krings (1995:328).
} 
En relación con la competencia de lectura de textos en inglés, Valero Garcés (1992) defiende la utilización de la traducción en este entorno basándose en la necesidad de los estudiantes de acceder a la información del material especializado disponible sólo en lengua inglesa y en su utilidad didáctica para que los estudiantes se familiaricen con lo que denomina la 'gramática del texto' (Valero Garcés 1992:186). Tudor (1987) va más allá al plantear que el potencial de la traducción con fines didácticos no está suficientemente explotado: «translation, as the process of conveying messages across linguistic and cultural barriers, is an eminently communicative activity, one whose use could well be considered in a wider range of teaching situations than may currently be the case» (Tudor 1987:273).

Tal como apuntamos anteriormente, la investigación de las lenguas para fines específicos se centra alrededor de dos grandes núcleos. Por una parte, tenemos los resultados de la investigación didáctica, en la que muchos de los trabajos de investigación se basan en el estudio pormenorizado de casos y de situaciones reales (véase, por ejemplo, Sullivan y Girginer 2002). Por otra parte, existe un creciente interés por la investigación descriptiva, en la que el objetivo de los trabajos de investigación es contribuir a la descripción de la lengua utilizada en un entorno de uso en particular (véase, por ejemplo, Louhiala-Salminen 2002; White 2003), o en varios entornos diferentes de uso de la misma lengua (véase, por ejemplo, Moore 2002), o bien en entornos de uso equiparables en diferentes lenguas (véase, por ejemplo, Charteris-Black y Musolff 2003; Martín Martín 2002; Salager-Meyer et al. 2003). En numerosas ocasiones estos trabajos presentan asimismo una aplicación a la didáctica de la lengua para fines específicos de los resultados obtenidos (véase, por ejemplo, Hewings y Hewings 2002; Moreno 2003; Pinto dos Santos 2002; Samraj 2002; Soler 2002).

Así, en el campo descriptivo, observamos que la investigación sobre el léxico y la terminología está dejando paso a una pujante presencia de los aspectos pragmáticos y textuales relacionados con los textos especializados utilizados en los entornos profesionales relevantes para la metodología de estos cursos, por influencia de los paradigmas adoptados en el campo de la lingüística y, especialmente, del análisis del discurso ${ }^{13}$. Hay, por tanto, un creciente interés por la descripción de la lengua de especialidad y la utilización didáctica del texto especializado.

\footnotetext{
${ }^{13}$ Los estudios terminológicos se están desarrollando en otros ámbitos vecinos a las lenguas con fines específicos, en su mayoría dentro del campo de la terminología. Este campo se suele inscribir en la investigación en traducción, con Cabré en España y Sager en el Reino Unido como dos de sus más visibles representantes.
} 
Si bien desarrollaremos con mayor profundidad en los Capítulos 4 y 5 las cuestiones más estrechamente relacionadas con el concepto de lenguaje especializado y de comunicación que utilizamos, queremos especificar aquí qué tipo de trabajos descriptivos son más relevantes para nuestro objeto de estudio. Queremos señalar, marcando así unos límites que son necesarios (dada la cantidad y variedad ingente de trabajos publicados que se inscriben en la investigación relacionada con las lenguas para fines específicos), cuáles son los trabajos cuyos resultados pueden realizar aportaciones a nuestro trabajo y a otros trabajos que se desarrollen bajo una perspectiva semejante a la nuestra, de acuerdo con la concepción de la lengua de especialidad utilizada en el proyecto de enseñanzaaprendizaje de Inglés para Fines Específicos.

Además de otros parámetros de selección, nos interesan aquellos trabajos cuyo objeto de estudio coincide con alguna de las variedades de la lengua que se van a considerar pertinentes para el curso. Así, en general (y a menos que se especifique lo contrario) consideraremos pertinentes los estudios referentes a las variedades denominadas 'Inglés Científico', 'Inglés Técnico' e 'Inglés Académico', particularmente los que se refieren a las manifestaciones de esas variedades desde una perspectiva textual.

Por otra parte, nos interesan asimismo los trabajos de investigación cuyo objeto de estudio sea, preferiblemente, el tipo de traducción que se suele utilizar en el aula de lenguas para fines específicos, y que responde a la denominación genérica de 'traducción especializada'. La justificación empleada es que este tipo de traducción es justamente la que se utiliza en la actividad de traducir textos especializados. La relación de la denominada traducción especializada con la traducción general presenta un evidente paralelismo con la situación de la lengua para fines específicos en relación con la lengua general, que trataremos más adelante. Álvarez Rodríguez, Corchado y Oncins (1992:72) opinan que «la traducción para fines específicos se diferencia de la traducción general o normal, en la medida en que también los registros específicos se diferencian del discurso general», y Flores García redunda en la misma línea: «la enseñanza de la lengua para fines específicos, así como la llamada traducción especializada surgen y se desarrollan en un mismo contexto y por las mismas razones: responder de forma más puntual a las necesidades de una sociedad en evolución» (Flores García 1999:173).

No obstante, la traducción especializada no puede ser valorada en relación con la tipología de Holmes porque responde a una clasificación de tipo textual de la 
traducción, por lo que su función o funciones didácticas no podrían ser determinadas únicamente al asociar este tipo de traducción con un entorno particular de enseñanza-aprendizaje. Es decir, cuando hablamos de traducción especializada estamos utilizando una clasificación de tipo lingüístico (es decir, que es pertinente para la lingüística) pero no de tipo didáctico, por lo que dicha clasificación no es pertinente para la didáctica. La cuestión de fondo es que, al igual que la traducción general, podemos llevar a cabo tareas de traducción especializada en el aula como un medio de la enseñanza y también como un fin de ésta.

El problema más escurridizo para valorar la utilización de la traducción especializada en relación con la metodología adoptada en un curso de Inglés para Fines Específicos es que actualmente la traducción está ausente de las metodologías de la enseñanza y el aprendizaje de la lengua inglesa. Esto significa que la decisión de introducir tareas de traducción en un curso de estas características se toma al margen de la metodología por la que se ha optado al hacer la planificación, puesto que los modelos actualmente vigentes de enseñanza y aprendizaje de Inglés General y de Inglés para Fines Específicos no contemplan la utilización o explotación didáctica de la traducción.

La repercusión de esta falta de tratamiento en nuestro trabajo conlleva que nuestra argumentación tendrá que basarse en un marco de referencia a partir del que podamos contemplar la posibilidad de establecer unas funciones didácticas para la traducción de forma no arbitraria ni subjetiva. Para lograr esto, vamos a acudir al marco de la didáctica general, entendiendo que cualquier didáctica especial, como la didáctica de las lenguas extranjeras, debe, necesariamente, desarrollarse de un modo coherente y compatible con las líneas trazadas por la didáctica general.

Rodríguez Espinar (1999) describe tres métodos didácticos clásicos, que denomina respectivamente, 'afirmativo', 'interrogativo' y 'demostrativo', y que detallamos de forma esquemática a continuación:

a) Método Afirmativo:

Dirigido a reproducir el modelo del profesor. El proceso de aprendizaje finaliza sabiendo el alumno lo que ha expuesto el profesor.

Reclama al profesor/a dominio del tema y de las técnicas de exposiciónexpresión.

El alumnado, como colectivo, no sabe del tema, es necesario motivarle y deben estar en condiciones de recibir el contenido a exponer.

b) Método Interrogativo: 
Dirigido a la generación de respuestas que lleven a nuevas preguntas.

El profesor/a sabe del tema, como animador maneja las técnicas de animación y tiene capacidad para convertir en reflexión colectiva las aportaciones individuales.

El colectivo de alumnos/as discute, analiza, responde, reflexiona, deduce, descubre.

c) Método Demostrativo:

Dirigido a mostrar una acción (competencia observable) a fin de comprender la secuencia del proceso y automatizar su ejecución.

El profesor/a monitor/a hace y explica la secuencia de su acción.

El alumnado no sabe hacer lo que muestra y debe aprender a reproducir la acción con idéntico patrón al enseñado.

De acuerdo con esta clasificación, podemos plantear la hipótesis de que las tareas de traducción tendrán gran utilidad cuando se adopta una metodología interrogativa, ya que la traducción se presta muy bien como base para la discusión, el análisis y la reflexión colectivos, dada su naturaleza compleja y subjetiva (dependiente del individuo). Asimismo, podemos sugerir que las tareas de traducción no tendrán mucha utilidad cuando adoptamos un método afirmativo o bien un método demostrativo.

El alumnado, como colectivo, no suele tener la sensación de que no sabe sobre la lengua (sobre cómo funciona, sobre cómo utilizarla como un instrumento para lograr con eficacia lo que quiere) o de que no sabe cómo traducir. No obstante, sí suele tener la sensación de que no sabe suficiente lengua inglesa (básicamente, de que hay muchas palabras y/o estructuras sintácticas que no sabe) o de que no sabe traducir con suficiente corrección (justamente porque no sabe suficiente lengua inglesa). En este sentido, podemos decir que el aprendiz tiene habitualmente la sensación de que ya conoce el procedimiento básico de traducir en cuanto a su finalidad (poner en otra lengua diferente el texto que se le suministra) y a las tareas y estrategias que conlleva (que se suelen limitar a leer el texto suministrado, buscar palabras en un diccionario y escribir un nuevo texto).

Además de esto, Rodríguez Espinar señala que la metodología está en relación directa con los objetivos establecidos para el aprendizaje, que a su vez dependen del contexto de enseñanza y aprendizaje considerado. De hecho, todos los factores que forman parte de la planificación de la enseñanza deben estar relacionados entre sí de forma coherente. En última instancia, la valoración de la 
utilización de las tareas de traducción debe ser tomada en consideración de acuerdo con los demás factores de la planificación.

Siguiendo con el marco establecido por la didáctica general, y por lo que se refiere a la adecuación entre la metodología elegida, los objetivos que se pretenden alcanzar y los papeles asignados tanto al profesor como al alumno en el proceso de aprendizaje, podemos seguir las directrices que Rodríguez Espinar traza en la siguiente tabla de forma esquemática. En dicha tabla, podemos observar qué método se relaciona con cada clase de objetivo y de proceso o de acción llevada a cabo por el profesor y por el grupo de alumnos, de acuerdo con la tipología de objetivos educacionales establecida por Bloom y sus colaboradores (Bloom et al. 1956; Krathwohl, Bloom y Masia 1964):

\begin{tabular}{|c|l|l||}
\hline \multicolumn{1}{|c|}{ Objetivo } & \multicolumn{1}{|c|}{ Proceso/Acción } & \multicolumn{1}{c|}{ Método } \\
\hline \multirow{2}{*}{ COGNOSCITIVO $^{14}$} & $\begin{array}{l}\text { Transmisión del } \\
\text { PROFESOR al } \\
\text { ALUMNO. Comprensión, } \\
\text { análisis y recuerdo por el } \\
\text { alumno/a }\end{array}$ & $\begin{array}{l}\text { Facilitador de la } \\
\text { exposición del profesor y } \\
\text { recepción del alumno/a }\end{array}$ \\
\hline \multirow{2}{*}{ AFECTIVO } & $\begin{array}{l}\text { Interacción profesor- } \\
\text { alumnado. ANIMACIÓN } \\
\text { del grupo. Situación de } \\
\text { COMUNICACIÓN }\end{array}$ & $\begin{array}{l}\text { Facilitador del diálogo } \\
\text { en grupo, análisis de una } \\
\text { realidad y búsqueda de } \\
\text { soluciones específicas }\end{array}$ \\
\hline PSICOMOTOR & $\begin{array}{l}\text { Proceso demostrativo de } \\
\text { una ACCIÓN }\end{array}$ & $\begin{array}{l}\text { Potenciador de la } \\
\text { participación: } \\
\text { PRÁCTICA (Repetición } \\
\text { y automatización de } \\
\text { conductas) }\end{array}$ \\
\hline
\end{tabular}

Tabla 2. Relación entre los objetivos y la metodología didáctica (Rodríguez Espinar 1999)

\footnotetext{
${ }^{14}$ En realidad, Rodríguez Espinar denomina 'cognitivo' este tipo de objetivo. No obstante, hemos modificado este término para hacerlo consistente con el resto de nuestro trabajo, donde utilizamos el término 'cognitivo' y sus variantes para referirnos a los aspectos relativos a la cognición y 'cognoscitivo' y sus variantes para referirnos a los aspectos propios o relacionados con los conocimientos.
} 
Según esta relación entre objetivos y métodos didácticos, la metodología interrogativa es apropiada para alcanzar objetivos de tipo afectivo. Así, en este trabajo nos centraremos específicamente en la funcionalidad de la traducción para la consecución de este tipo de objetivos en tareas abordadas mediante una metodología interrogativa. No obstante, Rodríguez Espinar señala que «la última concreción metodológica toma lugar en el conjunto de actividades de aprendizaje que desarrollan los alumnos en los diferentes momentos del proceso de enseñanzaaprendizaje», y que las estrategias metodológicas adecuadas son 'aquellas que toman en consideración la interacción entre objetivos, contenido y grupo' (Rodríguez Espinar 1999:133). Por lo tanto, para poder valorar la adecuación de las estrategias metodológicas, debemos describir previamente las características del proyecto de enseñanza-aprendizaje, por lo que no descenderemos a un gran nivel de detalle en esta cuestión aquí.

\subsection{Nueva propuesta de las funciones didácticas de la traducción a partir de un enfoque comprehensivo}

Como ya señalamos en las dos secciones anteriores, la taxonomía que se utiliza tradicionalmente para clasificar los distintos tipos de función didáctica de la traducción no puede tratar todo su potencial de forma exhaustiva, debido a que esta clasificación asocia tipos de traducción con entornos educativos específicos, lo cual no es consistente con una concepción global del fenómeno de la traducción y, por consiguiente, carece de apoyo de tipo teórico. Así, a la vista de la insuficiencia de la tipología didáctica clásica de la traducción para dar cuenta de los distintos tipos de traducción que se emplean con una finalidad didáctica, en esta sección vamos a proponer una tipología alternativa de la traducción desde la perspectiva de la didáctica que contemple la traducción como un elemento susceptible de adoptar una gama variada de funciones en el proceso educativo, de acuerdo con el cometido que se le asigne en el enfoque didáctico y que se base en los fundamentos de la didáctica general, como marco teórico más comprehensivo en este caso.

Rodríguez Espinar (1999) especifica de qué contenidos se debe componer y qué fases debe seguir la planificación de la enseñanza, por lo que nos parece un marco suficientemente amplio en el que basarnos para delimitar la funcionalidad de la traducción. Para no extendernos excesivamente sobre esta cuestión, vamos a reproducir en dos tablas cuáles son los contenidos y fases de la planificación 
docente, comenzando por la planificación de la enseñanza que, como resultado, nos llevará al Plan Docente del curso que vamos a impartir.

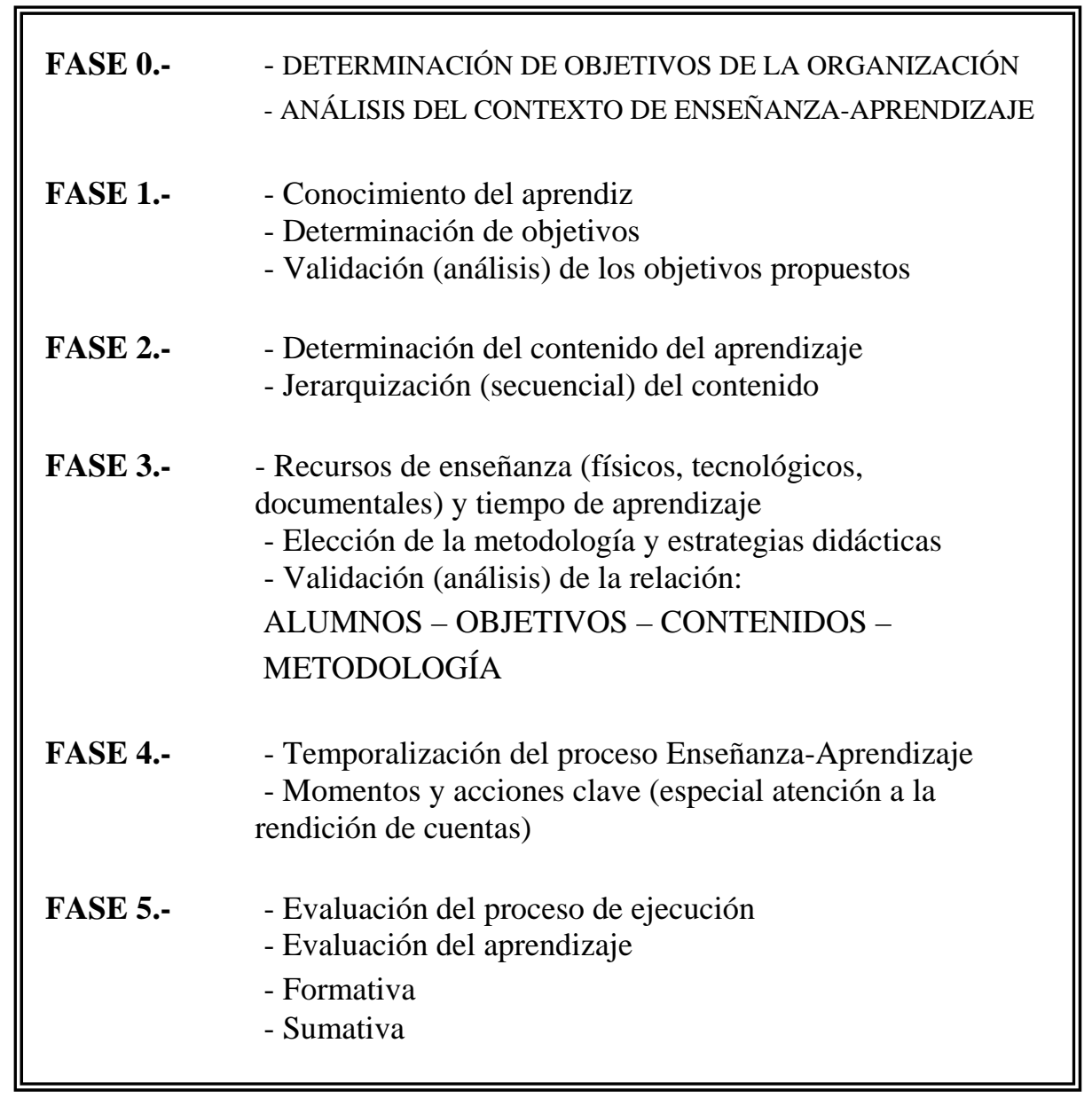

Tabla 3. Contenidos y fases de la planificación de la enseñanza (Rodríguez Espinar 1999)

Por lo que se refiere a los elementos que componen nuestra tipología didáctica de la traducción, éstos son identificados con los componentes del proceso de enseñanza-aprendizaje, tal como están representados en los contenidos de la planificación docente de acuerdo con su presencia en el Plan Docente resultante. Nos basamos en el Plan Docente ya que, de acuerdo con Rodríguez Espinar, se trata de un documento que recoge aquellos aspectos del proyecto de enseñanza- 
aprendizaje que son pertinentes específicamente en el nivel universitario, y que sirve para garantizar la calidad del proceso:

En el caso concreto de la planificación de la enseñanza universitaria, y en el nivel o marco de una asignatura, aquella se concreta en el llamado Plan Docente de la asignatura (Programa en la antigua denominación). Este Plan Docente tiene una especial importancia en aquellas instituciones, centros, departamentos o profesorado que le dan el valor de contrato público que explicita el compromiso de estudiantes y docentes. [...] Si se asume la publicidad del Plan Docente como documento de compromiso entre institución (profesorado) y alumnado, éste se constituye en un valioso instrumento para asegurar la calidad del propio proceso de enseñanzaaprendizaje. (Rodríguez Espinar 1999:126)

A continuación podemos ver, a modo de resumen, el repertorio de componentes del Plan Docente.

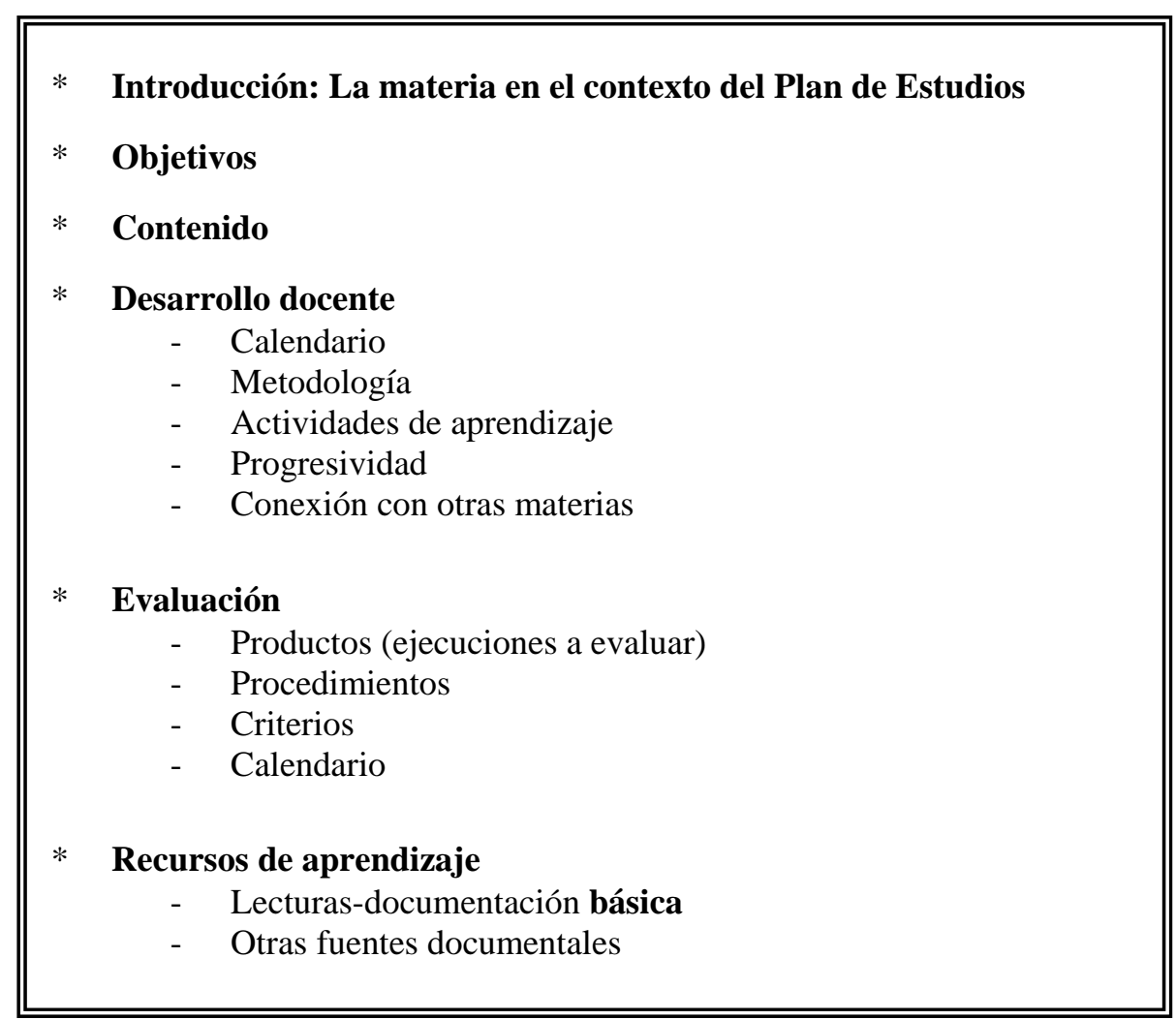

Tabla 4. Componentes del Plan Docente (Rodríguez Espinar 1999) 
De acuerdo con los componentes que intervienen en la planificación de la enseñanza y, como resultado de ésta, del Plan Docente de una asignatura o curso, la traducción puede tener las cuatro funciones didácticas que proponemos a continuación:

- Traducción como objetivo

- Traducción como contenido

- Traducción como actividad de aprendizaje

- Traducción como procedimiento de evaluación

Tabla 5. Las funciones didácticas de la traducción desde un enfoque comprehensivo

Estas funciones didácticas se definen para la traducción desde la perspectiva de que se trata de una destreza susceptible de ser enseñada y aprendida, con independencia de que se adopte una concepción de la traducción más abierta o más limitada, y de que, como actividad de tipo lingüístico, puede a su vez contribuir a la adquisición de otros objetivos educacionales relacionados con el lenguaje.

\subsubsection{La traducción como objetivo}

Como ya hemos visto anteriormente, Morales Vallejo (1995b) propone tres criterios de selección para establecer los objetivos, comenzando por la adopción de objetivos que ya están formulados desde un nivel superior del entorno educativo, y continuando por los criterios que se basan en el análisis de las necesidades de los estudiantes así como en el análisis de la asignatura o de la materia, es decir, de las necesidades propias del aprendizaje.

Desde el punto de vista de los criterios de selección utilizados, podemos hablar de tres tipos de objetivos, que corresponden respectivamente a uno de los tres criterios de selección.

Así, por lo que respecta al primer criterio y en relación con la educación universitaria en España, la traducción puede tener la función didáctica de objetivo educacional formulado a instancias superiores únicamente cuando nos referimos a la planificación de los Estudios de Traducción, pero este tipo de objetivo no se establece en ningún caso para la enseñanza de lenguas extranjeras (incluyendo la 
enseñanza del Inglés para Fines Específicos). El hecho de que no existan objetivos educacionales formulados a partir de este criterio puede ser utilizado como argumento de que la traducción no debe ser un objetivo de los cursos de lenguas extranjeras ni tampoco de los cursos de lenguas para fines específicos.

No obstante, la formulación de criterios a nivel superior es únicamente uno de los criterios que nos llevan a la selección de unos objetivos o de otros en la planificación educativa. Para tratar los otros dos criterios de selección, vamos a continuar con la terminología establecida a partir de la diferenciación de Widdowson entre necesidades de los aprendices y necesidades del propio aprendizaje (v. 2.2), entre 'metas' y 'objetivos' de la enseñanza respectivamente.

Cuando decimos que la traducción es identificada como la meta principal del curso, lo que la enseñanza suele perseguir es que el aprendiz adquiera la denominada 'competencia traductora' o 'traslativa'. Esta competencia ha sido definida por distintos autores (véase, por ejemplo, Hurtado Albir 1999), si bien no existe un acuerdo acerca de qué subcompetencias la componen. Por ejemplo, Zabalbeascoa presenta una 'relación de los posibles ingredientes que constituyen la competencia traductora' que recoge las siguientes subcompetencias:

- Conocimiento consciente (o sensibilidad o intuición exacta) de lo que supone e implica traducir. Estar al día de las técnicas, recursos y tipos de ayuda para el traductor.

- Conocimiento o especial sensibilidad de la naturaleza de (i) fenómenos lingüísticos y comunicativos; (ii) las diferencias que pueden llegar a existir entre las lenguas y las culturas, así como la subjetividad de sus perspectivas; (iii) una amplia gama de recursos retóricos.

- Buena formación general académica e intelectual y la experiencia de haber leído una gran variedad de tipos de textos en más de una lengua. La experiencia de haberse relacionado con diferentes tipos de personas en diferentes ambientes, también en más de una lengua y cultura.

- Educación formal en traducción y en análisis, interpretación y producción de textos sobre todo de la lengua materna incluyendo un componente contrastivo con otras lenguas y otras convenciones textuales y comunicativas.

- Experiencia como traductor y/o en otros tipos de redacción de textos.

- Cierto nivel de inteligencia y capacidad de razonamiento lógico e inferencial, junto con una memoria que permita sacar el máximo provecho a todas las experiencias y la capacidad de análisis y otras destrezas necesarias.

(Zabalbeascoa 1999:36-37)

La traducción suele ser identificada como la meta principal de muchos de los cursos de traducción pertenecientes a los estudios superiores conducentes a la titulación oficial de traductor. Se suele tratar de una meta que no es posible alcanzar con la realización de un único curso, sino de una serie de ellos, incluso de todos los 
que componen el Plan de Estudios de una titulación. Por esta razón, podemos hablar asimismo de casos en los que se definen metas a largo plazo, que son las que abarcan más de un curso. Por ejemplo, Mayoral Asensio (1999:54) señala que el diseño de la actual Licenciatura de Traducción e Interpretación en España responde al objetivo de «permitir una semiespecialización de sus titulados» sin descartar tampoco la no especialización, es decir, la formación de traductores generalistas. El análisis de necesidades llevado a cabo fue el siguiente, de acuerdo con Mayoral Asensio:

La formación de traductores generalistas ya no respondía a las exigencias del mercado y la formación de traductores muy especializados se veía contraproducente para el futuro profesional de los titulados, además de exigir unos recursos fuera del alcance de la generalidad de las universidades. (Mayoral Asensio 1999:54)

Como podemos ver en el análisis de Mayoral, habitualmente las metas a largo plazo no responden a un único tipo de criterio, sino que suelen ser establecidas a partir de una valoración más general que incluye asimismo otros tipos de factores y que cuando se refieren específicamente al Plan de Estudios de una titulación aglutinan necesariamente los objetivos establecidos por la instancias superiores.

Los Estudios de Traducción, al igual que el resto de titulaciones universitarias españolas, están comenzando a acometer una nueva planificación educativa con la finalidad de que estos estudios puedan converger con los de las titulaciones análogas del resto de países que componen actualmente el Espacio Europeo de Educación Superior. Así, una parte de las metas establecidas para las titulaciones universitarias españolas es aplicable por igual para todos los sistemas universitarios europeos que se adhieran a las directrices establecidas en sucesivos documentos acordados para todo el Espacio Europeo de Educación Superior. Si nos atenemos a la Declaración de la Conferencia de Rectores de las Universidades Españolas (CRUE) sobre el Espacio Europeo de Educación Superior, emitida tras la Asamblea General celebrada en Santander el 12 de septiembre de 2003, podemos decir que las titulaciones universitarias establecerán en su próximo Plan de Estudios unas metas que impliquen la «renovación de la metodología y el enfoque del desarrollo de las enseñanzas, desplazando el énfasis hacia el aprendizaje y la perspectiva de los estudiantes». En este sentido, las metas de la enseñanza vendrían a coincidir con las metas del aprendizaje.

No obstante, recordemos que, de acuerdo con Widdowson, no sólo son relevantes las necesidades de los aprendices para la planificación del curso, sino 
también las necesidades del propio aprendizaje, es decir, lo que los alumnos deben hacer para poder aprender. Por tanto, los objetivos del curso toman un signo diferente y, puesto que se relacionan más estrechamente con lo que implica educar, podemos decir que son éstos los objetivos más merecedores del calificativo 'educacionales'.

Como objetivo educacional, la traducción permite el aprendizaje de otra cosa diferente, que se ha identificado como la meta del aprendizaje, y que no tiene por qué ser necesariamente la competencia traductora. Por ejemplo, la meta de un curso de posgrado es conocer a fondo la cultura sumeria, y aprender a traducir textos es contemplado en el enfoque didáctico como un paso necesario para alcanzar esa meta. Este paso necesario para alcanzar la meta final es considerado un objetivo educacional del curso, por lo que en la planificación de éste se le dedica una parte de los contenidos (por ejemplo, estudiando los respectivos sistemas de codificación y otras cuestiones relevantes de lingüística contrastiva) y se introducen actividades de aprendizaje que consisten, por ejemplo, en la realización práctica de traducciones del sumerio al castellano. El logro de estos objetivos debe ser susceptible de ser evaluado y, por lo tanto, se contempla en la planificación del curso la realización de una prueba de traducción con el fin de evaluar la consecución de este objetivo en particular.

En el entorno del Inglés para Fines Específicos no solemos encontrar con mucha frecuencia (al menos no como para pensar que se trata de una situación generalizada en todo el entorno universitario español) situaciones en las que la traducción sea la meta del aprendizaje del curso de Inglés para Fines Específicos, por lo que la cuestión más importante para nuestro trabajo en relación con esta función didáctica es la relevancia que la traducción puede tener como un objetivo de tipo educacional, más que como una meta de la enseñanza.

Por otra parte, podemos especificar también qué tipo de objetivo educacional puede adoptar la traducción como función didáctica. Bloom y sus colaboradores establecen tres tipos de objetivos educacionales (Bloom et al. 1956; Krathwohl, Bloom y Masia 1964), denominados respectivamente, cognoscitivos, afectivos y psicomotores (con sus subclasificaciones internas). Aunque trataremos estos tipos con mayor detalle en el Capítulo 6, podemos señalar aquí que la traducción no es necesariamente susceptible de adoptar como función cualquier tipo de objetivo educaciónal, aunque si es posible enseñarla, entonces debe necesariamente poder adoptar la función de al menos un tipo o una subclase de objetivo educacional. 
No obstante, tal como señala Rodríguez Espinar (1999), siguiendo las fases de la planificación de la enseñanza, una vez que decidimos proponer unos objetivos determinados, éstos deben ser validados tras un análisis de la situación y previamente al establecimiento de los contenidos que se tratarán en el curso. Este análisis incluye la consideración de los objetivos establecidos en los niveles superiores, de las características del contexto de enseñanza y aprendizaje, así como las características específicas del grupo de aprendices. Por esta razón, solamente podemos considerar la validez o la idoneidad de la traducción para este tipo de función didáctica en relación con las características específicas de un contexto de enseñanza y aprendizaje. Las repercusiones que esto tiene para nuestro trabajo apuntan a la necesidad de referirnos a un contexto lo más específico posible, si bien debemos evitar al mismo tiempo descender a un nivel de detalle tal que no podamos llegar a ningún tipo de generalización acerca de las cuestiones que estamos tratando.

\subsubsection{La traducción como contenido}

La traducción puede ser identificada con los contenidos específicos del curso en relación con los conocimientos, destrezas y actitudes que deben ser aprendidos y cuyo aprendizaje se evalúa. Esto es lo que sucede habitualmente en un curso de traductología, en el que se pueden tratar contenidos relacionados con el «conjunto de elaboraciones intelectuales en torno a la traducción, incluidas tanto las teorizaciones y modelos metodológicos, como las generalizaciones de técnicas y las descripciones de ejemplares concretos» (Peña y Hernández Guerrero 1994:29). Zabalbeascoa (1999:38) diferencia, dentro de los Estudios de Traducción, entre asignaturas de tipo instrumental y asignaturas teóricas, refiriéndose en este segundo caso a asignaturas «de modelos lingüísticos para la traducción y teorías de la traducción». Dentro de este segundo grupo, Zabalbeascoa señala que los contenidos pueden ser de tipo 'documental', es decir, que dan información «de las diferentes corrientes de pensamiento que existen y han existido en la teorización sobre la traducción», o bien un enfoque más 'instrumental', presentando «un método de traducción, un modelo de traducción, y unas técnicas de aplicación general» (Zabalbeascoa 1999:39).

En general, la traducción se debe incorporar como uno de los contenidos del curso siempre que se haya establecido como uno de los objetivos del mismo, con independencia de que ésta sea tratada en un curso para futuros traductores profesionales o en cualquier otro entorno de enseñanza. Además, el aprendizaje de 
los contenidos tratados en el curso debe ser comprobado mediante una prueba de evaluación. En el entorno del Inglés para Fines Específicos la traducción no suele ser tomada como un objetivo o una meta del curso, por lo que no es habitual que forme parte de los contenidos del curso.

En cualquier caso, atendiendo a los contenidos y fases de la planificación de la enseñanza propuestos por Rodríguez Espinar (1999) (reproducidos aquí en la Tabla 3), sólo podemos determinar que la traducción adopte esta función didáctica tras el análisis de los objetivos establecidos, por lo que la validez de la traducción para esta función didáctica únicamente puede ser considerada en relación con los objetivos que se especifican para una situación determinada. Igualmente, de acuerdo con la tipología de objetivos educacionales propuesta por Bloom y sus colaboradores (Bloom et al. 1956; Krathwohl, Bloom y Masia 1974), para cada tipo de objetivo tenemos un tipo análogo de contenidos (cognitivos, afectivos y psicomotores, con sus subclasificaciones internas detalladas), por lo que la traducción debe tener validez para adoptar la función didáctica de al menos un tipo o una subclase de contenido. En términos generales, se interpreta que el aprendizaje de contenidos de tipo cognitivo tiene como resultado la adquisición de conocimientos de tipo declarativo. Análogamente, el aprendizaje de contenidos afectivos conlleva la adquisición de conocimientos de tipo actitudinal, mientras que el aprendizaje de contenidos de tipo psicomotor conlleva la adquisición de conocimientos procedimentales.

\subsubsection{La traducción como actividad de aprendizaje}

A pesar de que la traducción suele estar ausente de los objetivos y contenidos de los cursos de Inglés para Fines Específicos, no obstante suele ser utilizada en ocasiones como una actividad que permite el aprendizaje de la lengua. En estos casos, la traducción se considera una tarea o actividad útil, y se introduce como tal en la metodología del curso por diversas razones ${ }^{15}$. Algunos autores opinan que «se presta muy bien al repaso y la consolidación del material ya aprendido en clase» (Álvarez Rodríguez, Corchado y Oncins 1992:72), que su ejercitación sirve para adquirir experiencia en la propia destreza y que sirve de «ejemplo del uso y abuso de los anglicismos de frecuencia» (Arauz 1992:180), etc. Si observamos otros

\footnotetext{
${ }^{15}$ En este trabajo utilizamos indistintamente las denominaciones 'tarea de traducción' y 'actividad de traducción'.
} 
campos de aplicación diferentes, la traducción suele ser el medio principal de facilitación práctica del aprendizaje en cursos de lenguas clásicas como el latín.

En realidad esta función didáctica es la única del repertorio propuesto aquí cuya utilidad es defendida por algunos autores en relación con la didáctica de las lenguas extranjeras y de las lenguas para fines específicos. Zaro (2001) ha estudiado la utilidad de la traducción para la didáctica de las lenguas extranjeras y destaca el valor que tiene la traducción como instrumento didáctico en la clase de lengua extranjera, señalando en particular su utilidad como estrategia comunicativa, como instrumento para comprobar la comprensión, como ejercicio de consciencia gramatical y léxica, así como de consciencia pragmática y cultural.

La cuestión crucial en relación con esta función didáctica es cuándo o cómo podemos saber si una actividad de aprendizaje tendrá utilidad en un contexto específico. En este caso, la validez o idoneidad de la traducción para esta función didáctica no puede ser analizada sino en relación con la metodología adoptada para el curso. No debemos olvidar que la metodología, en última instancia, constituye la materialización práctica de un modelo de adquisición o de aprendizaje de conocimientos, por lo que debemos hacer explícito cuál es el modelo seguido. En el presente trabajo, esta cuestión es tratada en mayor profundidad en el Capítulo 3.

Como ya hemos señalado con anterioridad, el Inglés General y el Inglés para Fines Específicos comparten las mismas opciones metodológicas, por lo que en principio la validez de la utilización de la traducción como una actividad de aprendizaje es la misma en ambos campos si nos atenemos únicamente a su idoneidad en relación con la metodología. A pesar de esto, la traducción puede ser una actividad útil en unos contextos de enseñanza y aprendizaje asociados típicamente con el Inglés para Fines Específicos pero inútil o no idónea en unos contextos de enseñanza y aprendizaje típicos del Inglés General (o viceversa). Esto es debido a que, además de la relación existente entre la metodología adoptada y las actividades de aprendizaje elegidas, una vez establecidas las actividades y la metodología que utilizaremos, debemos analizar la relación resultante «ALUMNOS - OBJETIVOS - CONTENIDOS - METODOLOGÍA», tal como señala Rodríguez Espinar (v. Tabla 3).

Teniendo en cuenta únicamente consideraciones de tipo teórico dentro del marco de la didáctica general, ya hemos sugerido anteriormente que las tareas de traducción, debido a su propia naturaleza, parecen ser idóneas para una metodología interrogativa y, dado que la metodología interrogativa es adecuada para alcanzar objetivos de tipo afectivo (v. Tabla 2), podemos hacer extensiva la idoneidad de la 
traducción para este tipo de objetivos. De acuerdo con el tipo de acciones que Rodríguez Espinar sugiere para la utilización de un método interrogativo aplicado a la consecución de objetivos de tipo afectivo, cuando asignamos a la traducción este tipo de función didáctica, las tareas de traducción deben ser utilizadas como actividades de interacción entre el profesor y los alumnos y desarrollarse como situaciones de comunicación. En el Capítulo 6 propondremos un modo específico de llevar esto a cabo, con el objetivo de mostrar la plausibilidad de utilizar la traducción como una actividad de este tipo, si bien esta propuesta debe ser tomada únicamente como un ejemplo de las posibilidades potenciales de la traducción cuando se le asigna una función didáctica como ésta.

\subsubsection{La traducción como procedimiento de evaluación del aprendizaje}

Existen diversos procedimientos de evaluación del aprendizaje, si bien en este trabajo nos vamos a referir únicamente a los dos tipos más comunes, denominados respectivamente 'evaluación sumativa' y 'evaluación formativa'. Si utilizamos la traducción como un procedimiento de evaluación sumativa, lo que estamos valorando mediante la traducción es si los contenidos del curso han sido aprendidos y si los objetivos han sido alcanzados (véase, por ejemplo, Farahzad 1992:273). En cambio, si la traducción se emplea como un procedimiento de evaluación formativa, el propósito de esta evaluación consiste en recoger datos acerca de los conocimientos de los aprendices en diferentes momentos del curso con el fin de utilizar la información obtenida como un diagnóstico o como feedback del aprendizaje (véase, por ejemplo, Dollerup 1994).

Desde la perspectiva de la enseñanza, la introducción de un tipo u otro (o de ambos tipos) de evaluación en la planificación docente no tiene que ver con la naturaleza de los contenidos o con los objetivos del curso, sino con el tipo de certificación que debe recibir el aprendizaje (en cuanto a la utilidad de la evaluación sumativa), así como con el feedback necesario para introducir las modificaciones necesarias en la planificación. Dado que la planificación se hace antes de que el curso comience, la evaluación formativa es utilizada como fuente de datos que nos informe acerca de la marcha del curso y que podremos contrastar con la proyección prospectiva que hemos plasmado en la planificación, y por tanto, revisar de nuevo la relación resultante «ALUMNOS - OBJETIVOS - CONTENIDOS - 
METODOLOGÍA», tal como señala Rodríguez Espinar (v. Tabla 3), de acuerdo con los datos reales obtenidos.

Aun sin llegar a admitir los supuestos peligros que según algunos autores conlleva utilizar la traducción como un procedimiento para evaluar la competencia en la lengua extranjera, a los que ya nos referimos anteriormente, debemos admitir que la traducción presenta ciertos problemas cuando se le asigna este tipo de función didáctica, y que han sido puestos de manifiesto en su mayoría por los investigadores del ámbito de los Estudios de Traducción. Una buena parte de estos problemas se asocia con la complejidad extrema que la traducción presenta en relación con la aplicación de criterios objetivos de evaluación. No nos vamos a detener en esta cuestión aquí, puesto que creemos que es más oportuno dedicarnos a ella con mayor profundidad en el Capítulo 6, pero sí queremos señalar en esta descripción general que el hecho de que la traducción se considere un fenómeno extremadamente subjetivo puede ser asimismo aprovechado en beneficio de la enseñanza. Nuestro argumento se basa en que la realización de tareas de traducción en el aula permite poner de relieve diferencias asociadas al individuo que la lleva a cabo, aun cuando estas diferencias sean más difíciles de tratar cuando la traducción es utilizada como un procedimiento de evaluación sumativa que cuando la función didáctica que le asignamos es la de un procedimiento de evaluación formativa, tal como explicaremos a continuación.

\subsubsection{La traducción como método de evaluación para el aprendizaje}

De un modo muy general, y desde una perspectiva basada en el profesor, Blanco Prieto (1996:42) resume que la evaluación puede tener tres funciones diferentes dentro del proceso de enseñanza-aprendizaje: la obtención de información, la formulación de juicios y la toma de decisiones.

Con el fin de clasificar con mayor precisión las funciones de la evaluación, e integrando al mismo tiempo la perspectiva del aprendiz, Morales Vallejo (1995a) distingue a su vez cinco funciones principales que la evaluación puede realizar en el entorno de la didáctica general, y que se resumen del siguiente modo:

1. Comprobar la consecución de los objetivos propuestos en el curso y en qué medida o grado han sido alcanzados

2. Informar sobre el aprendizaje. El receptor de la información puede ser el propio profesor, el alumno, o bien terceras personas involucradas en el proceso (padres, otros profesores, etc.) 
3. Orientar, motivar y contribuir al aprendizaje. Principalmente se contempla esta función desde dos perspectivas:

a. La evaluación es utilizada como un refuerzo del aprendizaje, mediante la identificación de los propios errores, o como una consolidación de lo aprendido

b. La evaluación es utilizada como un condicionante del aprendizaje, ya que el esfuerzo del estudiante (qué y cómo estudia) se delinea de acuerdo con el tipo de prueba de evaluación que va a realizar, así como con el resultado de evaluaciones anteriores. La influencia de la evaluación es tal que, de acuerdo con Morales Vallejo (1995a:31), «el mejor método de cambiar el estilo de estudio del alumno es cambiar el tipo de evaluación»

4. Clarificar los objetivos, con el fin de que el profesor pueda reformularlos o cambiarlos en caso necesario. Se trata de obtener información dirigida a optimizar el plan del curso, bien durante el transcurso del mismo, o bien con vistas a la planificación de ediciones posteriores del mismo curso

5. Proporcionar datos necesarios para la realización de investigaciones en el ámbito educativo

La razón por la que hemos optado por introducir en esta sección un apartado específico que trate la evaluación como método de facilitación del aprendizaje (evaluar para aprender) es nuestro interés por analizar, de entre todas las funciones didácticas que podemos asignar a la traducción, una función que no es tan claramente clasificable como las demás y que ha dado pie al título de nuestro trabajo.

A diferencia de la evaluación sumativa, cuya utilización fundamental suele ser la certificación de la competencia alcanzada tras la realización del curso, la característica más sobresaliente de la evaluación formativa es, justamente, su utilidad como medio para facilitar el aprendizaje. Por consiguiente podemos afirmar que, si bien todos los procedimientos de evaluación nos proporcionan información acerca del estado de conocimientos de los aprendices, sólo la evaluación formativa es utilizada como un procedimiento útil para aprender. Siguiendo este planteamiento, podemos decir que los procedimientos de evaluación formativa son un tipo de actividad de aprendizaje que, a diferencia de las otras actividades introducidas en la planificación del curso, son utilizadas por el profesor para obtener datos con los que tomar decisiones relativas al curso. Esto significa que las condiciones que se deben dar para llevar a cabo las actividades que van a ser utilizadas como procedimientos de evaluación formativa no tienen por qué ser 
especiales, sino que las actividades se pueden desarrollar en las mismas condiciones que cuando no van a ser utilizadas para la evaluación, excepto que en este caso es siempre necesario contar con un procedimiento de recogida de información. Es decir, a diferencia de los procedimientos de evaluación sumativa, las actividades de aprendizaje utilizadas como procedimientos de evaluación formativa no necesitan ser llevadas a cabo en condiciones de examen. Desde esta perspectiva, para que una actividad de aprendizaje sea utilizada como método de evaluación formativa, necesitamos, además de un procedimiento de recogida de información, un baremo de corrección. En el caso de la traducción, como veremos más adelante, este criterio de corrección no tiene unas características o unos valores normalizados.

Por otra parte, a diferencia de otro tipo de tareas más simples, la utilización de tareas de traducción como actividades de aprendizaje siempre requiere poner de manifiesto cuál es el baremo de corrección que se utiliza, con independencia de que la actividad se lleve a cabo como un procedimiento de evaluación formativa o no. La equivalencia entre un TT y su correspondiente TO no es evidente, sino que debe ser hecha explícita mediante algún tipo de constructo ad hoc. En el caso de la utilización didáctica de la traducción para cursos destinados a más de un único aprendiz, esto es aún más evidente puesto que la actividad comporta la producción no de un único TT, sino de una cantidad de ellos, por lo que el criterio debe ser hecho explícito con el fin de que los aprendices puedan comprender qué tiene su texto de aceptable o no al compararlo, además de con el TO, también con los de sus compañeros. En general, en el presente trabajo nos vamos a referir a la macrofunción didáctica de la traducción que aglutina la función de evaluación formativa y la de actividad de aprendizaje como la macrofunción de 'medio de facilitación del aprendizaje ${ }^{16}$.

El repertorio de funciones didácticas de la traducción que hemos propuesto en este trabajo es mucho más completo que el utilizado tradicionalmente en el entorno de la lingüística aplicada. El hecho de que en una tipología como la que presentamos, la traducción se clasifique de acuerdo con su función didáctica,

\footnotetext{
${ }^{16}$ Nos referimos con 'macrofunción' a una función didáctica compleja en el sentido de que puede aglutinar desde un punto de vista teórico varias funciones de las definidas en el repertorio. La definición de esta macrofunción nos facilitará el tratamiento general de la funcionalidad de la traducción en el contexto que hemos elegido y he ahí la razón de nuestro proceder. En la práctica, es decir, cuando la función es establecida dentro de la planificación de la enseñanza, las funciones no son complejas en este sentido ya que, si elegimos explícitamente que la traducción sea una actividad de aprendizaje, entonces estamos descartando la recogida de datos con el fin de llevar a cabo una evaluación formativa.
} 
implica una disociación entre la función de la traducción y la concepción subyacente del propio fenómeno de la traducción, al contrario de lo que ocurre en la descripción de Bühler, donde se identifican función y concepción fenomenológica. Desde la perspectiva que proponemos, la concepción fenomenológica que el diseñador del curso adopte acerca de la traducción condicionará el tipo de función que se le asigne a la traducción en la misma medida que en que la concepción previa de la materia representada en los contenidos del curso condiciona el tipo de objetivos, métodos y actividades de aprendizaje que se elegirán en cada caso.

Pensamos que esta tipología es más útil que la de Holmes para dar cuenta de todos los casos posibles de manifestaciones de la traducción en entornos educativos porque se puede aplicar con independencia de las concepciones fenomenológicas de la traducción y de la lengua. Se trata de una clasificación amplia porque no sólo abarca aquellos casos que habitualmente contempla la didáctica de la traducción, sino también los que se producen en entornos didácticos distintos del entorno de la traducción profesional. En este sentido, se aborda la utilización didáctica de la traducción de manera única y comprehensiva. Consideramos que sólo es posible analizar la validez o la idoneidad de la función didáctica de la traducción para un proyecto de enseñanza-aprendizaje con un modelo como éste. Por esta razón creemos que el modelo propuesto es más potente para generar investigaciones, cuya necesidad ya apuntaba Holmes (1988), conducentes a demostrar la eficacia o ineficacia de la traducción.

No obstante, en un trabajo como éste no podemos aspirar a comprobar la validez de todas las funciones didácticas de la traducción en todos los casos posibles. En este sentido, nuestro objetivo se limita aquí a proponer un marco que sea suficientemente coherente desde una perspectiva teórica como para permitir llevar a cabo investigaciones didácticas acerca de la validez o idoneidad de las diferentes funciones de la traducción. Por lo que concierne a nuestro trabajo, este marco referencial es tomado como una hipótesis que nos permitirá ofrecer una explicación coherente de la función que vamos a elegir para tratar la traducción desde una perspectiva didáctica en mayor profundidad. Dado el carácter dual de las actividades de aprendizaje que son utilizadas como procedimiento de evaluación formativa, creemos que el análisis de esta doble función puede tener interés en relación con la traducción como una actividad de aprendizaje que presenta una cierta complejidad. Por lo que se refiere al contexto de análisis que hemos elegido, y que no es otro que el del Inglés para Fines Específicos, creemos que el análisis de las tareas de traducción cuando tiene esta doble función es relevante teniendo en 
cuenta que, de acuerdo con Zaro (2001), la traducción suele ser utilizada en el entorno de las lenguas extranjeras esencialmente con la función de actividad de aprendizaje.

Para finalizar, podemos resumir señalando cómo en este capítulo hemos comenzado por analizar nuestro objeto de estudio a partir de la diferenciación entre dos tipos de traducción diferentes para la didáctica, de acuerdo con la clasificación de Holmes, para pasar a proponer otro modelo más comprehensivo de las funciones de la traducción en el aula cuyos elementos son un reflejo de los elementos constituyentes del diseño didáctico en la didáctica general. Al mismo tiempo, hemos delimitado nuestro objeto de estudio al centrarnos en el entorno educativo del Inglés para Fines Específicos (y, dentro de éste, en la enseñanza y el aprendizaje de Inglés Científico, Inglés Técnico e Inglés Académico) en relación con los aprendices de nivel universitario en España.

Hemos descrito algunos aspectos de la didáctica especial de las lenguas extranjeras, particularmente en relación con el proceso de enseñanza-aprendizaje de las lenguas para fines específicos. El punto de vista general adoptado acerca de este proceso ha sido el del profesor encargado de la planificación de cursos de este tipo. Han recibido, por lo tanto, una mayor atención aquellos aspectos relacionados con la enseñanza que la que hemos dedicado a los aspectos referentes al aprendizaje. En el capítulo siguiente abordaremos los aspectos más relevantes relacionados con el proceso educativo desde el punto de vista del aprendiz y del propio aprendizaje, relacionándolos con los procesos y estrategias de tipo cognitivo que los Estudios de Traducción engloban bajo la denominación genérica de 'traducción como proceso', y que la didáctica general estudia en relación con los conocimientos y objetivos de tipo procedimental y actitudinal. 


\section{La traducción como medio de facilitación del aprendizaje del Inglés para Fines Específicos}

\subsection{Introducción}

Desde un enfoque general de la didáctica, la educación se contempla como un proceso con un componente teleológico en relación con el aprendizaje. En el proceso educativo, la formación (o instrucción) es el vehículo de este componente teleológico, cuyo objetivo es el aprendizaje. En los capítulos anteriores hemos tratado algunos aspectos relacionados con la traducción y las lenguas para fines específicos desde el punto de vista del diseñador de los cursos de Inglés para Fines Específicos. Hemos contemplado, por tanto, el proceso de enseñanza-aprendizaje desde la perspectiva de la enseñanza y del enseñante. No obstante, para poder establecer las características específicas del diseño del curso y de este modo poder determinar la relevancia de la traducción para el proceso educativo es preciso considerar, asimismo, ciertos aspectos relacionados con el aprendizaje del Inglés para Fines Específicos, con los aprendices que van a tomar parte en el curso y, en general, con el modo de aprender. Para tratar estos aspectos en relación con el proceso educativo, la atención que hemos dedicado a la enseñanza en el capítulo anterior se desplaza ahora al aprendizaje. Así, a lo largo de este capítulo, nuestro centro de atención va a recaer fundamentalmente sobre el aprendiz, si bien retomaremos la perspectiva del enseñante en la última parte (v. 3.4).

En nuestra aproximación al proceso de enseñanza-aprendizaje, el aprendiz es concebido como un agente activo en la adquisición de la lengua. Según Chaudron (1985), esta noción del aprendiz como miembro activo del proceso ya se encuentra 
de forma subyacente en la diferencia establecida por Corder entre la noción de input y la de intake:

The simple fact of presenting a certain linguistic form to a learner in the classroom does not necessarily qualify it for the status of input, for the reason that input is «what goes in» not what is available for going in, and we may reasonably suppose that it is the learner who controls this input, or more properly his intake. This may well be determined by the characteristics of his language acquisition mechanism. (Corder 1981:9)

Chaudron señala que, para la investigación sobre segundas lenguas, la cuestión crucial es precisamente analizar de qué se compone ese mecanismo de adquisición que determina cuál es el intake. Así, la mayor parte de la investigación en este campo se ha centrado, por una parte, en los aspectos relacionados con la interlengua del aprendiz y, por otra, en aquellos aspectos que tienen que ver con los procesos cognitivos del aprendizaje.

Nuestra intención no es la de recoger aquí el estado de la investigación sobre el aprendizaje de la segunda lengua o de las lenguas extranjeras globalmente, sino la de analizar únicamente aquellas cuestiones que sean relevantes para tratar las funciones didácticas de la traducción en relación con el aprendizaje del Inglés para Fines Específicos o, en un marco más general, con el aprendizaje de las lenguas extranjeras. Esto explica por qué en este capítulo no dedicaremos demasiada atención a cuestiones, como por ejemplo la interlengua, que suelen ser tratadas mucho más exhaustivamente en otros trabajos en el ámbito de la investigación de la didáctica de las lenguas extranjeras.

Siguiendo la concepción de Corder de input y de intake que hemos mencionado más atrás, pensamos que las formas y los significados que constituyen los textos que se traducen en el aula de Inglés para Fines Específicos no tienen el rango de input propiamente dicho. La utilización de material textual auténtico puede responder a la intención del profesor de que el aprendiz, a partir del texto, incorpore e integre información lingüística nueva en su interlengua, pero ésta no es la única posibilidad.

Chaudron define la 'interlengua' como «the current state of the learner's knowledge of the TL [...] representations of rules and structures that the learner has acquired» (Chaudron 1985:2), pero cuando el material textual es introducido para llevar a cabo la tarea de traducir, sólo se puede esperar que este material constituya una forma de input si el concepto de traducción utilizado se equipara con un ejercicio lingüístico gramatical. Si, por el contrario, la traducción se presenta como un acto de comunicación intercultural, puede que el material sea utilizado de todos 
modos por el aprendiz como intake, a fin de cuentas, como dice Corder, está «available for going in», pero no se introduce en el aula con el fin de que los aprendices integren la información lingüística del texto en su emergente gramática de la segunda lengua o de la lengua extranjera (Chaudron 1985). En este sentido, la investigación acerca de la interlengua en relación con la traducción como fenómeno intercultural se suele restringir al análisis de sujetos bilingües (véase, por ejemplo, Krings 1986:263). Por consiguiente, dado que las características particulares de los aprendices para los que se analiza el proceso educativo en este trabajo no coinciden con las de los sujetos bilingües, la relevancia de la investigación acerca de la interlengua para los fines de este trabajo es bastante dudosa.

En otro orden de cosas, al aludir a los procesos cognitivos del aprendizaje, entramos en el terreno del conocimiento y de sus distintos tipos. A partir de Ryle (1949), el conocimiento se suele discriminar en dos tipos: el conocimiento declarativo (knowing that) y el conocimiento procedimental (knowing how). En la investigación sobre segundas lenguas y lenguas extranjeras, el conocimiento ha sido estudiado en relación con la competencia del aprendiz, pero Widdowson (1983) establece una ulterior distinción entre competencia y capacidad. Para Rutherford (1987:15) esta distinción es equivalente a la clasificación de Ryle de tipos de conocimiento.

Por su parte, la didáctica general considera que la competencia está constituida por tres aspectos:

1. los conocimientos, que están asociados con el saber y que coinciden con el knowing that de Ryle

2. las destrezas, que se asocian con el hacer, coincidiendo con el knowing how de Ryle

3. las actitudes, que en el entorno del proceso de enseñanza-aprendizaje universitario asociamos con el actuar como los profesionales de un campo de especialización (véase, por ejemplo, Blanco Prieto 1996:62)

En la didáctica del Inglés para Fines Específicos, el aspecto actitudinal se identifica con la meta del aprendizaje y, por tanto, funciona como un punto de referencia para describir la competencia que se desea alcanzar, marcando qué significa alcanzar la meta o no alcanzarla y, en consecuencia, pudiendo constituir un criterio de valoración de la actuación del aprendiz. Para Ryle, este criterio de valoración ya está implícito en el concepto de conocimiento procedimental:

What is involved in our descriptions of people as knowing how to make and appreciate jokes, to talk grammatically, to play chess, to fish, or to argue? Part 
of what is meant is that, when they perform these operations, they tend to perform them well, i. e. correctly or efficiently or successfully. Their performances come up to certain standards, or satisfy certain criteria. But this is not enough. The well-regulated clock keeps good time and the well-drilled circus seal performs its tricks flawlessly, yet we do not call them 'intelligent'. We reserve this title for the persons responsible for their performances. To be intelligent is not merely to satisfy criteria, but to apply them; to regulate one's actions and not merely to be well-regulated. A person's performance is described as careful or skillful, if in his operations he is ready to detect and correct laspses, to repeat and improve upon success, to profit from the examples of others and so forth. He applies criteria in performing critically, that is, in trying to get things right. (Ryle 1949:29)

La actuación del sujeto se valora positivamente como un comportamiento crítico en el que éste ejerce control sobre su propia actuación con el objeto de llevarla a cabo con éxito.

Desde el punto de vista de la didáctica del Inglés para Fines Específicos, la meta del aprendizaje se identifica, como ya hemos mencionado, con el comportamiento del experto. En este sentido, el desarrollo de la subcompetencia actitudinal, o el aprender a actuar como el profesional del campo de especialización, es más relevante aquí que en los entornos de aprendizaje de Inglés General, donde la meta no se identifica con ningún tipo de especialización en particular. Así, uno de los objetivos globales del proceso educativo se identifica con la adquisición de conocimientos procedimentales que permitan, por un lado, adquirir y usar las destrezas necesarias y, por otro, con la adquisición de los valores, actitudes y creencias que se identifican con las atribuidas al experto. Este enfoque es consistente con el de Hutchinson y Waters mencionado en el capítulo anterior, así como con el de la denominada 'psicología de la instrucción'.

Al plantearse cómo instruir a los sujetos aprendices, lo más problemático resulta establecer «cómo puede facilitarse el paso de un estado general de ignorancia a otro, final, de conocimiento o competencia» (Sánchez Miguel 1993:10). Para poder abordar esta cuestión, según Sánchez Miguel hay que definir previamente:

(a) el punto de partida, el estado inicial del aprendizaje

(b) la meta, el estado final, que deseamos alcanzar

(c) los medios de facilitación mediante los cuales podemos pasar de un punto a otro, es decir, del estado inicial al final

Según Sánchez Miguel, el estado final se establece a partir de nuestro conocimiento sobre cómo actúan las personas expertas o competentes: el experto es, 
en definitiva, la meta. De ahí la importancia que han cobrado últimamente los contenidos actitudinales en los diseños curriculares. Asimismo, para establecer cuál es el estado inicial debemos definir también cuáles son los conocimientos de tipo declarativo, las habilidades, estrategias y las creencias del aprendiz. Naturalmente, entre el estado inicial y el final hay o puede haber otros estados intermedios y, más importante aún, unos mecanismos que permiten pasar de un estado de competencia a otro. Finalmente, y una vez definidos el punto de partida y el de llegada, resta por establecer los medios de facilitación, que consisten en las actividades y recursos de aprendizaje que se proporcionarán a los alumnos y en el modo de presentarlos para facilitar el cambio, estableciendo cuál es el papel del aprendiz, cuál es el del instructor y cuál es la dinámica que se debe establecer entre ellos, incluyendo, por lo tanto, la metodología y las estrategias didácticas.

Por lo que respecta a este trabajo, la cuestión que queremos dilucidar es cómo puede la traducción facilitar el aprendizaje del Inglés para Fines Específicos. En este sentido, planteamos la hipótesis de que las tareas de traducción son útiles para desarrollar la subcompetencia actitudinal asociada a la actuación experta. Así, si adoptamos la concepción de Ryle del conocimiento procedimental, los aspectos más interesantes que tratar en relación con el aprendizaje del Inglés para Fines Específicos se relacionan con la actuación crítica del sujeto y son el control sobre la actuación, la consciencia del sujeto cuando actúa y la metacognición. En definitiva, nos preocupan aquí aquellos aspectos relacionados con lo que los Estudios de Traducción denominan 'traducción como proceso'.

En este capítulo dedicado al aprendizaje, además de los aspectos que acabamos de apuntar, incluimos también una sección (v. 3.4) en la que definimos el contexto educativo donde el aprendizaje se lleva a cabo. La razón de esto es que uno de los factores que debemos tener en cuenta para poder establecer la función de la traducción es, precisamente, el contexto educativo, ya que, como afirma Nunan, «the context in which any teaching takes place will have a major influence on what is both feasible and desirable» (Nunan 1995:133). El contexto nos da información indirecta acerca de las características de los propios aprendices y, como ya mencionamos en el capítulo anterior, este análisis nos proporciona, a su vez, información acerca de las metas del curso.

Por otra parte, a pesar de que hasta este momento hemos estado manejando indistintamente la denominación 'didáctica de la segunda lengua' y 'didáctica de las lenguas extranjeras', antes de continuar nos parece oportuno precisar cuál de estos dos tipos de didáctica e investigación es más interesante para nuestro trabajo. La 
necesidad de introducir esta precisión parte de nuestro deseo de investigar en aquellas fuentes que abordan la didáctica del Inglés para Fines Específicos y, por extensión, la didáctica de la lengua inglesa en contextos similares o equivalentes al que nosotros estamos considerando en este trabajo. No obstante, debemos asimismo precisar que buena parte de la investigación que se lleva a cabo en este campo no utiliza de forma rigurosa la distinción entre segunda lengua y lengua extranjera para acotar la validez de los resultados, por lo que no nos ha podido servir realmente como criterio de selección de fuentes relevantes para la investigación. Aún así, nos parece necesaria esta aclaración para poder precisar los límites de validez de nuestro trabajo mediante la identificación de cuál es el contexto relevante para nuestra investigación. La diferencia entre contextos es un criterio que consiste en establecer distinciones en las relaciones posibles entre los aprendices de la lengua y los contextos linguísticos donde se lleva a cabo el aprendizaje. Es decir, que contempla la influencia del contexto en el aprendizaje de la lengua como una relación específica entre la lengua que se utiliza predominantemente en el entorno físico donde se lleva a cabo el aprendizaje, la lengua nativa del aprendiz y la lengua (no nativa) que éste aprende.

De acuerdo con Stern (1983), está comúnmente aceptada la necesidad de establecer una distinción entre aprender una lengua diferente de la lengua nativa del aprendiz en el país donde se habla esa lengua, y aprender una lengua no nativa fuera del territorio donde la lengua es utilizada. Para marcar esta distinción, se utilizan respectivamente los términos 'second language learning' y 'foreign language learning'. Richards, Platt y Platt (1992:143) definen la segunda lengua así: «In both Britain and North America, the term 'second language' would describe a native language in a country as learnt by people living there who have another first language». Siguiendo a los mismos autores, la lengua extranjera se define como ' $a$ language which is not a native language in a country', que se estudia «either for communication with foreigners who speak the language, or for reading printed materials in the language» (Richards, Platt y Platt 1992:142).

Es interesante señalar que la investigación sobre la didáctica de la lengua inglesa que recibe mayor atención por parte de los investigadores es la que se ocupa de la enseñanza y el aprendizaje del inglés como segunda lengua (English as a Second Language o ESL). Probablemente esto sucede porque la investigación del inglés como segunda lengua «has been strongly influenced by the North American language situation where there is generally more focus on the inmigrant situation 
(TESOL) than on the learning of foreign languages by native speakers of English» (Faerch y Kasper 1986:211).

Por su parte, los contextos considerados por la investigación que se ocupa del inglés como lengua extranjera (English as a Foreign Language o EFL) se refieren a la situación específica en la que la lengua que se aprende no se habla en el lugar donde se lleva a cabo el aprendizaje. El contexto educativo que consideramos en nuestro trabajo, que se refiere al aprendizaje del Inglés para Fines Específicos en el entorno universitario en España, corresponde a esta situación, ya que estamos considerando un entorno donde la lengua predominante además coincide con la lengua nativa del aprendiz. Desde una perspectiva geográfica, este contexto se identifica con el territorio español ${ }^{1}$.

Una de las diferencias entre las posibles situaciones de aprendizaje de la lengua no nativa que es relevante al considerar el aprendizaje del Inglés para Fines Específicos se refiere a los distintos propósitos que se persiguen en el aprendizaje, y que Stern describe así:

\begin{abstract}
The purposes of second language learning are often different from foreign language learning. Since the second language is frequently the official language or one of two or more recognized languages, it is needed 'for full participation in the political and economic life of the nation' [...]; or it may be the language needed for education [...]. Foreign language learning is often undertaken with a variety of different purposes in mind, for example, travel abroad, communication with native speakers, reading of a foreign literature, or reading of foreign scientific and technical works. A second language, because it is used within the country, is usually learnt with much more environmental support than a foreign language whose speech community may be thousands of miles away. A foreign language usually requires more formal instruction and other measures compensating for the lack of environmental support. By contrast, a second language is often learnt informally ('picked up') because of its widespread use within the environment. (Stern 1983:16)
\end{abstract}

Teniendo en cuenta esta distinción, el Inglés para Fines Específicos se asocia naturalmente con la concepción de la lengua inglesa como una lengua extranjera, ya que una de sus características es la variedad de propósitos diferentes que aglutina. En el contexto que estamos considerando en este trabajo, se puede

\footnotetext{
${ }^{1}$ Únicamente vamos a considerar el territorio español monolingüe, es decir, aquellas zonas del país donde se habla solamente una de las lenguas oficiales con el fin de neutralizar la variable asociada a las diferencias de contexto entre zonas monolingües y zonas bilingües e incluso entre diferentes zonas bilingües. Actuamos de esta manera ya que, desde nuestro punto de vista, las diferenciaciones de contexto ulteriores no son productivas en nuestro trabajo puesto que nos llevarían a un grado de especificidad excesivo para la caracterización que queremos hacer del contexto relevante. Queda pendiente, por tanto, la validez de los resultados de este trabajo para otros contextos que no sean monolingüies.
} 
asimismo reconocer la concepción subyacente del inglés como lengua extranjera en la didáctica del Inglés para Fines Específicos en que esta enseñanza se lleva a cabo principalmente mediante la instrucción formal, si bien Sánchez Manzano asocia esta característica a la didáctica de la lengua inglesa en general: «en la realidad social española, a no ser en circunstancias especiales o muy concretas, es pertinente hablar del inglés como lengua extranjera, es decir, aquella que se estudia formalmente en el instituto, en la universidad, etc.» (Sánchez Manzano 1999:12).

En un contexto caracterizado por una situación en la que el inglés es una lengua extranjera, esta autora señala que «los presupuestos que se manejan son los del aprendizaje y no los de la adquisición de una lengua» (Sánchez Manzano 1999:12). Esta distinción es pertinente para nuestro trabajo puesto que implica diferentes consideraciones de los procesos que llevan a que un sujeto sea capaz de comunicarse en una lengua no nativa para él. Por esta razón, vamos a comenzar por tratar en la sección 3.1 la dicotomía 'adquisición / aprendizaje', para lo cual nos basaremos en el trabajo de Krashen (1981), si bien, tal como señala Corder (1981:186), la distinción entre adquisición y aprendizaje es anterior a este autor. Tomaremos esta dicotomía como una discriminación conceptual fundamental basada en el propio sujeto que desea tener los conocimientos que le permitirán comunicarse en una lengua diferente a su lengua nativa y también basada en los procesos que le permitirán lograrlo.

Actualmente, los aspectos relacionados con el aprendizaje de la lengua suelen estar asociados con las metodologías que la didáctica especial de las lenguas extranjeras denomina 'métodos alternativos' (Ortner 1998; Rutherford 1987:29). Es decir, se suelen considerar en general más relevantes aquellos métodos que se basan más directamente en teorías cognoscitivas del aprendizaje que los basados en descripciones de los sistemas de las lenguas que se desea aprender, o bien en los aspectos contrastivos entre esos sistemas y los de la lengua materna del aprendiz.

Ateniéndonos a la relación que Sánchez Manzano (1999:12) establece entre la concepción del inglés como lengua extranjera y la utilización de los presupuestos que se refieren al aprendizaje (frente a los involucrados en la adquisición de la lengua), nuestro enfoque se centra principalmente en el aprendizaje y no en la adquisición. En los presupuestos relacionados con el aprendizaje, destaca por encima de otras consideraciones el concepto de 'consciencia'. En la sección 3.2 nos ocuparemos de este complejo concepto con el fin de relacionarlo con la metacognición. Los procesos de tipo metacognitivo serán analizados a continuación, 
especialmente en relación con el enfoque de resolución de problemas, para considerar sus ventajas potenciales para el aprendizaje.

A continuación, en la sección 3.3 nos centraremos en la utilidad de la traducción como medio de facilitación del aprendizaje del Inglés para Fines Específicos en relación con el concepto de competencia y sus componentes, considerándolo uno de los aspectos relevantes en un enfoque centrado en el aprendiz y el aprendizaje. Trataremos, asimismo, la dicotomía 'competencia / capacidad' para establecer qué tipos de objetivos de la enseñanza y aprendizaje del Inglés para Fines Específicos vamos a utilizar como marco referencial para tratar en este trabajo la funcionalidad didáctica de la traducción.

Por último, en la sección 3.4 vamos a centrarnos en las características del contexto que consideramos pertinentes para nuestro marco referencial desde un punto de vista descriptivo. La necesidad de incluir estas características particulares responde al deseo de presentar una descripción suficiente (aunque no exhaustiva) del marco que hemos elegido para poder tratar la funcionalidad didáctica de la traducción en relación con unos parámetros reales, de modo que esta funcionalidad pudiera ser evaluada sin limitar la valoración a supuestos establecidos idealmente y, por lo tanto, con dudosa aplicabilidad práctica. Este nivel de detalle es asimismo necesario de acuerdo con la didáctica general, en relación con la elección de una metodología en particular frente a las demás, si bien no es el único de los factores que afectan la eficacia de la metodología que utilizamos.

De la Cruz (1999:58) señala que, de acuerdo con la investigación didáctica, no hay un método mejor que otro en términos absolutos, sino que «la excelencia de un método depende de su ajuste a varios factores: objetivos que se persiguen, características de los estudiantes, exigencias de la asignatura, personalidad del profesor, condiciones físicas y materiales del centro y clima de clase». En este sentido, planteamos la hipótesis de que la eficacia de una metodología en un contexto determinado de enseñanza-aprendizaje depende básicamente de dos tipos de consideraciones.

Desde un punto de vista cuantitativo, consideramos que la eficacia de la metodología depende de la cantidad de factores relevantes que el proyecto educativo sea capaz de integrar, en el sentido de que cuanto mayor sea el número de factores considerado, más aumentarán nuestras expectativas de que la planificación del curso será eficaz para alcanzar los objetivos propuestos. Por otra parte, consideramos también una dimensión cualitativa en la que se contempla que la eficacia de la metodología no depende únicamente de la cantidad de aspectos integrados en el 
proyecto, sino también de que los factores relativos a la enseñanza y el aprendizaje de ese proceso educativo en particular dependientes directamente de la situación de enseñanza-aprendizaje (incluyendo tanto los aspectos constitutivos y regulativos del proceso como los contextuales) estén integrados de forma pertinente entre sí ${ }^{2}$. No obstante, la investigación didáctica nos proporciona algunas conclusiones en relación con la elección y la eficacia de la metodología que son relevantes para este capítulo centrado en el aprendizaje:

Para los objetivos de bajo nivel, por ejemplo, la adquisición y comprensión de la información, cualquier método es adecuado y equivalente.

Para los objetivos superiores, por ejemplo, el desarrollo del pensamiento crítico y aprendizaje autónomo, los métodos centrados en los alumnos son más adecuados y eficaces.

Los resultados superiores obtenidos con los métodos adecuados son atribuidos más a la cantidad y calidad de trabajo personal que exigen que al método per se. (De la Cruz 1999:58)

Estas conclusiones tienen una influencia en nuestro enfoque del aprendizaje del Inglés para Fines Específicos, incluyendo nuestra concepción acerca de cómo la traducción puede facilitar el aprendizaje de éste.

\subsection{Perspectivas sobre el aprendizaje de la lengua}

Como ya mencionamos en la introducción a este capítulo, al tratar el aprendizaje de una lengua, se suele diferenciar entre este concepto, que hemos caracterizado de un modo aproximativo como 'el fin de la instrucción', y la adquisición de la competencia lingüística o bien de la competencia comunicativa. Esta distinción teórica se suele asociar con diferentes enfoques didácticos, con diferentes contextos de aprendizaje, e incluso con diferentes sujetos aprendices.

$\mathrm{Al}$ distinguir entre ambos tipos de procesos internos, la adquisición se suele asociar con el modo como se internaliza y desarrolla la competencia de la lengua materna, mientras que el aprendizaje se asocia con la manera de desarrollar la competencia de una lengua no materna. En última instancia, el aprendizaje se relaciona con procesos intencionales y conscientes, y la adquisición con procesos

\footnotetext{
${ }^{2}$ Se puede consultar el trabajo de Dahlgren y Pérez Paz (1993) en el ámbito de las lenguas para fines específicos en el contexto universitario español como un ejemplo ilustrativo de adaptación de la metodología a las características específicas del contexto en el que se plantea el proyecto de enseñanza-aprendizaje.
} 
inconscientes sobre los que no podemos ejercer control, aunque sí podemos favorecer que ésta se produzca. Krashen plantea la hipótesis de que la competencia lingüística se produce en los adultos como resultado de dos tipos de procesos interrelacionados, que son la adquisición y el aprendizaje (Krashen 1981). En esta concepción la adquisición se define como

[...] un proceso subconsciente característico de la internalización «natural» del lenguaje típica de los niños, tanto en el caso de la lengua materna como en el de las otras lenguas. Este proceso de construcción creativa consiste en la aplicación de estrategias universales que conducen a la adquisición del sistema adulto o nativo, según el caso. (Krashen 1977:143)

Desde esta perspectiva, el aprendizaje es definido de una forma mucho más restringida a la que hemos visto hasta ahora. Aquí el aprendizaje es entendido como «un proceso consciente característico de la internalización formal del lenguaje que implica la retroalimentación, la corrección de errores y la explicitación de reglas» (Krashen 1977:143). Para Krashen (1981:12), la distinción entre adquisición y aprendizaje es útil porque ayuda a interpretar «findings in all areas in second language acquisition research and practice», incluyendo las variaciones individuales observadas de acuerdo con la actuación.

No obstante, debemos señalar que nosotros adoptamos la perspectiva de la didáctica general sobre el aprendizaje, entendiendo que el aprendizaje de la lengua extranjera comparte procesos y estrategias cognitivos con otros tipos de aprendizaje. Lo que nos resulta más interesante en el modelo de adquisición de la lengua extranjera de Krashen es la importancia que se le da a la consciencia dentro del proceso de aprendizaje, ya que desde nuestra perspectiva ésta tiene un papel fundamental en el aprendizaje.

A diferencia de Krashen, nosotros interpretamos el aprendizaje de un modo general que comprende más factores que el feedback, la corrección de errores y la explicitación de reglas lingüísticas. Entendemos el aprendizaje como una 'construcción del significado', es decir, como un proceso en el que «el estudiante no se limita a adquirir conocimiento, sino que lo construye, utilizando la experiencia previa para descubrir el significado de la nueva información» (Beltrán Llera 1999:20), de modo que se da una participación activa en el aprendizaje tanto por parte del profesor como del estudiante:

[...] el estudiante resulta mucho más activo e inventivo, y su papel corresponde al de un ser autónomo, autorregulado, que conoce sus propios procesos cognitivos y tiene en sus manos el control del aprendizaje. Consiguientemente, el papel del profesor no se limita a transmitir la información, sino que 
participa activamente en el proceso de construcción del significado del estudiante, haciendo de mediador entre la estructura del conocimiento y la estructura cognitiva del sujeto. Se trata, pues, de conocimiento construido y compartido. (Beltrán Llera 1999:20)

Creemos que una concepción del aprendizaje como ésta implica la necesidad de que la consciencia ocupe una posición central en la enseñanza y el aprendizaje, para lograr que el estudiante conozca sus propios procesos cognitivos, pueda ser efectivamente autónomo, y pueda ejercer un control efectivo sobre su actuación y sobre su aprendizaje.

Muchos de los esfuerzos de la investigación acerca del aprendizaje (en sentido amplio) se concentran en aumentar nuestro conocimiento de los procesos internos que están involucrados en la adquisición de una lengua, con el fin de aplicar estos conocimientos a la producción de métodos que favorezcan la adquisición. La cuestión de la dificultad intrínseca para obtener información verificable acerca de estos procesos que son de naturaleza interna ha hecho que las teorías formuladas como resultado de estas investigaciones sean a menudo criticadas o puestas en duda. Esto es común a las investigaciones que se han empezado a llevar a cabo acerca de los procesos cognitivos implicados en la traducción, como veremos más adelante.

Los trabajos de Krashen son una referencia clásica, tanto por sus hipótesis acerca de la adquisición de la segunda lengua como por las críticas que algunas de estas hipótesis han suscitado, pero hay muchos otros trabajos sobre el desarrollo de la competencia lingüística que también se han desarrollado a partir de la observación del comportamiento humano. Una parte de estos trabajos se ha concentrado en la comunicación lingüística entendida como un proceso de adquisición de conocimientos. En este grupo se inscriben trabajos de muy diversos tipos. Algunos estudian el desarrollo de la adquisición de la primera lengua. Otros se concentran en la observación de sujetos que adquieren la segunda lengua, particularmente en situaciones de inmersión larga o permanente ${ }^{3}$. Otros estudios se basan en la observación del comportamiento de sujetos bilingües, como el trabajo elaborado por Cummins y Swain (1986) sobre el bilingüismo en el entorno educativo en Canadá, o en la comparación entre el comportamiento de los sujetos bilingües y los sujetos monolingües, como los trabajos recopilados, por ejemplo, en la obra de Idiazabal (1991).

\footnotetext{
${ }^{3}$ Krashen (1981) presenta una ilustrativa revisión de investigaciones de este tipo llevadas a cabo en Estados Unidos.
} 
En los trabajos de este tipo, la tendencia que se sigue es la de utilizar como parámetros contrastivos de los sujetos estudiados las dicotomías adulto/niño, nativo/no nativo, y bilingüe/monolingüe. El objeto de la investigación suele ser el análisis de la secuencia de adquisición de ciertos elementos lingüísticos como, por ejemplo, morfemas gramaticales, de acuerdo con lo que Krashen denomina el 'orden natural' de adquisición. No obstante, se ha criticado que, independientemente de que los estudios empíricos señalen semejanzas (además de algunas diferencias) entre el orden de adquisición de ciertos elementos en la primera lengua y en la segunda, este orden lineal no refleja adecuadamente la adquisición de la segunda lengua. Por ejemplo, Corder plantea la objeción de que el desarrollo de la gramática no consiste en un crecimiento que se produzca mediante una determinada secuencia lineal, sino que más bien ocurre como un crecimiento orgánico y simultáneo a todos los niveles: «the spontaneous development of a grammar in the learner is organic. Everything is happening simultaneously» (Corder 1981:187).

En este sentido, estos trabajos pueden servir para organizar las secuencias de elementos lingüísticos en cierto orden de progresividad en el Plan Docente o en un manual, siguiendo una correlación determinada por la naturalidad de su ocurrencia, del mismo modo que se suele seguir un orden específico, por ejemplo comenzando por el rojo, para enseñar los colores a los niños.

No obstante, por un lado, la objeción que plantea Corder (1981) refleja que, en términos generales la utilidad de estos trabajos para la didáctica es escasa, o al menos discutible, además de poco relevante para la didáctica del Inglés para Fines Específicos tal como se desarrolla en España. Como veremos más detalladamente en la sección 3.4, la mayoría de los sujetos que siguen estos cursos en entornos educativos medios y superiores en España suelen caracterizarse por su poca o prácticamente nula exposición a la lengua inglesa en situaciones reales, de ahí que hablemos de aprendizaje de la lengua extranjera más que de adquisición. Para describir las consecuencias de esta situación debemos hablar de una gran heterogeneidad cuantitativa y cualitativa en la lengua adquirida. Esto, traducido a otros términos, quiere decir que el crecimiento orgánico y simultáneo de la lengua extranjera de estos aprendices ha ocurrido (y probablemente siga ocurriendo) de forma desigual, o bien simplemente alejada de lo que se podría identificar como un orden natural en una única secuencia lineal.

Por otra parte, esto nos lleva a la idea subyacente en las palabras de Corder (1981) de que la hipótesis del orden lineal no tiene apenas poder explicativo como modelo de representación de la adquisición tal y como ésta sucede en la realidad, al 
menos en esta realidad, sino que refleja más bien una idealización útil para la investigación a partir de una visión atomizada e insuficiente del lenguaje y a partir de un contexto de aprendizaje característico, pero que no es representativo en este caso.

Existen otros trabajos que se concentran en el desarrollo de la competencia como interacción social, es decir, como un proceso de cambio o crecimiento en los conocimientos del sujeto a partir de la negociación y el intercambio de conocimientos entre miembros de un mismo grupo social y/o de una misma cultura, o bien entre miembros de distintos grupos sociales y/o de distintas culturas. Un modelo de aprendizaje como interacción social suele incluir, además de factores de tipo individual, factores supraindividuales. El énfasis aquí no se encuentra en la búsqueda del comportamiento uniforme, como en los trabajos descritos más atrás. Es decir, lo importante no es encontrar qué caracteriza a todos los aprendices de la lengua, sino por el contrario lo que se busca es dar cuenta de la propia diversidad y variabilidad del aprendizaje en relación con las diferencias individuales, colectivas y sociales. Esta tendencia no constituye exactamente un marco de referencia original de la investigación sobre el aprendizaje de la lengua, sino que coincide con una de las tendencias actuales de la didáctica general (véase, por ejemplo, Lozano Martínez 1998). El planteamiento común a estos trabajos parte, al contrario que en los aludidos anteriormente, del deseo de dar cuenta de la diversidad manifiesta tanto en la realidad social como en el contexto educativo, e incluye la presencia e importancia de la cultura en el aprendizaje de la lengua y en la lengua que se aprende (véase, por ejemplo, Alderson y Urquhart 1984b:62-64; Brown 1990; Cots 1994; Gutiérrez Almarza y Beltrán Llavador 1996; Steffensen y Joag-Dev 1984), así como el papel activo del sujeto aprendiz (Nunan 1996).

Algunos conceptos básicos que caracterizan los dispares trabajos que se pueden agrupar bajo este enfoque son: la lengua como comunicación (inseparable de su contexto de uso), la comunicación como acción social (normalización) e interacción individual (negociación) y la relación dialéctica entre ambas, el estado de conocimientos previos del aprendiz como base de integración del conocimiento nuevo (tanto para comprender como para aprender), el aprendizaje autónomo (unido a la variabilidad de estilos de aprendizaje), así como la relevancia del papel de la consciencia y de la metacognición en este proceso. Como resumen general, este enfoque se caracteriza por la utilización de un modelo subyacente más complejo de lenguaje, que se aleja de la idealización característica de los trabajos que describíamos más atrás y que, por el contrario, busca representar de forma más fiel 
la lengua tal como es utilizada por sus usuarios y, por lo tanto, desde una aproximación descriptiva. Desde el punto de vista de la didáctica especial de las lenguas extranjeras, este enfoque sirve de revulsivo a la aproximación gramatical del lenguaje en las metodologías anteriores porque revisa el objeto (qué es el lenguaje) y los métodos (cómo funciona) utilizados hasta entonces.

Por otra parte, se rechaza la idea de que el aprendizaje de la lengua siga una determinada secuencia lineal, basándose en investigaciones sobre los distintos estilos individuales de aprendizaje cognoscitivo. Los trabajos que se recogen en la obra de Duda y Riley (1990) son un ejemplo de esto, aunque los antecedentes hay que buscarlos en el campo de la psicología de los años cincuenta (Jones 1993). La concepción subyacente de aprendizaje en esta perspectiva se puede resumir en la siguiente definición de Foster (1999:69): «language learning is a developmental, organic process that follows its own internal agenda». La adquisición, desde esta perspectiva, no se identifica con el aprendizaje, basándose en que la lengua no se adquiere en el mismo orden en que se presenta para su aprendizaje pero, ahora, la adquisición no depende del orden natural marcado por el lenguaje, sino de las características idiosincráticas del propio individuo que aprende.

Foster explica que esta perspectiva del aprendizaje se relaciona con el desarrollo de diferentes enfoques metodológicos aglutinados bajo la denominación común de 'enfoque por tareas'. Esta perspectiva sitúa al aprendiz en un papel activo, ya que lo que estos enfoques tienen en común es la convicción de que dar a los aprendices «tasks to transact, rather than items to learn, provides an environment which best promotes the natural language learning process» (Foster 1999:69). Bajo esta perspectiva, el proceso natural de aprendizaje de la lengua pasa a identificarse con el estilo individual de aprendizaje, en lugar de con un determinado orden lineal marcado por secuencias lingüísticas universales. El estilo de aprendizaje es un aspecto del proceso de aprendizaje que representa «a component of the whole "learning how to learn" concept which has become particularly relevant in the context of independent or self-directed learning» (Jones 1993:195).

El papel del aprendiz ocupa una posición central porque es él, y no el profesor, quien en definitiva va a marcar su propia ruta de aprendizaje a partir de sus conocimientos previos, intereses particulares, y demás circunstancias personales. El papel del profesor es el de mero facilitador del aprendizaje y, en última instancia, su meta es la de conseguir que el aprendiz sea independiente y autónomo (Elorza 2000; Kindelán Echevarría 1998-1999; Nunan 1995). Como dice Nuttall (1982:21), «your job as a teacher is to make your own help unnecessary». A 
este respecto, la didáctica general explica el proceso educativo como un continuo entre el polo de la enseñanza y el polo del aprendizaje. Este continuo se interpreta como una transición progresiva que debe transcurrir de la enseñanza (el sujetocomo-estudiante comienza siendo dependiente del profesor) al aprendizaje (el sujeto-como-aprendiz termina siendo independiente del profesor), tanto en un sentido horizontal (de principio a fin de curso) como vertical (del primer curso al último). En este sentido, Nunan aboga por «the development of curricula and materials which encourage learners to move toward the fully autonomous end of the pedagogical continuum» (Nunan 1995:134).

La cuestión que nos concierne aquí es la funcionalidad de la traducción para facilitar o promover el cambio hacia la autorregulación del aprendizaje. Creemos que la traducción implica ciertas actividades, tales como buscar información, sopesar diferentes posibilidades de interpretación y de expresión, o tomar decisiones que implican elegir unas opciones y desechar otras, que son idóneas como actividades de aprendizaje en relación no sólo con una metodología interrogativa, sino también con la promoción del aprendizaje autónomo bajo un enfoque general que la Comisión Europea ha bautizado como learning to learn.

No obstante, para que la traducción constituya un medio efectivo de facilitación del aprendizaje bajo este enfoque, las actividades de traducción deben ser realizadas como «ejercicios de consciencia gramatical y léxica» y/o «ejercicios de consciencia pragmática y cultural», de acuerdo con la clasificación de Zaro (2001) que vimos en el capítulo anterior. Bajo este enfoque, las actividades de traducción son interpretadas como ejercicios destinados a aumentar o elevar el nivel de consciencia de los aprendices, por lo que a continuación vamos a detenernos a analizar el concepto de consciencia.

\subsection{Monitor, consciencia y metacognición}

Una crítica contra las conclusiones de Krashen se refiere a que, en su modelo de adquisición de la lengua, el aprendizaje tiene una importancia marginal (Ortner 1998:160). Para Krashen, el conocimiento consciente de la segunda lengua se identifica con el conocimiento de reglas gramaticales y no es productivo en su enfoque porque no se presupone que este conocimiento consciente pueda llegar a convertirse en conocimiento adquirido. 
No obstante, para poder explicar cierta actuación de los hablantes adultos de la segunda lengua, Krashen recurre al denominado 'modelo del monitor', tal como había hecho previamente Labov, para explicar algunas variaciones observadas en la actuación de hablantes de la primera lengua (Krashen 1977). Mediante el uso de este constructo cognoscitivo llamado 'monitor', Krashen explica cómo el sujeto ejerce un control consciente sobre su producción lingüística, bien en el mismo momento de la producción, o bien con posterioridad a ésta. El tipo de control ejercido actúa como un corrector consciente de la producción lingüística.

Este constructo es utilizado por Krashen para diferenciar entre la actuación de los adultos y la de los niños, de tal modo que se interpreta que los adultos disponen de dos modos de alcanzar la competencia lingüística:

[...] dos sistemas posibles e independientes para utilizar [la segunda] lengua, uno adquirido, que se desarrolla de modo similar al de la adquisición del lenguaje por los niños, y otro aprendido, desarrollado conscientemente y casi siempre en situaciones formales. (Krashen 1977:144)

Por otra parte, el monitor también es utilizado para dar cuenta de variaciones entre la producción oral y la producción escrita en la segunda lengua. Se interpreta que en las producciones espontáneas el monitor no actúa, mientras que sí interviene en las producciones más cuidadas o elaboradas. En este sentido, las variaciones entre la producción oral y la escrita se diferencian, además de en el tiempo disponible en cada caso, en una mayor atención al realizar la tarea junto con un resultado más elaborado, así como en un mayor control de ésta una vez finalizada.

Para Krashen, el modelo del monitor sirve asimismo para establecer tipos de aprendices:

\begin{abstract}
El modelo predice que el grado de utilización consciente del monitor por parte de los hablantes será variable. En uno de los extremos estarán los que parecen utilizar el monitor siempre que sea posible, y que, por consiguiente, muestran una actuación variable. [...] En el otro extremo se sitúan los adultos que no parecen utilizar nunca el monitor, incluso cuando las condiciones se lo permiten. (Krashen 1977:149-150)
\end{abstract}

De acuerdo con el modelo del monitor, podemos plantear la hipótesis de que, al utilizar la segunda lengua, el sujeto puede ejercer un control consciente sobre su producción lingüística dependiendo de las siguientes variables:

a. que el sujeto sea un adulto o un niño 
b. que la producción sea escrita, o bien que ésta se produzca en un entorno dialógico de comunicación oral espontánea. Las diferencias en el uso del modo utilizado para la producción lingüística se asocian aquí con diferentes grados de espontaneidad y de elaboración, de tal modo que se interpreta que la atención dedicada en cada caso a la realización de la tarea no es igual en parte debido a diferencias en el nivel de atención requerido por las interacciones comunicativas que se asocian típicamente con el modo oral y con las que se asocian con el modo escrito, incluyendo el grado de elaboración del producto resultante

c. que el sujeto tienda a mostrar espontáneamente en sus actuaciones el ejercicio del control consciente o no

Además de estos aspectos, debemos añadir otra variable más. Foster (1999) alude a la influencia que la aplicación de la metodología tiene sobre el sujeto en cuanto al modo de realización de la tarea:

\begin{abstract}
Learners may be encouraged to prioritize a focus on meaning over a focus on form, and thus be led to use fluent but unchallenging or inaccurate language. Because language does not have to be well-formed in order to be meaningful, it is easy to see how learners could successfully complete a task using illformed or undemanding language, supplemented by gesture or intonation, rather than trying out their 'cutting edge' interlanguage. (Foster 1999:69)
\end{abstract}

De acuerdo con Foster, el profesor puede hacer que la atención del aprendiz se concentre en un aspecto relativo al modo de realización de la tarea u otro, por ejemplo que el aprendiz ponga su atención en qué decir y preste menos atención a cómo decirlo, o viceversa. Por su parte, el aprendiz puede mostrarse más o menos conservador en su actuación. Puede utilizar expresiones, ideas o juicios de valor acerca de cuya adecuación, pertinencia o corrección puede no estar seguro, o bien puede evitar hacerlo, también puede mostrar en su actuación un mayor o menor temor a equivocarse y puede actuar así de forma consciente, o bien sin darse cuenta de ello. ¿Qué significa entonces decir que el aprendiz es consciente de su aprendizaje? y, lo que es más, ¿qué importancia tiene que el aprendiz sea consciente o no para que logre aprender a comunicarse en una lengua extranjera?

A pesar de los intentos en esta dirección, no existe una respuesta absoluta y definitiva sobre la función que cumple la consciencia en el aprendizaje. No obstante, sí podemos describir con mayor precisión lo que se esconde detrás de la primera pregunta que hemos formulado.

La cuestión acerca de la importancia de la consciencia (o de la ausencia de ella) para el aprendizaje de la lengua ha estado siempre en el centro del debate en la 
didáctica especial de las lenguas extranjeras. Para Schmidt (1994), una de las causas de tal controversia consiste justamente en la falta de precisión de este concepto, representado en inglés por el término 'consciousness" 4 .

Schmidt toma en consideración las diferentes acepciones que el concepto de consciencia tiene en sus usos cotidianos, y analiza las que son especialmente relevantes para la didáctica teórica y práctica de la lengua. Así, llega a clasificar cuatro tipos de consciencia: la consciencia como intencionalidad, como atención, como conciencia, y como control.

\subsubsection{Consciencia como intención}

Este tipo de consciencia se relaciona con los objetivos, metas, deseos, o planes y se refiere a la actitud deliberada del aprendiz respecto de su actuación.

Schmidt (1994:15) presenta para este tipo de consciencia un ejemplo que toma de Bialystok: la intención consciente del aprendiz que intenta aumentar su exposición a la lengua de forma independiente fuera de clase. En este ejemplo se enfatiza que el sujeto intente aumentar el aprendizaje fuera del propio curso, ya que esta autora excluye la práctica en el aula porque considera que el aprendiz no tiene un control voluntario sobre ella. No obstante, nosotros adoptamos una posición más abierta porque entendemos que los aprendices muestran una intención consciente cuando asumen la realización de una tarea en el aula. Esta intención consciente se manifiesta, por ejemplo, cuando un aprendiz asume de forma voluntaria la presentación pública de una tarea que ha realizado individualmente al resto de los sujetos del aula. Creemos que la implicación del aprendiz en el aprendizaje responde a su propia intención consciente y voluntaria, y que esta implicación incluye un mayor o menor grado de aceptación del papel del profesor y de su propio papel en el aprendizaje. Krashen (1981) denomina 'motivación integradora' a este tipo de implicación y la considera un factor de tipo actitudinal.

\footnotetext{
${ }^{4} \mathrm{Al}$ menos en la variedad de español que se utiliza en España, el término 'consciencia' recoge de forma global, aunque alternándose en algunas ocasiones con el término 'conciencia', los conceptos que la lengua inglesa diferencia mediante los términos 'consciousness' y 'awareness'. La mayoría de la bibliografía consultada sobre esta cuestión está escrita en inglés, por lo que nos ha parecido más pertinente ahondar en el tema siguiendo el análisis de Schmidt de este concepto según sus acepciones en inglés cuyos matices, por otra parte, son tan válidos para el argumento que planteamos como si la cuestión se hubiera tratado de acuerdo con la terminología correspondiente al uso en España.
} 
Por lo que concierne a la utilización de la traducción como un medio de facilitación del aprendizaje, este tipo de consciencia se refiere a aquellos aspectos relacionados con la asunción de la realización de la tarea de traducción y con el grado de implicación con que el aprendiz desarrolla la tarea (por ejemplo, en la exhaustividad de las búsquedas de información, etc.).

\subsubsection{Consciencia como atención}

Según Tomlin y Villa (1994), el sistema humano de atención consta de tres componentes principales:

a) la alerta, es decir, el estado general de disposición para tratar la información o los estímulos que se presenten (Schmidt 1994:17; Tomlin y Villa 1994:190)

b) la orientación, que consiste en la asignación específica de la atención a un estímulo en particular (Schmidt 1994:17). La idea principal es que esta asignación tiene consecuencias facilitadoras o inhibidoras para el procesamiento ulterior en función de que la información se produzca como se esperaba, o bien inesperadamente (Tomlin y Villa 1994:191)

c) la detección, definida como el proceso de selección de una información en particular (Tomlin y Villa 1994:192), y que otros autores denominan 'atención focal' (Schmidt 1994:17)

En cuanto a las actividades de traducción, interpretamos este tipo de consciencia en relación con los aspectos de ejecución de la tarea de traducción que tienen que ver con el procesamiento de la información textual. Si interpretamos la actividad de traducir desde el marco de los procesos cognitivos implicados en la resolución de problemas, podemos partir de la hipótesis de que la consciencia del aprendiz está alerta al acometer la interpretación del TO con el fin de producir su TT. Así, durante la interpretación del TO y la producción del TT (procesos que suceden de forma simultánea y recursiva), la consciencia del aprendiz se dirige hacia ciertos elementos que llaman su atención. Entendemos, asimismo, que la intepretación del TO se lleva a cabo como un proceso individual en el que se da una relación de interacción entre el aprendiz y el texto, y que esta interacción sucede bidireccionalmente (bottom-up y top-down) como un proceso integrado, tal como describen Carrel y Eisterhold (1983:557). Esta hipótesis es útil para explicar cómo no todos los aprendices detectan los mismos problemas ni fijan su atención en los mismos elementos, por lo que es razonable esperar que no todos los TTs de un mismo TO sean iguales. 
Por otra parte, partimos de la hipótesis de que la traducción tiene una funcionalidad didáctica potencial basándonos en la presuposición de que es posible manipular la atención focal de los aprendices con una finalidad didáctica.

\subsubsection{Consciencia como conciencia (awareness)}

Tomlin y Villa (1994:193) definen la conciencia como «a particular state of mind in which an individual has undergone a specific subjective experience of some cognitive content or external stimulus».

Schmidt (1994:18) explica que, aunque se suelen distinguir varios niveles de consciencia de este tipo, la cuestión del aprendizaje no consciente, tal como la tratan tanto la psicología como la linguística aplicada, se suele referir casi siempre al nivel superior, como cuando se es consciente de una regla o una generalización. Este tipo de consciencia incluye, entre otras, la habilidad de tener conciencia de uno mismo o self-consciousness.

Situándose en el paradigma cognoscitivo, Schmidt analiza el trabajo de Reber (1989; 1992) sobre el conocimiento y el aprendizaje implícitos. Así, llama nuestra atención sobre el concepto de conocimiento implícito, que excede lo que los aprendices son capaces de expresar, y que es tomado como el resultado de un proceso inconsciente de inducción. Esta concepción corresponde con la que se suele tener en el campo de la lingüística aplicada sobre el conocimiento implícito: «second language learning is commonly believed to involve induction without awareness, and learners 'know' more than they can express» (Schmidt 1994:18).

$\mathrm{Al}$ contrario que con el conocimiento implícito, la psicología no ha prestado mucha atención a la cuestión relativa a la comparación inter pares que los propios aprendices hacen de los resultados de sus actuaciones, es decir, del output. Sin embargo, según Schmidt, este aspecto del aprendizaje tiene una gran importancia para la lingüística aplicada. Basándose aquí principalmente en lo que Klein (1986) denomina 'the matching problem' y otros autores, como Krashen (1981), el proceso de 'noticing the gap', Schmidt explica cómo Klein plantea que los aprendices deben intentar comparar el resultado de su propia actuación con otros aprendices, de tal modo que el aprendizaje se da por finalizado cuando el aprendiz ya no puede detectar ninguna discrepancia entre el resultado de su actuación y el resultado comparado. Siguiendo a Klein, Schmidt propone que, para poder solucionar este 'matching problem', «learners must somehow step outside of themselves to attain a 
perspective on their own performance» (Schmidt 1994:19). En otras palabras, los aprendices deben adoptar una perspectiva metacognitiva.

Cuando la actividad de traducir es abordada en el aula mediante un método interrogativo (v. 2.3), se pone explícitamente de manifiesto este 'matching problem', ya que se comentan y discuten en común diferentes opciones producidas por los aprendices.

Como ya hemos señalado al tratar la consciencia como atención, los textos producidos por los aprendices siempre presentan diferencias entre sí. El tratar estas diferencias en grupos de discusión tiene claras ventajas para desarrollar la conciencia de la propia actuación (qué se hace o se ha hecho y qué efectos o repercusiones tendrá sobre los lectores) frente a otros tipos de tareas o de actividades de aprendizaje. Por ejemplo, frente a tareas introducidas en la planificación con el objetivo de desarrollar o poner en práctica estrategias comunicativas en la lengua extranjera. Las ventajas de las actividades de aprendizaje que se realizan mediante un método interrogativo se derivan de que discutir o comentar la propia actuación implica la reflexión sobre ésta y también sobre otras opciones que quizá ni siquiera hayan sido consideradas por el aprendiz en el proceso de producción del texto. En las actividades de aprendizaje que persiguen el desarrollo de estrategias comunicativas orales, por ejemplo, no se suele aplicar un método interrogativo, dado que el énfasis recae sobre la producción y no sobre el análisis de ésta.

No obstante, en el caso de las tareas de traducción no podemos afirmar, sin introducir una matización, que el aprendizaje finaliza cuando deja de haber discrepancias entre los resultados obtenidos entre unos aprendices y otros. La producción de TTs refleja diferentes tipos de interpretación y realización de la misma tarea, sin que ello implique necesariamente que el resultado de las actuaciones de los aprendices deba ser idéntico. Por esta razón, la falta de discrepancias entre las distintas actuaciones no significa que todos los TTs sean idénticos, sino que el aprendiz se haya hecho consciente de las implicaciones de dichas discrepancias, incluyendo en este hacerse consciente las implicaciones textuales y comunicativas de la utilización específica que ha hecho de la herramienta del lenguaje. Esto no es en absoluto un objetivo fácil de alcanzar pero no debemos olvidar que las actividades de traducción se prestan con mayor facilidad que otras actividades de aprendizaje a practicar el desarrollo de la autopercepción de la actuación del aprendiz. Esta autopercepción es un requisito necesario para lograr alcanzar el último de los tipos de consciencia aquí tratados, que no es otro que el 
control sobre la propia actuación. En este sentido, el objetivo de abordar la actividad de traducir mediante un método interrogativo no es la neutralización de las discrepancias existentes entre las diferentes actuaciones de los aprendices, sino la formación y/o formulación de juicios de valor que en definitiva lleven al aprendiz al control de dichas discrepancias. En definitiva, se trata de promocionar la formación de una actitud analítica, crítica y evaluadora de la propia actuación y de la de otros.

\subsubsection{Consciencia como control}

Schmidt concibe el control y la atención como un mismo proceso desde el punto de vista teórico. Justifica esta clasificación de dos tipos diferentes para poder resaltar las peculiaridades del aspecto que desea enfatizar en cada caso. Así, mientras que el foco de interés en la consciencia como atención se centraba en el procesamiento del input o 'aducto', ahora el énfasis recae en el procesamiento del output o "educto' 5 .

El concepto de consciencia como control no recibe una valoración positiva de forma unánime. Para Krashen, el control es más bien un estorbo para la adquisición. Así, aunque acepta el papel del monitor como constructo cognoscitivo desde un punto de vista descriptivo de la adquisición, subyace la idea de que éste frena la adquisición de algún modo. No obstante, habida cuenta de las diferencias descritas entre adquisición y aprendizaje, en nuestro enfoque el control consciente es interpretado como un paso previo a la actuación experta y, en este sentido, ocupa una posición central en nuestro modelo de aprendizaje.

Desde una perspectiva general, Schmidt (1994) matiza, basándose en el trabajo de Reason (1984), que el control tanto puede ser positivo como negativo para el resultado de la tarea que se realiza. Hay errores que se producen porque no se ha prestado la atención necesaria a la tarea en un momento crítico (el control ha sido insuficiente). Pero también hay errores que se producen porque se ha prestado atención a una actividad rutinaria cuando habría sido mejor para el resultado actuar maquinalmente (el control ha sido contraproducente). El tipo de tarea es, al menos parcialmente, responsable del modo de actuación más apropiado en cada caso.

Por lo que respecta al aprendizaje de una segunda lengua, Schmidt distingue el aspecto técnico de la actuación, es decir, la destreza que muestra el

\footnotetext{
5 'Aducto' y 'educto' son las formas elegidas por Muñoz Liceras (1992) para contar con alternativas en español a los términos input y output. No incluimos ninguna forma alternativa en español para intake porque esta autora no trata expresamente este aspecto.
} 
aprendiz, de lo que se refiere al control en la ejecución de la tarea (control consciente o actuación automática) en relación con las etapas del aprendizaje:

In the early stages, learners are often aware of using mental translation, trying to remember paradigms they have been taught in class, and painfully groping for words and structures to express their intentions. As learning progresses, there is a gradual shift to a stage in which more and more attention is devoted to what one wants to say, with the process of grammaticization becoming more and more automatic. (Schmidt 1994:20)

En este sentido, podemos complementar las variables implicadas en el control consciente que un sujeto puede ejercer sobre su producción lingüística añadiendo el estadio de aprendizaje en el que se encuentra. Asimismo, podemos matizar la variable que hemos relacionado con el modo de interacción que se suele asociar típicamente al medio oral o al medio escrito, en cuanto al modo de llevar a cabo la tarea.

Como ya hemos visto en relación con el modelo del monitor, el hecho de que el output se produzca en el transcurso de una interacción comunicativa oral espontánea sincrónica, o bien en el entorno de una comunicación asíncrona y escrita, se asocia con la atención dedicada en cada caso a la realización de la tarea y a la elaboración o espontaneidad del producto resultante. No obstante, hemos de considerar también que la necesidad de ejercer el control consciente viene definida al menos en parte por el tipo de tarea que se está realizando. Diferenciamos, por tanto, entre el grado de elaboración que el sujeto dedica voluntariamente a la producción lingüística (su implicación en la realización de la tarea), así como del control que es capaz de ejercer con éxito, del control y la elaboración que la propia tarea precisa.

En suma, el corolario de variables del control consciente que el sujeto puede ejercer sobre su output es el siguiente:

1. Estadio vital del sujeto: adulto o niño.

2. Estadio del aprendizaje: etapa inicial, etapas intermedias, o etapa avanzada.

3. Estilo cognoscitivo personal de aprendizaje: uso espontáneo y habitual del monitor o tendencia a la no utilización de éste.

4. Implicación voluntaria en la realización de la tarea: grado de control y grado de elaboración que el sujeto está dispuesto a llevar a cabo ${ }^{6}$.

\footnotetext{
${ }^{6}$ En última instancia es el aprendiz el que acepta o rechaza la realización de la tarea, así como el que asume uno u otro grado de implicación en ella, tal como muestra el trabajo de Pinto da Silva
} 
5. Influencia de la metodología que se emplea para la realización de la tarea: grado de control y grado de elaboración que el profesor pide al sujeto.

6. Tipo de tarea: grado de atención (input), grado de control (output) y grado de elaboración que la tarea requiere (v. 3.2.4).

Estas variables están organizadas en orden descendente (de mayor a menor) de acuerdo con el grado de independencia que tienen del profesor. Así, los dos primeros factores son totalmente independientes, mientras que el tercero tiene una dependencia discutible ${ }^{7}$. La cuarta variable, por su parte, es dependiente del profesor puesto que afecta al grado de motivación. El profesor es responsable también de la metodología que se emplea, así como de la elección de las tareas que los aprendices realizarán durante el curso, por lo que las tres últimas variables dependen de éste de forma evidente. Así, los cuatro últimos factores representan diversos modos que el profesor tiene a su disposición para influir indirectamente en el control consciente del sujeto. Se considera que, aunque ni el profesor ni el aprendiz pueden ejercer ningún control sobre la adquisición de la lengua, el aprendizaje es controlado por el profesor cuando lo planifica, facilita y evalúa, y por el propio aprendiz cuando pone su voluntad, intención y demás medios a su disposición para aprender.

El control consciente que el sujeto puede ejercer sobre su producción, así como el control que a su vez el profesor puede ejercer sobre éste, son una cuestión de sumo interés y también de preocupación para la didáctica especial de las lenguas extranjeras. En estos momentos, la didáctica no está en condiciones de afirmar taxativamente cuál es la óptima utilización del control consciente del aprendiz para su aprendizaje, ya que el papel de la consciencia en el aprendizaje de la lengua no está suficientemente esclarecido, tal como señalamos al comenzar a tratar este concepto. No obstante, podemos partir de la presuposición de que la consciencia efectivamente participa de algún modo en el aprendizaje:

Assuming that consciousness is a late evolutionary development, it may be reasonable to assume that the primary processes of learning are those of the cognitive unconscious (Reber, 1992, 1993), but it is equally reasonable to wonder what functions are served by this evolutionary development. One answer that has been proposed is that consciousness is essential for learning

(1992), donde se presenta una evidencia real de actitud de rechazo a la realización de la tarea en el contexto del Inglés para Fines Específicos.

\footnotetext{
${ }^{7}$ Se interpreta que hay una mayor o menor dependencia en función de que se haya adoptado una postura más o menos innatista. Desde nuestra perspectiva, el estilo cognoscitivo personal de aprendizaje es modificable.
} 
(Baars, 1988; Block, 1991). Since language is also a late evolutionary development, there is reason enough to suspect (though not, of course, to assume) that consciousness and language learning may be intimately connected. (Schmidt 1994:22)

Desde el punto de vista del aprendizaje de la segunda lengua, esta relación entre consciencia y aprendizaje se suele traducir en términos de la fluidez del aprendiz ${ }^{8}$. Por otra parte, las teorías de la psicología cognitiva que se relacionan con esta cuestión son aquellas que tratan sobre el desarrollo del procesamiento automático9 ${ }^{9}$. Así, la fluidez y el comportamiento automático (no controlado conscientemente) son identificados con las etapas intermedias y avanzadas del aprendizaje:

Spontaneous, fluent language performance is unconscious only in the sense that it is accomplished without the conscious retrieval of explicit knowledge that may have been used as an aid to production in earlier, novice stages of development. (Schmidt 1994:21)

Según Just y Carpenter (1987:281), los componentes de una destreza se consideran automáticos si cumplen tres condiciones:

1. Son evocados por un estímulo sin ningún esfuerzo ni decisión conscientes.

2. Precisan poca capacidad de procesamiento para su ejecución, por lo que es más probable que se automaticen procesos que correspondan al nivel más bajo de procesamiento, como la decodificación de las letras en la lectura, que otros procesos que requieren un nivel más alto de procesamiento.

3. Permiten el paralelismo funcional. Es decir, permiten que otros procesos se produzcan simultáneamente, no sólo entre diferentes niveles de procesamiento, sino también dentro del mismo nivel.

La automatización de los procesos se relaciona con la fluidez al considerar que los procesos llegan a ser automáticos si se utilizan de forma extensiva. Para Just y Carpenter (1987:349), uno de los efectos de la práctica es que aumenta la velocidad de ejecución. Además, en destrezas que conllevan tanto componentes

\footnotetext{
${ }^{8}$ Para Schmidt (1994:21), «the problem of control in second language learning is essentially the problem of accounting for fluency». Schmidt identifica la fluidez con la destreza en lugar de con el conocimiento, haciendo hincapié sobre «the performance aspect of actually doing something in real time rather than the knowledge of how something is to be done» (Schmidt 1992:359).

${ }^{9}$ El modelo cognoscitivo de J.R. Anderson, que diferencia entre conocimientos declarativos y procedimentales, planteando el aprendizaje en tres etapas (cognoscitiva, asociativa y automática), está bastante extendido en este campo. Véase, por ejemplo, la aplicación de O'Malley y Chamot (1990) de este modelo al aprendizaje de segundas lenguas.
} 
perceptivos como cognoscitivos (como leer o sumar), la práctica extensiva permite que el proceso demande menor atención y menos capacidad disponible en la memoria a corto plazo. De este modo, el sujeto tiene más tiempo y más recursos a su disposición para dedicarlos a otros procesos más complejos. Por ejemplo, la práctica extensiva de la lectura permite que el lector automatice la decodificación de las letras y signos de escritura, el reconocimiento de palabras y otros procesos de nivel bajo, y dedique su atención a la comprensión de lo que lee, que es un proceso mucho más complejo y de nivel más alto ${ }^{10}$. La automatización se puede producir de dos modos distintos: bien cuando varias producciones que se utilizan repetidamente en una secuencia fija se comprimen compilándose en una producción única, o bien cuando varias producciones pasan, de ejecutarse secuencialmente, a ejecutarse en paralelo $^{11}$. Este modelo de automatización de los procesos cognitivos del sujeto es consistente con la visión de Corder del aprendizaje como un crecimiento orgánico y simultáneo a todos los niveles y no como una secuencia lineal (v. 3.1), así como con los modelos utilizados en la investigación sobre el aprendizaje de segundas lenguas y en la investigación sobre la traducción como proceso (Börsch 1986; Faerch y Kasper 1986; Gerloff 1986; Jääskelainen y Tirkkonen-Condit 1999).

Al igual que Schmidt (1994:20), consideramos que el aprendizaje de una segunda lengua conlleva, además de los aspectos cognoscitivos relacionados con el estado de conocimientos, valores y creencias del sujeto, un aspecto técnico que se refiere a la destreza de ejecución. Desde la perspectiva de la didáctica, podemos tratar ambos aspectos de forma separada. Así, el aspecto técnico tiene que ver con los conocimientos de tipo procedimental (saber cómo o saber hacer), los cuales a su vez se relacionan con el comportamiento estratégico ${ }^{12}$. Cuando este comportamiento estratégico está conscientemente controlado por el sujeto, entonces se inscribe en la denominada 'metacognición', tal como veremos a continuación.

\footnotetext{
${ }^{10}$ Tanto el aprendizaje de una lengua como la traducción pueden ser tomados como destrezas complejas en este sentido.

${ }^{11}$ Just y Carpenter (1987) denominan 'producción' a cada unidad de un proceso.

${ }^{12}$ Existen muy diversas definiciones de 'estrategia', varias de las cuales han sido recogidas por Pritchard (1990:275). Aquí nosotros adoptamos una concepción abierta como es la de van Dijk y Kintsch (1983:64-65): «Intuitively, a strategy is the idea of an agent about the best way to act in order to reach a goal». Estos autores señalan la conveniencia de interpretar las estrategias como una representación cognoscitiva de algún tipo y, así, incorporan este aspecto al concepto redefiniéndolo así: «a strategy is a global representation of the means of reaching that goal» (van Dijk y Kintsch 1983:65).
} 


\title{
3.2.5 Metacognición
}

Según la descripción de Cardelle-Elawar, la metacognición tiene gran importancia para aprender a utilizar estrategias cognitivas de forma eficaz:

\begin{abstract}
Metacognition is a theoretical construct that refers to an individual's conscious awareness of his or her own thought processes. Metacognition is related to self-knowledge and self-evaluation. It is essential to the development of students' ability to learn cognitive strategies, such as self-questioning, widen the application of these strategies and gain conscious control over them [...]. Students with metacognitive knowledge are aware of their strengths and limitations during the act of learning. Metacognitive awareness predisposes these students to learn how, when and why to use cognitive strategies. (Cardelle-Elawar 1995:82)
\end{abstract}

Aunque Cardelle-Elawar se centra en el desarrollo de la metacognición en el aprendizaje de las matemáticas, esta cuestión también ha sido tratada en el aprendizaje de la lengua extranjera por autores como Harris (1997) o, en España, Tragant (2000). Esta preocupación por la metacognición está relacionada con la tendencia metodológica actual a potenciar, por encima de otros tipos de aprendizaje, el aprendizaje autónomo. Se considera que el aprendizaje autónomo es más apropiado para dar cuenta de la diversidad del aula, así como para proporcionar al aprendiz herramientas que le permitan actualizar sus conocimientos en un entorno en el que las formas que adopta la información cambian rápidamente a causa de los avances tecnológicos (Slaouti 1999). Todo esto ha producido un creciente interés por este tipo de aprendizaje en el entorno de la didáctica especial de las lenguas extranjeras, tal como se puede comprobar en algunos recopilatorios recientes de bibliografía sobre el aprendizaje autónomo (Sinclair 1999; Victori 2000).

Para que los aprendices puedan desarrollar un aprendizaje autónomo, la didáctica debe ocuparse de aquellos aspectos del aprendizaje que contribuyan a dar cuenta de las diferencias entre unos aprendices y otros. Es decir, si el grupo de aprendices deja de ser tomado como un conjunto homogéneo de sujetos que se comportan de un modo ideal, y pasamos a preguntarnos acerca de la forma más conveniente de aprendizaje para un grupo de aprendices que piensan, se comportan, y aprenden de modos diferentes, entonces nos interesa ahondar en aquellos aspectos que puedan ser útiles para abordar la diversidad del aula. La metacognición es pertinente para la didáctica en este sentido porque, como explican Fischer y Mandl (1982:339), ésta se refiere a «all those reflective processes, and the results of such processes, as they serve an individual's own thinking or problem-solving processes, the way they operate and their effectiveness». 
Por lo que respecta al comportamiento estratégico desde el enfoque de resolución de problemas, la investigación de estos procesos cognitivos es muy exhaustiva en el campo de la psicología experimental, ya que este tipo de proceso ofrece la ventaja, frente a la investigación de otros tipos de pensamiento, de que el investigador puede asignar a los sujetos una tarea previamente definida $\mathrm{y}$, por tanto, puede definir con precisión la conducta que espera de ellos (Greene 1975).

En este sentido, podemos considerar abordar las tareas de traducción desde el enfoque de resolución de problemas interpretando el comportamiento del traductor al llevar a cabo la tarea como un comportamiento de tipo estratégico, en el que la actuación del traductor está guiada por un plan trazado con el fin de alcanzar el objetivo, que consiste en la producción del TT. Esta interpretación sólo es pertinente al abordar la traducción desde una perspectiva dinámica y comunicativa. Nos referimos a una concepción de la traducción que, por una parte, contemple la naturaleza dinámica del significado y, por otra, asuma los aspectos involucrados en la interacción social desde la perspectiva de la comunicación intercultural. Coincidimos en esta interpretación con el filósofo Cencillo cuando afirma que los procesos cognitivos no pueden ser aislados del contexto social:

[...] en los procesos cognitivos humanos [...] todo llega socioculturalmente
filtrado por algún sistema paramétrico vigente y en virtud de un aprendizaje
[y, como consecuencia de esto,] por significado no sólo hay que entender [...]
lo que un término o enunciado transmiten en abstracto a un determinado
receptor, sino también lo que un «objeto» o tipo concreto de realidad ejercen
como función para un sujeto determinado, dentro de una situación
determinada y en un contexto sociocultural concreto. (Cencillo 1988:14)

En este sentido, debemos tener en cuenta la relación dialéctica existente entre el sujeto como individuo y el sujeto como miembro de una comunidad o grupo social. Como puso de manifiesto Labov en sus trabajos acerca del habla de los habitantes de la ciudad de Nueva York en los años sesenta, la actuación individual del sujeto adopta unas características particulares debidas, en parte, a la influencia que el grupo social ejerce sobre él. En nuestro caso, el entorno social que consideramos pertinente para nuestro trabajo se describe más adelante.

Los psicólogos cognitivos señalan que esa actuación no puede ser interpretada de forma adecuada a menos que sepamos lo que el sujeto está tratando de hacer (Greene 1975:51). Es decir, para poder dar cuenta de la actuación lingüística de un sujeto, debemos relacionar su comportamiento particular con la situación social en que se produce su actuación. En este contexto, la resolución de problemas se inscribe en la necesidad del sujeto de encontrar y utilizar las 
estrategias que le permitan lograr la comunicación en los términos que desea. Si, además, queremos explicar en qué consisten los procesos cognitivos implícitos en esa actuación, debemos relacionar el comportamiento particular del sujeto con un plan general en el que se definen los objetivos que el sujeto desea alcanzar con su actuación.

En el campo de la traducción teórica, estos aspectos se recogen en el marco general adoptado, entre otros, por autores como Reiss, Vermeer, o Nord. No obstante, por lo general el enfoque de resolución de problemas se suele utilizar en el campo de la traducción con el fin de dar cuenta del resultado del proceso de traducir, más que para explicar los procesos internos involucrados en la traducción. La razón de esto hay que situarla en la necesidad tradicional que los traductores han sentido de explicar las diferencias entre un TT y su correspondiente TO en términos cualitativos. La comparación contrastiva entre textos en este ámbito ha sido tratada a lo largo de los siglos como un problema producido por la inexistencia de un punto objetivo de comparación que fuera independiente de ambos textos, es decir, de un tertium comparationis que funcionara a imagen y semejanza de otros instrumentos objetivos de medición que han sido creados o descubiertos por el hombre. Aunque actualmente está extendida la convicción de que el significado no posee entre sus propiedades la de ser estático, sino dinámico, y por tanto no presenta la estabilidad adecuada para poder ser utilizado como instrumento contrastivo absoluto entre traducciones con la precisión necesaria, el enfoque de resolución de problemas tiende a seguir restringiéndose a la comparación textual, probablemente porque la preocupación de los investigadores por los aspectos relacionados con los procesos cognitivos del sujeto que traduce es muy reciente ${ }^{13}$.

No obstante, en la incipiente investigación de la traducción como proceso de tipo cognitivo, el enfoque de resolución de problemas se sitúa en relación con el comportamiento estratégico del traductor, ya que la propia concepción de lo que constituye una estrategia es inseparable del concepto de problema traslativo: «a translation strategy is a potentially conscious procedure for the solution of a

\footnotetext{
${ }^{13}$ Hay otras razones más por las que el empeño de que el significado sea el criterio de comparación textual es poco práctico. Si se adopta una perspectiva dual del lenguaje, el contenido y la forma entran en conflicto en la traducción porque la relación que se establece entre ellos suele ser diferente en un TT y en su correspondiente TO. Si se interpreta el lenguaje mediante un modelo de tres estratos, como hace por ejemplo Halliday, las variables implicadas son excesivamente numerosas como para tratar la comparación entre textos únicamente en términos del significado de los mismos.
} 
problem which an individual is faced with when translating a text segment from one language to another» (Lörscher 1991:76).

Desde el punto de vista de la psicología en el contexto de la resolución de problemas como proceso cognitivo, Greene sigue a Niesser para definir un 'problema' como «algo que ocurre sólo en aquellas ocasiones en las que la respuesta evidente, previamente aprendida no es apropiada, ya que sólo entonces tiene uno que producir una nueva solución» (Greene 1975:20).

Esta perspectiva permite dar cuenta del comportamiento individual y creativo de los sujetos, ya que las nuevas soluciones no consisten en respuestas previamente aprendidas, sino que provienen del bagaje particular del propio sujeto. Como explica Greene, aunque el sujeto se enfrente con un problema nuevo, la solución se produce a partir de estrategias que ya conoce:

No hay duda de que incluso cuando nos enfrentamos con el más embrollado problema, hacemos uso de métodos y estrategias que han trabajado bien antes en vez de comenzar desde cero en cada ocasión. Lo que interviene aquí es la relación entre el pensamiento actual y la experiencia anterior. (Greene 1975:20-21)

Si contemplamos el aprendizaje de una lengua extranjera por adultos desde el marco cognoscitivo de resolución de problemas, podemos explicar ciertas diferencias observadas entre la adquisición de la primera lengua y la de la segunda basándonos en el conocimiento metacognitivo del aprendiz cuando emprende el aprendizaje de la lengua extranjera. Uno de los rasgos distintivos entre ambos tipos de aprendizaje es, precisamente, la experiencia anterior que tiene el aprendiz del uso de una lengua y de la comunicación en general, por no mencionar la patente diferencia en su estado de conocimientos de tipo declarativo cuando comienza la adquisición de la primera lengua y cuando comienza el aprendizaje de otra u otras.

Esa experiencia anterior, que es única para cada sujeto, da como resultado un estado particular de conocimientos en revisión permanente. Estos conocimientos son muy variados pero podemos establecer una clasificación muy general entre conocimientos procedimentales y declarativos, y a su vez podemos dividir estos últimos en conocimientos generales del mundo y conocimientos específicos de un dominio del saber en particular. Estos conocimientos participan en mayor o menor grado de acuerdo con la tarea que realiza el sujeto. Así, cuando el proceso que el sujeto lleva a cabo consiste, por ejemplo, en aprender a partir de textos, los conocimientos involucrados son tan diversos como los que Fischer y Mandl describen: 
[...] to be able to plan one's studying adequately, one must also know how much time one has to spend on the task of reading, how important it is to reach some goal, and how much effort one has to invest to reach it, all of which call for further information regarding the difficulty of the text or one's individual strengths or weaknesses in reading skill or domain-specific prior knowledge. (Fischer y Mandl 1982:342)

Lo que nos preocupa desde el punto de vista de la didáctica es cómo abordar las diferencias en el estado de conocimientos entre los distintos aprendices y cómo potenciar el comportamiento estratégico con el fin de lograr un aprendizaje eficaz. Fischer y Mandl afirman, apoyándose en resultados experimentales que comparaban la actuación de aprendices buenos y malos, que las diferencias de eficiencia en el aprendizaje no se pueden reducir a diferencias en el estado de conocimientos. Sugieren que, por esta razón, si queremos mejorar la eficiencia del aprendizaje, no es suficiente con aumentar la reflexión durante éste, sino que más bien los sujetos con dificultades de aprendizaje deberían aprender dónde concentrar su atención:

Poor performers do not perform badly because they lack the metacognitive language or awareness needed to regulate learning [...] there also is no evidence for corresponding differences in executive monitoring and control, at least with regard to the amount and intensity of executive activities. But there are obvious differences in the focus and directionality of self-reflection during reading: While the good readers score below the poor readers with regard to those variables which refer to the reader's time-in variant traits ([...] references to the learner's self-concept as a learner, [...] to the task-learner interaction, as well as [...] the learner's specific orientation towards the content area), they score higher in those domains which relate to actual, online processing demands [...]. The poor readers apparently behave like a rabbit facing a snake: They are so heavily concentrating on their own invariable state and the pending task, that their regulatory capacity is almost completely absorbed. The good readers, on the contrary, are not concerned as much with their status as a learner, and, hence, are able to focus on processing relevant information economically. (Fischer y Mandl 1982:347)

Como ya mencionamos en el capítulo anterior, aprender Inglés para Fines Específicos en grupo conlleva aspectos peculiares como el que la homogeneidad del grupo sea únicamente prospectiva ${ }^{14}$. Para un entorno educativo de esas

\footnotetext{
${ }^{14}$ Aunque potencialmente sea también posible un punto de partida homogéneo, en la realidad esto no se suele dar en el entorno estudiado aquí. En este sentido, estamos de acuerdo con DudleyEvans y St John (1998:3-4). Estos autores objetan que Robinson (1991) propone la homogeneidad de los grupos de Inglés para Fines Específicos como un rasgo característico de éste y que esto puede llevar a confusión. Independientemente de que la afirmación de Robinson pueda ser válida para el entorno denominado 'English for Professional Purposes' (v. Dudley-Evans y St John 1998:6), el caso es que las clases homogéneas de aprendices no representan una característica habitual en el entorno académico estudiado en este trabajo excepto de un modo prospectivo.
} 
características, las tareas cuya finalidad estriba en desarrollar los conocimientos metacognitivos del aprendiz tienen una doble utilidad didáctica. Por un lado, ayudan a que el aprendiz aprenda a adoptar una perspectiva sobre su propia actuación, como aconseja Klein (v. 3.2.1). En definitiva, le ayudan a ejercer un control crítico sobre su comportamiento y los resultados de éste, lo cual influye sobre el modo como el aprendiz integra los conocimientos nuevos con los que ya posee. Por otra parte, este tipo de tareas ofrece una clara ventaja para el profesor, ya que le permite extraer información acerca de las concepciones de los aprendices sobre ellos mismos, sus estilos cognoscitivos de aprendizaje y, en nuestro caso, sobre el concepto de lenguaje y de traducción que utilizan. Esta variada información le permite al profesor distinguir entre distintos tipos de aprendices y, por consiguiente, adaptar y revisar los objetivos, los contenidos y la forma de tratarlos, de acuerdo con las características específicas del grupo y de cada aprendiz y en función de la meta propuesta.

En el caso de la traducción, para que la actividad de aprendizaje permita aprovechar esta doble utilidad didáctica, necesitamos establecer tareas cuyo objetivo sea más amplio que la producción del TT. Dado que el TT es insuficiente como fuente única de datos, ya que presenta el resultado de las tomas de decisión de los aprendices pero no las estrategias seguidas para resolver los problemas afrontados, ni tampoco la descripción de dichos problemas, para poder contar con esta información es necesario introducir en la tarea de traducción una herramienta que sirva para estos fines, y a la que nos referiremos con mayor detalle en el Capítulo 6.

Por otra parte, aunque ya hemos señalado que nuestro interés en este trabajo se va a centrar en la funcionalidad didáctica de la traducción en relación con la consecución de objetivos de tipo afectivo, nuestro interés por los aspectos relativos a traducción como un medio de facilitación de la adquisición de conocimientos de tipo metacognitivo nos hace plantearnos la cuestión relativa a la naturaleza de la competencia que queremos que los aprendices alcancen mediante la enseñanza del Inglés para Fines Específicos tal como la describimos en este trabajo. A tal efecto, en la sección siguiente vamos a establecer por qué elementos está constituida esa competencia comunicativa especializada o restringida que el aprendiz de Inglés para Fines Específicos desea alcanzar, y a la que nos hemos referido anteriormente y, especialmente, qué potencial tiene la traducción para facilitar el aprendizaje que permita alcanzarla. Para lograr esto, analizaremos cuáles son los componentes de la competencia comunicativa en relación con la traducción como tarea de facilitación del aprendizaje. 


\subsection{Traducción, competencia comunicativa y capacidad}

Tras un análisis de los trabajos publicados sobre la enseñanza y la evaluación de la lengua desde el punto de vista comunicativo, Canale y Swain (1980) llegaron a la conclusión de que, a pesar de las diferentes concepciones existentes sobre el enfoque comunicativo de la enseñanza, la competencia comunicativa incluye, como mínimo, cuatro áreas de conocimientos y destrezas (v. Cummins y Swain 1986:168).

Estas cuatro áreas han sido clasificadas por Canale y Swain como 'competencia gramatical', 'competencia sociolingüística', 'competencia discursiva' y 'competencia estratégica'. Estos autores presuponen que:

a. Los aprendices pueden desarrollar la competencia en cualquiera de estas áreas de forma relativamente independiente.

b. Los aprendices y los nativos se diferencian en el dominio relativo de estas destrezas.

c. Cada destreza está involucrada en un grado u otro en función de cada tarea en particular.

En el caso del Inglés para Fines Específicos, el segundo presupuesto se puede matizar en el sentido de que, en lugar de entre el aprendiz y el nativo, el contraste en el dominio de las destrezas se puede establecer entre el aprendiz y el experto, que no tiene por qué ser hablante nativo de la lengua pero sí miembro de la comunidad profesional del campo de especialización. La meta del aprendizaje del Inglés para Fines Específicos es alcanzar una competencia comunicativa equiparable a la de los otros miembros de la comunidad profesional y, en particular, equiparable a la competencia que le permita al miembro de esta comunidad de habla comunicarse en lengua inglesa con los demás miembros en términos de igualdad funcional, de tal modo que la competencia comunicativa no se identificará con ninguna variedad de los hablantes nativos a menos que la comunidad de habla en la que el aprendiz desee integrarse esté compuesta por ellos o hayan elegido esa variedad por alguna razón en particular.

Cummins y Swain resumen brevemente las características de las cuatro áreas de la competencia comunicativa así: 
Grammatical competence is understood to reflect knowledge of the language itself. It includes knowledge of vocabulary and rules of word formation, pronunciation/spelling and sentence formation. Such competence focuses directly on the knowledge and skills required to understand and express accurately the literal meaning of utterances.

Sociolinguistic competence addresses the extent to which utterances are produced and understood appropriately in different sociolinguistic contexts, depending on contextual factors such as topic, status of participants and purposes of the interaction. Appropriateness of utterances refers to both appropriateness of meaning and appropriateness of form.

Discourse competence involves mastery of how to combine grammatical forms and meanings to achieve a unified spoken or written text in different genres such as narrative, argumentative essay, scientific report or business letter. Unity of a text is achieved through cohesion in form and coherence in meaning. Cohesion deals with how utterances are linked structurally to facilitate interpretation of a text. For example, the use of cohesion devices such as pronouns, synonyms, ellipsis, conjunctions and parallel structures serves to relate individual utterances and to indicate how a group of utterances is to be understood logically or chronologically as a text. Coherence refers to the relationships among the different meanings in a text where these meanings may be literal meanings, communicative functions, or social meanings.

Strategic competence refers to the mastery of communication strategies that may be called into action either to enhance the effectiveness of communication or to compensate for breakdowns in communication due to limiting factors in actual communication or to insufficient competence in one or more of the other components of communicative competence. (Cummins y Swain 1986:168-169)

El enfoque de Canale y Swain es apropiado para describir el potencial de la traducción para el Inglés para Fines Específicos de acuerdo con las cuatro áreas propuestas. Al presuponer que la subcompetencia de cada área se puede desarrollar de forma independiente y que su participación en el aprendizaje depende de la tarea que se realiza, podemos llevar a cabo un análisis individual de cada subcompetencia en función de una tarea dada.

Por otra parte, podemos aprovechar el hecho de que la capacidad de mediación entre lenguas ya se ha desarrollado de manera natural en los aprendices desde el momento en que comienzan a aprender una segunda lengua y, de este modo, no es necesario introducir la traducción en nuestra planificación del curso como uno de los contenidos, sino que podemos considerar su funcionalidad didáctica como una de las actividades de aprendizaje o como un método de evaluación formativa (esto es, como un medio de facilitación del aprendizaje) de todas las subcompetencias que constituyen la competencia comunicativa, o bien únicamente de una de ellas. Siguiendo este planteamiento, a continuación vamos a situar la traducción como tarea en relación con el tipo de aprendizaje con el que se puede asociar en cada caso. 


\subsubsection{Traducción y aprendizaje de la gramática}

La descripción de Canale y Swain de la competencia gramatical se basa en el concepto de competencia utilizado por Chomsky, denominada asimismo 'competencia lingüística' y que, muy someramente esbozada, consiste en el conocimiento que tiene el hablante de las oraciones de su lengua. Este conocimiento linguístico «constitutes a generative device for the production and reception of correct linguistic forms» (Widdowson 1983:7).

No obstante, según ha ido avanzando el tiempo, y especialmente a partir del trabajo de Hymes (1972), el concepto de competencia ha pasado a incorporar también los aspectos referentes a los conocimientos del uso social del lenguaje y, al hacerlo, el énfasis se ha desplazado precisamente hacia los aspectos de la competencia que se refieren a la comunicación, considerando que la competencia comunicativa incluye la competencia lingüística o gramatical y que, por tanto, se encuentra en un nivel taxonómico superior.

Por otra parte, este cambio de perspectiva ha promovido a su vez cambios en la metodología de la enseñanza del inglés como lengua extranjera. Pero, a pesar de que el cambio ha surgido como una necesidad de que el esquema epistemológico utilizado represente de forma apropiada nuestra interpretación actual de qué es y cómo se produce la comunicación lingüística, este cambio no tiene por qué representar mejoras automáticas y directas para la didáctica. Es decir, los cambios epistemológicos no están intrínsecamente relacionados con los cambios en el paradigma vigente de la didáctica, en el sentido de que un esquema epistemológico más completo o que representa la interpretación de la realidad de forma más eficiente que otro no tiene por qué influir positivamente en la eficacia de la metodología empleada. Tal como explica Moran (1999), en la etapa obligatoria de la enseñanza de la lengua inglesa en España, estos cambios, reflejados en la Ley Orgánica de Ordenación General del Sistema Educativo (1990), son conflictivos:

[The] assertion of the primacy of communicative competence is perhaps a necessary corrective to an exclusive emphasis on formal elements of language, but $[\ldots]$ I wonder if the authors of the curriculum are not overstating the case. It is true that in language use, formal elements such as syntactic structures, lexis, and cohesive devices are subordinate to the expression of human meanings and intentions. But is grammar (seen in a broad sense as the interrelation of phonological, syntactic and semantic elements) really only one aspect of communicative competence, of equal, or subordinate, status to others? There is surely a case for saying that grammatical competence is in some sense basic, or at least should have chronological priority. (Moran 1999:154-155) 
Lo que nos interesa aquí del planteamiento de Moran es, precisamente, la posible repercusión en la metodología de la relación entre la competencia gramatical y el resto de subcompetencias de la competencia comunicativa.

Como sugiere Moran, es lógico que la competencia gramatical tenga cierta prioridad sobre las demás subcompetencias en la secuenciación de la planificación de la enseñanza dado que, para comunicarnos de forma eficaz, debemos tener conocimientos del funcionamiento de los elementos que componen los diferentes sistemas de la lengua y, para ello, es necesario conocer cuáles son los elementos constituyentes de los sistemas. Debemos, por tanto, conocer la composición y el funcionamiento de los sistemas lingüísticos para poder servirnos de ellos con eficacia en la comunicación.

Por lo que concierne a la funcionalidad didáctica de las tareas de traducción, si tenemos en cuenta que la traducción (tal como la contemplamos en este trabajo) conlleva la interpretación y producción de textos con una finalidad comunicativa, entonces podemos concluir que la traducción no es un medio apropiado para facilitar el aprendizaje de gramática desde un punto de vista formal, es decir, en relación con los elementos constituyentes de los diferentes sistemas de la lengua. Incluso aun cuando consideráramos adoptar un enfoque contrastivo sobre los aspectos formales de la gramática, contraponiendo los sistemas pertenecientes a dos lenguas diferentes, las tareas de traducción implican sólo indirectamente el contraste de sistemas lingüísticos.

Al realizar tareas de traducción, es habitual que nos enfrentemos con un problema traslativo que consiste en la necesidad de elegir entre diferentes opciones expresivas, ya que en nuestro TT sólo aparecerá una de ellas. Si bien es cierto que la consideración de las diferentes opciones disponibles se basa en el repertorio específico del sistema lingüístico en cuestión (semántico, sintáctico, etc.), en cualquier caso las decisiones acerca de las expresiones que se van a utilizar en el TT no se toman sin tener en cuenta los aspectos funcionales que entran en juego en ese texto en particular, tanto contextuales como co-textuales (v. De Beaugrande 1980a:12-13). En este sentido, el tipo de competencia gramatical que podemos considerar en relación con la funcionalidad de la traducción como medio de facilitación del aprendizaje es de tipo funcional, más que de tipo formal.

Hemos mencionado ya que la utilización de la traducción que se ha hecho tradicionalmente en el aula de lenguas extranjeras corresponde a una concepción excesivamente simplista del fenómeno, donde la atención se centra en la producción de formas lingüísticamente correctas. Sin embargo, esta crítica no implica que exista 
una incompatibilidad de tipo teórico entre la traducción y su utilización para facilitar el aprendizaje de la gramática de la lengua extranjera.

Desde nuestra perspectiva, la traducción puede (y debe) ser tomada en toda su complejidad sin tener que descartar su funcionalidad didáctica como medio de facilitación del aprendizaje gramatical en términos absolutos. Realmente no existen razones de carácter teórico para adoptar una concepción simplista de la traducción en entornos didácticos ajenos a los Estudios de Traducción, por lo que, desde una perspectiva teórica, no podemos justificar que en el aula de Inglés para Fines Específicos se adopte un enfoque reduccionista sobre la traducción.

Por otra parte, no conviene olvidar que debemos descartar la utilidad de la traducción para aprender reglas gramaticales, de modo que la gramática cuyo aprendizaje puede ser facilitado mediante tareas de traducción es una gramática funcional y aplicada.

Aunque no consideremos la traducción en relación con el aprendizaje de reglas gramaticales, sí podemos vislumbrar la utilidad de este tipo de tarea para mejorar la competencia gramatical necesaria para interpretar textos escritos. Nos referimos aquí a una gramática que se asocia con la lectura del texto en relación con la comprensión de éste y, por consiguiente, intrínsecamente ligada al significado. Si bien no está muy claro en la clasificación de Cummins y Swain (1986) dónde trazar la línea divisoria entre la competencia gramatical funcional y la competencia discursiva, nos atenemos aquí a la interpretación de estos autores de la competencia gramatical, que incluye los conocimientos y destrezas que son necesarios para comprender y expresar con precisión mensajes con significado literal. A este respecto, consideramos que los aspectos relacionados con la decodificación y análisis gramatical de los mensajes están incluidos en la competencia gramatical, si bien su funcionamiento se relaciona con las actividades de comprensión y producción de textos y no de repertorios lingüísticos.

En cuanto a los aspectos gramaticales involucrados en los procesos de comprensión que intervienen en la lectura, los psicólogos del campo cognitivo Mitchell, Cuetos y Zagar señalan la importancia del procesamiento sintáctico en el proceso global de lectura:

For a start, [syntactic processing or parsing] plays a crucial role in enabling readers to compute the appropriate relationships between the people or objects referred to in the sentence. In addition, contextual effects may in turn allow this information to play a part in word-recognition and other processes. Overall, its importance in reading for meaning is perhaps brought home most poignantly by the severe comprehension difficulties shown by agrammatic aphasic patients. (Mitchell, Cuetos y Zagar 1990:286) 
Teniendo en cuenta la importancia del procesamiento sintáctico en la comprensión del texto, podemos plantear el aprendizaje de la gramática mediante tareas de traducción a partir de la consideración de los aspectos del análisis gramatical que son comunes a las lenguas que intervienen en la traducción, en nuestro caso el inglés y el español ${ }^{15}$.

Según Mitchell, Cuetos y Zagar, los procedimientos generales de análisis sintáctico que realizan los angloparlantes nativos son dos:

In general terms there are two kinds of computation that a parser has to perform. First, it has to categorize word strings in terms of preexisting structural categories or combination of categories. Second, it has to establish appropriate dependency relationships between these units. (Mitchell, Cuetos y Zagar 1990:287)

A partir de ahí, la tarea de traducción se puede concentrar en aquellos aspectos contrastivos que muestran las diferencias de comportamiento de las gramáticas de las dos lenguas que participan en la traducción. No obstante, hay que tener en cuenta que existen dificultades para utilizar información sobre estas diferencias a causa de la escasez de trabajos descriptivos de otras lenguas diferentes de la inglesa (Mitchell, Cuetos y Zagar 1990:288). A pesar de esto, podemos mencionar algunos ejemplos en relación con el inglés y el español.

Mitchell, Cuetos y Zagar (1990) sugieren, a partir de resultados experimentales, que cuando hay ambigüedad en la estructura sintáctica los procedimientos sintácticos utilizados para asociar varias subestructuras en una oración no tienen la misma distribución entre los hablantes de cada lengua. Estos procedimientos incluyen típicamente dos estrategias, denominadas 'minimal attachment' y 'late closure', que se basan en el concepto de estrategia de Frazier: «strategies serve to improve readers' general processing efficiency by allowing people to take in new material as rapidly as possible and by enabling them to

\footnotetext{
${ }^{15}$ Esta base común de partida es muy importante porque las diferencias pueden ser notables en función del par de lenguas que interviene en la traducción, y es en el nivel sintáctico donde estas diferencias pueden ser más drásticas:
}

The problem of generalizing across languages emerges at all levels in the study of the reading process. Local or language-specific processes can potentially occur at the prelexical level of analysis and during word recognition, as well as during syntactic analysis and higher level aspects of textual processing. However, the implications are perhaps most serious in the process of parsing, because it is at the level of syntax that linguistic variation is arguably most marked. (Mitchell, Cuetos y Zagar 1990:286) 
minimize the load imposed on short-term memory» (Mitchell, Cuetos y Zagar 1990:290) ${ }^{16}$.

Mitchell, Cuetos y Zagar (1990) llevaron a cabo un experimento con una estructura ambigua del tipo «Andrew had dinner yesterday with the niece of the teacher who belonged to the Communist party» / «Andrés cenó ayer con la sobrina del maestro que está [sic] en el partido comunista». Estos investigadores descubrieron mediante un cuestionario que los sujetos angloparlantes tendían en su mayoría $(58.0 \%)$ a utilizar la estrategia de 'late closure', es decir, a asociar la oración de relativo final («who belonged to the Communist party») al último candidato que había aparecido («teacher»), mientras que los sujetos hispanoparlantes prefirieron claramente $(62.3 \%)$ asociar este elemento («que está en el partido comunista») al candidato anterior («sobrina»). Si bien estos investigadores señalan que los resultados obtenidos deberán ser corroborados por experimentos sobre este procesamiento en tiempo real, la cuestión relevante para nosotros es que estas descripciones y comparaciones sobre el comportamiento de las gramáticas de las lenguas relevantes para el aprendiz tienen utilidad para la didáctica. Tales descripciones comparativas nos permiten diseñar tareas en las que los aprendices puedan observar cómo se utiliza la gramática para producir significado y experimentar esto en cada lengua. En este sentido, la traducción parece apropiada para facilitar este tipo de aprendizaje gramatical.

Para no extendernos innecesariamente, únicamente incluiremos aquí otro ejemplo más, que suele ser tratado típicamente (aunque de diversas formas) en el aula de Inglés para Fines Específicos en relación con los aspectos gramaticales relevantes para los tipos de texto tratados en estos cursos. Se trata de las diferencias en el modo como se lleva a cabo el procedimiento de nominalización en cada lengua. Nos referimos aquí a lo que Mitchell, Cuetos y Zagar describen como «the fact that in some languages [like English] the adjectives [sic] premodify the noun whereas others [e.g., Spanish and French] are based on postmodification» (Mitchell,

\footnotetext{
${ }^{16}$ Mitchell, Cuetos y Zagar describen estas estrategias así,
}

Minimal attachment acts in such a way as to assign the simplest possible structure to a string of words, and as this is the configuration which is quickest and easiest to compute, the strategy ensures that processing is completed within the shortest possible time. Late closure guarantees that new constituents are immediately attached to an existing structure. This avoids the additional memory load which may otherwise be imposed when a constituent is held in isolation for a period of time before eventually being integrated with prior material. (Mitchell, Cuetos y Zagar 1990:290) 
Cuetos y Zagar 1990:297). Halliday (1998), por su parte, se refiere al 'grupo nominal' como un recurso extremadamente potente para generar significado, ya que se puede expandir más o menos indefinidamente (v. 5.2.4.1).

Estadísticamente, el potencial de expansión del grupo nominal presenta diferencias interlingüísticas, como sugieren las palabras de Mitchell, Cuetos y Zagar, pero también interdiscursivas. Por ejemplo, Halliday (1998:207) nos recuerda que, mientras que la densidad media de palabras léxicas en una claúsula es apenas mayor de dos en el inglés espontáneo hablado, en el discurso científico esta media es muy superior ${ }^{17}$. Estas diferencias de nominalización se prestan a ser tratadas mediante las tareas de traducción, ya que ahí suelen surgir frecuentemente ante los aprendices en forma de problemas traslativos. En este sentido, podemos sugerir que la traducción tiene utilidad para facilitar el aprendizaje de la competencia gramatical, entendida en el sentido funcional descrito anteriormente.

\subsubsection{Traducción y competencia sociolingüística}

La competencia sociolingüística, según la interpretación de Canale y Swain, se relaciona con el contexto en el que los hablantes pertenecientes a un grupo social determinado utilizan la lengua para comunicarse.

En el entorno del Inglés para Fines Específicos, este contexto de uso se identifica con las situaciones que se asocian típicamente con la comunicación producida por, entre y para los profesionales del campo específico considerado. Estos profesionales, como miembros pertenecientes a la misma comunidad de habla, son capaces de distinguir en cada situación ciertas configuraciones lingüísticas que se asocian convencionalmente con la situación donde aparecen y, por tanto, pueden discriminar entre distintos tipos de texto según confluyan ciertas características lingüísticas y ciertas situaciones de uso. Pueden, asimismo, reconocer qué es lo que ocurre normalmente en cada situación y, por lo tanto, cuál es la norma de uso en su entorno de habla. Así, pueden determinar qué es apropiado para la situación y qué no lo es.

A diferencia de la competencia gramatical, que suele ser interpretada en términos de la cantidad y tamaño de los conjuntos de reglas correctas adquiridas por el hablante, la competencia sociolingüística se interpreta en función de la capacidad

\footnotetext{
${ }^{17}$ Halliday (1998:193) presenta algunos ejemplos ilustrativos, tales como: «the model rests on the localised gravitational attraction exerted by rapidly oscillating and extremely massive cloud loops of cosmic string».
} 
del hablante de adaptarse al medio. Es decir, se entiende que un hablante posee mayor competencia sociolingüística cuanto más capaz es de desenvolverse en diferentes situaciones comunicativas.

La competencia sociolingüística tiene una importancia que trasciende de lo puramente aconsejable a lo estrictamente necesario cuando la competencia comunicativa en la lengua extranjera es utilizada como requisito en el acceso a un puesto de trabajo, tal como se desprende de trabajos como el de Scheuer (2001).

La competencia comunicativa en lengua inglesa constituye uno de los requisitos presentes en muchas de las ofertas de empleo en España, como hemos tenido ocasión de comprobar en un estudio anterior ${ }^{18}$. Para poder acceder a un puesto de trabajo en el que el inglés es un requisito excluyente, el aspirante suele ser entrevistado en esa lengua. Scheuer (2001) ha estudiado las características de un número de entrevistas en las que los aspirantes a un puesto de trabajo obtuvieron el empleo y las ha comparado con las características de entrevistas en las que los aspirantes al mismo puesto no tuvieron éxito. Sus conclusiones ponen de manifiesto la extremada importancia de la competencia sociolingüística para el resultado de la entrevista:

It is demonstrated that felicitous interviews, i.e. interviews resulting in a job offer, reflect the breadth of applicants' stylistic repertoires. Since stylistic repertoires are properties of social groups, and not of individuals, it is found that success in job interviews may depend more on social categories than on displaying individual competence. (Scheuer 2001:223)

A pesar de que el estudio de Scheuer no ha sido llevado a cabo en España, sino en Dinamarca, y con las reservas obvias sobre la generalización de estos resultados, este estudio nos muestra cómo la competencia sociolingüística puede marcar y restringir la entrada al mundo profesional del aprendiz que termina su preparación y que se encuentra en la delgada línea que le separa de la pertenencia a una comunidad profesional.

En términos generales, cualquier hablante pertenece a más de un grupo social y, por consiguiente, se enfrenta con situaciones en las que se comunica de forma muy diversa, adaptando su habla en función de la situación. No obstante, en este punto nos interesa principalmente la relación del hablante con el grupo social

\footnotetext{
${ }^{18}$ Se analizó la situación del inglés como requisito para acceder al puesto de trabajo en más de quinientos anuncios de oferta de empleo de la sección Negocios del periódico El País. Los resultados de este trabajo fueron presentados bajo el título «El inglés como recurso intencional en las ofertas de empleo en España» en el Simposio Internacional: Lingüística y Sociedad que tuvo lugar el 25 y 26 de mayo de 1995 en la Universidad de Salamanca.
} 
en su calidad de grupo cerrado. En este caso, el acceso al grupo está restringido únicamente a ciertos miembros de la sociedad, a quienes aquí denominamos 'profesionales'. La diferencia más relevante entre el aprendiz y el profesional consiste, desde este punto de vista, en que el aprendiz no es miembro de la comunidad de habla todavía, mientras que el profesional sí pertenece a ella. Cabe destacar que esta comunidad de habla puede no corresponder con ningún espacio geográfico ni cultural en particular, sino que sus miembros pueden pertenecer a diversos países, lenguas y culturas. En tales casos, la lengua inglesa suele funcionar frecuentemente como un vehículo general de comunicación intercultural en este entorno profesional restringido.

De acuerdo con la descripción de Canale y Swain, que es consistente con lo que sugiere Scheuer, el concepto de competencia sociolingüística está relacionado con el estado de conocimientos del aprendiz como miembro de un grupo social (más que como individuo). Precisamente una de las dificultades del aprendizaje de este aspecto de la competencia comunicativa proviene, tal como ya hemos apuntado anteriormente, del hecho de que el aprendiz aún no ha entrado a formar parte de la comunidad de habla a la que pertenecen los profesionales. Podríamos decir que, al igual que el niño atraviesa un proceso de socialización en el que va adquiriendo progresivamente las estrategias y conocimientos necesarios para desenvolverse como miembro de la sociedad en la que crece, el aprendiz adquiere de forma progresiva los conocimientos, estrategias y actitudes que le permitirán comunicarse en situaciones reales como un profesional, es decir, como los demás miembros de su grupo social.

Desde el punto de vista de la didáctica general, este complejo proceso de 'socialización profesional' hace aconsejable la inclusión de contenidos actitudinales relacionados con este aspecto del proceso de aprendizaje. Como explica Blanco Prieto, podemos hablar de dos tipos de actitudes, las generales y las específicas. Las actitudes específicas, denominadas también 'científicas y profesionales', justamente se refieren a las disposiciones que facilitan la actividad profesional (v. Blanco Prieto 1996:62). Además de esto, creemos que es muy adecuado incluir contenidos de este tipo en los cursos de Inglés para Fines Específicos en la educación universitaria porque contribuyen positivamente a lograr un aprendizaje significativo y porque implican un énfasis en aspectos del lenguaje que están relacionados con el éxito en la comunicación. En este sentido, creemos que la consecución de objetivos educacionales de tipo afectivo contribuye a que el aprendiz disponga de herramientas que le permitirán ser aceptado en la comunidad profesional con mayor 
facilidad que cuando no se incluyen este tipo de objetivos y de contenidos en la planificación docente.

Para poder detallar de forma más precisa en qué consisten las actitudes profesionales que deben adquirir los aprendices en el entorno del Inglés para Fines Específicos, debemos especificar previamente a qué entorno profesional nos estamos refiriendo. La utilización de una denominación genérica como 'Inglés Técnico' no se corresponde con ningún entorno de actividad profesional con la precisión necesaria así que, al desarrollar la planificación docente, será necesario caracterizar convenientemente la actividad profesional que desarrollará el aprendiz tras su periodo de formación, si bien no descenderemos a ese nivel de descripción ya que nuestra mayor preocupación aquí se centra en cómo puede la traducción contribuir al desarrollo de la competencia sociolingüística.

En primera instancia, es obvia la utilidad didáctica de la traducción para que el aprendiz aprenda a actuar como un profesional cuando en el repertorio de actividades profesionales se incluye la traducción de o al inglés de los tipos de texto que se asocian con tal situación comunicativa en ese entorno ${ }^{19}$. Ésta es la clase de justificación que más frecuentemente se emplea en el entorno del Inglés para Fines Específicos, como ya vimos en el capítulo anterior. Desde esta perspectiva, la tarea de traducir es introducida en el diseño didáctico con un objetivo actitudinal, para contribuir al desarrollo de la actitud que permitirá que la actuación del aprendiz se equipare con la del profesional. Aquí, las metas y objetivos del aprendizaje coinciden. Nos situamos, por tanto, en una interpretación del Inglés para Fines Específicos donde los aspectos referentes a las necesidades del aprendizaje no revisten tanta importancia como aquellos que se relacionan con las necesidades de los aprendices (v. 2.2.).

Lo que ya no resulta tan evidente, en una interpretación del Inglés para Fines Específicos como ésta, es la utilidad de esta tarea cuando la necesidad de

\footnotetext{
${ }^{19}$ Scheuer sugiere que la competencia sociolingüística se manifiesta mediante la actuación al observar que, en las entrevistas de trabajo estudiadas por él, el comité de selección pide a los candidatos una presentación oral en la que pueden utilizar la información que ya han enviado previamente al cursar su solicitud:
}

It is interesting that the committee emphasizes that the applicant is free to repeat the written application. This indicates that Extract 1 is first of all an invitation to perform, since repeating given information does not inform (Grice, 1975). This demonstrates the authentic status of spoken language. Social accountability is obtained through oral performance, this is the committee's object of measurement for getting to know the applicant as an individual (...). (Scheuer 2001:229) 
traducir no se encuentra entre las actividades que se asocian con el comportamiento profesional de un ámbito particular. No obstante, esta tarea es extremadamente útil para desarrollar la competencia sociolingüística desde nuestra perspectiva del Inglés para Fines Específicos.

Hemos sugerido que la competencia sociolingüística se refiere específicamente al uso de la lengua como herramienta de interacción social. En este sentido, el desarrollo de esta competencia tiene que ver asimismo con el desarrollo de actitudes que permiten que el aprendiz utilice la lengua con precisión al comunicarse y al interpretar lo que otros dicen, pero también que actúe lingüísticamente de una forma crítica, como diría Ryle.

Cuando el objetivo que se plantea es desarrollar la competencia sociolinguística del aprendiz, el foco de interés del aprendizaje no sólo recae en cómo el significado literal se construye e interpreta en la comunicación, sino también en la construcción e interpretación del significado en su dimensión social (Halliday 1978). Aquí la perspectiva del aprendiz sobre el lenguaje en uso es esencialmente interpretativa. Sin embargo, Canale y Swain ponen el énfasis sobre una perspectiva claramente valorativa, puesto que la competencia sociolingüística se identifica con el reconocimiento del grado de aproximación a la norma de uso de las configuraciones lingüísticas en relación con el contexto en que aparecen («the extent to which utterances are produced and understood appropriately in different sociolinguistic contexts» (Cummins y Swain 1986:168)) mediante un parámetro de evaluación relativa ('ser más o menos apropiado'), de tal suerte que el aprendiz que es competente es capaz de discernir el grado relativo de proximidad o lejanía de una configuración determinada respecto de la norma de uso en esa situación, tal como se supone que son capaces de hacer los profesionales.

Desde un enfoque global sobre la noción de competencia comunicativa de Hymes, Widdowson se opone a esta concepción evaluativa de la competencia porque, en su opinión, no recoge la perspectiva del usuario del lenguaje sino la del analista, pretendiendo que ambas son equiparables y, en definitiva, ofreciendo una visión sobre el funcionamiento del lenguaje demasiado conductista:

[communicative competence] seems to imply an analytic, rather than a user, perspective and to assume an equation between user and analyst models of language. [...] competence seems to imply conformity, either to code (linguistic competence) or to social convention (communicative competence). The assumption seems to be made that language behaviour is rule governed, determined by a knowledge system which has only to be invoked and applied on particular occasions for communication to take place. In other words, language behaviour is a matter of compliance. (Widdowson 1983:25) 
En este sentido, la traducción es una forma de comunicación especial, con peculiaridades que hacen que la competencia necesaria para traducir con eficiencia y eficacia sea diferente de la competencia comunicativa que describe Widdowson, porque en la traducción el énfasis de la tarea no recae en la creación de significado (Widdowson 1983:25), sino en la recreación de significado previamente creado por otro usuario del lenguaje. Desde nuestro punto de vista, a la capacidad interpretativa del significado creado por otro se añade aquí la capacidad evaluativa y crítica sobre el modo de creación de ese significado.

Según esto, una de las perspectivas que la traducción como tarea puede proporcionar al aprendiz consiste en la percepción de que los elementos lingüísticos elegidos por él o por otro para comunicar algo (incluyendo la información que se suministra) son más o menos apropiados. Siguiendo a Grice (1975), esto implica que esta tarea puede contribuir a que el aprendiz desarrolle la capacidad de discriminar si una configuración lingüística determinada cumple de forma apropiada las máximas de cooperación en relación con la situación donde se manifiesta, así como de describir cómo lo hace. Esta tarea ayuda al aprendiz a adoptar una perspectiva sobre la comunicación de acuerdo con la dimensión interpersonal del significado ya que, a diferencia de lo que ocurre al introducir al aprendiz en otras situaciones comunicativas, en la traducción el aprendiz debe asumir un papel que consiste en ponerse en lugar de todos los demás participantes, como un actor que debiera interpretar todos los personajes de una obra (y quizás también dirigirla). De este modo, el aprendiz debe adoptar a un tiempo la perspectiva de usuario del lenguaje y la de analista.

Esta capacidad de evaluación crítica de las producciones lingüísticas exige que el aprendiz aplique un esquema conceptual acerca del funcionamiento del lenguaje en uso. En el aula de Inglés para Fines Específicos, los conocimientos y concepciones previas del aprendiz sobre el funcionamiento del lenguaje (y de la traducción) suelen ser escasos y tener un enfoque marcadamente reduccionista. Las actitudes de los aprendices acerca de la valoración de su actuación y de la de otros en la comunicación suelen dirigirse hacia los parámetros de corrección en términos absolutos. Los aprendices tienden a valorar las configuraciones lingüísticas como 'correctas' o 'incorrectas' en sí mismas y, al hacerlo, revelan una falta de percepción de los factores que intervienen en el contexto de situación en el que la configuración aparece. Muñoz Martín (1995) recoge algunas de estas ideas preconcebidas acerca del lenguaje en uso, que no son exclusivas de este entorno educativo ni de este tipo de aprendices: 
* Las lenguas son mejores que los dialectos.

* Las lenguas progresan o decaen.

* Muchas personas no saben hablar.

* Las mujeres hablan mejor que los hombres.

* Los andaluces y los argentinos hablan mal el español.

* Hay lenguas, como el alemán, que son muy precisas, y otras, como el francés, que son muy lógicas, lo que explica la situación de los países que las hablan.

* Hay que evitar el uso descuidado del lenguaje.

* Los vulgarismos y los insultos degradan el lenguaje.

* La lengua escrita es mejor que la hablada.

* El lenguaje de la técnica y de la ciencia es más preciso y más claro que el de la literatura.

* El significado está en las palabras.

(Muñoz Martín 1995:vii)

En esta misma línea, Richterich (1980) asocia este tipo de presuposiciones con los estudiantes adultos en particular:

He [the adult student] tends to think that learning a language means learning lists of words, grammatical rules and conjugations parrot-fashion; in his desire for tangible results, he confuses the acquisition of knowledge with its practical application and the change of attitudes, for which it is obviously more difficult to produce concrete evidence. (Richterich 1980:64)

Si introducimos tareas de traducción en el programa del curso de Inglés para Fines Específicos, indirectamente podemos incidir sobre este esquema epistemológico de los aprendices. Podemos transformar las actitudes de los aprendices sobre cómo se produce la comunicación en su entorno profesional, especialmente si desarrollamos tareas de traducción a partir de una concepción de la traducción como comunicación intercultural e interacción social como la de Reiss y Vermeer o la de Nord, donde se tienen en cuenta tanto los factores intratextuales como los que dependen de la situación comunicativa, que incluyen (entre otros) la relación social entre los participantes.

La utilidad potencial de la traducción para desarrollar este tipo de conocimientos actitudinales se debe, al menos en parte, a que la traducción no tiene por qué ser uno de los contenidos del curso. Podemos utilizar la traducción como un medio para facilitar la adquisición de los conocimientos actitudinales necesarios para alcanzar la competencia sociocultural requerida para comunicarse en el entorno profesional con éxito. Así, creemos que se puede lograr desarrollar una actitud diferente hacia el lenguaje mediante el contraste de dos sistemas de valores socioculturales diferentes, incluso sin hacer que la traducción sea uno de los contenidos o de los objetivos del curso, únicamente utilizando las tareas de traducción como actividades de aprendizaje y de evaluación formativa. Creemos, 
por tanto, que podemos inducir ese cambio de actitud de un modo indirecto. Esto es muy importante desde la perspectiva de la didáctica ya que no debemos olvidar que, al contrario de lo que sucede con el inglés en otros entornos, la finalidad del aprendizaje del Inglés para Fines Específicos no es de naturaleza lingüística ni traductológica, tal como nos recuerda Widdowson:

In ESP we are dealing with students for whom the learning of English is auxiliary to some other primary professional or academic purpose. It is clearly a means of achieving something else and is not an end in itself; and that something else has been independently formulated as a set of aims, and any course of instruction designed with these in mind will have established its own appropriate objectives accordingly. This being so, ESP is (or ought logically to be) integrally linked with areas of activity (academic, vocational, professional) which have already been defined and which represent the learners' aspirations. The learning of ESP is in consequence an essentially dependent activity, a parasitic process, and it follows that the pedagogy of ESP must be dependent too. It has no purposes of its own; it exists only to service those that have been specified elsewhere. (Widdowson 1983:108-109)

En cualquier caso, el éxito al intentar producir un cambio epistemológico en las actitudes de los aprendices sobre el funcionamiento del lenguaje depende directamente de la concepción de traducción que se utilice en la tarea para que la atención del aprendiz se pueda centrar convenientemente en aspectos que sean relevantes para la competencia sociolingüística, tales como los factores que se utilizan para describir el contexto social, a los que volveremos en el próximo capítulo.

\subsubsection{Traducción y competencia discursiva}

La competencia discursiva es concebida por Canale y Swain como el acervo de conocimientos que permite producir unidades textuales pertenecientes a distintos géneros. Por extensión de esta concepción, entendemos que la competencia discursiva es asimismo la que permite comprender un texto. El texto es entendido aquí como una manifestación tangible del discurso que puede ser comprendida mediante la interpretación, a través de las marcas textuales, de las relaciones semánticas que se establecen en él, es decir, mediante lo que Crombie (1985) denomina 'predicción relacional' (relational prediction), y de los mecanismos cohesivos utilizados (v. Halliday y Hasan 1976), en relación con el contexto donde el texto aparece. Así, la competencia discursiva permite específicamente interpretar y producir macrounidades lingüísticas de rango superior a la oración. Entendemos que el aprendiz se relaciona con la competencia discursiva en un sentido amplio 
como gestor de textos. Dado que nuestro trabajo se centra especialmente en la utilización de textos escritos en la didáctica del Inglés para Fines Específicos, la competencia discursiva será uno de los objetivos del curso de Inglés para Fines Específicos.

Aunque el modo de transmisión de estas macrounidades que denominamos textos puede ser oral o escrito, lo cual suele conllevar diferencias en sus configuraciones típicas, aquí nos limitaremos a considerar (como unidades textuales relevantes para nuestro trabajo) textos auténticos producidos por hablantes nativos, lo que Dubin, Eskey y Grabe (1986:137) denominan 'textos naturales' y definen como: «examples of the target language as used by native speakers for authentic, communicative goals». Procedemos de este modo, descartando la utilización de textos producidos por profesionales que no son hablantes nativos de la lengua inglesa, para evitar introducir un factor más en el repertorio de variables que afecta a los textos y que podría llevar a interpretar que la utilización de ciertos elementos presentes en el texto en cuestión obedece a que la lengua inglesa no es la primera lengua del productor del texto.

Como ya hemos apuntado en el capítulo anterior, en el aula de Inglés para Fines Específicos los materiales más utilizados para llevar a cabo las tareas programadas son los textos escritos especializados, incluyendo los textos académicos producidos en la lengua extranjera. En general, en el entorno de la enseñanza universitaria, las estrategias de lectura son consideradas de suma importancia. Esta situación es común al entorno educativo universitario de otros países y no exclusivo del panorama español, tal como nos muestran Levine, Ferenz y Reves:

The ability to read academic texts is considered one of the most important skills that university students of English as a Second Language (ESL) and English as a Foreign Language (EFL) need to acquire. It should be noted that for the most part reading instruction in the ESL and EFL university courses tends to focus on text processing, on the reader's understanding of the language of the text. (Levine, Ferenz y Reves 2000:1)

En el entorno universitario español, el foco de atención de las tareas de lectura en el aula suele recaer, en particular, en aquellos aspectos que se refieren al reconocimiento de diferentes tipos de texto y a la comprensión de la información textual. Es poco frecuente que el aprendiz realice tareas muy creativas de producción textual, por lo que el desarrollo de la competencia discursiva se suele limitar a los aspectos que tienen que ver más directamente con el reconocimiento y, 
en su caso, la aplicación de modelos previamente aprendidos (la estructura-tipo de una carta de reclamación, por ejemplo) ${ }^{20}$.

En este sentido, la tarea de traducir ofrece más ventajas que las tareas de localización y reconocimiento de la información para desarrollar la competencia discursiva, puesto que implica tanto procesos textuales de comprensión como de producción. Tiene la ventaja añadida, frente a otro tipo de tareas con textos escritos, de que al traducir los tipos de texto típicos del campo de especialización se están manejando los géneros textuales tal como se manifiestan en dos sistemas distintos, de modo que es posible diferenciar los mecanismos que corresponden al lenguaje como instrumento de conceptualización y comunicación de ideas, de los recursos propios de cada sistema lingüístico y de cada sistema de valores culturales.

La traducción es una tarea compleja en la que interviene, además del concurso de dos sistemas lingüísticos, un proceso de lectura y comprensión de un texto (escrito, en nuestro caso) y de producción y comprensión de otro texto (también escrito, en este caso) a partir del cronológicamente anterior. Al considerar la tarea de traducir en relación con la competencia discursiva de los aprendices, debemos mencionar tres aspectos que se suelen poner de manifiesto con frecuencia en el comportamiento de los aprendices de Inglés para Fines Específicos pertenecientes al entorno estudiado aquí, aunque no son exclusivos de este tipo de aprendices, ni tienen por qué corresponder con aprendices de Inglés para Fines Específicos en otros entornos educativos. Estos aspectos se refieren en particular al comportamiento del aprendiz como lector de textos.

En primer lugar, con una competencia comunicativa limitada para comprender textos en lengua inglesa y en algunos casos con renuencia a realizar la tarea de lectura (terreno en el que en muchos casos no siente seguridad), el aprendiz frecuentemente tiende a acometer la lectura del texto en lengua inglesa concentrándose en la comprensión de la información textual a un nivel local. Además, tiende a asociar el significado únicamente con el léxico, de modo que principalmente se concentra en el significado literal del fragmento que está leyendo y traduciendo en ese momento. Esto parece indicar que el aprendiz tiene dificultades para comprender el texto globalmente, en el sentido de que su procesamiento de lo

\footnotetext{
${ }^{20}$ Se suele justificar la escasa presencia de tareas creativas de producción textual en los cursos de Inglés para Fines Específicos apelando a la masificación de las aulas. No obstante, conviene recordar que se está generalizando sobre un entorno de aprendizaje que no tiene por qué coincidir absolutamente con todos los cursos de Inglés para Fines Específicos que se imparten actualmente en España. Por otra parte, González (2002:361) señala que esa masificación no es exclusiva de la universidad española y hace extensiva esa situación a la mayoría de universidades europeas.
} 
que lee no conlleva la consolidación progresiva del significado, asociada al procesamiento de arriba abajo (v. 4.1.3), sino que parece limitarse al procesamiento léxico y, en menor medida, sintáctico. El aprendiz no actúa como lo suele hacer cuando lee un texto en su lengua materna para traducirlo a otra, o para buscar información, o para aprender de él. En resumen, al leer textos especializados producidos en lengua inglesa, el aprendiz tiende al procesamiento de cada secuencia local de abajo arriba (Greene 1986:54).

En los niveles más bajos de comprensión, este comportamiento del aprendiz se suele producir con independencia del tipo de tarea de lectura que tenga entre manos, es decir, es un modo de actuar espontáneo y no dependiente del objetivo de la lectura. Sin embargo, el objetivo de la tarea de lectura es muy importante puesto que es el que puede delimitar que se favorezca el uso de unas estrategias u otras. De ahí la importancia de marcar adecuadamente, al formular la tarea, qué es lo que queremos conseguir con la lectura, puesto que leer no es un fin en sí mismo. Cooper describe qué ocurre cuando se proponen tareas de lectura sin un objetivo claro: «if readers do not know what they are reading for, then they are more likely to try to understand everything; and unpractised readers tend to do this word by word» (Cooper 1984:134).

Por otra parte, el aprendiz puede realizar la lectura sin llegar a comprender lo que ha leído. Es decir, éste tiene que tener la intención voluntaria de comprender el texto, de poner los recursos y estrategias a su disposición para procesar la información textual. En realidad, el aprendiz puede leer sin comprender (trascodificar en el nivel más bajo de procesamiento), leer procesando superficialmente (esto suele implicar que las relaciones semánticas entre entidades conceptuales del texto se realizan de forma arbitraria, ignorando la secuenciación y la jerarquía establecida, en lugar de interpretando las marcas textuales), o bien leer procesando en profundidad.

Como ya vimos anteriormente (v. 3.2.4), el aprendiz puede ejercer un cierto grado de control u otro sobre su output o educto de acuerdo con un repertorio de variables que incluye su implicación voluntaria en la realización de la tarea y también el tipo de tarea de que se trate, en cuanto al grado de atención, de control y de elaboración que ésta precise. Estos aspectos son igualmente influyentes para el procesamiento de la lectura. Así, podemos decir que el modo como el aprendiz lleva a cabo la lectura del texto en inglés depende, al menos, de los siguientes tres factores: 
1. Su voluntad para comprender la información del texto (o aprender de él). Desde el punto de vista de la didáctica, este aspecto está directamente relacionado con la motivación.

2. La complejidad del texto para el aprendiz. Específicamente, la facilidad o la dificultad del procesamiento depende de la coincidencia o discrepancia existente entre los conocimientos necesarios para comprender el texto y los que posee el aprendiz.

3. La pericia del autor del texto. Específicamente, el modo de procesamiento depende de la eficiencia de los procedimientos y recursos empleados por el autor para que el texto diga lo que él quiere tal como quiere decirlo.

Aquí debemos precisar que, aunque ya señalamos antes que este comportamiento del aprendiz se suele producir con independencia del objetivo de la lectura, la necesidad de reproducir el texto en otro texto obliga al aprendiz a que los niveles mínimos de procesamiento sean más profundos cuando realiza tareas de traducción que cuando realiza otras tareas con textos escritos. A la vista de esto, la traducción parece una actividad de aprendizaje óptima para desarrollar los aspectos de la competencia discursiva que afectan al modo de procesamiento de la información textual. Cuando la actividad de traducción se desarrolla como una evaluación formativa, podemos ver con bastante claridad dónde se han producido problemas de procesamiento de la información textual del TO, ya que este tipo de problemas suele resultar en la presencia de información absurda o falsa en el TT.

A falta de estudios específicos que describan el comportamiento real de los sujetos españoles que se encuentran en el entorno educativo que estamos considerando, y a falta de un consenso mínimo acerca de las diferencias reales de problemas de lectura en relación con las diferencias entre lenguas (v. Alderson 1984:2-4), el comportamiento que estamos describiendo se interpreta en el presente trabajo como equiparable en términos generales con el de los sujetos con problemas de comprensión de lectura tal como son representados en los estudios llevados a cabo en la investigación sobre lectura en el ámbito de la psicología cognitiva y del aprendizaje de segundas lenguas y de lenguas extranjeras. Nos referimos a los sujetos que se suelen identificar como 'poor readers'.

De forma más precisa, dentro del ámbito de la educación universitaria, Cooper (1984) establece dos tipos de lector en función de su experiencia previa con la lengua inglesa en el entorno académico. El denominado 'practised reader' «has pursued a large part of his previous education through the medium of English and may be expected to cope adequately with the demands of his university textbooks», 
mientras que el denominado 'unpractised reader' «has pursued his previous education through the medium of his first language, and has studied English as a foreign language» (Cooper 1984:122). El tipo de aprendiz considerado en este trabajo corresponde al segundo tipo de lector.

No obstante, debemos precisar que, dada la heterogeneidad característica de los grupos de aprendices del Inglés para Fines Específicos, esta descripción se toma como aplicable a muchos o la mayoría de los aprendices considerados en el entorno estudiado aquí y producida probablemente por dos tipos distintos de causas: o bien problemas de lectura del aprendiz (en su lengua materna y/o en la lengua extranjera), o bien problemas relacionados con el hecho de que la competencia comunicativa del aprendiz en lengua inglesa no haya superado el hipotético umbral mínimo al que se refieren Alderson y Urquhart (1984a:26) en los comentarios al trabajo de Alderson (1984). Este planteamiento es puramente especulativo, por lo que únicamente debe ser tomado como una hipótesis de trabajo, ya que, como afirma Upton (1997):

\begin{abstract}
Reading in a second language (L2) is not a monolingual event; L2 readers have access to their first language (L1) as they read and many use it as a strategy to help comprehend an L2 text. Due to difficulties in observing the comprehension process, little research has been conducted to try to determine what roles the L1 and L2 play in the reading strategies of L2 readers or how these roles vary at different proficiency levels. (Upton 1997:1)
\end{abstract}

Por otra parte, cuando consideramos el comportamiento del aprendiz de una lengua extranjera como lector de textos, la traducción puede ser asimismo estudiada en relación con el uso mental espontáneo que el aprendiz hace de ella cuando lee textos escritos en la segunda lengua. En este ámbito, Kern (1994) también apoya la hipótesis de la existencia de un umbral mínimo de competencia al aludir a la utilización de la traducción mental cuando el procesamiento de la lectura sufre un atasco en cuello de botella, pero para Kern este nivel umbral puede referirse tanto a la competencia comunicativa como a la competencia discursiva: «this bottleneck may require that some critical threshold of language development and/or L2 reading ability be attained before translation can be minimized in L2 reading» (Kern 1994:446).

Kern ha estudiado el papel de la traducción mental en el procesamiento de textos escritos en una segunda lengua, con el fin de ahondar en la influencia de la lengua materna en el aprendizaje de otra lengua. Al igual que Upton, Kern señala que una de las diferencias básicas y evidentes entre la comprensión de la primera lengua y la de la segunda es que el lector de un texto escrito en una segunda lengua 
tiene dos lenguas a su disposición en lugar de una. Kern sugiere que este tipo de traducción «is not always an undesirable habit to be discouraged at all costs but, rather, an important developmental aspect of L2 comprehension processes» (Kern 1994:442). No obstante, debemos matizar que Kern se refiere con 'traducción mental' a un proceso específico mucho más restringido que el concepto de traducción que estamos empleando en este trabajo, tal como podemos ver en su propia definición de 'traducción':

Translation is defined as a mental reprocessing of L2 (French) words, phrases, or sentences in L1 (English or other familiar language) forms while reading L2 (French) texts. [...] unlike traditional uses of the term, translation here does not imply any overt oral or written product but, rather, implies a mental representation of L1 forms as its product. Translation is clearly an example of a process that is functional only when the reader is reading texts written in a nonnative language. (Kern 1994:442-443)

El interesante artículo de Kern describe los resultados de un estudio realizado con dos grupos anglófonos de aprendices de francés, clasificados de acuerdo con su habilidad como lectores en francés (un grupo con sujetos de gran habilidad y el otro con sujetos de poca habilidad). Los resultados referentes a los beneficios potenciales de la traducción en relación con el procesamiento textual indican la utilidad de la traducción para facilitar el procesamiento semántico y permitir la consolidación de significado que, de otro modo, permanecería fragmentado y para aligerar la carga de la memoria ${ }^{21}$. También es útil para reducir las barreras afectivas causadas por la lectura en la segunda lengua ${ }^{22}$. Kern también

\footnotetext{
${ }^{21}$ Según Kern,
}

Translation may reduce the load placed on cognitive resources in at least two ways. First, because familiar words can be stored in working memory faster and more effectively than unfamiliar words [...]. Second, once words are translated into English form, it may be that they can be more effectively combined into meaningful propositions by means of $\mathrm{L} 1$ chunking processes. The net result is that once a segment of text has been translated into a more familiar form, the reader's comprehension processes may proceed as they do in the L1, unimpeded by inefficient semantic and integrative processing. In other words, translation may allow the reader to establish a mental scratch-pad, or semantic buffer, where phrase-level and discourse-level meaning can be represented and assembled in the L1. (Kern 1994:449)

${ }^{22}$ Kern explica de este modo cuáles son las repercusiones de las barreras afectivas que ha encontrado en el grupo de aprendices con poca habilidad para leer textos en francés,

Because L2 readers tend to be insecure in their ability to comprehend L2 texts, unfamiliar words and expressions tend to shake readers' already precarious level of confidence, making them feel that in order to understand the text they will have 
se refiere al contexto de uso de la traducción mental, en cuanto al uso intermitente o continuo de ésta en relación con factores tales como la longitud de las oraciones y la complejidad sintáctica y semántica. Por último, los resultados también se refieren al uso estratégico de la traducción mental que hicieron los aprendices en su estudio, y que se resumen en la consolidación de significado, la retención de información contextual, la aclaración de funciones sintácticas, la verificación de tiempos verbales y la comprobación de la comprensión.

Por otra parte, aunque la utilización de la traducción mental a menudo se interpreta como un indicio de que los aprendices han efectuado un cambio de arriba abajo a un procesamiento de abajo arriba en la lectura, Kern encuentra ciertas evidencias que le llevan a sugerir que este tipo de traducción algunas veces facilita procesos asociados con el procesamiento de arriba abajo, tales como la síntesis de significado y la metacognición.

A pesar de que los resultados del estudio de Kern no tienen por qué ser extrapolables a la didáctica especial de las lenguas extranjeras, sí apuntan a que, al menos potencialmente, este tipo de traducción es útil para el aprendizaje de la competencia discursiva y de la competencia estratégica. Desde nuestro punto de vista, si la traducción mental es útil para desarrollar estos tipos de competencia, las tareas de traducción ostensible también pueden ser útiles. Esta utilidad se derivaría, precisamente, de la ventaja de aprovechar la utilización espontánea que el aprendiz hace de la traducción mental al leer textos escritos en la lengua extranjera, y se apoya en las dos hipótesis formuladas por Kern a partir de los resultados de su estudio:

Mental translation during $\mathrm{L} 2$ reading can facilitate the generation and conservation of meaning by allowing the reader to represent portions of L2 text that exceed cognitive limits in a familiar, memory-efficient form. As L2 learners become more proficient at reading L2 texts, they will rely less on translation in their efforts to comprehend. (Kern 1994:455)

El comportamiento de los aprendices que incluye la traducción mental estudiada por Kern se puede integrar en nuestro enfoque didáctico teniendo en cuenta dos aspectos complementarios.

En primer lugar, la traducción mental en la lectura permite que el aprendiz se concentre en el significado del texto, por lo que la atención del aprendiz se puede

to capture every last detail. This preoccupation with «getting it all right» leads to word-by-word reading and translation. (Kern 1994:457) 
dirigir más fácilmente hacia los aspectos concernientes a la competencia discursiva que si no contamos con la transformación de la información a la lengua materna del aprendiz. Kern sugiere que «it [...] may be the case that L2 readers use translation not so much for control of vocabulary but rather for control of propositional content» (Kern 1994:450). A este respecto, sugiere que el fin último de la traducción puede ser la transformación de la información en una representación más usable. Así pues, puede que el aprendiz transforme la información en un afán por comprender el texto, de hacerlo más claro, lo cual es consistente con la tendencia que algunos autores interpretan como uno de los universales del comportamiento en la traducción: «the translators' well-known habit of tending to make explicit in the target text what was implicit in the source text» (Chesterman 1993:4). Este afán por hacer más explícito el TT de lo que es el TO entra en contradicción con el papel del traductor como mediador invisible, por lo que las tareas de traducción pueden ser útiles para fomentar el control consciente del producto lingüístico que se va a crear, en este caso otro texto. Se trata, por tanto, de tomar un punto de partida de la traducción que coincida con la actuación espontánea del aprendiz para, progresivamente, al tiempo que se supone que irá desapareciendo su apoyo en la traducción mental como medio de facilitar la comprensión textual, introducir un concepto más complejo de traducción que le pueda facilitar el aprendizaje de la competencia discursiva.

El segundo aspecto referente al comportamiento del aprendiz como lector de textos se refiere a que, como consecuencia del comportamiento de este tipo de lector que se caracteriza por su tendencia al procesamiento de abajo arriba, concentrándose localmente en cada cadena de elementos de forma sucesiva sin llegar a una interpretación global del texto, el aprendiz probablemente utiliza unidades de procesamiento locales como el sintagma y la oración y, por tanto, pasa por alto los problemas asociados con el texto como unidad global de procesamiento, o bien los interpreta únicamente como problemas locales.

En el caso de las tareas de traducción realizadas en el aula por estos aprendices, esto produce resultados en los TTs en los que las unidades mayores que la oración se ven afectadas (como puede ser el caso, por ejemplo, de la falta de cohesión producida por problemas de concordancia entre elementos correferentes interoracionales). Si los aspectos macrotextuales no pueden ser explicados ni controlados sino tomando el texto como unidad de procesamiento y análisis, se desprende que este comportamiento de los aprendices afecta a la calidad global de los TTs. Hay que añadir también que, si el concepto de gramática utilizado en el 
aula al llevar a cabo la tarea también se basa únicamente en la oración como unidad superior de análisis, esto no hará sino reforzar la perspectiva previa del aprendiz. En tal caso es dudoso que llegue a aprender a percibir otros niveles estructurales (ni, por tanto, a resolver los problemas asociados a éstos) sino a base de mucho esfuerzo, intuición y experiencia. Es decir, el aprendiz quizá acabe desarrollando dentro del entorno educativo esta capacidad de percibir el texto, pero al margen del planteamiento didáctico $\mathrm{y}$, por consiguiente, fuera del control del proceso de enseñanza-aprendizaje y, probablemente, del suyo propio. Esto supone dejar la calidad del resultado de la tarea en manos del azar. Por esta razón, este modo de realizar la tarea de traducción no se puede asociar con una actuación crítica como la descrita por Ryle y que reproducíamos en la introducción de este capítulo.

Por último, cuando el significado no se interpreta como el resultado de un proceso interactivo de construcción que realiza el sujeto al leer el texto y, por tanto, como un proceso dinámico, entonces el aprendiz tiende a plantear la tarea de traducir como una búsqueda de la opción correcta, pasando por alto que el potencial de significado no se actualiza necesariamente como una relación de uno a uno entre lenguas (v. 4.2.1). Cuando la perspectiva del aprendiz sobre la tarea de traducir se caracteriza por la búsqueda de información correcta, la mayor parte de los esfuerzos de éste se dirigen a la localización de información, en detrimento de otros tipos de comportamiento estratégico. En este caso, la herramienta más importante para el aprendiz es el 'almacén de información' (los materiales de referencia, las bases de datos, los diccionarios, etc.), ya que los problemas con los que se enfrenta son percibidos por él como problemas de tipo léxico.

Por otra parte, la tarea de traducir implica que el aprendiz debe comportarse como un productor de textos. Así, debe tomar decisiones acerca de qué elementos formarán parte de su texto y cómo lo harán. Debe, además, decidir cuándo ha finalizado su tarea, es decir, cuándo ha traspasado su texto lo que De Beaugrande y Dressler (1981) denominan el 'umbral de finalización' (threshold of termination). Esto exige un control sobre la ejecución y el resultado de la tarea que otros tipos de tareas en los que intervienen textos escritos no precisan, como por ejemplo las actividades de comprensión de textos que se basan en la localización de información. La importancia de la tarea de traducir en este caso es comprensible si tenemos en cuenta que el control consciente de la propia actuación y de los resultados de ésta suele ser valorado positivamente en tareas que precisan elaboración, como es el caso de la producción de lenguaje escrito en situaciones de comunicación profesional o en entornos académicos. 


\subsubsection{Traducción y competencia estratégica}

Como área de la competencia comunicativa, la competencia estratégica se refiere, según Canale y Swain, al conocimiento del aprendiz sobre los procedimientos a su disposición para actuar sobre la efectividad de los recursos empleados para comunicarse en cada situación particular y, en general, sobre la calidad de la comunicación.

Desde una concepción teleológica del lenguaje en uso, se interpreta que la utilización de unos procedimientos específicos y la elección de unos recursos en concreto y no de otros depende, además de las características de la situación en que se produce la comunicación, de las intenciones y propósitos del productor del mensaje. Así, entendemos que todo acto de comunicación lingüística aspira a ser no sólo ostensible, sino también exitoso, lo que conlleva la intención del productor del mensaje de utilizar los recursos y procedimientos que le permitan alcanzar su objetivo del modo más eficiente posible, tal como han señalado Sperber y Wilson (1986). Esto es consistente con la concepción de Ryle, que ya mencionamos al principio de este capítulo, sobre el comportamiento humano como una actuación crítica. Y lo que es más, ese impulso de comunicarse de forma eficiente ocurre tanto si el sujeto es consciente de ello como si no lo es (Sperber y Wilson 1986:49).

Por consiguiente, podemos afirmar que la competencia estratégica no sólo implica unos conocimientos de tipo procedimental que son de extremada importancia para lograr el éxito en la comunicación, sino que su desarrollo debe ocupar un lugar prominente en la didáctica del Inglés para Fines Específicos.

Siguiendo a Parikbaht (1985), Pinto da Silva opina que la competencia estratégica parece ser «a language-related ability rather than language-related knowledge» (Pinto da Silva 1992:15), identificando de este modo competencia estratégica con habilidad y, por tanto, con un conocimiento de tipo procedimental y no con un conocimiento de tipo declarativo.

En un sentido amplio, dentro del ámbito de la didáctica general, Blanco Prieto (1996) define las habilidades como 'las capacidades manuales o intelectuales que tiene el sujeto para realizar algo’ y afirma también que «las habilidades son el telón de fondo de los procedimientos» (Blanco Prieto 1996:56). En este sentido, la habilidad ya se encuentra en el aprendiz (aunque puede que en estado latente) y lo que podemos lograr mediante el proceso de enseñanza-aprendizaje es su desarrollo. A su vez los procedimientos, que en el ámbito de la didáctica general tienen por objetivo final el aprendizaje de una destreza (manual, mecánica o intelectual), comprenden las técnicas y las estrategias, además de las habilidades. 
Así, en el ámbito de la didáctica general, las técnicas se definen como 'un conjunto de acciones ordenadas que se dirigen hacia el logro de unos objetivos concretos', mientras que las estrategias son contempladas como «las capacidades intelectuales que tiene el alumno para dirigir y ordenar sus conocimientos con objeto de llegar a unas determinadas metas. Representan la táctica a seguir para llevar a cabo un determinado plan de actuación ante una situación concreta» (Blanco Prieto 1996:56). Este autor destaca una diferencia entre las técnicas y las estrategias. Existe una relación entre técnica y habilidad, de tal suerte que las técnicas son aprendidas en función de las habilidades que el aprendiz posee, al tiempo que las habilidades son potenciadas, desarrolladas y consolidadas según se ejerciten mediante la práctica de unas determinadas técnicas. Por otra parte, las estrategias conllevan mayores dificultades para ser aprendidas que las técnicas:

[...] las estrategias son los procedimientos más complejos y los que presentan mayor número de dificultades a la hora de enseñarlos ya que hacen referencia a procesos mentales. Resulta muy fácil el aprendizaje de una determinada técnica, pero es bastante complicada la enseñanza de una estrategia, ya que se necesita dotar al alumno de unos esquemas mentales y unas capacidades difíciles de adquirir para aquel que potencialmente carece de ellas. (Blanco Prieto 1996:58)

Desde el punto de vista de la didáctica especial de las lenguas extranjeras, Pinto da Silva, al igual que otros autores, distingue entre dos tipos de estrategia: 'estrategias de reducción' (reduction strategies), que son las que llevan al hablante/aprendiz a reducir o incluso a evitar la comunicación cuando surge un problema, y 'estrategias de consecución' (achievement strategies), que son aquellas que utiliza el hablante/aprendiz cuando intenta compensar sus deficiencias en la segunda lengua con el fin de que la comunicación no se suspenda (Pinto da Silva 1992:12). Desde esta perspectiva, la utilización de la traducción mental descrita por Kern constituye una estrategia de consecución, ya que es empleada por el aprendiz para paliar sus deficiencias al procesar el texto escrito en la lengua extranjera. En opinión de Johnstone (1989), tal como recoge Pinto da Silva, el uso de estrategias de consecución no sólo puede incidir sobre la efectividad de la comunicación, sino que puede asimismo potenciar el aprendizaje. Esto es consistente con la segunda hipótesis de Kern, aunque no tiene por qué darse necesariamente una relación de causa-efecto, sino que más bien la utilización de estas estrategias parece continuar hasta que el aprendizaje llega a un nivel, interpretado como un umbral de conocimientos, que las hace innecesarias. Sin embargo, la sospecha de Johnstone de 
que el uso de estas estrategias sirve para potenciar el aprendizaje le lleva a recomendar que se favorezca su utilización.

Por otra parte, si la utilidad del desarrollo de la competencia estratégica es la de proporcionar al aprendiz la herramienta que le permite comunicarse con éxito, la competencia estratégica será la que le permita resolver los problemas que se encuentre, no sólo para lograr comunicarse o para evitar hacerlo, como refleja la clasificación utilizada por Pinto da Silva y otros autores, sino para lograr que la comunicación (tanto su producción como su interpretación) sea eficiente, es decir, para lograr «enhance the effectiveness of communication» (Cummins y Swain 1986:169). En este sentido, nos parece relevante el trabajo llevado a cabo por Salaberri Ramiro (1999) en el que trata, entre otros aspectos, el uso de la traducción en el transcurso de la comunicación hablada, en relación con el discurso del profesor y de los alumnos en el entorno del aula de lenguas extranjeras en la educación primaria y secundaria.

Retomando la definición de Blanco Prieto de estrategia, la competencia estratégica del aprendiz de Inglés para Fines Específicos tiene que ver con la capacidad intelectual de éste para dirigir y ordenar sus conocimientos con objeto de llegar a una determinada meta.

Por ejemplo, la meta de un aprendiz en una situación dada consiste en entrar a trabajar como ingeniero eléctrico en National Power. En este caso particular, el desencadenante de la comunicación es un anuncio publicado en una revista para estudiantes de ingeniería (v. Anexo A), a partir del cual el aprendiz va a solicitar un puesto de trabajo en dicha empresa. En esta situación, el aprendiz elabora y lleva a cabo una táctica determinada que, en esta situación, incluye tomar decisiones sobre un plan de actuación que recoge acciones puntuales o complejas (que a su vez se componen de otras acciones) como las que se sugieren a continuación:

* Ampliar la información del anuncio (¿pedirla por teléfono o por correo electrónico?)

* Conseguir la dirección postal de National Power (¿pedirla por teléfono o por correo electrónico?)

* Enviar la solicitud de empleo (¿por correo electrónico o vía superficie?, ¿adjuntar un CV pormenorizado o sólo mencionar lo más interesante?)

* Enviar el CV en inglés (¿elaborarlo o pedirle a alguien que lo haga?, ¿con o sin foto?, ¿en qué formato?, ¿enviarlo por correo electrónico o vía superficie?) 
Blanco Prieto alude a que, en buena medida, la dificultad de enseñar una estrategia estriba en la necesidad de dotar al aprendiz de unos esquemas mentales y capacidades que en principio no posee. En el caso del ejemplo que acabamos de ofrecer, si lo que desea el aprendiz y lo que ha sido marcado como meta del curso de Inglés para Fines Específicos es lograr ser capaz de desenvolverse en una situación análoga a la presentada, parece bastante claro que lo que necesita el aprendiz abarca mucho más que un repertorio de léxico especializado.

Hay que tener en cuenta también que, por muy similares que sean las situaciones análogas a ésta (cuyo esquema conceptual podríamos titular «Solicitar un puesto de trabajo en un entorno anglófono»), el repertorio de las acciones consideradas, las desechadas y las aceptadas (es decir, el potencial de actuación del sujeto) puede variar considerablemente, así que no es probable que la táctica más productiva sea exactamente la misma en dos situaciones distintas. Entonces, se da una paradoja al plantear el diseño de cursos de Inglés para Fines Específicos en el entorno considerado en nuestro trabajo, debido a que en la etapa terciaria de la educación no podemos saber con mínima exactitud o precisión qué necesidades específicas concernientes a la comunicación en lengua inglesa va a tener cada aprendiz para ser admitido en la comunidad profesional como un miembro más. A este respecto, no podemos considerar equiparable el establecimiento de metas en este entorno con el de otros entornos de aprendizaje del Inglés para Fines Específicos que suelen ser considerados característicos, como el descrito por Giménez (1996) en el capítulo anterior y sobre el que volveremos en la sección siguiente.

En este orden de cosas, surge de nuevo la cuestión del establecimiento de las metas y los objetivos del curso, preguntándonos no sólo ¿qué es entonces lo que el aprendiz debe aprender?, sino también ¿cómo debe aprenderlo?

\subsubsection{Competencia comunicativa y capacidad}

En este trabajo adoptamos una concepción del aprendizaje como desarrollo personal, asumiendo la necesidad de dotar al aprendiz de unos esquemas mentales y capacidades nuevos ${ }^{23}$. Esta concepción supone contemplar la didáctica del Inglés

\footnotetext{
${ }^{23}$ Esta es una idea bastante extendida y no únicamente adoptada por los especialistas del campo de las Ciencias de la Educación. Por poner un caso del campo de las matemáticas, el profesor Gilbert Strang (Massachusetts Institute of Technology), en el prólogo a su manual Calculus, redunda en la misma aproximación al afirmar que «in the end, teaching a subject comes down to teaching a person» (Strang 1991:xv).
} 
para Fines Específicos desde una perspectiva mucho menos restrictiva que aquella que se plantea como meta del curso el desarrollo de una competencia comunicativa especializada en los términos descritos por Widdowson:

\begin{abstract}
We can define training as the development of competence to deal with a limited range of problems identified in advance. Courses of instruction are based on a specification of what these problems are and aim at providing trainees with formulae which can be applied to these problems. Obviously, some flexibility has to be allowed for, since there is always likely to be some lack of fit between formula and problem. But training can, of its nature, only allow for relatively minor adjustment. Difficulties will arise if a problem needs to be interpreted and redefined before it can fit a formula, or if a formula itself needs to be modified to account for an unforeseen problem. Such situations, which involve not simply the application but the exploitation of knowledge, call for the engagement of capacity. (Widdowson 1983:8)
\end{abstract}

Widdowson (1983) contempla la cuestión de la especificidad del Inglés para Fines Específicos como una línea continua entre dos polos. En el extremo de mayor especificidad, el de necesidades y metas más restringidas, se encuentra la concepción de la didáctica del Inglés para Fines Específicos como una formación específica donde los objetivos educacionales y las metas son coincidentes, y donde los aprendices adquieren un número determinado de técnicas que les permiten resolver una variedad limitada de problemas previamente identificados. La meta que se desea alcanzar en este caso es el desarrollo de una competencia comunicativa especializada que permita al aprendiz desenvolverse en una serie específica de situaciones que han sido formalizadas previamente. No se establecen objetivos educacionales que respondan a necesidades del propio aprendizaje del Inglés para Fines Específicos, sino únicamente objetivos que responden a un repertorio mayor o menor de necesidades reales o prospectivas de los aprendices.

En el otro extremo de la línea de la especificidad, se encuentra la concepción de la didáctica del Inglés para Fines Específicos que se preocupa de los aspectos relacionados con las características de la materia que se desea aprender y con los procesos de aprendizaje de esos conocimientos. Aquí se contempla el proceso de enseñanza-aprendizaje como una educación general del aprendiz, tal como se conciben los cursos de Inglés General, donde la meta es el desarrollo de la competencia del aprendiz sin restricciones y sin una aplicación automática o muy inmediata definida. Los objetivos de la educación en este extremo de la línea no coinciden con las metas del aprendizaje, sino que se establecen de acuerdo con criterios educativos y sirven para lograr alcanzar la meta establecida. El propósito general que se establece es el desarrollo de la capacidad del aprendiz para utilizar el 
lenguaje de tal modo que él mismo pueda alcanzar las metas que se marque y la competencia que desee.

Como sugiere el propio Widdowson, la posición idónea para la didáctica del Inglés para Fines Específicos será aquella que comprenda un grado de especificidad que le permita controlar la distancia entre objetivos y metas:

[...] an ESP enterprise has to be located on a scale of specificity which in effect controls the degree of equivalence between objectives and aims. Training appears towards one end of this scale and education towards the other. A shift in orientation towards specificity brings objectives into closer alignment with aims. This narrows the distance between schemata and active use, and equivalently between formula and problem. (Widdowson 1983:107)

Como consecuencia de estas consideraciones, exponemos a continuación las conclusiones derivadas para el presente trabajo. Debemos tener presente la pertinencia para la didáctica de las lenguas para fines específicos de discernir entre objetivos educacionales (que responden a las necesidades de la didáctica) y metas del aprendizaje (que responden a las necesidades presentes o prospectivas del aprendiz). Por lo tanto, abandonamos cualquier modelo didáctico donde no se establezcan distinciones entre objetivos y metas del aprendizaje. Queremos asimismo establecer que el objetivo educacional general aplicable en el entorno tratado en el presente trabajo será el desarrollo de la capacidad del aprendiz. Entendemos que es el desarrollo de la capacidad del aprendiz el que, en última instancia, le permitirá a éste comunicarse con éxito en las situaciones en que se vea envuelto en su futuro entorno profesional. Por otra parte, este objetivo educacional es consistente con el planteamiento de objetivos que hace Van Ek: «language is a means of communication. [...] The aim of foreign language learning is first and foremost the ability to communicate verbally. Language-learning objectives, therefore, are to be defined in terms of "adequate verbal behaviour in language communication situations”» (Van Ek 1980:93). Por último, contemplamos la competencia (bien lingüística, bien comunicativa) como una meta potencial del proceso de enseñanza-aprendizaje, pero no como un objetivo educacional del curso.

Según Widdowson, el concepto de competencia comunicativa introducido por Hymes se refiere a aquellos aspectos del comportamiento lingüístico humano que se pueden formalizar en un modelo de descripción y, debido a esto, podemos decir que se trata del constructo de un analista. Así, este concepto resulta de gran utilidad para analizar, por ejemplo, las características de una comunidad de habla a través del análisis de las manifestaciones de las variables que la constituyen, pero tiene una utilidad mucho más limitada como constructo didáctico porque no se basa 
en un modelo cognoscitivo del aprendiz o del usuario del lenguaje. En este sentido, nos parece más pertinente para la didáctica adoptar la capacidad como objetivo educacional del aprendizaje del Inglés para Fines Específicos, entendiendo ésta como:

[...] the ability to solve problems and, equivalently, to make meanings by interpreting a particular instance (an event, an expression) as related to some formula, thereby assimilating the instance into a pre-existing pattern of knowledge, or, when necessary, by modifying the available formulae so that the instance can be accommodated within them. In this way, capacity works both to exploit the existing competence and also to extend that competence to make provision for creativity and change. Capacity so defined is the driving force behind both the acquisition and the use of language. (Widdowson 1983:106)

Al mismo tiempo, al adoptar el desarrollo de la capacidad del aprendiz para utilizar el lenguaje como objetivo educacional pertinente para la didáctica del Inglés para Fines Específicos, hemos de considerar las repercusiones que esto tiene para los fines de nuestro trabajo.

En el capítulo anterior hemos propuesto una tipología didáctica de la traducción de acuerdo con su pertinencia como objetivo educacional, como medio de facilitación del aprendizaje, o como método de comprobación de la competencia comunicativa especializada alcanzada. Sin embargo, la evaluación del aprendizaje no se efectúa sobre las metas del curso, sino sobre los objetivos educacionales formulados. Así, la función evaluadora de la traducción debe ser analizada en cuanto a su potencial para comprobar el desarrollo de la capacidad del aprendiz para resolver problemas, construir significados y, en definitiva, utilizar y aumentar su propia competencia para utilizar el lenguaje con éxito.

En esta sección hemos analizado el potencial de la traducción en su función de medio de facilitación del aprendizaje de las distintas áreas de la competencia comunicativa descritas por Canale y Swain. Ahora, al introducir el desarrollo de la capacidad como objetivo educacional, estamos poniendo en el punto de mira una noción ampliada de la competencia estratégica descrita por Canale y Swain.

La competencia estratégica se puede describir como un tipo de conocimiento procedimental, de acuerdo con la concepción de actuación crítica de Ryle. Retomando la opinión de Rutherford recogida en la introducción de este capítulo, en la que se equipara la distinción entre tipos de conocimiento de Ryle con la distinción entre competencia y capacidad de Widdowson, sugerimos que, desde el punto de vista de la didáctica especial de las lenguas extranjeras, el desarrollo de la competencia estratégica supone desarrollar la capacidad del aprendiz para crear en 
situaciones comunicativas soluciones propias a problemas nuevos para él. Este objetivo resulta más productivo que el desarrollo de una competencia estratégica entendida en términos de un repertorio cerrado de técnicas útiles para resolver un número limitado de problemas identificados previamente. Desde nuestra perspectiva, comunicar lo que queremos y comprender lo que otros nos comunican son actividades complejas en las que participan muchos más aspectos que la simple aplicación de unas técnicas de identificación y resolución de problemas, y lo mismo puede afirmarse de la traducción.

Tenemos la convicción de que realizar tareas de traducción ayuda a que el aprendiz adopte una perspectiva sobre su propia actuación, tal como recomienda Klein (v. 3.2.3), y de este modo contribuye al desarrollo de su capacidad metacognitiva. La razón de esto es que, al emplear una concepción compleja de la traducción en la que la tarea se plantea como un acto comunicativo en el que intervienen diversos participantes distintos del propio traductor (como mínimo, el autor del TO, los receptores del TO y los receptores prospectivos del TT, aunque Nord señala la importancia que también tiene el cliente que hace el encargo y que, por tanto, desencadena todo el proceso), el aprendiz debe necesariamente ponerse en lugar de los otros y, al hacerlo, se sitúa en una posición que le exige evaluar críticamente su propia actuación. La tarea de traducción conlleva, por consiguiente, un desarrollo de la capacidad cognoscitiva del sujeto desde los tres aspectos implicados en nuestra concepción de la traducción como un proceso.

En primer lugar, el aprendiz se familiariza mediante la realización de las tareas de traducción con aquellos aspectos del proceso de traducir que son consustanciales de la propia actividad, según los requisitos procedimentales de la propia tarea. Así, la traducción se relaciona con el repertorio de variables involucradas en el control consciente que el sujeto puede ejercer sobre su producción lingüística de acuerdo con el tipo de tarea que realiza.

Además de esto, al abordar las tareas de traducción, el aprendiz pone en marcha sus recursos, tácticas y estrategias para realizar las tareas de acuerdo con el grado de control y de elaboración que desea dedicarles según su propio plan de actuación, su implicación y su estilo cognoscitivo de aprendizaje. La configuración de este plan de actuación precisa la reflexión y el análisis que el aprendiz considere necesarios para que las decisiones que tome sean coherentes con el propósito que desea alcanzar. Así, el comportamiento del aprendiz se relaciona con el repertorio de variables involucradas en el control consciente que el sujeto puede ejercer sobre su output de acuerdo con su implicación voluntaria en la realización de la tarea. 
Desde esta perspectiva, la traducción es considerada como una tarea relacionada con los procesos cognitivos dependientes del propio sujeto y, en particular, de la capacidad estratégica individual del aprendiz.

Por último, desde una perspectiva evolutiva de la realización de tareas de traducción, las expectativas del profesor se centran en la utilidad de la práctica extensiva de la actividad de traducir. Se espera que el aprendiz se familiarice y adquiera soltura en la realización de la tarea al tiempo que desarrolla progresivamente su capacidad metacognitiva. En este sentido, la realización extensiva de tareas de traducción se relaciona con el repertorio de variables del control consciente que el sujeto puede ejercer sobre su output de acuerdo con la influencia de la metodología utilizada, incluyendo el grado de control y de elaboración que el profesor pide al aprendiz.

De modo específico, interpretamos que ha habido un desarrollo de la capacidad metacognitiva del aprendiz cuando éste es capaz, no de ejercer, sino de mostrar que ha ejercido un control sobre su propia actuación. Así, interpretamos que el aprendiz ha actuado críticamente cuando es capaz de manifestar en qué ha consistido tal control, es decir, cuando es capaz de describirlo, justificarlo y suministrar ejemplos reales del control ejercido sobre su producción lingüística.

Al igual que sucede con otros procesos de tipo cognitivo, la realización de la tarea de traducir no conlleva la verbalización de la actuación del traductor, en el sentido de que no se perciben manifestaciones ostensibles ni espontáneas de los procesos internos del traductor. Dicho de otro modo, como el TT no puede ser tomado como muestra fehaciente del comportamiento crítico del traductor aunque sea el resultado de éste, es obvio que, para que el aprendiz pueda dar cuenta del control ejercido, es preciso que introduzcamos en la metodología un instrumento accesorio cuya función será la de proporcionar al aprendiz las herramientas necesarias para dar cuenta de su comportamiento estratégico.

Este constructo pedagógico será tratado en profundidad más adelante. No obstante, queremos señalar aquí que nuestro deseo de integración del constructo en el enfoque didáctico seguido en este trabajo implica que nuestras expectativas sobre la utilidad del constructo incluyan su influencia en la eficiencia en el aprendizaje, no sólo de aquellos sujetos con dificultades para aprender a partir de textos escritos, sino en la eficiencia de todos los aprendices.

Nuestra consideración subyacente es que la introducción y utilización del constructo influirá en los conocimientos y expectativas de los aprendices acerca del funcionamiento del lenguaje como herramienta de comunicación y, por 
consiguiente, será útil para contribuir al desarrollo de la capacidad de los aprendices para comunicarse. Como consecuencia, servirá también para que éstos logren alcanzar el objetivo del curso, respetando al mismo tiempo el estilo cognoscitivo de cada uno, puesto que se favorece su utilización personalizada. No obstante, debemos señalar que nuestra interpretación del estilo cognoscitivo personal del aprendiz se refiere a la utilización de unas estrategias que no tienen por qué coincidir con las de otro aprendiz, es decir, se refiere a la actuación personal y creativa y, en este sentido, no coincide con la interpretación de Krashen de tipos de aprendiz en función del uso o no del monitor. La utilización del constructo implica en todos los casos la utilización del monitor, puesto que se trata, precisamente, de actuar de forma consciente.

La hipótesis que formulamos consiste en que la utilización del constructo pedagógico diseñado para que el aprendiz pueda verbalizar su actuación al traducir provocará el procesamiento guiado y controlado de la tarea y, al mismo tiempo, servirá para recuperar algunos de los conocimientos implícitos de los aprendices sobre el funcionamiento del lenguaje, que servirán como base de integración de otros nuevos. La presuposición subyacente es que, de acuerdo con el concepto de conocimiento implícito mencionado anteriormente, el aprendiz, como usuario del lenguaje, posee muchos más conocimientos sobre el funcionamiento del lenguaje (incluyendo presuposiciones falsas como las que menciona Muñoz Martín) de lo que es capaz de expresar. Por consiguiente, mediante este constructo, el aprendiz puede acceder a algunos de estos conocimientos y utilizarlos para actuar estratégicamente en la tarea. El profesor, a su vez, podrá acceder a la información verbalizada por el aprendiz y, de este modo, podrá analizar y valorar tanto la naturaleza de esos conocimientos, como la táctica seguida por el aprendiz. Basándonos en Jacobs y Farrell, las expectativas a largo plazo apuntan a que el aprendiz finalmente sea capaz de analizar y valorar su propia actuación y, por tanto, adquiera progresivamente autonomía:

Self-assessment provides yet another way for second language students to develop their autonomy (Lee, 1998; Rothschild \& Klingenberg, 1990). The idea is for learners to develop their own internal criteria for the quality of their work, rather than being dependent on external evaluation, often by the teacher, as the sole judge of their strengths and weakness [sic]. Developing these internal criteria enables learners to make informed decisions about how to move their learning forward. With self-assessment, no longer do students have to wait for the teacher to tell them how well they are doing and what they need to do next. Yes, the teacher remains generally the more knowledgeable and experienced person in the classroom, but the goal is for students to move toward and perhaps even beyond, the teacher's level of competence. Placing 
value on learners' knowledge helps them feel more capable of playing a larger role in their own learning. (Jacobs y Farrell 2001:6)

Hasta este momento, en el presente capítulo hemos tratado los aspectos más sobresalientes del aprendizaje del Inglés para Fines Específicos para nuestro enfoque didáctico, para llegar a establecer como objetivo educacional relevante el desarrollo de una capacidad para utilizar el lenguaje que facilite al aprendiz la adquisición de la competencia necesaria para comunicarse en lengua inglesa como un profesional de su campo de especialización. Desde este enfoque didáctico nos centramos, por tanto, en los aspectos de la competencia del Inglés para Fines Específicos que tienen que ver con la adquisición y uso de destrezas lingüísticas en un sentido amplio, así como con el desarrollo de actitudes que permitan al aprendiz la actuación profesional. En la siguiente sección, vamos a considerar la influencia del contexto educativo en relación con el objetivo educacional que hemos seleccionado y complementaremos la descripción del aprendiz de Inglés para Fines Específicos tratado en nuestro trabajo, caracterizándolo de acuerdo con sus conocimientos, expectativas, motivaciones y actitudes.

\subsection{El contexto de aprendizaje del Inglés para Fines Específicos}

Hemos mencionado la necesidad de tener en cuenta el contexto en el que se diseña el proyecto educativo para poder decidir con un criterio sólido qué es posible y qué es deseable enseñar y aprender, tal como señalaba Nunan a través de las palabras que reproducíamos al comienzo de este capítulo. Por consiguiente, éste va a ser nuestro centro de atención a lo largo de esta sección. De modo más específico, nos interesa particularmente analizar el desarrollo de la capacidad del aprendiz como objetivo educacional del curso de Inglés para Fines Específicos en relación con la influencia proveniente del contexto educativo.

Para lograr esto, vamos a ampliar los límites del contexto utilizado al principio de este capítulo. Hemos introducido el concepto de contexto de aprendizaje con el fin de establecer distinciones en las relaciones posibles entre los aprendices de la lengua y los contextos lingüísticos donde se lleva a cabo el aprendizaje. En este sentido, hemos contemplado la influencia del contexto en el aprendizaje de la lengua como una relación específica entre la lengua que se utiliza predominantemente en el entorno físico donde se lleva a cabo el aprendizaje, la 
lengua nativa del aprendiz y la lengua (no nativa) que éste aprende, y esto nos ha permitido adscribir este trabajo a la investigación de la didáctica de las lenguas extranjeras y considerar con mayor profundidad los aspectos relacionados con el aprendizaje más que los que se asocian con la adquisición de la lengua, mediante la identificación del contexto de aprendizaje con el territorio monolingüe español.

Aquí, sin embargo, vamos a considerar el contexto de aprendizaje en otro sentido y con otros fines. En esta sección, nos interesa el contexto en el que se inscribe el proyecto de enseñanza-aprendizaje como un factor determinante de los objetivos educacionales $\mathrm{y}$, al considerar este aspecto, el contexto no va a ser contemplado como un territorio, sino como una entidad normalizadora. Esto significa que analizaremos nuestro enfoque didáctico en relación con una concepción de la comunidad educativa y sociocultural del aprendiz cuya localización geográfica se identifica con Europa. Desde este punto de vista, consideramos que el entorno europeo es pertinente para nuestro fin $y$, en consecuencia, será analizado a través de las instituciones que representan el espacio en el que se enmarca el entorno educativo considerado en este trabajo, y que se agrupan bajo la denominación general de Espacio Europeo de Educación Superior. La razón subyacente por la que nos parece necesario tratar la cuestión desde esta perspectiva es que, tal como mencionamos en el capítulo anterior, los criterios de selección de objetivos del proyecto de enseñanza-aprendizaje incluyen la consideración de los objetivos propuestos por otros niveles superiores del proceso educativo, según Morales Vallejo (1995b). Por tanto, estudiaremos las propuestas elaboradas por el organismo supranacional que constituye los límites más amplios (y los más generales) de nuestro entorno educativo, la Unión Europea, a través de las dos instituciones a cuyo amparo se desarrolla la política lingüística de la Unión, es decir, el Consejo de Cooperación Cultural del Consejo de Europa y la Comisión Europea.

La elección de la Unión Europea como el contexto educativo más idóneo para analizar la pertinencia de nuestro objetivo educacional merece una explicación, puesto que parece más lógico contar en primer lugar con el contexto más inmediato (que, en este caso, es la universidad española) en lugar de ir al contexto más amplio y, por tanto, al menos específico. Así, comenzaremos por explicar en el siguiente apartado las razones por las que hemos desechado la institución universitaria en España como contexto idóneo para analizar la pertinencia de nuestro objetivo educacional, para pasar a continuación a dar cuenta de los aspectos más relevantes para nuestro propósito de la política lingüística de la Unión Europea. 


\subsubsection{La Unión Europea como contexto educativo supranacional para la enseñanza y el aprendizaje de lenguas}

Algunos autores barajan la posibilidad de que las diferencias en el aprendizaje de las lenguas estén relacionadas con las propias diferencias culturales, según lo cual la enseñanza y aprendizaje de una lengua no tendría una misma realización en todos los entornos educativos, sino que se vería afectada, entre otros factores, por diferencias de tipo cultural. De hecho, esta posibilidad ha llevado a que una de las actividades programadas por el European Centre for Modern Languages para el periodo 2000-2002 dentro del área de interés denominado 'language awareness, intercultural competence, multilingual matters' consista, precisamente, en un proyecto denominado «The influence of different learning cultures» que busca ahondar en la influencia que las diferencias culturales relacionadas con las distintas lenguas tienen en la educación lingüística, en la metodología, así como en la interacción entre la teoría y la práctica ${ }^{24}$. Las cuestiones a las que se intenta dar respuesta en ese proyecto actualmente en marcha son las siguientes:

\footnotetext{
To what extent do learning cultures influence progress in language teaching and learning?

Do different languages require different approaches to methodology?

How can the flow between theory and practice be improved?

(Medium-term Programme of Activities 2000-2002:21)
}

Si consideramos la enseñanza y el aprendizaje de lenguas en España, es decir, si tenemos en cuenta el entorno inmediato donde se desarrollan los proyectos educativos sobre lenguas modernas que son considerados en este trabajo de forma específica, creemos que es de suma importancia dar respuesta a estas cuestiones, particularmente a la primera, ya que es la que podría arrojar luz sobre las posibles peculiaridades de la didáctica del Inglés para Fines Específicos en este entorno. A la espera de que éste u otros proyectos semejantes que haya en marcha puedan dar fruto, contamos únicamente con información puntual sobre la situación de la enseñanza y aprendizaje del inglés en España, la cual nos muestra un panorama bastante pesimista. Una muestra de ello es el comentario referente a la enseñanza de idiomas incluido por el Consejo Escolar del Estado en su Informe sobre el Estado y Situación del Sistema Educativo Español del Curso 1997/98 celebrado el 1 de

\footnotetext{
${ }^{24}$ El European Centre for Modern Languages fue creado por iniciativa de Austria y con el beneplácito del Consejo de Europa en 1994 y establecido en Graz, Austria.
} 
octubre de 1999, especialmente si lo comparamos con las recomendaciones del Consejo de Europa hechas diez años antes, y que veremos en el apartado siguiente:

Cabe destacar que si bien existe una implantación obligatoria de la enseñanza de idiomas dentro del ámbito de la educación formal, ésta es bastante deficitaria, ya que no proporciona al alumno la capacidad de desarrollo de los conocimientos, lo que conlleva grandes carencias, especialmente en la expresión oral, debido al número de alumnos por clase, entre otras razones, por lo que se insta a las Administraciones Educativas a la revisión de esta circunstancia. (Informe sobre el Estado y Situación del Sistema Educativo Español. Curso 1997/98)

Por otra parte, si analizamos la situación en España del Inglés para Fines Específicos, podemos resumir sus rasgos característicos así:

1. Los estudiantes que acceden a la universidad española tienen en su mayoría una competencia comunicativa en lenguas extranjeras bastante deficitaria, a la vista del comentario del Consejo Escolar del Estado incluido aquí, y puesto que las condiciones de masificación aludidas no han variado sino por las secuelas del descenso del índice de natalidad.

2. El Inglés para Fines Específicos en España se desarrolla mayoritariamente en el entorno universitario.

3. La, al parecer generalizada, falta de estabilidad del Inglés para Fines Específicos en el entorno universitario incide en la precariedad de las condiciones en las que los proyectos educativos se llevan a cabo, si bien hay que señalar que esta situación es común a otros muchos países (Swales 1984:10-13).

4. Al igual que en otros entornos universitarios, el hecho de que el Inglés para Fines Específicos en la universidad española no tenga una condición estable hace que resulte extraordinariamente costoso obtener un balance de su situación que permita extraer conclusiones mínimamente generalizables.

Se puede afirmar que la situación actual es el resultado de la coyuntura que se produce a partir de la entrada en vigor de la Ley Orgánica 11/1983, de 25 de agosto, de Reforma Universitaria, y especialmente tras la recomendación que el Consejo de Universidades hizo en 1992 de situar el aprendizaje de lenguas extranjeras fuera de los planes de los estudios superiores.

En diciembre de 1991, la Sección de Recursos Humanos y Educación de la Comunidad Europea hizo público un Memorándum sobre la Enseñanza Superior en Europa para que fuera sometido a debate en los países miembros. En España, la Secretaría del Consejo de Universidades organizó una reunión en Almagro en la que una quincena de responsables académicos, junto con los técnicos del Consejo, 
analizaron y debatieron sobre la información recogida en el memorándum. El resultado de este debate fue presentado en la Sesión del Pleno del Consejo de Universidades del 20 de julio de 1992.

En lo que se refiere al conocimiento de lenguas extranjeras, se pone de manifiesto la importancia concedida por la entonces Comunidad Europea a éstas y la meta que la Comunidad propone para los años siguientes en relación con la competencia comunicativa de los estudiantes universitarios europeos:

El Memorándum aborda de modo expreso el problema del conocimiento de los idiomas como elemento de la dimensión europea del sistema universitario, elemento clave con carácter general y específico para la movilidad. El objetivo que el Memorándum propone es que al menos la población universitaria conozca las lenguas extranjeras comunitarias y que a fines de la década del 90 [sic] el ambiente multilingüe caracterice a las instituciones de enseñanza superior. (Consejo de Universidades 1994:74)

Por su parte, la reflexión fruto del debate mantenido en Almagro parte del siguiente planteamiento: «si para la generalidad de los países este reto es importante, para España, que adolece en este punto de un auténtico síndrome de insularidad, el reto es capital» (Consejo de Universidades 1994:74-75). A partir de ahí, se plantean tres líneas de reflexión, de las cuales únicamente reproducimos la segunda y la tercera, por ser las más directamente relacionadas con la situación expuesta más atrás:

$2^{\text {a }}$ Valorar de modo efectivo el conocimiento de lengua extranjera en el cómputo de créditos de cada titulación. [...] Frente a la alternativa tradicional de los planes de estudio entre la nada y la lengua extranjera como asignatura «maría» y con improductiva recarga de plantillas en carreras arbitrariamente determinadas, se admite que los planes puedan reflejar materias obligatorias y optativas con créditos sin docencia específica, que se obtienen mediante la superación de una prueba. Este sistema estimula la formación en lenguas extranjeras y elude las enojosas y poco fructíferas horas/semanas con profesores destinados a fracasar en su función docente y funcionalmente difíciles de reutilizar en otros programas.

Ahora bien, para que este sistema promocional tenga efectos sociales justos probablemente se requiere poner en marcha en las Universidades lo que es ya experiencia en algunas y constituye el último objeto de reflexión en este tema.

$3^{\text {a }}$ Programas específicos e intensivos de formación en lengua extranjera por las propias Universidades.

Aunque la experiencia existe, es limitada, lo que tiene causas sobre todo financieras. Valdría la pena meditar sobre cómo extender estas experiencias. Una vía podría ser la «contratación» de subvenciones específicas por parte de las Administraciones educativas contra programas de las Universidades. Uno de los elementos de esos contratos marco podría ser la reserva de un porcentaje relevante de plazas para becarios, que paliaría las condiciones materiales de acceso desigual a la lengua extranjera hoy 
imperantes. Estos programas podrían configurarse con la colaboración de jóvenes docentes de Universidades extranjeras, interesadas [sic] en estancias en España y con la de los recursos humanos disponibles en el sistema educativo general, Bachillerato y Escuelas Oficiales de Idiomas, para lo que habría que instrumentar la pertinente compatibilidad, que en este caso no resuelve la figura del asociado. (Consejo de Universidades 1994:75-76)

Hemos reproducido los términos del debate con una cierta extensión ya que nos resulta revelador el hecho de que, para reflexionar acerca de la situación en la universidad española en relación con la competencia comunicativa de los estudiantes españoles en las lenguas de la Unión Europea, el enfoque utilizado no considera en ningún momento argumentos relacionados con la didáctica especial de las lenguas extranjeras, sino que más bien se detecta la intención de derivar a otras instancias la solución del problema de cómo conseguir en términos realistas que «el ambiente multilingüe caracterice a las instituciones de enseñanza superior» a finales de los noventa, tal como recomienda el memorándum de la Comunidad Europea.

En tal situación no nos parece que se den unas condiciones apropiadas para determinar si el objetivo educacional establecido en este trabajo es coherente con respecto a los objetivos establecidos por la universidad, puesto que ésta no define explícitamente ningún objetivo lingüístico específico para paliar la situación peculiar del síndrome de insularidad aludido.

Además de una política determinada que detalle cómo se prevé la consecución de unos objetivos específicos en relación con la competencia comunicativa de los estudiantes universitarios, el contexto educativo tiene utilidad en nuestro trabajo como fuente de información acerca del aprendiz, particularmente de sus conocimientos, expectativas y actitudes.

En lo que concierne a la política lingüística, probablemente la única generalización posible es la participación de estudiantes en los diferentes programas europeos de movilidad (Sócrates, etc.), si bien esta participación es muy desigual entre unas titulaciones y otras. En carreras que precisan una dedicación muy alta, como las carreras técnicas en general, es decir, en aquellas carreras donde sólo un porcentaje reducido o muy reducido de estudiantes logra titularse en el mismo número de años que cursos tiene la titulación, existe una cierta renuencia a solicitar una beca de movilidad porque en muchos casos la estancia en otro país europeo se contempla como un retraso en la culminación de los estudios, y se le da prioridad a esto frente a las ventajas que pueda proporcionar esa estancia. Por este motivo, la participación en programas europeos de movilidad no es una fuente de información muy relevante para este trabajo desde nuestro punto de vista, ya que no se puede considerar que constituya una práctica habitual en los estudios superiores de forma 
general si nos basamos en el bajo porcentaje de estudiantes que disfrutan de estos programas en relación con el total de estudiantes de la universidad española.

Por otra parte, el contexto universitario como fuente de información sobre el aprendiz puede ser útil únicamente si existen estudios específicos sobre estas cuestiones. Un ejemplo de esto es el estudio realizado por García-Beltrán et al. (1998), en el que trazan un perfil de los alumnos de nuevo ingreso en la Escuela Técnica Superior de Ingenieros Industriales de la Universidad Politécnica de Madrid con la finalidad de que esta información pueda ser utilizada para adecuar los contenidos de las asignaturas de la carrera. Desgraciadamente, este estudio sólo analiza los conocimientos de Matemáticas, Físicas, Química y Dibujo Técnico, por lo que no nos proporciona información relevante para nuestros propósitos. Otro ejemplo, esta vez relacionado con el Inglés para Fines Específicos, es el estudio realizado en la Universidad de Oviedo por González Pozueta y Álvarez González (1992). Se trata de un estudio prospectivo sobre la demanda de lenguas instrumentales como asignaturas de libre elección, por lo que tampoco nos proporciona información sobre los objetivos educacionales o los conocimientos de los aprendices, ya que se basa en las metas prospectivas del aprendizaje.

A este respecto, podemos resumir diciendo que no disponemos de información relevante y contrastada que nos pueda ayudar a dibujar un perfil fidedigno y exhaustivo de los conocimientos, expectativas, actitudes y metas del aprendiz de Inglés para Fines Específicos en el entorno universitario español. Así, hemos de reconocer que las escasas generalizaciones que podamos señalar, aunque basadas en la experiencia real propia y ajena, no deben ser tomadas sino como el único perfil disponible en estos momentos ante la necesidad de caracterizar al grupo de aprendices de Inglés para Fines Específicos en el entorno universitario español actual. Por consiguiente, la exhaustividad queda más allá de nuestras posibilidades presentes de descripción, luego la fiabilidad de la información que este entorno nos puede proporcionar es escasa en relación con los aspectos relacionados con los aprendices reales de Inglés para Fines Específicos en la universidad española, y completamente nula con respecto al establecimiento y a la evaluación de los objetivos educacionales de estos cursos.

Por otra parte, la presencia de programas de traducción en el entorno del Inglés para Fines Específicos o de la utilización de tareas de traducción como medio de facilitación del aprendizaje es completamente marginal, por lo cual tampoco podemos generalizar acerca de la política universitaria que se sigue respecto del 
papel de la traducción, si bien podemos señalar que esta situación no es peculiar de la universidad española:

As the 'information age' hits its full stride, the new millennium looks uncertain in many ways. But we can be certain that information and information technology make a sound investment, now and in the foreseeable future. As a key strategy in the global acquisition and dissemination of information, translation and translator training must be a major part of that investment for any university aspiring to genuine excellence.

Instruction and training in translation could be established in the university in several formats:

A. establishing general-purpose translation courses within existing language departments;

B. establishing special-purpose translation courses within the respective faculties and departments in strategic areas across the curriculum;

C. establishing an interdisciplinary translation centre with the status of a programme.

D. establishing an independent translation centre with the status of a department or faculty;

E. establishing a graduate programme to award degrees in professional translation. [...]

As far as I know, Option B would be quite novel for most universities. Some do have courses in English for Special Purposes (or Academic Purposes) in specific fields of study, but these are rarely sustained or comprehensive, nor are they strategically integrated with the respective departments. More often, they are consigned to some language centre or programme with a purely provisional and preparatory function for students at low levels. Also, such courses tend to approach English in isolation from other languages and deal mainly and unsystematically with vocabulary. In consequence, little explicit concern is devoted to languages in contact or to translation. (De Beaugrande 2000b)

Desde nuestra perspectiva, tras descartar la pertinencia del entorno universitario en España para analizar las cuestiones que queremos tratar, el contexto educativo que nos parece más productivo para nuestros fines es aquel que, encontrándose en un nivel de aplicación más amplio y superior al ámbito universitario, no sólo define de forma explícita una política lingüística determinada, sino que también afecta a cualquier tipo de proyecto educativo desarrollado en la universidad española. En este sentido, la Unión Europea constituye un entorno que se ajusta muy bien a esta descripción, ya que su influencia en la política universitaria española de las dos últimas décadas es palpable, tal y como se desprende del siguiente fragmento, que se encuentra en la Ley de Reforma Universitaria (Ley Orgánica 11/1983, de 25 de agosto):

[...] la previsible incorporación de España al área universitaria europea supondrá una mayor movilidad de titulados españoles y extranjeros, y se hace necesario crear el marco institucional que permita responder a este reto a 
través de los planes de estudio y la flexibilización de los títulos que se ofertan en el mercado de trabajo. (Fuente García 1992:67)

Desde que España forma parte de la Unión Europea, la preocupación por la enseñanza y el aprendizaje de lenguas extranjeras ha cobrado una dimensión nueva. Ningún proyecto educativo puede obviar las repercusiones socioeconómicas del compromiso contraído con la adhesión de España a la Unión Europea, como manifestación del deseo de integración en un espacio supranacional que defiende la igualdad y la libre movilidad de las personas pertenecientes a sus estados miembros.

La integración en Europa ha supuesto, entre otras cosas, la apertura del horizonte laboral a un entorno multicultural y multilingüe, lo cual conlleva la exigencia de un gran esfuerzo para garantizar las condiciones de igualdad a la vista de la creciente competitividad existente en todos los campos de actividad académica y profesional ${ }^{25}$. En este orden de cosas, para que la libre movilidad de personas y el intercambio de ideas sea una realidad, la Unión Europea ha adoptado una política lingüística de igualdad que ha propiciado la puesta en marcha de sucesivos proyectos sobre la enseñanza y el aprendizaje de lenguas en el seno del Consejo de Cooperación Cultural dependiente del Consejo de Europa y que, a su vez, han producido sucesivos programas de acciones lingüísticas promovidos por la Comisión Europea.

Por otra parte, debemos tener en cuenta la idea que subyace a la política lingüística del Consejo de Europa, a saber: la unidad europea como espacio de integración de la diversidad cultural y lingüística. Este concepto de unidad en la diversidad es la causa de que los proyectos que se han puesto en marcha desde la creación del Consejo de Cooperación Cultural hayan dirigido sus esfuerzos, además de hacia los sectores más desfavorecidos por la diversidad, hacia el establecimiento de pautas generales comunes de actuación lingüística, como la definición de niveles comunicativos comunes para todas las lenguas de acuerdo con los objetivos del aprendizaje en cada nivel (waystage, threshold, y vantage), así como el establecimiento de un marco referencial teórico (el Common European Framework

\footnotetext{
${ }^{25}$ Esto se puede ver en recomendaciones como las recogidas en la Recommendation No. $R$ (89) 10 o más recientemente en la Recommendation No. $R$ (98) 6 reproducida por Trim (1998:18 y siguientes) y también en el epígrafe titulado «Reinforcing European competitiveness and preserving employment through education and training» del informe Accomplishing Europe Through Education and Training elaborado por el Grupo de Estudio sobre Educación y Formación de la Dirección General XXII de la Comisión Europea (Study Group on Education and Training Report).
} 
of Reference) o, en estos momentos, la creación de un pasaporte lingüístico (el European Language Portfolio) sobre el que se está trabajando.

Si retomamos la metáfora de Widdowson en la que la didáctica del Inglés para Fines Específicos se sitúa sobre la línea continua en cuyos extremos se encuentran respectivamente la especificidad y la generalidad de la lengua que se enseña, es evidente que la perspectiva del Consejo de Europa sobre la didáctica de las lenguas se sitúa mucho más próxima al extremo general, que corresponde con un concepto de la enseñanza más educativo que formativo, en el que existe una preocupación por el establecimiento de objetivos educacionales diferentes de las metas específicas que se deseen alcanzar con el aprendizaje de la lengua.

No obstante, a pesar de que este enfoque general sobre la enseñanza y el aprendizaje de las lenguas podría implicar una despreocupación por la didáctica de las lenguas para fines específicos, el afán por dar cuenta de la diversidad de forma democrática hace que el Consejo se interese asimismo por todas las distintas manifestaciones de tal diversidad. Además de los aspectos relativos a las diferentes culturas presentes en el panorama de Europa, que se traducen en un gran interés por el desarrollo de la competencia intercultural de los aprendices, con su pujante presencia en los programas lingüísticos, el Consejo tiene presente la importancia de la diversidad en el aprendizaje de lenguas, que se manifiesta en los distintos modos de aprender, así como en las diferencias entre los propios aprendices. Esto se puede observar en el Preámbulo a la Recommendation No. $R$ (82) 18 adoptada por el Comité de Ministros del Consejo de Europa sobre las lenguas modernas el 24 de septiembre de 1982:

It is [...] not only linguistic and cultural diversity that present us with a lifelong challenge. Learners, too, vary widely in their needs, motivations, characteristics and resources. How are confronted [sic] with great variety in respect of training, experience, personality and conditions of work ? What should be accepted and respected ? What should be critically examined with a view to change and reform ? This is the «challenge of diversity» as we pursue the major objective set by the Committee of Ministers «to facilitate communication and interaction among Europeans of different mother tongues in order to promote European mobility, mutual understanding and cooperation, and overcome prejudice and discrimination». (Council for Cultural Cooperation 1989:7)

En lo que se refiere a nuestro trabajo, las áreas de interés que han sido tratadas por el Consejo de Cooperación Cultural dependiente del Consejo de Europa, así como por la Dirección General XXII de la Comisión Europea, y que más estrechamente se relacionan con nuestros propósitos en esta sección, se pueden 
delimitar a partir de ese concepto de diversidad analizando especialmente aquellos aspectos que se refieren al tipo de aprendices que nos interesa y a la especificidad de la lengua que se enseña y que se aprende, tal como se refleja en los distintos modos de aprendizaje. Para llevar esto a cabo, en la sección siguiente estudiaremos con mayor detalle las directrices teóricas del Consejo de Europa en relación con el aprendizaje de las lenguas modernas, tal y como aparecen recogidas en el denominado Marco de Referencia Europeo.

\subsubsection{El Marco de Referencia Europeo y sus antecedentes en relación con el Inglés para Fines Específicos y con la traducción}

El criterio elegido para comparar la vasta diversidad de proyectos educativos y sus correspondientes resultados en toda la extensión de la Unión Europea, el denominado 'sistema de créditos' (unit/credit system), refleja una concepción global de la educación donde el objetivo educativo que hemos considerado en este trabajo es consistente con el planteamiento general, tal como sintetiza Richterich las características de este sistema en lo que concierne a la educación de adultos:

Units of work

A unit of work is a coherent set of attainments (theoretical and practical) and experience giving proof of proficiency at a given level.

After mastering the content of this unit, the student acquires a certain credit rating which is paid into a «training account» which may take the form of an individual pass-book...

The consitution of aggregates

An aggregate is a collection of units of different kinds leading up to a diploma or the equivalent. Three «axes» of progress are proposed.

A professional or specialised axis which combines the various units directly centered on the determining profession that is chosen (it may be engineering or teaching, for example) and corresponds to a given standard.

A general axis combines the units considered necessary for the proper utilisation of what is learned on the first axis. Thus, in the case of an electronics engineer's certificate, axis No. 1 would consist of units of electricity, electronics, mathematics etc. and axis No. 2 would consist of oral expression, socio-economic information, languages etc.

Thirdly, a development axis comprises work not directly connected with the profession but aimed to develop the individual's personality. Using the same example of the electronics engineer's certificate, these would be 'cultural' units or a second language. By working on these three axes, the student 
acquires a certain capital point which entitles him to the «diploma» corresponding to this standard as soon as the three minimum requirements are satisfied. (Richterich 1980:67)

Este enfoque del proceso general educativo de adultos resulta muy conveniente para nosotros, ya que la enseñanza de lenguas para fines específicos en los estudios universitarios en España suele ocupar, o bien una posición en el eje general, o bien en el eje de desarrollo. En nuestro planteamiento particular en este trabajo, ubicamos la enseñanza del Inglés para Fines Específicos en el tercer eje, con el propósito de desarrollar la personalidad individual del aprendiz y en el que es coherente y pertinente establecer la capacidad del aprendiz como un objetivo educacional de la enseñanza.

Por lo que respecta al tipo de aprendices, en líneas generales se puede observar que el concepto global de aprendiz manejado por el Consejo de Cooperación Cultural es consistente con el utilizado en este trabajo:

[...] in accordance with the doctrine of human rights at the very centre of the work of the Council of Europe, [the Council for Cultural Co-operation] has promoted the view of education as a continuing process aimed at the steady development of the free, socially responsible, self-aware and self-reliant individual.

Correspondingly, the series of projects which have been conducted by the CDCC since 1971 has attempted to promote the kind of language learning that leads to:

a) more and better communication, mutual understanding and tolerance as well as active cooperation among European peoples;

b) the steady and purposive development of the learner as a communicator, as a learner and as a socially responsible, individual personality.

(Council for Cultural Co-operation 1989:8) ${ }^{26}$

Sin embargo, cuando intentamos localizar la información relacionada específicamente con los aprendices del Inglés para Fines Específicos en el entorno universitario, nos encontramos con dificultades causadas por el modo desigual de división de los grupos estudiados en los distintos proyectos, recomendaciones y acciones referentes a la enseñanza y aprendizaje de las lenguas en el seno de la Unión Europea, por lo que el resumen que ofrecemos a continuación puede resultar fragmentario para quien busque la exhaustividad del relato pero creemos que es suficiente para nuestros fines, teniendo en cuenta los límites y el propósito de nuestro trabajo.

\footnotetext{
${ }^{26}$ Las siglas CDCC corresponden al Consejo de Cooperación Cultural.
} 
En la Recommendation No. $R$ (82) 18 los grupos de aprendices que el Comité de Ministros del Consejo de Europa considera de interés son cuatro, de los cuales el segundo es el que concierne a los aprendices que tratamos en este trabajo, que son «language learners beyond the stage of compulsory education (senior secondary classes, students, adults)» (Girard y Trim 1988:9) ${ }^{27}$. Así, las medidas específicas referentes a este grupo se expresan en dicha recomendación en los siguientes términos:

To encourage educational institutions to provide facilities for the continuation of language learning by all students in upper secondary, higher and further education, as appropriate to their special fields of work and study, in order to facilitate international professional mobility and co-operation at all levels.

To ensure that adequate resources are available to enable students who have completed their full-time education to acquire further knowledge of language in accordance with their professional, social and personal needs and motivations.

To take all measures necessary to enable adults who have had hitherto little or no chance of learning a modern language for communicative purposes. (Girard y Trim 1988:91)

Posteriormente, en el Proyecto No. 12 «Learning and teaching modern languages for communication», puesto en marcha por el Consejo de Cooperación Cultural a partir de la Recommendation No. $R$ (82) 18, se establecen cuatro comisiones cuyo trabajo consiste en explorar y explotar las posibilidades de las recomendaciones recogidas en 1982 para cada uno de los grupos de interés. Sin embargo, estos grupos ahora pasan a ser distribuidos de otro modo, por lo que nuestros aprendices entrarían dentro del trabajo desarrollado por la Commission $C$, Post-school education ${ }^{28}$.

Dentro de la diversidad de la denominación 'post-school education', esta comisión encuentra la conveniencia de «distinguish between adult education on the one hand and non-specialist university learners on the other»y, a propósito de este segundo grupo, acuerda hacer las siguientes consideraciones:

In the Europe of the nineties', university students as a group will have increasing requirements in terms of initial and advanced foreign language

\footnotetext{
${ }^{27}$ Los cuatro grupos que se mencionan son: «school pupils, language learners beyond the stage of compulsory education (senior secondary classes, students, adults), migrants and language teachers» (Girard y Trim 1988:9).

${ }^{28}$ El repertorio completo de comisiones está formado por las cuatro comisiones siguientes: Commission A, Primary and lower secondary education; Commission B, Upper secondary education; Commission C, Post-school education; Commission D, Language education for first and second generation migrants (v. Council for Cultural Co-operation 1989).
} 
training as a result, in particular, of growing international mobility in higher education courses and the occupations for which they are a preparation.

In many cases, the existing university system seems inadequately equipped to meet satisfactorily this demand for language learning facilities, a demand which, in both quantitative and qualitative terms, is bound to take on new importance and new forms.

International co-ordination and co-operation, particularly at inter-university level, should be reinforced for the purpose of:

- comparing experience of methods for the organisation of language learning systems with academic aims;

- defining the conditions to be met by teaching materials and approaches to cope with this growing demand;

- encouraging, in particular, the publishing sector and producers of media documents to cater for this section of the population so vital for the future of Europe.

(Council for Cultural Co-operation 1989:95-96)

Pero, más importante para nuestro enfoque didáctico, en la conferencia donde se expone y analiza el Informe Final del Proyecto No. 12 con el fin de hacer recomendaciones al Consejo de Cooperación Cultural y al Consejo de Europa acerca de las acciones futuras en el campo del aprendizaje de lenguas, y que se celebró del 22 al 25 de marzo de 1988 en Estrasburgo, se incluye una recomendación (No. R.8.7.3. del Informe Final) dentro del apartado dedicado al post-school language learning en la que se promueve «consider the feasibility of developing modes integrating the specification of objectives for occupationally oriented foreign language learning with objectives for personal development, social skills and cultural interests» (Council for Cultural Co-operation 1989:18). En la propia conferencia, el asesor del proyecto John Trim interviene para abordar las opciones de futuras acciones y se pronuncia del siguiente modo sobre el occupationally oriented foreign language learning:

\begin{abstract}
It has become increasingly clear to many of our member governments that one or more modern languages are no longer a marginal extra qualification for certain trades and professions, but increasingly a key qualification, a necessary aspect of preparation for tomorrow's world. However, they do not see the solutions to lie in a narrow technical training in «language for special purposes», especially where a vocational orientation is introduced into the general education of young people, where exposure to a foreign language and culture can and should serve the interest of other objectives such as personal development, social skills and cultural interests. (Council for Cultural Cooperation 1989:64-65)
\end{abstract}

Desde esta perspectiva, el aprendizaje del Inglés para Fines Específicos se sitúa en una posición similar a la sostenida por Widdowson y a la adoptada en este trabajo. Así, el desarrollo de la capacidad necesaria para que el aprendiz logre adquirir la competencia que precisa para comunicarse en lengua inglesa como un 
profesional de su campo de especialización se revela como un objetivo educacional consistente tanto con las recomendaciones específicas que afectan a los aprendices considerados, así como con el espíritu general del Consejo de Cooperación Cultural y el Consejo de Europa en lo que concierne a la enseñanza y el aprendizaje de lenguas, y que se puede ilustrar muy bien con estas palabras de Richterich presentadas en la conferencia:

[...] it is possible, without running the risk of gross error, to put forward the hypothesis that the learning of a modern language plays a certain role in an individual's general education, as it can help him to speed up and diversify the acquisition of cognitive and affective aptitudes whilst developing his sense of social responsibility. (Council for Cultural Co-operation 1989:60)

Tras la finalización del Proyecto «Learning and teaching modern languages for communication», el Consejo de Co-operación Cultural del Consejo de Europa pone en marcha el Proyecto «Language learning for European citizenship», que culmina con la elaboración de la Recommendation No. $R$ (98) 6, y en la que las medidas específicas que nos conciernen se recogen en dos epígrafes distintos, expresándose en los siguientes términos:

D. Vocationally-oriented language learning

16. In the period of transition from full-time education to working life, and at all stages of vocational preparation and training, offer all young people language courses wherever possible and appropriate so as to widen their access to information, equip them to participate in international projects, prepare them for taking up an occupation and increase their vocational mobility.

17. Ensure a balance between vocational, cultural and personal development by offering language courses that combine general and vocational components.

18. Promote training courses that use a flexible approach (modules, for example) to meet special vocational needs so that credit is given progressively as competences are built up. [...]

G. Specification of objectives and assessment

25. For all European national and regional languages, develop realistic and valid learning objectives - such as are to be found in «threshold level» type specifications developed by the Council of Europe - so as to ensure quality in language learning and teaching through coherence and transparency of objectives.

26. Encourage institutions to use the Council of Europe's Common European Framework of Reference to plan or review language teaching in a coherent and transparent manner in the interests of better international co-ordination and more diversified language learning.

27. Encourage the development and use by learners in all educational sectors of a personal document (European Language Portfolio) in which they can record their qualifications and other significant linguistic and cultural experiences in an internationally transparent manner, thus motivating learners 
and acknowledging their efforts to extend and diversify their language learning at all levels in a lifelong perspective.

28. Encourage institutions engaged in assessment and certification - especially those which award recognised qualifications - to make their objectives, criteria and procedures clear both to candidates and teachers, thus facilitating the comparability of qualifications and European mobility.

29. Promote the development of varied forms of assessment and recognition of plurilingual competences which take into account the considerable diversity of needs, paying particular attention to the definition of objectives for partial competences and the assessment of their attainment.

30. Promote and facilitate the awarding of certificates and diplomas at the end of a course of study followed in more than one language. (Trim 1998:22-23) (énfasis nuestro)

Podemos resumir al hilo de estas medidas, que la concepción didáctica de las lenguas para fines específicos manejada admite unas peculiaridades metodológicas consistentes en la posibilidad de adoptar una concepción modular de la enseñanza que lleve al aprendizaje de competencias parciales (lo cual es consistente asimismo con la concepción de desarrollo de la competencia comunicativa que hacen Canale y Swain, como ya hemos visto en la sección 3.3) y con una definición de objetivos y de métodos de evaluación particulares, pero siempre dentro de un marco teórico común a toda la enseñanza y el aprendizaje de lenguas modernas, que en el caso de la Unión Europea está constituido por el Common European Framework of Reference o Marco de Referencia Europeo.

Este marco teórico constituye actualmente un punto de referencia de la didáctica especial de las lenguas modernas en este entorno geográfico, tanto por su comprehensivo enfoque teórico como por su desarrollo en la definición de todos los aspectos relacionados con las metodologías de las lenguas modernas y, sobre todo, por el establecimiento de diferentes niveles de competencia comunicativa aplicables a todas las lenguas de la Unión.

Por otra parte, el marco referencial se ha desarrollado a partir de un concepto amplio de la comunicación, teniendo en consideración de forma explícita la traducción como actividad lingüística implicada en la comunicación intercultural. Por esta razón, es pertinente para nuestro trabajo no sólo como criterio relevante para la definición de objetivos desde el punto de vista de su carácter supranacional, sino también porque responde a un enfoque teórico consistente con el de este trabajo.

En este marco referencial se interpreta que la competencia comunicativa del aprendiz o del usuario del lenguaje es activada mediante diversos tipos de actividades lingüísticas (v. Council for Cultural Co-operation 1996). Estas actividades se pueden dar bien de forma hablada, bien de forma escrita, o bien 
utilizando ambos medios, y se clasifican como actividades lingüísticas relacionadas con la 'recepción', la 'producción', la 'interacción' y la 'mediación'.

La interacción, donde al menos dos personas participan en un intercambio oral o escrito (en el que se producen acciones en las que participan tanto la producción lingüística como la recepción y, en ocasiones, también actividades de mediación), ocupa una posición central en este enfoque, haciendo de este modo hincapié en que la importancia del uso de la lengua, así como de su aprendizaje, estriba en la capacidad para comunicarse que se desarrolla mediante las actividades de interacción.

No obstante, la recepción y la producción (orales y/o escritas) ocupan un lugar destacado de acuerdo con las capacidades que su aprendizaje posibilita. Las actividades de recepción son determinantes para la lectura, para seguir los medios de comunicación o para muchas formas de aprendizaje, tales como comprender el contenido de un curso o consultar libros de texto y otros tipos de material textual.

Por su parte, las actividades de producción son fundamentales debido a su función en muchos campos académicos y profesionales (por ejemplo, en las presentaciones orales o en la emisión de informes), y también a causa del valor social específico que se asocia con ellas en cuanto a los juicios de valor que la gente se forma sobre las personas a partir de su fluidez al hablar o a las actitudes que adopta en función del acento u otros rasgos lingüísticos y paralingüísticos de un interlocutor o de un orador (véase, por ejemplo, Bourhis et al. 1975), siendo estos juicios de valor y estas actitudes de gran relevancia cuando, además, el interlocutor o el orador están utilizando una lengua extranjera (Young 2003) ${ }^{29}$.

Además de esto, tanto en su aspecto de producción como en el de recepción, las actividades de mediación (orales y/o escritas) permiten producir una (re)formulación de un TO para terceras personas que no tienen acceso directo a ese texto, mediante la traducción o la interpretación, y mediante un resumen o bien un documento completo. Las actividades lingüísticas de mediación, el (re)procesamiento de un texto ya existente, ocupan un lugar destacado en el funcionamiento lingüístico habitual de nuestras sociedades.

El Marco de Referencia Europeo (v. Council for Cultural Co-operation 1996) señala asimismo que estas actividades lingüísticas están contexualizadas en

\footnotetext{
${ }^{29}$ De hecho, Young (2003) sugiere que los aspectos paralingüísticos, así como el tono de voz, ejercen mayor influencia sobre la actitud de los oyentes que la propia habilidad lingüística, por lo que deberíamos contemplar en el diseño de actividades de producción la importancia de estos aspectos en relación con la relevancia de incluir actividades destinadas a ejercitar los aspectos paralingüísticos y vocales en la producción en lengua extranjera.
} 
dominios que pueden ser muy diversos. No obstante, estos dominios se clasifican en relación con el aprendizaje de lenguas en cuatro amplios grupos generales: el dominio público, el dominio personal, el dominio educativo y el dominio ocupacional.

El dominio público se refiere a todo aquello que se relaciona con la interacción social que podríamos considerar habitual en un entorno urbano en occidente. Este tipo de interacciones incluye las relacionadas con la Administración, así como las interacciones de tipo comercial o mercantil, las actividades de ocio y cultura de carácter público, y las interacciones con los medios de comunicación.

Como complemento al dominio público, el dominio personal abarca las relaciones familiares, así como las prácticas sociales de tipo individual. En este dominio se incluyen actividades tales como leer por placer, escribir un diario personal o mantener una afición particular.

El dominio educativo se refiere al contexto de aprendizaje o de formación, habitualmente de carácter institucional, donde la meta consiste en la adquisición de unos conocimientos o unas destrezas específicos.

Por último, el dominio ocupacional comprende todo aquello que tiene que ver con las actividades y relaciones de una persona en el ejercicio de su ocupación habitual.

De acuerdo con el Marco de Referencia Europeo, estos dominios se interrelacionan de un modo que se puede representar gráficamente así:

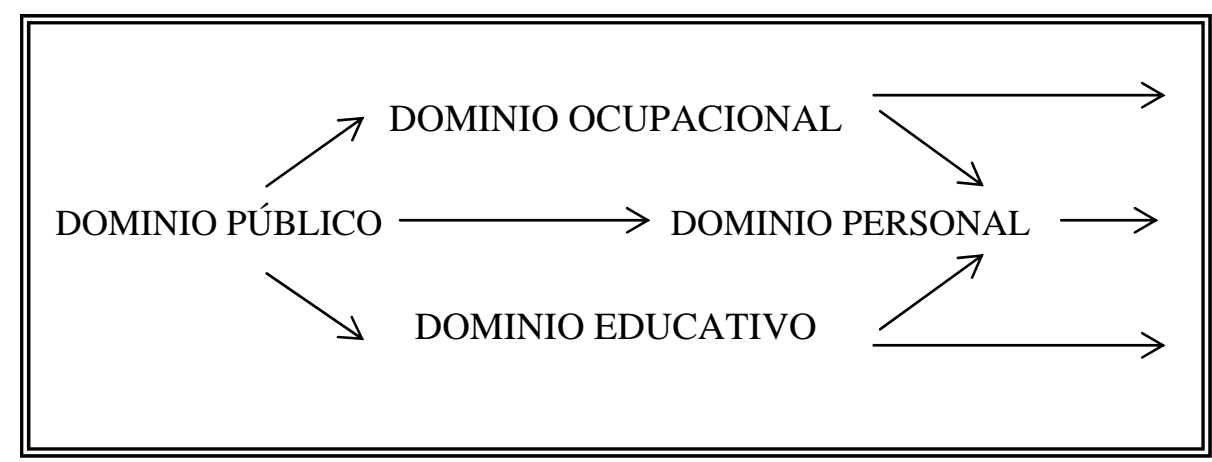

Figura 1. Interrelación de los dominios que contextualizan las actividades lingüísticas (adaptada de Council for Cultural Co-operation 1996) 
En un extremo, además de las interacciones y transacciones de tipo social y administrativo y los contactos con los medios de comunicación, el dominio público se extiende hacia los demás dominios, actuando a menudo como una vía de acceso necesaria. Tanto en el dominio educativo como en el ocupacional muchas interacciones y actividades lingüísticas se desarrollan dentro del funcionamiento social normal del grupo, sin ninguna relación específica con las tareas profesionales o con las de aprendizaje. Por su parte, el dominio personal tampoco debe ser tomado como una esfera aparte ni ajena al resto de los dominios ya que, tal como señala el Marco de Referencia Europeo (v. Council for Cultural Co-operation 1996), la penetración de los medios de comunicación de masas en la vida privada y familiar, el reparto de documentos públicos en los buzones privados, la propaganda y la publicidad, o los textos que aparecen en los productos utilizados en la vida diaria privada, son una muestra de esta interrelación entre el dominio público y el personal.

En el esquema mostrado en la Figura 1 podemos observar cómo en el extremo contrario al ocupado por el dominio público, el dominio personal representa la vía de salida. Lo que se sugiere aquí es que en el dominio personal se individualizan o personalizan las acciones que el usuario de la lengua lleva a cabo en los otros dominios y cómo, aun sin dejar de ser un agente social, el usuario se comporta como individuo. Algunos de los ejemplos que se citan en el Marco de Referencia Europeo incluyen acciones como la elaboración de un informe técnico, la preparación de una presentación en clase y actividades de otra índole como la realización de una compra (v. Council for Cultural Co-operation 1996). Estos ejemplos sirven para ilustrar algunas de las múltiples acciones que permiten que la personalidad individual se exprese de otro modo que en relación con el dominio público, el educativo o el profesional de los que, en un espacio y tiempo determinados, forman parte las actividades lingüísticas que corresponde con el dominio personal.

Al mismo tiempo, el Marco de Referencia Europeo ha emprendido la tarea de establecer descriptores específicos que ilustren las distintas categorías de las actividades lingüísticas, tanto en el modo oral como en el escrito. Una muestra de esto se presenta en la Tabla 6, que recoge los descriptores correspondientes a las actividades lingüísticas de recepción. 


\begin{tabular}{|c|c|}
\hline \multicolumn{2}{|c|}{ RECEPCIÓN } \\
\hline ORAL & ESCRITA \\
\hline Comprensión global de audición & Comprensión global de lectura \\
\hline $\begin{array}{l}\text { Escuchar como miembro de una } \\
\text { audiencia } \\
\text { - } \quad \text { Escuchar avisos e instrucciones } \\
\text { - Escuchar la radio y grabaciones } \\
\text { de audio } \\
\text { - Ver películas y la televisión }\end{array}$ & $\begin{array}{ll}\text { - } & \text { Leer correspondencia } \\
\text { - } & \text { Leer para orientarse } \\
\text { - } & \text { Leer para obtener instrucciones }\end{array}$ \\
\hline
\end{tabular}

Tabla 6. Descriptores de las actividades comunicativas de recepción (Council for Cultural Co-operation 1996)

Aunque la tarea de detallar estos descriptores de forma específica para cada nivel de los previamente definidos por el Consejo de Europa es ciertamente ardua y prolija, el Marco de Referencia Europeo ha alcanzado un gran nivel de desarrollo. Lamentablemente para nosotros, las actividades de mediación son las menos desarrolladas hasta la fecha. Con toda probabilidad, este retraso se debe a dos motivos de distinta índole. El primero es la ausencia de este tipo de actividades en las metodologías que se utilizan actualmente en la didáctica especial de las lenguas extranjeras, como ya mencionamos en el capítulo anterior. El segundo motivo es el hecho de que tradicionalmente la traducción no ha sido contemplada, ni desde la didáctica de las lenguas ni desde la didáctica de la traducción, como un fenómeno categorizable en distintos tipos de actividad más allá de la discriminación entre traducción (como manifestación escrita y diferida) e interpretación (como manifestación oral y simultánea o consecutiva), o entre 'traducción directa' (de la lengua extranjera a la lengua materna) y 'traducción inversa' (de la lengua materna a la lengua extranjera).

Dicho esto, no obstante debemos apostillar que, aunque en la didáctica de la traducción la categorización se suele basar en tipologías textuales, identificando así tipos de traducción con tipos de texto, algunos autores establecen categorías a partir de otros parámetros, tales como la finalidad que se persigue al traducir, como es el caso en la ‘teoría del escopo’ de Reiss y Vermeer (1991). Hurtado Albir (1999), por ilustrar una posición más explícitamente orientada a la didáctica, complementa una categorización textual de la traducción con otra paralela, a la que esta autora denomina 'modalidades de traducción', y que se resume en la Tabla 7. 


\begin{tabular}{|c|c|}
\hline $\begin{array}{c}\text { MODO } \\
\text { TRADUCTOR }\end{array}$ & $\begin{array}{l}\text { MODALIDAD DE } \\
\text { TRADUCCIÓN }\end{array}$ \\
\hline SIMPLE & $\begin{array}{l}\text { - Traducción escrita } \\
\text { - Interpetación simultánea } \\
\text { - Interpretación de enlace } \\
\text { - Susurrado }\end{array}$ \\
\hline COMPLEJO & $\begin{array}{ll}\text { - } & \text { Traducción a la vista } \\
\text { - } & \text { Interpretación consecutiva }\end{array}$ \\
\hline $\begin{array}{l}\text { SUBORDINADO } \\
\text { SIMPLE }\end{array}$ & $\begin{array}{ll}\text { - } & \text { Doblaje } \\
\text { - } & \text { Traducción teatral para } \\
\text { - } & \text { Traduccena } \\
\text { - } & \text { Tradón de canciones cantadas } \\
\text { - } & \text { Traducción de comión de carteles } \\
\text { - } & \text { Trablicitarios } \\
& \text { y crucigramas }\end{array}$ \\
\hline $\begin{array}{l}\text { SUBORDINADO } \\
\text { COMPLEJO }\end{array}$ & $\begin{array}{ll}\text { - } & \text { Subtitulación } \\
\text { - } & \text { Supratitulación musical }\end{array}$ \\
\hline
\end{tabular}

Tabla 7. Modo traductor y principales modalidades de traducción (Hurtado Albir 1999)

Por su parte, la clasificación empleada en el Marco de Referencia Europeo únicamente establece diferentes modos de traducir en cuanto a la utilización del modo hablado o escrito, al igual que sucede con el resto de las actividades comunicativas contempladas. Esta clasificación actualmente recoge los descriptores que se detallan en la tabla siguiente aunque, como ya hemos mencionado antes, los descriptores referentes a este tipo de actividades se encuentran aún en fase de desarrollo. 


\begin{tabular}{|c|c|}
\hline \multicolumn{2}{|c|}{ MEDIATION } \\
\hline SPOKEN & WRITTEN \\
\hline Overall Interpretation & Overall Translation \\
\hline $\begin{array}{ll}\text { - } & \text { Informal Interpretation } \\
\text { - } & \text { Simultaneous } \\
\text { Interpretation at } \\
\text { Meetings, Conferences } \\
\text { - } \quad \text { Consecutive } \\
\text { Interpretation (e.g. } \\
\text { speeches, tours) } \\
\text { - } \quad \text { Glossing Signs, } \\
\text { Notices, Menus, etc. } \\
\text { - Summarising, Glossing } \\
\text { Gist (of articles etc.) } \\
\text { - } \quad \text { Paraphrasing Specialist } \\
\text { Texts for Others }\end{array}$ & $\begin{array}{ll}\text { - } & \begin{array}{l}\text { Informal Translation } \\
\text { of Personal Letters }\end{array} \\
\text { - } & \text { Literary Translation } \\
\text { - } & \begin{array}{l}\text { Exact Translation } \\
\text { (legal, commercial, }\end{array} \\
\text { scientific) }\end{array}$ \\
\hline
\end{tabular}

Tabla 8. Descriptores de las actividades comunicativas de mediación (Council for Cultural Co-operation 1996)

A la vista de los diferentes planteamientos clasificatorios, cabe profundizar acerca de nuestra propia posición con respecto a la traducción como medio de facilitación del aprendizaje del Inglés para Fines Específicos.

Las tareas de traducción cuya utilidad para la didáctica del Inglés para Fines Específicos consideramos aquí pertenecen (por exclusión) a la modalidad denominada 'traducción escrita', de acuerdo con la categorización de Hurtado Albir, y a su vez corresponden (de nuevo por exclusión) con el descriptor general 'exact translation (legal, commercial, scientific)' del repertorio de descriptores del Marco de Referencia Europeo. Esto es, se trata de tareas de traducción especializada.

Además de esto, siguiendo el enfoque marcadamente orientado hacia la acción del Marco de Referencia Europeo, estas tareas se relacionan con la competencia estratégica de los aprendices, así como con el procesamiento textual: 
Communication and learning involve the performance of tasks which are not solely language tasks even though they involve language activities and make demands upon the individual's communicative competence. To the extent that these tasks are neither routine nor automatic, they require the use of strategies in communication and learning. In so far as carrying out these tasks involves language activities, they necessitate the processing (through reception, production, interaction or mediation) of oral or written texts. [...]

Depending on the strategy adopted, the performance (or avoidance, postponement or redefinition) of the task may or may not involve a language activity and text processing (reading instructions for dismantling, making a telephone call, etc.). Similarly, a learner at school who has to translate a text from a foreign language (task) may look to see if a translation already exists, ask another learner to show what he or she had done, use a dictionary, try to work out some kind of meaning on the basis of the few words or structures he or she knows, think of a good excuse for not handing in this exercise, etc. (all possible strategies). For all the cases envisaged here there will necessarily be language activity and text processing (translation/mediation, verbal negotiation with a classmate, letter or verbal excuses to the teacher, etc.). (Council for Cultural Co-operation 1996)

Podemos observar que el concepto de estrategias comunicativas y de aprendizaje utilizado aquí es más abierto que el empleado por Pinto da Silva (v. 3.3.4), ya que en éste podemos observar cómo se tienen en cuenta las diferencias individuales de comportamiento estratégico. En este sentido, el Marco de Referencia Europeo prevé la manifestación de distintos estilos cognoscitivos de aprendizaje para cada grupo de aprendices, lo cual es consistente con un enfoque centrado en el aprendiz como sujeto activo del proceso de aprendizaje. Por otra parte, la traducción permite la utilización de tareas en las que este tipo de diversidad se manifiesta de forma palpable y, desde este punto de vista, esto la convierte en un medio adecuado para facilitar un aprendizaje de la lengua entendido, tal como señalaba Corder (v. 3.1), como un desarrollo orgánico que es único para cada aprendiz. En este sentido, su utilización puede ser especialmente aconsejable cuando se trata de grupos claramente heterogéneos, tal como suele ser el caso habitual de los cursos de Inglés para Fines Específicos en el entorno universitario español.

Por otra parte, si bien en el capítulo anterior situábamos la homogeneidad de los grupos de Inglés para Fines Específicos únicamente en las metas de los aprendices, a la vista de las consideraciones referentes al comportamiento estratégico y a los otros aspectos cognoscitivos que han sido expuestos a lo largo de este capítulo dudamos de que en el plano de lo real, es decir, en la propia fuente de observación que nos sirve asimismo para cotejar estas observaciones desde una posición teórica, incluso las metas del aprendizaje sean realmente homogéneas. 
Desde un enfoque que identifica al aprendiz como un individuo adulto y responsable, tal como el delineado por el Consejo de Europa para el entorno que consideramos aquí, la homogeneidad en las metas del aprendizaje es únicamente potencial pero no necesariamente cierta puesto que el establecimiento de las metas del aprendizaje depende de los propios aprendices, que son individuos autónomos, creativos, libres y distintos entre sí. La imagen de unas metas homogéneas es obviamente una falsa impresión si no viene avalada por un análisis riguroso de las necesidades, expectativas, conocimientos y actitudes de los aprendices. Se nos plantean entonces varias preguntas: ¿dónde queda entonces el margen para la generalización?, ¿hasta qué punto podemos transferir las características de un contexto de aprendizaje a otro nuevo?, ¿volvemos a la necesidad de establecer, para cada situación específica, en qué punto exacto de la línea continua entre lo general y lo específico nos vamos a situar?

Desde la didáctica teórica, lo que nos planteamos es hasta qué punto una descripción de los rasgos característicos de los cursos de Inglés para Fines Específicos como la de Giménez (1996) es transferible desde la situación particular del Instituto de Estudios Superiores de Córdoba (Argentina) al variopinto panorama que se dibuja en el horizonte del entorno universitario español. Nos preguntamos, por ejemplo, si los aprendices de este entorno reaccionan de igual modo o están motivados de la misma forma que los que Giménez (1996:234) describe: «ESP students, especially those who need English at work, are more likely to put into practice what they have learnt as soon as they leave their classrooms, reinforcing language errors through frequent practice».

En definitiva, nos preguntamos cuál o cuáles de todas las variables que participan en el desarrollo del proyecto educativo son susceptibles de presentar un menor grado de variación entre todos los proyectos. Cuáles, por tanto, son más versátiles para adaptarse a un mayor número de situaciones contingentes (lo cual, en el entorno del Inglés para Fines Específicos, implica una variabilidad intrínseca muy elevada) y tienen un mayor potencial para generar líneas didácticas afines en el entorno, más amplio, de la didáctica especial de las lenguas extranjeras.

Así, en una comparación entre distintos entornos de aprendizaje como la que hemos tratado, debemos tener en cuenta qué aspectos son idiosincráticos de la propia situación y distinguirlos de aquellos que son comunes a otros entornos distintos.

Por ejemplo, según algunos autores, un elemento que hay que tomar en consideración está consituido por las expectativas de los propios aprendices acerca 
de su aprendizaje. Subyace aquí la interpretación de que no es suficiente con que los aprendices adquieran los conocimientos o destrezas deseados, sino que además tienen que ser conscientes de ello: «It would seem that learning must not only take place, it must also apparently be seen to take place» (Swales 1984:15). Esto equivale a decir que, de un modo u otro, los aprendices deben tener algún tipo de convicción o ser conscientes de que se han aprendido algo nuevo. Es decir, es necesario el desarrollo de la metacognición.

En este sentido, como afirma Harris (1997:14), «language-learning classrooms are clearly affected by cultural expectations, particularly in terms of perceptions of progress». Si la necesidad de que el aprendiz tenga algún tipo de percepción acerca de su propio aprendizaje es común a todos los aprendices, se trata por tanto de un rasgo cognoscitivo que podemos tener en cuenta con independencia del entorno disponible o de las características de un proyecto en particular. Se trata de una característica del aprendizaje sobre la que podemos generalizar a pesar de que, como señala Harris, las manifestaciones de esa percepción den resultados diferentes en función del entorno cultural considerado:

In many countries, learning is still regarded as the digestion of a body of knowledge, and progress seen in terms of how much can be memorized and reproduced. This means that students' perceptions can clash with the procedural goals of communicative foreign language learning. These observations are borne out of surveys of students beliefs. Brindley (1984:97), in a study of adult migrant learners in Australia, found that most of them feel that 'learning consists of acquiring a body of knowledge'. Horwitz (1987:123) found that students of different cultural backgrounds see learning as the mastery of a series of language items, demonstrating a 'restricted view of language learning'.

While such expectations are traditionally associated with Far Eastern learners, students in many European countries (like Spain and Greece) appear to have similar expectations. While students who are learning in an Englishspeaking environment can constantly measure their progress in terms of language use, many of those studying in their countries of origin will have these attitudes towards learning constantly reinforced. For most secondary school and university students, foreign language study is a very small part of the curriculum, so can be affected by 'interference' from other subject areas. This can make it hard for students to shift from viewing progress in quantitative, declarative terms (performance/skills). The result is that many students become used to equate learning with mastery of grammar and vocabulary, as opposed to actual performance. (Harris 1997:14-15)

Harris (1997:15) va más allá aún al afirmar, asociando esta idea a Horwitz, que las expectativas que el aprendiz tiene sobre el aprendizaje pueden afectar a las estrategias de aprendizaje que utilizan los aprendices. En este sentido, las tareas de 
traducción son útiles para modificar las presuposiciones (y, por tanto, las expectativas) de los aprendices acerca de la lengua y del lenguaje.

Por otra parte, en el caso particular que nos ocupa en estos momentos, observamos que este objetivo es totalmente consistente con el enfoque teórico adoptado por el Consejo de Europa tal como se formula a través del Marco de Referencia Europeo.

Además de esto, desde una perspectiva teórica de la didáctica, nos parece una ventaja añadida conceder mayor relevancia en el proyecto educativo a los objetivos de la enseñanza que a las metas establecidas por los aprendices, con el fin de poder llegar a un grado aceptable de generalización de los aspectos que integran la didáctica del Inglés para Fines Específicos y la de las lenguas extranjeras. En otras palabras, los objetivos educacionales no presentan, ni siquiera potencialmente, la heterogeneidad que parece caracterizar los proyectos de enseñanza-aprendizaje de Inglés para Fines Específicos, tal como sucede con las metas del aprendizaje así como con el resto de variables que dependen de los aprendices. Este rasgo de los objetivos los hace más versátiles y con un mayor potencial para la didáctica teórica que, por ejemplo, el análisis de necesidades, el cual, desde nuestra perspectiva, supone un procedimiento con un escaso potencial para extraer conclusiones generalizables más allá de diferentes enfoques de categorización de las necesidades de los aprendices, si bien se trata de un procedimiento indispensable para asegurarse de que un proyecto educativo se adapta con eficacia a una situación concreta.

A lo largo del presente capítulo, nuestro centro de atención ha recaído sobre el aprendizaje y, en particular, sobre algunos aspectos dependientes del aprendiz. Hemos utilizado una noción de dinámica aprendiz que corresponde a un sujeto activo y adulto que es en buena medida responsable de su propio aprendizaje aunque, como señala Nunan (1995), esto no significa dar por sentado que las aspiraciones y presuposiciones de los aprendices acerca del aprendizaje de la lengua sean necesariamente las más acertadas:

It is a mistake to assume that learners come into the language classroom with a natural ability to make choices about what and how to learn. I believe there are relatively few learners who are naturally endowed with the ability to make informed choices about what to learn, how to learn it, and when to learn. [...] A learning-centered classroom carries learners toward the ability to make critical pedagogical decisions by systematically training them in the skills they need to make such decisions. Such a classroom is constituted with complementary aims. Whereas one set of aims focuses on language content, the other focuses on the learning process. Learners are therefore systematically educated in the skills and knowledge they will need in order to make informed choices about what they want to learn and how they want to learn. Rather than assuming that the learner comes to the learning arrangement with critical 
learning skills, the sensitive teacher accepts that many learners will only begin to develop such skills in the course of instruction. (Nunan 1995:134)

Considerando la distinción de Widdowson entre objetivos y metas del aprendizaje, podemos matizar las palabras de Nunan señalando que la didáctica de la lengua que sigue un enfoque centrado en el aprendiz y en el aprendizaje observa el establecimiento de objetivos educacionales centrados en el propio proceso de aprendizaje. Es decir, lo que para Nunan son 'complementary aims', bajo nuestra perspectiva se trata de objetivos educacionales.

A la vista de este tipo de objetivos, hemos analizado la relevancia de aquellos aspectos que se refieren al papel de la consciencia y del control del procesamiento del lenguaje para el aprendizaje. Este enfoque nos ha llevado a establecer como objetivo educacional más pertinente para la didáctica del Inglés para Fines Específicos el desarrollo de la capacidad del aprendiz, de acuerdo con la definición de capacidad de Widdowson (1983:106), que la interpreta como «the driving force behind both the acquisition and the use of language». Asimismo, hemos considerado la utilidad de la traducción para facilitar el aprendizaje de diversos tipos de subcompetencias comunicativas y, en general, como medio de facilitación de un aprendizaje que lleve a la adquisición de conocimientos de tipo procedimental, incluyendo tanto procesos (técnicas y estrategias) asociados a las actividades comunicativas en el entorno del Inglés para Fines Específicos, como actitudes, especialmente las que se relacionan con el comportamiento de los profesionales en contextos específicos asociados típicamente con el desarrollo de la actividad profesional. Además de esto, hemos sopesado tanto la pertinencia del objetivo educacional descrito como la utilidad de las tareas de traducción, en relación con un contexto educativo específico, cuyos presupuestos se recogen y describen en el denominado Marco de Referencia Europeo.

Creemos que el Marco de Referencia Europeo constituye un criterio sólido para poder establecer si el desarrollo de la capacidad del aprendiz puede constituir un objetivo educacional apropiado para los cursos de Inglés para Fines Específicos y, como consecuencia, podemos concluir que, puesto que este objetivo no presenta inconsistencias con respecto del Marco de Referencia Europeo, sino que es afín a su visión integral del proceso de aprendizaje, es posible establecer este objetivo de carácter global. Asimismo, concluimos que no sólo es posible hacerlo, sino también deseable, ya que lo que pretendemos que el aprendiz alcance a largo plazo mediante el logro de este objetivo redunda tanto en el 'modelo de profesional' al que aspira el aprendiz de Inglés para Fines Específicos, como al 'modelo de ciudadano europeo' 
que se dibuja en los proyectos de la Comisión Europea en materia de lenguas, tal como hemos esbozado en la última sección de este capítulo.

Por último, queremos hacer hincapié en que la pertinencia de un objetivo como el definido ha de establecerse de acuerdo con la concepción de lengua que el responsable del proyecto educativo utilice, así como en relación con la concepción subyacente que los aprendices manifiesten de la lengua en general y del Inglés para Fines Específicos en particular. Análogamente, la utilidad de las tareas de traducción ha de matizarse en función de la concepción fenomenológica de la traducción que se maneje, incluyendo qué se entiende por 'traducción especializada'. Por esta razón, y con el fin de detallar cuál es nuestra posición sobre estas cuestiones, en el capítulo siguiente centraremos nuestros esfuerzos en describir qué entendemos por lengua de especialidad y por traducción especializada. Además, teniendo en cuenta que en el presente trabajo las actividades comunicativas que reciben nuestra mayor atención son las actividades de mediación en su modalidad escrita, cuya relevancia viene avalada por su inclusión en el Marco de Referencia Europeo, abordaremos nuestra concepción lingüística de las lenguas de especialidad y de la traducción a través de una aproximación al lenguaje escrito. 


\section{La lengua de especialización: concepto y análisis}

\subsection{Introducción}

Desde que surgió el concepto de lengua para fines específicos tras la Segunda Guerra Mundial, la evolución en su conceptualización ha estado ligada a la evolución de la didáctica de las lenguas extranjeras y estrechamente asociada al desarrollo de la linguística, debido a la propia relación entre el concepto de lengua para fines específicos y el concepto de lenguaje. Las características específicas de la relación entre ambos conceptos han ido sufriendo variaciones no excluyentes, de modo que actualmente coexisten diversos modos de considerar qué es una lengua para fines específicos $\mathrm{o}$, como también es denominada, una lengua de especialización. Por lo tanto, si queremos responder adecuadamente a la pregunta ¿qué es una lengua de especialización? debemos explicar primero cuál es nuestra concepción acerca del lenguaje para poder ubicar convenientemente qué lugar ocupa.

Asimismo, es muy importante establecer la relación entre las aportaciones teóricas de la lingüística, así como las aportaciones descriptivas, y las aplicaciones que estos dos tipos de aportaciones tienen para la didáctica de las lenguas extranjeras. En nuestro trabajo, esta importancia se traslada concretamente a las características particulares que presenta la relación entre las teorías y las descripciones del lenguaje y la didáctica del Inglés para Fines Específicos, especialmente en cuanto a aquellos aspectos que son relevantes cuando consideramos las tareas de traducción como un medio de facilitación del aprendizaje. 
Por otra parte, la concepción del lenguaje que utilicemos debe cumplir el requisito de ser lo suficientemente comprehensiva como para dar cabida tanto a los fenómenos asociados a las lenguas para fines específicos como a la traducción. En este sentido, en primera instancia necesitamos un modelo de uso del lenguaje. Si, como indica Sánchez (2001:11), las dos tendencias más comunes en la historia de la lingüística han sido el prescriptivismo y el descriptivismo, podemos afirmar que nuestro concepto de lenguaje parte de una aproximación descriptivista. Dado que nuestro objetivo educacional es el desarrollo de la capacidad del aprendiz para utilizar el lenguaje, necesitamos un modelo que nos explique cómo es utilizado el lenguaje. Nos resulta mucho más útil, para poder plantear un proyecto de enseñanza-aprendizaje coherente con este objetivo, contar con los datos referentes a cómo es la lengua que se produce en los contextos de uso relevantes, que apoyarnos en un modelo prescriptivo sobre cómo debería ser utilizada de acuerdo con unos criterios arbitrarios de corrección.

Teniendo esto en cuenta, nos interesan como fuentes de información los trabajos elaborados a partir de estudios acerca del uso del lenguaje mediante el análisis de corpus y, especialmente, los que se realizan sobre el lenguaje cuyo uso se asocia con los ámbitos considerados más relevantes en este trabajo. Nos interesan particularmente, por tanto, los estudios centrados en el discurso científico, el técnico y el académico, tal y como se manifiestan en inglés y en español, dado que son las dos lenguas con las que trabajamos en las tareas de traducción.

Además de una concepción comprehensiva del lenguaje, necesitamos que dicha concepción permita dar cuenta de forma integrada de las tres dimensiones que vamos a considerar en relación con los fenómenos involucrados en la lengua para fines específicos y en la traducción. De acuerdo con el enfoque de Halliday (1978), estas tres dimensiones se refieren al lenguaje como comunicación, tanto en su dimensión social como en su dimensión individual y, teniendo en cuenta el modo como se produce la comunicación, también en su dimensión textual.

Para tratar aquellos aspectos que se suelen asociar con las lenguas de especialización, y en particular con los aspectos específicamente relacionados con el Inglés para Fines Específicos y con la traducción como fenómenos lingüísticos, en este capítulo vamos a fijarnos en dos centros de interés: el difuso concepto de lengua de especialización y el análisis del lenguaje, teniendo en cuenta tanto los parámetros relevantes como los diversos tipos de unidad analítica.

En la primera sección abordaremos el concepto de lengua de especialización desde distintas perspectivas. En este capítulo, la pregunta general 
sobre la que vamos a indagar es, precisamente, qué es la lengua de especialización. Existen diferentes aproximaciones a esta cuestión, por lo que la respuesta depende en gran medida del ángulo epistemológico en el que se sitúe el investigador y, por extensión al entorno del aula de Inglés para Fines Específicos, de la postura personal del profesor. Por tanto, abordaremos el concepto de lengua de especialización considerando dos posiciones diferentes que se relacionarán con lo que desde la didáctica se entiende por lengua para fines específicos. Asimismo, situaremos la lengua de especialización en relación con el concepto de restricción desde un ángulo más comprehensivo que el adoptado por Cabré (1993).

Presentaremos a continuación el modelo de uso del lenguaje de Halliday (1978) y daremos cuenta de los parámetros que este lingüista incluye en un modelo de uso del lenguaje.

En la tercera y última sección nuestra atención se dedicará a establecer la situación de la lengua de especialización dentro del modelo de Halliday y de otros modelos analíticos utilizados en el ámbito del Inglés para Fines Específicos, para lo cual nos detendremos en el concepto de género. Como concepto general, una lengua para fines específicos aglutina cualquier forma de comunicación lingüística que se asocia típicamente con un entorno profesional. No obstante, tal como ya apuntamos con anterioridad, en el contexto educativo contemplado en el presente trabajo, hemos considerado pertinentes las variedades identificadas como Inglés Científico, Inglés Técnico e Inglés Académico y, por lo tanto, nuestra argumentación referente al concepto de género y a otros tipos de unidad de análisis se desarrolla principalmente dentro de los límites de su aplicabilidad para estas tres variedades.

\subsection{Concepto y descripción de la lengua de especialización}

Una respuesta clásica a la pregunta acerca de qué enseñar en un curso de Inglés para Fines Específicos suele ser 'el lenguaje específico del campo temático'. Para el aprendiz, habitualmente esto se refiere principalmente al conjunto de términos que asocia con los conocimientos específicos de su campo de especialización, mientras que para el profesor la respuesta tiene unas implicaciones que son más o menos complejas según el modelo de idealización del lenguaje que utilice. En cualquier caso, independientemente de la concepción lingüística de la que se parta para abordar los contenidos del curso de Inglés para Fines Específicos, 
lo cierto es que siempre se utiliza una idealización de algún tipo acerca de por qué elementos está constituida y cómo funciona la lengua sobre la que recaerá el interés del curso.

Para poder analizar en profundidad el concepto de lengua de especialización que utilizamos en este trabajo, debemos tratar dos cuestiones previas. La primera se refiere precisamente a la confusión conceptual que se ha detectado en el entorno de las lenguas para fines específicos en cuanto a la terminología empleada y a los propios conceptos de lenguaje y de lengua de especialidad, que se utilizan de forma variopinta y en ocasiones indiscriminada ${ }^{1}$. El segundo aspecto que trataremos en detalle se refiere a las diferentes aproximaciones que se suelen emplear para describir la lengua de especialización. De nuevo nos encontramos con que no sólo coexiste una variedad de enfoques, a los cuales nos referiremos a partir de la clasificación que emplea Lankamp (1988), sino que también observamos que las descripciones de la lengua utilizada por los profesionales para comunicarse entre sí se construyen a partir de muy diversos métodos de análisis y se centran en aspectos muy variados y diferentes entre unos análisis y otros, por lo que es prácticamente imposible formarse una idea general del panorama actual en lo que al estado de la descripción de las lenguas de especialización se refiere.

En el entorno de la didáctica de las lenguas para fines específicos, el léxico especializado suele ser en numerosas ocasiones identificado, no sólo por el aprendiz sino también por el profesor de Inglés para Fines Específicos, como el área de conocimientos más importante de entre todos los aspectos implicados en las lenguas de especialidad. Paralelamente, en la didáctica de la traducción también se suele prestar una atención especial a lo que Rabadán denomina 'tecnolecto', y que describe como un tipo de variación de uso de la lengua (Rabadán 1991a:90) que presenta unas características particulares:

A menudo se identifica el tecnolecto con un campo terminológico específico debido a que el vocabulario es, precisamente, el factor que distingue con mayor claridad estas variedades. Las terminologías propias de campos de estudio determinados presentan ciertas características que nos ayudarán a bosquejar el esqueleto teórico de un tecnolecto. El fin de un texto marcado por la dominante campo es informar con precisión y economía a un lector que dispone de un volumen de experiencia extralingüística suficiente para descodificarlo. La complicidad explícita que aquí existe entre el emisor (autor

\footnotetext{
1 Lerat (1997:17) pone de relieve cómo en este ámbito se suelen ignorar las diferencias conceptuales entre las expresiones 'lengua' y 'lenguaje', que en inglés suelen ser confundidas bajo la expresión genérica 'language’.
} 
o traductor) y el lector determina algunos de los rasgos de las terminologías de los TPE (textos para propósitos específicos): a) precisión rigurosa en los significados, esto es, una correspondencia casi absoluta entre el sistema conceptual del campo y su expresión lingüística; b) alto grado de normalización, que resulta en una mayor economía lingüística, y c) uniformidad lógica de los conceptos y sus formas de expresión en las distintas lenguas. (Rabadán 1991a:90)

La terminología, como identificación y simplificación del tecnolecto, suele tener una gran presencia en el programa de contenidos de muchos cursos de lenguas para fines específicos. Esto suele conllevar que la concepción subyacente de lenguaje a partir de la que se elabora el concepto de lengua de especialización corresponda a un concepto centrado en el léxico, más que a una perspectiva general sobre el funcionamiento del lenguaje. En este sentido, una concepción de este tipo suele estar más próxima al objeto de estudio de la lexicología o de la terminología y, desde esa perspectiva, es fácil adoptar un enfoque limitado sobre otros fenómenos lingüísticos diferentes a los involucrados en el nivel semántico de las palabras ${ }^{2}$.

Probablemente, la razón del interés por los aspectos léxicos de la lengua de especialización es que el análisis de la lengua que se va a enseñar comienza por la observación de los modos de representación del conocimiento en las muestras que se eligen para analizar. Ahí, el léxico de baja frecuencia, las palabras o las secuencias de palabras con las que nos topamos en raras ocasiones, resulta más llamativo que otros mecanismos que son comunes a otras muestras de lenguaje de otros contextos de uso diferentes. En cualquier caso, pensamos que el interés por el léxico especializado mostrado en el ámbito de las lenguas para fines específicos justifica que sea tenido en cuenta en nuestra aproximación conceptual a la lengua de especialización, ya que creemos que contribuye al asentamiento y pervivencia de una concepción restringida de ésta.

\subsubsection{Divergencias conceptuales: aproximación didáctica, aproximación terminológica y aproximación lingüística}

\footnotetext{
Algunos autores utilizan la expresión 'lengua para fines específicos' (u otras similares) y la expresión 'lenguaje especializado' (o 'lengua de especialización' u otras similares) indistintamente, mientras que otros asocian la

${ }^{2}$ Creemos que la posición de terminólogos como Sager, que sitúa la terminología como una disciplina próxima a la lexicología pero fuera de la lingüística (Sager 2001), contribuye a que se dé un enfoque de este tipo.
} 
primera denominación con el ámbito de la enseñanza de lenguas y las otras denominaciones con el ámbito de la terminología (v. Cabré 1993:132). Para nosotros, el hecho de que coexistan diversas expresiones para referirse a este concepto es un indicio de su falta de claridad (Santiago Guervós 1999).

Está comúnmente asumido que el concepto de lengua para fines específicos surgió en el ámbito de la enseñanza de lenguas extranjeras y, por consiguiente, la denominación de 'lengua para fines específicos' apela a la finalidad de la adquisición de ésta. Es decir, esta denominación indica que la lengua se aprende 'no porque sî', como en el caso de la 'lengua general', sino porque existe una razón específica que además está ligada a una situación concreta de uso de la lengua. Desde una aproximación didáctica, por tanto, no podemos desligar el concepto de lengua del concepto de didáctica de la lengua. Es decir, la lengua para fines específicos se define desde esta aproximación como la lengua que se enseña o aprende con el fin de que el aprendiz sea capaz de comunicarse en situaciones específicas relacionadas con ámbitos profesionales o expertos en las que se producen, transmiten y reciben conocimientos especializados, en definitiva, en las situaciones en las que se construye el conocimiento especializado.

Por otra parte, para algunos profesores de lenguas para fines específicos, la lengua de especialidad consta fundamentalmente de un conjunto de expresiones que sirven para denominar las nociones que forman un área de conocimiento muy tematizada $\mathrm{y}$, en este sentido, su concepción de la lengua se puede considerar restrictiva, puesto que su definición de la lengua se basa en una definición de la terminología ${ }^{3}$.

Precisamente el afán por definir cómo es la lengua que se utiliza en este tipo de situaciones determinadas por el grado de especialización de sus participantes y de los conocimientos que se intercambian es el que nos lleva a la segunda denominación, la de 'lengua de especialización', 'lengua especializada' o 'lengua de especialidad'. Con esta denominación, el concepto se desliga del ámbito de la didáctica para considerar su situación en el sistema lingüístico. La lengua de especialización forma parte del sistema lingüístico, es una parte de la lengua. Es, además, una parte de la lengua que, por un lado, designa conceptos especializados, es decir, se utiliza para la representación de los conocimientos y, por otro, sirve para que los especialistas se comuniquen esos conocimientos entre $\mathbf{s i ̂}^{4}$. En este sentido,

\footnotetext{
${ }^{3}$ Véase la definición de 'terminología' de Lerat (1997:17).

${ }^{4}$ No existe unanimidad acerca de que la comunicación especializada sea únicamente la que se produce entre expertos. Según el paradigma utilizado, también se suele incluir dentro de la
} 
cumple lo que Givón denomina las dos megafunciones del lenguaje humano, a saber, la representación del conocimiento y la comunicación del conocimiento representado (Givón 1999:21). La pregunta que se plantea, por tanto, no es si se trata o no de una lengua, sino más bien de qué parte de la lengua se trata.

Desde una perspectiva abierta como la que adoptamos en este trabajo, creemos que el hecho de referirse a la lengua desde un enfoque didáctico no justifica la utilización de una expresión diferente cuando consideramos la lengua desde otras aproximaciones no didácticas, por mucho que los aspectos relevantes para la didáctica no sean pertinentes desde otras aproximaciones a la lengua. En este sentido, la opción lógica sería elegir una de las denominaciones que suelen ser utilizadas. No obstante, no pensamos que este trabajo constituya el marco adecuado para resolver esta cuestión, aunque sí lo sea para plantear su existencia. En este caso, nos parece que la actitud más prudente en aras de la claridad de nuestra exposición es la de utilizar la expresión 'lengua especializada', 'de especialidad' o 'de especialización' cuando nos estemos refiriendo al propio sistema o conjunto de subsistemas lingüísticos y su funcionamiento, es decir, «the particular language of a profession or groups of professions, or an academic discipline» (Lankamp 1988:16), y 'lengua para fines específicos' cuando estemos haciendo mención al enfoque pedagógico de la lengua como meta de la enseñanza, en el sentido de «the curricular requirements of potential learners in language courses geared to a profession, a group of professions, or an academic discipline» (Lankamp 1988:16).

A pesar de que para Hutchinson y Waters (1987) el Inglés para Fines Específicos no conlleva ningún tipo especial de lenguaje, en su enfoque estos autores se centran tanto en los aprendices y en el contexto de aprendizaje como en la lengua que los aprendices necesitan conocer. Se parte de la base de que los resultados del análisis de necesidades podrán ser utilizados para establecer con exactitud cuáles serán los contenidos que serán incluidos en el curso y cuáles serán los medios más apropiados para tratar esos contenidos. Podemos afirmar que existe, por tanto, una necesidad de establecer qué se entiende por la lengua que los aprendices necesitan aprender, ya que en el entorno del Inglés para Fines Específicos se suele partir del supuesto de que el objetivo no es toda la lengua, al contrario de lo que ocurre en el entorno del Inglés General.

comunicación especializada la que se produce entre los expertos y otros receptores no expertos (véase, por ejemplo, Iglesias Iglesias 1999), del mismo modo que en ocasiones se consideran como textos especializados los textos cuya función predominante es la divulgación de la ciencia (v. 5.1). 
Según citan Dudley-Evans y St. John (1998), Strevens entiende el Inglés para Fines Específicos como una forma de enseñanza de la lengua inglesa que reúne una serie de características, cuatro características 'absolutas' y otras dos 'relativas'. Entre estas características se incluye que los contenidos del Inglés para Fines Específicos siempre se relacionan con unas disciplinas, actividades u ocupaciones específicas, y que el interés se centra en la lengua relevante para esas disciplinas, actividades u ocupaciones (v. Strevens 1988). No obstante, Dudley-Evans y St. John (1998:3) plantean la objeción de que la concepción de Strevens del Inglés para Fines Específicos puede llevar a confusión, ya que al relacionar el Inglés para Fines Específicos con un cierto tipo de contenidos, se puede contribuir a perpetuar la falsa impresión de muchos profesores de que el Inglés para Fines Específicos está necesariamente ligado a un contenido temático en particular.

Se puede intuir cuán extendida está esta presuposición en todo el ámbito de la didáctica de las lenguas para fines específicos si nos atenemos a lo habitual que resulta encontrarse con proyectos educativos de este entorno en los que el mayor peso de los contenidos recae sobre el léxico, la adquisición de vocabulario y, especialmente, la terminología. Podemos afirmar también que esta presuposición va más allá de las consideraciones didácticas y trasciende al propio concepto de lenguaje que subyace a muchos análisis del discurso especializado. Y lo que es más, este modo de abordar la lengua de especialización, que Lankamp (1988) denomina 'enfoque terminológico', parece ser el más extendido en los estudios sobre lenguas de especialización realizados por expertos provenientes de los propios campos de especialización analizados, lo cual nos lleva a la conveniencia de tratar el concepto de lenguaje que se está utilizando en los análisis de las lenguas de especialización, así como en el ámbito del aula de Inglés para Fines Específicos, en términos comparativos entre una aproximación terminológica y una aproximación lingüística a la lengua de especialización.

Desde una perspectiva didáctica sobre la lengua de especialización, el tipo de información que a los investigadores de las lenguas para fines específicos les interesa obtener se relaciona con «registers, genres and associated language that students need to be able to manipulate in order to carry out the activity [they need to master]» (Dudley-Evans y St. John 1998:4).

Las palabras de Dudley-Evans y St. John son un reflejo de cómo se aborda el conocimiento sobre la lengua en este campo. En este sentido, la información lingüística que se maneja en el ámbito de las lenguas para fines específicos suele estar generada a partir de un proceso de selección de la lengua relevante en el que 
en primer lugar se elige el material lingüístico a partir del cual se va a extraer la información. Este material tradicionalmente ha consistido en muestras de lenguaje escrito, tomadas como ejemplos de lo que Rabadán (1991a:90) denomina 'textos para propósitos específicos', sobre las que se han utilizado diversos modelos analíticos.

A medida que se ha ido abordando el desarrollo de estudios descriptivos acerca de la lengua utilizada en distintos entornos de la comunicación y en distintos contextos sociales, se han ido acuñando también distintos modos de analizar la lengua como objeto de estudio en el ámbito de los campos relacionados con el lenguaje. Si bien no existe unanimidad acerca de qué modelo analítico utilizar, situación producida precisamente por la utilización de diferentes conceptos de lengua, más adelante trataremos con mayor profundidad el concepto de registro y el de género, ya que son los más utilizados en los análisis del discurso especializado y del Inglés para Fines Específicos, en relación con la utilización de diferentes modelos de análisis (v. 4.3.1).

Para la terminología, una lengua especializada se define como un subconjunto de la lengua general y se caracteriza pragmáticamente mediante tres variables: la temática, los usuarios, y las situaciones comunicativas (Cabré 1993:139). En esta caracterización subyace la convicción de que los términos no pueden ser descritos ni estudiados de forma aislada, sino en relación con su contexto de realización, ya que siempre se crean y utilizan en contexto y no en el vacío. Según Cabré, esto significa que la lengua de especialización únicamente se puede caracterizar pragmáticamente de forma adecuada mediante la conjunción de los tres factores mencionados.

Siguiendo este planteamiento, podemos afirmar entonces que ni la temática ni ningún otro de los factores mencionados sirve de forma aislada para la caracterización de la lengua de especialización, en el sentido de que la mera aparición en un texto de un término como 'paleontológico', por ejemplo, no constituye necesariamente una prueba de que se trate de un texto especializado (en el Anexo B reproducimos un texto auténtico en el que aparece el término aludido y cuya clasificación como texto especializado depende en gran medida del concepto de texto especializado que se aplique). Del mismo modo, tampoco podremos deducir que se está empleando una lengua especializada en una situación determinada por el mero hecho de que los interlocutores sean especialistas en epigenética. Análogamente, en nuestro enfoque acerca de la didáctica de las lenguas para fines específicos, la temática no justifica por sí sola la caracterización de una 
lengua de especialización y por tanto no debe ser tomada sino en relación con la situación específica en la que el lenguaje es utilizado por los profesionales para comunicarse entre sí, además de otros factores involucrados en el uso del lenguaje, que veremos más adelante.

Sager define la terminología como «el estudio y el campo de actividad relacionado con la recopilación, la descripción y la presentación de términos, es decir, los elementos léxicos que pertenecen a áreas especializadas de uso en una o más lenguas» (Sager 1990:21). Asimismo, considerando la base semántica de la terminología, este autor distingue las tres dimensiones, definidas a continuación, que constituyen diferentes aproximaciones al estudio de la terminología:

- dimensión cognitiva, que trata en general la relación entre las formas lingüísticas y los contenidos conceptuales

- dimensión lingüística, que se centra principalmente en los procesos de nominalización

- dimensión comunicativa, que analiza los términos desde el punto de vista de su eficacia funcional y su normalización; es decir, en relación con el uso que se les asigna dentro del sistema social

No obstante, hay que hacer hincapié en que los terminólogos están interesados en el lenguaje principalmente desde el punto de vista de lo que es inventariable y uniforme. Así, se aborda el estudio de los términos desde una perspectiva en la que la referencialidad del léxico aparece categorizada intrínsecamente entre dos posibles opciones, o bien una referencia general o bien una referencia especial, y el propio léxico es contemplado como un conjunto limitado compuesto por un número finito de elementos:

El léxico de un lenguaje especializado refleja las características de organización de la disciplina mediante un intento de suministrar tantas unidades léxicas como conceptos convencionalmente establecidos existan en el subespacio, y mediante la restricción de las referencias de cada unidad léxica dentro de una región bien definida. El léxico de un lenguaje especializado, además de contener un gran número de elementos dotados de la propiedad de la referencia especial, también contiene elementos de referencia general que normalmente no parecen ser específicos de una disciplina o disciplinas y cuyas propiedades referenciales son uniformemente vagas o generalizadas. Los elementos caracterizados por una referencia especial dentro de una disciplina son los «términos» de esa disciplina, y colectivamente forman su «terminología»; aquellos que funcionan como referentes generales dentro de una variedad de sublenguajes simplemente se llaman «palabras», y la totalidad forma el «vocabulario».

Puesto que el número de elementos léxicos dentro de una lengua es finito, puede que algunos elementos doblen su función de tal forma que una 
palabra funcione como término en distintos lenguaje especializados (por ejemplo, «ruido» en la teoría de la comunicación). (Sager 1990:42-43)

Como se puede ver, el interés de los terminólogos se centra particularmente (y en muchos casos exclusivamente) en «los elementos caracterizados por una referencia especial» dentro del repertorio disponible en una lengua. En este sentido, su objeto de estudio es mucho más restringido que el de la lingüística, en cuanto que el interés de ésta recae en el lenguaje desde una perspectiva global. Por otra parte, identificar terminología con lengua de especialización presenta serias dificultades en el entorno de la didáctica de las lenguas para fines específicos, que están relacionadas con la incapacidad para justificar la elección de la parcela de lenguaje que se presenta como especializado y de los elementos que supuestamente la componen. Por ilustrar este punto con un ejemplo, podemos citar el caso de un manual de español comercial publicado en España en 1998 donde el autor incluye al final de la obra un glosario elaborado con los términos utilizados en el manual, en el que se excluye explícitamente el léxico de uso no específico. No obstante, en el glosario se pueden encontrar, entre otras, las expresiones léxicas 'lista', 'saco', y 'sobre'. Es obvio que estas expresiones se recogen en el glosario porque han aparecido en los textos utilizados en el manual pero ya no es tan obvio hasta qué punto se puede afirmar que se trate de términos pertenecientes al denominado español comercial y no de palabras elegidas a causa de un aspecto particular de su significado potencial.

A nuestro juicio, el objeto de estudio de la terminología es demasiado reducido para cubrir las necesidades de un proyecto de enseñanza-aprendizaje de una lengua para fines específicos como el contemplado aquí, donde hay que abarcar muchas de las complejidades que presenta el lenguaje en uso más allá de los mecanismos específicos de nominalización, conceptualización y referencia de una lengua en particular. Precisamente son estas complejidades las que hacen necesario que nos basemos en una teoría lingüística de carácter general. Pensamos en una teoría general sobre el lenguaje que, además de aglutinar todos los aspectos involucrados en el lenguaje en uso, nos permita centrarnos tanto en aspectos locales, como el uso de un término en un texto dado, como en aspectos de alcance y repercusiones mucho más amplios, tales como los involucrados al considerar todo un género. Una teoría general como ésta podrá dar cuenta de cómo se utiliza el lenguaje para construir, negociar, y comprender significados, y en ella la relación entre significado y lenguaje ocupará una posición central. En nuestro enfoque, esta relación se contempla como una relación dialéctica y dinámica en la que el lenguaje 
no es tomado como una simple reproducción especular de una (la) realidad objetiva, sino que más bien consideramos, como Meix Izquierdo, que la propia relación del individuo con su entorno es de naturaleza dialéctica:

Ni el significado ni la imagen reflejan una realidad en-sí y establecida de manera definitiva, sino que la relación cognitiva del ser humano con su medio implica a ambos recíprocamente en un proceso dialéctico de interacción en el que los términos «interior» y «exterior» constituyen los polos de una relación dinámica en la que ambos se apoyan y contraponen sin cesar. (Meix Izquierdo 1993:15)

Asumimos, además, que el lenguaje no sólo es un medio a disposición del individuo, en tanto que sujeto social, sino que forma parte activa de esta relación dialéctica entre el individuo y su entorno social, contribuyendo inherente y radicalmente a los procesos de socialización de éste ya desde su infancia, así como a la creación y cambio de los valores sociales vigentes en cada momento en cada comunidad sociocultural y, por consiguiente, de las normas vigentes en las comunidades profesionales. Es en este sentido en el que volvemos a insistir, siguiendo a Hutchinson y Waters y a otros autores, en que el Inglés para Fines Específicos es más un modo de enseñar la lengua, que un tipo de lenguaje específico. Por tanto, si desde una perspectiva pragmática hablamos de 'lengua especializada' cuando consideramos la lengua natural como un «instrumento de transmisión de conocimientos especializados» (Lerat 1997:17), entonces la lengua especializada que se quiere enseñar será la que corresponde con aquella que permita a los aprendices transmitir y recibir información y comunicarse con éxito en los entornos especializados que se asocian con su futura profesión.

Pero la lengua que permite comunicarse en contextos profesionales es, realmente, toda la lengua. Es decir, es el sistema lingüístico el que constituye una herramienta de comunicación, el lenguaje como sistema de comunicación, y su realización concreta como lengua particular, y no sólo una parte del sistema. La función específica de la terminología en la comunicación en entornos especializados no está completamente determinada pero, en cualquier caso, como dice Lerat, para poder comunicarnos utilizamos recursos ordinarios, es decir, recursos propios de la lengua como actualización del sistema o conjunto de sistemas lingüísticos, que están asociados con la comunicación en general y no con un uso específico: «una lengua especializada no se reduce a una terminología: utiliza las denominaciones especializadas (términos) y también los símbolos no lingüísticos en enunciados que utilizan los recursos ordinarios de una lengua concreta» (Lerat 1997:18). 
Desde nuestra perspectiva, la especialización del entorno donde se produce la comunicación es entendida en un sentido semiótico como el nivel de dificultad para comprender lo que sucede en la comunicación en relación con las características particulares de los participantes. Pero este nivel de dificultad para comprender no está asociado exclusivamente con los profesionales, sino que se trata de un concepto relativo en el sentido de que hay una relación directa entre las dificultades de comprensión en la comunicación y la afinidad o familiaridad entre los participantes y el entorno o la situación. A su vez, cuanto mayor es esta afinidad, el discurso que se produce en esa situación típicamente se sustenta cada vez más en los conocimientos compartidos entre los participantes, de tal modo que puede resultar críptico para otras personas que no tienen afinidad con esa situación comunicativa. Es importante llamar la atención sobre el hecho de que la utilización de la terminología es sólo uno de los múltiples aspectos del discurso que se asocia típicamente con una situación en particular, tal como nos muestra la sociolingüística, si bien Sager señala que el uso de la terminología se relaciona estrechamente con el estado de conocimientos especializados del hablante:

Sin duda, los términos sólo se utilizan como tales si el usuario ya posee la configuración del conocimiento que determina el papel del término en un sistema estructurado. El caso límite de esta restricción es la necesidad de que el término nuevo se aprenda a la vez que se adquiere el nuevo conocimiento, por ejemplo, a través de los libros de texto; un término adquirido sin tener conciencia de la configuración convencional de conocimiento a la que se refiere es inútil comunicativamente. (Sager 1990:43)

De un modo análogo al de los terminólogos cuando utilizan como parámetros la temática, los usuarios y las situaciones comunicativas para describir pragmáticamente un lenguaje de especialización, pero desde una perspectiva más amplia que la adoptada por la terminología sobre el lenguaje, podemos describir una situación lingüística como diferente de otra basándonos en tres aspectos generales. Halliday (1978:31), en su concepción tripartita del lenguaje, se refiere a estos aspectos describiéndolos como «what is actually taking place», «who is taking part» $\mathrm{y} \ll$ what part the language is playing».

No obstante, al contrario de lo que ocurre con la terminología, el propósito de la lingüística para discriminar entre unas situaciones y otras no es el de poner de manifiesto los rasgos diferenciadores de una situación particular frente a otras para construir una tipología de situaciones, sino que más bien persigue determinar qué hace que el lenguaje varíe entre ellas y en qué consisten esas variaciones. En este sentido, la finalidad del análisis del lenguaje en uso es dar cuenta de la variación 
lingüística, con el objetivo de poder describir qué significados y expresiones son más probables en un registro determinado. Desde esta perspectiva, las tres variables a las que se refiere Halliday determinan de forma conjunta «the range within which meanings are selected and the forms which are used for their expression» (Halliday 1978:31). Así, cuando los terminólogos se preguntan ¿qué términos aparecen característicamente en una situación comunicativa en particular?, los lingüistas más bien se preguntan ¿qué recursos semánticos (de qué se habla y cómo se dice) asocian los miembros de una comunidad determinada con una situación típica?

Siguiendo este planteamiento, nuestra perspectiva acerca de la lengua de especialización tampoco implica una identificación total entre la lengua general y aquella. Es decir, sí pensamos que es posible y provechoso estudiar los rasgos que caracterizan la lengua utilizada en un contexto profesional específico. Sin embargo en nuestra perspectiva acerca del lenguaje, próxima a la de Halliday (1978), subyace una concepción de lenguaje restringido diferente a la utilizada por los terminólogos, tal como veremos a continuación.

\subsubsection{La lengua de especialización como restricción de la lengua general}

Aunque uno de los rasgos que más típicamente se asocian con los lenguajes especializados sea, precisamente, la diversidad existente entre ellos en cuanto a las características específicas de sus temáticas, usuarios y situaciones comunicativas, Cabré menciona un «elemento relevante que tendería a justificar la unidad del lenguaje especializado por encima de su diversidad» (Cabré 1993:147). Se trata de la facilidad para la comunicación intercultural que muestran los especialistas del mismo campo de conocimiento cuando se comunican entre sí en diferentes lenguas, y que Cabré describe del siguiente modo:

Parece bastante evidente que el especialista de una determinada materia es capaz de entender con relativa facilidad textos de su especialidad expresados en otra lengua, aunque sea incapaz de mantener en esa misma lengua una conversación oral sobre un tema banal o de entender una pregunta relativa al mundo cotidiano. La respuesta a esta situación debe buscarse en las unidades y reglas del juego controladas que poseen los lenguajes de especialidad, con carácter internacional y a menudo establecidos voluntariamente por sus usuarios. Esos elementos -junto a la restricción temática- facilitan la intercomprensión. Cuanto más especializado es un lenguaje más restringido es el número de usuarios, y más internacionales resultan sus unidades y sus reglas. 
Esta circunstancia, que no se da en la lengua común, constituye un factor que permite diferenciar el lenguaje general respecto del especializado, y un factor de unión de los lenguajes especializados entre sí. (Cabré 1993:147)

Podemos pensar que ese subconjunto está determinado por el propio sistema lingüístico en cuanto que sólo ciertos elementos del sistema pertenecen a dicho subconjunto. Siendo éste el caso, los especialistas de una determinada materia serían capaces de entender textos de su especialidad expresados en otra lengua o de entenderse entre ellos aunque tuvieran una limitada competencia comunicativa por una cuestión de probabilidad estadística. Es decir, la probabilidad de toparse con un término desconocido será mucho menor que en la comunicación no especializada si, como dice Cabré, una mayor especialización en el lenguaje significa un número de usuarios más restringido, y unas unidades y reglas más internacionales: cuanto más reducido estadísticamente sea el subconjunto de expresiones y significados probables, más fácil resultará controlar la comunicación especializada.

Para Cabré, la facilidad relativa del especialista para comprender textos de su campo producidos en otra lengua es una consecuencia de las características específicas de los lenguajes especializados, más que de la eficiencia de los propios especialistas para comunicarse entre sí. En términos generales, según este planteamiento, el Inglés para Fines Específicos sería una denominación genérica utilizada para aglutinar las formas características de comunicación lingüística en ciertos entornos profesionales. Esta perspectiva se basa, fundamentalmente, en la presuposición de que los lenguajes especializados son restringidos en el sentido de que poseen características idiosincráticas distintas de las de la lengua común. Así, Cabré define la relación entre una lengua de especialización, el lenguaje general y la lengua común del siguiente modo,

Los lenguajes de especialidad están en relación de inclusión con respecto al lenguaje general y en relación de intersección respecto de la lengua común, con la que comparten características y con la que mantienen una relación de trasvase constante de unidades y convenciones. (Cabré 1993:140)

Pero la restricción de la lengua de especialización se refiere aquí a las características particulares que adoptan las variables que, como ya hemos mencionado, Cabré utiliza para describir un lenguaje de especialización: la temática, los usuarios y las situaciones comunicativas.

En un sentido estricto, esta restricción se interpreta como una simplificación, ya que el objetivo de la descripción consiste en poner de manifiesto lo que hace que ese lenguaje sea diferente del lenguaje general y de la lengua 
común, en caracterizarlo a través de lo que lo hace distinto. Así, entendemos que una lengua de especialización caracterizada mediante la enumeración de sus rasgos distintivos y la exclusión de sus rasgos comunes presenta una descripción incompleta porque corresponde a una idealización simplificada del lenguaje. Al caracterizar los lenguajes de especialización únicamente mediante sus rasgos distintivos se corre el riesgo de esbozar una mera caricatura de las lenguas de especialidad. Dado que el objetivo de la terminología se centra en una parcela bien delimitada del lenguaje (específicamente, los términos de una lengua, así que el área de interés inmediata es el léxico), puede que las repercusiones de tomar los lenguajes de especialización como compendios de léxico más o menos característico de un ámbito profesional no sean muy palpables, pero es evidente que las consecuencias son muy diferentes en el caso de la didáctica especial de las lenguas para fines específicos. Como mínimo, la utilización en el aula de una idealización simplificada del lenguaje contribuye a fomentar en los aprendices la confusión entre un compendio de conocimientos léxicos y el propio lenguaje de especialidad, que posee todas las complejidades propias de su condición de fenómeno lingüístico de comunicación y producción, transmisión y recepción de conocimientos ${ }^{5}$.

En su modalidad escrita, un caso extremo de lenguajes restringidos que corresponden a este tipo de idealización simplificada está representado por los denominados 'lenguajes controlados', que Hartley y Paris definen así:

These are stringent sets of writing rules or guidelines designed to prevent authors from introducing ambiguities into their texts, and they are increasingly used in the commercial world for authoring technical documents such as maintenance and user manuals. Very often these documents then serve as the source from which translations are produced into a large number of target languages. (Hartley y Paris 2001:307)

A pesar de las dificultades que señalan estos autores para ofrecer descripciones completas de los lenguajes controlados, debido a que la mayoría de ellos no son de dominio público, Hartley y Paris (2001) ofrecen un esbozo de rasgos característicos a partir de algunas descripciones parciales disponibles de lenguajes controlados basados en la lengua inglesa.

Según estos autores, una buena parte del tiempo que se emplea en la creación de un lenguaje controlado está dedicada a la definición del lexicón, cuyo tamaño a su vez reflejará la complejidad del dominio que el lenguaje controlado

\footnotetext{
${ }^{5}$ Por esta razón De Beaugrande (1997:325) señala que una lengua para fines específicos es «a "fuzzy" system with a doubtful status in "mainstream linguistic theory"».
} 
pretende cubrir. Además de esto, como uno de los objetivos de estos lenguajes es evitar la ambigüedad en la información, cada entrada en el lexicón se define con un único sentido y mediante una única forma con el fin de eliminar la polisemia y la homografía. Otra de las reglas léxicas aparentemente comunes a los lenguajes controlados basados en el inglés, y que de nuevo persigue evitar la ambigüedad, está constituida por la prohibición de utilizar «clusters of more than three nouns» (Hartley y Paris 2001:311), de tal modo que, si esto sucede, el texto deberá ser revisado como se sugiere en el siguiente ejemplo de Farrington citado por Hartley y Paris (2001:311):

Texto:

Insert the forward strut rear angled needle roller bearing housing.

Texto revisado:

Insert the housing of the rear-angled needle-roller bearing on the forward strut.

Si comparamos esta regla de producción con muestras auténticas de discurso científico y técnico, se puede esperar que exista un desfase entre el modo de funcionamiento propuesto por los lenguajes controlados y el comportamiento de la lengua real. Por ejemplo, Dixon y Bortolussi (2001:14) señalan lo siguiente en relación con la presencia de ambigüedad en los textos: «even non-fiction documents are prey to problems of ambiguity. For example, legal documents such as treatises or constitutions are continually subjected to a process of interpretation in which scholars debate what might have been intended by the authors».

A este respecto, nosotros prestamos especial atención a las variedades de inglés relevantes para este trabajo desde un punto de vista descriptivo, y no prescriptivo como el que emana de los lenguajes controlados. Es decir, el objetivo que nos lleva a trazar una descripción de las variedades mencionadas no es la de proponer cómo debe ser la lengua que tienen que producir los aprendices en el aula en el sentido de establecer unas directrices como las de los lenguajes controlados, sino más bien mostrar cómo es la lengua que los profesionales producen, cómo hacen para expresar lo que quieren transmitir, con qué dificultades se enfrentan y qué resultados obtienen, cuándo se comunican con éxito.

Por otra parte, debemos recalcar que los lenguajes controlados, tal como se caracterizan según Hartley y Paris, por una parte responden a una necesidad real de comunicarse de forma eficaz, y por otra, presentan un grado de elaboración que exige al usuario los conocimientos necesarios para poder seguir reglas como ésta: «use connecting words to join connecting sentences that contain related thoughts», o 
bien «keep procedural sentences as short as possible (20 words maximum) [sic]» (Hartley y Paris 2001:312). Este último aspecto ilustra cómo la utilización de un lenguaje controlado consiste en la aplicación de directrices basadas «on the intelligence and experience of human authors for their sensible interpretation and application to their writing tasks» (Hartley y Paris 2001:313). Según esto, un lenguaje controlado precisa, cuando menos, los conocimientos, la experiencia y el control implicados en las tareas de producción y valoración crítica de textos, incluyendo los conocimientos gramaticales necesarios para comprender las implicaciones de la terminología utilizada, por ejemplo, para comprender qué significa exactamente 'procedural sentence'.

En cualquier caso, insistimos en que aprender a comunicarse en un entorno profesional generalmente no es tan simple como parece sugerir la idea de adquirir y aplicar el repertorio de reglas de un lenguaje controlado, por muy elaborado que éste sea. Frente a la producción, transmisión y recepción de textos creados a partir de un conjunto limitado de formas lingüísticas tremendamente convencionalizadas y combinadas mediante la aplicación de reglas recopiladas en un manual, nos encontramos con las múltiples complejidades de la lengua viva, dinámica y versátil que se utiliza (con mayor o menor éxito) para producir, transmitir, comprender o adquirir conocimientos y, en este sentido, nos encontramos con las dificultades propias de la comunicación en cualquier entorno social.

Halliday (v. Hernández Hernández 2000) llama la atención acerca de cómo Firth utiliza una noción de lenguaje restringido según la cual los significados que expresamos al comunicarnos no son elegidos del total de posibilidades que el sistema tiene a nuestra disposición, sino de un conjunto más limitado de opciones: «any typical discourse [...] belongs to some restricted language, so that the meanings that are expressed are not, as it were, selected from within the totality of the language, they are selected from within some fairly special subset» (Hernández Hernández 2000:234).

Según este planteamiento, el discurso que se produce entre una madre y un hijo pequeño en una situación cotidiana, pongamos por caso, es tan restringido como lo es el que se produce entre dos ingenieros mecánicos que hacen cálculos para diseñar un brazo robótico (como ejemplo posible de situación prototípica entre expertos de un campo de especialización). El concepto de restricción utilizado por Firth resulta más dinámico que el empleado por los terminólogos si nos atenemos, por una parte, a las dificultades de comprensión que ambos discursos (madre-hijo e ingeniero-ingeniero) plantean para personas ajenas a la situación y, por otra, al 
hecho de que los interlocutores, tanto en una situación como en la otra, tienen unas expectativas más o menos precisas acerca de cómo se va a desarrollar la comunicación en cada momento. Esto implica que las posibilidades contempladas no son tan numerosas ni aleatorias como cabría suponer si consideramos, como los terminólogos, que una lengua especializada es inherentemente restrictiva frente a la lengua general, y que la restricción de la primera se encuentra en los términos y no en los propios usuarios del lenguaje. En este sentido, nos preocupa dilucidar cuál es la naturaleza de ese 'fairly special subset' de donde el usuario del lenguaje elige los significados que expresa, si tal subconjunto coincide con el subconjunto de la lengua general aludido por Cabré. Nos interesa asimismo establecer cómo realiza el usuario la selección de significados y cómo interpreta los significados expresados por su/s interlocutor/es; en definitiva, cómo utiliza el lenguaje para comunicarse en el entorno profesional del que forma parte, y en el que el aprendiz de Inglés para Fines Específicos algún día también participará.

Desde esta perspectiva, el estudio de la lengua de especialización constituye un análisis del uso de la lengua en el que el límite del estudio se sitúa de acuerdo con ciertos factores de tipo extralingüístico cuya concurrencia se utiliza para identificar una situación de uso determinada. En este sentido, los análisis de las lenguas de especialización utilizan los mismos métodos que los análisis de usos de la lengua que no se identifican con contextos especializados. Teniendo esto en cuenta, pensamos que únicamente cabe hablar de dos tipos de análisis en función del alcance de los resultados esperados y no de una clasificación de subconjuntos dentro de la lengua.

Así, únicamente consideraremos aquellos análisis que se llevan a cabo con el fin de obtener información acerca de cómo funciona el lenguaje en uso y, por consiguiente, los textos (véase, por ejemplo, Tolchinsky et al. 2000), y que se pueden clasificar dentro de lo que se denomina 'análisis del registro' y de un modo más general 'análisis textual', y aquellos análisis cuya finalidad es la de investigar qué caracteriza los diferentes tipos de discurso, y que se inscriben en el denominado 'análisis del discurso' (véase, por ejemplo, Alonso et al. 2002), incluyendo los estudios sobre el 'análisis del género'. En nuestra opinión, estas diferencias de análisis no tienen que ver con el modo del discurso, como en algunas ocasiones se tiende a utilizar esta clasificación, sino con la situación del concepto de texto y de discurso dentro del modelo de lenguaje que se utiliza, tal como veremos más adelante (v. 4.3.2). No obstante, en el campo de las lenguas de especialización, los análisis de las muestras lingüísticas (normalmente textos escritos) se llevan a cabo 
de acuerdo con cuatro enfoques diferentes, según la descripción de Lankamp (1988), si bien las conclusiones finales de este autor apuntan a la productividad de lo que denomina 'enfoque sociolingüístico'.

\subsubsection{Divergencias descriptivas: enfoque terminológico, enfoque estilístico, enfoque educativo y enfoque sociolingüístico}

Lankamp (1988) ha analizado la relación entre el uso de la terminología y la comprensión de textos de medicina. Nos resulta interesante que, aun centrando su interés en los aspectos léxicos de la lengua de especialidad, su aproximación a la lengua médica no coincide con la habitual aproximación terminológica, sino que mantiene una concepción de la lengua de especialidad que podríamos denominar 'abierta'. Así, comienza por describir distintas aproximaciones al estudio de la lengua médica, que él analiza con el fin específico de definir en términos lingüísticos la noción de lengua médica.

Según este autor, los estudios recientes sobre la lengua utilizada en el campo de la medicina se pueden clasificar en cuatro tipos, de entre los cuales el que denomina 'enfoque terminológico' es el más utilizado por los especialistas provenientes del campo de la medicina, es decir, por los propios médicos. Lankamp describe este enfoque como aquel que indaga «the nature of concepts and terms with the purpose of creating consistent intra- and interlinguistic terminologies» (Lankamp 1988:15).

En nuestro trabajo, lo que hemos descrito como la 'perspectiva de la terminología' para abordar la lengua de especialización implica una concepción estática del significado, que se manifiesta en la interpretación de Sager (1990:42) de que «el léxico de un lenguaje especializado refleja las características de organización de la disciplina mediante un intento de suministrar tantas unidades léxicas como conceptos convencionalmente establecidos existan en el subespacio», y que se contrapone a la concepción del significado como un proceso de negociación. En este enfoque, el significado es tomado como algo estático porque se identifica con la convencionalización de los conocimientos y de su expresión léxica. Intuimos una concepción estática semejante en la descripción de Barnes, que veremos más adelante, de los rasgos característicos de una comunidad científica, ya que a través de sus palabras se desprende que la relación entre el científico y la realidad no corresponde con una posición dialéctica, como la descrita por Meix 
Izquierdo (v. 4.1.1), sino que los conocimientos que estudia el científico son tratados como entidades esencialmente convencionales, independientes y ajenas al mismo, y la realidad es tomada como una entidad objetiva a la que se puede acceder con diferentes medios. En una concepción semejante de la realidad y del conocimiento de ésta, el significado no puede sino ser interpretado como una entidad estática. Por una parte, esto significa que la posición de Barnes con respecto a la comunicación nos parece en cierto sentido próxima a la de Cabré. Pero por otra parte, la proximidad entre la posición de Barnes y el enfoque terminológico no resultaría sorprendente teniendo en cuenta la afirmación de Lankamp de que este enfoque es el más utilizado por los propios especialistas (aunque no conviene olvidar que Lankamp se refiere a los especialistas del campo de la medicina).

El segundo de los enfoques descritos es denominado 'enfoque estilístico' y, según Lankamp, de nuevo esta aproximación es más utilizada por los especialistas médicos que por los lingüistas. El mayor aspecto diferenciador entre esta aproximación y la terminológica recae en que el interés aquí se centra en el grado de dificultad o facilidad de comprensión y eficiencia de la comunicación, más que en los aspectos relacionados con la formación de términos y repertorios terminológicos. A propósito de la relación entre el uso de términos médicos muy especializados y la dificultad para comprender los textos, Lankamp se plantea la posibilidad de que el uso de esta terminología resulte menos efectiva que la utilización de términos semánticamente equivalentes más conocidos pero sugiere que el uso de términos médicos muy especializados puede responder al objetivo de restringir la comprensión del texto únicamente a los expertos, es decir, a los miembros pertenecientes a la comunidad profesional, utilizando lo que denomina un 'código profesional':

The use of a professional code which is intended to be comprehensible only to members of that profession, perhaps for reasons of brevity and efficiency of communication, perhaps to exclude outsiders, seems to follow automatically in professional communication and the expertise which is usually involved in such communication [...]. (Lankamp 1988:16)

Las palabras de Lankamp sugieren que los especialistas contemplan la pertenencia al grupo en términos de posesión de unos rasgos idiosincráticos, o bien de un modo de conducta específico que incluiría un comportamiento lingüístico determinado. Por tanto, el lenguaje utilizado por los expertos para comunicarse entre sí se contemplaría en términos de la posesión de un código especial, de tal 
modo que sólo los que poseyeran ese código serían reconocidos por los demás miembros como pertenecientes efectivamente al grupo.

El código puede ser entendido en esta aproximación en un sentido similar al de una colección de reglas o de normas, que es una de las acepciones del término que recoge el Diccionario de uso del español de María Moliner (1987) y, en este sentido particular, se aproxima a las 'unidades y reglas del juego controladas' mencionadas por Cabré. Descrito así, el código se asemeja considerablemente a los lenguajes controlados tratados por Hartley y Paris. No obstante, en un sentido más amplio, también cabe interpretar el código como un tipo de comportamiento (no necesariamente verbal) encaminado a lograr el reconocimiento del resto de los miembros de la comunidad. Para Halliday (1978:68), entender el código como una forma de comportamiento tiene sus ventajas. Desde la perspectiva de nuestro trabajo, la ventaja principal es que de este modo podemos interpretar las manifestaciones textuales del código en términos de manifestaciones de la relación que el autor del texto establece con el receptor, haciendo el texto más simple o más complicado de acuerdo con los conocimientos que el autor exige al lector, es decir, como un filtro. Este filtro, sin embargo, no es representativo del texto especializado puesto que, tal como explica Conde, supone únicamente la manifestación de una postura deliberada que el autor del texto adopta con respecto del lector, con independencia del tipo de texto de que se trate ${ }^{6}$.

Además de estas dos aproximaciones a la descripción de la lengua médica utilizadas mayoritariamente por los especialistas del campo de la medicina, Lankamp se refiere a otros dos enfoques, utilizados más bien por los lingüistas, y que denomina 'enfoque educativo' y 'enfoque lingüístico'.

Según las aproximaciones a la lengua desde el enfoque de la didáctica o 'enfoque educativo', la lengua médica se define bien como una variante de la lengua de especialidad, como una lengua para fines especiales o específicos, o bien como un registro científico-técnico, según a qué autor nos remitamos. No obstante, en general todas estas perspectivas comparten un enfoque similar en la relación entre la descripción de la lengua y la aplicación de esta descripción al ámbito de su enseñanza.

A su vez, en la aproximación lingüística o 'enfoque lingüístico', Lankamp divide los estudios que se realizan sobre la lengua médica en dos tipos, según el

\footnotetext{
${ }^{6}$ Según Conde, «la simplicidad se opone a la complejidad en el nivel de exigencia del aparato crítico (es decir, de bagaje cultural y personal, además de conocimiento técnico y perspicacia) que el autor del texto reclama de su lector» (Conde 1996:93).
} 
estudio se haya realizado cuantitativamente o bien partiendo de una perspectiva sociolingüística.

El análisis cuantitativo implica una definición de la lengua de especialidad en términos del índice de frecuencia en la aparición de ciertos elementos lingüísticos, normalmente léxicos. Lankamp señala las dificultades de esta aproximación para obtener una descripción de la lengua médica, dificultades análogas a las que nos enfrentaríamos si nos planteáramos la descripción de otras variedades de la lengua. El problema, según Lankamp, radica en que un método únicamente cuantitativo de análisis no puede dar cuenta de la lengua médica de forma apropiada, ya que no es capaz de detectar todas las formas de lexicalización relevantes. La causa de esto es que se suele utilizar la palabra como unidad de análisis debido a las dificultades existentes en determinar otro tipo de unidad léxica y, por tanto, para Lankamp la utilidad de este método para caracterizar una variante de la lengua se ve mermada: «as frequency counts seldom cover extended terms and as there is no absolute agreement about lexicalized expressions, figures on the occurrence of terms tend to be of limited value» (Lankamp 1988:18).

Si utilizamos como unidad de análisis la palabra, o la expresión léxica formada por un único elemento, no hay nada que impida que el resultado en el análisis de palabras más frecuentes del Español Comercial, por seguir con un ejemplo anterior (v. 4.1.1), contenga elementos léxicos como 'lista', 'saco' o 'sobre'

${ }^{7}$. Este problema, producido por la dificultad para establecer otra unidad de análisis

\footnotetext{
${ }^{7}$ No tiene por qué resultar sorprendente la alta frecuencia de palabras como 'lista', 'saco' o 'sobre' si tomamos el Español Comercial como la lengua utilizada por los profesionales en las situaciones asociadas típicamente con el mundo de los negocios y el comercio y que, según Brenes García y Lauterborn, incluye aspectos muy diversos:
}

Al profesional de los negocios internacionales se le exigen habilidades comunicativas formales e informales en una segunda lengua, al menos. Entre otras, las destrezas formales consisten en escribir documentos comerciales, hacer exposiciones o participar en reuniones. Para tener éxito en este tipo de comunicaciones se deben aprender una serie de expresiones y términos que pertenecen al código de la lengua comercial, para así poder hacer una exposición sobre un nuevo producto, o redactar una carta de pedido, si fuera necesario. Además de estas comunicaciones formales típicas del mundo de los negocios, la comunicación informal está cobrando cada vez más importancia. Ésta ocurre siempre que dos personas intercambian información relativa a la empresa, por escrito $\mathrm{u}$ oralmente, mezclando el registro coloquial de la lengua con el profesional de los negocios. La mayor parte de la comunicación oral que tiene lugar en la empresa forma parte de la comunicación informal: una conversación entre secretaria y jefa, entre dos colegas del mismo departamento, o una negociación entre dos socios que se acaban de conocer. (Brenes García y Lauterborn 2002:9-10) 
que sirva para discernir entre las unidades léxicas relevantes (simples o compuestas por varios elementos) y las que no lo son, hacen que Lankamp concluya descartando el método cuantitativo de análisis.

A pesar de que sin duda la lingüística computacional ha avanzado en la determinación de unidades léxicas de análisis en los años que nos separan del estudio de Lankamp, estamos de acuerdo en que, para describir apropiadamente una lengua de especialidad, es necesaria la utilización de un método cualitativo de análisis y no únicamente un método cuantitativo. Según Lankamp, la alternativa más extendida al enfoque cuantitativo es la que denomina 'aproximación sociolingüística' (sociolinguistic approach), y que define como aquella perspectiva donde la definición lingüística de la lengua médica se da principalmente en términos de los participantes y de las situaciones comunicativas. Se trata de una aproximación que contempla la lengua médica como un registro, refiriéndose éste a las «varieties of language appropriate to different occasions and situations of use which are used by a single speaker» (Lankamp 1988:20).

La aproximación a la lengua de especialidad como variedad lingüística nos parece apropiada, ya que implica una perspectiva sobre el lenguaje lo suficientemente abierta como para dar cuenta de las distintas variedades de lengua que se aglutinan bajo la denominación general de lengua de especialidad, a la vez que permite la descripción de la lengua utilizada en contextos considerados especializados utilizando los mismos parámetros que para describir otros usos no asociados con estos contextos. Esto significa que este enfoque está por encima de las diferencias particulares entre unas variedades y otras, lo cual es útil en el ámbito de las lenguas para fines específicos, habida cuenta de los problemas que plantean estas divisiones para abordar la didáctica del Inglés para Fines Específicos con el nivel mínimo de generalización necesario, de acuerdo con la perspectiva de Widdowson.

Esta aproximación nos permitirá abordar la traducción a partir del mismo modelo que utilizamos para la lengua de especialidad, puesto que es compatible con un modelo general de funcionamiento del lenguaje. Desde esta perspectiva, consideraremos la traducción especializada como aquella que relaciona distintas lenguas a través de un mismo tipo de variedad lingüística que se manifiesta de modos diferentes en cada caso ${ }^{8}$. Por otra parte, la hipótesis de la existencia de una

\footnotetext{
${ }^{8}$ Vamos a considerar únicamente la validez de este planteamiento para la traducción especializada ya que, cuando traducimos textos literarios, puede que la relación entre las lenguas del par asociado no se dé a través de un mismo tipo de variedad lingüística si, como proponen Dixon y Bortolussi (2001), los textos narrativos de ficción no son comunicativos en el mismo sentido que
} 
misma variedad lingüística con diferentes manifestaciones en distintas lenguas puede dar una explicación alternativa a la paradójica facilidad que Cabré achaca al especialista para comprender textos de su campo en otra lengua a pesar de su deficiente competencia comunicativa en esa lengua, y que para esta autora constituye una de las justificaciones que nos permiten hablar de la lengua de especialidad como algo unitario y con entidad propia. La cuestión que queda por resolver es la naturaleza de esta variación lingüística, lo cual nos proponemos dilucidar en las siguientes dos secciones.

En la sección siguiente presentaremos las características de un modelo de funcionamiento del lenguaje, el modelo socio-semiótico de Halliday (1978), relacionándolo específicamente con las variedades funcionales contempladas en este trabajo. A lo largo de este capítulo hemos estado manejando el concepto de variación de un modo muy general representado a través de las ideas de diversidad y uniformidad del lenguaje. No obstante, al considerar la lengua de especialidad como una variedad funcional de la lengua, debemos precisar qué es exactamente lo que esto implica, para lo cual daremos cuenta de los parámetros de descripción que utilizaremos, al tiempo que iremos presentando una perspectiva general sobre el funcionamiento del lenguaje.

\subsection{Parámetros de descripción del uso del lenguaje}

Abordar la descripción del uso del lenguaje con el requisito de que esa aproximación sea capaz de abarcar tanto los fenómenos involucrados en la comunicación especializada, tal y como se produce en los entornos profesionales, como los fenómenos involucrados en la comunicación intercultural implica adoptar una visión pragmática acerca del lenguaje. Entendemos esa visión pragmática en un sentido general, como «the relation between linguistic signs or symbols and the human users of these symbols in certain contexts» (House 2001:58).

Dado que la aproximación a la descripción del uso del lenguaje a partir de la concepción de Halliday (1978) sobre el funcionamiento de éste nos resulta más productiva que un acercamiento desde otras concepciones más limitadas, en esta

los no ficcionales. No obstante, para la traducción literaria en cuanto a la relación entre comunidades, lenguas y culturas, nos remitimos a la validez de la Teoría de Polisistemas desarrollada por Even-Zohar. 
sección vamos a especificar cuáles son los factores que habremos de tratar al abordar la descripción de la lengua de acuerdo con el modelo esbozado por este lingüista. Esto, en definitiva, supone poner de manifiesto cuál es nuestra posición determinada en relación con la concepción sobre el lenguaje que manejamos al abordar la didáctica de las lenguas extranjeras.

Para otros modelos de análisis del lenguaje, particularmente los construidos a partir de concepciones ideales del lenguaje universal, la oración suele constituir la unidad básica de análisis, por lo que el texto suele ser tomado como un conjunto de extensión variable compuesto por unidades básicas (oraciones). Para el modelo de Halliday, el texto no es un cúmulo de oraciones sino que constituye una unidad semántica y dinámica, tal como veremos más adelante. Esta perspectiva sobre el rango del texto dentro del sistema lingüístico nos permite dar cuenta del funcionamiento del lenguaje según sus manifestaciones textuales de un modo más capaz que si adoptamos un modelo de lenguaje limitado al ámbito de la oración, ya que los modelos que utilizan unidades superiores a la oración se plantean asimismo explicar el funcionamiento de los niveles supraoracionales, así como la integración entre los distintos niveles textuales. Por estas razones, así como por la extensa propagación de esta aproximación que bajo la denominación de 'lingüística sistémico-funcional' actualmente constituye una sólida corriente lingüística y los avances logrados por ella en las descripciones del funcionamiento del lenguaje, nos parece que el modelo propuesto por Halliday es muy apropiado para abordar la descripción del material textual que se va a utilizar en el curso de Inglés para Fines Específicos, la descripción de las manifestaciones lingüísticas asociadas con los contextos especializados más relevantes para el curso, y también para situar convenientemente el fenómeno de la traducción en tanto que fenómeno lingüístico involucrado en las tareas didácticas contempladas en este trabajo.

La utilidad del modelo de Halliday sobre el funcionamiento del lenguaje se enmarca dentro de esa visión pragmática sobre el lenguaje que mencionábamos más atrás, y se basa en que este modelo parte de una concepción tripartita del sistema lingüístico, entendiendo éste como un sistema estratificado complejo en el que se distinguen un sistema semántico, otro gramatical (entendido como lexicogramatical, es decir, incluyendo el léxico), y un sistema fonológico. Cada uno de estos sistemas es concebido como un sistema de alternativas potenciales, de lo que el usuario del lenguaje puede hacer con él.

De acuerdo con House (2001:57), una visión pragmática acerca del lenguaje implica que debemos observar éste «as embedded in, and part of, a more 
comprehensive semiotic system». Para Halliday (1978:108), los ingredientes de una teoría sociosemiótica sobre el lenguaje son el texto, la situación, el registro, el código, el sistema lingüístico, y la estructura social. Así, para poder describir el uso del lenguaje debemos considerar cómo se manifiestan estos aspectos en cada caso particular.

Desde una perspectiva asimismo pragmática, Cabré (1993:129) considera la lengua de especialidad como «un conjunto de posibilidades determinadas por los elementos que intervienen en cada acto de comunicación». Esos elementos intervinientes son identificados como «los interlocutores (emisores y destinatarios, con todo el conjunto de características que les son propias), las circunstancias comunicativas, y los propósitos o intenciones que se propone el acto de comunicación» (Cabré 1993:129). En realidad, se trata de una definición tan general que no identifica ningún subconjunto específico dentro de la lengua, sino que define la propia lengua. Si el análisis descriptivo de la lengua debe estar necesariamente ligado a la descripción del contexto de uso, entonces no hay diferencia entre abordar la definición de la lengua de especialidad y abordar la definición de la lengua. Por consiguiente, desde un enfoque pragmático no podemos establecer una diferencia clara entre describir la lengua y describir la lengua de especialidad porque el objeto del análisis es el mismo y el resultado de la descripción también. No obstante, esto no significa que neguemos la utilidad del concepto de lengua de especialidad, ni tampoco que pongamos en duda la conveniencia para la didáctica del Inglés para Fines Específicos de abordar su descripción.

En una concepción sobre el funcionamiento del lenguaje como la que estamos exponiendo, la descripción del sistema se construye a través de las manifestaciones concretas de éste. Es decir, nuestro acceso al lenguaje se produce a través de la lengua. En este sentido, la descripción de una lengua de especialidad constituye la descripción de las manifestaciones lingüísticas que comparten una misma variable.

Si se adopta una perspectiva estrecha sobre el lenguaje, esta variable suele ser la temática, mientras que desde una perspectiva pragmática, esta variable se identifica habitualmente con el contexto de situación de uso del lenguaje y, en el caso específico de las lenguas de especialidad, este contexto suele estar descrito como un contexto profesional o especializado. Así, si nos planteamos la cuestión de la generalidad o la especificidad de la lengua que consideramos relevante para la didáctica de las lenguas para fines específicos (como una extensión del argumento de Widdowson sobre la decisión de adoptar un enfoque más general o más 
específico sobre el curso de Inglés para Fines Específicos), nuestra opinión es que una concepción sobre el lenguaje como la descrita por la lingüística sistémicofuncional no adolece de adoptar una posición demasiado general sobre la lengua relevante para los fines de este trabajo.

Si, como señala Matthiessen (2001), la relación entre el sistema estratificado del lenguaje y una manifestación lingüística de éste (un texto) consiste en una 'instanciación' (instantiation) del potencial del sistema, es decir, en una realización del sistema en un caso particular (v. Martin 1998:8; Martín Miguel 1998:165), entonces nuestras descripciones son necesariamente descripciones específicas, puesto que describen manifestaciones únicas, y esto las sitúa en el extremo de la especificidad. Sin embargo, las generalidades que formulamos a partir de esas descripciones concretas son generalizaciones sobre el funcionamiento del sistema. La postura de Halliday consiste en adoptar una posición intermedia en lo que concierne al grado de abstracción de las descripciones.

\subsubsection{Texto}

Como ya sugerimos anteriormente, desde una perspectiva sociosemiótica del lenguaje, el texto es la unidad básica de los procesos semánticos de producción, transmisión y recepción del conocimiento. No pertenece exclusivamente a una categoría linguística, por lo que debe ser definido según criterios sociocomunicativos (Schmidt 1973:149) y, en este sentido, constituye un puente entre el sistema lingüístico y el sistema semiótico.

El texto, como unidad semántica, presenta la selección de significados que ha sido elegida previamente por el autor. Estos significados se eligen a partir de la gama paradigmática de elección semántica que está presente en el sistema. Como ya hemos apuntado antes, Halliday concibe el sistema lingüístico como un sistema estratificado de sistemas de alternativas potenciales, denominando a este conjunto de posibles opciones el 'potencial de significado'.

Dado que los sistemas de las distintas lenguas no presentan gamas paradigmáticas de selección equivalentes en el número y tipo de elementos que las forman (aunque sí se puede hablar de mayores o menores grados de convergencia entre pares de lenguas concretos), es obvio que el potencial de significado difícilmente se actualiza como una relación de uno a uno entre lenguas. Esta característica del sistema lingüístico explica, al menos en parte, por qué la traducción es contemplada como un fenómeno extremadamente complejo por 
algunos autores, cuyo énfasis suele incluir la clásica cita de Richards en la que la traducción se presenta como «probably the most complex type of event yet produced in the evolution of the cosmos» (véase, por ejemplo, Bell 1991:34; Brislin 1976:79; Gentzler 1993:17; Holmes 1988:73,104; Santoyo 1983:255; Steiner 1975:48; 1992:50).

Para caracterizar exhaustivamente este potencial de significado, Halliday distingue dos dimensiones distintas tomadas de Malinowski en el concepto de contexto: el denominado 'contexto de cultura', que corresponde al potencial del sistema en su total exhaustividad, y el denominado 'contexto de situación', que es más restringido puesto que corresponde al potencial del significado bajo las condiciones establecidas por la situación ${ }^{9}$.

El potencial de significado puede ser interpretado en ambas dimensiones. Cuando lo interpretamos en el contexto de la cultura, el potencial de significado está constituido por todo el sistema semántico del lenguaje, por lo que su descripción escapa a nuestras posibilidades (y también a nuestros objetivos) ${ }^{10}$. Pero el potencial de significado también puede caracterizarse en el contexto de la situación de uso, donde se representa como la gama de opciones que es característica de un tipo específico de situación (Halliday 1978:109). En este contexto, no todo el sistema semántico está involucrado, sino únicamente el sistema (o el conjunto de subsistemas) semántico que caracteriza el lenguaje asociado con un tipo particular de situación o contexto social.

El texto, bajo esta perspectiva, constituye la actualización de los elementos del sistema elegidos por el autor para una situación concreta y es, por tanto, una configuración única. Esta consideración del texto lo hace susceptible de que pueda ser tratado como una unidad, tanto para la comunicación como para el análisis y, por extensión, el texto es susceptible de ser clasificado taxonómicamente desde distintas aproximaciones que utilizan un número más o menos variado y extenso de parámetros de clasificación. Se ha dedicado un gran esfuerzo a la clasificación de

\footnotetext{
${ }^{9}$ Halliday se refiere a los siguientes trabajos de Bronislaw Malinowski: "The problem of meaning in primitive languages". Supplement 1 to C. K. Ogden and I. A. Richards, The meaning of meaning. (International Library of Psychology, Philosophy and Scientific Method.) London: Kegan Paul., 1923 y Coral gardens and their magic, 2. London: Allen \& Unwin/New York: American Book Co., 1935.

${ }^{10}$ No podemos elaborar un repertorio con todos los significados posibles del sistema semántico del lenguaje porque se trata de un sistema virtual, es decir, es una unidad funcional de elementos cuyo potencial no ha sido puesto aún en uso, es decir, no ha sido actualizado (v. De Beaugrande 1980a:16) o realizado (v. Halliday 1978:39).
} 
textos tanto en el campo de la lingüística aplicada como en el de la traducción. Por ejemplo, en el entorno especializado que nos ocupa y en relación con la traducción, Rabadán (1991a) distingue los 'textos para propósitos específicos' (TPE) de otros textos (literarios), y establece una clasificación de tres tipos de TPE según las características de la variedad lingüística utilizada: textos científicos y técnicos, textos legales y correspondencia comercial.

\subsubsection{Situación}

Halliday (1978:109) describe la 'situación' como «the environment in which the text comes to life» y señala que se trata de un concepto muy asentado en el campo de la lingüística, que Malinowski identifica con el 'contexto de situación' al distinguirlo del 'contexto de cultura'.

Podemos describir la situación de acuerdo con las características particulares que concurren en la producción, difusión y recepción de un texto concreto, recopilando los datos factuales sobre su producción, difusión y recepción. No obstante, Halliday apunta que, para que el concepto de 'contexto de situación' pueda ocupar un lugar determinado en una teoría general sobre el lenguaje desde una perspectiva social, las situaciones deben ser descritas como tipos de situación, es decir, con un grado de abstracción tal que permita hacer generalizaciones sobre ellas. En este sentido, no nos interesa la descripción de un caso, sino la descripción de un tipo de casos que constituya «an abstract representation of the environment in terms of certain general categories having relevance to the text» (Halliday 1978:109).

Halliday define el tipo de situación como una constelación de significados que derivan del sistema semiótico que consituye la cultura. Es decir, interpreta el contexto de situación como una estructura semiótica, como un contexto social que consta de «those general properties of the situation which collectively function as determinants of text, in that they specify the semantic configurations that the speaker will typically fashion in contexts of the given type» (Halliday 1978:110), y que a su vez deriva del contexto de cultura.

El contexto social es la fuente principal de información que los participantes en la comunicación utilizan para interpretar lo que está ocurriendo y lo que el interlocutor quiere decir, así como para poder elaborar expectativas acerca de lo que va a ocurrir a continuación. Esta información relaciona el texto con el sistema lingüístico y con el sistema social. Así, Halliday contempla este constructo teórico 
como una estructura semiótica que puede ser representada mediante el compendio de tres dimensiones que se refieren a: 'field', referente a la actividad social que se está llevando a cabo, y que algunos autores denominan en español 'campo' (Albentosa Hernández 1998; Muñoz Martín 1995) y otros 'ámbito' (Álvarez de Mon 1993); 'tenor': el papel de las relaciones interpersonales de los participantes en la comunicación tal como se plasman en el texto, denominado 'tenor' (Albentosa Hernández 1998; Muñoz Martín 1995) o 'tono' (Álvarez de Mon 1993); y 'mode’: el canal simbólico o retórico, que se suele denominar 'modo' (Albentosa Hernández 1998; Muñoz Martín 1995) o ‘medio' (Álvarez de Mon 1993).

El campo o ámbito incluye el tema que trata el texto, de entre otras manifestaciones de lo que está sucediendo en la acción social. A pesar de que Halliday insiste en que es la conjunción de estas dimensiones la que representa el contexto social, lo cierto es que esta dimensión suele ser frecuentemente utilizada como medio principal de clasificación textual, como sucede, por ejemplo, con los tipos de TPE de Rabadán (1991a) que hemos mencionado más atrás ${ }^{11}$.

Por su parte, el tenor o tono incluye el grado de formalidad como uno de los modos de descipción de la relación interpersonal existente entre los interlocutores de acuerdo con el texto. Por último, el modo o medio, como canal de transmisión elegido, se refiere a si la comunicación se produce de forma oral o escrita y constituye para Halliday una variable de tipo funcional.

Estas dimensiones no son tipos de uso del lenguaje ni simples componentes del escenario donde se sitúa la comunicación, sino que constituyen el marco conceptual de representación del contexto social, entendido como un entorno semiótico activo donde la gente intercambia significados y no como un simple escenario.

En este trabajo esperamos que una teoría general como ésta, en la que el contexto de situación tiene una posición fundamental para describir las características del texto, sea capaz de cobijar todos los tipos potenciales de contexto de situación, de tal modo que no se produzcan incoherencias derivadas del hecho de que, cuando tratamos la utilización de textos en el aula, debemos gestionar varios contextos de situación simultáneamente. Cuando un texto es utilizado como un 'texto didáctico', es decir, cuando se le asigna una función didáctica, coexisten al mismo tiempo dos contextos de situación: el contexto de la situación de uso original

\footnotetext{
${ }^{11}$ Véase también Álvarez de Mon (1993:714) a propósito de la utilización de esta dimensión para determinar cuáles son los textos técnicos.
} 
de donde hemos tomado el texto y el contexto de la situación didáctica donde pasamos a situarlo y a utilizarlo ${ }^{12}$.

Debemos hacer un inciso en este punto para señalar que en este trabajo únicamente tenemos en cuenta la utilización en el aula de material auténtico, es decir, de 'textos auténticos' (Harmer 1983:146) o 'textos naturales' (Dubin, Eskey y Grabe 1986:137). Podemos señalar diversas razones que justifican la decisión de considerar únicamente este tipo de material didáctico, pero la que más nos concierne en esta sección consiste en que una de las características de utilizar un modelo como el de Halliday es, precisamente, la utilización de material lingüístico auténtico para mostrar qué y cómo es el lenguaje. Así, consideramos que las descripciones elaboradas a partir de este modelo tienen validez para mostrar el uso del lenguaje tal y como se produce en la realidad pero no tienen por qué ser válidas para textos que no han sido producidos en situaciones reales de uso independientes de la situación didáctica. En resumen, los datos que la lingüística sistémico-funcional de Halliday considera legítimos son aquellos que toma de la realidad. Martín Miguel explica por qué la Gramática Sistémica Funcional (GSF) utiliza este criterio:

La GSF se preocupa de estudiar cómo una lengua es capaz de cumplir satisfactoriamente las funciones sociales de comunicación interpersonal. Al tratar de describir y comparar lenguas o variedades de una misma lengua, la GSF se propone emplear un modelo que permite descubrir cómo la forma de una lengua o de una variedad de esa lengua está determinada por su función social. De ahí que la GSF muestre un interés especial por describir variedades de una lengua que dependen de situaciones sociales: registros y dialectos sociales. (Martín Miguel 1998:70)

Por lo que respecta a la didáctica teórica de las lenguas extranjeras, el hecho de que en el aula concurren varios tipos de situación en relación con los textos que se utilizan con diversas funciones didácticas debe ser tenido en cuenta al afrontar las tareas que se van a introducir en el proyecto de enseñanza-aprendizaje relacionadas con la utilización de material textual.

\footnotetext{
${ }^{12}$ Podemos aportar un ejemplo de interferencias entre ambos contextos de situación mencionando el caso de algunos estudiantes que, cuando llevan a cabo una tarea de traducción, tienden a identificar al profesor como el destinatario de sus traducciones, a pesar de que las instrucciones de la tarea les indican que las características de su traducción se deben equiparar a las del TO, incluyendo un contexto de situación equivalente.
} 


\title{
4.2.3 Registro
}

El 'registro' se define como «the configuration of semantic resources that the member of a culture typically associates with a situation type» (Halliday 1978:111). En el modelo de lenguaje de Halliday, el registro se contrapone al dialecto, representando ambos los dos tipos básicos de variedad linguí́stica. Esta distinción define el registro como una variedad de la lengua que depende del uso que se hace de ella, mientras que el dialecto se interpreta como una variedad de la lengua que depende de quién y cómo es su usuario: «the dialect is what the person speaks, determined by who he is; the register is what a person is speaking, determined by what he is doing at the time» (Halliday 1978:110).

El registro constituye una variedad lingüística de tipo semántico de la cual el texto es tomado como un caso particular. A pesar de que en el texto el potencial de significado se realiza mediante selecciones específicas de palabras y estructuras, Halliday propone la caracterización del registro en términos (semánticos) más abstractos, al igual que, como ya hemos mencionado, proponía en el caso del contexto de situación:

\begin{abstract}
Both the situation and the register associated with it can be described to varying degrees of specificity; but the existence of registers is a fact of everyday experience - speakers have no difficulty in recognizing the semantic options and combinations of options that are 'at risk' under particular environmental conditions. Since these options are realized in the form of grammar and vocabulary, the register is recognizable as a particular selection of words and structures, but it is defined in terms of meanings; it is not an aggregate of conventional forms of expression superposed on some underlying content by 'social factors' of one kind or another. It is the selection of meanings that constitutes the variety to which a text belongs. (Halliday 1978:111)
\end{abstract}

Por otra parte, como el registro determina a qué variedad pertenece el texto de acuerdo con el uso que se hace del lenguaje, entonces puede ser utilizado como parámetro de análisis y clasificación de textos. Pero aquí nos topamos asimismo con el concepto de género textual, cuyos límites y concepciones se suelen solapar con los del registro. Probablemente la cuestión se origina en que los textos son tomados como casos particulares, es decir, como realizaciones concretas, de un determinado género y también, como ya hemos mencionado, como casos particulares o realizaciones concretas de una determinada variedad semántica, es decir, de un registro. Puede que esta confusión esté asimismo causada por el hecho de que Halliday no tiene en cuenta el concepto de género, por lo que el desarrollo teórico y la aplicación práctica de ambos conceptos ha transcurrido generalmente de forma 
paralela con muchos solapamientos. Según Swales (2001:12), Halliday no ha utilizado este concepto ni lo ha incorporado a su modelo de funcionamiento del lenguaje por considerarlo demasiado ambiguo y subjetivo ${ }^{13}$. No obstante, dado que el concepto de género está muy extendido en el ámbito de la investigación de las lenguas para fines específicos, gracias particularmente al trabajo de Swales (1981; 1990), creemos que esta cuestión merece un espacio más extenso, por lo que la abordaremos con más detenimiento en la última sección de este capítulo.

\subsubsection{Código}

Halliday interpreta este concepto como «the principle of semiotic organization governing the choice of meanings by a speaker and their interpretation by a hearer» (Halliday 1978:111). Es en este sentido como interpretamos la noción de código profesional, el cual, según Lankamp (1988:16), es utilizado en las comunidades profesionales. Tal como sugerían sus palabras (v. 4.1.3), las razones por las que una comunidad profesional utiliza un código particular no son claramente identificables, pero todas se desprenden del hecho de que el código viene a constituir una norma de conducta para los miembros del grupo. Esta norma de conducta puede implicar tanto pautas de comportamiento verbal como no verbal.

Halliday (1978:111) explica que, a diferencia de los registros y los dialectos, los códigos no son variedades lingüísticas, sino que constituyen órdenes simbólicos de significados generados por el sistema social que se actualizan en el lenguaje a través del registro, ya que es este último el que determina la orientación semántica de los participantes en la comunicación en un contexto social determinado. Los códigos son los responsables de regular el proceso de activación de los sistemas semánticos del lenguaje, que se lleva a cabo mediante los determinantes situacionales de éste (campo, tenor y modo). Según esta concepción, son los códigos los que controlan la transmisión de los modelos culturales (o subculturales) mediante los agentes sociales constituidos por la familia, el grupo de pares, es decir, de iguales (en nuestro caso, la comunidad profesional) y la escuela, por lo que actúan como filtros culturales ${ }^{14}$.

\footnotetext{
${ }^{13}$ Albentosa Hernández (1998:84-85) nos recuerda que el propio Swales consideraba en 1990 que el concepto de género era 'escurridizo' (slippery).

${ }^{14}$ Un cuarto de siglo después de las palabras de Halliday, cabe plantearse el papel de los medios de comunicación, particularmente la televisión, como un cuarto grupo de agentes sociales.
} 


\subsubsection{Sistema lingüístico}

El modelo tripartito de lenguaje de Halliday se compone de un estrato semántico (que es el que recibe la mayor atención en el modelo), de un sistema lexicogramatical y de un sistema fonológico. El sistema semántico es entendido en términos funcionales más que cognitivos. Así, desde este modelo se interpreta que el sistema semántico está compuesto por tres componentes funcionales, denominados respectivamente, 'función ideacional', 'función interpersonal' y 'función textual'.

Estos componentes funcionales son «the modes of meaning that are present in every use of language in every social context» (Halliday 1978:112). En este sentido, Halliday interpreta el texto como un producto de los tres componentes, como «a polyphonic composition in which different semantic melodies are interwoven, to be realized as integrated lexicogrammatical structures» (Halliday 1978:112).

Así pues, la función ideacional representa el potencial de significado del usuario del lenguaje en la medida en que éste es un observador. Se refiere, por tanto, a las relaciones del hablante con el mundo. Por consiguiente, este componente es el responsable de la expresión de los fenómenos del entorno, es decir, de todo lo que forma parte del significado ideacional del lenguaje:

\footnotetext{
[...] the things - creatures, objects, actions, events, qualities, states and relations - of the world and of our own consciousness, including the phenomenon of language itself; and also the 'metaphenomena', the things that are already encoded as facts and as reports. (Halliday 1978:112)
}

Halliday considera que el lenguaje codifica la experiencia cultural mediante el componente ideacional, y de este modo el hablante codifica su experiencia individual como miembro de la cultura, es decir, como individuo que ocupa una posición particular en el sistema social.

El componente interpersonal representa el potencial de significado del usuario del lenguaje en la medida en que éste es un intruso, ya que es el componente mediante el cual el hablante se introduce en el contexto de situación, tanto para expresar sus propias actitudes y opiniones, como para influir en las actitudes y el comportamiento de los interlocutores. Este componente expresa los tipos de relación entre los participantes en la comunicación que se asocian con la situación, tales como la relación entre entrevistador y entrevistado. Estos tipos de relación constituyen el significado interpersonal del lenguaje. 
El componente textual representa el potencial del usuario del lenguaje para construir textos. Para Halliday es en este potencial, precisamente, donde estriba la relevancia del lenguaje. Este componente es el responsable de proporcionar textura al texto y de expresar la relación entre el lenguaje y el entorno, incluyendo tanto el entorno verbal (lo que se ha dicho o escrito antes), como el entorno situacional. En este sentido, el componente textual es responsable de la actualización de los otros dos componentes, puesto que los significados ideacionales e interpersonales únicamente pueden actualizarse en combinación con los significados textuales. Es justamente esta dependencia del componente textual la que nos permite considerar el texto como una fuente apropiada para tratar como datos analíticos no sólo aquellos elementos relacionados con los factores intratextuales del texto, sino también los elementos asociados con el contexto de situación del texto, es decir, con los factores de tipo extratextual.

Tal como señala Halliday (1978:113), estos tres componentes se reflejan en el sistema lexicogramatical del lenguaje como redes discretas de opciones. Por ejemplo, en la cláusula (clause) la función ideacional está representada por la transitividad y la función interpersonal por la modalidad, mientras que la función textual está representada por un conjunto de sistemas a los que se denomina conjuntamente 'tema'. Cada uno de estos tres conjuntos de opciones se caracteriza por presentar unas restricciones estrictas a nivel interno pero no tan estrictas externamente, es decir, entre unos conjuntos y otros.

\subsubsection{Estructura social}

Para Halliday (1978:113), la estructura social tiene gran relevancia en una teoría sociolingüística desde tres aspectos fundamentales que podemos resumir de este modo:

(a) La estructura social define y dota de significado a los diferentes tipos de contexto social en el que los significados son intercambiados en la comunicación.

(b) La estructura social determina los distintos modelos familiares de la comunicación, regulando los significados y estilos de significados que se asocian con contextos sociales dados.

(c) La estructura social interviene a través de los efectos de la jerarquía social, en forma de castas o clases sociales. En un sentido amplio, también podemos incluir aquí la jerarquía de los grupos sociales constituidos por comunidades 
profesionales, y que son los que más directamente nos conciernen en este trabajo.

En el modelo de Halliday (1978), al igual que el registro se considera una variedad lingüística asociada directamente con el texto, el dialecto social es una variedad lingüística que se asocia con la estructura social. Así, el dialecto social se define como una manifestación directa de la jerarquía social y, al mismo tiempo, como una expresión simbólica de la propia jerarquía, manteniéndola y reforzándola de diversos modos. Por ejemplo, para Halliday la asociación del dialecto con el registro, es decir, «the fact that certain registers conventionally call for certain dialectal modes» (Halliday 1978:113), expresa la relación entre clases sociales y la división del trabajo ${ }^{15}$.

Por último, Halliday generaliza acerca de la importancia de la estructura social en una teoría sociosemiótica del lenguaje señalando, por una parte, su presencia a través de las alteraciones del sistema semántico, y por otra, su papel activo en la evolución de los sistemas y procesos semánticos:

The social structure is present in the forms of semiotic interaction, and becomes apparent through incongruities and disturbances in the semantic system. Linguistics seems now to have largely abandoned its fear for impurity and come to grips with what is called 'fuzziness' in language; but this has been a logical rather than a sociological concept, a departure from an ideal regularity rather than an organic property of sociosemiotic systems. The 'fuzziness' of language is in part an expression of the dynamics and the tensions of the social system. It is not only the text (what people mean) but also the semantic system (what they can mean) that embodies the ambiguity, antagonism, imperfection, inequality and change that characterize the social system and social structure. [...] The social structure is not just an ornamental background to linguistic interaction, as it has tended to become in sociolinguistic discussions. It is an essential element in the evolution of semantic systems and semantic processes. (Halliday 1978:114)

A lo largo de esta sección hemos presentado los aspectos específicos involucrados en la descripción del uso del lenguaje según el modelo de funcionamiento del lenguaje de Halliday (1978). De acuerdo con este modelo, las únicas variedades lingüísticas que se contemplan son el registro y el dialecto social, por lo que la lengua de especialización no tiene un rango específico aparte, sino que es considerada como un registro, entendiendo éste como una variedad lingüística de tipo funcional:

\footnotetext{
${ }^{15}$ Una de las características de los sistemas sociales es, precisamente, que presentan algún tipo de división del trabajo (v. Matthiessen 2001:49).
} 
A register is a set of meanings that is appropriate to a particular function of language, together with the words and structures which express these meanings. We can refer to a 'mathematics register', in the sense of the meanings that belong to the language of mathematics (the mathematics use of natural language, that is: not mathematics itself), and that a language must express if it is used for mathematical purposes. (Halliday 1978:195)

No obstante, tal como señalamos anteriormente (v. 4.2.4), la consideración de la lengua de especialización como un registro entra en principio en conflicto con la extendida consideración de ésta como un género, por lo que en la sección siguiente vamos a analizar los conceptos relacionados con esta cuestión según el modelo de Halliday y el concepto de género de Swales ${ }^{16}$.

\subsection{Las unidades analíticas del texto}

Dentro del ámbito de la lingüística aplicada y particularmente en el entorno de las lenguas para fines específicos, el concepto de género ha constituido un gran centro de interés desde que fue utilizado por Tarone, Dwyer, Gillette e Icke en un trabajo presentado en la TESOL Convention de 1981 en Detroit sobre el uso de la voz activa y la voz pasiva en dos artículos científicos de astrofísica. El término 'género' es utilizado por estos autores por primera vez en el campo de las lenguas para fines específicos para referirse a las diversas clases de tipos de texto asociados típicamente con un campo específico de conocimientos:

We are unaware of any other studies which (a) examine the frequency of usage of passive voice within a single field, and within a single genre within that field (e.g. textbooks, journal papers, etc.); or which (b) perform a rhetorical analysis to determine the systematic functions of passive voice, as opposed to active, within the text as a whole. (Tarone et al. 1988:191)

Swales (1988:192) asocia la utilización del término 'género' en este trabajo con el creciente interés en lo que él denomina 'audience analysis' (la relación prospectiva que se establece entre el autor y el lector) y su relación con el éxito (o fracaso) en la consecución del propósito de la comunicación.

No obstante, es interesante observar que Tarone y sus colaboradores también se refieren al concepto de registro en el mismo trabajo, en relación con el

\footnotetext{
${ }^{16}$ Se trata de consideraciones que en su mayoría ya hemos expuesto recientemente (v. Elorza 2003c).
} 
análisis de la frecuencia y distribución del uso de ciertos elementos gramaticales como método comúnmente aceptado y utilizado para diferenciar características peculiares de uso entre distintas variantes, como el Inglés General y el Inglés Científico y Técnico. Pero en los análisis que ellos mencionan se ponen de relieve varios problemas metodológicos y teóricos. Por ejemplo, no parece estar muy clara la finalidad del método aplicado. ¿Es la finalidad de su análisis el caracterizar una variante de la lengua como en el caso de Lankamp (1988)? Tampoco está muy claro el tipo de clasificación de los textos elegidos para formar el corpus de análisis (¿qué tipo de afinidad se establece entre «texts from a variety of scientific and technical fields»?), o el límite de los campos de conocimiento contemplados (¿qué comprenden exactamente los «belles lettres fields»?). Es bastante confusa la utilidad de la información extraída de los análisis, no sabemos muy bien qué se muestra, o se demuestra, que nos permita hacer conclusiones más generales que las que afectan al uso local de la lengua en los textos del corpus elegido:

It has long been accepted that one of the most salient grammatical features of
the register of English for Science and Technology (EST), as compared to
registers of 'general English', is its relatively frequent use of the passive form
of the verb. Frequency counts of verb tense and aspect performed on corpora
of data which combine texts from a variety of scientific and technical fields do
seem to show that, overall, the passive voice is used extensively in EST [...].
For example, Robinett (1980) performed such an analysis on a combination of
texts from scientific, as opposed to belles lettres fields, and found that when
all verb phrases containing be in each group of fields were analysed, $46 \%$ of
those occurring in scientific texts were passive constructions, while only $29 \%$
of those in the belles lettres corpus were passive. The only study of which we
are aware which examines the frequency of usage of the passive voice within
one particular field is Wingard's (1981) study of verb forms and functions in
six medical texts; interestingly, Wingard finds that verbs in the active voice
outnumber verbs in the passive. (Tarone et al. 1988:191)

En el comentario a la presentación del trabajo de Tarone et al. (Swales 1988), al igual que en el comentario de otros trabajos presentados en su recopilación, Swales señala la necesidad de tomar el resultado de estos trabajos con cautela, fundamentalmente por falta de verificación. Desde nuestro punto de vista, esta cautela es también necesaria porque en muchos de los análisis llevados a cabo (incluso actualmente), la ausencia de modelos teóricos explícitos en el diseño de los análisis hace muy difícil la valoración de los resultados. A pesar de esto, el ingente volumen de trabajos publicados sobre análisis relacionados con el uso de las lenguas en contextos profesionales hace posible hablar de diferentes tendencias en la investigación. 


\subsubsection{Análisis del género y análisis del registro}

Probablemente la pauta más característica de la investigación referente al análisis del género es que los análisis textuales siempre se suelen emprender dentro de un proyecto educativo o a partir de éste. Cabe pensar que es justamente esta característica la que lleva a Dudley-Evans a calificar de prescriptivo al análisis del genéro, en el sentido de que puede ser utilizado para hacer recomendaciones útiles para la didáctica, mientras que considera descriptivo el análisis del registro ${ }^{17}$. No obstante, en nuestro enfoque vamos a considerar ambos tipos de análisis desde un punto de vista descriptivo. Ya que nuestra valoración didáctica recae sobre las tareas que se realizan sobre los textos en el aula, partimos del supuesto de que el análisis textual está directamente relacionado con alguna tarea de finalidad didáctica y no se realiza per se. En general, en el ámbito del Inglés para Fines Específicos, la finalidad que se suele atribuir al análisis textual es descriptiva porque el propósito inicial que se plantea es el de establecer cómo es la lengua que se va a enseñar. Dudley-Evans esboza cómo suele ocurrir el proceso donde se inscribe el análisis del género (especialmente en relación con los géneros asociados al Inglés Científico y Técnico):
Today genre analysis dominates work in EST. The normal progression is to start with a needs analysis, progressing to a genre analysis (which links communicative with psychological and social aspects of the field) to see how texts work, and finally the writing of materials based on these analyses. (Dudley-Evans 1999; from Dudley-Evans's presentation at 'LSP Forum'99' reported by Les Kirkham 1999 for the TESOL Arabia Special Interest Group on Business English)

Otra tendencia de la investigación descriptiva que ha centrado el interés de la investigación en el entorno de las lenguas para fines específicos, denominada 'análisis del registro' (register analysis), se contempla bajo la perspectiva del registro como un tipo de variación lingüística, de acuerdo con el modelo de Halliday en el que se contemplan dos tipos de variación: la que depende del usuario del lenguaje y la que depende del uso. Para denominar este último tipo de variación lingüística, que se denomina también 'variación funcional', se utiliza el término 'registro'. Ghadessy (1994) enumera ejemplos de ambos tipos de variación, identificando las lenguas de especialización como variedades funcionales:

\footnotetext{
${ }^{17}$ En Dudley- Evans, T. (1987:2), según cita de Robinson (1991:26).
} 
Dialects, idiolects, sociolects, and genderlects are examples of the first type [variation based on the user of language], while the language of science and technology, legal English, the language of buying and selling, and the language of classroom interaction belong to the second type [variation based on the use of language]. (Ghadessy 1994:287)

El análisis del género ha sido identificado como una de las tendencias en el ámbito de la didáctica del Inglés para Fines Específicos (García Mayo 2000) y son numerosos los autores que han realizado avances en la descripción de la lengua utilizada en entornos profesionales a partir de este enfoque (de entre los trabajos más recientes, véase, por ejemplo, Candlin, Bhatia y Jensen 2002). A este respecto, Swales señala que «the amount of scholarly attention given to genre in recent years has clearly enriched our understanding of what genres are, how they form intertextual networks, and how they might be studied» (Swales 2001:12). No obstante, también señala que esta preocupación por los géneros, que ha ocupado los esfuerzos de la mayor parte de la investigación en el campo del Inglés para Fines Específicos en los últimos veinte años, no está exenta de problemas que afectan al propio concepto de género, así como a su aplicabilidad para la didáctica:

However, this considerable intellectual effort has - true to the peculiar nature
of the academy - also problematized the concept, thus rendering it rather
difficult to apply to pedagogical contexts without being encumbered by post-
modern anxieties. For one example, Berkenkotter \& Huckin in their rightly
influential 1995 volume stress that «genre knowledge is a form of situated
cognition, inextricable from professional writers procedural and social
knowledge» (1995:13). While as a theorist I might easily assent to such a
proposition, as a teacher of writing I am puzzled as to how I am going to cope
with those doctoral students who come from across the schools and colleges of
my university to attend our classes and yet who inhabit, in their disciplinary
contexts, very different epistemological and socio-academic worlds. (Swales
2001:12)

Se puede observar que el interés de Swales por los géneros se basa principalmente en su potencial para la didáctica como fuente de información sobre la lengua relevante. Esto conlleva que para este autor la cuestión de la adaptación conceptual del término 'género', término que habitualmente es utilizado en la literatura o el cine (Swales 1986) y que pasa a ser introducido y desarrollado en el campo de la lingüística aplicada, es secundaria. Por consiguiente, Swales deja sin dilucidar si la introducción de este término en la lingüística aplicada se debe a una necesidad producida por una carencia en los modelos teóricos de uso del lenguaje. Sin embargo, parece más probable que su utilización simplemente se deba a una aproximación intuitiva a los textos relacionados con una situación profesional concreta, basándose en la supuesta existencia de los géneros en el mundo real: 
I would suggest that a genre-approach not only makes sense as a way of structuring the narrow world of the classroom, but also reflects a reality beyond that narrow world. In effect, we operate in society, both at work and at play, partly through a repertoire of genres that most of us add to and become more proficient in as we become older. And we can see this by noting how frequently we use genre names in our everyday conversation and how easily we understand them. (Swales 1986:13)

Curiosamente, esta interpretación de los géneros como tipos intuitivos de texto coincide con la de Cook acerca de los tipos discursivos:

Far from being an academic abstraction, the notion of discourse type is something we all use everyday in order to orient ourselves towards the communication in which we are involved. Languages abound with names for discourse types, and in English there are a good number of quite ordinary words, for example: recipe [...] Such terms and their currency are another instance of the importance of top-down discourse processing. Tell somebody that 'It's just a joke', 'It's supposed to be a poem', 'No speeches please' or 'Let's have the meeting first and a chat later' and they will process or produce the discourse quite differently. There is no need to introduce any technical terms for discourse types, nor should we hesitate to name them to our students for fear of burdening them with jargon. They are a metalanguage, but one which exists in everyday language and is as useful for the foreign student as the native speaker. (Cook 1989:95)

No obstante, independientemente de la utilidad de tipo práctico del concepto intuitivo de género o de tipo discursivo, desde una aproximación teórica debemos aclarar qué situación ocupan dentro de los modelos de uso del lenguaje conceptos como el de género, el de registro, el de tipo discursivo, u otros utilizados de forma similar.

No es fácil resolver esta cuestión por diversas razones. Si nos fijamos en el modelo de Halliday (1978), nos encontramos con que el concepto de género no es utilizado por este autor. Ya hemos mencionado que Swales (2001:12) es de la opinión de que Halliday huye de este concepto por considerarlo demasiado subjetivo. Sin embargo, podemos argumentar que, si el modelo de Halliday (o cualquier otro modelo teórico) es suficientemente comprehensivo, entonces lo que Swales y otros autores denominan 'género' puede estar representado en él bajo otra denominación o con una conceptualización diferente. Esto es precisamente lo que vamos a explorar en la siguiente sección.

Existe también una razón de tipo práctico para intentar aclarar esta cuestión. La coexistencia actual de varias líneas de investigación en el campo del Inglés para Fines Específicos con denominaciones poco claras entre sí, como 'análisis del género', 'análisis del discurso' y 'análisis del registro', hace que a menudo estas denominaciones sean utilizadas indistintamente $\mathrm{y}$, por tanto, que el 
panorama de la investigación en este campo resulte confuso. Nos parece que la utilización de un marco teórico de referencia único es mucho más simple y productivo para analizar y evaluar el resultado de trabajos adscritos a diferentes tendencias de la investigación ${ }^{18}$.

Una muestra de la poca claridad que rodea a esta cuestión se observa si comparamos la concepción de Tarone et al. (1988) del género como una clase de tipos textuales, con una concepción como la de Swales (1986) en la que el género es equiparable a un tipo discursivo tal como Cook lo define (1989). Esta confusión no se reduce al ámbito de las lenguas para fines específicos, sino que afecta igualmente a otros entornos de la lingüística aplicada, tales como el campo de la traducción (v. García Izquierdo 2000), por lo que es doblemente relevante en este trabajo para poder integrar todos los aspectos involucrados en el lenguaje como interacción social intercultural en un mismo modelo de funcionamiento de éste.

Para poder desenmarañar toda esta confusión terminológica y explicar nuestra posición sobre esta cuestión, vamos a comenzar por reconducir en la sección siguiente las diferencias conceptuales entre los diferentes términos utilizados de forma confusa hacia dos conceptos más generales que la lingüística relaciona unánimemente: texto y discurso.

\subsubsection{Texto y discurso}

A pesar de que existe unanimidad en que los conceptos de texto y discurso están directamente relacionados, su interrelación, así como la noción que representa cada uno de ellos, son motivo de controversia:

Se han impreso muchas páginas y se han dedicado muchas horas de discusión a la pasión inútil de establecer las supuestas diferencias existentes entre «texto»y «discurso». Quien escribe estas líneas no tiene noticia en ningún caso equiparable en otros ámbitos del conocimiento: lo que unos lingüístas llaman «texto»es, precisamente, lo que otros denominan «discurso»y viceversa. Existe unanimidad en el desacuerdo. (Bonilla 1997:9)

\footnotetext{
18 A pesar de que cada tendencia de investigación tiende a utilizar sus propios métodos y a interesarse por objetos de estudio diferentes, lo cierto es que se producen solapamientos, tal como sugiere, por ejemplo, Dudley-Evans en relación con el método de Swales ('analysis of moves') utilizado comúnmente en el análisis del género: «genre analysis is not always concerned with the analysis of 'moves'; it also embraces, for example, studies of tense usage [...], lexical frequency [...] and classification of reporting verbs used in academic text» (Dudley-Evans 1994:220).
} 
Cook (1989) interpreta el texto como «a stretch of language interpreted formally, without context» (Cook 1989:156). Cook considera únicamente los elementos formales del texto, eliminando cualquier aspecto relacionado con el uso del texto en la comunicación, mientras que interpreta el discurso como «stretches of language perceived to be meaningful, unified, and purposive» (Cook 1989:158), es decir, incorporando asimismo los aspectos pragmáticos del lenguaje. La consideración del contexto es, en este caso, la que marca la diferencia entre texto y discurso, siendo ambos porciones de lenguaje. Por su parte, Lavandera (1990) considera que el texto es un producto del discurso y se sitúa en unas coordenadas temporales concretas, mientras que el discurso es interpretado como lengua puesta en uso, es decir, como habla emitida, tal como se muestra más abajo. En la aproximación de Cook la relación entre texto y discurso se interpreta en términos formales y pragmáticos pero ambos conceptos derivan de otro concepto más general, el de lenguaje. Lavandera, partiendo de la dicotomía de Saussure entre lengua y habla, sitúa el concepto de discurso en el ámbito del habla y, a partir de éste, deriva el concepto de texto:

Hay quien tiene miedo de llamar texto al discurso, discurso a lo que es un texto. Lo importante es explicitar cómo se van a emplear aquí estos términos. Nosotros vamos a usar discurso como palabra más amplia, más general. Texto, lo usaremos para distinguir, en algún caso, lo producido en un determinado momento del discurso. Discurso será entonces simplemente habla emitida y habrá momentos en que hablaremos de la situación del discurso y momentos en que hablaremos del discurso mismo. (Lavandera 1990:10)

Como podemos ver, para Lavandera el problema de qué entendemos por texto y por discurso no es más que una cuestión de distintos enfoques y posicionamientos del lingüista. Estas posiciones pueden variar en función de los objetivos de la investigación que se lleva a cabo en un momento dado, del tipo de conocimientos que persigue alcanzar ${ }^{19}$. En este sentido, estamos de acuerdo con esta autora en la importancia de hacer explícito qué se entiende por cada uno de estos términos. De hecho, pensamos que no sólo es importante, sino estrictamente

\footnotetext{
19 Además de las preferencias de tipo personal, estos intereses están a su vez directamente relacionados con los propios intereses de la disciplina, tal como señala De Beaugrande:
}

However much data a researcher may gather and evaluate, data can be significant only with respect to the cognitive interests of a discipline (v. Kuhn 1970; Schmidt 1975): commitments to seeking certain kinds of knowledge. Especially in linguistics, what constitutes worthwhile data, or how data should be treated, is by no means self-evident. (De Beaugrande 1980a:2) 
necesario cuando la utilización de estos términos es confusa en cuanto al solapamiento entre conceptos. Creemos que esta confusión está directamente relacionada con la falta de unanimidad que, como ya hemos mencionado, existe en la utilización de los términos de género y registro. Desde nuestra posición, tenemos la convicción de que la cuestión de fondo de estos problemas conceptuales reside en el papel que se le asigna al texto y al discurso, lo cual, en definitiva, implica asimismo la asunción de un cierto modelo de lenguaje en cada caso particular. Así pues, pensamos que la función que se le asigna al texto en cada conceptualización de las utilizadas por los diferentes investigadores contribuye en gran medida a la utilización de una terminología en particular, de acuerdo con lo que se toma en cada caso como unidad de análisis, así como con los resultados esperados.

A pesar de que en este trabajo la función didáctica de los textos ocupa una posición central, somos conscientes de que la función fundamental del texto no es la función didáctica, sino que su importancia, incluso desde una perspectiva didáctica, deriva de la función que se le asigna de manera natural en la situación original donde se produce, en cuanto que «verbal record of a communicative act», como lo definen Brown y Yule (1983:6). Siguiendo a De Beaugrande (1997), entendemos que tanto el texto como el discurso son los canales principales mediante los que la gente se pone en contacto con el lenguaje, por lo que la descripción de la lengua de especialidad está necesariamente ligada a los textos:

\begin{abstract}
If we define a text as a communicative event [...], a discourse would be a set of interconnected texts, the primary instance being the conversation. It would follow that text and discourse are the main channels for people to encounter language. If so, all work for cultivating or studying the language would have been at least implicitly or indirectly concerned with texts, even though only a few were explicitly or directly so. (De Beaugrande 1997:21)
\end{abstract}

Si para Cook los conceptos de texto y de discurso derivan directamente del concepto general de lenguaje (son porciones de éste), y para Lavandera el concepto de texto deriva del de discurso (el texto se produce en el discurso), De Beaugrande se sitúa en una posición distinta a ambos con respecto de la relación conceptual entre texto y discurso, ya que este autor toma el concepto de texto como noción central y, a partir de ésta, deriva el concepto de discurso.

De Beaugrande interpreta los textos como «meaningful configurations of language intended to communicate» (De Beaugrande 1980a:1), siendo precisamente su rasgo fundamental el hecho de que los textos siempre se dan en la comunicación, producidos por un único participante, y dentro de unos límites temporales (tal como apunta Lavandera también). A partir de esta concepción básica de texto, el discurso 
es interpretado como «a set of mutually relevant texts», como «a progression of occurrences that may be continued at a later time» (De Beaugrande 1980a:2). Por último, en un rango superior, De Beaugrande sitúa el 'universo del discurso', que define como «the total constellation of mutually relevant discourses in a group or society» (De Beaugrande 1980a:2). Esta noción de universo del discurso surge, tal como este autor apunta, a partir de la idea de intersección del dominio de cada discurso con los demás (Van Dijk 1977:127). Desde esta perspectiva, la lengua relevante para nuestro enfoque consiste en la lengua que se manifiesta en los textos que constituyen el universo del discurso científico, el universo del discurso técnico y el universo del discurso académico, tal como se manifiestan en la lengua inglesa y en la lengua española.

Para De Beaugrande (1980a:1), el cambio progresivo de la lingüística del texto hacia una posición central dentro de la disciplina del estudio del lenguaje parece estar marcando un cambio de paradigma científico (Kuhn 1962) en muchos países. Un cambio que describe como una desviación del interés por el lenguaje representado en oraciones acontextuales, hacia una nueva preocupación por las manifestaciones del lenguaje tal como se producen de forma natural, es decir, por los textos.

Esta preocupación por el texto es afín a la mostrada por los investigadores que trabajan en la descripción de la lengua en el ámbito de la didáctica de las lenguas para fines específicos. El texto es el punto de partida para la descripción de la lengua que se considera relevante para el aprendiz. Desde las diferentes aproximaciones a la descripción de la lengua mediante el análisis textual, la lengua que se considera didácticamente relevante es identificada por unos como aquella que es representada a través del registro textual, mientras que otros la describen mediante la caracterización del género textual y, por último, otros la caracterizan mediante los rasgos que le asignan al discurso asociado con un contexto determinado. En todas estas nociones subyace una interpretación particular del concepto de tipo de texto. Así, el texto es tomado como unidad de análisis con el fin de extraer conclusiones que sean extrapolables a una cierta tipología.

El texto es interpretado como un caso particular de un registro por Halliday (1978) y otros lingüistas en su misma línea. Ya vimos anteriormente que el registro determina a qué variedad pertenece el texto de acuerdo con el uso que se hace del lenguaje desde un punto de vista semántico. Así, el texto es concebido como una unidad semántica que presenta la selección de significados del autor. Podemos decir que, en el caso de la lingüística sistémico-funcional de Halliday, el concepto de 
registro está representado dentro del modelo de uso del lenguaje y tiene una función clara. Por consiguiente, podemos esperar que los resultados de un análisis del registro de un texto o de un corpus de textos ofrezcan información acerca del propio registro, es decir, acerca de la variedad funcional semántica a la que pertenecen los textos analizados con respecto de los elementos lingüísticos elegidos para expresar los significados presentes en esos textos, y con respecto a la propia presencia de unos u otros significados en particular.

Si definimos el texto como un acto esencialmente comunicativo, de acuerdo con la concepción de De Beaugrande, el texto también es interpretado como un caso particular de género por Swales y muchos de los investigadores del ámbito del Inglés para Fines Específicos que trabajan con el análisis de géneros. Swales define el género como un acto comunicativo entendido y reconocido socialmente por los participantes en cuanto a sus fines, como se puede comprobar en la definición reproducida a continuación. El texto, según la interpretación de De Beaugrande, es asimismo intencional y comunicativo. Pero Swales, además, relaciona de forma inherente el texto con las tareas que se realizan basándose en él, como se puede observar en el apartado (d) de su definición:

a) A genre is a recognized communicative event with a shared public purpose and with aims mutually understood by the participants within that event.

b) A genre is, within variable degrees of freedom, a structured and standardized communicative event with constraints on allowable contributions in terms of their positioning, form and intent.

c) Overt knowledge of the conventions of genre is likely to be much greater in those who routinely or professionally operate with that genre rather than in those who become involved with it only occasionally.

d) Societies give genre names to types of communicative event that they recognize as recurring. Named genres are manifestations through spoken or written texts (or both) and their associated text-based tasks.

e) Modified genre-names (survey article, issue memo, panel discussion) indicate features that a speech community finds salient and thus provide a way into sub-genres.

(Swales 1986:13)

Según Dudley-Evans (1994:219), el género, como concepto utilizado en el ámbito del Inglés para Fines Específicos, se diferencia del concepto literario de género en que el primero se caracteriza por su intención comunicativa, mientras que el género literario se distingue por sus rasgos formales. De acuerdo con esta interpretación, la intención comunicativa es el rasgo distintivo del género, ya que puede diferenciar un género de un registro y también un género de otros géneros:

Communicative purpose is [...] the defining feature by which a genre such as the academic article is distinguished from other genres and by which the 
consideration of genre is distinguished from the consideration of register. The use of genre in ESP or applied linguistics is thus distinct from its use in literary criticism, where a particular genre, for example a tragedy, a comedy or a novel, is distinguished by its form. (Dudley- Evans 1994:219)

Independientemente de lo controvertido de la afirmación de Dudley-Evans de que los géneros literarios se distinguen formalmente, sobre lo que no nos vamos a detener puesto que se trata de una cuestión alejada de los intereses de nuestro trabajo, si nos atenemos a las concepciones de registro y de género esbozadas más atrás podríamos establecer una distinción entre ambas nociones basándonos en que el registro es susceptible de ser utilizado para describir textos desde una perspectiva semántica, para poner de manifiesto los elementos lingüísticos y los significados, expresados en el texto mediante esos elementos, como datos analíticos de tipo semántico. Por su parte, el género sería útil para describir textos desde una perspectiva semiótica, es decir, para poner de manifiesto los elementos lingüísticos y los significados del texto como datos analíticos de tipo semiótico.

No obstante, si nos fijamos en el tipo de resultados y de conclusiones a las que se suele llegar, esta distinción no es real. Los análisis de géneros y los análisis de registros textuales no se diferencian por el tipo de datos que utilizan, sino más bien por el modo de denominar y clasificar esos datos, por la manera de tratar el material textual. A nuestro parecer, la diferencia fundamental entre estos distintos tipos de análisis estriba en la utilización de diferentes unidades analíticas.

De Beaugrande distingue entre unidades de tipo teórico y unidades de tipo práctico ${ }^{20}$. Esta distinción es útil para explicar las diferencias entre la utilización de diferentes conceptos de tipo o clase textual (género, registro, discurso, etc.), que hacen tan confuso el panorama de la investigación. Así, la importancia que se le da a cada tipo de unidad está relacionada con el modelo de lenguaje que se considera en cada caso, y la finalidad del análisis. El género, por poner un caso, ha sido utilizado tradicionalmente para distinguir entre textos literarios y no literarios (entre novelas y manuales de instrucciones, por ejemplo), así como para diferenciar distintas clases de textos literarios (entre novela, poesía y teatro, por ejemplo), si bien este término ha sido tomado y utilizado de forma distinta para analizar tipos de textos asociados con situaciones profesionales.

Para De Beaugrande (2000a), el hecho de tomar un concepto, como el de género, de otro campo o ámbito diferente y aplicarlo al análisis de textos asociados

\footnotetext{
${ }^{20}$ Según comunicación personal (correo electrónico de 9 de abril de 2002).
} 
con otro tipo de situación no supone un problema si esta forma de proceder resulta útil para obtener resultados en los análisis textuales:

\begin{abstract}
We need to examine a comprehensive range and variety of authentic texts and explore what sorts of properties deserve to be accounted for [...]. We can apply whichever categories and concepts of previous 'linguistics' seem productive, but we can also apply ones from adjacent fields, such as literary studies, cognitive science, artificial intelligence, ethnography, economics, and political science $[\ldots]$ - whatever bases we can enlist in exploring how speakers do select and combine words inside phrases, clauses, sentences, or any other relevant units, such as paragraphs, essays, or science textbooks. (De Beaugrande 2000a)
\end{abstract}

Creemos que los análisis de textos son aptos para llegar a conclusiones acerca del comportamiento textual en relación con los significados que son apropiados para una función lingüística en particular y con las palabras, estructuras sintácticas, y demás recursos del sistema lingüístico que se usan para expresar esos significados (v. Halliday 1978:195), así como para conocer los estilos característicos de producción textual en situaciones típicas o en ciertos grupos (v. De Beaugrande 1980a:243) ${ }^{21}$. En este sentido, los análisis de textos auténticos pueden proporcionarnos información referente a un único tipo discursivo, a varios tipos, o también información que se refiere al universo del discurso.

Según la concepción de De Beaugrande, la utilización de distintos tipos de unidades analíticas no implica que existan diferencias de nivel entre unas unidades y otras, sino que apunta más bien a diferencias de rango y, en este sentido, el discurso no ocupa un nivel distinto al del texto, sino únicamente un rango superior. Es decir, el hecho de que unos análisis utilicen el género como unidad y otros el titular, por poner un ejemplo, implica únicamente diferencias de rango en el nivel de análisis pero no de niveles lingüísticos, como ocurriría si comparamos el análisis fonológico de un texto con el análisis morfológico.

De Beaugrande utiliza los términos 'nivel' y 'rango' de forma diferenciada (De Beaugrande 1980a; 1984:93). Para este lingüista, el nivel es un concepto de tipo teórico que corresponde con un modelo en el que se interpreta que el lenguaje está compuesto por distintos sistemas que se sitúan en diferentes niveles pero que actúan simultáneamente, de tal modo que cada nivel se interpretea como «the total aspect of a participating language system»(De Beaugrande 1980a:7). Puesto que los

\footnotetext{
${ }^{21}$ El estilo del texto se interpreta como «the characteristic mapping procedures selected to produce a text» (De Beaugrande 1980a:9). Estos procedimientos son los que controlan la interacción entre la cohesión, lo que De Beaugrande denomina 'conectividad secuencial' (sequential connectivity), y la coherencia del texto o 'conectividad conceptual' (conceptual connectivity).
} 
niveles son de naturaleza teórica, las unidades que se manejan en cada nivel lingüístico son unidades de tipo teórico. Según De Beaugrande, estas unidades son el fonema, el morfema, el lexema y el sintagmema y se relacionan en forma de «dynamic form-function connections» (De Beaugrande 1997:183).

Por su parte, el concepto de rango es interpretado por De Beaugrande como «a unit of a given dimension in a hierarchy of size (e.g. word, sentence, etc.)» (De Beaugrande 1980a:7). Así, un rango es una unidad de tipo práctico, cuya utilidad primordial es proporcionar «practical terms with heuristic functions for promoting a convergence of data and a consensus among investigators more readily than would theoretical terms with strictly formal definitions» (De Beaugrande 1997:183).

Según esta aproximación, mientras que el concepto de nivel está por encima de todo el lenguaje (cada elemento está situado en un único nivel lingüístico), el rango es un concepto específico para cada unidad, de tal modo que la relación que se establece entre texto y discurso es una relación de rango y no de nivel, aunque esa relación pueda ser establecida de diferentes formas, tal como se puede observar al comparar la interpretación de Cook, la de Lavandera y la de De Beaugrande. Al tratarse de unidades de tipo práctico, las taxonomías que podemos establecer a partir del concepto de rango son mucho más numerosas y flexibles que las que se elaboran a partir de las unidades teóricas, ya que nos permiten que una muestra extraída de un texto pueda ser tratada analíticamente desde diversas aproximaciones al mismo tiempo. Por ejemplo, una palabra puede ser tomada como tal palabra pero también como un conjunto de sílabas o de letras, como una secuencia de fonemas o como parte de un sintagma, al igual que un discurso puede ser interpretado como un conjunto de textos:

For the forms we actually see as stretches of text, we can use the terms for ranks like those envisioned in British functional linguistics: Sound/Letter Syllable - Word - Collocation - Phrase - Clause - Clause Complex Sentence/Utterance - Discoursal Move - Discourse Episode - Text Discourse. Here, the practical part-whole relations are largely stipulated by the ordinary senses of the terms for ranks - e.g., a Syllable being a part of a Word and being pronounced as a unit, or a Phrase being a sequence of Words - and hold no profound theoretical significance. (De Beaugrande 1997:183)

Desde esta perspectiva, tanto el género como el registro son unidades prácticas que ocupan un rango superior al texto, al igual que sucede con el discurso según la interpretación de De Beaugrande. En este sentido, la confusión que existe entre los conceptos de género, de registro e incluso de discurso está originada en la propia consideración del texto como un tipo o clase de otra cosa, es decir, como 
ejemplo o muestra (token) de un prototipo, que es concebido como una unidad de rango superior. Esta confusión proviene de la falta de unanimidad en la adopción de un criterio único, por lo que parece que en la práctica la utilización de estas unidades no sirve para potenciar «a convergence of data and a consensus among investigators», tal como defiende De Beaugrande (1997:183). Lo que es más, esta falta de unanimidad no sólo afecta al análisis y clasificación de los textos en el ámbito de la didáctica de las lenguas para fines específicos, sino también al ámbito de la didáctica de la traducción, donde la clasificación tipológica de las traducciones ha recibido interés constante por parte de los investigadores y, por tanto, se observa el mismo tipo de confusión en la utilización de distintas unidades de forma aleatoria. Cabe señalar que, como indica García Izquierdo (2000), el interés por el concepto de tipo textual y por las clasificaciones tipológicas está, también en este ámbito, relacionado con la didáctica.

Para no extendernos innecesariamente, sólo mencionaremos dos ejemplos mediante los cuales se puede observar la falta de unanimidad en la utilización de unidades prácticas en el ámbito de la traducción. Estos ejemplos nos parecen suficientemente ilustrativos ya que en ambos casos se considera un modelo de lenguaje afín y, por tanto, no cabe plantearse que la falta de unanimidad entre ellos se deba a la utilización de diferentes modelos lingüísticos. Por una parte, Hatim y Mason (1990:69) utilizan como unidades con categoría semiótica el texto, el discurso y el género, mientras que, por otra parte, House utiliza el lenguaje, el registro y el género como categorías pertenecientes a distintos niveles cuya relación no se explica en términos de rango, sino en términos de realización:

In order to determine the function of a text -consisting of an ideational and an interpersonal function component- which must be kept equivalent in translation, the original text is analysed at the levels of Language, Register and Genre. The relationship between these three levels can be seen in terms of semiotic planes which relate to one another in a Hjelmslevian contentexpression way with Genre being the content-plane of Register, and Register being the expression-plane of Genre. Register in turn is the content-plane of Language, and Language is the expression-plane of Register. Register is divided into Field, Tenor and Mode. (House 2001:66) ${ }^{22}$

Para terminar, no nos queda sino explicar cúal es nuestra opción ante un panorama tan diverso. Dado que nuestro enfoque pretende ser comprehensivo, nos

\footnotetext{
${ }^{22}$ House no establece diferencias entre rangos y niveles por lo que, aunque sitúe estas categorías en diferentes niveles, esto no implica que esta autora considere que se trate de unidades de tipo teórico.
} 
parece que la mejor postura consiste en mantener una posición abierta. Esto implica adoptar una caracterización general de las tipologías textuales, evitando establecer tipos y subtipos ad hoc para el tipo de textos que se asocian con los contextos que estamos tratando. Esta actitud es coherente con el tipo de enfoque didáctico que hemos adoptado a lo largo de este trabajo en cuanto al grado de generalización posible y deseable. Se trata de una posición conveniente teniendo en cuenta que no hemos restringido la validez de nuestro planteamiento a un único tipo textual ni a un único tipo de variación funcional o de discurso específico, sino a todos los que se asocian típicamente con el Inglés Científico, Técnico y Académico. En este sentido, creemos que la unidad práctica básica más útil para la descripción de la lengua desde una perspectiva abierta es el texto, según la concepción y el criterio de De Beaugrande, cuyas características veremos con mayor detenimiento en el capítulo siguiente.

En nuestro planteamiento subyace la convicción de que es más fructífera la descripción de la lengua relevante para el aprendiz de Inglés Científico, Técnico y Académico desde una aproximación proveniente de la lingüística textual y del análisis del discurso, cuyo objeto de estudio son el texto y el discurso y cuyo objetivo consiste en explicar precisamente cómo funcionan aquellos, y no desde otros acercamientos a la lengua, incluyendo los desarrollados en el ámbito de la didáctica del Inglés para Fines Específicos. Esta convicción se basa en que, en la investigación desarrollada en el entorno del Inglés para Fines Específicos, el objetivo de la descripción de la lengua no constituye un fin en sí mismo, sino que se trata fundamentalmente de un medio para acceder al input que se quiere tratar en el curso de lengua. Así, la unidad analítica que se suele adoptar para la descripción textual corresponde más bien a la que utilizan intuitivamente los especialistas del campo de conocimientos relevante, que son al mismo tiempo miembros de la comunidad donde se produce la comunicación, pero que generalmente no se pueden considerar en sentido estricto analistas del lenguaje que producen e interpretan como usuarios.

Esto significa que, aunque la justificación que se suele emplear en este ámbito para llevar a cabo análisis sobre unidades intuitivas de tipo genérico se basa en su facilidad para ser reconocidas intuitivamente por los aprendices de los cursos y por los usuarios de los textos, en realidad esta justificación no es de tipo lingüístico. Es decir, no hay razones de carácter lingüístico que se puedan esgrimir para optar por una unidad analítica tan confusa como el género y, desde esta perspectiva, nos parece más razonable adoptar una unidad práctica establecida desde 
la propia lingüística textual. La ventaja evidente de actuar de este modo es que, al adoptar una unidad de tipo general con diferentes rangos, podemos dar cabida a todo tipo de análisis y de fenómenos lingüísticos, incluyendo por consiguiente el análisis de textos en la traducción.

Desde este enfoque, el texto es contemplado como una entidad única y holística compuesta por una cantidad indeterminada de elementos que poseen, entre otras, la propiedad de ser interpretados como representación de las opciones elegidas estratégicamente por el autor. En la traducción, tanto la producción del TO como la del TT son interpretadas como actividades teleológicas (v. Rabadán 1991b:45) en las que el texto se configura a partir de unos objetivos intencionales que incluyen, según Reiss y Vermeer (1991), la asignación al texto de una o varias funciones específicas.

En cuanto al discurso, debemos señalar con respecto a las variedades contempladas en nuestro trabajo, que el discurso científico y el discurso técnico suelen ser tomados en el ámbito de la didáctica como una única clase de textos. Esta variedad normalmente se denomina 'lenguaje científico-técnico' y se estudia mediante el análisis de lo que se suele clasificar como 'texto científico-técnico'. Análogamente, la didáctica del Inglés para Fines Específicos suele considerar el Inglés Científico-Técnico como una única variedad funcional de la lengua. En términos generales, se suele interpretar que tanto la variedad científica como la variedad técnica ocupan un mismo espacio socio-semiótico (White 1998), a pesar de que las diferencias existentes entre la ciencia, la técnica y la tecnología han sido abordadas y caracterizadas tanto desde enfoques epistemológicos (Vega Encabo 1996) como filosóficos (Quintanilla 1989) y son comúnmente aceptadas. White señala que ambas variedades lingüísticas presentan rasgos distintivos, tales como diferencias de preferencia al optar por ciertos usos léxicos, es decir, preferencias distintivas en cuanto a la selección de modos de expresión: «while the discourses of science and technology access the same set of lexical resources for their specialist terminology, they display different preferences in their use of these resources» (White 1998:269).

En este sentido, la caracterización de una lengua de especialidad, al igual que la de otras variedades funcionales de la lengua, conlleva desde nuestra posición la consideración de un modelo general de funcionamiento del lenguaje en uso que sea capaz de dar cuenta de todos los factores involucrados en la comunicación y no sólo de forma excluyente en un tipo determinado de comunicación. Asimismo, como quiera que nuestro interés se centra en la producción, transmisión (incluyendo 
la traducción como medio de transmisión intercultural) y recepción de conocimientos por medio de la escritura, podemos servirnos de forma particular de un modelo que dé cuenta de las características específicas de la comunicación escrita, especialmente de aquellas relevantes para la comunicación intercultural mediante la traducción de textos en entornos profesionales.

A lo largo de este capítulo dedicado al concepto de lenguaje que utilizamos en nuestro trabajo, nos hemos centrado en diversos aspectos relacionados con el uso del lenguaje desde distintas perspectivas. No obstante, es preciso que adoptemos un enfoque general que sirva para integrar todos los aspectos puntuales que hemos ido tratando. Este enfoque debe ser suficientemente comprehensivo para albergar todo tipo de fenómenos relacionados de un modo u otro con el uso del lenguaje, incluyendo de forma explícita el fenómeno de la traducción. En esta línea, precisamente, se centra el trabajo de Matthiessen (2001), en el que nos detendremos a continuación.

\subsubsection{Perspectiva global sobre la traducción en relación con el texto como unidad analítica}

En este bloque, que sirve de cierre a la sección dedicada a las unidades analíticas del texto, queremos tratar dos aspectos distintos en relación con este tema. Dado que nuestro interés por los textos en el presente trabajo de investigación está directamente relacionado con la traducción, en primer lugar nos parece pertinente hacer extensiva nuestra argumentación acerca de las unidades analíticas textuales a las traducciones que se van a realizar a lo largo del curso de Inglés para Fines Específicos, especialmente en relación con la función didáctica que estamos considerando. Como quiera que, como ya hemos mencionado, la confusión en cuanto a las unidades analíticas también está presente en el ámbito de la traducción, es necesario en cierto sentido que hagamos explícita nuestra posición sobre la tipología de las traducciones, a pesar de que nuestro afán es puramente utilitario en cuanto que sólo perseguimos la coherencia en la utilización de unas unidades u otras, más que un interés de tipo epistemológico por esta cuestión en particular.

El segundo aspecto, en el que nos vamos a basar para desarrollar paulatinamente el primero, consiste en situar la traducción en relación con las dimensiones que componen y organizan el espacio semiótico en el que se produce la comunicación, no sólo desde el punto de vista de la tipología, sino también en cuanto a la comparación intertextual. Para tratar ambos aspectos desde una 
perspectiva común y afín a la esbozada hasta el momento, nos basaremos en un reciente trabajo de Matthiessen.

Desde la perspectiva de la lingüística funcional, Matthiessen (2001) persigue ubicar la traducción en el entorno más amplio que se pueda contemplar desde una aproximación científica. Según este autor, este entorno está definido por una tipología comprehensiva compuesta por sistemas de todas clases. En esta tipología los sistemas se ordenan según su complejidad, desde los sistemas físicos hasta los sistemas semióticos.

En su trabajo, Matthiessen busca la contextualización de la traducción como una consecuencia de las reflexiones que se plantea a partir de la observación de estudios recientes sobre la traducción, y particularmente como reacción a la tendencia actual que este autor detecta, según la cual el fenómeno de la traducción es considerado desligándolo de otras cuestiones potencialmente relevantes. En nuestro caso, la contextualización de la traducción es necesaria para poder poner de manifiesto cuáles son los aspectos de este fenómeno que vamos a tomar en consideración desde nuestro enfoque didáctico. Necesitamos precisar cuáles son las unidades que vamos a utilizar en nuestro análisis de los textos que intervendrán en las tareas de traducción, si, por ejemplo, nos vamos a basar en una unidad como el género o como el registro, tal como suelen hacer los investigadores del ámbito del Inglés para Fines Específicos, y qué tipo de datos vamos a manejar en consecuencia.

Tal como hemos señalado en el bloque temático anterior, la unidad práctica que nos resulta más versátil para analizar textos, incluyendo el análisis de éstos dentro de las tareas de traducción, es el propio texto. Esto significa que hemos descartado centrar nuestro análisis en unidades propias de los niveles lingüísticos teóricos, específicamente el fonema, el morfema, el lexema y el sintagmema (De Beaugrande 1997:183). Sin embargo, esto no implica que los análisis se realizarán únicamente a un nivel general o insuficientemente detallado.

Hemos elegido trabajar con el rango textual del lenguaje puesto que es el único rango lingüístico que nos permite adoptar una perspectiva general acerca del lenguaje en uso y, al mismo tiempo, escudriñar en detalle las realizaciones concretas de éste, variando nuestro enfoque de lo más general a lo más particular y viceversa, de acuerdo con nuestras necesidades e intereses particulares en un momento dado y, por consiguiente, integrando un enfoque de arriba abajo con un enfoque de abajo arriba. Esto implica que podemos analizar los textos utilizando para ello todas las unidades de tipo práctico que sean de utilidad en el sistema paradigmático en el que se sitúa el rango textual, variando a voluntad el rango de la unidad de análisis 
(palabra, oración, grupo nominal, párrafo, texto, registro, discurso, etc.) en función de los objetivos y las necesidades establecidos en cada momento.

Como resultado, la complejidad de este amplio abanico de posibilidades analíticas se vuelve a nuestro favor. Nos referimos a la versatilidad resultante al considerar la aplicabilidad de las tareas de traducción en contextos didácticos muy diversos en cuanto al estado de conocimientos de los aprendices. Esta versatilidad se basa, particularmente, en la variedad de posibilidades que se refieren al modo de aplicación del análisis, así como al grado de exhaustividad en la aplicación. Asumimos que esta variabilidad de aplicación depende directamente de las necesidades y conocimientos específicos de cada grupo de aprendices, así como de los aspectos específicos que reciben nuestro interés en cada caso particular, como cuando nos planteamos el propósito de analizar en los textos el comportamiento de una estructura textual en concreto, por poner un caso que sólo puede ser tratado mediante el análisis de unidades de rango textual pero no mediante el análisis de unidades más limitadas.

Por otra parte, al aludir al sistema en el que se sitúa el rango textual, no nos referimos a las características sistemáticas del texto desligando la participación de los niveles lingüísticos, ya que sería muy poco productivo un análisis textual en el que se ignorara la existencia de niveles lingüísticos (teóricos) o en el que se obviara la utilidad de otros rangos (prácticos). Tampoco simplificamos el rango textual hasta el punto de suponer que corresponde con un sistema, el lenguaje, capaz de operar de modo independiente de los demás sistemas involucrados en la comunicación humana.

$\mathrm{Al}$ igual que sucede cuando sistematizamos otros niveles lingüísticos, como el fonológico o el morfológico, el sistema al que nos referimos resulta ser un complejo o un conglomerado de sistemas interrelacionados que cuentan con dos tipos de control regulativo, un control interno que actúa sobre el repertorio de opciones combinatorias disponibles y permisibles del sistema, y un control externo que regula la interacción de éste con otros sistemas:

When each language level is systematized, the entire language appears as an intersystem the workings of which depend on the interaction of participating systems [...]. Each system has internal controls that regulate the availability of options and the allowability of combinations; and external controls which regulate that system's interactions with other systems. Both kinds are indispensable to the production and utilization of texts [...]. (De Beaugrande 1980a:9-10) 
Los mecanismos de control actúan regulando el conglomerado de sistemas que componen el lenguaje, independientemente de qué complejo específico se trate. Cada conglomerado supone una configuración única de los sistemas virtuales en particular que lo constituyen. Esto significa que, aunque cada lengua es diferente de las demás, no obstante comparte ciertas características sistémicas con todas las demás lenguas. Una de estas características es que, independientemente de cómo sea una configuración dada, de cómo sean sus sistemas constituyentes o de qué potencial de significado tenga, los mecanismos de control interno y externo son los encargados de regular el comportamiento del conglomerado, es decir, de la lengua de que se trate.

Al considerar el fenómeno de la traducción, estamos tratando la relación que se establece entre configuraciones de sistemas que pueden estar más próximas o más alejadas en cuanto a las características particulares de los sistemas que las constituyen. En un sentido más amplio, el sistema lingüístico es a su vez un complejo de configuraciones con características idiosincráticas y también con características comunes a todas las demás configuraciones. Para Halliday y otros muchos lingüistas, la característica más relevante que comparten todas las configuraciones lingüísticas es que constituyen un sistema de tipo socio-semiótico.

Matthiessen se ha planteado cuál es la relación entre los sistemas sociosemióticos y otros tipos de sistemas y considera que los fenómenos que intervienen en la traducción se encuentran en un entorno compuesto por una jerarquía de complejidad creciente que consta de cuatro órdenes de sistemas, entre los que se encuentran los sistemas semióticos:

(i) Systems of the first order are physical systems, ranging in size from subatomic particles or strings to the entire universe, but subject throughout to the laws of physics. (ii) Systems of the second order are biological systems. They are physical systems with the added property of «life»: they are selfreplicating. (iii) Systems of the third order are social systems. They are biological systems (and hence also physical systems) with the added property of value: this means, among other things, that they are organized as social groups according to some form of division of labour. (iv) Systems of the fourth order are semiotic systems. They are social systems with the added property of meaning. Semiotic systems are systems for making meaning and to be able to make meaning they have to be stratified into at least two levels of strata - content and expression. Stratification is a kind of organization that distinguishes semiotic systems from systems of all other kinds. (Matthiessen 2001:49)

Para poder ilustrar de modo gráfico esta jerarquía de sistemas de complejidad creciente, Matthiessen (2001:50) ha elaborado la siguiente figura: 


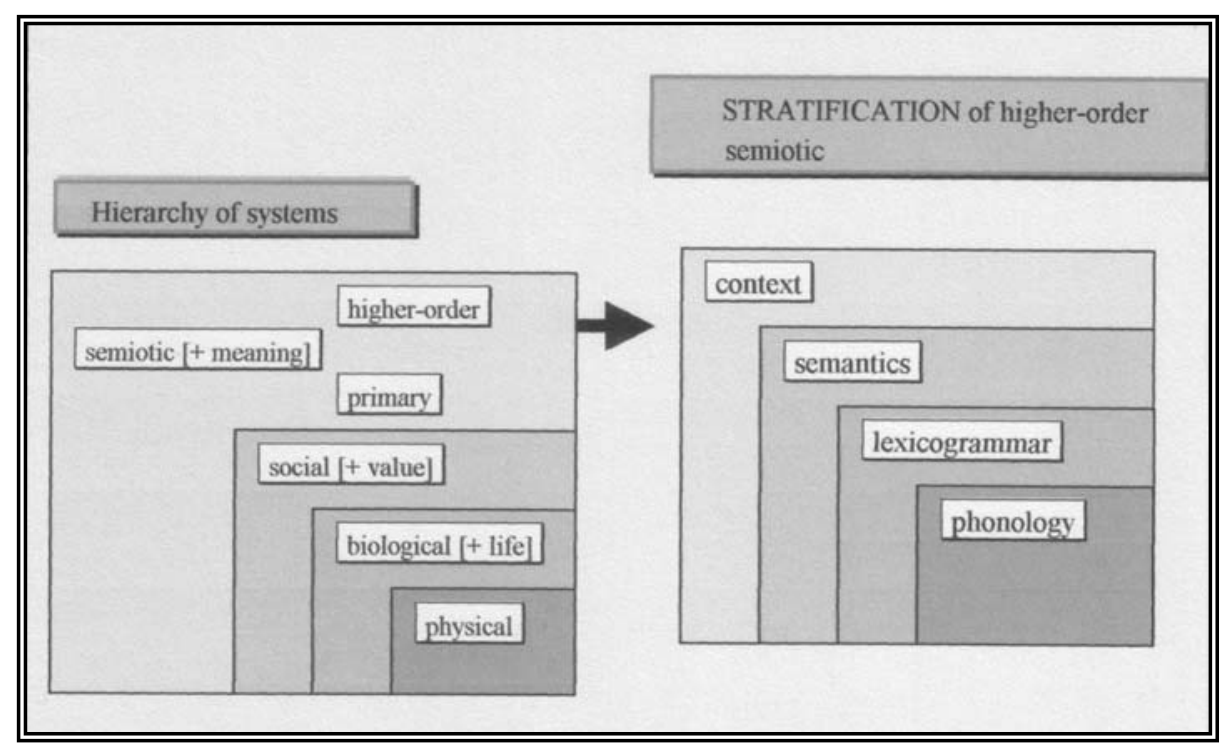

Figura 2. Modelización teórica del lenguaje como sistema socio-semiótico (Matthiessen 2001)

Según esta concepción, el lenguaje es un sistema semiótico, pero también un sistema social (estudiado por la sociolingüística), un sistema biológico (estudiado por la neurolingüística y por la fonética articulatoria) y un sistema físico (estudiado por la fonética acústica). No obstante, existen muchas otras formas de sistemas semióticos, incluyendo la expresión facial, los gestos, etc., que también han recibido el interés de la investigación en el ámbito de la traducción (véase, por ejemplo, Poyatos 1997), y que acompañan al lenguaje hablado o que pueden ser utilizados de forma independiente, además de otros sistemas que acompañan al lenguaje escrito o que pueden ser utilizados independientemente, como el dibujo, la pintura, etc.

Este enfoque teórico es consistente con el de Gentzler (1993), que sigue la clasificación de Jakobson de traducción 'intralingüística', 'interlingüística' e 'intersemiótica', y también con Bühler cuando afirma que la traducción «should be seen as a multi-channel communication phenomenon [...] and also should be studied within the overall framework of semiotics» (Bühler 1987:112).

Aunque podemos clasificar los sistemas semióticos en diferentes tipos de acuerdo con una tipología comprehensiva de tales sistemas, Matthiessen opina que una distinción crítica para la interpretación del lenguaje como una clase de sistema 
semiótico es la distinción que Halliday establece entre sistemas semióticos primarios y sistemas semióticos de orden superior

Los sistemas semióticos primarios están compuestos por dos únicos estratos, por lo que son microfuncionales en cuanto a su modo de significación, es decir, sólo pueden crear significado de un modo a un tiempo. Los protolenguajes infantiles constituyen una clase de sistemas semióticos primarios puesto que sólo tienen dos estratos: el nivel de la expresión y el nivel del contenido; es decir, carecen del nivel lexicogramatical. El sistema de señales de la circulación es otro ejemplo de sistema semiótico primario.

A su vez, los sistemas semióticos de orden superior están compuestos por tres estratos, por lo que son metafuncionales en cuanto a su modo de significación, ya que el significado puede ser creado de diversos modos al mismo tiempo. En estos sistemas, el nivel del contenido está a su vez estratificado en un plano semántico y un plano lexicogramatical.

Según este planteamiento, el lenguaje no sólo es considerado un sistema semiótico humano, sino probablemente también el único sistema de esta clase que es propiamente de orden superior, lo que hace que su posición sea única en la traducción intersemiótica (v. Matthiessen 2001:66).

La traducción es considerada por Matthiessen como un proceso que se da «within systems of all kinds or between systems of all kinds» (Matthiessen 2001:50). No obstante, teniendo en cuenta que la traducción supone una reproducción (o, en otras palabras, una replicación) de un texto en una lengua $A$ a partir de otro texto construido en una lengua $B$, traducir conlleva necesariamente la asignación de significado. Por consiguiente, la traducción se sitúa en los sistemas de cuarto orden, es decir, en los sistemas semióticos:

Translation is unique to semiotic systems; it is a semiotic process. This still leaves open the possibility that translation occurs both between semiotic systems and systems of other orders and within semiotic systems. We could say that when human beings construe experience of systems of any kind into meaning, they are «translating» non-semiotic patterns into semiotic ones [...]. The limiting case is perhaps the situation where people construe perceptual representation linguistically. If we interpret perception as a set of bio-semiotic systems (as suggested in Halliday \& Matthiessen 1999:606-10), we can say stretching the term translation- that bio-semiotic representations, e.g. representations construed by the human visual system, are translated into linguistic representations. [...]

However, it seems more helpful to model this as a process of construing experience as meaning [...] and to recognize translation as a special form of construal -one that takes place within systems of the fourth order: (experience construed as) meaning in one system is (re)construed as meaning in another. 
If we confine translation to semiotic systems in this way, this still leaves open the possibility that translation may occur between semiotic systems of different kinds (what Roman Jakobson called intersemiotic translation) as well as between systems of the same kind, e.g. between languages (Jakobson's interlingual translation). (Matthiessen 2001:51)

La traducción no es un reflejo pasivo del original, sino más bien «a creative art of reconstruing the meanings of the original as meanings in the 'target'» (Matthiessen 2001:64). Así, independientemente de que las transformaciones entre distintos sistemas semióticos sean consideradas traducciones o no, Matthiessen señala que esas transformaciones están situadas en un nivel de abstracción suficientemente por encima del nivel específico de la modalidad de la expresión como para hacer que dichas transformaciones sean posibles, lo que en términos lingüísticos equivale a decir que «they are located at the level of semantics rather than at the level of lexicogrammar (or the level of expression); and they are located within roughly the same context (of culture) as the original» (Matthiessen 2001:64) ${ }^{23}$. Según este autor, esto se ve muy claramente cuando consideramos la traducción de un protolenguaje infantil a una lengua. Como ya hemos visto antes, los protolenguajes infantiles son sistemas semióticos de tipo primario, lo que significa que únicamente disponen del nivel de la expresión y del nivel del contenido pero no del nivel lexicogramatical. Por consiguiente,

protolinguistic content can thus be «translated» into linguistic content only at the level of semantics within language; but since language is a higher-order semiotic with a level of lexicogrammar, the translations will inevitably impose lexicogrammatical patterns on the translations. (Matthiessen 2001:64)

Asimismo, Matthiessen continúa señalando que la realización del nivel más bajo dentro de cada sistema semiótico tiene un papel importante a la hora de determinar cómo se traducen los significados. De modo más específico, el nivel lexicogramatical del lenguaje es un recurso que sirve para construir representaciones más o menos esquematizadas, que varían en cuanto al grado de generalización o de especificidad, así como al grado de abstracción o concreción y también al grado de expansión, desde configuraciones nucleares hasta configuraciones muy expandidas. Según Matthiessen, la capacidad para construir representaciones constituye un aspecto importante de la potencia de un sistema semiótico de orden superior con un nivel lexicogramatical. Otros aspectos

\footnotetext{
23 Matthiessen (2001:52-64) analiza algunos ejemplos de transformaciones entre diferentes sistemas semióticos, tales como la traducción de varios pasajes de Macbeth a una pintura al óleo.
} 
igualmente importantes en relación con la potencia de un sistema tal incluyen la organización metafuncional (es decir, los modos de creación de significado que suceden simultáneamente pero que pueden varíar de forma independiente entre sí) y el potencial de la metáfora, interpretada por Matthiessen como la capacidad del propio sistema semiótico para reconstruir la experiencia.

Como ya hemos mencionado anteriormente, el lenguaje es considerado el único sistema semiótico humano que es propiamente de orden superior. Un aspecto que incide en esta idea viene dado por la noción de 'zona de convergencia', que Matthiessen toma de otros investigadores (Damasio y Damasio 1992; según referencia de Matthiessen 2001:66) porque cree que ayuda a explicar por qué el lenguaje tiene el poder de integrar significados provenientes de diferentes sistemas semióticos. Según este autor, esta noción está relacionada con la hipótesis de Michio Sugeno, cuya comprobación se está llevando a cabo en el Tokyo Institute of Technology (Matthiessen 2001:66), y según la cual el lenguaje constituye el recurso primario para la fusión de información proveniente de distintas fuentes semióticas. En este sentido, el lenguaje vendría a constituir una zona de convergencia de los sistemas semióticos. La hipótesis de trabajo es que el lenguaje es el único sistema semiótico al que todos los demás sistemas semióticos (humanos) pueden ser traducidos, a pesar de que las traducciones entre diferentes sistemas no sean literales: «they are bound to be very 'free' because they have to be done at the level of semantics and thus be abstracted away from lower-level 'renderings' of meaning» (Matthiessen 2001:66).

Matthiessen continúa señalando que, si aceptamos la traducción intersemiótica como una clase de traducción, entonces podemos ver claramente que la traducción debe ser modelizada en primera instancia como una correspondencia (o transformación) de significados (en el nivel de la semántica) ${ }^{24}$. Podemos asimismo percibir cómo esta correspondencia debe ser representada por una correspondencia difusa, debido a su indeterminación ${ }^{25}$. No obstante, cuando consideramos la traducción entre sistemas semióticos de la misma clase, podemos esperar razonablemente que aumente drásticamente el potencial de la traducción, de modo que cuando traducimos entre dos lenguas habrá muchos más puntos de contacto que cuando traducimos entre una lengua y otro tipo de sistema semiótico.

\footnotetext{
${ }^{24}$ La 'modelización' implica la simulación de procesos.

25 La experiencia práctica nos muestra que los aprendices tienden a representar esta correspondencia como una correspondencia unívoca o incluso biunívoca.
} 
Al traducir entre dos lenguas podemos establecer correspondencias entre dos sistemas gramaticales, además de entre dos sistemas semánticos, por lo que la traducción interlingüística se define como «translation where it is possible to translate between wordings at the level of lexicogrammar» (Matthiessen 2001:66).

Asimismo, Matthiessen señala la importancia de tener un cierto sentido de los límites externos de la distancia tipológica de los sistemas lingüísticos involucrados cuando traducimos entre lenguas. Podemos esperar razonablemente que los límites externos puedan ser definidos para ciertos sistemas gramaticales en relación con las lenguas cuya distancia tipológica sea máxima en cuanto a estos sistemas $^{26}$. Pero, si la traducción entre lenguas tipológicamente distantes representa un extremo de la escala de diferencias en la traducción, Matthiessen señala que podemos esperar razonablemente que el otro extremo de la escala esté representado por la traducción entre variedades de la misma lengua, lo que Jakobson denomina la 'traducción intralingüística'.

Por lo que concierne a la traducción entre variedades de la misma lengua, Matthiessen explora tanto la traducción entre variedades dialectales como entre variedades de registro. Para la relación entre variedades dialectales, este autor señala que las diferencias traslativas son mínimas:

Since dialect variation is characterized by phonological variation and to some extent by lexicogrammatical variation but the semantics remain constant (as noted in e.g. Halliday 1978, dialects represent different ways of saying the same thing), translation should constitute a minimal transformation of meanings and also a minimal transformation of many lexicogrammatical patterns. (Matthiessen 2001:67)

Pero en cuanto a las variedades de registro, Matthiessen señala que la traducción como tal entre textos de diferentes registros no es posible. Según el enfoque sistémico funcional, la variación de un registro a otro implica a su vez una variación de los significados que se expresan (Halliday 1978:35). A pesar de esto, se produce una excepción cuando el cambio de registro es utilizado como recurso humorístico, por ejemplo, cuando el programa de una asignatura de un curso académico es presentado como el prospecto de un medicamento, como se puede observar en el Anexo C) ${ }^{27}$.

\footnotetext{
${ }^{26}$ La tipología lingüística es tomada como una tipología de sistemas (lexicogramatical, semántico, etc.), más que como una tipología de las lenguas en su totalidad (v. Matthiessen 2001:67).

${ }^{27}$ Matthiessen señala que la gente es consciente de esta imposibilidad, y una muestra de ello es que la adaptación parcial de un registro a otro ha sido también explorada en el campo literario. Las «Instrucciones para subir una escalera» de Julio Cortázar (Historias de Cronopios y de Famas)
} 
En cualquier caso, frecuentemente se realiza lo que este autor denomina 'partial translation', que implica un cambio de registro (Matthiessen 2001:69). Los cambios de registro incluyen, entre otros tipos, las transformaciones de registros hablados a registros escritos y viceversa. Éstas conllevan únicamente cambios de modo pero no de campo o de tenor, por lo que se asocian con el tipo de transformaciones que se producen entre lenguas tipológicamente muy distantes (Matthiessen 2001:70).

Matthiessen explora cuáles son los límites de la traducción mediante el análisis de los límites de la traducción intersemiótica y de la traducción intralingüística, con el fin de delimitar el dominio de aplicabilidad de la traducción dentro del sistema de sistemas que componen nuestro mundo fenomenológico tal como lo conocemos desde una perspectiva científica. Así, el dominio de la traducción se sitúa en los sistemas de cuarto orden, es decir, en los sistemas semióticos. Desde esta perspectiva, el proceso de traducir se lleva a cabo en términos de los recursos de que disponen los sistemas involucrados.

Siguiendo a este lingüista, podemos asumir las siguientes presuposiciones. En primer lugar, los recursos de cada lengua o sistema semiótico están representados de forma independiente entre sí como una colección de sistemas monolingües o monomodales y sólo se relacionan mediante aserciones que especifican las correspondencias traslativas ${ }^{28}$. Además de esto, suponemos que los recursos de cada lengua o sistema semiótico están totalmente integrados en un único sistema multilingüe o multimodal, y esta integración posibilita la traducción, si bien este sistema existe independientemente de que la traducción se produzca o no.

Tal como señala el propio autor, una de las consecuencias de adoptar esta perspectiva es que podemos interpretar la traducción en los términos de una teoría difusa, es decir, como una cuestión de grado (Matthiessen 2001:73). Esto nos resulta conveniente, tanto si comparamos recursos de distintos sistemas como si comparamos textos y tipos textuales de distintas lenguas, ya que los recursos nunca son exactamente iguales:

For example, while both the mood grammars of both English and German include 'imperative' mood types that have the same basic value in the mood

constituyen un ejemplo de este tipo de adaptación, en el que el registro de los manuales de instrucciones se adapta a la narración literaria breve (además de otros juegos lingüísticos que tienen que ver, entre otras estrategias textuales, con un uso anómalo de la correferencia).

${ }^{28}$ En esta línea interpretamos el binomio textual de Rabadán, así como su concepción dinámica de la equivalencia translémica (Rabadán 1991a; 1991b). 
systems of the languages, they do not overlap entirely in the grammar and as Teich has found in a study of instructional texts, they differ semantically, at least in the register of procedural instruction. (Matthiessen 2001:73)

Por su parte, Wilss también redunda en la misma idea:

Even between languages which are closely related typologically -for example English and German- there are sizable structural differences in the syntactic, syntagmatic, and lexical categories. This means that cases where the SL [source language] textual segments can be transferred into the TL [target language] on the basis of a lexical and/or syntactic one-to-one correspondence are relatively rare, especially if TE [translation equivalence] not only of content, but also of style, is to be preserved. (Wilss 1982:64)

La traducción interlingüística, que es la que nos interesa específicamente en nuestro trabajo, siempre se lleva a cabo entre sistemas semióticos que tienen una cierta distancia tipológica, por lo que invariablemente presentan diferencias entre sí. A pesar de que esto resulta obvio, no es en absoluto irrelevante.

Tradicionalmente la traducción de textos se ha interpretado como un fenómeno mediante el cual textos producidos en distintos momentos y sistemas se relacionaban en términos de igualdad. No obstante, más que un rasgo característico que se revela al comparar un TT con su correspondiente TO, dicha igualdad es un valor asignado al TT por su productor.

Lo que hace el productor de ese segundo texto al asignarle el rasgo añadido de 'traducción del texto $\mathrm{X}$ ' es establecer entre ambos textos una relación que De Beaugrande, como veremos más adelante, denomina 'intertextual'. Si únicamente centramos nuestra atención en comparar ambos textos mediante una lectura rápida, lo que el ojo humano ve con total seguridad es que se trata de textos diferentes. Es la diferencia o variación intertextual, y no la igualdad, lo que más llamativamente caracteriza a dos textos que se comparan, tal como explica Gentzler: «what has become clear is the large degree of variability in translated texts» (Gentzler 1993:67). En este sentido, y en la misma línea que Halliday, Wilss opina que la variabilidad, más que una propiedad singular de los TTs, es una propiedad de las lenguas naturales, lo cual significa que no hay un único modo de expresar lo que queremos decir y, paralelamente, que no hay un único modo de traducir:

Natural languages [...] are basically variability-oriented. For any linguistically difficult passage or sentence, let alone paragraph or text, there are «often many equally good and in different respects equally adequate versions» (Newmark 1979, 101). This means that, as a rule, more than one adequate TL [target language] equivalent is available for a SL [source language] textual segment. The translator thus frequently finds himself in a conflict-and-decision-marked situation during the translation process [...], a situation which becomes all the 
more difficult to master, the more complex the textual segment to be translated is in terms of syntax, semantics and stylistics. (Wilss 1982:64-65)

Ésta es la razón por la que nos resulta conveniente interpretar la traducción en términos de grados relativos y no en términos de correspondencias absolutas.

Desde esta perspectiva, la igualdad entre el TT y el TO viene a constituir, en primera instancia, una declaración de intenciones del productor del TT. Dicho de otro modo, el traductor se propone crear (re-crear) un texto mediante un tipo o modo específico de producción textual en el que se estipula el prerrequisito de que el texto que va a producir debe ser igual o equivalente a otro texto previo que se toma como modelo y que se asume como creativamente original.

La lingüística contrastiva pone el énfasis en la comparación entre los diferentes sistemas lingüísticos. No obstante, los recursos de cada lengua o sistema semiótico sólo se pueden relacionar con los de otra lengua o sistema mediante aserciones que especifiquen las correspondencias traslativas, tal como sugiere Matthiessen $(2001: 72)^{29}$. Además de esto, la especificación de dichas correspondencias depende de los usuarios del lenguaje y no de correspondencias establecidas a priori entre los propios sistemas lingüísticos. Por consiguiente, podemos concluir que la diferencia o igualdad entre un TT y su correspondiente TO no se deduce a partir de correspondencias estables entre sistemas semióticos, sino mediante la asignación de valoraciones de tipo ético. Nord diferencia muy acertadamente entre la 'lealtad' del traductor al cliente que hace el encargo de traducción y su 'fidelidad' al TO, pero ambos tipos de servidumbre constituyen conductas de tipo ético, situadas en el ámbito extratextual, aunque esto no significa en absoluto que sean ajenas al texto.

De acuerdo con Nord, la asignación de un valor de tipo ético, como es la fidelidad, a la comparación entre un TT y su correspondiente TO se identifica comúnmente con el concepto de equivalencia, pero sin embargo esta identificación no ha sido muy fructífera para especificar las correspondencias entre TTs y TOs:

\begin{abstract}
A translation is normally expected to render «faithfully» all the relevant features of the source text. It is a fairly common assumption, and also one often held by linguists and literary critics, even, that the concept of faithfulness or «fidelity» can be equated with «equivalence», as is illustrated by Königs' statement that «aiming at equivalence is implicit in the very definition of translating or translation» [...]. Here, equivalence means «the greatest possible correspondence between source text and target text».
\end{abstract}

\footnotetext{
${ }^{29}$ Para un enfoque diferente, véase, por ejemplo, Hewson y Martin (1991).
} 
This rather unreflected equation of translation and equivalence appears to be responsible for the deplorable fact that the eternal discussions about fidelity and freedom or liberty in translation have got us absolutely nowhere. The line between fidelity (being faithful) and servility (being too faithful) on the one hand, and liberty (being free) and libertinage (being too free, i.e. adapting or «even» paraphrasing) on the other, is drawn according to the criterion that a «too faithful» or «too free» version is not equivalent and therefore cannot be regarded as a translation proper. (Nord 1991:22)

En esta línea, Chesterman concluye lo siguiente: «(total) equivalence is a red herring, in that it is unattainable, and hence not a useful concept in translation theory» (Chesterman 1997:9).

Por otra parte, estas valoraciones éticas se efectúan sobre correspondencias que se establecen en cada caso particular, es decir, entre manifestaciones o actualizaciones de los sistemas y no en el ámbito virtual de éstos. Esto implica que, independientemente del tipo de valoración ética que se les asigne, las correspondencias se establecen en el entorno del texto y del discurso y, en este sentido, la adopción del texto como unidad de análisis es coherente con esta concepción de la traducción, además de conveniente para considerar el análisis de las traducciones en el aula.

Utilizar el texto como unidad práctica de análisis de las correspondencias entre un TT y su TO, además de presentar las ventajas de utilizar como marco de referencia todo el aparato crítico desarrollado por la lingüística textual, nos proporciona indirectamente un modo práctico de evitar los problemas derivados de la carencia de una unidad teórica consensuada en el ámbito de los Estudios de Traducción. Esta carencia conlleva, entre otras consecuencias, la imposibilidad de establecer una clasificación tipológica de las traducciones que esté al mismo tiempo suficientemente consensuada.

La aparente falta de resultados para encontrar una unidad consensuada podría ser el resultado de una despreocupación achacable al desfase entre la tradicional práctica de la traducción y la comparativamente reciente conceptualización teórica de ésta, desfase al que ya nos referimos al principio de este trabajo, y al que Gentzler (1993:43) alude de este modo: «people practised translation, but they were never quite sure what they were practising». No obstante, la búsqueda de una unidad de tipo teórico que nos permita categorizar el fenómeno de la traducción se remonta, según Rabadán, a la Antigüedad Clásica: «ever since Cicero departed from the dogma of the word-for-word rendering, theorists have been confronted with the need for a concrete and reliable unit of translation (UT) » (Rabadán 1991b:38). Por otra parte, podemos pensar que esta falta de resultados se 
debe a la dificultad intrínseca de la búsqueda, tal como sugieren algunos autores, por ejemplo, Santoyo: «verdad es que existe la conciencia de que la identificación y el estudio de [las unidades mínimas de traducción] ha de resultar fundamental para la traducción. Pero ¿cuáles son y dónde están?» (Santoyo 1983:256).

Rabadán señala tres razones fundamentales para explicar la falta de consenso acerca de la unidad mínima de traducción:

(1) the long-standing dependency of translational research on purely linguistic procedures, (2) the great complexity of the models of text analysis and their unrelatedness to translation, and (3), most important of all, the inherent indeterminacy of the central notion of translation equivalence. (Rabadán 1991b:38)

En el ámbito de la traducción podemos encontrar todo tipo de clasificaciones tipológicas y, dado que en nuestro trabajo nos centramos en lo que se denomina 'traducción especializada', nos vamos a detener brevemente en esta cuestión.

En general, podemos afirmar que se suelen utilizar principalmente dos criterios alternativos para establecer taxonomías en el ámbito de la traducción.

Uno de ellos, que suele adoptar la forma de contraste de tipo binario, utiliza como criterio de clasificación el tipo de equivalencia que se busca o que se establece entre el TT y el TO. A propósito de este aspecto, Chesterman cita diferentes tipos de equivalencia y de traducción utilizados por diversos autores:

A metaphor states that two different entities are identical in some respect: $\mathrm{X}=$ Y. Source text and target text are «the same». Exactly what this «sameness» consists of is, of course, open to endless debate.

One frequent ploy is to break up equivalence into various subtypes, for instance a binary opposition between two main types. Nida (1964) distinguishes between formal and dynamic equivalence, for instance, formal focusing on the message itself (aiming at the same form and meaning) and dynamic on its reception (aiming at the same effect). These two are not mutually exclusive, however; formal equivalence may exist (in theory) at the lower grammatical levels of morpheme, word, phrase, perhaps up to sentence breaks, while dynamic equivalence more naturally has to do primarily with the text as a whole (see Jakobsen 1994a). Other scholars prefer different labels but make the same basic distinction between two main kinds of translation: semantic vs. instrumental (Newmark 1981), overt vs. covert (House 1981), documentary vs. instrumental (Nord 1991), imitative vs. functional (Jakobsen 1994a). (Chesterman 1997:9)

El segundo criterio es más sofisticado que el anterior, puesto que la equivalencia se subdivide en más tipos y se establece una jerarquía prioritaria entre 
ellos que Chesterman relaciona con factores comunicativos como el tipo de texto y el contexto de situación:

Other classifications have been more complex: equivalence has split up into functional, stylistic, semantic, formal or grammatical, statistical and textual subtypes, and then hierarchies are posited which give some subtypes higher priority than others. [...] Such priorities obviously depend also on text-type, communicative situation, etc. In literary translation, for instance, it is commonly assumed that there should be a «sameness» of image or conceptualization, i.e. a kind of stylistic-semantic equivalence. (Chesterman 1997:9)

Adoptando una posición ecléctica sobre estas clasificaciones en relación con la didáctica de la traducción, creemos que el primer tipo de clasificación binaria es útil para ser utilizado como un criterio de actuación general, similar a lo que Toury (1995) denomina 'normas preliminares' (preliminary norms) ${ }^{30}$. Asimismo, el segundo tipo es útil para interpretar las correspondencias entre el TT y el TO como casos particulares de manifestaciones intertextuales de tipos de situación, registro, género, discurso, etc., así como para poner de manifiesto cómo son las correspondencias específicas que el traductor establece entre el TT y el TO, es decir, para poder analizar y describir qué características particulares tiene ese binomio textual (Rabadán 1991a) en concreto, tanto en niveles macrotextuales como microtextuales. Este tipo de clasificación es semejante a lo que Toury denomina 'normas operativas' (operational norms), que son las que intervienen en las decisiones que el traductor toma durante el proceso de traducción.

Desde una perspectiva cognitiva, asumimos que las correspondencias del binomio textual adoptan unas características determinadas como consecuencia de una serie de tomas de decisión del traductor que conducen hasta el resultado final del proceso, la producción del TT, de un modo similar al de otros procesos cognitivos que intervienen en la producción textual.

Pero además de esto, y como consecuencia de las diferencias tipológicas existentes entre los sistemas semióticos involucrados al traducir, al menos en el entorno de la didáctica el par de lenguas que se asocia mediante la traducción es relevante desde el punto de vista teórico para el resultado final del proceso de traducción, por lo que creemos que debe tener algún tipo de presencia en el modelo

\footnotetext{
${ }^{30}$ En un sentido más productivo para la didáctica, no interpretamos aquí las normas como valores compartidos por un grupo social, sino más bien como pautas de actuación a partir de las cuales el comportamiento individual puede ser evaluado, siguiendo a Toury: «norms also serve as criteria according to which actual instances of behaviour are evaluated.» (Toury 1995:55).
} 
didáctico que se utilice, aunque no sea relevante para el modelo de traducción utilizado, ya que es más productivo un modelo teórico que pueda dar cuenta de la traducción independientemente de las características específicas que adopte en un momento y para una situación determinada. Y lo que es más, no sólo el par de sistemas lingüísticos involucrados es relevante, sino también la direccionalidad específica del par de lenguas de los textos en relación con la lengua materna del traductor (Marmaridou 1996) ${ }^{31}$. Por esta razón, debemos restringir con mayor precisión los límites de nuestro trabajo y, en consecuencia, nos ceñimos específicamente a la traducción del inglés al español, siendo el español la lengua materna mayoritaria de los estudiantes.

Por lo que respecta a los factores comunicativos que se relacionan con las jerarquías de equivalencias del segundo criterio citado por Chesterman (1997:9), el tipo de traducción relevante para nosotros se asocia con un contexto de situación identificado con el entorno profesional y académico de los estudiantes considerados en nuestro proyecto de enseñanza-aprendizaje. En nuestro modelo didáctico consideramos la traducción realizada entre textos producidos mediante el modo escrito de comunicación o 'traducción escrita' (Hurtado Albir 1999), así como los tipos de texto que se suelen asociar típicamente con las situaciones profesionales y académicas de estos estudiantes y que se suelen denominar 'textos especializados',

\footnotetext{
${ }^{31}$ En realidad, la relevancia de estas cuestiones afecta al modelo didáctico que se utilice y también al modo de aplicación del modelo analítico que emplearemos en las tareas de traducción. Según los objetivos que Nord (1991) desea alcanzar, los aspectos mencionados no son relevantes para el modelo de análisis textual orientado a la traducción que esta autora propone:
}

In my view, it should be possible to produce a model of translation-oriented text analysis without reference to the specific characteristics of the source or target languages. It should not depend on the translator's level of competence (i.e. on whether he/she is a professional or a trainee) and should be valid for both directions, i.e. translating into as well as out of the translator's native language. The model thus produced can then serve as a general theoretical basis for translation studies, translator training and translation practice. The translator who has been trained to work with the model using one particular language and culture pair as a basis should also be in a position to apply it to other language and culture pairs, given the necessary proficiency in language and culture. (Nord 1991:1-2)

No obstante, como veremos más adelante, nosotros adaptaremos el modelo de acuerdo con la diferencia entre los objetivos que persigue Nord con su modelo de análisis y la aplicación que nosotros queremos analizar de las tareas de traducción en el aula de Inglés para Fines Específicos. La adaptación que haremos implica la consideración de aspectos relacionados con el par de lenguas asociado, así como con su direccionalidad en relación con la lengua materna del aprendiz, ya que consideramos que sí son relevantes para nuestra aplicación del modelo, de acuerdo con los objetivos que se le asignan al análisis. 
'textos para propósitos específicos' o TPEs (Rabadán 1991a). De acuerdo con los tipos de textos involucrados se trata, por tanto, de traducción especializada o, según los descriptores del Marco de Referencia Europeo, 'traducción exacta'.

Por otra parte, aunque es muy común el hecho de clasificar la traducción a partir de una tipología textual, como sucede al dividir los tipos de traducción entre traducción literaria y traducción especializada, Rabadán (1991b) plantea una objeción a que la unidad teórica mínima de traducción sea de tipo textual.

$\mathrm{Al}$ estudiar las aproximaciones que se han realizado en el campo de los Estudios de Traducción a la cuestión de la unidad mínima traslativa de tipo teórico, Rabadán describe tres enfoques distintos relacionados con el concepto de lenguaje subyacente en cada uno de ellos, y que denomina respectivamente, el 'enfoque lingüístico-formal', el 'enfoque semántico-textual' y el 'enfoque binario'.

Rabadán (1991b) descarta el primer enfoque porque, al aproximarse al fenómeno de la traducción a partir de una concepción formal del lenguaje, los procesos y productos de la traducción son analizados en términos de categorías lingüísticas y el significado, o bien se deja fuera de los intereses de la disciplina, o bien se equipara con el léxico. Por último, esta autora critica que bajo este enfoque la equivalencia se interpreta como la suma total de los equivalentes de rango menor, y además se considera que ésta es independiente de cualquier clase de contexto extralingüístico.

A continuación, Rabadán explica cómo, bajo el enfoque semántico-textual, es el texto el que se considera la unidad mínima de traducción: «instead of 'lexical chunks' or syntactically delimited units, the whole text was regarded as the basic UT [unit of translation]» (Rabadán 1991b:39-40). Así, la equivalencia se convierte en una cuestión de funciones textuales y tipos de texto, ya que se parte de una concepción funcional del lenguaje y, por tanto, éste se liga intrínsecamente a su uso real. Por igual motivo, se tienen en consideración tanto factores contextuales (aquellos factores de tipo físico y social que intervienen en el contexto de comunicación del TO y en el del TT) como factores co-textuales, relacionados con la propia estructura interna del texto (De Beaugrande 1980a:12-13). Dentro de este enfoque, Rabadán menciona dos unidades: el 'textema' (texteme), acuñado por Even-Zohar, y la 'unidad de procesamiento' (processing unit) definida por De Beaugrande (1980b).

Even-Zohar define el textema del siguiente modo: «a texteme is a unit of literary syntagmatics, a function of specifically local textual relations, i.e., those which can be conceived of as exclusively subordinated to the "textual relation 
proper.” (Even-Zohar 1990:247). Por su parte, De Beaugrande define la unidad de procesamiento como «that stretch of text which is apperceived as a surface structure and processed into a configuration of meaning» (De Beaugrande 1980b:34).

Aun centrándose en distintos aspectos del mismo fenómeno, ambas unidades se refieren a la traducción literaria. En el primer caso esto no sólo es evidente en la propia definición de textema, sino que esta unidad se define desde la aproximación de la 'teoría de polisistemas' y el resto de la investigación desarrollada por Even-Zohar, que se refiere específicamente a la producción, difusión y recepción de obras literarias en los distintos sistemas socio-semióticos. Dado que no podemos aceptar automáticamente la validez para la traducción especializada de teorías desarrolladas en principio para la traducción literaria, cabría cuestionarse la aplicabilidad de sus teorías para la traducción especializada en este punto pero, teniendo en cuenta los objetivos de nuestro trabajo, creemos que éste no es el lugar más adecuado para ello. A su vez, en la cita que utiliza Rabadán, De Beaugrande se refiere específicamente a la idoneidad del verso como unidad de procesamiento de la lectura en la traducción poética, pero no a la idoneidad de la unidad de procesamiento como unidad mínima de traducción, como se puede ver en este fragmento más amplio de la misma cita:

\begin{abstract}
From the standpoint of reader processing, we are probably justified in viewing the rearrangement of material within one line as much less important or damaging than rearrangement among different lines. The line of poetry is a very plausible processing unit, i.e., that stretch of text which is apperceived as a surface structure and processed into a configuration of meaning. Hence, to shift material from one line to another is to displace the distribution of processing units. Shifts within a line would have no such psychological consequences. (De Beaugrande 1980b:34)
\end{abstract}

Por otra parte, Rabadán (1991b:40) plantea que el texto se ha descartado como unidad mínima de traducción debido, principalmente, a los problemas que presentaba su análisis: «the great complexity [...] of the manifold models of text analysis, and the indeterminacy of text length, led scholars to stress the need for a smaller unit, suitable for analytic purposes».

No obstante, Rabadán critica también la idoneidad del textema o de la unidad de procesamiento porque, en su opinión, no reúnen los requisitos necesarios para constituir una unidad mínima que sea específica de la traducción:

Unlike formal-linguistic units, both the texteme and the processing unit allow the translator to improve his or her understanding of the text and its constituent parts while maintaining the integrity of the message. Moreover, these units, either functional or interpretative, depart from the traditional 
method in that they have no fixed «material» boundaries. Yet, they are not operative in a descriptive analysis of translations, the main reasons being that they are unilateral and only apply to the ST [source text] and do not provide any feature which specifically defines them as UTs [units of translation]. (Rabadán 1991b:41)

Por estas razones, Rabadán plantea que el enfoque binario es el más adecuado para establecer una unidad mínima de traducción. Según esta autora, en esta aproximación binaria el centro de atención recae sobre el texto-en-situación, como una parte integral del polisistema semiótico y cultural de llegada, y la traducción es interpretada como un proceso dinámico de comunicación cuyo objetivo es la producción de un TT «for the benefit of the ultimate receivers» (Rabadán 1991b:41). Así, la equivalencia traslativa se contempla como una cuestión de dinámica relacional, a lo largo de un continuo en uno de cuyos extremos se encuentra lo que es adecuado, y al otro, lo que es aceptable.

Toury explica qué significa que una traducción sea adecuada y/o que sea aceptable:

Translation behaviour within a culture tends to manifest certain regularities, one consequence being that even if they are unable to account for deviations in any explicit way, the persons-in-the-culture can often tell when a translator has failed to adhere to sanctioned practices.

It has proven useful and enlightening to regard the basic choice which can be made between requirements of the two different sources as constituting an initial norm. Thus, a translator may subject him-/herself either to the original text, with the norms it has realized, or to the norms active in the target culture, or in that section of it which would host the end product. If the first stance is adopted, the translation will tend to subscribe to the norms of the source text, and through them also to the norms of the source language and culture. This tendency, which has often been characterized as the pursuit of adequate translation, may well entail certain incompatibilities with target norms and practices, especially those lying beyond the mere linguistic ones. If, on the other hand, the second stance is adopted, norm systems of the target culture are triggered and set into motion. Shifts from the source text would be an almost inevitable price. Thus, whereas adherence to source norms determines a translation's adequacy as compared to the source text, subscription to norms originating in the target culture determines its acceptability. (Toury 1995:56-57)

Este autor, a partir de una definición de Even-Zohar, explica en qué consiste que una traducción sea adecuada: «an adequate translation is a translation which realizes in the target language the textual relationships of a source text with no breach of its own [basic] linguistic system» (Toury 1995:56). En este sentido, interpretamos que esta concepción de traducción adecuada frente a traducción aceptable conlleva dos tipos contrapuestos de equivalencia y, por consiguiente, 
corresponde a uno de los tipos de oposición de la clasificación binaria de Chesterman que reproducimos más atrás, en la que el criterio de clasificación consiste en la adherencia a las normas del sistema socio-semiótico de uno de los dos textos.

A partir de esta concepción, Rabadán concluye que la equivalencia actúa como la propiedad definitoria de todo TT, y, en línea con lo que sugería Matthiessen, interpreta la equivalencia también como una cuestión de grado y no como una propiedad de correspondencias absolutas: «since every TT is, in one way or another, equivalent to its ST, the point is not whether the TT is "optimally equivalent", but what kind or degree of translation equivalence it shows» (Rabadán 1991b:41).

Por consiguiente, dado que la equivalencia es la propiedad definitoria de la traducción, entonces Rabadán concluye que la unidad mínima de traducción debe ser una unidad de equivalencia y menciona dos unidades de este tipo. En primer lugar, se centra en el denominado 'inforema', que esta autora describe como una unidad contrastiva bilingüe en la que el contenido del mensaje se asocia con el léxico y que, en su opinión, no es apta para trabajar con traducciones de poca calidad, tan frecuentes en el entorno de la didáctica. A continuación, Rabadán describe el denominado 'translema', que Santoyo define como «la unidad mínima de equivalencia interlingüística, susceptible de permutación funcional y no reducible a unidades menores sin pérdida de su condición de equivalencia (Santoyo 1983:258).

De acuerdo con esta concepción funcional de la unidad de traducción, Rabadán resume sus fundamentos metodológicos del siguiente modo:

1. UTs are abstract entities consisting of textual-linguistic material from both ST and TT. Their existence depends on the global relation of translation equivalence which holds together the textual pair ST-TT. It is also this relation which defines both texts as original and translation respectively.

2. If translemes are made up of bi-textual material, under no circumstances should the units obtained from the unilateral analysis of the ST be considered translemes. They will only be textual (or interpretative) units, their particular specification being of little consequence when applied to the TT.

3. Translemes can only be established a posteriori, by means of a translational comparison TT-ST. These units are only valid for that particular textual pair and do not exist outside the context TT-ST.

4. The translemes obtained from the comparison disclose both the relational hierarchy which defines the underlying model of translation equivalence and the initial norm (Toury 1980) chosen by the translator.

5. Being relational by nature, translemes do not exist in either ST or TT separately: their abstract specification is intertextual and their actual realizations are bi-textual. (Rabadán 1991b:43) 
Hay algunos aspectos interesantes en la concepción de Rabadán sobre la unidad mínima de traducción. En primer lugar, Rabadán condiciona la existencia de la unidad de traducción a la relación global de equivalencia que se establece entre dos textos, y que los cualifica como TO y TT. Para De Beaugrande, esta relación, tal como ya mencionamos antes, es una relación de intertextualidad en la que la mediación se produce entre diferentes conglomerados de sistemas lingüísticos (De Beaugrande 1980a:291). En segundo lugar, la relación que se establece entre uno o varios TTs y un TO, es decir, la relación translémica, es una relación textual que depende intrínsecamente del traductor, con las implicaciones, tanto de tipo cognitivo como ético, que esto conlleva:

The danger is that the translator will interpose his or her own receiver experience as the only possible one for the text. For example, the translator might bridge or fill in all discontinuities and discrepancies such that the goal language receiver finds the text wholly devoid of informativity and interest. [...] Instead of arguing over «free» versus «literal» translating, we might find the true opposition in «receiver-based» and «translator-based» translating: only the former can claim communicative equivalence. The question of how and whether forms or meanings are preserved can only be settled in such a framework. (De Beaugrande 1980a:291-292)

Además de esto, la relación translémica es una relación interpretativa cuando se analiza qué grado de similitud o de variación presentan uno o varios TTs y un TO entre sí. Ya que Rabadán asume que los translemas revelan la jerarquía relacional que define el modelo subyacente de equivalencia traslativa, así como la norma inicial, esto también supone asumir que el análisis contrastivo es válido para extraer información acerca de los procesos internos que han llevado al traductor a producir un texto con los elementos y características del TT, procesos tales como la aplicación de estrategias, la toma de decisiones, o la resolución de problemas. Por último, cabe señalar que, mientras que la relación global de equivalencia es una propiedad de los sistemas virtuales del lenguaje, ya que hace posible la mediación entre unos sistemas y otros, la relación translémica es una propiedad de los sistemas actuales, ya que siempre se establece entre textos.

Según la concepción de Rabadán y Santoyo, el 'translema' es la unidad mínima de traducción. Sin embargo, de acuerdo con la distinción entre niveles y rangos de De Beaugrande, el translema no pertenece a un nivel del lenguaje, sino más bien a un rango textual (en este caso, a un rango intertextual) y, por tanto, desde nuestra perspectiva se trata de una unidad de tipo práctico y no de una unidad teórica. Como decíamos al principio de esta sección, podemos considerar para el análisis textual todas las unidades de tipo práctico que sean de utilidad en el sistema 
en el que se sitúa el texto, variando el rango de la unidad de análisis en función de los objetivos y las necesidades establecidos en un momento dado. A la secuencia de unidades de tipo práctico que enumeramos anteriormente: palabra, oración, grupo nominal, párrafo, texto, registro y discurso, ahora añadimos también el translema, entendiendo que se trata de una unidad con utilidad práctica en el análisis textual en el entorno de la traducción, es decir, cuando existe una relación intertextual de equivalencia entre varios textos, uno de los cuales es tomado como un TO y el otro u otros, como TTs.

Dicho esto, debemos añadir también que el concepto de translema no presenta contradicciones con el marco textual desarrollado por De Beaugrande y otros lingüistas, y por consiguiente no es excluyente con respecto al texto como unidad de análisis, sino que más bien está concebido como una unidad especializada en el análisis intertextual en la traducción, por lo que se puede considerar incluido en el marco de la lingüística textual. A pesar de que Rabadán desecha el texto a favor de una unidad más pequeña y manejable de análisis, De Beaugrande, al igual que otros autores, considera el texto «as the most valid unit of translation» (De Beaugrande 1998; véase también, por ejemplo, De Beaugrande1978; Nord 1991). Desde nuestra perspectiva, la cuestión crucial al abordar el análisis textual no reside tanto en el tipo de unidad que utilicemos (probablemente porque nuestra preocupación e intereses son distintos de los de Rabadán), como en el criterio utilizado para llevar a cabo el análisis, así como en el objetivo que se persigue alcanzar con dicho análisis.

Dado que nuestro interés se centra en la utilización de las tareas de traducción como un medio de facilitación del aprendizaje de unos conocimientos de tipo actitudinal, nos resulta en principio más útil la utilización de un tipo de unidad que sea reconocible por el aprendiz de modo intuitivo, como es el caso del texto pero no del translema. En este sentido, la experiencia práctica nos aconseja utilizar la noción intuitiva de texto para irla modelando progresivamente. Esta progresión parte del concepto de texto especializado utilizado por el aprendiz, en el que habitualmente se incluye la información estructurada en párrafos pero se excluye la información de los títulos, subtítulos y otros tipos de encabezamientos, así como la información de tipo no verbal (gráficos, fotografías, etc.). Debido a que esta concepción del texto es excesivamente fragmentaria y excluyente, solemos optar por movernos hacia una concepción del texto como una unidad de tipo global (holística) y comunicativamente intencional (teleológica). Posteriormente, el siguiente paso consiste en establecer qué tipo de relación consideramos entre el TT y el TO. Es 
decir, nos movemos hacia el concepto más complejo de texto asociado a otro texto, fase en la que debemos reformular el concepto intuitivo de equivalencia, el cual, como ya hemos mencionado, suele ser interpretado como una relación de correspondencia biunívoca, hacia un concepto de equivalencia más dinámico y asociado con el contexto comunicativo de los textos involucrados. 


\section{La comunicación especializada: entorno socio- semiótico, entorno textual y entorno cognitivo}

\subsection{Introducción}

En el presente capítulo nos proponemos describir nuestra concepción del uso del lenguaje de acuerdo con su dimensión socio-semiótica (5.1), con su dimensión textual (5.2) y con su dimensión cognitiva (5.3), lo cual supone considerar el mismo fenómeno desde ángulos diferentes que no son en absoluto excluyentes entre sí. No obstante, debemos precisar que nuestra meta no es suministrar una caracterización de los rasgos distintivos de la comunicación especializada, sino más bien señalar aquellos aspectos que es necesario tener en cuenta para cualquier investigación rigurosa que aspire a una caracterización tal, incluyendo parámetros útiles para el análisis y la descripción de las lenguas. En un sentido más modesto, nos interesan especialmente los aspectos más relevantes que conciernen a la descripción de los textos que utilizaremos en el aula y que responden a una concepción del texto como «a communicative event wherein linguistic, cognitive, and social actions converge, and not just as the sequence of words that were uttered or written» (De Beaugrande 1997:10). Esta convergencia implica que el texto constituye un sistema de conexiones entre elementos y unidades multifuncionales:

We can regard the text as a system of connections among various elements: sounds, words, meanings, discourse, participants, actions in a plan, and so on. Since these elements clearly belong to different types, the text must be a multisystem comprising multiple interactive systems. And it must have units that are multifunctional, e.g. a word being a pattern of sounds, a piece of a phrase, an instruction to 'activate' a meaning, and so on. (De Beaugrande 1997:11) 
Para tratar estas cuestiones, comenzaremos presentando en la sección 5.1 un modelo de transmisión del conocimiento científico (Barnes 1985) utilizado en el campo de la sociología de la ciencia, con el fin de situar convenientemente la comunicación especializada en un entorno social. A continuación, el sección 5.2 describiremos el modelo de factores constitutivos y regulativos del texto desarrollado por De Beaugrande y Dressler (De Beaugrande 1980a; De Beaugrande y Dressler 1981), y lo complementaremos con el modelo propuesto por Nord (1991) para el análisis textual en la traducción. Para finalizar, en la sección 5.3 trataremos de un modo general la dimensión cognitiva del lenguaje para detenernos con mayor atención en la 'teoría de los esquemas' por su relevancia para dar cuenta de algunos aspectos relacionados con la comprensión de la información textual.

El orden que seguimos en este capítulo para ir exponiendo nuestras consideraciones y presentando los diferentes modelos en los que nos basaremos no es un orden casual, como tampoco lo es el hecho de que la sección central, que corresponde con el enfoque textual, sea más extensa que las demás. Hemos decidido partir desde un enfoque socio-semiótico de la comunicación considerando la naturaleza esencialmente social del lenguaje y situar en el otro extremo (al final del capítulo) un enfoque más bien centrado en el individuo volviendo a centrar nuestra atención en el aprendiz De este modo, la parte central, dedicada a los aspectos textuales de la comunicación, actúa como un puente que sirve de nexo entre la sociedad y el individuo en la comunicación y en la transmisión de conocimientos.

\subsection{La comunicación especializada: entorno socio- semiótico}

Debemos comenzar señalando que en esta sección vamos a tratar la comunicación especializada como un mecanismo de transmisión de conocimientos. El concepto de especialización del que partimos se refiere a un tipo de comunicación restringida por los contextos de situación que se le asignan, de acuerdo con la noción de restricción de Firth que hemos visto anteriormente (v. 4.1.2). Según esta noción, la comunicación entre una madre y un hijo pequeño en una situación cotidiana implica un discurso tan restringido como el producido en una situación comunicativa prototípica entre profesionales. No obstante, para tratar de un modo más preciso cómo es el discurso asociado con las variantes que más nos interesan en este trabajo, el Inglés Científico, el Inglés Técnico y el Inglés 
Académico, en esta sección vamos a acotar el concepto de restricción desde otro aspecto más.

Si para Cabré y otros terminólogos la especialización supone una restricción que se sitúa en los términos de la lengua, y para Firth y Halliday la restricción se localiza en el tipo de situación comunicativa que se produce, ahora vamos a fijarnos en el tipo de conocimientos que se transmiten mediante la comunicación.

Lerat (1997:17) alude a la concepción de las lenguas para fines específicos de Sager y otros autores, para quienes éstas son contempladas como «medios de comunicación lingüística necesarios para vehicular la información especializada entre especialistas de una misma materia». Si nos planteamos la transmisión de conocimientos desde una perspectiva socio-semiótica en la que esa transmisión es interpretada como comunicación en un entorno socio-semiótico cuyos miembros son profesionales de un mismo campo científico, entonces a lo que Lerat se refiere cuando habla de «vehicular la información especializada» es a la transmisión del conocimiento científico. Así, en un sentido amplio, la comunicación especializada se suele identificar con la comunicación científica.

Por otra parte, a la vista de las propiedades asignadas por Matthiessen a los sistemas socio-semióticos, desde un punto de vista sistémico podemos afirmar que la comunicación científica posee rasgos característicos tales como una cierta estructura jerárquica y unos valores y significados propios. Podemos decir que estos rasgos característicos constituyen un cierto tipo de cultura, si bien en un sentido diferente a las culturas que se identifican habitualmente en una descripción social, etnológica o antropológica. Widdowson diferencia entre ambos tipos de sistema cultural, de acuerdo con una clasificación en la que el sistema cultural que corresponde a la comunicación científica es considerado un 'sistema cultural secundario' independiente de los sistemas culturales asociados con diferentes sociedades: «the concepts and procedures of scientific inquiry constitute a secondary cultural system which is independent of primary cultural systems associated with different societies» (Widdowson 1979:51).

Desde nuestro punto de vista, este sistema cultural secundario está estrechamente relacionado con el contexto de situación y el contexto de cultura, si bien no corresponde con ninguno de estos dos conceptos en su totalidad. Según Widdowson, un sistema cultural secundario no se identifica con ninguna cultura en particular, sino que es compartido por todos los miembros de la comunidad científica y posee unas convenciones propias: 
So although for example a Japanese, and a Frenchman, have very different ways of life, beliefs, preoccupations, preconceptions, and so on deriving from the primary cultures of the societies they are members of, as scientists they have a common culture. In the same way, I take it that the discourse conventions which are used to communicate this common culture are independent of the particular linguistic means which are used to realize them. Thus, for example, the expression of cause and effect relations and the formulation of hypotheses are necessary rhetorical elements in scientific discourse, but they can be given a very wide range of linguistic expression. So I would wish to say that scientific discourse is a universal mode of communicating, or universal rhetoric, which is realized by scientific text in different languages by the process of textualization. (Widdowson 1979:51-52)

Desde esta perspectiva, podemos establecer similitudes entre lo que Widdowson denomina cultura secundaria y el contexto de situación. Halliday (1978) interpreta el contexto de situación como una estructura socio-semiótica que consta de ciertas propiedades generales de la situación que actúan colectivamente como determinantes del texto, haciendo específicas las configuraciones semánticas que los usuarios del lenguaje asocian típicamente con los contextos tipificados. La diferencia consiste en que, para Widdowson, la cultura secundaria corresponde a una estructura socio-semiótica del lenguaje y, por tanto, virtual, que consta de ciertas propiedades generales de la situación que actúan colectivamente como determinantes del discurso científico. Probablemente una estructura de estas características es lo que corresponde más consistentemente con el concepto de género en su interpretación semiótica.

Podemos pensar que el planteamiento de Widdowson viene a ratificar el argumento que Cabré utiliza para «justificar la unidad del lenguaje especializado por encima de su diversidad» (Cabré 1993:147): los especialistas del mismo campo de conocimiento son capaces de comunicarse entre sí en diferentes lenguas con facilidad debido a que el discurso científico no se asocia con ninguna cultura primaria en particular ${ }^{1}$. La diferencia radical entre el planteamiento de Cabré y el de Widdowson no proviene de que la afirmación en sí sea falsa o cierta (en cualquier caso, se trata de una hipótesis), sino en la justificación que cada uno de ellos utiliza para llegar a conclusiones similares. Cabré, como ya hemos visto, basaba su razonamiento en que los lenguajes de especialidad poseen un conjunto limitado de unidades y reglas, así como un repertorio restringido de temas, por lo que son descritos como sublenguajes limitados tanto formal como funcionalmente.

\footnotetext{
${ }^{1}$ Aquí, la identificación de la lengua inglesa como la lengua propia de la cultura científica, o como la lengua más utilizada en la construcción del discurso científico, conlleva la consideración del inglés como una lengua franca.
} 
Por el contrario, Widdowson se basa en los mecanismos de creación de significado del discurso científico, con independencia de las características particulares que cada textualización pueda adoptar en función de la lengua de que se trate. Desde esta perspectiva, los lenguajes de especialidad poseen y utilizan todos los recursos de cada lengua, por lo que no se interpretan como algo diferente de la lengua general, sino que son la lengua general que se utiliza para crear, transmitir e interpretar conocimientos científicos y, en general, para comunicarse en contextos de situación asociados con la comunicación especializada. Conocimientos que, por otra parte, ni siquiera conforman un acervo que podamos considerar, para la enseñanza, que esté homogéneamente compartido por toda la comunidad científica ya que, tal como señalan Bloom y sus colaboradores, los conocimientos están de todos modos necesariamente ligados a una geografía y a una cultura primaria en particular:

No han de olvidarse [...] los aspectos geográficos y culturales de los conocimientos, ya que los conocimientos de un grupo no han de ser poseídos obligatoriamente por otro grupo, clase o medio cultural. Queremos indicar con todo ello que el conocimiento es siempre fragmentario y relativo, nunca globalizado e inmutable. (Bloom et al. 1956:44)

Desde una aproximación lingüística, la comunicación científica nos interesa precisamente en cuanto a los mecanismos específicos que el discurso científico utiliza, incluyendo los mecanismos lingüísticos asociados con cada lengua en particular $\mathrm{y}$, en concreto, con la lengua inglesa y con la lengua española. No obstante, si nos centramos en las características del entorno socio-semiótico donde se desarrolla la comunicación, en quiénes son los participantes de la comunicación científica y en cómo es su estructura semiótica, nos parece muy revelador ver cómo se define la propia comunidad científica.

Así, desde la sociología de la ciencia y, específicamente, desde la posición de especialista en el campo de las ciencias de la naturaleza, Barnes (1985) aborda la transmisión de conocimientos científicos como un proceso sistematizado y colectivo y nos ofrece una descripción de la comunicación científica a partir de la consideración de que «los científicos individuales están vinculados en un sistema organizado y eficaz de conocimientos» (Barnes 1985:37). Asimismo, señala que cualquier comunidad científica se define fundamentalmente por las características comunes de sus miembros y los procedimientos que comparten, y describe estos rasgos comunes incluyendo, a diferencia de lo que sucede en la perspectiva adoptada por Bloom y sus colaboradores, la consideración de un acervo homogéneo 
de conocimientos compartidos por igual por todos los miembros de la comunidad científica en cuestión. Para Barnes, por tanto, la comunidad científica es considerada como un grupo social homogeneizado mediante las convenciones que actúan como normas de comportamiento significativo e, igualmente, la comunicación científica responde a este mismo modelo social altamente convencionalizado:

Los científicos de cualquier área comparten una formación prolongada e intensiva que les lleva a pensar y actuar de forma parecida. La cuestión no es tan sólo que reciben el mismo conjunto de conocimientos aceptados y que todos ellos adquieren las mismas aptitudes y competencias técnicas. Además, adquieren un lenguaje y vocabulario comunes, unas convenciones comunes para la definición de unidades y escalas de medida, unos signos y símbolos comunes $\mathrm{y}$, asimismo, unos sistemas taxonómicos y unos esquemas y nomenclaturas comunes. La realidad no exige todas estas cosas; a la realidad no le importa si se la mide en pies o en metros, y no insiste en el hecho de que los electrones tienen carga negativa y los protones positiva. Pero para ser científico es fundamental asimilar y comprender esas convenciones y en la formación científica se otorga a estos aspectos la mayor importancia y se obliga a los estudiantes a que los practiquen hasta que los dominen por completo como si fueran una segunda naturaleza. La consecuencia es que los científicos de un área determinada pueden comunicarse de forma inmediata, y que todos ellos tienen la capacidad de aprender unos de otros y la capacidad de evaluar el trabajo de los demás.

Sin embargo, en la comunidad científica existen, además de esas capacidades, una serie de procedimientos habituales, unas formas normales de actuar que permiten asegurar que esas capacidades se utilicen en la forma adecuada, que los individuos aprendan rápidamente unos de otros y evalúen el trabajo de los demás. Como consecuencia, la investigación de cada uno de los científicos se basa en el conocimiento de todos ellos, y el juicio de cada científico está condicionado por el juicio de los demás. De esta forma la investigación resulta mucho más eficaz, pues se saca el máximo fruto a los recursos técnicos e intelectuales de que dispone cada científico y se reducen al mínimo las consecuencias de sus defectos y excentricidades. (Barnes 1985:38)

Uno de los procedimientos habituales de funcionamiento de la comunicación científica, según la descripción de Barnes, se refiere al modo de transmisión del conocimiento científico. En el entorno de la sociología de la ciencia, la comunicación científica es entendida como un modo de transmisión de conocimientos científicos y se identifica con la publicación de los resultados de las investigaciones que llevan a cabo los científicos.

Aquí únicamente queremos ilustrar cómo son descritas por los propios científicos las redes convencionales de transmisión de conocimientos en este ámbito, por lo que sólo vamos a ofrecer una panorámica de los componentes de este modelo de comunicación científica, con el fin esbozar el tipo de estructura social al que Barnes se refiere. 
En este modelo de comunicación científica se parte de la presuposición de Ziman (1968) de que el conocimiento solamente es conocimiento científico cuando es público, porque previmente se le ha dado difusión, y consensuado, porque está evaluado y avalado por los propios miembros de la comunidad científica. Esto nos permite comprender la extrema importancia de la evaluación de la investigación como parte estructural del modelo que mostramos más adelante (v. Figura 3).

Como ya hemos señalado previamente, Barnes describe la comunicación científica desde la perspectiva del científico y no desde la del lingüista. Se trata, por tanto, de una aproximación más émica que ética ${ }^{2}$. Aquí, nuestro interés al considerar el punto de vista del especialista se suma a lo que Swales (1988:192) describe como «a current concern to discover and evaluate the opinions of professionals involved in the genre», y que explica así:

Until recently, it was generally argued that the only admissible data were the texts themselves; today at least some researchers are interested in discovering what the users of certain communicative conventions believe to be the rationale for those conventions. (Swales 1988:192)

En este sentido, aunque la utilización de normas o rutinas convencionales de una comunidad profesional está, al menos en parte, condicionada por la estructura socio-semiótica de la comunidad o sistema cultural, nuestro mayor interés se centra en los mecanismos que permiten el acceso a la comunidad científica. ¿Cómo puede el aprendiz ingresar en la comunidad profesional y qué conocimientos debe adquirir para poder crear y recrear el discurso científico? ${ }^{3}$

De entre todas las investigaciones que han publicado sus resultados, el proceso de convencionalización en una comunidad científica implica la asunción, en cada momento histórico, de ciertos conocimientos como conocimiento aceptado (lo que corresponde con las etapas A - D de la Figura 3). Una vez que el conocimiento ha sido evaluado y aceptado, la siguiente etapa (identificada como E en la Figura 3)

\footnotetext{
${ }^{2}$ De acuerdo con el denominado 'materialismo cultural', el análisis émico de los datos depende del informante que suministra los propios datos: si los informantes están de acuerdo con la descripción e interpretación de los datos, entonces éstos se consideran correctos. Por el contrario, el análisis ético de los datos no se basa únicamente en el informante, sino también en las explicaciones proporcionadas por los observadores, que además utilizan métodos científicos consensuados. El materialismo cultural considera que se deberían utilizar ambos tipos de análisis (véase la página sobre materialismo cultural de Soo Kyung Lim en la URL: http://www.indiana.edu/ wanthro/mater.htm; véase también De Beaugrande 1997:55).
}

\footnotetext{
${ }^{3}$ Según Widdowson, «the ultimate aim of a language teaching course is to develop the ability to create and recreate discourse from the resources of linguistic knowledge» (Widdowson 1979:162).
} 
consiste en la incorporación de éste al acervo de conocimientos de la especialidad de que se trate. A partir de esta situación, por una parte se produce un proceso permanente de revalidación (etapa F de la Figura 3) y por otra, el conocimiento se difunde mediante los canales asociados típicamente con la comunidad científica, incorporándose al conocimiento de la disciplina (etapa G en la Figura 3). El aprendiz, antes de llegar a ser un miembro más de una comunidad científica o profesional, se sitúa en una etapa de transición en la que paulatinamente va accediendo al acervo de conocimientos de la disciplina en cuestión (etapa que comprende $\mathrm{H}$ e I en la Figura 3).

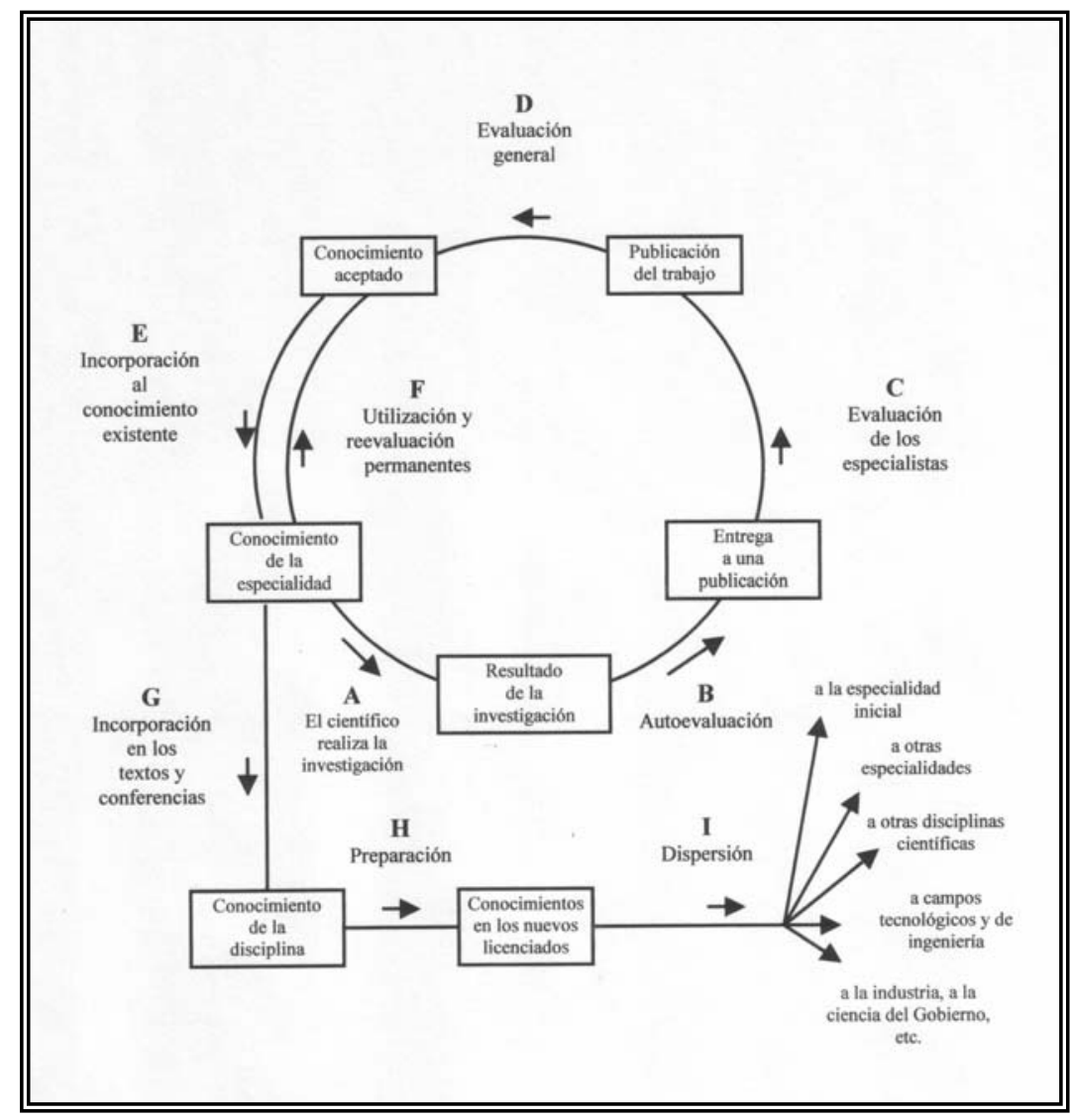

Figura 3. La comunicación y la evaluación de la investigación (Barnes 1985)

Widdowson (1979) explica cómo el aprendiz va adquiriendo progresivamente las estrategias que le permitirán comprender, asimilar y producir 
conocimientos especializados. La adquisición de estas estrategias tiene que ver en parte con cómo es tratado el conocimiento. Widdowson reconoce diferencias en el tratamiento del conocimiento cuando éste es tratado por el discurso de la instrucción, es decir, por el discurso académico utilizado en la formación de los aprendices, y cuando éste es tratado por el discurso científico en las diferentes etapas de aceptación del conocimiento de la disciplina. Estas diferencias se asocian también con un tipo de sistema cultural u otro. En la etapa de aprendizaje Widdowson relaciona el tratamiento del conocimiento con la cultura individual del aprendiz, debido a la necesidad que éste tiene de establecer vínculos con su propia experiencia:

The discourse of scientific instruction, of science as a subject, such as appears in textbooks, for example, is different from the discourse of scientific exposition, of science as a discipline, such as appears in research papers. I think we can account for these differences by ranging them on a single rhetorical scale which connects the primary culture with the secondary culture of science. What I mean by this is that scientific instruction at different levels introduces both the concepts and procedures of scientific inquiry and at the same time, as a necessary concomitant, the rhetorical principles of scientific discourse. Instruction at the early stages makes reference to the learner's own experience and so relates to his primary culture but as instruction proceeds the secondary culture is developed, and the student gradually approximates to a scientist. Thus the discourse of science as a subject is a means of presenting the discourse of science as a discipline. (Widdowson 1979:52)

Esta necesidad de establecer vínculos con la experiencia personal del aprendiz como medio para incorporar los conocimientos científicos nos lleva a asumir la relevancia del discurso académico, además del discurso científico y el discurso técnico, como fuente de material con funcionalidad para la didáctica especial de las lenguas para fines específicos en el entorno considerado en este trabajo.

Por otra parte, podemos decir que el aprendiz se ha convertido en experto o miembro de pleno derecho de la comunidad científica cuando ha logrado acceder al conocimiento especializado y, además, cuando ha sido aceptado como igual por los demás miembros del grupo. No obstante, el conocimiento científico no es propiedad de la comunidad científica, sino que es público (Ziman 1968). Esto significa que la interacción entre la cultura primaria y la cultura secundaria se produce en ambas direcciones. De la cultura primaria a la secundaria, los conocimientos se van especializando cada vez más, en cuanto a su propia complejidad y también en cuanto al tratamiento que reciben; de la cultura secundaria a la primaria, se produce lo que se denomina (entre otras expresiones) 'divulgación científica'. La 
divulgación científica supone una re-creación del significado en diversos tipos de discurso, como el de los textos de Stephen Jay Gould (profesor de geología de la Universidad de Harvard y prolífico autor de obras de divulgación científica), cuyas características han sido estudiadas por Fuller (1998), o bien el discurso de los textos de ciencia-ficción, analizado por Cranny-Francis (1998). A pesar de la convicción de Ziman de la naturaleza pública del conocimiento científico, no debemos olvidar que, tal como señala Lankamp, la transmisión del conocimiento mediante un código profesional implica que el discurso científico tiene un carácter exclusivo. Martin y Veel explican los términos de esta controversia:

Over the years the question of 'exclusivity' in science language has been raised many times. The technicality and abstraction which characterises scientific language is a double-edged sword. Whilst it extends the meaning potential of language considerably, allowing for new kinds of relationships between grammar and semantics to construe new kinds of meanings, the very process of technicality and abstraction renders scientific language inaccessible to many [...]. The differential access to scientific meaning amongst individuals means that the meaning potential of scientific language can be easily translated into a tool for political and economic domination within and between societies. This phenomenon has been commented upon both by lay observers, who criticise the 'jargon' of science and technology, and by critical theorists, who express concerns that the users of scientific forms language [sic] (including linguists) employ scientific language purely to enhance their own power and prestige, and not for the construal of distinct kinds of knowledge. (Martin y Veel 1998:31)

En cualquier caso, mediante la hipótesis de la existencia de una cultura primaria y una cultura secundaria, Widdowson nos ofrece un modo de comprender la interacción entre el discurso académico, donde los conocimientos científicos son relacionados con la experiencia previa que el aprendiz ha adquirido en la cultura primaria, y el discurso científico, donde los conocimientos científicos adquieren la condición de tales.

Por otra parte, como se puede observar en el modelo de Barnes, el campo tecnológico y el de la ingeniería, asociados con el denominado discurso técnico, son considerados campos diferentes de las ciencias puras y, por consiguiente, cabe suponer que, si esta división se corresponde con diferencias discursivas, estas diferencias serán identificables y, además, relevantes para la didáctica especial de las lenguas para fines específicos en el entorno estudiado aquí.

En este sentido, cabe destacar que, a pesar de que el discurso científico y el discurso técnico ocupan un mismo espacio socio-semiótico, White (1998) ha descubierto preferencias distintivas en cuanto a la selección de modos de expresión, por lo que es importante no tomar ambas variedades funcionales como una sola. 
Halliday (1998) también alude a diferencias entre el discurso científico y el discurso técnico en el modo de realizar la nominalización de entidades.

En cualquier caso podemos afirmar que, tanto el discurso académico como el discurso técnico, vienen a confluir en el discurso científico. Volviendo al modelo de Barnes, a partir de que el conocimiento especializado se incorpora en la disciplina, éste se va transmitiendo como discurso académico y se va dispersando a diferentes campos y disciplinas, pasando así a transmitirse también como discurso técnico. Por tanto, el discurso científico supone un referente para el discurso académico y para el discurso técnico en el sentido de que es como discurso científico como se crea el conocimiento científico.

No obstante, a continuación veremos cómo, más que transmitirse, el discurso científico se manifiesta de diferentes modos adaptándose a las características específicas que adopta la situación en particular, y que esto sucede mediante un proceso que Martin y Veel denominan 'reformulación' o 'recontextualización'.

\subsubsection{La recontextualización del conocimiento científico}

Aunque acabamos de afirmar que el discurso científico es un referente para el discurso académico y para el discurso técnico, esto no significa que el discurso académico ni el técnico deriven del discurso científico en el sentido de que posean rasgos claramente diferenciadores relacionados con lo que se suele denominar 'ciencias puras' o 'básicas' y 'ciencias aplicadas'. Lo que queremos decir es que el discurso científico posee una gran capacidad de reformulación, así que en cierto modo aglutina a los discursos asociados con aplicaciones específicas, debido a la tendencia de la actividad científica de recontextualizar significados, tal como señalan Martin y Veel:

One of the main reasons science has remained a dominant discourse in western society is its ability to reformulate itself for new purposes and contexts. Indeed, one of the inherent characteristics of scientific discourse is its malleability -it is difficult to identify any 'pure' or 'original' form of science, from which 'applications' arise. 'Research science' cannot be easily distinguished from 'applied science' in the way that 'philosophy' or 'ethics' can be distinguished from 'law', because empirical methods of investigation require that even the 'research science' be about something. There is little room for speculative philosophy of the type seen in the humanities. Scientific discourse has always evolved in specific contexts and to meet specific needs. As Halliday has observed (1993), whenever new contexts for scientific activity emerge there is a tendency to borrow meanings from existing contexts, 
to reconfigure and reorder them according to the principles of the new contexts. (Martin y Veel 1998:83)

Desde una perspectiva global, esta recontextualización del discurso científico se relaciona con la condición de canónico que tiene el discurso científico:

As chaos theory has taught us, a project of this kind [reconstructing an evolutionary trajectory of science discourse], however rewarding, tends to draw attention away from side currents and dead ends, and thus tends to idealise certain kinds of science discourse as mainstream. (Martin 1998:4)

Tal como señala Martin, en el contexto educativo generalmente se espera que los estudiantes aprendan un discurso científico canónico, por lo que el discurso académico implica una reformulación de este discurso canónico.

Debemos subrayar la importancia de la capacidad de reformulación del discurso científico para que no caigamos en el error de identificar éste con una única forma establecida de conocimiento (conocimiento aceptado, conocimiento existente, conocimiento especializado, etc.), ni éste último con un acervo estático o invariable del estado de las cosas, tal como en ocasiones suele suceder. Por ejemplo, Rey (2000:64), describe los textos científicos como textos con un contenido prácticamente universal y carentes de valor estético lo cual, cuando menos, implica una aproximación canónica al discurso científico, si bien este mismo autor reconoce diferencias entre «le mode d'élaboration des concepts scientifiques et le mode d'exposition de ces mêmes concepts» (Rey 2000:66).

Por otra parte, podemos identificar la tendencia a considerar el conocimiento como algo estable o invariable como una concepción clásica de la ciencia. Las leyes de Newton son un ejemplo de este tipo de concepción, en el que no se consideran aspectos tales como la irreversibilidad de los procesos. Tal como explica Prigogine, en la segunda mitad del siglo XIX un físico vienés apellidado Boltzmann identificó lo que se denomina la 'paradoja del tiempo', y que Prigogine resume así:

El tiempo -tal como fuera incorporado en las leyes fundamentales de la física desde la dinámica newtoniana clásica hasta la relatividad y la física cuánticano autoriza ninguna distinción entre pasado y futuro. Todavía hoy y para numerosos físicos la siguiente es una verdadera profesión de fe: a nivel de la descripción fundamental de la naturaleza no hay flecha del tiempo. (Prigogine 1996:7-8)

Identificar esta paradoja supuso «poner en evidencia la contradicción entre las leyes de la física newtoniana -basadas en la equivalencia entre pasado y futuro- 
y toda tentativa de formulación evolucionista que afirmara una distinción esencial entre futuro y pasado» (Prigogine 1996:8). Prigogine explica cómo esta paradoja afectaba a la concepción vigente del conocimiento científico y cómo hoy en día esta concepción de la ciencia sigue viva:

En esa época las leyes de la física newtoniana eran aceptadas como la expresión de un conocimiento ideal, objetivo y completo. Puesto que dichas leyes afirmaban la equivalencia entre pasado y futuro, cualquier tentativa de atribuir una significación fundamental a la flecha del tiempo aparecía como una amenaza a ese ideal. [...]

La situación no ha cambiado hoy. Numerosos físicos consideran la mecánica cuántica (en el ámbito de la microfísica) como la formulación definitiva de la física, tal como en la época de Boltzmann los físicos consideraban definitivas las leyes de la física newtoniana. (Prigogine 1996:8)

No obstante, el discurso científico dispone de distintos tipos de recursos para la creación de significado científico y su gran capacidad de reformulación está estrechamente relacionada con una combinación de recursos semióticos que da como resultado diferentes formas de construcción y expresión de los significados científicos:

Thus this process of reformulation, or 'recontextualisation', places pressure on the semiotic resources used to construe scientific meanings. As new fields of activity, new sets of social relationships and new modes of expression emerge, new forms of language develop. Thus the written language of 'school science' -its genres and lexico-grammatical patterns- is different from the written language of 'industry science'; and both are different from the written language of 'university science'. (Martin y Veel 1998:84)

Martin y Veel aducen tres razones por las que se produce la recontextualización del discurso científico, que identifican con la emergencia o la especialización de un campo de actividad científica, con la configuración de nuevos conjuntos de relaciones sociales y con la aparición de nuevos modos de representación y (re)producción del conocimiento, tal como veremos a continuación.

\subsubsection{Emergencia o especialización de un nuevo campo científico}

De acuerdo con Martin y Veel, la emergencia de nuevos campos de actividad científica, o bien la especialización de un campo existente, es una situación frecuente en el campo médico y en el tecnológico:

There are many instances of this kind of recontextualisation in the areas of technology and medicine. The arrival of the technology of optical fibres, for 
example, required that meanings which had evolved in the study of light, electronics and chemistry coalesced and entered into new sets of relationships in order to construct a new field of activity, one concerned with the transmission of electronic signals through light and the use of chemicals to control the way signals are transmitted. The result is a whole new body of knowledge, one with its own hierarchies of knowledge and its own specialists at various levels with access to this knowledge. (Martin y Veel 1998:83)

\section{Veel (1998) ha estudiado la recontextualización que se produce con el} surgimiento de la ecología como una ciencia que conlleva una perspectiva particular sobre el mundo, lo cual supone una tensión entre la utilización que hace de las configuraciones gramaticales y textuales asociadas tradicionalmente con la ciencia por un lado (para poder obtener el reconocimiento que necesita como disciplina viable) y por otro su intento de reconfigurar la relación entre el ser humano y el mundo natural en el discurso científico:

Academic and educational debate places much emphasis on the new. Every decade or so we are told of a new approach which will 'completely revolutionise the way we look at' the world. The ascendancy of environmentalist perspectives in the sciences has produced perhaps the greatest change to scientific thinking this century. In many ways the discourse of environmentalism is revolutionary. It challenges and attempts to combine some very fundamental philosophical divisions in Western society, such as those between 'scientific' and 'non-scientific' ways of thinking about the world, and attempts to negotiate one of the most difficult disjunctions in scientific thought, that between the local and contextually dependent and the abstract and generalisable. In language this has resulted in distinctive textual and grammatical configurations and patterns which make it possible to talk of a 'language of environmentalism'. As well, environmentalist discourse appears to make original use of other semiotic systems, especially visual images, to construe new meanings [...].

While the discourse of environmentalism might be new, how new is the language? Within language we have a large, but limited, set of resources for realising meanings. As with other innovative discourses, environmentalism takes resources which already exist within 'natural language' (i.e., language used by humans) and re-configures them in original ways. Thus the linguistic building blocks of environmentalism are the same as those of other academic disciplines: genres of report, explanation and exposition, sequential, causeand-effect and taxonomically organised fields, prosodic realisation of appraisal, grammatical metaphor, lengthy nominal groups, etc. What is new is the way these elements are put together. The language of environmentalism is revolutionary not because it rejects the linguistic resources used to construe meanings in traditional science (and other disciplines) but because it takes up these resources, combines them with other resources -in particular humanitiesstyle rhetoric and visual images- and construes new meanings. The purpose of doing this, if we are to accept the assertions of environmentalists, is to enable us to construct an epistemological relationship between humans and the environment that values scientific knowledge in a different way, as a tool that will permit the survival of the human race and promote responsible use of finite physical resources. (Veel 1998:148-149) 
En cualquier caso, los cambios causados por la aparición de nuevas áreas de actividad científica, o por la especialización de áreas ya existentes, no son suficientes en sí mismos para explicar las causas de la recontextualización del conocimiento científico, sino que debemos complementar esta explicación con otros aspectos involucrados, tales como las características específicas que adoptan las relaciones sociales entre los participantes en el discurso científico.

\subsubsection{Configuración de nuevas relaciones sociales}

Martin y Veel citan la configuración de nuevos conjuntos de relaciones sociales para usuarios del discurso científico como la segunda de las razones por las que se produce la recontextualización del discurso científico. Aquí nos interesa particularmente la reformulación del discurso científico en cuanto a las relaciones sociales que se establecen en el entorno educativo, especialmente durante los ciclos superiores:

\footnotetext{
Systems of knowledge developed in the 'field of production', as Bernstein calls them (1996:112-5), are systematically reshaped according to the power, time and space relationships of the school system, the 'recontextualising field'. In order to exist within the school system knowledge must be in a form that allows the roles of the 'teacher' and the 'taught' to emerge. It must be divisible into the time units allocated (lessons, weeks, terms, years, primary, junior secondary, senior secondary, etc.). Most importantly, it must exist in a form that can be assessed, so that students can be distributed across the spectrum from 'successful' to 'unsuccessful'. In the end, the science we see in a recontextualising field such as schooling is often very different from the science we see in a field of production such as the research laboratory. (Martin y Veel 1998:84)
}

Podemos añadir que la reformulación del discurso científico en cuanto a las relaciones sociales que se establecen en el entorno educativo es muy variable. Aún dentro de un área tan específica como los manuales universitarios, género típicamente ligado al discurso académico, podemos encontrar grandes diferencias en cuanto a la explotación de los recursos utilizados por los autores de estas obras (por lo general, especialistas en la materia que son investigadores y profesores) para establecer relaciones sociales con los lectores (los estudiantes universitarios a quienes va dirigido el manual, cuyo profesor en ocasiones es el propio autor del manual) al recontextualizar el discurso científico.

Desde una perspectiva textual, las relaciones sociales se asocian con recursos tan variados como la expresión de la modalidad (en cuanto a que la modalidad no sólo muestra la actitud del hablante con respecto a la condición de 
certeza de la proposición, sino que, al mismo tiempo, hace que el autor de un texto sea visible, es decir, que su postura o actitud ante lo que dice trascienda a lo explícito) o la expresión de la distancia social entre el autor y el lector, por lo que un análisis textual puede poner de manifiesto los recursos utilizados por diferentes autores. Nos sirve como ejemplo de estas diferencias la comparación entre dos manuales universitarios de amplia difusión en el campo de la ingeniería, como son Introduction to Applied Mathematics (Strang 1986) y Fundamentals of Engineering Thermodynamics (Moran y Shapiro 1992), de los que reproducimos unos fragmentos como ejemplos ilustrativos en los Anexos D y $\mathrm{E}^{4}$. Por último, debemos tener también en cuenta que la variación en el modo de reformulación del discurso científico en cuanto al establecimiento de las relaciones sociales entre sus usuarios puede ser aún mayor y más compleja si consideramos también la recontextualización del discurso científico como discurso académico español, y no sólo como discurso académico inglés. Esto es, la variedad puede ser mayor si aumentamos las variables, incorporando variables asociadas a diferencias en los entornos educativos (incluyendo diferencias lingüísticas y culturales).

Por otra parte, el discurso académico se puede considerar como una clase de discurso pedagógico. Christie considera que el discurso pedagógico, el cual conlleva procesos que implican «the building of subjectivity: the building of aspects of identity, as well as the structuring and ordering of experience in some way» (Christie 1998:152), sufre diversos modos de reformulación, pudiendo encontrarse en relaciones ajenas a las puramente educativas. Según este planteamiento, además de las relaciones que se establecen entre profesor y alumno, estas relaciones

\footnotetext{
${ }^{4}$ Si bien no nos vamos a detener aquí en un análisis pormenorizado de ambos textos, hemos optado por incluirlos en los apéndices puesto que serán utilizados más adelante como fuente de referencia de algunos ejemplos reales de traducciones llevadas a cabo por aprendices en el entorno considerado en este trabajo, de modo que el análisis comparativo queda a discreción del lector. Para una referencia más rápida a las diferencias de reformulación del discurso científico, me remito a la comparación de Myers (1992) entre dos textos científicos que versan sobre la misma cuestión: «a typical university textbook's account of the processing of split genes» $\mathrm{y}$ «the opening of one of the several journal articles to which one could trace the discovery of this fact about RNA processing» (Myers 1992:9). Este autor compara específicamente tres aspectos «personal and impersonal subjects», «tense» $\mathrm{y}$ «modalities». Este último aspecto se refiere a «all the modifications of the facticity of a claim (applied linguists might call most of them hedges)» (Myers 1992:10), si bien De Beaugrande considera, de un modo más general, que la modalidad se refiere a «the probability or necessity of a statement regarding some world» (De Beaugrande 1980:9). En este sentido, nuestra concepción de la modalidad se adapta al objetivo del análisis textual en cuanto que las expresiones de la modalidad son interpretadas como indicios de actitudes deliberadas del autor del texto frente a la información que suministra y/o frente al lector a quien se dirige.
} 
incluyen también las que se establecen entre asistente social y asistido o entre médico y paciente.

Esto indica que las relaciones sociales varían en función del modo de recontextualización del discurso, pero no necesariamente en función del entorno donde se establecen tales relaciones dado que, como sugiere Christie, se pueden encontrar indicios de relaciones sociales comunes entre conjuntos de usuarios diversos. Por consiguiente, los conjuntos genéricos de relaciones sociales entre usuarios que se asocian típicamente con un discurso particular no son sino una opción disponible, puediendo adoptar múltiples manifestaciones lejos de los rígidos planteamientos prescriptivos que se les asigna en el entorno de la didáctica en numerosas ocasiones.

\subsubsection{Aparición de nuevos modos de representación y (re)producción del conocimiento}

Martin y Veel mencionan la aparición de nuevos modos de representación y (re)producción del conocimiento como la tercera de las razones por las que el conocimiento científico atraviesa procesos de recontextualización:

Scientific discourse, together with its related technological fields [...], has always led the way in this kind of recontextualisation. Scientific diagrams, for example, have for a long time been just as valid a mode of representing scientific knowledge as written language. The history of scientific diagrams goes back as far as the history of modern science itself. Since the very earliest days scientific texts have been at the very least 'bi-modal', comprising written language and diagrams. As new technologies have developed modes of representation of scientific knowledge have proliferated. Nowadays a scientific text may consist of almost infinite combinations of written language , diagrams, images, tables, graphs, mathematical symbols, sound and moving images. Each mode of representation is a semiotic system unto itself, with its own 'grammar' or patterns of relationships between elements. (Martin y Veel 1998:84)

Lemke (1998) ha estudiado la recontextualización del conocimiento científico que surge de la interacción de distintos sistemas semióticos en textos científicos actuales. A diferencia de otros trabajos sobre la semiótica de sistemas no lingüísticos, Lemke plantea que los sistemas semióticos que son complementarios entre sí, incluyendo el lenguaje, las tablas, los gráficos, las imágenes y los diagramas, no se limitan a añadir significado al texto, sino que en realidad producen nuevos órdenes de significado. Así, para Lemke, el texto científico representa una forma primitiva de hipertexto en cuanto que no posee una estructura lineal y además 
tiene un orden más abierto de lectura, lo cual tiene ciertas implicaciones en cuanto a la construcción cognitiva del significado:

Scientific text is not primarily linear, it is not meant to be read according to a unique implied sequence and represents a primitive form of hypertext ( $\mathrm{v}$. Lemke 1993d). Footnotes represent an optional branch for readers, so do figures and their captions, and the parenthetic or main-text expressions such as '(Table 3)' or 'as seen in the first table' which point to them. Spoken language is linear in this respect, but no visual semiotic can be, for all are at least twodimensional and any one-dimensional sequence represented in twodimensions can be accessed at any point at any time. Many scientists, after reading the title and abstract, may skip to the end to see an endnote telling who supported the research or to skim the references for familiar and unfamiliar citations. They may well read the tables or graphs first, and then their captions, and only then the main text. Some may pay more attention to the equations than to the words in which they are embedded. These are the habits of expert readers, those who could themselves have written this text or one very like it. (Lemke 1998:95-96)

Mediante las consideraciones de Martin y Veel acerca de la habilidad del discurso científico para reformularse en función de sus nuevos objetivos y contextos, hemos ido describiendo el discurso científico desde una perspectiva socio-semiótica, en la cual la comunicación científica se asocia con unos procesos y redes de transmisión del conocimiento científico donde el discurso científico se va recontextualizando incesantemente y donde lo que habitualmente denominamos 'texto científico' resulta ser una etiqueta genérica que recoge todo un abanico de manifestaciones diferentes 5 .

Desde el punto de vista del texto científico (y, por extensión, del texto especializado), la posición de Lemke supone un cambio interesante frente a otras concepciones más tradicionales de la unidad textual en cuanto que, puesto que es capaz de dar cuenta de modos de representación más variados, se trata de una perspectiva más abierta que las que únicamente consideran el sistema semiótico lingüístico. Esto es más acorde con una perspectiva general sobre la descripción del lenguaje en uso que tenga en cuenta la versatilidad de los modos (bien sean actuales, pasados o futuros) de representación del conocimiento y de construcción del significado:

\footnotetext{
${ }^{5}$ La variedad de manifestaciones recogidas bajo la denominación común de 'textos científicos' es crucial para diferenciar entre niveles de reconocimiento de los investigadores, a los que Myers (1992) se refiere en su aproximación al libro de texto especializado bajo el epígrafe «Textbooks in the Life of a Scientist», así como para diferenciar entre contextualizaciones del conocimiento en la comunicación científica, a las que Myers (1992) se refiere bajo el epígrafe «Textbooks in the Life of a Fact».
} 


\begin{abstract}
When we investigate how meaning is made, we can no longer assume that actual social meanings, materially made, consist only in the verbal-semantic relations (paradigmatic, syntagmatic, intertextual) by which we have previously defined them. We must now consider what meaning-in-use usually organises, orients and presents, directly or implicitly, through the resources of multiple semiotic systems. What the logocentrism of a few prominent genres of purely verbal text (e.g. unillustrated novels, academic articles in philosophy and the humanities) has distracted us from, perhaps the pervasively multimodal disposition of scientific and technical text can remind us of. (Lemke 1998:111)
\end{abstract}

Teniendo en cuenta esta perspectiva comprehensiva sobre la unidad textual, a continuación vamos a desarrollar con mayor profundidad aquellos aspectos de la comunicación especializada relacionados con su dimensión textual, incluyendo los aspectos de la comunicación intercultural más relevantes para nuestro trabajo.

\title{
5.2 La comunicación especializada: entorno textual
}

Desde un punto de vista general, podemos afirmar que los mecanismos textuales de transmisión del conocimiento en la comunicación especializada son análogos a los de cualquier otro tipo de comunicación mediante textos.

Tal como hemos visto en la sección anterior, una concepción comprehensiva del texto como la de Lemke nos hace entrever que el texto es una unidad compleja en cuanto a sus constituyentes y funcionamiento, por lo que vamos a analizar qué son y cómo funcionan los textos desde una perspectiva general. La idea subyacente es que abordar la dimensión textual de la comunicación especializada centrándonos únicamente en las características de lo que hemos denominado 'textos especializados', o TPEs para Rabadán, implica una reducción innecesaria de la perspectiva, ya que su caracterización no deriva tanto de su condición de especializados, (en cuanto a una cierta conjunción de características del contexto de situación donde esos textos son producidos y difundidos, de su registro, género, participantes y, en general, de aspectos que se relacionan con la pragmática de la comunicación lingüística y con su dimensión socio-semiótica), como de su condición de textos, es decir, de artefactos que la gente es capaz de crear y de interpretar para comunicarse entre sí de modo eficiente, así como para crear significado y fijar conocimientos; artefactos sofisticados que, no obstante, utilizamos cotidianamente. 
La lingüística sistémico-funcional considera que el texto es una unidad de tipo semántico que no es el resultado de la suma o acumulación de las oraciones en el sentido de que no consta de oraciones, sino que, como matizan Halliday y Hasan, se materializa o codifica mediante oraciones:

\begin{abstract}
A text is best regarded as a semantic unit: a unit not of form but of meaning. thus it is related to a clause or sentence not by size but by realization, the coding of one symbolic system in another. A text does not consist of sentences; it is realized by, or encoded in, sentences. If we understand it in this way, we shall not expect to find the same kind of structural integration among the parts of a text as we find among the parts of a sentence or clause. The unity of a text is a unity of a different kind. (Halliday y Hasan 1976:2)
\end{abstract}

Esto significa que el texto constituye una entidad mucho más compleja y cualitativamente diferente de la oración (De Beaugrande 1980a) y que, en todo caso, es posible dar la vuelta al planteamiento y abordar la oración como un texto (Sinclair 1994) pero no al contrario. En cualquier caso, aunque el texto y la oración tienen una relación de rango entre ellos, no se diferencian en términos cuantitativos:

The text is not simply a larger «rank» than the sentence [...], despite the views of some researchers [...]. A text may be no longer than a single word, and it may be composed of elements without sentence status (e.g. road signs, advertisements, telegrams, and so on). (De Beaugrande 1980a:16)

Por último, el texto es una unidad dinámica y sensible en relación con los procesos mediante los cuales es producido y comprendido.

Una aproximación habitual a la definición de texto suele comenzar introduciendo el concepto de textura con el propósito de discernir entre lo que es texto y lo que no lo es. De acuerdo con Halliday y Hasan, la textura se define como la propiedad que un texto tiene de 'ser texto': «a text has texture, and this is what distinguishes it from something that is not a text» (Halliday y Hasan 1976:2). No obstante, en este trabajo no nos interesa la noción de textura como criterio de validación de lo que es un texto. La razón de este desinterés es que, desde un punto de vista descriptivo de la lengua relevante para la didáctica del Inglés para Fines Específicos, partimos del supuesto de que en la comunicación especializada tal como se produce en el mundo real no vamos a encontrar no-textos, sino únicamente textos, por lo que los no-textos no tienen mayor interés que el de un constructo útil para ilustrar más claramente la textura, tal como señala De Beaugrande: «the notion of a "non-text" is not crucial, because the occurrence of non-texts usually signals a refusal or inability to communicate» (De Beaugrande 1980a:15). 
Los textos producidos en el aula son susceptibles de ser tomados como casos de 'no texto', si nos fijamos en aquellos que resultarían ineficaces para lograr éxito en la comunicación al ser difundidos en un entorno comunicativo real debido a sus anomalías o deficiencias. Igualmente sucede con los TTs que presentan una gran acumulación de anomalías o deficiencias, o que se alejan significativamente del TO y que, por tanto, podrían ser considerados casos de 'no-traducción'. No obstante, en nuestro enfoque partimos del supuesto inicial de que todos los textos producidos en aula son casos de 'texto' desde el momento en que han sido producidos con el propósito de comunicar algo. Así, nuestra aproximación al texto se basa en la intencionalidad del productor en lugar de en la corrección de los resultados obtenidos, ya que este enfoque nos resulta más productivo para los objetivos didácticos planteados (entre los que no se incluye un marcado énfasis en el dominio de la corrección lingüística ni en el uso normativo de las reglas gramaticales).

En general, abordar la descripción de textos supone un cambio de perspectiva acerca del estudio del lenguaje, ya que intentar definir y analizar la textura de los textos supone considerar que los textos son objetos empíricos. De acuerdo con De Beaugrande, no sólo el lenguaje puede ser contemplado como un sistema (o más bien como un conglomerado jerárquico de sistemas), sino que la noción de sistema también es aplicable al texto, si bien de modo diferente:

\footnotetext{
The intersystem of a natural language such as English is composed of virtual systems: functional unities of elements whose potential is not yet put in use, e.g. the repertories of sounds, grammatical forms, sentence patterns, concept names, etc., which a particular language offers its users; in contrast to these repertories, a text is an actual system: a functional unity created through processes of decision and selection among options of virtual systems [...]. (De Beaugrande 1980a:16)
}

Desde esta perspectiva, De Beaugrande considera la evolución del texto como un proceso que denomina 'actualización' y que interpreta como una cualidad que constituye el criterio esencial para identificar un texto como tal. En resumen, De Beaugrande viene a decir que un texto tiene textura, que tiene la propiedad de ser texto, porque es un sistema que ha sufrido un proceso de actualización. Sin embargo, esto no es suficiente para definir el texto, ya que es igualmente cierto que los no-textos representan asimismo actualizaciones de lenguaje. Se hace por tanto evidente que tenemos que matizar más qué implicaciones tiene el proceso de actualización.

Lo que nos resulta interesante de la noción de textura de Halliday y Hasan es su capacidad para mostrar la necesidad de reconocer los textos como entidades 
empíricas y no sólo como constructos teóricos. A pesar de esto, una noción sobre lo que implica ser texto tan general como el concepto de textura de Halliday y Hasan necesita ser cualificada con mayor precisión para que realmente pueda tener capacidad explicativa o meramente analítica. En este sentido, la noción de textualidad (De Beaugrande 1980a; De Beaugrande y Dressler 1981) viene a suplir la falta de precisión de la noción de textura.

Para De Beaugrande, la denominada 'textualidad' se deriva de los procedimientos de la utilización de textos para comunicarse, de tal modo que esta noción se constituye a partir de su preocupación por encontrar el modo de definir «the abilities that make people actually competent to produce and understand texts with consistent (though not universal) success» (De Beaugrande 1980a:15). Aquí, el centro de atención al abordar la descripción del lenguaje pasa a recaer sobre los factores que hacen que la gente logre comunicarse de modo competente mediante textos. Por consiguiente, la descripción de los textos se lleva a cabo mediante el estudio de su textualidad, entendida como el factor complejo que representa los procedimientos comunicativos implicados en la comunicación textual.

Analizar la dimensión textual de la comunicación especializada de este modo descriptivo nos permite adoptar una perspectiva general sobre los textos pero también establecer grupos de características limitadas sobre ciertos textos y, al mismo tiempo, considerar la traducción como un tipo de comunicación textual que presenta unos rasgos particulares ${ }^{6}$.

Para poder analizar en detalle el proceso de actualización del lenguaje, De Beaugrande y Dressler (De Beaugrande 1980a; De Beaugrande y Dressler 1981) han propuesto un repertorio de variables, denominadas 'normas' o 'criterios de textualidad' (standards of textuality), en las que nos detendremos a continuación.

\footnotetext{
${ }^{6}$ Las particularidades de la traducción pueden ser muy variadas con respecto a otros tipos de comunicación textual. Por citar un ejemplo, nos podemos preguntar acerca de la influencia de la estructura superficial del TO en relación con la elección de unas estructuras sintácticas determinadas para el TT en el caso de la traducción. De Beaugrande (1980a:14) afirma que los factores psicológicos son más relevantes para el texto que para la oración puesto que en el procesamiento mental la oración es sólo un formato heurístico entre otros para lograr los objetivos de la comunicación, tales como expresar y recuperar conocimientos. Además, basándose en un estudio de Bransford y Franks, De Beaugrande afirma que los límites de la oración se establecen tarde durante el proceso de producción textual y se descartan pronto durante el proceso de comprensión. Sin embargo, en el caso de la producción textual basada en un texto anterior, es decir, en un TO, podemos afirmar que las oraciones del TO ejercen cierta influencia sobre las oraciones del TT en cuanto al tipo de estructuras sintácticas, tipos de componentes, orden de los elementos y también los propios límites oracionales, al menos si nos atenemos a la experiencia personal con las traducciones que los estudiantes producen en el aula.
} 
Para De Beaugrande y Dressler, analizar textos es el modo de contribuir a una ciencia textual capaz de describir o explicar tanto las características comunes como las que pueden registrar diferencias entre textos y entre tipos de textos. A su vez, el objetivo general del análisis textual consiste en averiguar cómo se produce el funcionamiento de los textos en la comunicación:

We ought to find out what standards texts must fulfil, how they might be produced or received, what people are using them for in a given setting of occurrence, and so forth. The words and sentences on the page are reliable clues, but they cannot be the total picture. The more pressing question is how the texts function in human interaction. (De Beaugrande y Dressler 1981:3)

En resumen, podemos decir que el planteamiento de De Beaugrande y Dressler es afín a una interpretación del lenguaje como sistema de comunicación socio-semiótica, pero aquí la atención se sitúa sobre el texto como objeto de estudio para describir en qué consiste, de qué elementos se compone y cómo funciona. Desde esta perspectiva, el texto es interpretado como un «acontecimiento comunicativo que cumple siete normas de textualidad» (De Beaugrande y Dressler 1997:35; De Beaugrande y Dressler 1981:3). Por lo que se refiere al objetivo de nuestro trabajo, al considerar la utilidad de las tareas de traducción como medio para que los aprendices adquieran y empleen unas estrategias de comportamiento semejantes a las que utilizan los expertos cuando se comunican entre sí, estamos teniendo en cuenta los aspectos de los aprendices que se relacionan con sus características como usuarios de textos especializados, tanto en lo que concierne a la comunicación en inglés como en español.

\subsubsection{Criterios de textualidad}

De Beaugrande y Dressler denominan las siete normas o criterios de textualidad, respectivamente, 'cohesión', 'coherencia', 'intencionalidad', 'aceptabilidad', 'informatividad', 'situacionalidad', e 'intertextualidad'. A continuación, describiremos en qué consiste cada uno de estos criterios y qué relación mantienen entre sí.

\subsubsection{El criterio de cohesión}

La primera norma que caracteriza la textualidad de un acontecimiento comunicativo, el criterio de cohesión, se refiere, en un sentido muy amplio, al modo 
como se conectan entre sí secuencialmente los componentes superficiales del texto ${ }^{7}$. Este modo de conexión de los elementos superficiales está sujeto a dependencias formales, de modo que los componentes de la superficie del texto no aparecen asociados de modo fortuito, aleatorio o universal, sino que su mutua dependencia está limitada por unas restricciones derivadas de las normas y formas gramaticales de cada lengua, es decir, establecidas por las reglas del sistema lingüístico según su especificación en cada lengua en particular. Esto explica que, en la traducción, raramente veamos una apariencia similar entre la configuración de los elementos superficiales de un TT y la configuración de su correspondiente TO: no sólo las palabras y oraciones son diferentes, sino que el modo de conexión entre los diferentes elementos también lo es.

No obstante, aunque los elementos del texto superficial nos sirvan de pistas para interpretar la información textual, en cuanto que la aparición de unos elementos textuales determinados (y no otros) en una disposición particular (única para cada texto) nos sirve como base de interpretación y guía para la comprensión del texto, la superficie textual no es decisiva en sí misma para interpretar el texto, por lo que la comunicación eficaz no se consigue a menos que haya interacción entre la cohesión textual y las demás normas de textualidad (De Beaugrande y Dressler 1981). Malmkjaer señala a este respecto la importancia que han ido cobrando lo que hasta hace unas décadas se consideraban aspectos desligados de la interpretación de mensajes lingüísticos:

\begin{abstract}
Since the 1960s a great deal of effort has gone into listing the kinds of clues which writers and readers, speakers and hearers can rely on (see, for example, Hymes 1964; Lewis 1970; Halliday 1978; Brown and Yule 1983; Sperber and Wilson 1986). This has made us very aware of the importance of the communicative situation and of background knowledge, both of the world and of the person we are interacting with and other similar persons we have met in similar situations, and also of the surrounding discourse, or, as it is also called, the co-text. (Malmkjaer 1993:143)
\end{abstract}

\title{
5.2.1.2 El criterio de coherencia
}

La segunda norma, denominada 'coherencia', se refiere al modo como se relacionan entre sí los componentes del texto que no son superficiales, regulándolos así: «la coherencia regula la posibilidad de que sean accesibles entre sí e interactúen de un modo relevante los componentes del mundo textual, es decir, la configuración

\footnotetext{
${ }^{7}$ De Beaugrande y Dressler denominan 'texto superficial' (surface text) «the actual words we hear or see» (De Beaugrande y Dressler 1981:3).
} 
de los conceptos y de las relaciones que subyacen bajo la superficie del texto» (De Beaugrande y Dressler 1997:37) ${ }^{8}$.

Estos autores denominan 'concepto' a «una estructuración de conocimientos (o contenidos cognitivos) que el hablante puede activar o recuperar en su mente con mayor o menor unidad y congruencia», mientras que las 'relaciones' son «los vínculos que se establecen entre los conceptos que aparecen reunidos en un mundo textual determinado» (De Beaugrande y Dressler 1997:37; De Beaugrande y Dressler 1981:4). Así pues, las relaciones son de naturaleza semántica y se clasifican tipológicamente en función de los conceptos que vinculen. En este sentido, la unidad básica de una semántica del procesamiento es la 'proposición', definida como «a relation obtaining between at least two concepts» (De Beaugrande 1980a:66). En un sentido más restringido, Sánchez Miguel define las proposiciones como «afirmaciones con un significado pleno que permiten un juicio de verdad y falsedad» (Sánchez Miguel 1993:256). Además, dada su naturaleza semántica, tal como explica Crombie, las relaciones de coherencia son necesarias para determinar el valor del discurso:

\begin{abstract}
The study of semantic relations involves the study of discourse values, where the discourse value of an utterance may be defined as its significance or communicative function within a discourse, as distinct from its sentence meaning or conceptual content. Sentence meaning is determined largely with respect to the interaction between words and the structures in which they occur; discourse value is determined largely with respect to the interaction between sentence meaning and context. (Crombie 1985:2)
\end{abstract}

Teniendo en cuenta que las relaciones de coherencia se dan en el texto tanto de forma explícita (mediante conectores u otros marcadores discursivos) como implícita, la coherencia está asimismo asociada a los procesos de 'inferencia', que De Beaugrande y Dressler (1981:6) definen como «the adding of one's own knowledge to bring a textual world together», de tal modo que consideran que «a text does not make sense by itself, but rather by the interaction of text-presented knowledge with people's stored knowledge of the world». Puesto que la interacción es directamente dependiente del lector del texto, los procesos de inferencia no se

\footnotetext{
${ }^{8}$ La cita correspondiente al texto original se encuentra en la obra citada de De Beaugrande y Dressler (1981:4). No obstante, se ha optado por utilizar, además del original, la versión española de Bonilla (1997) como punto de referencia en cuanto a la terminología utilizada en relación con la lingüística textual. Para evitar la falta de unanimidad en la terminología del campo del discurso, que ya hemos mencionado previamente, nos ha parecido pertinente optar por una obra que, como la de Bonilla, funciona en su correspondiente polisistema como una obra original o, como diría House (1981), como una 'traducción inadvertida' (covert translation).
} 
desarrollan de modo uniforme, por lo que no son extrapolables a todas las lecturas que se hagan de un texto. Si queremos describir lo que sucede, debemos tener en cuenta que las teorías y los métodos de la lingüística textual deben ser probabilísticos en lugar de deterministas, en el sentido de que deben dilucidar lo que suele suceder normalmente, pero no siempre necesariamente (De Beaugrande y Dressler (1981).

Estas dos primeras normas de textualidad, la cohesión y la coherencia, constituyen dos conceptos centrados en el texto. De Beaugrande y Dressler señalan que, además de las nociones centradas en el propio texto, necesitamos también otras nociones centradas en los usuarios involucrados en la comunicación textual, tanto en lo que concierne a los receptores como a los productores de los textos, que son las que describiremos a continuación.

\subsubsection{El criterio de intencionalidad}

La tercera norma de textualidad se denomina 'intencionalidad' y se refiere a la actitud del productor del texto en cuanto que el conjunto de acontecimientos comunicativos debe constituir un texto coherente y cohesivo que sirve para llevar a cabo las intenciones de su autor, tales como alcanzar una meta determinada de acuerdo con un plan de actuación. En este sentido, las inferencias que hacen los receptores de un texto están estrechamente relacionadas con las implicaturas del autor (véase, por ejemplo, Reyes 1990), de tal modo que existe una relación directa entre lo que el autor implica y lo que el receptor infiere. En cuanto a la posibilidad de que la falta de cohesión o la incoherencia del texto impidan alcanzar las metas discursivas, De Beaugrande y Dressler señalan que, al menos en la comunicación oral espontánea, los receptores suelen ejercer una «cierta tolerancia hacia producciones de sus interlocutores que difícilmente pueden considerarse como cohesionadas y coherentes» (De Beaugrande y Dressler 1997:41; De Beaugrande y Dressler 1981:7). Aunque el texto no sea completamente coherente y cohesivo, esto no siempre conlleva que se produzcan trastornos en la comunicación, si bien se parte por defecto del supuesto de que el autor ha utilizado o va a utilizar los recursos que están a su disposición del mejor modo posible para lograr los fines que desea alcanzar mediante la comunicación.

Por lo que se refiere a la comunicación escrita, dado que habitualmente no se suele transmitir con la misma espontaneidad que la comunicación oral, y especialmente cuando se trata de una transmisión intercultural con el concurso de la traducción de un TO a un TT, la utilización óptima de los recursos que el autor tiene 
a su disposición se relaciona directamente con la decisión de establecer cuándo se ha alcanzado el umbral de finalización del texto.

\subsubsection{El criterio de aceptabilidad}

Asimismo desde la posición del receptor, la cuarta norma de textualidad, denominada 'aceptabilidad', se refiere a la actitud del receptor del texto en cuanto que el conjunto de acontecimientos comunicativos es asumido como un texto coherente y cohesivo que tiene algún tipo de utilidad o relevancia para el propio receptor: «what text receivers engage to do by accepting something as text, e.g., understand, consider, react, and so on» (De Beaugrande 1997:14).

De acuerdo con De Beaugrande y Dressler (1981:7), esta actitud es sensible a factores tales como el tipo de texto, el contexto social o cultural, o el atractivo de las metas planteadas. Dentro de la actitud del receptor se incluye la opción de ser tolerante con las anomalías o dificultades del texto, y que está relacionada con los procesos de inferencia que hemos mencionado más atrás. En definitiva, tal como explica De Beaugrande, si bien la cuestión de la gramaticalidad o agramaticalidad de un texto se suele tratar en términos de oposición binaria, un texto es considerado aceptable o no aceptable en términos de una gradación compleja en la que intervienen de forma relevante motivaciones de carácter contextual, de tal modo que «a text must be relevant to a situation of occurrence, in which a constellation of strategies, expectations, and knowledge is active» (De Beaugrande 1980a:12). Esta noción se basa en la consideración del texto como «the manifestation of a human action in which a person intends to create a text and instructs the text receivers to build relationships of various kinds» (De Beaugrande 1980a:13). Podemos ver que en esta interpretación subyace la perspectiva de que el texto es susceptible de ser tomado como un conjunto de instrucciones para el receptor, sobre lo cual, dada su conveniencia para nuestro enfoque didáctico, nos detendremos brevemente a continuación.

\subsection{El texto como conjunto de instrucciones para el receptor}

Actualmente está comúnmente aceptado como un hecho que la información que transmitimos es realmente interpretada y comprendida de formas distintas por cada receptor, independientemente de nuestras intenciones cuando producimos un texto escrito, tal como explica Reyes: 
Todos los textos, incluso los que fueron producidos con intención de total univocidad, como los legales, [son] susceptibles de interpretaciones diferentes, a veces más de una plausible. Cuanta mayor sea la distancia del contexto de origen, mayor será la inestabilidad (o, si se prefiere, la riqueza) de los significados de un texto. (Reyes 1990:60)

Admitimos, por tanto, la subjetividad de la interpretación textual y la situamos en el terreno de los procesos cognitivos del sujeto (entendiendo, por consiguiente, que la interpretación es variable porque depende de las características específicas e idiosincráticas de cada persona, tales como su estado de conocimientos acerca del tema sobre el que trata el texto o su relación con el autor) o bien, en un sentido filosófico, en el terreno de la libertad individual (entendiendo así que la interpretación es variable porque deriva de un acto voluntario, la lectura, que responde a diferentes aspiraciones de cada individuo en cada momento particular de tal modo que la propia interpretación estaría condicionada por las aspiraciones particulares del sujeto que lee en ese momento preciso). Pero, al mismo tiempo, también está comúnmente aceptado que el texto, como objeto físico, visible, tangible y terminado, es también objetivo en cuanto al sistema de elementos fijos que lo componen. Consta de un soporte que nos permite reconocer mediante alguno de nuestro sentidos, vista, tacto, oído, ¿etc.?, un sistema de elementos lingüísticos y semióticos a partir de los cuales construimos cierto significado ${ }^{9}$. Esto implica que el texto también puede ser considerado como un objeto susceptible de ser trasladado en el espacio con independencia de los participantes en la comunicación. Su objetividad estaría desligada así del receptor e incluso del propio autor.

Por otra parte, podemos asimismo considerar el texto como un constructo o artefacto que es objetivo en cuanto a su funcionamiento, que opera de forma análoga en toda ocasión. Según esta aproximación, cabe suponer que las inferencias que los receptores hagan a partir de su lectura serán muy similares, por lo que un modo habitual de representar la interacción entre el lector y el texto ha sido la representación del texto como un conjunto o listado de instrucciones dirigidas al receptor con la finalidad de que realice algún tipo de acción, sea lingüística o no.

Schmidt (1973) fue pionero en considerar el texto como un conjunto de instrucciones al tratar la cuestión del significado de los textos.

A partir de la extensión al ámbito del texto de la teoría de los actos de habla de Searle (1969), en la que los actos que ejecutamos al hablar (tales como hacer

\footnotetext{
9 'Sistema' aquí se refiere a «a unity of mutually relevant elements whose functions are determined by their respective contributions to the workings of the whole» (De Beaugrande 1980a:2).
} 
afirmaciones, preguntas, promesas, dar órdenes, etc.) son tomados como una representación de formas de comportamiento dirigidas por reglas, Schmidt (1973) esboza lo que él mismo denomina una 'semántica de la instrucción'.

En su argumentación acerca del significado, Schmidt parte de la consideración de los lexemas, que interpreta del siguiente modo:

Los lexemas, desde el punto de vista de la semántica de la instrucción, son constituyentes del texto, analíticamente aislables, pero jamás aparecen aislados en el sistema de la lengua; están integrados verbalmente en campos lexemáticos (subsistema de un léxico). La posición del lexema en el campo lexemático define sus posibilidades de aplicación; dicho con otras palabras, el campo-contexto asigna al lexema sus posibilidades generales de funcionamiento en textos, los limita y estabiliza por un conjunto de conexiones comprobadas por su continua repetición o aparición. [...]

El lexema aislado no se refiere a un nivel extraverbal correlativo o a correlaciones, sino al correspondiente campo lexemático que se puede interpretar como un complejo de reglas e instrucciones dirigidas a interlocutores que se refieren (en actos comunicativos de forma determinada), a factores verbales y no verbales de la actividad comunicativa, es decir, a los modelos de la realidad válidos en él. (Schmidt 1973:63)

En la misma línea interpretativa, De Beaugrande define un concepto como «a block of instructions for cognitive and communicative operations» (De Beaugrande 1980a:67). Y, en un rango mayor, el texto se puede definir como «an ordered set of instructions to a communication partner. It is only in communication that interlocutors realize the instructions of a text, i.e. its meaning» (Lörscher 1991:21). De esta forma, el texto «is interpretable to those who can, under prevailing conditions, build around that text a scenario or text world in which that text either might be true, or seems to conform to certain maxims of human behaviour, or both» (v. Tirkkonen-Condit 1991:6).

Por otra parte, la interpretación del texto como un conjunto de instrucciones dirigidas al receptor puede ser englobada en una actitud, más general y entroncada en la retórica clásica, en la que el texto es tomado como una fuente de información y cuyo mecanismo para extraer la información textual es representado como un repertorio de preguntas que el texto responde. La concepción del texto como un conjunto de instrucciones para el lector se puede observar también en el ámbito de la literatura. El relato de ficción de Harry Kemelman titulado «The Nine Mile Walk» (1967) constituye un buen ejemplo ilustrativo de esta concepción o utilización del texto. En él, los protagonistas reconstruyen la situación comunicativa de un texto compuesto por una única oración ( $\mathrm{A}$ nine mile walk is no joke, especially in the rain»), así como el perfil de su autor. El proceso de construcción se 
lleva a cabo mediante las conjeturas que van formulando a partir de la (escasa) información que van extrayendo del texto junto con sus propias inferencias y suposiciones, que finalmente resultan ser acertadas. A su vez, Bell nos proporciona como ejemplo ilustrativo un poema de Rudyard Kipling:

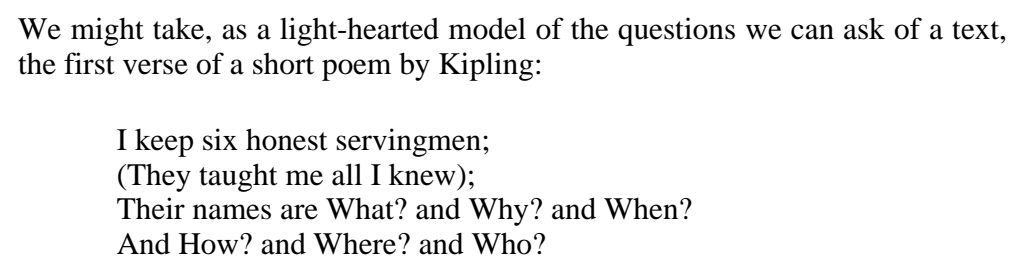

(Bell 1991:7)

Por lo que concierne al ámbito de la traducción, esta representación ha sido utilizada como pauta de actuación para tomar decisiones acerca de aspectos relacionados con la producción del TT. Por ejemplo, Nord explica cómo, en el 'modelo recursivo' (the looping model), «every [Original Text] is supposed to carry its own "translating instructions" telling the translator how it should be transferred» (Nord 1991:32). Como veremos en la sección siguiente, Nord utiliza un modelo de preguntas que se le pueden hacer al texto basado en la Nueva Retórica y que representa los factores que de un modo u otro intervienen en el texto.

En cualquier caso, la cuestión más ardua que debemos resolver si queremos utilizar un modelo de preguntas dirigidas al texto es, precisamente, cuáles son las preguntas relevantes que debemos formular. Es evidente que este repertorio de preguntas variará de unos autores a otros en función del concepto de lenguaje, de texto, y en nuestro caso también de traducción, que utilicen en cada caso. Así, volviendo a los criterios de textualidad que formulan De Beaugrande y Dressler, Bell (1991) explica que estos criterios han sido formulados, precisamente, para responder las cuestiones que el lector y el traductor necesitan preguntar al texto.

En realidad, los criterios de textualidad representan un modelo de los factores involucrados en la producción y transmisión de conocimientos mediante textos, incluyendo los aspectos relacionados con el uso que los usuarios del lenguaje hacen de los textos y, como tal modelo, tiene la condición de artefacto o constructo mediador entre lo que queremos explicar y lo que podemos percibir (De Beaugrande 1980a:4). De Beaugrande señala las situaciones que hacen necesaria la utilización de un modelo, concluyendo que, en mayor o menor grado, todas ellas se dan en la lingüística. Estas situaciones son las siguientes: 
1. when no known theory exists for a domain;

2. when a theory is known, but too complex for solving problems with currently available techniques;

3. when a theory is known and partly confirmed, but still incomplete;

4. when new research permits the correlation or integration of two or more known theories;

5. when the objects of investigation are too large, too small, too remote, or too arduous to allow direct observation and experimentation.

(De Beaugrande 1980a:4)

No obstante, desde el punto de vista de la didáctica de las lenguas extranjeras, debemos añadir una situación más en la que los modelos son necesarios. La utilización de modelos como el repertorio de criterios de textualidad nos permite transmitir en el aula de forma económica conocimientos que son necesarios para la comprensión del funcionamiento del lenguaje. En este sentido, la utilización de un procedimiento de preguntas relevantes contribuye a que los factores que hay que tener en cuenta sean comprendidos y recordados con mayor facilidad.

Cuando se tratan cuestiones lingüísticas con estudiantes cuyos conocimientos acerca del funcionamiento del lenguaje se basan en la experiencia que tienen como usuarios de éste, más que en un estudio profundo de la lingüística, entonces necesitamos formalizar de un modo rápido y sencillo aquellos conocimientos que los estudiantes ya poseen de un modo intuitivo para que puedan adquirir conocimientos nuevos, o según la perspectiva de Widdowson (1979), debemos enlazar los conocimientos de la cultura secundaria con la cultura primaria de los aprendices (v. 5.1). Para lograr esto, la utilización de modelos en forma de preguntas constituye potencialmente un método muy conveniente porque los aprendices pueden comprenderlo con facilidad y porque, subsidiariamente, sirve para fomentar la reflexión y, por tanto, el autoaprendizaje. Por ejemplo, la aceptabilidad del texto por parte del receptor, que apela directamente a la actitud crítica de éste sobre el texto, suele ser un criterio sobre el que los estudiantes de Inglés para Fines Específicos provenientes de campos de estudio científicos o técnicos no suelen tener experiencia directa ya que, cuando tratan con textos de su especialidad, suelen tender a tomarlos como aceptables por defecto, si bien comprenden sin dificultad que los textos pueden ser aceptados o rechazados por los receptores mediante una evaluación crítica. Este ejemplo se puede hacer extensivo a otros de los criterios que estamos tratando. En el caso que trataremos a continuación, las dificultades prácticas con las que el profesor a menudo se encuentra suelen estribar en lograr que los aprendices aprendan a distinguir entre lo que un texto presenta como información nueva y lo que es tratado como información previamente conocida por el lector (Elorza 2000). 


\subsubsection{El criterio de informatividad}

El quinto criterio que afecta a la textualidad se relaciona con el texto en cuanto a la información que éste nos proporciona.

$\mathrm{Si}$ interpretamos esta noción en términos absolutos, entonces consideraremos informativo aquello que resulta novedoso $\mathrm{y}$, por tanto, contemplaremos el texto como una noticia, como datos, ideas, opiniones (en definitiva, significados), que el autor hace públicos o revela por primera vez. Desde el punto de vista de la comunicación científica este aspecto es relevante en muchos casos. Para ilustrar esto con un ejemplo relacionado con la construcción del conocimiento científico, cabe señalar que la información que los textos hace pública por primera vez es relevante en relación con las autorías de los descubrimientos científicos.

No obstante, en cuanto a la textualidad de una manifestación lingüística comunicativa, la informatividad es interpretada en términos relativos. La relatividad a la que nos referimos implica que la información del texto no se asocia con el estado del conocimiento existente o del conocimiento aceptado de un campo de especialización (v. Fig.3). Por el contrario, la informatividad se relaciona, por una parte, con el estado de conocimientos que tiene el receptor prospectivo o receptor ideal del texto y, por otro lado, con el propio comportamiento de la información en el texto, en cuanto a la progresión o secuenciación de elementos que se sucede a lo largo de la estructura informativa del texto y que, como veremos más adelante, se diferencia del mecanismo de cohesión textual.

De Beaugrande y Dressler asocian la informatividad de un texto con «the extent to which the occurrences of the presented text are expected vs. unexpected or known vs. unknown/certain» (De Beaugrande y Dressler 1981:8-9), por tanto, con la expectación y los conocimientos de los receptores al interactuar con el texto. De Beaugrande asocia esta relatividad con la inestabilidad de los significados del texto a la que alude Reyes (1990), de tal modo que es muy difícil separar el significado de un texto de la representación cognitiva que los usuarios del texto hacen de su significado. En el caso de la mediación intercultural, el hecho de que habitualmente se dé un mayor número de textos y de participantes que en la comunicación intracultural supone un proceso más complejo aún:

It is indeed difficult to distinguish between the original 'meaning' of a text and the cognitive representation of the meaning in the mind of the persons involved with the text:

- the original text producer,

- the translator as text receiver in the source language, 
- the translator as text producer in the goal language,

- the receiver audience in the goal language.

(De Beaugrande 1980b:24)

Podemos resumir diciendo que la informatividad es, desde este enfoque, una noción que se refiere a la integración del significado del texto con los conocimientos del sujeto en cuanto al grado de coincidencia o desfase entre el conocimiento que proporciona el texto y el que el sujeto ya posee:

The principle of informativity subsumes the degree to which the knowledge that the text makes accessible does not fit your prior knowledge. So «information» is not just the content or message itself but the «goodness of fit» between the content or message versus what you knew already. (De Beaugrande 1997:14)

En cualquier caso, la informatividad del texto es un factor crucial en relación con su facilidad o dificultad para ser comprendido y, por consiguiente, con su valoración crítica. Esto significa que ocupará un lugar destacado en una didáctica centrada en el aprendiz, o también al considerar los conocimientos del traductor en relación con la información textual.

\subsubsection{El criterio de situacionalidad}

La situacionalidad, sexto criterio de la textualidad, se relaciona con los factores que hacen que un texto sea relevante con respecto a la situación en la que surge. Por ejemplo, este factor es responsable de que, si vemos un rótulo en la parte superior de una tienda con el texto «TODO A 100», interpretemos que el texto es el nombre de la tienda en cuestión y también de un tipo de negocio o tienda que se caracteriza por la venta a un precio bastante uniforme de una enorme variedad de productos de fabricación de bajo coste. Al mismo tiempo, la propia situación donde aparece este texto hace que rechacemos otras interpretaciones distintas como, por ejemplo, que el texto nos esté dando una indicación precisa para conducir a una determinada velocidad por ese lugar.

Tal como indican De Beaugrande y Dressler,

La influencia que tiene la localización situacional sobre el texto durante el encuentro comunicativo está mediatizada por la intervención (o mediación) de la subjetividad de los interlocutores, quienes suelen introducir sus propias creencias y sus propias metas en el modelo mental que construyen de la situación comunicativa en curso. Habitualmente, la evidencia que proporciona la situación real accesible por igual a los participantes en la interacción se mezcla con el conocimiento previo y con las expectativas que éstos tienen 
sobre cómo se organizan prototípicamente las situaciones en el mundo real.

(De Beaugrande y Dressler 1997:225)

En un sentido amplio, podemos considerar que la situación no sólo tiene influencia en nuestra interpretación de la textualidad, sino en nuestra interpretación de la relevancia de cualquier manifestación socio-semiótica, cuyo valor y significado son asignados e interpretados por nosotros mismos. Una comparación de la reacción despavorida de los asistentes a la proyección de la película de los hermanos Lumière donde se mostraba la llegada de un tren a una estación, frente a la reacción del público ante la misma película en otra situación diferente (por ejemplo, su exhibición en la actualidad dentro de un ciclo sobre los orígenes del cine), nos sirve como ilustración no sólo de la influencia de la situación en el efecto que nos causa un texto (u otro tipo de manifestación socio-semiótica), sino de que, efectivamente, esta influencia está mediatizada por los receptores de un modo subjetivo.

No obstante, la influencia de la situación no sólo está mediatizada por los receptores, sino también por el productor del texto, que ejerce su control reconduciendo o dirigiendo la situación comunicativa en su provecho. El control del productor es fácilmente observable en muchos textos publicitarios, si bien se trata de un ejercicio de control que afecta a todo el discurso (De Beaugrande 1994; De Beaugrande y Dressler 1981:163 y siguientes). De hecho, el productor del texto debe decidir cómo es el modelo de la situación que presenta al receptor. De Beaugrande y Dressler señalan que es muy frecuente que el productor del texto intente presentar un modelo de situación que en apariencia no ha sido mediatizado subjetivamente, aun cuando el productor intenta llevar a cabo una reconducción de la situación (situation monitoring). Sin embargo, estos autores diferencian entre esta reconducción hacia un modelo de situación determinado y lo que denominan 'dirección de la situación' (situation management), que implica una manipulación intencionada de la situación.

Por otra parte, la facilidad con que los receptores analizamos una situación determinada se debe a que, en lugar de hacer un análisis pormenorizado, costosísimo en tiempo y esfuerzo, utilizamos estrategias selectivas para fijar nuestra atención en unos determinados elementos en detrimento de otros, es decir, dedicando la mayor parte de nuestros recursos de procesamiento al análisis y el tratamiento de la información que nos ha resultado más interesante. Además de ésto, De Beaugrande y Dressler señalan que también utilizamos una serie de estrategias de ordenación estandarizada (normal ordering strategies) para percibir el mundo 
que, proyectadas sobre las secuencias lingüísticas, nos permiten seguir las pistas para localizar e interpretar la información más relevante del texto (De Beaugrande y Dressler 1997:212; 1981:147). Estas estrategias suponen pautas habituales de comportamiento que incluyen, por ejemplo, la narración de acontecimientos en el mismo orden temporal en el que éstos sucedieron en la realidad. No obstante, son estrategias que podemos asociar con situaciones de uso concretas, de modo que el hecho de que se trate de pautas de comportamiento conocidas nos permite asociar unas estrategias determinadas con unos tipos de texto en particular.

Así, si encontramos indicios en un texto que nos permiten interpretar que se trata de un texto literario, nos parecerá normal que aparezcan acontecimientos narrados en un orden diferente al que se supone que sucedió en la realidad. Es más, nos permitirá incluso interpretar que la realidad en que se supone que sucedieron tales acontecimientos es una realidad ficticia. Esto es relevante por lo que respecta a las estrategias que se utilizan en los tipos de texto que se suelen describir como textos especializados o TPEs y a nuestras expectativas acerca de lo que encontramos en ellos ya que, mientras que en un texto literario contamos con que el autor es libre de presentarnos un mundo diferente, un modelo de situación alternativo e infiel al mundo real, partimos del supuesto de que las estrategias que se utilizan en un texto especializado constituyen pautas que corresponden con las de un modelo de situación que es reflejo de la realidad que refiere, y que esa realidad es el mundo real.

La facilidad de la que hacemos gala cuando analizamos una situación determinada es posible porque identificamos dicha situación con un tipo o modelo y no como un caso único. Esta identificación afecta también al texto que estamos leyendo o interpretando, en cuanto que somos capaces de identificar un texto con una clase de textos en particular, que es un aspecto relacionado con el criterio que describiremos a continuación.

\subsubsection{El criterio de intertextualidad}

Este séptimo criterio de la textualidad parte del concepto de intertextualidad difundido por Kristeva. Específicamente, se refiere a los procesos que relacionan un texto con otros textos ya que, según este concepto, todo texto se construye a partir de otros, como un 'mosaico de citas' (Kristeva 1981:190). Así, en un sentido intertextual es lógico observar el texto como «a dynamic site in which relational processes and practices are the focus of analysis instead of static structures and products» (Martínez Alfaro 1996:268). Podemos decir que la intertextualidad 
implica la suma de los textos existentes, por lo que todo lector al leer un texto tiene siempre en cuenta la experiencia que, en cuanto lector, posee de otros textos. Así, la intertextualidad se define como el criterio de textualidad que se ocupa de los factores que hacen que la utilización de un texto dependa del conocimiento de uno o más textos encontrados previamente (De Beaugrande y Dressler 1981).

Por otra parte, esta relación existente entre unos textos y otros es la que nos permite considerar conceptos tan escurridizos como el de texto especializado, o bien el nexo que se establece entre un TT y su correspondiente TO. Este criterio es, en definitiva, el que utilizamos cuando llevamos a cabo clasificaciones de textos diferenciándolos dentro de una taxonomía.

No obstante, tal como señalan De Beaugrande y Dressler, ninguna tipología textual está exenta de problemas. Estos problemas no vienen sólo dados por el desmesurado tamaño y la subjetividad inherentes a cualquier tipología textual (De Beaugrande 1980a:195), sino porque «la mayor parte de los ejemplos reales no encaja completamente en las características exactas que se prevén en un tipo ideal» (De Beaugrande y Dressler 1997:250; 1981:183). Entendemos que el mero análisis de la presencia o ausencia de ciertos rasgos lingüísticos típicamente asociados con algunos tipos de texto constituye únicamente un síntoma de tendencias subyacentes, pero no sirve para explicar los tipos textuales en sí (De Beaugrande 1980a:195-196). Por el contrario, para poder clasificar tipos de texto, parece más productivo partir de un concepto dinámico que se ocupe de dar cuenta de las relaciones existentes entre textos, además de un repertorio flexible de categorías textuales que sea capaz de superar la inadaptabilidad de los textos reales a la rigidez de las categorías estáticas y de los parámetros binarios excluyentes (o prosa, o poesía, por ejemplo).

El criterio de intertextualidad es un concepto dinámico en este sentido, pero su importancia dentro del concepto global de textualidad depende de la clase de tipología o de análisis que nos resulte de interés en cada caso. No obstante, aunque en el presente trabajo no nos vamos a ocupar con exhaustividad de los problemas relacionados con la definición y constitución de tipologías textuales, ya que esto nos alejaría demasiado de nuestros objetivos, tampoco podemos evitar tratar, siquiera someramente, esta cuestión. En cualquier caso, podemos anticipar que adoptamos una actitud ecléctica en cuanto a la utilización de etiquetas que se asignan tradicionalmente a determinados textos identificados intuitivamente como textos pertenecientes a una misma clase o tipo, independientemente de los criterios utilizados para su definición. A continuación explicaremos las razones de esta actitud. 


\subsection{La clasificación de tipos de texto}

Desde el punto de vista de nuestro trabajo, debemos comenzar señalando que lo que entendemos como problemas relacionados con la tipología de textos afecta igualmente a cualquier intento de tipología traslativa, entendiendo que la relación existente entre un TT y su correspondiente TO es fundamentalmente una relación de tipo intertextual. Por consiguiente, el marco textual nos parece no sólo el más apropiado para tratar cuestiones relacionadas con tipos de texto, sino también para tratar cuestiones relacionadas con textos producidos mediante un proceso de traducción. Por tanto, la clasificación de diferentes tipos de traducción depende directamente de la clasificación de tipos textuales que barajemos, de tal modo que la tipología traslativa es identificada en un sentido amplio como una tipología textual.

Conviene recordar aquí que el objetivo de las clasificaciones tipológicas que planteamos en este capítulo no coincide exactamente con el propósito que persiguen las tipologías habituales en los ámbitos de los denominados 'estudios de traducción descriptivos" y "estudios de traducción teóricos", sino con aquellos que consideramos pertinentes para la didáctica de la traducción, entendida como objeto de estudio perteneciente al dominio de los 'estudios de traducción aplicados'. Esta perspectiva incluye la posibilidad de que el resultado de nuestras consideraciones acerca de la tipología textual de la traducción adopte unas características que puedan ser irrelevantes, o simplemente diferentes, para otros ámbitos de la disciplina. Por esta misma razón, los parámetros que vamos a considerar en nuestro análisis pueden variar respecto de los empleados en dominios ajenos a la didáctica de la traducción. No obstante cabría objetar que, para establecer una tipología textual pertinente para la didáctica, el método a seguir debería basarse en la tipología desarrollada por la rama descriptiva de la disciplina para, sobre ésta, generar teorías con validez suficiente y necesaria (al menos) para la didáctica de la traducción, de acuerdo con la relación dialéctica existente entre las tres ramas de la disciplina (van den Broeck 1992:114; Holmes 1988:78).

Según Holmes (1988), en la investigación sobre la traducción desde el punto de vista descriptivo, el interés suele recaer en la descripción de las traducciones existentes. El procedimiento para elaborar la descripción se suele basar en un análisis individual cuyo resultado es la descripción de un único TT en relación con un único TO, o un análisis comparativo mediante el que se describen comparativamente varias traducciones producidas, bien en una única lengua o bien en diferentes lenguas, en relación con un único TO. Tradicionalmente el análisis comparativo ha gozado de gran atención en la investigación académica de esta 
disciplina y los resultados obtenidos mediante estos análisis han proporcionado el material necesario para realizar estudios en corpus de traducciones mayores. En la práctica, para poder reducir a límites más manejables la variación que presentan las traducciones entre sí y con respecto al original, se suelen imponer restricciones a los corpus en cuanto a el periodo de tiempo en el que se han producido las traducciones, el tipo de texto, y la lengua de las traducciones que se analizan (por ejemplo, los estudios sobre las traducciones medievales de la Biblia en inglés). En cualquier caso, estos (y otros) criterios constituyen parámetros destinados a poner de manifiesto la relación intertextual entre uno o varios TTs y su respectivo TO. Por lo que concierne más directamente a nuestro trabajo, nuestro interés se centra particularmente en traducciones al español (específicamente al castellano, como la variedad del español que se utiliza en Castilla) de textos especializados producidos en inglés que puedan ser etiquetados como textos científicos, textos técnicos o textos académicos.

Dentro del marco de la lingüística textual, el concepto de intertextualidad no sólo constituye «the major factor in the establishment of text types, where expectations are formed for whole classes of language occurrences», tal como afirma De Beaugrande (1980a:20), sino que, según este autor, este criterio es más productivo para estudiar los tipos de texto que el análisis de la presencia o ausencia de rasgos interpretados (a menudo intuitivamente) como prototípicos, debido a que se desarrolla tanto a partir de factores lingüísticos como sociales, de acuerdo con la siguiente pauta:

1) A differentiation of social settings and participant roles leads to a differentiation of situation types.

2) The differentiation of situation types engenders reliance upon those text types held to have greater appropriateness.

3) The accrual of episodic knowledge about situations and texts fosters expectations about what is acceptable and effective in a given context.

4) People build strategies to fit those expectations and to control textual occurrences accordingly.

5) The priorities of control result in the relative dominances of surface features, e.g. word class proportions and syntactic complexity.

6) These surface dominances gain the status of heuristic patterns against which new texts can be matched.

7) The patterns may exert influence back on the control strategies applied to situation management.

(De Beaugrande 1980a:196)

Según De Beaugrande un 'tipo textual' es «a distinctive configuration of relational dominances obtaining between or among elements of (1) the surface text; (2) the textual world; (3) stored knowledge patterns; and (4) a situation of 
occurrence» (De Beaugrande 1980a:197). Las características predominantes que son relevantes pueden aplicarse a elementos de cualquier tamaño, dependiendo de las circunstancias que concurran en cada caso. Aun sin estipular exactamente cómo debe ser un texto que pertenece a un tipo dado, estos rasgos dominantes ejercen una poderosa influencia en las preferencias a la hora de seleccionar, organizar y analizar distintas opciones durante la producción y el procesamiento del texto. No obstante, como mucho podemos aspirar a obtener conjuntos difusos de textos entre los que se da solapamiento mutuo, de tal modo que algunos rasgos textuales serán específicos del dominio, es decir, peculiares para la situación, el tema y el conocimiento o el significado que se trata (De Beaugrande 1980a:197).

No deja de ser llamativo, sin embargo, que las extremas dificultades que nos encontramos para definir con rigor un tipo textual sean superadas con facilidad por los usuarios de los propios textos a la hora de clasificarlos de forma intuitiva (Cook 1989:95). Es posible que la aparente sencillez del proceso intuitivo de clasificación de los textos tenga que ver con el reconocimiento que el usuario hace de un texto particular como perteneciente a un prototipo determinado de textos. En cualquier caso, la facilidad que muestran los usuarios para reconocer tipos de textos supone una gran ventaja para la utilización didáctica de material textual. A pesar de los avances en el campo descriptivo del discurso asociado con dominios específicos, especialmente en lo que se refiere a la descipción del inglés (véase, por ejemplo, buena parte de los trabajos recogidos en Cortese y Riley 2002), en general podemos afirmar que actualmente no disponemos de información suficiente como para describir de un modo exhaustivo las características de los tipos de texto utilizados en un entorno profesional que sea suficientemente representativo de lo que el aprendiz va a encontrar al incorporarse profesionalmente al mundo laboral. Por esta razón, el hecho de que podamos contar con que los aprendices son capaces de reconocer de un modo intuitivo los textos utilizados en el aula como representantes de una clase textual determinada nos permite utilizarlos como una hipótesis de trabajo y de este modo poder hacer generalizaciones sobre la características relacionadas con el tipo o clase textual y, por añadidura, sobre el discurso típico del entorno profesional tratado.

Por otra parte, aunque sin información fiable no podemos explicar convenientemente las características textuales de un dominio particular, De Beaugrande sugiere el tipo de explicación que podemos asociar con algunas de las categorías textuales que se utilizan convencionalmente. De acuerdo con este lingüista, los textos científicos y los textos didácticos (que representan las únicas 
categorías convencionales citadas por De Beaugrande que podemos considerar relevantes para este trabajo) se pueden explicar a partir de expectativas acerca del comportamiento de los textos en relación con unas dimensiones u otras en particular, incluyendo las diferencias en el tratamiento que se hace del conocimiento científico y en su relación con la cultura primaria y con la cultura secundaria. De Beaugrande describe las expectativas correspondientes a los textos científicos y a los textos didácticos o académicos del siguiente modo:

In scientific texts, the textual world is expected to provide an optimal match with the accepted real world unless there are explicit signals to the contrary (e.g., a disproven theory). Rather than alternative organization of the world, a more exact and detailed insight into the established organization of the real world is intended. In effect, the linkages of events and situations are eventually de-problematized via statements of causal necessity and order.

In didactic texts, the textual world must be presented via a process of gradual integration, because the text receiver is not assumed to already have the matchable knowledge spaces that a scientific text would require. Therefore, the linkages of established facts are problematized and eventually de-problematized. (De Beaugrande 1980a:198)

De Beaugrande plantea que, si los tipos textuales dependen de las características de la situación, entonces la cuestión básica es cómo utiliza el lector las pistas a su disposición para clasificar textos de diferentes formatos como correspondientes a un tipo textual determinado, y concluye con una afirmación que se enmarca en lo que considera un principio general del procesamiento humano: «the less evidence there is in the immediately apperceived text, the more the text receivers will gather and utilize all kinds of cues» (De Beaugrande 1980a:199). De acuerdo con esta perspectiva, los lectores utilizamos todo tipo de pistas, las cuales se pueden encontrar tanto dentro como fuera del texto:

People can seek cues outside the text itself. Some situation types are institutionally defined regarding the text types to be used [...]. Explicit announcements may establish the situation type [...]. Appearances of particular speakers or of a writer's name in print can activate expectations about the forthcoming text type. A printed format, as in poems or newspapers, or a characteristic title, such as dime novels, may be influential. Even a specific topic, such as those in many technical reports, can act as a cue.

(De Beaugrande 1980a:199)

Este planteamiento nos lleva a pensar en la complejidad de utilizar una representación del procesamiento de los aprendices cuando interpretan los textos en el aula. Aunque el objetivo de la utilización de material textual en el aula no consiste en la clasificación de tipos textuales, la posibilidad de que en esta 
representación del procesamiento textual pueden tener relevancia pistas de procedencia muy diversa conlleva la necesidad de formular una representación compleja de la comprensión e interpretación de los textos en la que necesariamente debe tomar parte una gran variedad de componentes. No obstante, tan importante como el repertorio de componentes intra- y extratextuales que debemos tener en consideración es la relación que se establece entre ellos en cuanto al modo de interactuar entre sí. Esto es precisamente lo que pasamos a tratar a continuación.

\subsubsection{La regulación de la textualidad}

Según De Beaugrande, no todos los criterios que hemos visto en la sección anterior contribuyen a la creación de la textualidad del mismo modo, si bien corresponden al mismo tipo de principio constitutivo:

Of these seven criteria, two seem prominently text-oriented (cohesion and coherence), two prominently psychological (intentionality and acceptability), two prominently social (situationality and intertextuality), and the last, computational (informativity). But close investigation shows that none of the criteria can be appreciated without considering all four factors: language, mind, society, and processing. [...] These criteria of textuality figure as constitutive principles in the sense of Searle (1969:33ff.): whether or not something can be considered a text depends on whether these criteria are upheld. There must also be regulative principles in the sense of Searle which distinguish the quality of a sample already admitted as a text. (De Beaugrande 1980a:21)

La diferencia entre principios o reglas de tipo constitutivo y principios de tipo regulativo es explicada por Searle del siguiente modo:

We might say that regulative rules regulate antecedently or independently existing forms of behavior; for example, many rules of etiquette regulate interpersonal relationships which exist independently of the rules. But constitutive rules do not merely regulate, they create or define new forms of behavior. [...] Regulative rules regulate a pre-existing activity, an activity whose existence is logically independent of the rules. Constitutive rules constitute (and also regulate) an activity the existence of which is logically dependent on the rules. (Searle 1969:33-34)

Searle continúa ilustrando cómo son las formas típicas de expresión de las reglas regulativas frente a las formas de expresión de las reglas constitutivas del comportamiento:

Regulative rules characteristically take the form of or can be paraphrased as imperatives, e.g., «When cutting food, hold the knife in the right hand», or «Officers must wear ties at dinner». Some constitutive rules take quite a 
different form, e.g., «A check-mate is made when the king is attacked in such a way that no move will leave it unattacked», «A touch-down is scored when a player has possession of the ball in the opponents' end zone while a play is in progress». If our paradigm of rules are imperative regulative rules, such nonimperative constitutive rules are likely to strike us as extremely curious and hardly even as rules at all. Notice that they are almost tautological in character, for what the 'rule' seems to offer is part of a definition of «checkmate» or «touchdown». [...] Regulative rules characteristically have the form or can be comfortably paraphrased in the form «Do X» or «If Y do X». Within systems of constitutive rules, some will have this form, but some will have the form «X counts as $\mathrm{Y} »$, or «X counts as $\mathrm{Y}$ in the context $\mathrm{C}$ ». (Searle 1969:34-35)

$\mathrm{Si}$ retomamos el esquema de jerarquías de sistemas propuesto por Matthiessen (2001), podemos decir que los principios o reglas regulativos son los que proporcionan valor al comportamiento desde la perspectiva del lenguaje como un sistema social, mientras que los principios o reglas constitutivos son los que proporcionan significado al comportamiento desde la perspectiva del lenguaje como un sistema semiótico. En el caso del texto, los criterios de textualidad suponen la consideración del texto como un medio de comunicación desde el punto de vista semiótico, del mismo modo que los principios regulativos implican la valoración del texto desde un punto de vista social.

A partir del planteamiento de Searle, De Beaugrande asocia las reglas o principios regulativos de los textos no con la consecución de la textualidad, es decir, con el hecho de ser texto, sino con el diseño del texto en cuanto al modo de ser actualizado, es decir, con cómo ser texto (De Beaugrande 1980a:21). Por consiguiente, podemos partir de la hipótesis de que un texto está regulado por principios que afectan al éxito de su funcionamiento como texto, en cuanto al grado de aproximación al cumplimiento de la función o funciones para las que ha sido producido o a la consecución de los objetivos que se perseguían al producirlo.

De Beaugrande defiende la existencia de al menos tres criterios relacionados con el diseño del texto, que nosotros hemos asociado con la eficiencia de los procedimientos y recursos empleados por el autor para que el texto producido responda a sus intenciones en relación con su influencia en el modo de procesamiento del texto que lleva a cabo el aprendiz, y que son definidos de este modo:

The efficiency of a text results from its utilization in communication with the greatest returns for the least effort, so that processing ease is promoted. The effectiveness of the text depends upon its intensity of impact on text receivers, promoting processing depth, and upon its contribution toward the producer's goal, constituting the relevance of text materials to steps in a plan. The appropriateness of a text depends on the proportionality between the demands 
of a communicative situation and the degree to which standards of textuality are upheld. (De Beaugrande 1980a:21) ${ }^{10}$

Si consideramos el caso de la comunicación especializada por medio de la mediación intercultural, partimos del supuesto de que los textos que han sido producidos en una lengua para unos receptores dados mantienen una relación de intertextualidad con las traducciones producidas a partir de esos textos, cuyos receptores pertenecen a una cultura diferente y hablan una lengua distinta de los primeros.

Así, aunque los textos que se producen en un entorno comunicativo específico sean considerados o analizados de acuerdo con los principios constituyentes y regulativos comunes a todo texto, cuando estos textos han sido producidos mediante un proceso de traducción, entonces el análisis se hace más complejo aún. En la sección siguiente vamos a considerar algunos aspectos que se ponen de manifiesto cuando los textos son analizados desde este punto de vista.

\subsubsection{La comunicación especializada mediante la traducción}

En la sección anterior hemos considerado la comunicación especializada desde el punto de vista textual, es decir, como la creación y transmisión de conocimientos mediante textos. El elemento innovador que introduce esta sección centrada en la traducción consiste en considerar algunos aspectos específicos que se dan cuando en la cadena de transmisión de conocimientos se produce la mediación interlingüística. Esto sucede cuando, para que la transmisión de conocimientos sea llevada a cabo con éxito, se utilizan al menos dos textos producidos en al menos dos lenguas.

Subyace aquí la convicción de que al menos parte de la competencia necesaria para traducir de forma eficiente implica el desarrollo de la competencia textual. De acuerdo con De Beaugrande, este tipo de competencia incluye los siguientes conocimientos y procedimientos:

1. knowledge of the repertories of options in vitual systems of language;

2. knowledge of systemic constraints on the selection and combination of options;

3. knowledge of the beliefs, knowledge, and expectations shared by the communicative group or society about the «real world»;

4. knowledge of text types;

\footnotetext{
${ }^{10}$ Bonilla (1997) traduce estos criterios respectivamente como 'eficacia' (efficiency), 'efectividad' (effectiveness) y ‘adecuación' (appropriateness).
} 
5. procedures for utilizing virtual systems during actualization;

6. procedures for producing texts;

7. procedures for receiving texts;

8. procedures for maintaining textuality;

9. procedures for regulating informativity;

10. procedures for optimizing design criteria (efficiency, effectiveness, and appropriateness);

11. procedures for re-utilizing text-acquired knowledge from mental storage tasks like recalling, reporting, summarizing, or evaluating;

12. procedures for monitoring and managing situations by using texts;

13. procedures for building, implementing, and revising plans toward goals;

14. procedures for predicting the activities of other participants in communication and regulating one's discourse actions accordingly;

15. procedures for maintaining communication despite discrepancies, discontinuities, ambiguities, or non-expected occurrences.

(De Beaugrande 1980a:23-24)

Producir textos mediante la traducción implica el ejercicio de un control de los medios de que disponemos en una situación determinada (incluyendo el lenguaje como una herramienta a nuestra disposición) para producir un texto no sólo con la mayor eficacia, efectividad y adecuación (según la terminología empleada por Bonilla), sino además con la mayor fidelidad respecto del TO y la mayor lealtad hacia el cliente que encarga la traducción o el desencadenante de que ésta se produzca.

No obstante, nuestra interpretación de qué es y en qué consiste la traducción se basa en su inclusión dentro de un modelo general de comunicación humana y, análogamente, nuestra perspectiva acerca del papel de los textos dentro de este tipo de actividad humana se enmarca en este modelo general de comunicación que estamos esbozando a lo largo de este capítulo.

Así, entendemos en primera instancia que la traducción puede ser interpretada y explicada como un tipo de actividad humana en el sentido que resume Nord del siguiente modo:

Human actions or activities are carried out by 'agents', individuals playing roles. When playing the role of senders in communication, people have communicative purposes that they try to put into practice by means of texts. Communicative purposes are aimed at other people who are playing the role of receivers. Communication takes place through a medium and in situations that are limited in time and place. Each specific situation determines what and how people communicate, and it is changed by people communicating. Situations are not universal but are embedded in a cultural habitat, which in turn conditions the situation. Language is thus to be regarded as part of the culture. And communication is conditioned by the constraints of the situation-inculture. (Nord 1997:1) 
A partir de este enfoque general, Nord continúa explicando aquellos aspectos específicos relacionados con la comunicación a través de la mediación intercultural:

\begin{abstract}
In translation, senders and receivers belong to different cultural groups in that they speak different languages. Non-verbal forms of behaviour may be different as well. Senders and receivers thus need help from someone who is familiar with both languages (and cultures) and who is willing to play the role of translator or intermediary between them. In professional settings, translators don't normally act on their own account; they are asked to intervene by either the sender or the receiver, or perhaps by a third person. From an observer's point of view, this third party will be playing the role of 'comissioner' or 'initiator'; from the translator's point of view, they will be the 'client' or 'customer'. Initiators may have communicative purposes of their own or they may share those of either the sender or the receiver. Translating thus involves aiming at a particular communicative purpose that may or may not be identical with the one that other participants have in mind. (Nord 1997:2)
\end{abstract}

Dentro de la corriente traductológica que Nord representa, se establece una correlación entre el objetivo de la comunicación y la función que se le asigna al texto utilizado para comunicarse. Este hincapié en la función del texto ha dado lugar a que esta corriente sea denominada 'funcionalismo' o 'traducción funcional'. A pesar de la coincidencia, la lingüística sistémico-funcional y la traducción funcional utilizan el concepto de función de modo diferente.

El apelativo 'funcional' de la lingüística de Halliday parte de la concepción de que el sistema semántico del lenguaje se compone de tres tipos de función (ideacional, interpersonal y textual) que actúan simultáneamente, por lo que se trata de un enfoque centrado en las funciones del significado. A su vez, también se denomina 'funcional' a la corriente traductológica caracterizada por considerar la función o las funciones comunicativas asignadas al texto como el criterio mediante el cual podemos comparar una traducción con respecto a su original. En este caso se adopta, por tanto, una concepción teleológica de la comunicación para comparar textos de acuerdo con su equivalencia dinámica, si bien el concepto de equivalencia dinámica se basa, al igual que hace la lingüística sistémico-funcional, en una concepción dinámica del significado. En este sentido, aunque ambos enfoques utilizan la denominación 'funcional' desde diferentes puntos de vista, se trata de perspectivas compatibles acerca de la comunicación. House $(1981 ; 2001)$ representa la tendencia que más claramente se asocia con la investigación traductológica que aúna ambas concepciones de funcionalismo, si bien existen otros investigadores, como Hatim y Mason (1990), que se basan en la lingüística sistémico-funcional de Halliday. 
Por lo que a nosotros respecta, vamos a centrarnos más directamente en Nord (1991) para tratar la comunicación intercultural desde una perspectiva textual, ya que el planteamiento de esta investigadora nos resulta más conveniente para los fines didácticos de este trabajo en cuanto a la utilidad de la metodología utilizada, tal como veremos a continuación.

\subsubsection{Los factores analíticos del TO y del TT}

Ya hemos visto cómo es habitual que la representación de los mecanismos que utilizamos para extraer información de un texto tomen la forma de repertorio de preguntas que el texto debe responder. Dado que en el ámbito de la traducción una de las tareas implícitas al traducir consiste precisamente en analizar el TO con el fin de obtener la información necesaria para poder producir el TT, no es de extrañar que el procedimiento de tratar la información textual mediante una batería de preguntas y respuestas sea utilizado con mucha frecuencia como enfoque didáctico para el desarrollo y la práctica de estrategias analíticas para traducir. Este procedimiento también se suele asociar con lo que se denomina 'enfoque de resolución de problemas', y que se aplica como procedimiento en la resolución de casos específicos. Ya hemos aludido previamente a la asociación entre el enfoque de resolución de problemas y el comportamiento estratégico del sujeto (aprendiz de la lengua o traductor) para lograr éxito en la comunicación en los términos que desea, y también al hecho de que en el campo de la traducción teórica este enfoque se suele utilizar para dar cuenta del resultado de la actuación del traductor, y no para explicar los procesos cognitivos involucrados.

Existe una gran variación en el nivel de detalle o de generalización de las preguntas que se plantean o que se deben plantear los traductores cuando analizan un texto. Por ejemplo, para Mudersbach y Gerzymisch-Arbogast (1989:167-168) la pregunta más relevante está relacionada con la pertinencia de los conceptos necesarios para mantener la función del TO desde una perspectiva muy general: «if the function of a text calls for invariance, the translator no longer asks: "what is the lexical equivalent of $A$ in language $X$ ?" but rather "what concept in language $X$ can function in the (invariant) surrounding relational network as does $A$ in the given text?"».

No obstante, y aun a pesar de que estamos de acuerdo con Mudersbach y Gerzymisch-Arbogast en que es más productivo analizar el texto desde el punto de vista de su contenido proposicional que desde el nivel léxico, tal grado de 
generalidad no nos sirve para obtener información muy variada del texto, por lo que su operatividad desde la perspectiva de la didáctica no es muy grande.

Dado que en la enseñanza de la traducción es habitual analizar el TO como paso previo o concurrente a la producción del TT, no es probable que las preguntas excesivamente generales acerca del TO nos proporcionen el tipo de respuestas que necesitamos para producir el TT de forma controlada y rigurosa. Esto tiene suma importancia para la didáctica porque el tipo de análisis que se va a llevar a cabo suele ser el punto de partida para configurar las características metodológicas de cada curso de traducción, y dado que la concepción analítica depende del concepto de texto que se utiliza para describir el objeto del análisis y de los parámetros analíticos seleccionados como rasgos pertinentes, la elección del repertorio de preguntas que vamos a incorporar a la metodología debe ser capaz de permitirnos alcanzar nuestros objetivos didácticos.

En nuestra consideración de la utilidad de la traducción especializada como medio de facilitación del aprendizaje del Inglés para Fines Específicos, el análisis textual constituye la base del procedimiento pedagógico para facilitar el desarrollo y la utilización de estrategias metacognitivas, específicamente para potenciar la reflexión en las cuestiones relacionadas con el uso, la comprensión y la producción de textos especializados en lengua inglesa y en castellano. El constructo que utilizamos para llevar a cabo este análisis debe incorporar una taxonomía que represente un modelo de preguntas que se pueden hacer a un texto con el fin de desdencadenar los procesos de reflexión. En el caso de la taxonomía utilizada por nosotros, y que se basa en la taxonomía desarrollada por Nord, el análisis del TO es utilizado a su vez para establecer las instrucciones traslativas que permiten al aprendiz producir el TT de forma consciente y controlada. Nord resume su taxonomía mediante las siguientes macropreguntas:

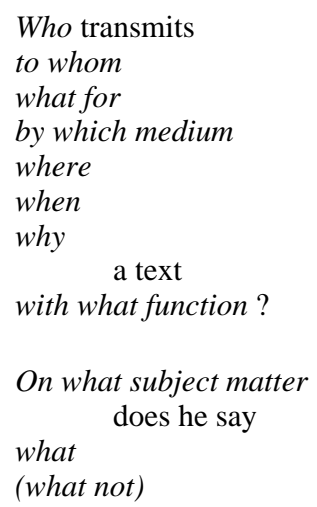




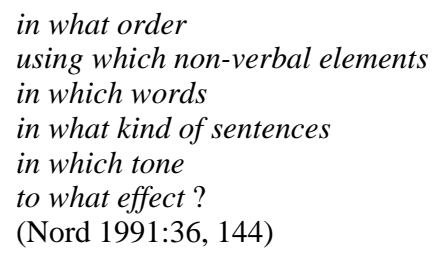

Este repertorio taxonómico es muy versátil porque nos permite la descripción de cualquier unidad dentro del rango textual con una exhaustividad que depende del enfoque analítico aplicado en cada caso y no de las limitaciones del modelo de representación. Es decir, las preguntas son lo suficientemente variadas y precisas como para poder centrarnos tanto en los aspectos más generales del texto como en los más específicos. Además, creemos que este repertorio resulta apropiado para representar eficazmente la interrelación entre los factores intratextuales y los factores extratextuales que intervienen en la concepción del texto como una entidad teleológica. Se trata de un repertorio elaborado con el objetivo didáctico de servir de marco de referencia para el tratamiento de los problemas específicos que se presentan en las tareas de traducción, por lo que es apto para ser utilizado igualmente si, como en este caso, se trata de realizar actividades de traducción en un entorno didáctico que no corresponde con el de la formación de traductores profesionales.

Por otra parte, este repertorio no es único. Muchos otros traductólogos y profesores de traducción han propuesto listas similares de parámetros analíticos. Bell, por ejemplo, propone un repertorio de preguntas que podemos hacerle al texto que está basado en los criterios de textualidad propuestos por De Beaugrande, y que reproducimos a continuación:

1. How do the clauses hold together? (cohesion)

2. How do the propositions hold together? (coherence)

3. Why did the speaker/writer produce this? (intentionality)

4. How does the reader take it? (acceptability)

5. What does it tell us? (informativity)

6. What is the text for? (relevance)

7. What other texts does this one resemble? (intertextuality) (Bell 1991:163-164)

Hay una diferencia evidente entre ambos repertorios en cuanto al número y grado de especificación de las preguntas que se formulan, y que se debe al enfoque particular que se adopta sobre el texto en cada caso. El repertorio de Bell responde fielmente a los criterios de textualidad de De Beaugrande, si bien Bell utiliza el 
término 'relevancia' en lugar del de 'situacionalidad', aun cuando ambos lingüistas conciben esta norma de textualidad del mismo modo:

Texts not only contain information, they possess a degree of relevance or situationality in so far as they exist for a particular communicative purpose and link communicative acts (discourse) to the situation in which they occur. Indeed, it is crucially important for the assessment of the appropriateness of a text to know where it occurred and what its function was in that situation.(Bell 1991:170)

Por su parte, Nord organiza los elementos sobre los que se interroga al texto en dos macropreguntas que se refieren a los aspectos extratextuales en el primer caso, y a los aspectos intratextuales del texto en el segundo, con la excepción del último elemento, que corresponde más bien a los principios que regulan la calidad del texto, si bien el orden de formulación de las preguntas no es relevante para el modelo.

A pesar de que el repertorio de Bell refleja de modo fiel los principios constituyentes del texto, el repertorio de Nord es más apto para ser utilizado didácticamente en el caso que nos ocupa, ya que posee una mayor usabilidad desde el punto de vista de su diseño.

La 'usabilidad', término que últimamente ha alcanzado una gran difusión en relación con el diseño de páginas web, se refiere a la relación que se establece entre el diseño y los usuarios del objeto diseñado e implica la presuposición de que «there are design implications when meeting the needs of people with different abilities» (The Center for Universal Design, 1997). El concepto de usabilidad deriva a su vez del concepto de diseño universal definido del siguiente modo por Mace: «universal design is the design of products and environments to be usable by all people, to the greatest extent possible, without the need for adaptation or specialized design» (The Center for Universal Design, 1997).

Creemos que el repertorio de Nord es más fácilmente usable que el propuesto por Bell porque demanda menos conocimientos lingüísticos a los sujetos que lo van a utilizar. Esto es relevante teniendo en cuenta que en este trabajo estamos analizando la función didáctica de la traducción en proyectos didácticos donde la competencia textual de los aprendices se identifica como la de usuarios de textos, pero en absoluto especialistas en el análisis textual. En definitiva, el repertorio de Nord es más adecuado que el de Bell para la didáctica de las lenguas para fines específicos en relación con el tipo de aprendices, ya que los conocimientos metalingüísticos necesarios para comprender las preguntas y 
asociarlas con un cierto tipo de datos textuales son menores que en repertorios como el de Bell.

Por otra parte, el repertorio de Nord presenta de forma jerárquica la interrelación de los elementos constituyentes y de los principios reguladores. Esto supone un intento de representar la confluencia simultánea e interrelacionada de todos los factores en el texto, y es justamente lo que hace posible que el análisis pueda ser llevado a cabo de múltiples modos comenzando por cualquiera de los parámetros analíticos. No obstante, el procedimiento de análisis, así como la relación existente entre estos parámetros, son concebidos por Nord de esta forma en particular:

Extratextual factors are analysed by enquiring about the author or sender of the text (who?), the sender's intention (what for?), the addressee or recipient the text is directed at (to whom?), the medium or channel the text is communicated by (by which medium?), the place (where?) and time (when?) of text production and text reception, and the motive (why?) for communication. The sum total of information obtained about these seven extratextual factors may provide an answer to the last question, which concerns the function the text can achieve (with what function?).

Intratextual factors are analysed by enquiring about the subject matter the text deals with (on what subject matter?), the information or content presented in the text (what?), the knowledge presuppositions made by the author (what not?), the composition or construction of the text (in what order?), the non-linguistic or paralinguistic elements accompanying the text (using which non-verbal elements?), the lexical characteristics (in which words?) and syntactic structures (in what kind of sentences?) found in the text, and the suprasegmental features of intonation and prosody (in which tone?).

The extratextual factors are analysed before reading the text, simply by observing the situation in which the text is used. In this way, the recipient builds up a certain expectation as to the intratextual characteristics of the text, but it is only when, through reading, he contrasts this expectation with the actual features of the text that he experiences the particular effect the text has on him. The last question (to what effect?) therefore refers to a global or holistic concept, which comprises the interdependence or interplay of extratextual and intratextual factors. (Nord 1991:36-37)

Como se puede observar, el modelo de Nord sitúa en una posición preponderante dos factores en particular: la función textual y el efecto que el texto produce en los receptores, tratándolos como factores integradores de otros factores.

Por lo que se refiere a la función del texto, frente a una única pregunta en el repertorio de Bell relacionada con este aspecto («what is the text for?»), que asocia directamente la función del texto con la intención comunicativa y con la situación en la que el texto se produce, Nord recoge tres parámetros diferentes relacionados con la función. Su presencia nos lleva a afirmar que este repertorio exige al análisis 
mayor sensibilidad al establecer la función del texto que el repertorio de Bell. Los parámetros en cuestión están representados por las siguientes preguntas:

- «what for?»

Esta pregunta se utiliza para analizar la intención comunicativa. En la 'teoría del escopo', esta pregunta hace también referencia a la situación futura que se desea alcanzar mediante la comunicación (Reiss y Vermeer 1991).

- «why?»

Esta pregunta se utiliza para analizar el motivo o la razón por la que se produce la comunicación. Según la 'teoría del escopo', hace referencia a la situación presente que se desea cambiar mediante la comunicación (Reiss y Vermeer 1991).

- «with what function?»

Esta pregunta se utiliza para asignar una función al texto como corolario del análisis de todos los factores de tipo extratextual, a partir de una concepción de la traducción inscrita en una teoría general de la acción:

Una teoría de la traslación, como teoría especial de la acción, parte de una situación en la que ya existe un texto de partida como «primera acción»; por tanto, la cuestion no es si y cómo se actúa, sino si y cómo se continúa (traduce/interpreta) qué acción. Desde este punto de vista, una teoría de la traslación es una teoría compleja de la acción.

De este modo, las decisiones de una traslación dependen de un principio dominante a partir del cual se decide si y qué se transfiere, así como la estrategia (el cómo) de esta traslación. (Reiss y Vermeer 1991:79-80)

Por otra parte, el efecto del texto recibe aún mayor relevancia que la función en el repertorio de Nord, puesto que es precisamente el factor que representa la interrelación de los aspectos intratextuales y los extratextuales, por lo que se trata del único factor global del repertorio.

El efecto del texto es interpretado por Nord (1991:130) como «a recipientoriented category». Nord distingue dos tipos diferentes de efecto: el efecto inmediato y el efecto de más largo alcance ${ }^{11}$. No obstante, esta autora señala que, para que un texto produzca un efecto en particular en el receptor, es necesario que el receptor se muestre abierto a la comunicación:

\footnotetext{
${ }^{11}$ Podemos relacionar el efecto inmediato con la eficiencia del texto en cuanto a la facilidad de procesamiento, mientras que el efecto de más largo alcance tiene que ver con la efectividad de los recursos empleados en cuanto a la profundidad de procesamiento, de acuerdo con la concepción de De Beaugrande (1980a:21).
} 
For a text to have an «effect» at all it is an essential prerequisite that the recipient can be influenced in the course of, and by, the communication process. He must be impressionable, capable of taking decisions and of being motivated to act. At the same time, the category of effect is based on the premise that words or texts indeed have an effect on the reader, and is therefore, basically, a «pedagogical» or «didactic» category. (Nord 1991:131)

Por otra parte, en la traducción el valor del efecto textual adquiere una dimensión más amplia que cuando consideramos únicamente el efecto que un texto cualquiera tiene en sus receptores, ya que el traductor puede incorporar en el TT un cambio de efecto de forma intencional con respecto del efecto del TO, tal como señala House:

In the act of translating, a translator is never simply 'saying' in one language what had been 'said' by someone else in another language, he is never simply taking words in one language and substituting them for words from another language. A translator does much more than manipulate strings of words: $\mathrm{He}$ performs actions when uttering words, i.e., he 'does things with words', and he does things never in vacuo but always in certain contexts or situations. Translation then is not only a language-internal phenomenon, it is a complex activity involving semiotic, linguistic, textual, lexical, social, cultural and psycholinguistic aspects. Translation is an accomplishment, in which a translator as mediator between two languages 'receives' a given text in a source language, understands and interprets it, and makes a new text in a target language from it, a text -we must add- which is to be equivalent in meaning in a given situation if this text is to be a translation. This postulate of equivalence implies, among other things, that the linguistic signs employed in a translation be used and be commonly used to the same extent that the signs in the original were used, such as if this is not the case, the effect is an intended one. (House 2001:57)

En cualquier caso, no sólo el efecto del texto es susceptible de una mayor complejidad cuando es analizado desde la perspectiva de la traducción. En general, podemos considerar que los textos asociados entre sí como TTs y TOs pueden ser analizados a partir de los criterios de textualidad establecidos por De Beaugrande. No obstante, es necesario tener en cuenta las peculiaridades que se dan cuando se establece un análisis de tipo contrastivo entre dos o más textos asociados por un proceso de traducción. Esto es lo que vamos a tratar a continuación.

\subsubsection{La relación entre el TO y el TT}

Hemos visto anteriormente que, en términos generales, la relación existente entre un TT y su correspondiente TO es considerada como una relación de naturaleza intertextual, lo cual implica para De Beaugrande una relación de tipo social. En el caso específico de textos asociados mediante un proceso de traducción, 
la intertextualidad conlleva aspectos muy diversos relacionados de un modo u otro con el comportamiento social del TT, incluyendo aspectos críticos como los que Toury denomina 'adecuación' y 'aceptabilidad', y que define así: «whereas adherence to source norms determines a translation's adequacy as compared to the source text, subscription to norms originating in the target culture determines its acceptability» (Toury 1995:56-57) ${ }^{12}$.

El comportamiento social del TT tiene que ver también con el efecto que el texto produce en un entorno social dado, de acuerdo con la situación concreta en la que el texto es producido y difundido, y también de acuerdo con la intención del autor (que aquí coincide con la persona del traductor), al igual que ocurre con cualquier otra clase de texto. En este sentido, un TT es susceptible de ser valorado críticamente en cuanto a su comportamiento social de igual modo que cualquier otro texto que no haya sido producido mediante un proceso de traducción. Por lo tanto, el TT puede ser evaluado de acuerdo con su rendimiento en la situación comunicativa.

Para llevar a cabo esta evaluación crítica, podemos utilizar un criterio de descripción y valoración que nos proporcione información acerca del rendimiento del texto, como el repertorio de principios constituyentes y regulativos propuesto por De Beaugrande. No obstante, desde una perspectiva estrictamente textual (o intratextual, según la diferenciación de Nord), los principios a los que el TT está sujeto no son exactamente los mismos que para cualquier texto que no tenga esta condición.

En el caso específico de un TT, el traductor-autor decide cómo es el diseño del texto rigiéndose por un principio regulativo adicional que no es pertinente más que cuando la relación intertextual se da entre textos asociados mediante un proceso de traducción.

De acuerdo con los principios regulativos de la textualidad podemos decir que, en el caso de la traducción, se suele partir de la hipótesis de que un TT, como tipo especial de texto, está regulado, además de por los principios que le afectan como tal texto, por al menos otro principio que afecta al éxito de su funcionamiento como traducción, en cuanto al grado de aproximación al TO, de acuerdo con un concepto de equivalencia entendido, en un sentido amplio como «the greatest possible correspondence between source text and target text» (Nord 1991:22).

\footnotetext{
${ }^{12}$ Véase también Rabadán (1991a:54).
} 
De Beaugrande interpreta la equivalencia textual como un principio regulativo de la actividad de traducir considerando que ésta funciona como guía en el proceso que lleva a la producción del TT y no como una propiedad de la relación intertextual:

If we view text and discourse as ongoing events, then 'equivalence' is not a deterministic attribute or formal property that two samples either do or do not possess, but a fluctuating guideline for ongoing operations. Translating would be an activity for generating coincidences for successive approximations while exploiting historical similarities as well as frozen accidents between the two languages, as the context requires [...]. The key question is not 'are these two samples equivalent?', but 'what control strategies reliably generate the coincidences that help to approximate equivalence, and how can trainees effectively acquire and develop them?' We can analyze samples of clues toward answering these questions, but we cannot expect to reach any universal or final definition of 'equivalence' as a free-standing abstraction. (De Beaugrande 1997:372)

En este sentido, dado que la equivalencia rige el modo como se establece la relación entre el TT y su correspondiente TO, esta relación es necesariamente problemática debido, por una parte, a las numerosas restricciones que afectan al proceso y, por otra, a la subjetividad de la valoración crítica del resultado, tal como señala De Beaugrande:

The need for coincidences makes translating an eminently problematic mode
of intertextuality. To produce the target text, the bottom-up engagement with
the source text must be balanced against your rich top-down knowledge and
experience of a large set of other texts, stipulating the unmarked strategies of
expression and the characteristic collocations of the two languages. The degree
of control a translator is obliged to exert might seem to compete with the
control of the original text producer. You need refined skills to efface yourself,
a bit like the portrayer of Ariel who repeatedly has to do the tricky stage
direction 'enter invisible' in Shakespeare's Tempest. You usually get noticed
only when the other participants, who typically hold naive building-block
notions of discourse being a string of words, decide to find fault with details of
your work. (De Beaugrande 1997:372)

Dado que los principios regulativos afectan al valor del texto desde la perspectiva del lenguaje como un sistema social, las restricciones que afectan a la traducción incluyen requisitos impuestos por aspectos sociales tales como la influencia de los participantes. Estos requisitos incluyen las diferencias que House (1981) señala entre el modo de traducir cuando el TT pasa desapercibido como tal traducción (covert translation) y cuando el TT es asumido por los receptores como la traducción de otro texto (overt translation). House diferencia entre estos dos tipos de traducción así: 
A covert translation is called for whenever an ST is not source-culture linked, and does not have independent status in the source language community; a covert translation is not marked pragmatically as a TT or a ST, but might equally well have been created in its own right [...]

An overt translation is called for whenever an ST is source-culture linked and has independent status in the source-language community. (House 1981:246)

Por su parte, las diferencias que Nord (1997) señala entre la traducción documental (documentary translation) y la traducción instrumental (instrumental translation) corresponden con restricciones derivadas de aspectos de tipo social. Nord define la 'traducción documental' de este modo:

Type of translation process which aims at producing in the target language a kind of document of (certain aspects of) a communicative interaction in which a source-culture sender communicates with a source-culture audience via the source text under source-culture conditions. According to which aspects of the source text are reproduced in the target text we distinguish interlineal, literal, philological and exocitizing documentary translations. (Nord 1997:138)

Por su parte, la 'traducción instrumental' es descrita así:

A type of translation process which aims at producing in the target language an instrument for a new communicative interaction between the source-culture sender and a target-culture audience, using (certain aspects of) the source text as a model. According to the degree of functional invariance we may distinguish between equifunctional, heterofunctional and homologous instrumental translations. (Nord 1997:139)

En ambas dicotomías, los diferentes modos de traducir representan opciones de diseño del TT que el traductor elige de acuerdo con ciertas características de la situación y, por consiguiente, la regulación se produce a partir de restricciones de tipo social o, de modo más general, por restricciones de naturaleza extratextual.

No obstante, si limitamos nuestro análisis a los aspectos textuales de la relación que se establece entre un TT y su correspondiente TO, debemos reiterar que, en primera instancia, se trata de una relación intertextual. Nord matiza aún más y, siguiendo a Reiss y Vermeer, define esta relación como de coherencia intertextual:

Intertextual Coherence [is the] relationship between the source and the target text within the framework of a Skopos-oriented translation (also 'fidelity'). The important point is that intertextual coherence should exist between source and target text, while the form it takes depends both on the translator's interpretation of the source text and on the translation Skopos. (Nord 1997:139) 
Así pues, la coherencia existente entre un TT y su correspondiente TO consta de unas características específicas de acuerdo con la finalidad o escopo de la traducción, así como con el grado de éxito que tengan las estrategias empleadas por el traductor para lograr que el TT cumpla su objetivo de la mejor manera posible. Para Reiss y Vermeer, la coherencia intertextual depende de que el TT sea lo más adecuado posible a la finalidad que persigue. Nótese, sin embargo, que Reiss y Vermeer interpretan el concepto de adecuación de un modo diferente a Toury. Mientras que para este último el TT se valora como adecuado (o poco adecuado) en relación con las normas vigentes para el TO, para Reiss y Vermeer (1991:124) el TT es adecuado (o no) en relación con la función que el proceso de traducción debe cumplir: «[la] adecuación en la traducción de un texto (o elemento textual) de partida se refiere a la relación que existe entre el texto final y el de partida teniendo en cuenta de forma consecuente el objetivo (escopo) que se persigue con el proceso de traducción». De este modo, Reiss y Vermeer desligan el concepto de adecuación del concepto de equivalencia, incluso desde una perspectiva didáctica:

\begin{abstract}
Se traduce pues de forma adecuada cuando se supedita consecuentemente la elección de signos a la finalidad de la traducción. Con ello también se vuelve innecesaria la diferencia un tanto artificial que Königs establece entre «equivalencia linguística» (que abstrae del grado de competencia del traductor) y «equivalencia didáctica» (que considera ante todo la competencia - en estadio de formación- del estudiante de lenguas). Lo que se pretende calificar aquí con el término de «equivalencia didáctica» no puede ser otra cosa que adecuación con vistas a un «objetivo de control» didáctico: la «expresión lingüística conforme con el sistema y acorde al grado de conocimientos lingüísticos adquiridos». Por consiguiente, los conceptos adecuación/adecuado se deben emplear en sentido procesual. También en el caso de que el objetivo de la traducción consista en producir un texto final equivalente al texto de partida, calificaremos la elección de signos en la lengua final de «adecuada»; la elección de signos en sí (es decir, el proceso de traducción) no puede ser calificada como «equivalente», sino tan sólo el resultado de esa elección. (Reiss y Vermeer 1991:124)
\end{abstract}

Teniendo en cuenta los fines de nuestro trabajo, consideramos relevante esta distinción puesto que la adecuación del TT se puede relacionar con las estrategias empleadas por el aprendiz en el proceso de traducción. Por consiguiente, consideramos que este concepto tiene un buen potencial didáctico para contribuir a que el aprendiz construya una concepción dinámica del significado, en la que la equivalencia textual es considerada únicamente como una posibilidad más, tal como hacen Reiss y Vermeer al definir la equivalencia del siguiente modo: 
Equivalencia [...] define una relación entre dos magnitudes que poseen el mismo valor, el mismo rango en sus respectivos campos y pertenecen a la misma categoría $[. .$.$] :$

Equivalencia expresa la relación entre un texto final y un texto de partida que pueden cumplir de igual modo la misma función comunicativa en sus respectivas culturas. [...]

Equivalencia es, según nuestra definición, un tipo especial de adecuación, es decir, adecuación cuando la función entre el texto de partida y el final se mantiene constante.

(Reiss y Vermeer 1991:124-125)

Por otra parte, al supeditar la equivalencia textual a la adecuación del TT, estamos adoptando un enfoque que, a nuestro juicio, es más productivo para analizar textos desde un punto de vista contrastivo que la utilización de otras nociones de equivalencia que no son dinámicas.

El enfoque al que nos referimos se basa en el supuesto de que la relación natural entre dos textos es una relación de variación o de desigualdad. Esta relación de variación procede de la concepción del texto como un objeto único, ya que se trata de una unidad funcional creada a partir de procesos únicos de selección y de decisión (De Beaugrande 1980a) y se basa en la consideración de la variación como una propiedad de las lenguas naturales (Wilss 1982:64) (v. 4.3.3). Por tanto, podemos considerar que la coherencia intertextual entre un TT y su correspondiente TO está potencialmente abierta a diversas opciones:

Si se traduce, por ejemplo, un texto técnico que en la cutura de partida se dirige a especialistas, también para especialistas, entonces es legítimo esperar que exista una relación de equivalencia entre el texto de partida y el final. El texto traducido debe tener el mismo valor comunicativo y ha de cumplir la misma función en la comunicación entre especialistas. Sin embargo, si el texto técnico de partida no se traduce para especialistas, sino para profanos en la materia, ya no podemos tener por objetivo la equivalencia textual. El texto se traducirá para el aficionado, interesado en informarse acerca de la materia que trate, de un modo que le permita entender el texto técnico, aunque no posea los conocimientos (sobre el tema y el lenguaje técnico) de un especialista. La elección de los signos lingüísticos se adecúa a la situación del lector de la cultura final, el cual se diferencia del lector de la cultura de partida en algo más que en el simple hecho de tener otra lengua materna, esto es -al margen de cualquier tipo de diferencias culturales que no entramos a debatir aquí-, por la diferencia significativa de los conocimientos previos sobre el tema en cuestión. Los lectores de un texto final tampoco se «corresponden» con los lectores de un texto de partida cuando, por ejemplo, se traduce para un público infantil o juvenil una novela de la literatura mundial [sic] que fue escrita para un público adulto. La consecuencia es que no podemos pretender ni exigir la equivalencia de la traducción; el valor de un texto final se distingue por su adecuación, es decir, por la elección apropiada de los signos linguiísticos en el plano sintáctico, semántico y pragmático, con respecto a las diferentes 
características del círculo de lectores al que se dirige. (Reiss y Vermeer 1991:122-123)

Así, desde la perspectiva funcional de la traducción, la coherencia intertextual está jerárquicamente supeditada a la coherencia (intra)textual y ésta, a su vez, a la función que condiciona el proceso de producción del TT:

Intertextual coherence is considered subordinate to intratextual coherence, and both are subordinate to the Skopos rule. If the Skopos requires a change of function, the standard will no longer be intertextual coherence with the source text but adequacy or appropriateness with regard to the Skopos [...]. And if the Skopos demands intratextual incoherence (as in the theatre of the absurd), the standard of intratextual coherence is no longer valid. (Nord 1997:32-33)

A la vista de todas estas consideraciones, debemos modificar la hipótesis planteada al principio de esta sección señalando que la traducción, como tipo especial de proceso textual, está regulada, además de por los principios que afectan al TT y al TO (y que identificamos con los principios constituyentes y regulativos propuestos por De Beaugrande), por al menos otro principio que afecta al éxito del TT. Este principio regulativo se refiere a la adecuación del TT a la función o escopo asignada a la traducción. Esta adecuación se identifica como una relación de equivalencia únicamente cuando la función comunicativa del TO y la del TT son identificadas como la misma.

A modo de resumen podemos señalar que, además de los principios regulativos que operan en el diseño de un TT por su propia condición de texto, su eficacia (efficiency), efectividad (effectiveness) y adecuación (appropriateness), hemos considerado un cuarto principio que es operativo en el caso de que la relación intertextual se establezca a partir de un proceso de traducción, y que es denominado igualmente 'adecuación' por García Reina, Martín de León y Witte (1996). Dada esta confusión terminológica, a continuación nos detendremos brevemente para establecer con claridad nuestra posición acerca de este parámetro utilizado como criterio de valoración textual.

\subsection{La adecuación como criterio evaluativo del TT}

En primer lugar, debemos destacar que el hecho de que la adecuación del texto esté sujeta a tal grado de variabilidad entre unas interpretaciones y otras es tomado como un síntoma de la extraordinaria dificultad intrínseca en la evaluación del texto, dada la cantidad y complejidad de factores involucrados. No obstante, debemos destacar también que no encontramos en los trabajos de los investigadores 
tantos problemas referentes a lo que podríamos denominar el rendimiento del texto, y que incluiría los principios a los que Bonilla se refiere como 'eficacia' y 'efectividad'. Por este motivo, creemos que existe una interpretación más o menos homogénea de qué se significa que un texto alcance con éxito su finalidad comunicativa, mientras que no hay un consenso tan claro acerca de cómo podemos evaluar un texto mediante otro tipo de parámetros. La cuestión que subyace a toda la variedad de interpretaciones al respecto consiste, precisamente, en dilucidar cuáles son los criterios pertinentes de evaluación del texto. Esto, siendo de suma importancia desde una perspectiva didáctica en general, supone una cuestión crucial al considerar la traducción como un medio para elevar el nivel de consciencia de los aprendices acerca del uso de la lengua de especialización.

Para proceder a intentar clarificar esta cuestión, vamos a comenzar por problematizarla aún más. Según la perspectiva que adopta Van Dijk, el concepto de adecuación de un texto está relacionado asimismo con el concepto de ser apropiado:

Mientras que decimos que una acción lingüística es apropiada (appropriate) o no en relación a ciertos conocimientos, deseos y actitudes de los interlocutores, podemos decir que una realización lingüística o un acto de habla son adecuados (adequate) o no en relación a otros factores situacionales como la actitud del hablante frente al oyente. (Van Dijk 1978:123)

A partir de un planteamiento semejante, podemos adoptar un criterio de evaluación como éste:

Adequacy: A text is (+ / -) adequate to the context of situation according to the writer's intentional and/or conscious attitude towards the reader (e.g. the author is condescending to the reader).

Appropriateness: A text is $(+/-)$ appropriate to the context of situation according to the reader's features (e.g. the reader's social status). (Elorza 2002:305)

Sin embargo, se plantea aquí un problema relacionado con el tipo de evaluación que queremos efectuar.

Si aceptamos la distinción utilizada por De Beaugrande a partir de Searle entre principios constitutivos y principios regulativos, podemos lanzar la hipótesis de que todos los aspectos evaluados que se refieran específicamente a criterios de tipo constitutivo lo que hacen es poner en tela de juicio la textualidad de un especimen textual en particular (en un caso extremo, si se trata de un texto o de un no-texto). Análogamente, podemos lanzar la hipótesis de que lo que hacen los aspectos evaluados que se refieren específicamente a principios de tipo regulativo es valorar el grado de éxito del diseño textual o, en otras palabras, su rendimiento 
como texto (en un caso extremo, si se logra alcanzar el cometido comunicativo del texto, o por el contrario no se alcanza en absoluto).

Siguiendo esta línea argumental, podemos presuponer que las valoraciones relacionadas con los principios constitutivos de la textualidad seguirán un modelo dual, de tal forma que podremos afirmar o negar las cualidades constitutivas de un texto diciendo, por ejemplo, si el texto es coherente o cohesivo o no lo es, o bien si es o no aceptable; en definitiva, una evaluación que nos permitiría concluir si el objeto analizado en cuestión se trata de un texto o no, aunque este tipo de evaluación no es crucial en nuestro trabajo.

Desde esta perspectiva, tenemos que plantear una objeción al planteamiento expuesto en trabajos anteriores (Elorza 2001; 2002) en cuanto a la interpretación de la valoración del texto como (+ / -) adecuado y (+ / -) apropiado, basándonos en que estos parámetros venían siendo utilizados para evaluar aspectos relacionados con los principios constituyentes de intencionalidad y de aceptabilidad, en un intento de conciliar el planteamiento de Van Dijk y el de De Beaugrande. No obstante, hemos detectado una cierta incompatibilidad entre ambos planteamientos, ya que Van Dijk considera que lo apropiado (o no) de una acción lingüística está relacionado con lo que él denomina 'contexto pragmático', y que define como «ciertos conocimientos, deseos y actitudes de los interlocutores» (Van Dijk 1978:123). Pero Van Dijk asocia directamente la esfera de las acciones lingüísticas con el comportamiento intencional (v. Van Dijk 1978:87 y siguientes), por lo que este aspecto está más relacionado con el principio de intencionalidad tal como lo concibe De Beaugrande que con el principio de aceptabilidad. Además, Van Dijk considera que un acto de habla o realización lingüística es adecuado (o no) en relación con lo que denomina 'contexto estilístico', definiéndolo a su vez como «una estructura de precondiciones situacionales sistemáticas que determinan la adecuación (o eficacia) del enunciado» (Van Dijk 1978:123), y que incluye aspectos tales como la actitud del hablante frente al oyente. Van Dijk (1978:124) relaciona estrechamente el estilo del texto con las estrategias comunicativas $^{13}$. No obstante, ya que utiliza indistintamente el término 'adecuación' y 'eficacia', podemos asociar más estrechamente este factor con uno de los principios regulativos propuestos por De Beaugrande. Por todo esto, pensamos que la distinción utilizada por Van Dijk no es productiva para la evaluación del comportamiento de los textos que vamos a analizar.

\footnotetext{
${ }^{13} \mathrm{Al}$ contrario que muchos lingüistas, Van Dijk no interpreta el estilo del texto como un factor meramente formal, sino que éste «se plasma tanto en la "forma" y el "contenido" de cada oración como en la "forma" y el "contenido" de todo el texto» (Van Dijk 1978:124).
} 
Por su parte, la distinción entre adecuación y aceptabilidad que Toury ha establecido, y que muchos traductólogos utilizan, se basa en la posibilidad de traducir de distintos modos en función de los diferentes objetivos que la traducción puede perseguir, por lo que se hace necesario establecer de antemano (o bien reconstruir en el análisis) cuál es o ha sido la norma vigente en la producción del TT, bien la norma de la cultura de origen, o bien la norma de la cultura de llegada. En contraposición con esta postura, lo que el enfoque funcionalista viene a decir con su concepción de la adecuación del TT es que no es necesario utilizar dos parámetros diferentes para evaluar algo que, a fin de cuentas, es el éxito o el rendimiento del texto producido en relación con la función (el escopo) del proceso de traducción, y que incluye la adopción de diversos modos de traducir en función de los objetivos establecidos en cada caso particular.

Pensamos que la propuesta de utilizar el criterio de adecuación desde un enfoque funcionalista resulta más útil para evaluar las traducciones que la utilización de los criterios propuestos por Toury porque supone un criterio más abierto (y por tanto más flexible) que los parámetros propuestos por este traductólogo. Por otra parte, se trata de una concepción compatible con los principios que regulan el texto en el modelo de De Beaugrande, por lo que nos parece pertinente utilizar la nomenclatura propuesta por Bonilla que incluye las formas generales 'eficacia', 'efectividad' y 'adecuación', sin establecer ulteriores distinciones, es decir, sin llegar al nivel de detalle de términos como el de ‘adecuación al escopo’ utilizado por García Reina, Martín de León y Witte (1996).

A lo largo de esta sección centrada en la comunicación especializada desde la perspectiva textual, hemos considerado aquellos aspectos constituyentes y regulativos que la comunicación especializada comparte con otros tipos de comunicación mediante textos, y también que los textos especializados comparten con otros tipos de texto, incluyendo textos producidos mediante una relación de coherencia intertextual con otros textos que se establece a partir de un proceso de mediación intercultural. Aunque esto no significa que estemos en situación de explicar en toda su extensión la enorme complejidad de estos fenómenos, De Beaugrande señala algunos principios de tipo restrictivo relacionados con el diseño del texto en la traducción, y que reproducimos a continuación:

The principle of interfacing the constraints of language with cognitive and social constraints [...] indicates how translators resolve disparities between the languages $[s i c][\ldots]$. The principle that processing runs on a current partial version of the language [...] suggests that some possible options offered by the total language are not even considered [...]. And the principle that several processing domains run in parallel and interchange data and constraints 
enables translation to maintain goals and topics while shifting the respective means of grammaticalizing and lexicalizing in the two languages. (De Beaugrande 1997:371-372)

Estos principios están sujetos a las limitaciones impuestas por los sistemas intermedios de control entre el lenguaje y el discurso, que son en definitiva los que nos indican en cada situación qué rasgos podemos interpretar como normales o no marcados o típicos de la situación, y que son de suma importancia en la evaluación de las traducciones puesto que son los que nos permiten establecer qué es normal y qué no lo es:

Among the most crucial factors for translating are the constraints of intermediary control systems between language and discourse, such as style, text type, and discourse for special purposes [...]. These would richly specify what sorts of coincidences are called for and what might count as 'literal' or 'free', e.g., in a poem versus a scientific treatise. (De Beaugrande 1997:373)

Queremos destacar el segundo principio mencionado por De Beaugrande, «processing runs on a current partial version of the language», que no consideramos específico de la traducción, sino que es vigente para el procesamiento textual de modo general. El interés que suscita este principio se debe a su gran relevancia cuando la didáctica se centra en las estrategias comunicativas que utilizamos en la comunicación lingüística, puesto que se refiere a procesos implicados en la comprensión y en la producción del texto o, en otras palabras, en el procesamiento de la información textual.

Desde la perspectiva de la investigación en didáctica de las lenguas extranjeras, la comprensión y la producción son probablemente las destrezas lingüísticas que reciben mayor atención por parte de los lingüistas que trabajan en este campo. Este interés es comprensible debido tanto a su importancia como destrezas comunicativas como a su complejidad.

En buena medida, la complejidad de los procesos implicados en la comprensión y en la producción estriba en la dificultad que implica la utilización (no necesariamente de forma precisa) de un mecanismo muy complejo de codificación de la información (el lenguaje en uso) junto con la utilización (tampoco necesariamente de forma precisa) de un mecanismo muy complejo de recuperación de la información (nuestras estrategias de comprensión), que nos lleva a enfrentarnos con problemas tales como la extraordinaria dificultad que nos supone el intentar establecer dónde se ubica el significado en un texto, o la aparente paradoja que encontramos en el hecho de que cualquier hablante sea capaz de comprender enunciados ambiguos sin la menor dificultad en su lengua materna pero 
no sea capaz de hacerlo en una segunda lengua (por poner un caso que en las clases de Inglés para Fines Específicos se suele tratar habitualmente mediante la comparación contrastiva entre ambas lenguas y al que ya nos hemos referido en relación con las preferencias en el modo como se lleva a cabo el procesamiento sintáctico en función de la lengua materna en 3.3.1). No obstante, en esta sección nos centramos especialmente en el modo de representación del conocimiento desde una perspectiva textual y no cognitiva, que dejamos para más adelante.

\subsubsection{La representación textual del conocimiento}

Para abordar la cuestión central de este apartado, comenzaremos por retomar de nuevo el concepto de comunicación desde el punto de vista de la transmisión de información, que ya tratamos someramente al hablar del criterio de informatividad en un apartado anterior.

Hemos sugerido anteriormente que la información textual se puede asociar con lo que se consideran conocimientos compartidos por los especialistas de un campo determinado de conocimiento. Pero los conocimientos se restringen al entorno social y al entorno cognitivo de la comunicación, de tal modo que no decimos que un texto contiene o transmite conocimientos, sino que contiene o transmite información. De Beaugrande indica que los términos 'conocimiento' (knowledge) e 'información' (information) se suelen utilizar en ocasiones de forma indistinta pero establece las siguientes diferencias entre ellos:

Knowledge is more dynamic and integrative. Its content is characteristically practical, and naturally acquired from lived experiences and directed institutions among a cultural community [...]. The operations for storing, retrieving, and using it are relatively effortless. When not in active use, it can undergo spontaneous evolution and elaboration in mental storage and generate more of itself. New knowledge being entered can reverberate through associated prior knowledge and update its specifications. Or, old knowledge can be creatively modified and adapted for unfamiliar or novel situations, often by relaxing degrees of aproximation and goodness of fit [...]

By contrast, information is more static and compartmentalised. Its content is characteristically theoretical, and consciously acquired from specialized activities. The operations of storing, retrieving, and using it are relatively effortful. When not in active use, it can undergo spontaneous conflation or degradation. New information being entered is unlikely to be integrated with prior information unless the mutual associations are expressly constructed. And old information can be rather difficult to modify or adapt to unfamiliar or novel applications. (De Beaugrande 2002:11-12) 
Desde una perspectiva social del conocimiento especializado suponemos que, a partir de nuestros conocimientos y planes individuales, verbalizamos información mediante textos, que el receptor interpreta esta información textual mediante sus conocimientos y planes individuales, y la incorpora de algún modo y en forma de conocimiento a su bagaje personal. No obstante, es posible analizar la información de un texto en función de su aportación al conocimiento aceptado o existente sobre algún tema en particular. Esto implica adoptar una perspectiva social sobre la información desde la que intentar responder preguntas tales como ¿qué aporta este texto en particular al conocimiento que ya poseemos (y que aceptamos como existente) sobre una materia?

Por otra parte, desde una perspectiva textual, De Beaugrande y Dressler señalan que el contenido del texto suele recibir mayor atención que otros aspectos textuales, y relacionan esta atención con el papel preponderante que le asignan a la coherencia, como principio que se refiere al rango proposicional del texto, en detrimento de otros subsistemas lingüísticos como el sintáctico o el fonológico, que compensan esta falta de atención con estrategias más llamativas:

\begin{abstract}
We use the term informativity to designate the extent to which a presentation is new or unexpected for the receivers. Usually, the notion is applied to content; but occurrences in any language system might be informative. The emphasis on content arises from the dominant role of coherence $[\ldots]$ in textuality, while language systems like phonemes or syntax seem subsidiary or auxiliary and hence less often in the direct focus of attention. Here, "attention" would be defined as the expenditure of processing resources that restricts the potential for other tasks at the same time [...]. Hence, if attention is focused on the coherence of concepts and relations, other systems are not given prominence unless deliberately handled in noticeably non-expected ways. (De Beaugrande y Dressler 1981:139)
\end{abstract}

Si además de esta atención general por el contenido textual, tenemos en cuenta aspectos relacionados con el uso que los aprendices suelen hacer de los textos académicos (considerándolos aquí como el tipo particular de texto especializado del que un estudiante universitario es un usuario habitual), entonces debemos añadir que el tipo de usuario sobre el que nos centramos en este trabajo suele aproximarse característicamente a la información textual desde esta perspectiva centrada en el acervo de conocimientos de la disciplina en cuestión. Por otra parte, esto es lógico si consideramos que los objetivos didácticos sobre los que suele recaer el énfasis en la mayoría de las asignaturas que un estudiante universitario debe cursar (al menos en España) para obtener una titulación superior en un campo científico o técnico se refieren a la adquisición de conocimientos de 
tipo declarativo ${ }^{14}$. Por tanto, los textos suelen ser contemplados más habitualmente como fuentes de información en ese sentido que, por ejemplo, como herramientas o modelos para aprender a producir textos similares.

No obstante, dado que en esta sección nuestro interés por el conocimiento especializado se centra en una perspectiva textual, es más pertinente abordar la información en relación con los mecanismos que utilizamos para crear significado, como dice Halliday, incluyendo tanto la producción como la difusión y la comprensión de los conocimientos mediante textos y, en particular, en relación con los mecanismos de representación de la información en el texto.

Ya hemos descrito anteriormente los criterios de cohesión y de coherencia mediante los cuales los elementos del texto están concatenados formando una unidad de tipo holísitico, diferente a la mera acumulación sumativa de unos elementos con otros. No obstante, para describir cómo se transmite la información en la comunicación textual se suele partir del modelo de transmisión de la comunicación que Shannon y Weaver denominaron la 'teoría matemática de la comunicación', y que trataremos inmediatamente después de presentar la descripción que De Beaugrande y Dressler hacen de cómo actúan algunos de los mecanismos informativos del texto:

Every text is at least somewhat informative: no matter how predictable form and content may be, there will always be a few variable occurrences that cannot be entirely forseen. Particularly low informativity is likely to be disturbing, causing boredom or even rejection of the text. The opening stretch of a science book runs like this:

\section{[15] The sea is water}

The fact asserted here is so well known to everyone that there seems to be no point in saying it here. The stretch of text is clearly cohesive and coherent, and undoubtedly intended to be acceptable as such. But it is nonetheless a marginal text because it is so uninformative. Not until we look at the continuation does the text's status seem more sound:

[15a] The sea is water only in the sense that water is the dominant substance present. Actually, it is a solution of gases and salts in addition to vast numbers of living organisms ...

\footnotetext{
${ }^{14}$ Probablemente el énfasis sobre el contenido de los textos, frente a otros aspectos relacionados con el comportamiento de éstos o con la construcción del significado, que suelen constituir la base material de la enseñanza, explica por qué frecuentemente se alzan quejas de profesores de materias especializadas referentes a la poca pericia de los estudiantes para manipular la información textual en la producción de resúmenes, esquemas u otras formas de síntesis que conllevan la aplicación de estrategias de comprensión y producción de textos.
} 
The assertion of the obvious fact in [15] functions as a starting point for asserting something more informative. The surface cue 'actually' signals that the well-known 'substance-of' relation [...] is not strictly accurate. The ensuing correction of a common view is less expected, so that the informativity of the whole passage is upgraded [...].

(De Beaugrande y Dressler 1981:9)

Como podemos observar, esta descripción parte del supuesto de que no todas las palabras en el texto son iguales desde un punto de vista jerárquico, sino que su valor es diferente no sólo en función del modo de concatenarse mediante la cohesión y la coherencia con las demás, sino también de su orden de aparición en el texto, de tal modo que el valor informativo de la primera proposición del ejemplo y el valor de la siguiente no son equiparables ni intercambiables, y podemos decir que este valor viene dado en parte por el orden que ocupa la proposición en el texto. Así, el punto de partida de un modelo de transmisión de la información es la siguiente premisa, que Bell enuncia de este modo:

Texts contain information and a measure of that is the informativity of the text. However, the calculation is not a simple one but depends on the notions of choice and probability. A text is seen as the realization of choices made from among sets of options. There are, at each point where a choice can be made, actual choices which are more, or less, probable. The less probable and predictable a choice is, the more informative and interesting it is. Conversely, choices which are wholly predictable are uninformative and uninteresting. (Bell 1991:167-168)

Esta premisa fue establecida por Shannon (1948) como una de las restricciones que actúan en la transmisión de un mensaje de un punto a otro, en relación con los problemas que presentaba la reproducción de un mensaje en un lugar diferente al lugar de emisión. Pero, dado que su interés era esencialmente técnico, este enfoque deja fuera de toda consideración el significado asociado con el mensaje emitido, tal como él mismo señala:

The fundamental problem of communication is that of reproducing at one point either exactly or approximately a message selected at another point. Frequently the messages have meaning; that is they refer to or are correlated according to some system with certain physical or conceptual entities. These semantic aspects of communication are irrelevant to the engineering problem. The significant aspect is that the actual message is one selected from a set of possible messages. (Shannon 1948:1)

Además de esto, tal como señala Greene, el contenido del mensaje y la información de éste son dos conceptos claramente diferenciables: 
La idea fundamental es que la información no tiene nada que ver con el contenido de un mensaje, sino que se define únicamente en términos de la cantidad de incertidumbre que se reduce. Si un resultado es ya por completo predecible, no hay incertidumbre acerca de él; por lo tanto, el mensaje enviado no lleva información. Mas si hay alguna duda o imposibilidad de predicción acerca de cuál será el mensaje, cuando éste se reciba llevará alguna información. (Greene 1975:115-116)

A pesar de la falta de relación entre la información del mensaje que se emite y el contenido de éste, Shannon hace extensiva la validez de su modelo de transmisión al lenguaje escrito, apoyándose en que el lenguaje se compone de un sistema de símbolos (letras) que es discreto y, por tanto, éstos conforman un conjunto finito:

We can think of a discrete source as generating the message, symbol by symbol. It will choose successive symbols according to certain probabilities depending, in general, on preceding choices as well as the particular symbols in question. A physical system, or a mathematical model of a system which produces such a sequence of symbols governed by a set of probabilities, is known as a stochastic process. We may consider a discrete source, therefore, to be represented by a stochastic process. Conversely, any stochastic process which produces a discrete sequence of symbols chosen from a finite set may be considered a discrete source. This will include such cases as:

o Natural written languages such as English, German, Chinese. [...]

(Shannon 1948:5)

Aunque este modelo de transmisión de la información no tiene en cuenta la información en relación con los conocimientos ni con el significado del mensaje que se emite, se trata de un modelo muy extendido en disciplinas tales como los estudios de comunicación, las ciencias de la información o la ingeniería de sistemas.

No obstante, a pesar de su popularidad, es un modelo criticado desde diversos puntos de vista. La primera objeción es, como es de esperar, que el modelo prescinde explícitamente del contenido o el significado de los mensajes, por lo que su validez como modelo explicativo acerca del funcionamiento de la comunicación es nula. Se trata, como señala Underwood (2002), de un modelo lineal, que representa la comunicación como un proceso que sucede en un sentido único (uno es emisor, papel activo, mientras que otro es receptor, papel pasivo). Probablemente la popularidad de que goza este modelo provenga precisamente de que representa la comunicación como un fenómeno bastante simple, ya que concentra toda su complejidad en la modelización matemática de las sucesivas transiciones del mensaje de un estado a otro hasta llegar al estado final de 'mensaje recibido'. 
Se trata de un modelo cuya concepción de la comunicación corresponde muy bien con la 'metáfora del conducto' (Reddy 1979): las ideas (las palabras, la información, etc.) son objetos; el mensaje (el texto, el libro, etc.) es un contenedor de la información; la información está contenida por el mensaje. Por su parte, los conocimientos (las ideas, etc.) que se desean transmitir son codificados (traducidos, transcritos) como información por el emisor, y esta información es descodificada nuevamente como conocimientos (ideas, etc.) por el receptor. El proceso de descodificación es considerado simétrico al proceso de codificación, de tal modo que, como resultado final, se interpreta que los conocimientos que finalmente tiene el receptor coinciden exactamente con los que envió el emisor ${ }^{15}$.

Por otra parte, lo más interesante de este modelo de transmisión de la comunicación consiste en que contribuye a explicar cómo progresa la información en el texto desde una perspectiva probabilística, si bien hay que precisar que las transiciones a las que se refería Shannon no coinciden exactamente con la transición que se produce a lo largo del texto de una proposición a otra y de un tema a otro. Las transiciones desarrolladas por Shannon han sido formuladas por la teoría de la información de este modo:

\begin{abstract}
Each event in a system has an 'information value' computed from how improbable it was at that particular moment. By inspecting all the sequences in the system's history, you could compute the 'probability' of any given 'transition' from one event to the next; the less probable the event, the more 'information' it carries. (De Beaugrande 1997:57)
\end{abstract}

Pero para poder interpretar las transiciones de la información en un texto, es necesario interpretar el texto a la vista de la 'teoría de sistemas', desarrollada con posterioridad al trabajo de Shannon y Weaver, y que De Beaugrande explica del siguiente modo:

\begin{abstract}
Systems theory congealed in the 1960s to describe the general principles whereby both behavior and mind operate as 'systems': each element in a system has the function of contributing to the total operation, and an action is an intentional event guiding the system's organization and evolution. (De Beaugrande 1997:57)
\end{abstract}

De acuerdo con esta interpretación del texto, podemos decir que el planteamiento desarrollado por Shannon, basado en una noción de probabilidad estadística según la cual «the greater the number of possible alternatives at a given

\footnotetext{
${ }^{15}$ Para un análisis de la 'metáfora del conducto' y otras metáforas conceptuales en relación con la mediación intercultural, véase Martín de León (2003).
} 
point, the higher will be the information value when one of them is chosen» (De Beaugrande y Dressler 1981:140), no corresponde con la comunicación que se lleva a cabo mediante una lengua ni por mediación intercultural. Para De Beaugrande y Dressler, el problema no consiste en que se elimine la noción de probabilidad de las teorías y de los modelos lingüísticos, sino que más bien sugieren que se debería sustituir esta noción de probabilidad basada en la estadística por una noción de probabilidad basada en el contexto o probabilidad contextual:

The decisive step would be to replace the notion of statistical probability with that of contextual probability. The crucial consideration is then not how often things occur together in any absolute frequency, but rather what classes of occurrences are more or less likely under the influence of systematic constellations of current factors. Quite possibly, a statistically rare configuration of surface expressions, underlying concepts, or plan steps, might be highly probable under appropriate conditions. At least it seems safe to conclude that the contextual probabilities are different in strength for the different elements in the text [...]. The question of how the various language systems interact to determine these probabilities is much less straightforward, and has not been well explored. (De Beaugrande y Dressler 1981:140-141)

Las dificultades que presenta la investigación sobre la probabilidad contextual se basan en parte en la sospecha de que este tipo de probabilidad se manifiesta de un modo idiosincrático no sólo en los diferentes contextos, sino también en los diferentes sistemas lingüísticos que conforman una lengua:

The strength of probability might well be unequal in the several systems. A sequence might be composed of syntactically probable elements (hence, having low informativity in its cohesion) but conceptually improbable ones (hence, having high informativity in its coherence) [...]. Ordinariness supports easy processing, while non-ordinariness renders processing an interesting challenge. (De Beaugrande y Dressler 1981:141)

Otra de las dificultades estriba en la cuestión de cómo establecer esta probabilidad, para lo cual De Beaugrande y Dressler proponen la utilización de tres órdenes diferentes de informatividad:

It seems unlikely that extremely exact numerical values can or should be assigned to each occurrence on every level. More plausible would be the assumption of a range of general probabilities, that is, measurements of higher or lower on an aproximate scale. For the time being at least, we might be content with a range of three orders of informativity, each sufficiently broad that human language users might be able to distinguish them during actual communication. If each occurrence is being selected from a fuzzy set of options, we might divide the range into: (a) upper degree, $(b)$ lower degree, and (c) apparently outside the set altogether. (De Beaugrande y Dressler 1981:141-142) 
Según esta interpretación, los tres órdenes de informatividad del texto se caracterizan y se producen de distinto modo, tal como mostraremos a continuación siguiendo las descripciones presentadas por De Beaugrande y Dressler.

En primer lugar, la informatividad de primer orden se caracteriza por un procesamiento de la información que apenas es percibido por nuestra atención y que se basa en la especialización de dos tipos de palabras desde el punto de vista informativo:

First-order occurrences are rather trivial, that is, so well integrated into a system or setting that they receive very slight attention [...]. In English, the so-called function words (articles, prepositions, and conjunctions), all of which signal relations rather than content, are usually so trivial that even frequent occurrences of them in a single text are hardly noticed. The slots where function words appear in a sequence are by and large well-defined. [...] In text reception, people might skip over function words and piece content words together in a kind of «fuzzy parsing». Text types requiring extreme economy, e.g. telegrams or road signs, often dispense with function words. [...]

Content words, on the other hand, would generally be more informative. There is, for one thing, a much larger set to choose from than for function words [...]. Content words activate more extensive and diverse cognitive materials [...], and can elicit more pronounced emotions or mental images than can function words. However, a text producer might alter or reverse the normal roles of these two word types. (De Beaugrande y Dressler 1981:142-143)

Por otra parte, la informatividad de primer orden no sólo se basa en los elementos que aparecen en el texto, sino que la probabilidad de su aparición se refiere también a su no aparición en absoluto, de tal modo que puede ser tan informativo un elemento por aparecer en el texto de forma inesperada como por no aparecer cuando se esperaba que lo hiciera:

First-order informativity would always be present in any text, whether or not higher orders were attained. Any occurrence, no matter how trivial, represents a rejection of non-occurrence as an alternative. Moreover, every occurrence must have the property of being the same or different as the preceding occurrence in that same system [...]. The simple oppositions of occurrence/non-occurrence and sameness/difference are in themselves quite trivial, though special focus may be created by breaking a repeated pattern. Many humans evidently subscribe to the so-called gambler's fallacy of expecting a series of the same occurrence to be broken soon [...]. (De Beaugrande y Dressler 1981:142-143)

Además de establecer diferencias entre estos dos tipos de palabras, De Beaugrande y Dressler describen el procedimiento normal de desarrollo de la informatividad de primer orden: 
The standard procedures applied to first-order occurrences in communication would be defaults (operations or selections assumed to be stipulated in absence of contrary indicators) and preferences (operations or selections routinely favoured over competing alternatives) [...]. These procedures minimize processing load, so that attention is reserved for higher-order occurrences. (De Beaugrande y Dressler 1981:143) (énfasis original)

Esta concepción coincide con la interpretación cognitiva de que el procesamiento de la información va transcurriendo por defecto sin contratiempos mientras no se produzcan alteraciones de las expectativas del lector, y es consistente con la sugerencia de Thiel recogida por Nord (1991:38) de que la aplicación consciente de un modelo de análisis textual como un método instrumental de resolución de problemas es superflua cuando el traductor no tiene problemas al producir el TT.

Por otra parte, el segundo orden de informatividad aparece cuando los elementos del texto superan el umbral de la probabilidad de primer orden, es decir, cuando estos elementos representan una probabilidad de aparición más baja:

When defaults or preferences are overridden, i.e. when occurrences are below the upper range of probability, we obtain second-order informativity. The presence of at least some second-order occurrences would be the normal standard for textual communication, since texts purely of the first order would be difficult to construct and extremely uninteresting. Upon occasion, firstorder occcurrences could be upgraded and third-order ones downgraded to keep this medium order [...]. (De Beaugrande y Dressler 1981:143-144)

Por último, la informatividad de tercer orden se produce cuando los elementos parecen estar fuera del conjunto de opciones probables de aparición, por lo que la atención hacia estos elementos se ejerce de forma consciente:

Occurrences which at first appear to be outside the set of more or less probable options convey third-order informativity. These are comparatively infrequent occurrences which demand much attention and processing resources, but which are, in return, more interesting. Discontinuities, where material seems to be missing from a configuration, and discrepancies, where text-presented patterns don't match patterns of stored knowledge, would be the usual kinds of third-order occurrences. (De Beaugrande y Dressler 1981:144)

Al contrario de lo que sucede con la informatividad de primer orden, en la que el procesamiento de la información transcurre sin contratiempos, cuando se topa con elementos textuales altamente inesperados, o bien que contradicen el modelo vigente de conocimiento que está construido en ese momento de la lectura, el lector se ve impelido a buscar un modo de acomodar dichos elementos perturbadores al modelo construido, por lo que el procesamiento ya no transcurre de modo 
inconsciente. Según De Beaugrande y Dressler, el lector se enfrenta en estos casos con un problema al que debe encontrar solución, resolviendo las discrepancias o supliendo las discontinuidades detectadas. Al hacerlo, el lector rebaja el nivel de informatividad transformándolo en otro más integrable con el procesamiento anterior:

The text receiver must do a motivation search -a special case of problemsolving- to find out what these occurrences signify, why they were selected, and how they can be integrated back into the continuity that is the basis of communication [...]. In effect, a successful search will show that the occurrence in question was within the range of options after all, though accessible only via some mediation. Accordingly, the search has downgraded the third-order occurrence into the second order. Downgrading could have several directionalities. If text receivers go back to find motivation in earlier occurrences, they are doing backward downgrading. If they wait to consider later occurrences, they are doing forward downgrading. If they move outside the current text or discourse, they are doing outward downgrading. The same distinction can be made for upgrading. (De Beaugrande y Dressler 1981:144)

El fin de tratar la información de tercer orden de este modo responde al impulso de volver a recuperar el equilibrio anterior del procesamiento de la información, lo cual exige un mayor o menor esfuerzo de procesamiento en función del tipo de conocimiento (específico, típico o accidental) que se ve afectado:

Senselessness (or nonsense) results from lack of continuity between an occurrence and the rest of our knowledge and experience, and is doubtless hard to tolerate $[\ldots]$. The degree to which a third-order occurrence is actually disturbing would depend on the strength of linkage affected [...]. An occurrence that ran counter to determinate knowledge would be more disorienting than one that ran counter to typical; and a violation of typical knowledge would be more disturbing than that of accidental. (De Beaugrande y Dressler 1981:145)

A continuación vamos a retomar el ejemplo de De Beaugrande y Dressler que reproducíamos al principio de este apartado para mostrar cómo se produce un cambio de nivel en la informatividad de un fragmento textual:

[15a] The sea is water only in the sense that water is the dominant substance present. Actually, it is a solution of gases and salts in addition to vast numbers of living organisms [...]

(De Beaugrande y Dressler 1981:9)

Tal como señalan De Beaugrande y Dressler, el conocimiento específico acerca de la composición del mar es presentado al comienzo del texto del ejemplo sin ninguna intención aparentemente especial, o bien, como dice Bonilla 
(1997:210), de forma objetiva: «the sea is water». No obstante, el propio productor del texto eleva el nivel de informatividad a partir de ahí. Vamos a ver cómo procede para hacerlo.

Comenzaremos señalando dos proposiciones complejas, que corresponden a su vez con las dos oraciones que componen el ejemplo [15a]:

Proposición $\mathrm{A}=$ The sea is water only in the sense that water is the dominant substance present.

Proposición $\mathrm{B}=$ Actually, it is a solution of gases and salts in addition to vast numbers of living organisms ...

Según De Beaugrande y Dressler, la información que aparece en la proposición A crea un estado inestable de información (an unstable information state).

El modo de crear esta inestabilidad consiste en que, a partir de la presentación de la información que Bonilla califica de objetiva («the sea is water»), el autor introduce un elemento, «only», con el fin de desestabilizar el nivel de informatividad anterior. Este elemento ejerce la función de anticipar el contraste o la oposición que constituye la proposición B frente a la primera. En este sentido, «only» constituye una expresión predictiva de la oposición o del contraste que se va a introducir a continuación y, por consiguiente podemos decir que constituye un desestabilizador del estado anterior de la información. La presencia de expresiones predictivas como ésta se puede detectar en textos de tipo argumentativo, tal como ha mostrado Hyde (1999). A su vez, el contraste semántico de la segunda proposición aparece marcado explícitamente mediante «actually», un nexo conjuntivo de tipo adversativo (de acuerdo con la clasificación de Halliday y Hasan 1976).

Así pues, podemos ver cómo en el fragmento se produce una transición desde una informatividad de primer orden (estabilidad en el procesamiento de la información), a una informatividad de segundo orden (nivel normal de la comunicación textual) mediante la introducción de un elemento predictivo que desencadena la inestabilidad, por lo que la informatividad del texto experimenta una progresión en aumento (upgrading).

De acuerdo con De Beaugrande y Dressler, la inestabilidad es presumiblemente incómoda para el receptor, por lo que constituye el revulsivo que hará que éste busque el modo de restablecer la estabilidad de la información: «the regulative release from such a state is a prime illustration of how communication represents a continual removal and restoration of stability» (De Beaugrande y Dressler 1981:145). De este modo, cuanto más profundamente se rompa la 
estabilidad del procesamiento, mayor esfuerzo exigirá el texto al lector para volver a recuperar la estabilidad.

Desde esta perspectiva, podemos considerar el modo en que el autor elige presentar la información al lector, de tal forma que no es la información en sí misma la que es novedosa o conocida, sino que es el modo de presentarla la que la sitúa en los ojos del lector como novedosa, previamente conocida, inesperada, inexplicable, etc.

Como consecuencia de este planteamiento, podemos plantear la hipótesis de que, gracias al modo de presentación de la información en cada caso (además de otros aspectos textuales), es posible esbozar un perfil del lector para el cual el autor ha producido el texto. Este perfil es de extrema utilidad cuando queremos lograr que el aprendiz se distancie del texto con el fin de que lo observe de modo crítico, y también para mostrarle que una fuente habitual de problemas con los que se enfrenta al leer y traducir textos especializados proviene precisamente de las diferencias que a menudo se dan entre sus conocimientos individuales y los que el autor del texto le supone a su lector ideal. Por estas razones, es pertinente para la didáctica de lenguas extranjeras aproximarse a la información textual desde una perspectiva así.

Es también de suma utilidad para la didáctica contemplar la información textual de este modo debido a la versatilidad analítica con la que podemos contar, ya que podemos elegir centrarnos con profundidad en la información aparecida en una pequeña porción de texto, es decir, en aspectos de alcance microtextual, o bien podemos querer considerar cómo se plasma y transforma la información de modo extensivo a lo largo de todo el texto adoptando una perspectiva más global o de alcance macrotextual.

Por otra parte, desde una perspectiva supratextual nos puede interesar analizar, describir o valorar de un modo más general cómo se plasma el conocimiento en el discurso científico, técnico o académico, ya que desde una perspectiva epistemológica, tal como señala Gotti, «specialised discourse seeks to supply the receiver with a conceptual apparatus, rather than with a source of terminology appropriate to the learning branch which is to be studied» (Gotti 1996: 219). En este caso, nos puede resultar de utilidad la perspectiva de Halliday, que considera la gramática como una teoría de la experiencia humana «in the sense that it imposes a categorisation by treating a certain cluster of phenomena as alike in certain respects, and hence setting this cluster apart from others which are treated as being different» (Halliday 1998). 
A continuación nos vamos a detener en las características del discurso científico inglés, principalmente según el análisis de Halliday (1998). Dada la imposibilidad de llevar a cabo esta tarea de un modo exhaustivo en un trabajo como éste, nuestro objetivo aquí no es una descripción detallada del discurso de la ciencia en inglés, sino que nos centraremos en el modo como la lexicogramática del inglés funciona típicamente en este tipo de discurso.

\subsubsection{La metáfora gramatical del discurso científico inglés}

Desde el punto de vista de la gramática sistémica funcional, Halliday (1998) afirma que el modelo gramatical (entendido como un síndrome de características gramaticales) favorito del discurso científico inglés moderno corresponde con un esquema en el que las claúsulas se relacionan secuencialmente entre sí y están construidas por figuras organizadas como grupos nominales ${ }^{16}$. Se trata de un esquema de este tipo:

(1) una secuencia de dos figuras se construye como una única claúsula, típicamente relacional

(2) cada figura se construye como un grupo nominal

(3) la relación lógico-semántica (conjuntiva) entre ellas se construye como un grupo verbal

El siguiente ejemplo tomado del propio Halliday (1998:193) sirve para ilustrar esta descripción:

Grupo Nominal

Grupo Verbal

Grupo Nominal rapid changes in the rate of evolution

are caused by

external events

Por otra parte Halliday afirma que, mientras que la densidad media de palabras léxicas en una claúsula apenas es mayor de dos en el inglés espontáneo hablado, en el discurso científico esta media es muy superior (Halliday 1998). El argumento es que esto sólo es posible gracias al gran potencial que el grupo nominal

\footnotetext{
${ }^{16} \mathrm{Si}$ bien ya hemos aludido en ocasiones anteriores al grupo nominal (nominal group) de acuerdo con la terminología de Halliday, nos parece oportuno señalar que este concepto no difiere excesivamente del de sintagma nominal (noun phrase). Halliday y Hasan justifican la utilización de esta terminología, basándose en que lo que sí difiere es el concepto de grupo verbal (verbal group) del de sintagma verbal (verbal phrase) y, por consiguiente, el grupo nominal responde a un marco conceptual diferente del sintagma nominal (Halliday y Hasan 1976:39).
} 
tiene en inglés, así como en otras lenguas, para crear significado, debido a su capacidad para expandirse más o menos indefinidamente.

Según Halliday, el grupo nominal tiene una estructura lógica basada en la modificación y consta de un núcleo (head) y de modificadores opcionales (modifiers). Algunos de estos modificadores preceden al núcleo (premodificadores), mientras que otros van detrás de él (postmodificadores). Esta estructura es sumamente importante para la lexicogramática de Halliday, porque la distinción entre la posición relativa de unos elementos modificadores u otros es pertinente desde el punto de vista semántico (Halliday y Hasan 1976). Así, esta estructura ocurre de forma simultánea a la dimensión relativa a la lógica de la experiencia (de acuerdo con la función del lenguaje para expresar los fenómenos del mundo real desde la perspectiva del sujeto). Esta dimensión experiencial se refleja en una subdivisión funcional de los modificadores, cuyo repertorio se puede ver en el ejemplo de Halliday y Hasan que reproducimos a continuación:

\begin{tabular}{|c|c|c|c|c|c|c|}
\hline & the & two & high & stone & walls & $\begin{array}{l}\text { along the } \\
\text { roadside }\end{array}$ \\
\hline $\begin{array}{l}\text { Structures: } \\
\text { logical }\end{array}$ & \multicolumn{4}{|c|}{ Premodifier } & Head & Postmodifier \\
\hline experiential & Deictic & Numerative & Epithet & Classifier & Thing & Qualifier \\
\hline Classes & determiner & numeral & adjective & noun & noun & $\begin{array}{l}\text { [prepositional } \\
\text { group] }\end{array}$ \\
\hline
\end{tabular}

Tabla 9. Estructura del gupo nominal en inglés (Halliday y Hasan 1976:40)

La expansión del grupo nominal se desarrolla en inglés de dos formas que son complementarias, tal como señala Halliday (1998), a partir de su concepto de 'grupo' como una palabra expandida. Esta expansión ocurre de diferente modo según se trate de un grupo nominal o de un grupo verbal:

Both verbs and nouns get expanded into groups, but while the verbal group expands grammatically, with complex tenses, modalities, phases and the like (processes get elaborated on the temporal dimension), the nominal group expands lexically, by the device known as modification: one noun functions as 
a kind of keyword, and other words are organised around it, having different functions with respect to this head noun. (Halliday 1998:196)

El principio semántico de la expansión del grupo nominal, así como su importancia para el discurso, consiste en situar la entidad participante a lo largo de ciertos parámetros que van desde el más ligado a la situación comunicativa (el deíctico), hasta el más asociado al sistema (el clasificador).

En inglés, esta expansión resulta como un movimiento de izquierda a derecha en el segmento pre-modificador del grupo nominal, empezando con el deíctico y terminando con el clasificador, tal como se puede ver siguiendo los elementos del ejemplo de la Tabla 9. El elemento deíctico («the») es el que sitúa la entidad desde el punto de vista de la situación comunicativa, mientras que el elemento clasificador («stone») la sitúa sistémicamente al subclasificarla. El resto de elementos se encuentra en el continuo existente entre ambos extremos.

En segundo lugar, Halliday (1998:196) señala que el grupo nominal también se puede expandir mediante el cambio de rango de las figuras clausales o sintagmáticas, como en «an animal with four legs / having four legs / which has four legs», siendo introducidas estas figuras en el esquema de pre-modificación de forma lexicalizada, como en «a four-legged animal».

El sistema de expansión del grupo nominal en inglés tiene gran relevancia desde la perspectiva de la didáctica de la lengua inglesa, puesto que, cuando se produce una acumulación de palabras léxicas en el esquema de premodificación del grupo nominal, a menudo estos elementos resultan ambiguos para los aprendices. Los siguientes ejemplos, tomados del mismo autor, ilustran a qué tipo de casos nos estamos refiriendo:

\section{Ejemplo 1:}

our forces need low-flying aircraft (clasificador) (=which fly low)

Ejemplo 2:

hit by a low-flying aircraft (epíteto) (=which was / is flying low)

No obstante, este tipo de ambigüedad puede no ser interpretada como una deficiencia en la estrategia utilizada por el autor del texto para expresar lo que quiere decir. Es decir, la ambigüedad detectada por el aprendiz no tiene por qué constituir una señal de que el efecto del texto (por lo que respecta a esa parte de la información) es poco eficaz, sino que cabe interpretar que lo que el aprendiz 
identifica como un caso de ambigüedad puede estar simplemente producido por el hecho de que su bagaje de conocimientos es diferente al del lector ideal o prospectivo del texto.

Según esto, podemos esperar razonablemente que, dado que Halliday identifica una tendencia a acumular palabras léxicas en la estructura premodificadora del grupo nominal en el discurso científico inglés, este mecanismo constituirá una abundante fuente de problemas de comprensión y, por consiguiente, se trata de un aspecto que es necesario incorporar específicamente a la didáctica del Inglés para Fines Específicos (v. Elorza 2000) y también a la didáctica de la traducción entre el par de lenguas español e inglés (v. Elorza 2003b), al menos en lo que respecta a la lectura y traducción de textos científicos en inglés.

De acuerdo con Halliday, otra de las características del discurso científico es el modo de construcción del 'flujo discursivo'. Asumiendo que la gramática de cualquier lenguaje (natural) es una teoría de la experiencia humana, Halliday (1998) apunta que, al tiempo de construir casos concretos de experiencia humana, la gramática también debe construirse a sí misma, mediante la creación de un flujo discursivo textual. De todos los mecanismos que contribuyen a la creación de este flujo, los más relevantes son aquellos asociados a la gramática de la claúsula, ya que es en ella donde concurren explícitamente el significado ideacional y el textual. En inglés, los dos sistemas que participan simultáneamente en la creación de este flujo son el temático, con las funciones denominadas 'tema' y 'rema', y el de la información, con las funciones denominadas 'dado' y 'nuevo'.

Ambos sistemas van dando ritmo al discurso regularmente, de tal modo que cada claúsula se va moviendo de un punto de prominencia a otro. En el discurso científico-técnico, la prominencia inicial suele constituir el tema, y supone el punto de partida desde el punto de vista del autor. Por el contrario, la prominencia final, que suele coincidir con el rema, conlleva el punto de vista del receptor. Al mismo tiempo, el sistema de la información tiene su propio dominio, la unidad de información, donde se establece la configuración de las funciones dado y nuevo mediante el sistema rítmico y de entonación en forma de grupo tonal. En lo que se consideran casos no marcados, las unidades de información se asocian con las claúsulas de tal modo que el tema de la claúsula se localiza en la porción donde se ubica lo dado, mientras que lo nuevo, que es lo que centra la atención, se ubica en la parte del rema.

Es decir, el autor toma como punto de partida lo que es presentado como información compartida, conocida y compatible con el bagaje de conocimientos del 
receptor, para llevar la atención y la mente de éste hacia la información nueva, que se encuentra en la parte final de la claúsula. Esto va ocurriendo sucesivamente hasta el final del texto de forma acumulativa. De este modo, una proposición que aparece repetidas veces a lo largo del texto va acumulando sucesivamente una carga informativa, de tal forma que podemos afirmar que la última aparición en el texto de dicha proposición se aleja, desde el punto de vista del alcance de las palabras que le da el receptor en su comprensión, de la primera ocasión en que la misma proposición aparecía en el texto.

Recordemos que esta característica no es exclusiva de un tipo de discurso determinado, sino que se corresponde con uno de los criterios de la textualidad. Para ver un ejemplo en un tipo de texto diferente, es muy ilustrativo el caso del relato de Truman Capote (1949) titulado «Children on Their Birthdays». Este relato tiene una estructura circular desde el punto de vista del criterio de la informatividad ya que la primera oración que abre la historia: «Yesterday afternoon the six-o'clock bus ran over Miss Bobbit», contiene la misma proposición que la última oración del relato: «That is when the six o'clock bus ran over her». En este caso particular, la diferencia en la carga informativa existente entre la primera aparición de la proposición y la última comprende la acumulación de toda la información textual a la que el lector va accediendo a lo largo de las veinte páginas de extensión del relato. Desde un punto de vista macroestructural, podemos decir que esta primera proposición constituye el macro-tema del relato, mientras que el resto, hasta llegar a la última oración, es su macro-rema.

Halliday se refiere a la progresión textual tal como se produce dentro de los límites de la estructura oracional, por lo que podemos decir que su descripción del sistema temático afecta a la coherencia local desde el punto de vista de las relaciones entre proposiciones que se expresan en un nivel local o microestructural. No obstante, es posible analizar también la estructura temática del discurso, analizando cómo operan la cohesión y la coherencia en un nivel global o nivel macroestructural al mismo tiempo (Brown y Yule 1983; Van Dijk y Kintsch 1983).

Desde una perspectiva didáctica, podemos suponer razonablemente que nos encontraremos con problemas asociados a posibles desfases entre los conocimientos de los lectores (los aprendices, en este caso) y la información textual cuando está dirigida a lectores prospectivos con conocimientos diferentes. Podemos suponer también que se podrán observar diferencias entre unos problemas y otros relacionadas con la relevancia de las proposiciones en un nivel microestructural y en 
un nivel macroestructural, y también con la relevancia relativa de la proposición en la estructura temática y en la estructura informativa del texto.

Así, en el caso de que el bagaje de conocimientos de los aprendices no coincida con los del lector ideal o prospectivo, los problemas locales de comprensión no tendrán la misma repercusión para la comprensión global del texto cuando sean producidos por información que el autor presenta como dada, que cuando los problemas afecten a la información que el autor presenta como nueva para el lector. Asimismo, podemos esperar que los problemas locales afectarán a su vez a la comprensión global del texto y viceversa ${ }^{17}$. En este sentido, creemos que es útil diferenciar los problemas que podamos diagnosticar en los aprendices de acuerdo con el alcance que éstos tengan para la comprensión textual y también en el caso de la producción textual mediante un proceso de traducción, además de otros factores como la función comunicativa predominante del texto.

De acuerdo con este planteamiento el texto, más que presentar o contener una cierta cantidad de información o de conocimientos, presenta una delicada y compleja ruta de acceso y de interpretación que cada lector aborda de un modo particular de acuerdo con su bagaje personal y sus objetivos. Pero entonces no podemos decir que el significado se localice en el texto, sino que más bien reside en el lector, tal como sugiere Smith:

If meaning is not inherent in surface structure, and surface structure is all that
passes between writers and readers (or between speakers and listeners), where
does the meaning come from? The only possible answer is that readers or
listeners must provide meaning themselves. (Smith 1978:73)

A continuación, en la sección siguiente, nos vamos a ocupar de la comunicación especializada precisamente desde la perspectiva del lector en relación con los procesos de tipo cognitivo que se dan en lo que podríamos denominar la parte individual e interna de la comunicación. En otras palabras, vamos a intentar explicar la respuesta dada por Smith.

\footnotetext{
${ }^{17}$ Según señala Greene, los problemas relacionados con la macroestructura del texto también afectan a la comprensión local:
}

The extraction of macrostructures is an ongoing process in language understanding. Far from waiting until the end of a text to decide what it was all about, readers continously make inferences about relevant macropropositions. Moreover, macropropositions have a great deal of influence on how the rest of a text is analysed. (Greene 1986:93) 


\subsection{La comunicación especializada: entorno cognitivo}

Como ya hemos mencionado en la sección anterior, cuando producimos y transmitimos conocimientos, así como cuando intentamos comprender lo que otros nos comunican, lo hacemos mediante estrategias que nos permiten integrar el conocimiento nuevo con los conocimientos que teníamos previamente. Como explica Smith, nos comunicamos y aprendemos a través de estrategias cuya finalidad es organizar la realidad compleja que vivimos como un determinado modelo del mundo:

What is that we have in our heads, that we carry around with us all the time in order to make sense of the world? It is not sufficient to answer 'memories', because the human brain is not like a souvenir album filled with an assortment of snapshots and records of past events. At the very least we would have to say that the brain contains memories-with-a-meaning; our memories are related to everything else that we know. But it is also not sufficient to say that our heads are filled with knowledge, in the sense of accumulation of facts and figures; the brain is not like an encyclopaedia or catalogue or even like a library, where useful information is filed away under the appropriate heading for ready reference. Certainly the human brain is not a vault in which the products of instruction are deposited when and if we attend to our teachers and our textbooks. Instead what we have in the human brain is a system, an intricately organized and internally consistent model of the world, built up as a resource of experience, not instruction, and integrated into a coherent whole as a result of continual effortless learning and thought. We know far more than we ever thought.

What we have in our heads is a theory, a theory of what the world is like, and this theory is the basis of all our perception and understanding of the world; it is the root of all learning, the source of all hopes and fears, motives and expectancies, reasoning and creativity. And this theory is all we have; there is nothing else. If we can make sense of the world at all, it is by modifying and elaborating our theory. The theory fills our minds; we have no other resource. (Smith 1978:78-79)

Una de las cuestiones que cabe plantearse es hasta qué punto nuestro modelo del mundo se parece al de nuestros semejantes, hasta dónde nuestro acervo de conocimientos se basa en experiencias únicas o en experiencias colectivas $\mathrm{y}$, específicamente desde una perspectiva didáctica, qué distancia separa las teorías del mundo de los aprendices de los modelos del mundo que utilizan los expertos; qué distancia, en definitiva, deben recorrer los aprendices para lograr integrar los conocimientos nuevos que se les presentan con los que ya poseen de modo que, tras el proceso de aprendizaje, no sean ya tan aprendices, y sí más expertos.

En la introducción al capítulo dedicado al aprendizaje, recogíamos cómo, para Sánchez Miguel, el estado final al que queremos llegar con el proyecto de enseñanza-aprendizaje se define a partir de nuestro conocimiento sobre cómo actúan 
las personas expertas. En términos generales, podemos afirmar que ser un experto implica tener asimilado un conjunto indeterminado de esquemas que son compartidos al menos por la mayoría de los expertos reconocidos en un campo de especialización. En el caso particular del conocimiento científico, desde la perspectiva de Kuhn (1962) ser experto significa asimismo tener asimilado el paradigma científico de la comunidad a la que el científico pertenece.

Desde un punto de vista general del funcionamiento del lenguaje, no tenemos por qué pensar que la comunicación en un entorno profesional es cualitativamente distinta a la comunicación en otros tipos de entorno. Si entendemos las lenguas de especialidad como las variedades de una lengua utilizadas por los profesionales de un campo de especialización para comunicarse con sus semejantes en relación con los conocimientos y actividades propios de ese campo de especialización, no creemos que estas variedades se puedan caracterizar convenientemente mediante la probabilidad estadística de aparición de unos términos determinados. Hay que tener en cuenta, además, las dificultades añadidas por el uso de la lengua inglesa en el ámbito internacional, tal como nos recuerda Sager:

\begin{abstract}
El inglés tiene una función doble, la de una lengua nacional de una serie de comunidades lingüísticas en Australia, Canadá, el Reino Unido, los Estados Unidos, etc. y como lenguaje de comunicación internacional o una lingua franca para las revistas científicas, los congresos, etc. Aunque esta doble función no es exclusiva del inglés, ya que el francés, el alemán, el ruso, el árabe tienen funciones dobles similares, el empleo internacional de inglés [sic] está tan extendido que afecta a la coherencia de la terminología en inglés, lo cual debe, por tanto, tratarse con extremado cuidado. (Sager 1990:297-298)
\end{abstract}

Por el contrario, la caracterización de una variedad responderá más bien a su probabilidad contextual, determinada por la influencia de lo que De Beaugrande y Dressler describen como «systematic constellations of current factors» (De Beaugrande y Dressler 1981:140-141).

Desde nuestra perspectiva, uno de estos «current factors» consiste en que los interlocutores en la comunicación especializada comparten un conjunto de esquemas. En este sentido, la caracterización y el análisis de los esquemas utilizados por los expertos de un campo determinado de conocimiento será extremadamente útil para establecer pautas características del nivel experto y, por consiguiente, 
contribuirá a la descripción del contexto donde se produce la comunicación especializada ${ }^{18}$. Por consiguiente, su valor para la didáctica parece incuestionable.

Una descripción de cómo estructuramos los conocimientos nos servirá para explicar, al menos parcialmente, cómo se produce la comprensión, cómo interpretamos, asimilamos o reaccionamos ante la información que abordamos al comunicarnos lingüísticamente por cualquier medio y también cómo utilizamos el conocimiento individualmente para generar más conocimiento. Van Dijk y Kintsch (1983) han propuesto un modelo de dos fases de uso de los conocimientos de tipo general, que han analizado en relación con la interacción textual, y que resumen muy escuetamente de este modo:

\begin{abstract}
After the activation of certain concepts on the basis of some input word or clause, some general knowledge fragment (e.g., of a frame or script) is activated and instantiated with the specific constants (Peter, Mary) of the text. This instantiation will in turn activate, and its information be added to, specific episodic memories about the same or similar situations, namely, the situation model. It is the thus activated or constructed information in the situation model that forms the knowledge base for understanding the text. For instance, we may activate or construct a situation model 'Fire in a restaurant', involving general information about restaurants, and general information about fires, added to personal experiences with such or similar fires. (Van Dijk y Kintsch 1983:308)
\end{abstract}

Si relacionamos el modelo de Van Dijk y Kintsch con el propuesto por Halliday para describir el funcionamiento del sistema temático y del sistema informativo que hemos mencionado en la sección anterior, las palabras o claúsulas que sirven de input para activar recuerdos específicos de la memoria episódica coinciden con el tema y la información dada. Así, podemos suponer que la función asignada a la información presentada por el autor como conocimientos compartidos entre él y el lector es, precisamente, la de activar los esquemas o recuerdos necesarios para comprender y asimilar el rema o la información nueva o presentada como nueva por el autor. En este sentido, el modelo de Van Dijk y Kintsch viene a reforzar nuestra convicción de la extrema importancia de esta cuestión en relación con la didáctica de las lenguas extranjeras en general, y del Inglés para Fines Específicos de forma especial.

\footnotetext{
${ }^{18}$ Una caracterización de los esquemas utilizados en un campo de especialización, si bien extremadamente compleja, es una tarea que contribuye a la descripción del discurso especializado desde un enfoque que va más allá de la superficie de los textos, tal como proponen Candlin, Bhatia y Jensen (2002) siguiendo a Cicourel.
} 
No obstante, no debemos olvidar que los distintos tipos de esquemas son utilizados estratégicamente con el fin de poder emplear de forma eficiente nuestros conocimientos y asimilar otros nuevos y, desde esta concepción, no debemos confundirlos con representaciones textuales (Van Dijk y Kintsch 1983:307). A pesar de esto, existe una estrecha relación entre las estrategias de uso del conocimiento y las estrategias discursivas desde un punto de vista estructural.

Desde una perspectiva cognitiva, podemos afirmar que cuando usamos el lenguaje para producir y transmitir conocimientos nuevos, así como para comprender los conocimientos que nos transmiten otros, utilizamos estrategias destinadas a interpretar lo que está ocurriendo en la comunicación y, al mismo tiempo, a crear expectativas acerca de lo que va a suceder a continuación. Por consiguiente, la transmisión de conocimientos implica diversos procesos complejos de tipo cognitivo por parte de los participantes en la comunicación. Un aspecto particularmente relevante desde el punto de vista de la didáctica de las lenguas específicas es el que está constituido por aquellos procesos involucrados en la comprensión de textos especializados.

Por otra parte, si consideramos nuestra relación con el texto desde un punto de vista sociolingüístico, y tomamos el texto como un medio de intercambio de conocimientos en un entorno social, la interpretación de lo que el texto significa se basa en parte en lo que ya sabemos:

From a sociolinguistic standpoint, a text is meaningful not so much because the hearer does not know what the speaker is going to say, as in a mathematical model of communication, but because he does know. He has abundant evidence, both from his knowledge of the general (including statistical) properties of the linguistic system and from his sensibility to the particular cultural, situational and verbal context; and this enables him to make informed guesses about the meanings that are coming his way. (Halliday 1978:61)

Tradicionalmente se ha considerado que la comprensión del significado de un texto no ficcional se producía como el resultado final de un proceso, como el producto de la lectura y de la interpretación del mensaje contenido en el texto, de acuerdo con un modelo como el descrito mediante la 'metáfora del conducto' (v. 5.2.4). Se interpretaba que el significado formaba parte del texto de modo permanente, estático y estable. Por consiguiente, la lectura se planteaba como una tarea cuyo objetivo era recuperar el significado del texto, en el sentido de localizarlo y aprehenderlo. Esta concepción estática del significado se encuentra en el trasfondo del paradigma utilizado hasta mediados del siglo XX para comparar textos paralelos 
(un TT con su correspondiente TO) mediante criterios absolutos de corrección, es decir, el clásico tertium comparationis al que ya nos hemos referido con anterioridad.

Más recientemente, se ha comenzado a contemplar el lenguaje como un medio complejo de comunicación en un entorno social y, por consiguiente, la traducción se ha empezado a concebir como un fenómeno de interacción social e intercultural. Desde esta perspectiva, el significado es considerado dinámico y no estático porque se va construyendo progresivamente a medida que el lector procesa la información textual y porque su construcción se va produciendo como un proceso de negociación entre el sujeto y el texto.

Según Halliday (1978), el texto representa una elección de entre todos los significados posibles. El propio texto, en tanto en cuanto su producción conlleva un proceso de elaboración que culmina al traspasar el umbral de finalización, es el resultado de un proceso de selección previa y, a este respecto, no puede ser tomado en consideración sino en relación con su contexto. Tal como señala Cortese (1988:191), el significado y la coherencia textuales ya no se consideran susceptibles de desligarse de los participantes en la situación comunicativa, sino que son tomados como «significant segments of the interaction of mind and text», siendo este último un estímulo «for the enlargement of the reader's cognitive environment» ${ }^{19}$.

Como ya hemos visto anteriormente, este enfoque ha sido adoptado no sólo por investigadores interesados por el texto desde el punto de vista de la lingüística, como De Beaugrande (1980a) y Schmidt (1973), sino también desde la perspectiva de la traducción, como Nord (1991). En general, actualmente se considera que el texto no es un mero continente del significado, sino que realiza una función que Carrell y Eisterhold (1983:556) resumen de este modo: «text, any text, either spoken or written, does not by itself carry meaning. Rather, [...] a text only provides directions for listeners or readers as to how they should retrieve or construct meaning from their own, previously acquired knowledge».

En el proceso de negociación del significado, los conocimientos asimilados a nuestra experiencia o a nuestros conocimientos generales acerca del funcionamiento del mundo, independientemente de su procedencia, nos ayudan a interpretar los conocimientos nuevos. Para que esto pueda ocurrir sin exigirnos un gran esfuerzo de procesamiento, ni una gran atención de nuestra consciencia,

\footnotetext{
${ }^{19}$ Según la concepción de esta autora, el texto se contempla como «the verbal entity through which minds come into contact» (Cortese 1988: 191).
} 
nuestros conocimientos se agrupan de forma organizada «as cognitive constructs or configurations of knowledge which we place over events so as to bring them into alignment with familiar patterns of experience and belief» (Widdowson 1983:54). Por tanto, estas configuraciones de conocimientos son utilizadas para categorizar y organizar la información de modo que ésta pueda ser interpretada, comprendida y/o recordada por nuestra mente de un modo eficaz y económico, con el fin de que se puedan emplear recursos en el procesamiento y realización de otras tareas que requieren más atención y esfuerzo a nuestra mente.

Las distintas formas de organizar los conocimientos que ya poseemos han sido estudiadas por diversos autores y han recibido denominaciones variadas, tales como 'marcos', 'esquemas', 'planes', 'guiones' o 'escenarios'. En 1932, el psicólogo británico Bartlett (1932) propuso el término 'esquema' (schema), que ha dado nombre a esta teoría (schema theory), y que Cook describe como «a mental representation of a typical instance» (Cook 1997:86). Un esquema consiste en la representación mental de los conocimientos organizados que están relacionados con situaciones típicas. Bartlett elaboró esta definición al observar cómo la información que recibía el sujeto era reformada por su memoria de modo que no resultara contradictoria con lo que para el propio sujeto era lo habitual o lo normal. Posteriormente, Bransford y Johnson (1972) mostraron mediante un experimento cómo estos esquemas de organización de los conocimientos tienen un papel muy importante en la facilidad o dificultad para comprender la información que el sujeto recibe, y también Chafe (1979) demostró experimentalmente la importancia de los esquemas culturales para la comprensión de la información.

Poco después, otros investigadores del campo de la Inteligencia Artificial descubrían distintas formas de organización mental del conocimiento. Schank y Abelson (1977) son los responsables de los 'guiones' o scripts; Minsky (1975) por un lado, y Bobrow y Winograd (1977) por otro, trabajaron con 'marcos' o frames; y por su parte, Rumelhart y Ortony (1977) se centraron en los 'esquemas' o schemata. A partir de los años 80, muchos otros investigadores (en su mayoría psicólogos del campo cognitivo pero también lingüistas) han trabajado sobre diversos aspectos en relación con las características y el papel de estas formas de organización mental del conocimiento $^{20}$. Como ejemplo de investigaciones más recientes podemos aludir al

\footnotetext{
${ }^{20}$ Por citar unos cuantos ejemplos de esa época, De Beaugrande (1980) se ha ocupado, al igual que Sanford y Garrod (1981), de la organización de los conocimientos en relación con el texto y su comprensión, Carrell y Eisterhold (1983) han estudiado particularmente las repercusiones de esta teoría en relación con la enseñanza de la lectura en la didáctica de las lenguas extranjeras y
} 
trabajo de Pritchard (1990), que ha estudiado la relación entre la utilización de esquemas culturales y la aplicación de distintas estrategias de comprensión en función de la familiaridad de la información para sujetos de diferentes culturas.

En términos más generales, Carrell y Eisterhold resumen cómo se produce el procesamiento de la información escrita de acuerdo con esta teoría:

The process of interpretation is guided by the principle that every input is mapped against some existing schema and that all aspects of that schema must be compatible with the input information. This principle results in two basic modes of information processing, called bottom-up and top-down processing. Bottom-up processing is evoked by the incoming data; the features of the data enter the system through the best fitting, bottom-level schemata. Schemata are hierarchically organized, from most general at the top to most specific at the bottom. As these bottom-level schemata converge into higher level, more general schemata, these too become activated. Bottom-up processing is, therefore, called data-driven. Top-down processing, on the other hand, occurs as the system makes general predictions based on higher level, general schemata and then searches the input for information to fit into these partiallysatisfied, higher order schemata. Top-down processing is, therefore, called conceptually-driven. (Carrell y Eisterhold 1983:557)

Con respecto al aprendizaje de lenguas extranjeras, hemos tratado anteriormente de un modo general algunos de los problemas que se pueden asociar con el procesamiento de la información cuando los aprendices tienen una competencia comunicativa limitada en la lengua que están aprendiendo en relación con los dos tipos de procesamiento aludidos por Carrell y Eisterhold. No obstante hay que señalar que, cuando el procesamiento de la información no requiere un esfuerzo extra de atención, el procesamiento de abajo arriba y el procesamiento de arriba abajo suelen ocurrir simultáneamente como un único macroproceso, es decir, de forma integrada.

Por otra parte, la complejidad del proceso de asimilación del conocimiento se puede intuir al observar la sofisticación de su organización. Los conocimientos no sólo no se organizan siempre de la misma forma (la diversidad de sus denominaciones es un indicio de ello), sino que incluso se establecen distintas variedades aunn dentro del mismo tipo de organización, siendo algunas de ellas ciertamente complejas. Por ejemplo, Sanford y Garrod (1981) recogen cómo Minsky establece hasta seis tipos de marco. Nos resulta muy interesante desde el punto de vista de la transmisión del conocimiento científico la última variedad de marco contemplada por Minsky. Basándose en la concepción de revolución

Widdowson (1983) ha tratado esta cuestión de un modo más general en relación con la lingüística aplicada a la didáctica del Inglés para Fines Específicos. 
científica de Kuhn, Minsky interpreta los paradigmas científicos como un marco de organización del conocimiento: «paradigms can be viewed as frames, indicating as they do the conceptual relationship between various observables and restricting the range of potential candidates (empirical observations) to fill the slots of the frame» (Sanford y Garrod 1981:34).

Van Dijk y Kintsch (1983:307) opinan que, aunque existen diferencias entre unos tipos y otros de organización del conocimiento, básicamente se trata de la misma idea. No obstante, no debemos presuponer que las diferencias entre unos tipos de organización y otros se basan únicamente en una mayor o menor complejidad de la organización (esquemas compuestos a su vez por otros esquemas, etc.), sino que parecen existir diferencias cualitativas, de tal modo que ciertos esquemas funcionan como modelos de organización conceptual, mientras que otros actúan como modelos de participación en la vida social. De acuerdo con Widdowson (1983:55), «if we take the term 'schema' as a superordinate denoting configurations of knowledge in general, we may say that we have ideational schemata on the one hand and interpersonal schemata on the other». Entonces, cuando hablamos de carencias en el estado de conocimientos de los aprendices, debemos especificar que solemos enfrentarnos a ambos tipos de carencia, y no sólo a las que conciernen a modelos de organización conceptual. Es más, en nuestra opinión, las carencias de la descripción de lo que podríamos denominar 'modelo experto' de participación en la vida social de la comunidad profesional en la que el aprendiz se va a integrar, así como sus posibles paliativos, constituyen una de las áreas más abandonadas por la didáctica del Inglés para Fines Específicos, si nos atenemos a la ausencia de contenidos de tipo actitudinal en los proyectos de enseñanza y aprendizaje de este ámbito.

A lo largo de este capítulo dedicado a nuestra concepción de la comunicación especializada nos hemos centrado con mayor detenimiento en los parámetros que afectan a la comprensión, utilización y producción de textos.

El marcado interés por mantener un enfoque textual sobre el lenguaje y la comunicación se justifica por el hecho de que el planteamiento específico de nuestro trabajo se basa esencialmente en el texto (tanto por lo que concierne a las funciones didácticas de éste, como a su importancia en cuanto a su peso relativo en la metodología del proyecto de enseñanza-aprendizaje) y por el papel central de éste en los modelos de comunicación. En el capítulo siguiente, vamos a situar el texto 
dentro del enfoque didáctico en una posición diferente. Los aspectos que van a pasar a tener relevancia serán aquellos que se refieren a los distintos tipos de evaluación que consideramos en este trabajo: la evaluación formativa y la autoevaluación. Por tanto, el texto pasa a ser a continuación un instrumento que permite al profesor y al aprendiz obtener diferentes tipos de información con una finalidad didáctica. 


\section{La evaluación y la traducción especializada como método de evaluación para el aprendizaje}

\subsection{Introducción}

Hemos dedicado los dos capítulos anteriores a hacer explícito el concepto de lenguaje que subyace en nuestras consideraciones teóricas acerca de la validez de la traducción como medio de facilitación del aprendizaje en el ámbito de la didáctica del Inglés para Fines Específicos. Ahora, nuestra atención en este capítulo se desplaza hacia la perspectiva de la didáctica general sobre esta cuestión, con el fin de poder situar nuestro objeto de estudio en toda su extensión desde un desarrollo teórico, cerrando por tanto un ciclo que nos ha llevado a tratar los numerosos aspectos involucrados desde la perspectiva de la didáctica de la traducción, de la didáctica del Inglés para Fines Específicos, del aprendizaje de las lenguas extranjeras, de la perspectiva lingüística acerca de la comunicación y de la traducción y que, finalmente, nos lleva a los aspectos más relevantes que encontramos en la didáctica general en relación con esta cuestión.

El aspecto central en el presente capítulo es el concepto de evaluación. Por una parte, se trata de un elemento necesario en cualquier proyecto de enseñanzaaprendizaje que se desarrolle de forma académica, como es el caso que nos ocupa, ya que el propio entorno institucional exige evaluar el aprendizaje de los alumnos. Pero también se trata de un concepto complejo y versátil en cuanto a su aplicación con fines didácticos, que puede requerir del aprendiz destrezas de gran complejidad en relación con el comportamiento estratégico y actitudinal y que, por consiguiente, nos resulta de gran interés. 
Para centrar convenientemente los aspectos que vamos a tratar a lo largo de este capítulo, conviene comenzar estableciendo qué entendemos por evaluación y qué implicaciones tiene este concepto tal como lo aplicamos en este trabajo.

La versión española del Marco de Referencia Europeo editada por el Instituto Cervantes define el término 'evaluación' como la «valoración del grado de dominio lingüístico que tiene el usuario [de una lengua]» (Marco de referencia europeo para el aprendizaje, la enseñanza y la evaluación de lenguas 2002:171). Se trata, por tanto, de una interpretación muy amplia en la que se incluyen tanto las pruebas de evaluación (los exámenes) como otros medios de los que nos podemos valer para valorar el dominio lingüístico o el progreso del aprendizaje, tales como la observación o los formularios de autoevaluación que comienzan a incluirse en algunos métodos de enseñanza (por ejemplo, Sinclair 1995). Esta amplitud interpretativa del concepto de evaluación nos resulta conveniente para considerar los aspectos relacionados con la traducción como un modo de evaluación formativa y también como un modo de autoevaluación, que son los aspectos específicos en los que nos centraremos con mayor detenimiento.

No obstante, debemos precisar que el hecho de que el término 'evaluación' sea utilizado de un modo tan amplio en la versión española del Marco de Referencia Europeo responde a que, bajo este término, se aglutinan dos aspectos que en inglés corresponden a dos términos diferentes, 'assessment' y 'evaluation', y que son definidos en la versión en inglés respectivamente del siguiente modo:

\begin{abstract}
Assessment is used [...] in the sense of the assessment of the proficiency of the language user. [...] Evaluation is a term which is again broader than assessment. All assessment is a form of evaluation, but in a language programme a number of things are evaluated other than learner proficiency for example the effectiveness of particular methods or materials, the kind and quality of discourse actually produced in the programme, learner/teacher satisfaction, teaching effectiveness, etc. (Common European Framework of Reference for Languages: Learning, Teaching, Assessment 2001:177)
\end{abstract}

En el presente trabajo, nos proponemos trabajar con ambos conceptos del siguiente modo.

Desde una perspectiva global de la didáctica de las lenguas extranjeras, nos proponemos evaluar (evaluate) en un nivel teórico la validez de las tareas de traducción como un método para facilitar el aprendizaje de una lengua extranjera. A su vez, desde una perspectiva más estrecha centrada únicamente en las tareas de traducción, nos proponemos valorar (assess) la utilización de estrategias destinadas a interpretar las situaciones comunicativas implicadas en la tarea y a resolver los 
problemas detectados. El criterio de valoración de la utilización de estas estrategias se relaciona con las pautas de actuación asociadas típicamente con el comportamiento de los expertos del campo de especialización en que se está formando el aprendiz (no como lo harían los traductores profesionales necesariamente, sino más bien de acuerdo con las pautas de razonamiento y con la aplicación de los modelos y valores característicos de los propios profesionales del campo).

Como quiera que las tareas de traducción exigen al individuo que las realiza la consideración consciente y atenta de (al menos alguno de los) diversos aspectos relacionados con la lengua utilizada, la información textual, la situación comunicativa, etc., podemos interpretar que, en este sentido, las tareas de traducción conllevan necesariamente la utilización de alguna estrategia que, mediante la reflexión, lleve al sujeto a las conclusiones necesarias que le permitan elaborar el TT de acuerdo con sus elecciones particulares. De este modo, las tareas de traducción pueden ser razonablemente consideradas por la didáctica como un medio potencialmente apropiado para la adquisición y/o utilización de estrategias de tipo metacognitivo y, al mismo tiempo, podemos plantearnos la posibilidad de evaluar (de emitir un diagnóstico acerca de) la aplicación que el sujeto ha hecho de este tipo de estrategias basándonos en los resultados de las decisiones que el sujeto ha tomado, es decir, en los propios datos que tomamos del texto.

No obstante, dado que los textos resultantes del proceso de traducir no son suficientes en sí mismos para hacer explícita la utilización de estrategias de tipo metacognitivo, nuestra valoración de la utilización de este tipo de estrategias se lleva a cabo mediante un constructo pedagógico desarrollado a tal efecto, basado en los criterios lingüísticos y textuales más relevantes que hemos descrito en el capítulo anterior, y que introduciremos más adelante. Ese constructo constituye nuestro instrumento de valoración (assessment) de las estrategias utilizadas por los aprendices, si bien podemos utilizar otros constructos diferentes, cuyas características dependerán de nuestra concepción subyacente sobre el lenguaje. En última instancia, nos interesa constatar que el constructo sea válido para poner de manifiesto la utilización de estrategias metacognitivas al realizar la tarea de traducción para que podamos establecer si las tareas de traducción constituyen un método útil para facilitar el aprendizaje de conocimientos actitudinales o, por el contrario, si carecen de validez teórica (y práctica) para lograr este objetivo.

Para tratar los aspectos más relevantes en relación con la evaluación en los dos sentidos apuntados más atrás, comenzaremos en la sección siguiente por 
establecer con mayor precisión las cuestiones más estrechamente relacionadas con la situación didáctica, para pasar a continuación a definir los diferentes tipos de evaluación de acuerdo con la tipología clásica utilizada por la didáctica general. Una vez hecho esto, dedicaremos la tercera sección del capítulo a delimitar los aspectos más relevantes que afectan a las tareas de traducción cuando son utilizadas en la evaluación formativa y como instrumento de autoevaluación. Para finalizar, presentaremos un constructo pedagógico que ha sido utilizado de forma práctica, con el fin de mostrar un ejemplo de cómo podemos llevar a cabo tareas de traducción con finalidad formativa en el ámbito de la didáctica del Inglés para Fines Específicos, así como en otros ámbitos de la didáctica especial de lenguas extranjeras.

\subsection{Qué enseñar, qué aprender, qué evaluar}

Por lo que concierne a nuestro enfoque didáctico del proyecto de enseñanza-aprendizaje de Inglés para Fines Específicos, el modelo de lenguaje de Halliday que presentamos en el Capítulo 4 nos resulta conveniente, ya que se centra en el contexto social de la comunicación, interpretando ésta como un tipo de comportamiento social. Desde esta perspectiva sobre la comunicación y los factores involucrados en ella, nuestro objetivo actitudinal, enseñar a actuar como los profesionales, puede ser interpretado como un objetivo didáctico destinado a lograr que el aprendiz se comunique en contextos especializados, adquieriendo o desarrollando estrategias de comportamiento social que se asocian típicamente con una comunidad profesional determinada.

Este objetivo a largo plazo será, a su vez, especificado en un curso de Inglés para Fines Específicos mediante el establecimiento de objetivos a corto plazo más específicos, tales como ser capaz de comprender qué implica la utilización de un determinado sistema de transacción comercial internacional (lo cual incluye, entre otras cosas, adquirir o utilizar un esquema determinado de los procesos implicados en este tipo de transacciones, así como el repertorio disponible de sistemas posibles de transacción), o bien ser capaz de presentar los resultados de una investigación realizada en un laboratorio ante una audiencia internacional en un congreso (lo cual incluye, entre otras cosas, adquirir o utilizar un esquema determinado de los procesos implicados en este tipo de eventos, así como del 
repertorio disponible de los sistemas posibles de difusión de los resultados de una investigación experimental).

Por otra parte, debemos tener asimismo en cuenta algunos aspectos relacionados con lo que entendemos por éxito en la enseñanza y el aprendizaje en este contexto de situación didáctica particular. En primer lugar, ya hemos aludido a la situación general de enseñanza y aprendizaje del Inglés para Fines Específicos en la universidad española actual. Una de las características de los estudiantes de carreras de áreas ajenas al campo de las humanidades es que un gran número de ellos no han experimentado lo que Sevilla (1996) define como el 'din in the head'. Es decir, no han experimentado la sensación de comunicarse en lengua inglesa de modo automático. En muchas ocasiones, incluso podemos afirmar que estos estudiantes nunca han tenido delante la oportunidad de comunicarse en inglés en situaciones reales, fuera del entorno del aula.

Si bien es evidente que esta situación está experimentando grandes cambios en la última década (en buena medida gracias a los esfuerzos de integración de la universidad española en el Espacio Europeo de Educación Superior, fundamentalmente a partir de la Declaración de Bolonia de 1999), hay que señalar que la aspiración de estos estudiantes al matricularse en cursos de Inglés para Fines Específicos no es por lo general la de alcanzar un nivel de conocimientos lingüísticos equivalente al de los profesionales de su campo de especialización pertenecientes a un país anglófono, es decir, el nivel de los hablantes nativos de su campo de especialización. Sus expectativas de aprendizaje suelen apuntar más bien a alcanzar un grado de competencia lingüística suficiente para desenvolverse en situaciones profesionales de tipo cotidiano con otros especialistas de otros países, no necesariamente nativos de países anglófonos. Una de las dificultades asociadas a este tipo de cursos estriba, precisamente, en definir cuál es el nivel que se desea alcanzar con el aprendizaje, de tal modo que los objetivos (objectives) puedan ser establecidos de acuerdo con las necesidades educacionales de cada curso pero también teniendo en cuenta las metas de los aprendices (aims), de acuerdo con la distinción de Widdowson (1983). No obstante, debemos recordar que únicamente los objetivos del curso son evaluables, mientras que las metas de los aprendices no lo son. En este sentido, otra de estas dificultades con las que nos enfrentamos estriba en elegir los procedimientos de evaluación más adecuados para cada situación particular, tal como señala Cunningham:

Teachers should be able to select the most appropriate assessment tools for making instructional decisions and be able to use the information appropriately. The accomplishment of this goal requires a broad range of 
assessment knowledge and skills, including an understanding of how to match specific assessment techniques with instructional goals. (Cunningham 1998:4)

Por lo que respecta al entorno de la enseñanza y el aprendizaje de lenguas extranjeras en Europa, y con el fin de ilustrar mediante un ejemplo cuál es el desarrollo actual en materia de evaluación de lenguas extranjeras en este entorno, podemos señalar que en los últimos años la asociación europea de evaluadores de lenguas ALTE (Association of Language Testers in Europe) ha elaborado dentro del proyecto BULATS (Business Language Testing Service) unas pruebas de evaluación de la competencia para comunicarse en situaciones profesionales asociadas al mundo de los negocios. Estas pruebas han sido desarrolladas para cuatro de las lenguas oficiales de la Unión Europea (inglés, francés, alemán y español) a partir del enfoque y los niveles marcados por el Marco de Referencia Europeo.

Es obvio que siguiendo un enfoque cuyo objetivo es la competencia comunicativa, el léxico no ocupa en estas pruebas una posición central, mientras que sí lo hacen las estrategias destinadas a lograr y mantener la comunicación, incluyendo las destinadas a comprender las situaciones comunicativas que se pueden asociar típicamente con la cultura donde se desarrollan las situaciones profesionales. Si bien es cierto que las situaciones utilizadas como modelo en los exámenes de BULATS de uso de la lengua en entornos profesionales se asocian típicamente al ámbito comercial y de los negocios, es fácil identificar otros posibles modelos de situación relevantes para los estudiantes universitarios españoles. Por ejemplo, las situaciones comunicativas derivadas de estudiar una parte de la carrera universitaria o de realizar sus prácticas laborales en otro país lingüística y culturalmente diferente son cada vez más relevantes como situación-modelo.

En cualquier caso, las situaciones profesionales que se utilizan como modelo de situación típica en la enseñanza y el aprendizaje de lenguas de especialización deben reflejar los aspectos culturales y pragmáticos que sean relevantes en cada caso, evitando cualquier clase de asepsia cultural. La cuestión es que, si aceptamos que el lenguaje no se produce en el vacío, sino que se trata de un fenómeno esencialmente social, la metodología del curso deberá incluir modelos de situación que recojan suficiente información sobre el contexto relevante para la comunicación. Dicho de otro modo, si consideramos que el contexto de situación no es separable del contexto de cultura, tanto los materiales elegidos para el curso, como los contenidos de éste, deben reflejar la relevancia de ambos tipos de contexto para el aprendizaje de la comunicación efectiva. 
Por otra parte, creemos que dichas situaciones-modelo no tienen por qué estar asociadas necesariamente con un lugar geográfico en particular, ya que actualmente la versatilidad que necesitan alcanzar los aprendices para comunicarse con efectividad en un entorno profesional se basa en que esa comunicación puede producirse en cualquier lugar, con interlocutores de cualquier procedencia geográfica y mediante cualquier medio tecnológico además del contacto directo. En este sentido, las tareas de traducción son útiles para contrastar diferentes modelos del mundo ya que ayudan a que el aprendiz se sitúe en relación con otros modos de pensar, de decir y de hacer. Así, en este contexto de situación didáctica, identificamos un mayor éxito del aprendizaje cuanto mayor sea la versatilidad alcanzada para lograr una comunicación efectiva en el mayor número de situaciones probables de los ámbitos profesionales asociados a ese campo de especialización. Esta noción de éxito del aprendizaje se asocia con una evolución, desde la tradicional identificación del nivel experto con la actuación del hablante nativo, a la definición de este nivel de acuerdo con el éxito del aprendiz en la comunicación desde el punto de vista de la competencia comunicativa adquirida (Gutiérrez Almarza y Beltrán Llavador 1996).

Por lo que se refiere a los materiales contemplados en este enfoque, concedemos una gran importancia al texto al considerarlo el único vehículo de comunicación lingüística. Esto significa que adoptamos una perspectiva abierta sobre el texto que nos permitirá considerar como tal cualquier muestra auténtica de lenguaje en uso. Nos centramos en la perspectiva textual particularmente porque estamos considerando tareas de traducción, manejo de material escrito, utilización de textos en el aula (contexto de situación didáctica) y fuera de ella (contexto de situación profesional), y porque nos interesan especialmente los mecanismos lingüísticos de transmisión de los conocimientos, que sólo pueden ser observados en el texto (y otras unidades prácticas de rango superior) y no en unidades lingüísticas discretas.

Hay que considerar también los aspectos relacionados con el aprendizaje como un macroproceso de tipo cognitivo, puesto que son relevantes en relación con la evaluación que vamos a llevar a cabo para comprobar si se ha producido un aprendizaje, cómo lo ha hecho, o bien si la evaluación puede ser un procedimiento potencialmente útil para suministrar información acerca de algún tipo de proceso cognitivo de los aprendices. En el capítulo anterior nos hemos referido a la transmisión de conocimientos desde un punto de vista cognitivo e individual, pero ahora esta perspectiva cognitiva nos interesa en relación con la evaluación del 
aprendizaje. Cunningham nos describe las diferencias relacionadas con la evaluación entre lo que denomina 'instrucción convencional' (conventional instruction) y que corresponde con el método afirmativo y el método demostrativo, según la clasificación de Rodríguez Espinar (1999), y la enseñanza basada en un enfoque cognitivo sobre el aprendizaje:

Conventional instruction is usually based on the principles of direct instruction which is teacher centered and utilizes whole class instruction. In a classroom where these techniques are used, the teacher begins with a clear idea about what students need to learn. These goals are achieved through the use of carefully written and sequenced instructional objectives. Student responses are expected to be convergent: that is, the teacher specifies in advance which answers are to be considered correct. [...]

In recent years, cognitive/constructivist approaches to instruction have risen to prominence. They are based on the belief that learning takes place most readily when students construct meaning from their environment. The mastery of a set of properly sequenced discrete skills is replaced by an emphasis on problem solving, synthesis, and application.

Cognitive/constructionist approaches can be thought of as being indirect and they tend to be more student-centered than teacher-centered. Within this system, useful learning opportunities can occur that are outside of the original intentions of the teacher. Student involvement and participation in the direction of instruction is encouraged. Students are expected to generate creative answers and are rewarded when they respond differently from other students. (Cunningham 1998:61)

El enfoque cognitivo o constructivista, de acuerdo con la descripción de Cunningham, no sólo es consistente con las características de nuestro enfoque sobre la didáctica del Inglés para Fines Específicos que hemos ido describiendo en este trabajo, en el que queremos valorar la finalidad didáctica de la traducción, sino que implica un tipo de metodología compatible con la utilización de tareas de traducción como actividades de aprendizaje. Como ya hemos señalado, la funcionalidad didáctica está siendo estudiada específicamente desde la consideración de un caso particular de evaluación formativa y de autoevaluación en el que la traducción es utilizada como una herramienta de aprendizaje y como una herramienta de evaluación al mismo tiempo, tal como describiremos a lo largo de este capítulo. En cualquier caso, el hecho de adoptar un enfoque cognitivo o constructivista tiene ciertas repercusiones sobre el tipo de objetivos didácticos que se establecerán y el tipo de instrucción que se llevará a cabo en el curso, tal como señala Cunningham ${ }^{1}$ :

\footnotetext{
${ }^{1}$ El propio Cunningham (1998:46) señala que este enfoque tiende a subestimar la importancia de establecer, en la programación del curso, una secuencia óptima de destrezas básicas, ya que el énfasis recae sobre la construcción holística del significado y las destrezas intelectuales de orden superior.
} 
Instructional planning in the presence of cognitive/constructionist approaches to instruction are not as obvious as those associated with the more highly structured direct instruction methods. Instructional objectives may still be identified, but they tend to be broader and to have a focus on the mastery of higher level functioning skills. These approaches are compatible with alternative assessment techniques that require the students to construct responses using their knowledge. The alignment of assessment with instruction is not a priority and may not even be considered desirable. Assessment is not given a high priority and therefore assessment planning is not an important aspect of cognitive/constructivist instructional systems. (Cunningham 1998:61)

El objetivo general que hemos establecido para nuestro proyecto de enseñanza-aprendizaje de Inglés para Fines Específicos, como ya hemos indicado, consiste en lograr que el aprendiz actúe de modo crítico, ejerciendo un control consciente sobre su actuación al comprender, traducir y producir textos especializados que se pueden asociar típicamente con su futuro campo profesional.

En cuanto al contexto de situación didáctica, la didáctica especial de las lenguas extranjeras debe tratar los problemas derivados del hecho de que el estado de conocimientos especializados del aprendiz no es similar al del profesional, lo cual debe ser tenido en cuenta aun sin olvidar que autores como James (1984) destacan la irrelevancia de los contenidos especializados en los cursos de Inglés para Fines Específicos precisamente porque la terminología no plantea problemas de adquisición. Esta cuestión es pertinente aquí ya que tiene, como mínimo, repercusiones sobre la elección de los textos y el material documental que se utilizarán en el curso. Sager, por su parte, hace una aportación diferente al defender la utilidad de la enseñanza de la terminología a los profesionales de cada campo de especialización, con el propósito de que los nuevos términos se acuñen de forma adecuada:

\footnotetext{
Se deberían enseñar a los científicos e ingenieros, así como a los traductores técnicos, unos principios sólidos de denominación de conceptos nuevos porque es probable que ellos estén relacionados más inmediatamente con la formación de términos que los terminólogos. (Sager 1990:293)
}

En cualquier caso, la utilidad de incluir en un curso de Inglés para Fines Específicos contenidos específicamente relacionados con la terminología y la formación de términos debe ser considerada no sólo en relación con los objetivos educacionales planteados o con los contenidos básicos del curso, sino también a la vista del estatus de la lengua inglesa en el mundo de la ciencia y de la tecnología, que Sager describe así: 
La evolución de la ciencia y la tecnología se realiza a un ritmo cada vez más rápido y afecta a más países y lenguas que nunca. En consecuencia, somos testigos del fenómeno doble de una expansión más amplia del inglés, como medio dominante en la comunicación científica y tecnológica, y el desarrollo paralelo de las terminologías en otras lenguas, de manera que en algunas materias existe una extensa cohabitación de terminología en inglés y otra lengua. Al mismo tiempo, hay una incertidumbre continua y creciente sobre la terminología en lengua inglesa desarrollada en zonas diferentes del mundo de habla inglesa que conduce a unas terminologías en inglés que rivalizan y a veces entran en conflicto. También se da el hecho de terminologías en lengua inglesa que entran en conflicto y rivalizan en inglés como lengua internacional. Cuando, por ejemplo, una innovación japonesa se da a conocer fuera de Japón en inglés paralelamente a una francesa o alemana en el mismo campo, que también se difunde en inglés al mundo en general. (Sager 1990:297)

En última instancia, y sin entrar a argumentar si la formación en terminología es prioritaria o no, desde nuestro enfoque interpretamos las palabras de Sager como un síntoma claro de que la uniformidad de las lenguas de especialización descrita por muchos lingüistas y deseada por los terminólogos es tan sólo aparente y, en consecuencia, en un proyecto de enseñanza y aprendizaje del Inglés para Fines Específicos no debiera nunca darse por sentada.

La cuestión global que estamos considerando en este apartado (qué enseñar, qué aprender, qué evaluar) adopta en nuestro enfoque unas características que, al menos en parte, pueden derivarse de lo que sucede cuando la comunicación se basa en el procesamiento del lenguaje escrito, incluyendo los aspectos que afectan al comportamiento estratégico de los lectores. En este contexto, Fernández Toledo (2000) ha indagado sobre el papel que tienen los diferentes tipos de conocimiento en el entorno universitario español (en concreto, en el campo de los estudios de Biblioteconomía y Documentación) en relación con el aprendizaje de inglés como lengua extranjera. Sus conclusiones, además de redundar en la hipótesis de la existencia de un nivel umbral, apuntan hacia la conveniencia de que los aprendices adquieran conciencia sobre las convenciones genéricas culturales asociadas a todo texto, y de que aumenten su nivel lingüístico general de la segunda lengua con el fin de mejorar su comprensión de lectura. Para nosotros, la competencia discursiva y la competencia lectora son dos aspectos involucrados igualmente en la interacción textual pero que presentan diferente potencial desde el punto de vista de la evaluación, por lo que nos parece pertinente detenernos momentáneamente en esta distinción.

La evaluación del aprendizaje lingüístico mediante textos se asocia habitualmente con actividades de evaluación de la comprensión lectora. Pero lo que nos interesa más desde nuestro enfoque no es exactamente la comprensión de la 
información textual, sino más bien una toma de conciencia por parte del aprendiz de cómo funciona el lenguaje en la comunicación para expresar significado y, específicamente, de qué hacemos los usuarios de la lengua inglesa y de la lengua española para comprender lo que sucede, desde el punto de vista de la comunicación, en las situaciones profesionales relevantes en cada caso. Es fácil comprender que, para lograr que el aprendiz adquiera conciencia de los procesos involucrados en la comunicación eficaz en entornos profesionales y desarrolle y/o utilice estrategias encaminadas a permitirle comunicarse con éxito, nuestro interés general no se centrará en unidades lingüísticas discretas (como por ejemplo los términos), ni tampoco en las reglas gramaticales que son relevantes en cada una de esas dos lenguas, sino más bien en el lenguaje como un instrumento integrado del que los aprendices disponen para comunicarse.

Así, en un sentido general, podemos decir que los objetivos didácticos del curso tendrán en común el propósito subyacente de que, con su consecución, los aprendices serán capaces de utilizar con mayor control la herramienta de comunicación de que disponen.

Además de un enfoque sobre el lenguaje que podamos calificar como 'abierto', también nos interesa lograr que el aprendiz adquiera una perspectiva analítica sobre el lenguaje, con el fin de que sea capaz de desarrollar una actitud crítica sobre su propia actuación y la de otras personas, por lo que el objetivo primordial de las tareas que se realizarán con textos no es que los aprendices comprendan la información textual con la mayor exhaustividad posible, sino más bien que logren analizar el discurso y su propia actuación como usuarios del lenguaje de un modo crítico y, en última instancia, que logren ser capaces de utilizar el lenguaje como lo hacen los profesionales de su campo de especialización.

Ya hemos señalado anteriormente la importancia de la función comunicativa predominante en el texto desde la perspectiva didáctica de Nord sobre la traducción y el análisis textual. En relación con el establecimiento de la relevancia de lo que vamos a enseñar, y específicamente relacionada con la cuestión de cómo abordar las tareas de traducción desde el punto de vista de su funcionalidad didáctica, vamos a utilizar una distinción establecida por Brown y Yule (1983) en relación con la funcionalidad del discurso desde una perspectiva general.

Brown y Yule diferencian dos funciones primordiales del discurso, una función de trasvase de información y una función de interacción entre los participantes en la comunicación. Estos autores señalan que lo habitual es que ambas funciones participen al mismo tiempo en el discurso. No obstante, les resulta 
de utilidad desde una perspectiva analítica diferenciar entre ambas funciones del siguiente modo:

\begin{abstract}
The analysis of discourse is, necessarily, the analysis of language in use. As such, it cannot be restricted to the description of linguistic forms independent of the purposes or functions which those forms are designed to serve in human affairs. While some linguists may concentrate on determining the formal properties of a language, the discourse analyst is committed to an investigation of what that language is used for. While the formal approach has a long tradition, manifested in innumerable volumes of grammar, the functional approach is less well documented. Attempts to provide even a general set of labels for the principal functions of language have resulted in vague, and often confusing, terminology. We will adopt only two terms to describe the major functions of language and emphasise that this division is an analytic convenience. It would be unlikely that, on any occasion, a natural language utterance would be used to fulfil only one function, to the total exclusion of the other. That function which language serves in the expression of 'content' we will describe as transactional, and that function involved in expressing social relations and personal attitudes we will describe as interactional. Our distinction, 'transactional / interactional', stands in general correspondence to the functional dichotomies -'representative / expressive', found in Bühler (1934), 'referential / emotive' (Jakobson, 1960), 'ideational / interpersonal' (Halliday 1970b) and 'descriptive / social-expressive' (Lyons, 1977). (Brown y Yule 1983:1)
\end{abstract}

Nuestra experiencia personal con el desarrollo de cursos en los que se ha seguido un enfoque como el que describimos en el presente trabajo nos sugiere que podemos esperar razonablemente que los aprendices se fijen fundamentalmente en la función de trasvase de información cuando comiencen a trabajar con los textos en el aula. No obstante, desde una perspectiva didáctica, si hemos de dar mayor énfasis a una de las dos funciones identificadas por Brown y Yule en relación con los objetivos didácticos del curso, nos resulta más pertinente la función discursiva de interacción entre los participantes, puesto que es la menos evidente para los aprendices. Por consiguiente, creemos que las tareas de comprensión textual que consisten en reformular o trasvasar la información textual no tienen tanto interés como las tareas de traducción, en cuanto que al traducir el aprendiz se debe situar, entre otras, en la posición de un autor que escribe a unos lectores prospectivos y compararse a su vez con el autor del TO. Por tanto, para poder trasvasar la información del TO con eficacia, debe asumir e intentar definir su distancia personal con otros participantes en una situación comunicativa compleja. Para llevar a cabo la tarea de traducción de forma eficaz debe, en consecuencia, tomar conciencia de la propia situación comunicativa (awareness), incluyendo todos los aspectos textuales (contextuales y co-textuales, intratextuales y extratextuales, macrotextuales y microtextuales) que le resulten relevantes para tomar las decisiones que la 
producción del TT le exige. Las tareas de comprensión lectora no suelen ser tan exigentes, por lo general, en el entorno de la didáctica del Inglés para Fines Específicos.

Desde el punto de vista del bagaje de conocimientos del aprendiz, tan relevante en la interacción textual, un texto puede presentar problemas de comprensión para el lector real que, en el caso de que el objetivo de la lectura sea la traducción del texto, potencialmente suponen una fuente de problemas de traducción (Elorza 2000; 2003b). Esto es debido a que el texto, como ejemplo de uso estratégico y selectivo del lenguaje, plantea unas exigencias determinadas acerca de los conocimientos previos necesarios para ser comprendido. Pero el mismo problema puede ser valorado de manera diferente por el aprendiz cuando éste actúa como lector y cuando actúa como traductor, ya que el problema detectado únicamente es relevante en relación con la tarea en curso, por lo que en unos casos puede no constituir siquiera un problema en absoluto. En general, un problema de traducción debe ser resuelto de un modo u otro para poder producir el TT, pero un problema de comprensión puede ser pasado por alto si no contribuye de forma significativa al nivel de comprensión requerido por la tarea. En este sentido, el enfoque centrado en el texto como vehículo de transmisión de conocimientos, de trasvase de información, está inscrito en un enfoque más amplio, en el que es tan relevante qué dice el texto como los medios de expresión que el autor utiliza de acuerdo con la situación comunicativa y sus objetivos al comunicarse, aunando las funciones de trasvase con las de interacción entre los participantes.

Por otra parte, en la evaluación de las tareas de comprensión de lectura se suele utilizar un criterio de certeza, mediante el cual se valora la información suministrada por el aprendiz (respondiendo preguntas sobre la información textual, o resumiendo el contenido del texto, por ejemplo) en cuanto a si es cierto o falso que eso es lo que dice el texto. Está actualmente aceptado que al acceder a la información textual mediante la lectura, procesamos información que proviene tanto del texto como de nuestro bagaje de conocimientos. Así, en el procesamiento cognitivo de la información textual interviene la formación de un modelo mental ad hoc, que en realidad contiene una cantidad indeterminada de elementos que no pueden ser localizados en el texto (como podemos comprobar experimentalmente si pedimos a varios sujetos que resuman una historia tiempo después de haberla escuchado), si bien pueden estar asociados a la información textual de un modo u otro (mediante implicaturas, por ejemplo). Podemos entonces esperar razonablemente que, si la interpretación de la lectura no se basa en la información 
textual como único almacén de datos, a partir del cual elaborar el modelo mental de representación de lo que dice el texto (al igual que sucede con otros tipos de comprensión), no podremos comprobar la comprensión únicamente mediante tareas en las que se pide al aprendiz que reformule, o recuerde, o reconstruya de algún modo la información textual, a menos que utilicemos un criterio más complejo que el de certeza. Por ejemplo, Alonso (1995) ha desarrollado un criterio objetivo de evaluación de resúmenes de acuerdo con el criterio de coherencia textual basado principalmente en la topicalización, y que resulta ser mucho más potente y sensible que el criterio de certeza, si bien cabe plantearse hasta qué punto al evaluar la elaboración de resúmenes (u otros tipos de tarea compleja) no se está evaluando algo más que la mera comprensión, como veremos más adelante.

Por su parte, la evaluación de las traducciones no suele llevarse a cabo mediante el criterio de certeza únicamente (aunque también podemos utilizarlo). Entran en juego aspectos tan sumamente variados que, independientemente de la concepción de la traducción que se esté utilizando, es poco frecuente que la certeza sea el criterio principal mediante el que se evalúa el TT al contrastarlo con el TO.

Cuando relacionamos la evaluación con el aprendizaje, se utilizan de modo distinto los textos al realizar actividades de comprensión y al traducir. En el primer caso, cuando utilizamos actividades de comprensión textual para la evaluación, lo que solemos evaluar es la capacidad de comprensión que el aprendiz ha desarrollado. Por el contrario, cuando utilizamos actividades de traducción para la evaluación, se suele evaluar (negativamente por lo general) el TT en comparación con el TO, lo cual se suele asociar mucho más fácilmente con el resultado (más o menos feliz) de una actuación concreta que con un aprendizaje.

Lo que sucede al evaluar un producto tan complejo como el TT es que no resulta tan evidente qué estamos evaluando exactamente en relación con el proceso de enseñanza-aprendizaje. Puede que ésta sea una de las razones que contribuyen a la falta de unanimidad a la hora de utilizar este tipo de tareas en el aula de Inglés para Fines Específicos. No obstante, ésta es una pregunta crucial para nosotros, ya que partimos de la base de que la evaluación solamente tiene razón de ser en relación con la enseñanza y el aprendizaje que se están llevando a cabo. ¿Qué capacidades del aprendiz podemos evaluar entonces cuando utilizamos la traducción como evaluación? En las siguientes secciones intentaremos dar respuesta a esta cuestión desde la perspectiva teórica de la evaluación desarrollada por la didáctica general. Para ello, comenzaremos por situar la cuestión en una dimensión más general que la que hemos seguido hasta este momento. 


\subsubsection{Taxonomía de objetivos de la educación: ámbito del conocimiento}

Desde la perspectiva de la didáctica general, la evaluación se define como el «conjunto de procesos sistemáticos de recogida, análisis e interpretación de información válida y fiable, que en comparación con una referencia nos permita llegar a una decisión optimizante» (Herrera García y Rodríguez Conde 2001). De acuerdo con este concepto general de evaluación, hay varios aspectos diferenciados que se pueden establecer y describir para cada proceso específico de evaluación, tales como los criterios que se van a emplear para evaluar o las decisiones que se van a tomar tras obtener los resultados de la evaluación, y que podemos ver a continuación de forma esquemática:

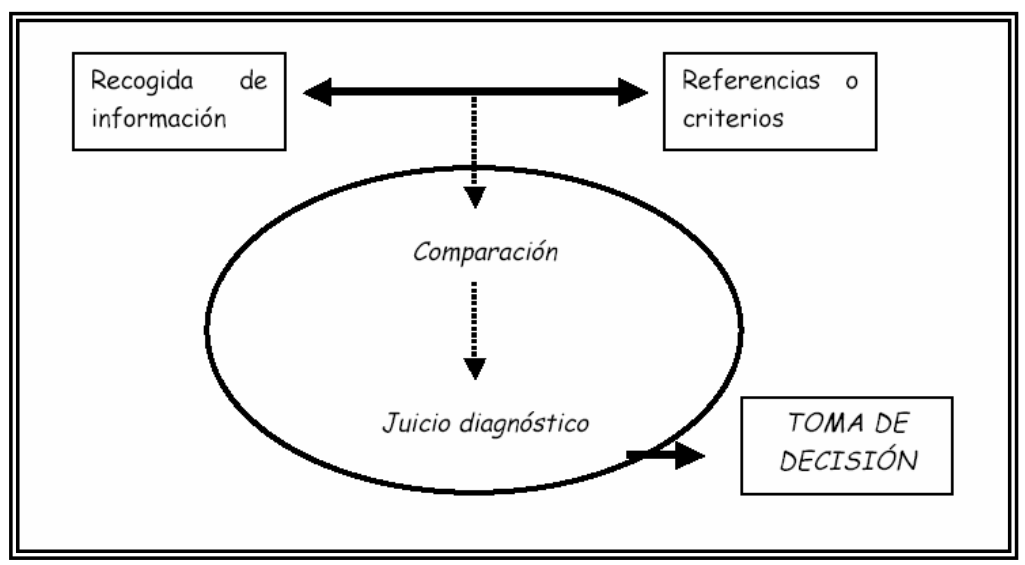

Figura 4. Aspectos involucrados en el concepto de evaluación (Herrera García y Rodríguez Conde 2001)

Las referencias o criterios aglutinan tanto los objetivos de la evaluación, es decir, lo que queremos evaluar, como los propios criterios que se emplean en la evaluación. Estos objetivos se suelen establecer de acuerdo con una clasificación que recoge todo tipo de contenidos: declarativos o conceptuales (se evalúa el saber), procedimentales (se evalúa el saber hacer) y actitudinales (se evalúa el valorar y el saber estar).

Por lo que concierne a este trabajo, hemos situado nuestro foco de atención sobre los objetivos relacionados con aquellos contenidos cuyo aprendizaje permitirá al alumno llegar a ser un buen profesional de su campo de especialización mediante el desarrollo de su capacidad para comunicarse en su entorno profesional con éxito. 
Es por esto que nuestros objetivos, tanto de la enseñanza como de la evaluación del aprendizaje, se relacionan de modo general con el aprendizaje de aquellos conocimientos que le permitan al alumno, en última instancia, aprender a actuar como el profesional de su campo de especialización. Por consiguiente, dado que el énfasis recae en saber hacer desde una perspectiva comunicativa, nos interesan los contenidos de tipo procedimental implicados en la comunicación, especialmente aquellos identificados con la competencia estratégica. Por otra parte, dado que el nivel experto se identifica asimismo con el desarrollo por parte del aprendiz de unas actitudes científicas y profesionales (Blanco Prieto 1996), nos interesan también los contenidos de tipo actitudinal.

Además, ambos tipos de conocimientos parecen ser deficitarios en el sistema educativo universitario español, si nos atenemos a las palabras de Blanco Prieto (1996:56) cuando afirma que la mayoría de los estudiantes universitarios de último año de carrera o ya licenciados declaran que no han recibido formación en contenidos procedimentales ni actitudinales a lo largo de sus estudios. Por consiguiente, pensamos que estos dos tipos de contenidos tienen mayor relevancia para la investigación educativa que los de tipo declarativo, a la vista del entorno educativo específico que hemos elegido para tratar la enseñanza y el aprendizaje del Inglés para Fines Específicos. En estas condiciones, en el presente capítulo vamos a valorar la utilización de tareas de traducción en relación con la consecución y evaluación de los objetivos más estrechamente relacionados con ambos tipos de contenidos, si bien nuestra atención se centrará especialmente en los objetivos de tipo actitudinal, por la necesidad de imponer límites a este estudio.

Para poder establecer convenientemente qué objetivos de la evaluación pueden ser más relevantes para valorar la utilización de tareas de traducción en un entorno del Inglés para Fines Específicos como el que hemos descrito en este trabajo, creemos necesario detallar primero con mayor detenimiento cuáles son los posibles objetivos de la educación desde la perspectiva de la didáctica general, para lo cual nos valdremos de la taxonomía de objetivos de la educación desarrollada por Bloom y sus colaboradores, conocida habitualmente como la Taxonomía de Bloom.

Esta taxonomía consiste en una clasificación del dominio cognitivo, que se presenta jerarquizado en diferentes categorías que representan el comportamiento que los aprendices pueden llevar a cabo como consecuencia de la instrucción. En ella, se identifican y describen los objetivos de dos ámbitos interrelacionados y complementarios en el aprendizaje, que son, respectivamente, el ámbito del conocimiento y el ámbito de la afectividad. La Taxonomía de Bloom es considerada 
útil para «determinar el nivel de concreción específica que han de poseer los objetivos al planificar las experiencias de aprendizaje y al aconsejar los procedimientos más convenientes para la evaluación» (Bloom et al. 1956:58). Por consiguiente, nos proporciona el marco de referencia adecuado para poder considerar la utilidad de las tareas de traducción como método de evaluación del aprendizaje.

Las categorías correspondientes al ámbito del conocimiento se resumen en la siguiente tabla:

\begin{tabular}{|c|c|}
\hline Conocimiento & $\begin{array}{l}\text { Recuerdo de conceptos específicos y } \\
\text { universales, de los métodos y procesos, o de } \\
\text { normas, estructuras o situaciones. }\end{array}$ \\
\hline Comprensión & Interpretación de datos o de ideas. \\
\hline Aplicación & $\begin{array}{l}\text { Transferencia del aprendizaje a situaciones } \\
\text { inéditas. }\end{array}$ \\
\hline Análisis & $\begin{array}{l}\text { Profundizar en los elementos, relaciones y } \\
\text { estructura de un determinado contenido. }\end{array}$ \\
\hline Síntesis & $\begin{array}{l}\text { Producción de un nuevo contenido a partir de } \\
\text { unos elementos dados. }\end{array}$ \\
\hline
\end{tabular}

Tabla 10. Taxonomía de los Objetivos de la Educación: ámbito del conocimiento (adaptada de Bloom et al. 1956)

El principio que sigue la organización de la taxonomía, en orden de complejidad ascendente, se basa en que «un acto simple y específico puede relacionarse con otros también simples para elaborar una conducta más compleja» (Bloom et al. 1956:30). De este modo, la taxonomía se relaciona con una cierta jerarquía de dificultades, de tal modo que podemos elaborar expectativas acerca de la resolución de problemas asociados con un tipo u otro de conocimientos, del tipo señalado por Bloom y sus colaboradores:

Los problemas que exigen el conocimiento de datos específicos se solventan generalmente mejor y con más frecuencia que los que exigen un conocimiento de conceptos universales y abstractos en una materia determinada. Los problemas que requieren el conocimiento de ciertos principios y conceptos se solucionan correctamente con más frecuencia que aquellos otros en que es necesario el conocimiento simultáneo de los conceptos y de ciertas aptitudes para aplicarlo a nuevas situaciones. Los problemas que exigen el doble proceso de análisis y de síntesis son más difíciles que los que exigen la comprensión. Si se analizan los resultados obtenidos por un individuo en un 
test integrado por cuestiones taxonómicas sencillas, se comprobará que son más elevados que los logrados en otro de cuestiones más complejas. (Bloom et al. 1956:30-31)

\subsubsection{Conocimiento}

Esta primera categoría se refiere específicamente al conocimiento en cuanto al recuerdo de conceptos. Debemos señalar que Bloom y sus colaboradores interpretan la actividad de recordar, desde el punto de vista de la evaluación, como «poner a disposición de la mente los materiales apropiados» (Bloom et al. 1956:226). En este objetivo se distinguen tres bloques de acuerdo con los diferentes tipos de conocimientos que podemos memorizar, y que recogemos a continuación de forma muy resumida.

El primer bloque de esta categoría se refiere al conocimiento de lo específico, entendido como la información mínima con la que se elaboran otras manifestaciones del conocimiento de mayor abstracción y complejidad. En este bloque se distinguen las siguientes categorías:

- El conocimiento de la terminología, que se refiere al conocimiento de símbolos específicos, tanto verbales como no verbales

- El conocimiento de hechos específicos, tales como fechas, lugares, acontecimientos, individuos, etc.

El segundo bloque se centra en el conocimiento de los métodos de estudio de los hechos específicos, que incluye los métodos para la estructuración, análisis, evaluación y crítica de los hechos. Según Bloom y sus colaboradores, este tipo de conocimiento se encuentra «en un nivel intermedio de abstracción entre el conocimiento específico, por un lado, y el conocimiento de los conceptos universales, por otro» (Bloom et al. 1956:227).

En este segundo grupo encontramos cinco categorías diferentes:

- El conocimiento de los convencionalismos, que se refiere al conocimiento de las formas típicas de tratamiento y presentación de ideas y fenómenos. Para Bloom y sus colaboradores, la caracterización de este tipo de conocimiento se basa en su función social:

Desde el punto de vista de la comunicación y de la precisión, los especializados en una materia se sirven de costumbres, estilos, prácticas y otros recursos que mejor convengan a sus fines y que mejor encajen con los fenómenos sometidos a su estudio. Ha de tenerse en cuenta que, aun cuando estas expresiones y convencionalismos se hallan cimentados en bases arbitrarias, incidentales o autoritarias, cumplen un cometido de gran utilidad 
por estar corroboradas por la aceptación general de los especializados en la materia, fenómenos o problema. (Bloom et al. 1956:227-228).

- El conocimiento de las tendencias y secuencias, por lo que respecta a los procesos, directrices y movimiento de los fenómenos en relación con el tiempo.

- El conocimiento de las clasificaciones y categorías, en relación con las que se consideran fundamentales en una materia determinada, o bien para un objetivo, un argumento o un problema en particular.

- El conocimiento de criterios que sirven para «evaluar hechos, principios, opiniones y actitudes» (Bloom et al. 1956:228).

- El conocimiento de la metodología, incluyendo los métodos, las técnicas y los procedimientos que se utilizan típicamente para llevar a cabo una investigación, o bien para tratar una clase de problemas o un tipo de fenómenos.

Por último, el tercer bloque de este tipo de objetivo educacional se refiere al conocimiento de los conceptos universales y abstractos de una materia dada, incluyendo el dominio de los esquemas y normas fundamentales que presiden la estructuración de ciertos fenómenos e ideas y que constituyen los niveles más altos de abstracción y de complejidad. En este bloque se distinguen los siguientes tipos de conocimientos:

- El conocimiento de los principios y generalizaciones, en relación con los conceptos abstractos que sintetizan las observaciones que hacemos de los fenómenos y que aportan una valoración en la explicación, descripción o predicción, al tiempo que sirven para establecer qué actos son adecuados o significativos.

- El conocimiento de las estructuras y teorías, en cuanto al conocimiento «del conjunto de principios y generalizaciones, al propio tiempo que de sus interrelaciones, que nos brindan una panorámica clara, cabal y sistemática de un problema, fenómeno o materia de gran complejidad» (Bloom et al. 1956:229).

Esta primera categoría de objetivos educacionales, en la que encontramos un nivel de diferenciación muy sensible entre unos tipos de conocimientos y otros, es singular con respecto de las demás categorías de la tabla. Ninguna de las demás se refiere a objetivos relacionados con los conocimientos, sino con las aptitudes y capacidades intelectuales, ni presentan caracterizaciones taxonómicas ulteriores tan sensibles como ésta. 
No obstante, dado que las categorías que describiremos a continuación tratan de aptitudes y destrezas, podemos relacionarlas con contenidos de tipo procedimental. En este sentido, las categorías que vienen a continuación nos resultan más interesantes para un enfoque didáctico de tipo constructivista que los objetivos educacionales relacionados con los conocimientos de tipo declarativo o conceptual y la evaluación de éstos.

Por otra parte, ya hemos señalado que los diferentes niveles de la tabla están interrelacionados entre sí de manera jerárquica de tal modo que cada clasificación de la tabla debe comprender las aptitudes y actitudes que se hallan por debajo en el nivel de complejidad (Bloom et al. 1956:135; Krathwohl, Bloom y Masia 1964:159) (o bien por encima según el orden correlativo de la tabla). En este sentido, se puede ver la necesidad de incluir en la planificación del curso objetivos educacionales específicamente destinados a lograr el aprendizaje de léxico, terminología, sintaxis u otros tipos de elementos lingüísticos discretos.

No obstante, en este trabajo no es relevante la cuestión de si el aprendizaje de un conjunto de términos o de otros elementos léxicogramaticales es un objetivo educacional más o menos importante o prioritario que otro tipo de objetivos. Los objetivos educacionales como la adquisición del conocimiento de una lista terminológica, por ejemplo, se relacionan con contenidos de tipo declarativo o conceptual, pero no con contenidos de tipo procedimental ni actitudinal, por lo que las consideraciones acerca de los objetivos y contenidos relacionados con el aprendizaje de elementos léxicogramaticales quedan fuera de este trabajo. Nuestro interés recae más bien en las actitudes y las destrezas de los aprendices.

Desde una perspectiva general, Bloom y sus colaboradores interpretan las aptitudes y destrezas como «ciertas modalidades estructuradas de acción y ciertas técnicas generales para la manipulación de los problemas y materias» (Bloom et al. 1956:230). Si bien reconocen que algunos problemas no precisan de una información técnica ni especializada porque se presupone que la información necesaria ya se encuentra en el fondo general de conocimientos del aprendiz, señalan que otros problemas requieren un mayor nivel de conocimientos y de capacitación para poder ser resueltos, por lo que puede ser indispensable una información técnica y especializada.

En el primer caso, cuando lo que se necesita para resolver un tipo específico de problemas son destrezas o capacidades intelectuales, lo que se trata de evaluar es «la capacidad del examinando para aplicar un método general a la nueva coyuntura problemática que trata de superar» (Bloom et al. 1956:50). Así, en la 
evaluación de una destreza o capacidad intelectual se le concede más importancia a «los procesos mentales de la estructuración y reestructuración de los datos precisos para alcanzar una meta específica» (Bloom et al. 1956:230).

Por contraposición, en el caso de las aptitudes intelectuales, el individuo debe recurrir a datos técnicos y específicos para resolver los problemas, por lo que las aptitudes intelectuales se pueden considerar «una combinación de conocimientos y de destreza y capacidad» (Bloom et al. 1956:50). No obstante, Bloom y sus colaboradores reconocen que, a pesar de la utilidad de esta diferenciación entre aptitud y capacidad intelectual para el análisis de resultados, la extraordinaria dificultad para clasificar los objetivos de la educación como aptitudes o como destrezas hacen que, en la práctica, no hagan uso de esta diferenciación y simplemente la señalen. Es por esto que todas las categorías restantes del ámbito del conocimiento que aparecen en la tabla, y que veremos a continuación, se relacionan de un modo u otro con la estructuración y reestructuración de la información sin diferenciar tajantemente entre aptitudes o capacidades intelectuales.

En última instancia, el establecimiento de objetivos educacionales relacionados con las aptitudes y capacidades intelectuales se basa, entre otros aspectos, «en el análisis de la naturaleza de la sociedad y medio cultural en que vivimos, en los conocimientos que tenemos a nuestra disposición y en el tipo de ciudadanos que se propone desarrollar la escuela» (Bloom et al. 1956:51). Podemos interpretar todos estos aspectos en la situación didáctica que estamos considerando en este trabajo a la vista de las características típicas de la comunidad profesional relevante para el curso de Inglés para Fines Específicos en cada caso particular. No obstante, como base común nos estamos centrando en las estrategias comunicativas en lengua inglesa necesarias para que el futuro profesional logre comunicarse con eficacia en su entorno de trabajo en aquellas situaciones en las que la comunicación se desarrollará en lengua inglesa.

Desde una perspectiva más amplia, estamos de acuerdo con Bloom y sus colaboradores (Bloom et al. 1956:51-52) en que el desarrollo de la capacidad de resolución de problemas (y, por consiguiente, el desarrollo de aptitudes y destrezas intelectuales) es necesario para que el aprendiz sea capaz de integrarse en un entorno sociocultural que sufre constantes e imprevisibles cambios, por lo que es extremadamente importante la enseñanza de procedimientos generales que permitan a los aprendices hacer frente a cualquier tipo de problema así como de conocimientos que sean aplicables a situaciones inéditas. 


\subsubsection{Comprensión}

Esta segunda categoría de la taxonomía, denominada 'comprensión', abarca tres tipos de objetivos:

- La transferencia, que indica que «un individuo puede expresar una comunicación en un lenguaje distinto, en términos diferentes o en otra forma de enunciación» (Bloom et al. 1956:102) ${ }^{2}$. Se identifica con un nivel poco complejo de comprensión relacionado con la integración de distintos elementos informativos: «por lo general, este problema estriba en dar sentido a las distintas partes de una comunicación consideradas aisladamente, aunque sus significados puedan sospecharse, al menos parcialmente, por el contexto en que se presentan dichas ideas» (Bloom et al. 1956:102).

- La interpretación, que representa el siguiente nivel de complejidad en la comprensión, y que Bloom y sus colaboradores describen así:

[La interpretación] consiste en considerar la comunicación como una expresión de ideas para cuya comprensión es necesaria una reestructuración de ellas dentro de la mente del propio interesado. Presupone también este proceso un cálculo de la relativa importancia de dichas ideas, de sus relaciones recíprocas y de su ilación con los conceptos generales comprendidos o definidos en la comunicación primitiva. (Bloom et al. 1956:103)

- La extrapolación, entendida como «las apreciaciones o pronósticos basados en el análisis de las direcciones, tendencias o circunstancias expuestas en la comunicación» (Bloom et al. 1956:103). Se diferencia principalmente de la siguiente categoría de la taxonomía, la aplicación, en que en la extrapolación las apreciaciones o pronósticos se fundamentan en unos datos determinados, mientras que en el caso de la aplicación, éstos se basan «en un proceso de abstracción que, procedente de otras experiencias, llega a aplicarse a la situación estudiada» (Bloom et al. 1956:103), como veremos a continuación.

\subsubsection{Aplicación}

La aplicación constituye la tercera categoría de la taxonomía. A diferencia del resto de niveles que hemos descrito, aquí no se establecen diferentes subclasificaciones, sino que la aplicación se define por contraste con la

\footnotetext{
${ }^{2}$ En otras de las múltiples versiones de la taxonomía, aquí es utilizado el término 'traducción' y no 'transferencia', probablemente para evitar confusiones con la siguiente categoría de la taxonomía, que se refiere más estrechamente a la transferencia del aprendizaje. No obstante, dado que nos estamos basando principalmente en la traducción de Isaías Acarreta para la edición de 1975 de la editorial Marfil, preferimos seguir únicamente la terminología utilizada en dicha edición para evitar posibles incoherencias.
} 
comprensión, es decir, con el nivel inmediatamente anterior en cuanto a complejidad.

Podemos explicar que la clasificación de este nivel no presente subdivisiones más sensibles aduciendo que, al tratar esta categoría, subyace la presuposición de que la aplicación de los métodos, teorías, principios o conceptos abstractos adquiridos previamente no sólo implica la comprensión de éstos, sino también la noción de que el aprendiz será capaz de aplicarlos de forma espontánea en situaciones nuevas:

\begin{abstract}
Para resolver un problema a nivel de la categoría de la comprensión, es absolutamente necesario que el alumno domine una abstracción en un grado suficiente para que pueda demostrar su uso correcto cuando se le invite a ello. Sin embargo, la «aplicación» exige algo más que esto. Tan pronto como al alumno se le plantea un nuevo problema, aplicará la adecuada abstracción sin que se le haya advertido de antemano si es o no correcta y sin habérsele preparado para utilizarla en esa circunstancia específica. Una prueba de la «comprensión» nos demostrará que el alumno podrá servirse de la abstracción cuando llegue a concretarse su uso. Una prueba de la «aplicación» servirá para demostrar que la usará correctamente cuando se enfrente con una situación adecuada en la que no se ha especificado ningún modo de solución. (Bloom et al. 1956:135)
\end{abstract}

Así pues, podemos señalar que la consecución de los objetivos que forman parte de la categoría inmediatamente anterior (es decir, de la comprensión), implica la posibilidad de aplicación de las abstracciones necesarias para comprender situaciones totalmente nuevas de tal modo que, en el nivel de la comprensión, la aplicación es tomada únicamente como un potencial adquirido por el aprendiz. Sin embargo, cuando tratamos la siguiente categoría (es decir, la aplicación), lo que estamos tomando en consideración no es el potencial del aprendiz para aplicar la abstracción de ciertos conocimientos adquiridos a la comprensión de situaciones nuevas, sino el propio uso efectivo de la aplicación de las abstracciones que sean necesarias.

Bloom y sus colaboradores presentan, en la figura que reproducimos a continuación, un esquema de un proceso típico de resolución de problemas de aplicación en seis etapas, en el cual los pasos que se relacionan específicamente con la aplicación son identificados por los autores como los correspondientes a las etapas que van de la primera a la cuarta. Se contempla la opción de seguir dos rutas alternativas en función de la familiaridad del aprendiz con el problema en cuestión, mientras que la comprensión se identifica con un problema que se inicia en la etapa quinta, sin que sean necesarias las demás etapas debido a la estructura del problema. 


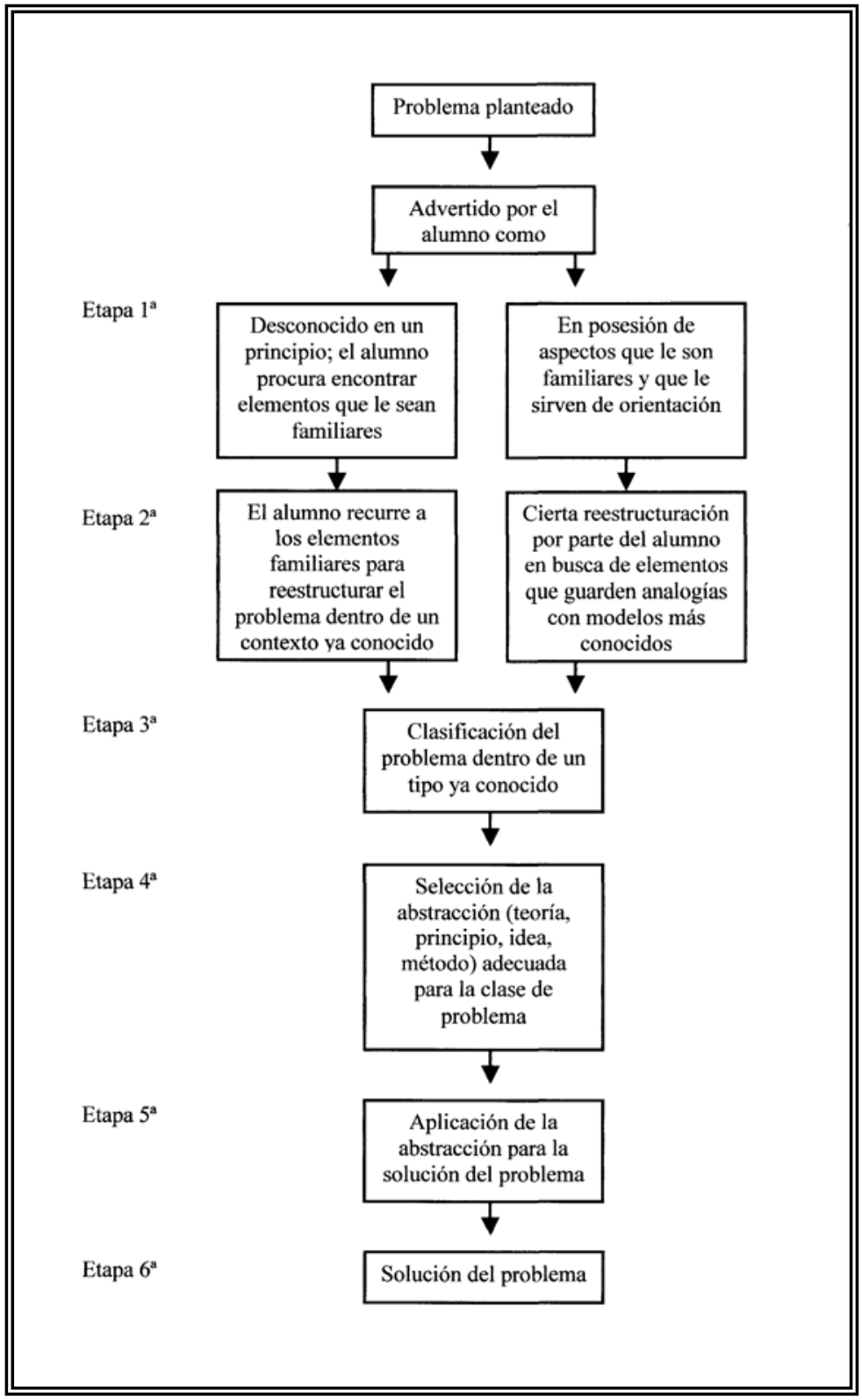

Figura 5. Etapas de un proceso de resolución de problemas de aplicación (Bloom et al. 1956)

La diferencia entre comprender y aplicar conocimientos a situaciones inéditas es crucial en una metodología donde el desarrollo de estrategias de tipo 
procedimental ocupa una posición prominente, como en un enfoque basado en la promoción del aprendizaje autónomo. Bloom y sus colaboradores explican la diferencia entre comprender y aplicar conocimientos en los siguientes términos:

Los trabajos de investigación han demostrado [...] que el hecho de comprender una abstracción no nos garantiza que el individuo sea ya capaz de aplicarla correctamente. Es indudable que al alumno le es necesaria cierta práctica en la reestructuración y clasificación de los problemas para llegar a aplicar la abstracción con cierta garantía.

(Bloom et al. 1956:137)

Desde una perspectiva más estrecha, esta diferencia redunda en que podamos valorar de distinto modo la función didáctica de los textos en tareas de comprensión y su función en tareas de traducción, e incluso que podamos establecer con mayor precisión si una tarea determinada tiene utilidad para evaluar la consecución de un objetivo educacional u otro. Como casos típicos de tareas complejas que requieren la comprensión y la aplicación de conocimientos a situaciones inéditas en el ámbito de la didáctica especial de las lenguas extranjeras, vamos a referirnos a la elaboración de resúmenes y a las actividades de traducción, con el fin de establecer algunas diferencias entre ellas.

En la sección 6.1 hemos mencionado un ejemplo en el que los resúmenes son utilizados como medio de evaluación, si bien debemos precisar que Alonso (1995) trata la elaboración de resúmenes como una actividad de aprendizaje en cursos de Filología Inglesa donde se ha establecido el objetivo educacional de aprender a elaborar resúmenes en lengua inglesa. Por tanto, mediante la elaboración de resúmenes los aprendices no sólo ponen de manifiesto su comprensión del texto, sino también su aptitud para resumir textos en inglés. En este sentido, mostrar el grado de comprensión del texto no es el objetivo primordial de la tarea. No obstante, la elaboración de resúmenes se suele utilizar frecuentemente en los cursos de lengua inglesa con esta única finalidad.

Alonso (1995) señala varias funciones didácticas diferentes para la tarea de elaboración de resúmenes en el entorno de la didáctica de las lenguas extranjeras:

Summary writing is a key exercise in language learning. In second language acquisition, its practice serves various purposes. It is used as a way to test the student's correct understanding of the passage read. It helps as well to develop the student's skills in paraphrasing, an activity which, in a language that is not one's own, demands a broad knowledge of alternative vocabulary and a good control of structures. In addition, the need to reduce the length of the passage and to synthesize its ideas requires a capacity to distinguish the gist from all irrelevant information. (Alonso 1995:151-152) 
Desde el punto de vista de la Taxonomía de Bloom, la elaboración de resúmenes exige una serie de aptitudes y capacidades intelectuales (decidir qué información es relevante y cuál no lo es, por ejemplo) que se relacionan específicamente en los distintos niveles de comprensión (transferencia, interpretación y extrapolación). No obstante, en la comprensión textual intervienen también de forma activa esquemas de conocimientos organizados que el sujeto utiliza para poder procesar la información de modo eficiente. Podemos argüir que, en realidad, en los procesos de comprensión de textos concurren, además la transferencia, interpretación y extrapolación de información, aspectos relativos a la aplicación de abstracciones relacionadas con los esquemas almacenados previamente por los usuarios del lenguaje. Por consiguiente, cuando pedimos a un aprendiz que elabore un resumen, debemos contar con que éste va a aplicar una serie de abstracciones basadas en esquemas de conocimientos almacenados previamente.

No obstante, el modo de aplicación de estas abstracciones al elaborar resúmenes, al traducir y al realizar otras tareas con un nivel de complejidad equiparable no es uniforme, de modo que unos sujetos tienden a atribuir relevancia a unas proposiciones o conceptos que en el texto no recibían tal relevancia y también al contrario, tal como se ha comprobado experimentalmente (De Beaugrande 1980:169 y siguientes). Por esta razón, es necesario enseñar a identificar lo que es relevante y qué importancia relativa tiene en el conjunto de la información textual. En la concepción de resumen utilizada por Alonso (1995), se identifica el resumen con la macroestructura textual, por lo que se excluyen las aportaciones de tipo personal del aprendiz ${ }^{3}$.

Lo que se desprende de esto es que, si utilizamos la elaboración de resúmenes con el objetivo de evaluar únicamente la comprensión de los aprendices, estamos utilizando un tipo de prueba que exige en su realización aptitudes más complejas que las que queremos evaluar. Por esta razón, la elaboración de resúmenes no es un instrumento apropiado cuando sólo se persigue evaluar la comprensión de un mensaje (en el sentido de transferencia, interpretación y extrapolación de información), a pesar de lo extendido de esta práctica en el entorno de la didáctica especial de las lenguas extranjeras. Es necesario contemplar su funcionalidad en cuanto a los niveles más complejos que implica, incluyendo el nivel de síntesis que veremos más adelante.

\footnotetext{
${ }^{3}$ Según comunicación personal (julio de 2004).
} 
Otro tanto puede afirmarse respecto de la utilización de tareas de traducción, y otras con un nivel de complejidad equiparable, para evaluar la comprensión de un texto. No obstante, podemos decir que la evaluación de la comprensión de un texto mediante la traducción suele ser más habitual cuando la traducción es considerada una herramienta didáctica para el aprendizaje y la evaluación de lenguas extranjeras como la descrita por Bühler (1987), y no como una herramienta de mediación intercultural.

Cuando la traducción se considera en este último sentido, las tareas de traducción no suelen ser utilizadas para evaluar de la comprensión. Esto no es de extrañar puesto que la elaboración de una traducción, al igual que la elaboración de un resumen, exige al aprendiz la aplicación de sus conocimientos (métodos, principios, etc.) a una situación que encuentra por primera vez. Una muestra de que en general los profesores son conscientes de lo inédito de la situación a la que se le enfrenta al aprendiz lo constituye el hecho de que, en numerosas ocasiones, cuando se le presenta a un estudiante una tarea de traducción (un encargo de traducción), las instrucciones de la tarea incluyen información extratextual específica referente a la situación comunicativa del TO y a la del TT. El propósito de incluir este tipo de información en las instrucciones de la tarea es el de poner a disposición del aprendiz claves que le lleven a la aplicación de ciertos principios que ha aprendido previamente, relacionados con las decisiones que debe tomar para poder producir un TT que sea adecuado a la situación comunicativa.

En cualquier caso, las tareas de traducción no sólo conllevan la resolución de problemas asociados con la comprensión de situaciones inéditas y la aplicación de las abstracciones necesarias en cada caso, sino que también implican los conocimientos, contenidos y objetivos educacionales asociados a las tres últimas categorías de la Taxonomía de Bloom, que representan aptitudes aún más complejas que las que hemos visto hasta este momento.

\subsubsection{Análisis}

Como siguiente categoría de la tabla, las aptitudes relacionadas con el análisis se encuentran en un grado de complejidad superior a las aptitudes de comprensión y aplicación, que Bloom y sus colaboradores describen así:

En la comprensión se subraya la importancia de la captación de significado y objetivos de la materia dada. En la aplicación se insiste sobre todo en la memorización y la atribución a una materia determinada de unos conceptos o principios generales adecuados. El análisis subraya de modo especial la fragmentación de la materia en sus partes integrantes, la detección de las 
relaciones entre ellas y el estudio de las características de su estructuración. Puede también proponerse como fin el desarrollo de técnicas y procedimientos para la transmisión de su mensaje o la exposición de las conclusiones de una comunicación. (Bloom et al. 1956:163)

El análisis, como ya hemos mencionado en diversas ocasiones a lo largo del capítulo anterior, suele formar parte de la metodología propia de la enseñanza de la traducción, por lo que el desarrollo de aptitudes analíticas suele constituir en muchos cursos de traducción un objetivo didáctico. También suele ser utilizado frecuentemente como una técnica de evaluación del aprendizaje bajo diversos enfoques y denominaciones. En este trabajo consideraremos el análisis en relación con un constructo pedagógico compuesto por dos tipos de herramientas, a las que hemos denominado 'informe de la traducción' y 'repertorio de variaciones entre el TT y el TO’, y del que daremos cuenta más adelante.

Como objetivo de evaluación, el análisis constituye en nuestro proyecto de enseñanza-aprendizaje un medio para evaluar la capacidad del aprendiz para detectar y describir situaciones comunicativas complejas (en cuanto que constituyen casos de mediación intercultural asociados a situaciones profesionales en ambas culturas), de acuerdo con sus constituyentes y sus factores regulativos. Esta capacidad de análisis se identifica en nuestro enfoque con la sensibilidad que el aprendiz necesita para tomar decisiones y actuar en función de las diferentes situaciones en las que se verá envuelto al comunicarse con otras personas en el ejercicio de su profesión. Las aptitudes analíticas constituyen un rasgo personal que se asocia con la capacidad de reacción, así como con la flexibilidad para adaptarse a situaciones nuevas. Tanto la capacidad de reacción como la capacidad de adaptación o flexibilidad suelen recibir una valoración social positiva o muy positiva en muchos entornos profesionales científicos y técnicos por lo que, en última instancia, podemos interpretar el desarrollo de las aptitudes analíticas de los aprendices como una evolución de éstos hacia el nivel experto que caracteriza a los profesionales de un campo de especialización.

Bloom y sus colaboradores establecen la siguiente subclasificación de aptitudes analíticas:

- El análisis de los elementos, considerando que el mensaje está compuesto por un conglomerado de gran número de aspectos, tanto explícitos como implícitos.

- El análisis de las relaciones, considerando las relaciones que se establecen entre los diferentes elementos, así como entre las distintas partes del mensaje. 
- El análisis de las normas de estructuración, que se encuentra en un nivel de complejidad superior a los otros dos tipos anteriores, ya que implica la consideración de las normas estructurales que el autor del mensaje ha aplicado. Bloom y sus colaboradores denominan 'normas estructurales' a «la estructura y organización de un mensaje» (Bloom et al. 1956:166).

No obstante, el constructo pedagógico que hemos desarrollado es más específico para la utilización de textos como herramienta de evaluación, ya que se basa en el criterio de textualidad.

\subsubsection{Síntesis}

En la Taxonomía de Bloom, la síntesis es descrita del siguiente modo:

No es sino un proceso de trabajo con elementos, partes, etc., para coordinarlos de tal suerte que lleguen a formar una estructura global que no hemos estudiado hasta ahora. Para ello, será necesaria una reestructuración de los factores fragmentarios de las experiencias precedentes para combinarlos con las nuevas hasta lograr un conjunto cuya integración sea más o menos perfecta. Se trata, dentro del campo de conocimiento, de la categoría que ofrecerá al lector el mayor número de posibilidades para poner de relieve su capacidad de creación. No obstante, hemos de recordar que no constituye una manifestación creadora sin trabas de ningún género, puesto que, por lo común, el alumno habrá de trabajar dentro de unos límites impuestos por las características de los problemas y materias específicos y, asimismo, por ciertas normas teóricas y metodológicas. (Bloom et al. 1956:184)

En cuanto a las diferencias entre esta categoría y la comprensión, la aplicación y el análisis, en esta taxonomía se explica de qué modo la síntesis constituye un nivel más complejo con respecto de éstos:

También la comprensión, la aplicación y el análisis se fundamentan en la agrupación de elementos y la interpretación del significado, mas todos estos procesos tienden a ser más fragmentarios y mucho menos completos que el de la síntesis. También se insiste en todos ellos mucho menos sobre el carácter de unidad y de originalidad que en la labor de síntesis. Es muy probable que la diferencia más importante entre dichos procesos y el de la síntesis radique en la posibilidad de que en los primeros debe trabajarse con un conjunto determinado de elementos o materias que constituyen por sí solos un todo, mientras que en la síntesis el alumno habrá de laborar con factores procedentes de muy diversos orígenes y encajarlos en una sola estructura casi insospechada hasta ese momento. De sus esfuerzos saldrá algo nuevo que podrá examinarse a través de uno o varios sentidos y que, decididamente, será algo más que los productos que le sirvieron de materia prima. Evidentemente, todo problema cuya tarea fundamental viene expresada por una labor de síntesis exige la presentación, en mayor o menor grado, de todos los demás procesos. (Bloom et al. 1956:184) 
La síntesis se relaciona con la capacidad de construir respuestas mediante la utilización de los propios conocimientos. Por esta razón, los objetivos de síntesis reciben gran atención desde el enfoque constructivista del aprendizaje (Cunningham 1998).

Por otra parte, la síntesis supone un nivel más complejo que el análisis como contenido y como objetivo educacional, puesto que aquí lo relevante no es que el aprendiz haga un repaso sistemático de todos los elementos, relaciones y normas de estructuración susceptibles de ser analizados, sino que, de entre todos los posibles, debe seleccionar y coordinar todos los elementos, relaciones y normas que va a utilizar para tomar las decisiones necesarias para producir el texto de acuerdo con su plan de actuación y el objetivo de la tarea.

Desde la perspectiva de la evaluación del aprendizaje de este tipo de contenidos, esta categoría se relaciona con la recogida de información acerca de lo que los aprendices saben hacer. Así, por lo que respecta a la enseñanza, el aprendizaje y la evaluación del Inglés para Fines Específicos, no nos referimos aquí a lo que los aprendices saben acerca del lenguaje, en cuanto que un sistema compuesto por repertorios de reglas gramaticales y conjuntos de elementos discretos, sino más bien a lo que saben hacer con el lenguaje. Lo que nos interesa saber mediante la evaluación, entonces, es con cuánto éxito son capaces de desenvolverse en ciertas situaciones comunicativas asociadas a su campo de especialización. El éxito en la comunicación implica utilizar con un determinado nivel de precisión las herramientas disponibles, la más inmediata de las cuales es, precisamente, el lenguaje, por lo que la síntesis es interpretada, cuando es utilizada como una herramienta de evaluación en este entorno, como un indicador del uso estratégico que el aprendiz es capaz de hacer de los recursos de la lengua en la comunicación.

La síntesis puede ser descrita con un mayor nivel de precisión. Bloom y sus colaboradores establecen la siguiente subclasificación de tipos de síntesis de acuerdo con el producto final resultante:

- La elaboración de un mensaje único, que sea «capaz de transmitir las ideas, sentimientos o experiencias del escritor o narrador a sus lectores y oyentes», lo cual incluye la «aptitud para redactar a través de una esmerada estructuración de ideas y frases» (Bloom et al. 1956:232). Las tareas de traducción son susceptibles de ser utilizadas para facilitar la consecución de objetivos de síntesis de este tipo. La producción del TT implica la elaboración de un mensaje que, excepto en aquellos casos en los que el efecto del TT es deliberadamente diferente al efecto del TO, busca ser fiel al TO (Nord 1991). 
Por esta razón, podemos considerar que la elaboración del TT, que es único, implica la utilización de la síntesis, de acuerdo con la descripción de Bloom y sus colaboradores:

Al crear su obra, el autor tiene también diversos propósitos, como informar, convencer, impresionar, describir o entretener. En todo caso, siempre aspira a provocar algún efecto (respuesta) en un círculo más o menos extenso de lectores. Para ello, recurre a ciertas modalidades de expresión, con unas formas y convencionalismos peculiares, con objeto de brindar al lector una estructuración de ideas y experiencias. (Bloom et al. 1956:185)

- La elaboración de un plan o una serie programada de actividades, según el cual se satisfagan las exigencias de la tarea propuesta al estudiante.

- La deducción de una serie de relaciones abstractas, de modo que éstas expliquen o clasifiquen ciertos datos o fenómenos específicos, o bien que resulten en ciertas aserciones o relaciones a partir de unas aserciones fundamentales o de unas representaciones simbólicas. Esta subclase incluye como aptitud intelectual la «capacidad para elaborar hipótesis correctas fundamentadas en el análisis de los factores sometidos a estudio, y para modificar dichas hipótesis de acuerdo con los datos aportados por otros nuevos factores o aserciones» (Bloom et al. 1956:233). Las tareas de traducción pueden tener utilidad para facilitar la síntesis de relaciones abstractas asociadas con el campo de especialización donde se sitúa el contexto situacional de los textos utilizados, dado que constituyen una variada fuente de información que es posible obtener a partir de los datos presentes en el texto. Cuando utilizamos los textos con esta finalidad, estamos considerándolos como pertenecientes a un tipo determinado. Lo que nos interesa especialmente en ese caso es la información relacionada con el registro y con el género asociados con la variedad de discurso al que el texto en cuestión pertenece.

El valor educativo de los objetivos de síntesis estriba, según describen estos autores (Bloom et al. 1956:188), en que la práctica de la expresión individual y la independencia de pensamiento y de acción son axiomáticas en una sociedad donde sus ciudadanos deben ser capaces de tomar sus propias decisiones. La aptitud de síntesis tiene ese mismo valor para cualquier proyecto de enseñanza-aprendizaje que aspire a integrarse plenamente en el Espacio Europeo de Educación Superior, estimulando, entre otras capacidades, la de aprender a aprender, así como la de aprender a lo largo de toda la vida, dentro de un enfoque constructivista. 


\subsubsection{Evaluación}

Finalmente, la última categoría de la taxonomía de objetivos educacionales en el ámbito del conocimiento, la evaluación, se define así:

[...] emisión de juicios sobre el valor de ciertas ideas, trabajos, soluciones, métodos, materiales, etcétera, teniendo en cuenta un fin determinado. Comprende la utilización de criterios y de normas para calcular hasta qué punto son exactos, efectivos, económicos o satisfactorios los resultados obtenidos. Dichos juicios pueden ser cuantitativos o cualitativos, y los criterios pueden referirse a los elegidos por el alumno o a los que se le entregan. (Bloom et al. 1956:208)

Aunque la evaluación aparece en el último lugar de la tabla, ya que conlleva en mayor o menor medida el resto de categorías, Bloom y sus colaboradores señalan que esto no implica necesariamente que se trate del último eslabón de la cadena de pensamiento o de la resolución de un problema:

Hay muchos casos en que el proceso de evaluación es el preámbulo para la adquisición de nuevos conocimientos, la expresión de un nuevo esfuerzo por lograr una comprensión o aplicación más correctas o una nueva práctica de los procesos de análisis o de síntesis. (Bloom et al. 1956:209)

De acuerdo con esta perspectiva, la evaluación no está únicamente limitada a la comprobación de la adquisición de conocimientos o aptitudes intelectuales, sino que tiene una amplia variedad de funciones, tal como veremos en la sección siguiente.

Se establecen en este apartado dos subclases de evaluación, de acuerdo con los criterios empleados en cada caso para evaluar:

- La emisión de juicios en función de la evidencia interna. Cuando el objetivo educacional es la emisión de juicios de este tipo, la valoración se elabora a partir de criterios internos del trabajo tales como la precisión o la coherencia.

- La emisión de juicios en función de los criterios externos. Se consideran criterios de tipo externo aquellos que son específicos de la clase a la que pertenece el trabajo que se evalúa. Este tipo de criterios tiene carácter arbitrario, ya que cualquier trabajo puede ser incluido simultáneamente en varias clases diferentes y, por consiguiente, es susceptible de ser evaluado con diferentes criterios.

Si lo que queremos es recoger información acerca de la capacidad de los aprendices para emitir juicios a partir de evidencias internas o externas, y además queremos utilizar las tareas de traducción para hacerlo, será indispensable utilizar un constructo específico que sirva para proporcionarnos tal información. La producción de un texto a partir de otro no constituye en sí misma una herramienta 
suficiente para llevar a cabo este propósito. No obstante, tal como veremos más adelante (v. 6.3.2.1), los cuestionarios y portafolios son instrumentos útiles para la recogida de este tipo de datos.

De acuerdo con la concepción de la traducción que utilizamos en este trabajo podemos afirmar, a la vista de la Taxonomía de Bloom, que las tareas de traducción no sólo están relacionadas con habilidades que tienen que ver con la resolución de problemas comunicativos y textuales, sino que son potencialmente útiles para facilitar la consecución de objetivos relativos a las categorías de comprensión, análisis, síntesis y evaluación, ya que estas categorías intervienen de modo característico en la realización de las tareas de traducción.

Por otra parte, al igual que hay materias que marcan un tipo de contenidos por encima de otros (Herrera García y Rodríguez Conde 2001), podemos decir que hay unos sistemas de recogida de información más adecuados que otros para comprobar el grado de consecución de un objetivo educacional. En este sentido, una tarea de traducción constituye un instrumento de recogida de información más sofisticado que, pongamos por caso, un test de elección múltiple, cuando queremos comprobar las aptitudes de un aprendiz para analizar, sintetizar y evaluar información textual. No obstante, es necesario precisar que, dado que el TT no es suficientemente explícito para ser utilizado como instrumento único de recogida de datos, deberá ser complementado con otro u otros instrumentos de mayor precisión que el propio texto.

De acuerdo con nuestro planteamiento de la enseñanza y el aprendizaje del Inglés para Fines Específicos, el objetivo didáctico general con respecto del cual vamos a sopesar la utilidad de las tareas de traducción ha sido formulado como 'enseñar a actuar como los profesionales'. Ahora bien, para poder establecer las implicaciones de este objetivo para la planificación del curso, debemos a su vez establecer otros objetivos de carácter más específico. Aun cuando no queramos entrar en un nivel de detalle demasiado particular (lo cual será necesario en la planificación de un curso real), tenemos que estipular, cuando menos, qué tipo de competencias queremos desarrollar para poder establecer convenientemente los contenidos del curso, así como cuáles serán los posibles papeles de las tareas de traducción. Desde esa perspectiva, hemos puesto nuestro mayor interés en los contenidos de tipo procedimental y de tipo actitudinal, relegando la cuestión del aprendizaje de conocimientos de tipo declarativo a un plano secundario en este 
trabajo ${ }^{4}$. En este sentido, además de la importancia de los objetivos educacionales que se corresponden con contenidos de tipo procedimental, también son relevantes los objetivos relacionados con contenidos de tipo actitudinal, que son justamente en los que nos vamos a centrar a continuación.

De acuerdo con la Taxonomía de Bloom, existe una correlación entre el concepto de conciencia del proceso de aprendizaje (en el sentido de 'consciencia' o awareness) y la taxonomía de objetivos educacionales, que se desarrolla del siguiente modo:

Uno de los rasgos más característicos de todo el proceso de la taxonomía es la existencia de una escala de reflexión o de conciencia. Así, por ejemplo, los actos propios del campo cognoscitivo se caracterizan por un mayor grado de conciencia por parte del individuo que los realiza, mientras que los del campo afectivo son, por lo general, mucho más inconscientes. (Bloom et al. 1956:31)

Es posible que esa inconsciencia con que realizamos los actos de tipo afectivo sea una de las principales razones por las que el establecimiento de objetivos educacionales y de contenidos relacionados con este ámbito esté prácticamente ausente de las programaciones de los cursos de Inglés para Fines Específicos en el entorno universitario, dadas las dificultades que se pueden prever para evaluar el aprendizaje de este tipo de contenidos.

A pesar de este inconveniente, está comúnmente aceptada la idea de que el objetivo a largo plazo de la enseñanza de destrezas relacionadas con la comunicación en entornos profesionales es lograr que el aprendiz sea capaz de comunicarse desenvolviéndose como los expertos de su campo en términos de igualdad. Teniendo esto en cuenta, podemos decir entonces que existe una justificación basada en el establecimiento de objetivos a largo plazo del aprendizaje para incluir este tipo de contenidos en un curso de Inglés para Fines Específicos. Esta justificación se hace más patente en aquellos casos en que se detectan grandes disparidades entre los valores y actitudes que muestran poseer los aprendices y los

\footnotetext{
${ }^{4}$ Esto en ningún caso implica que este tipo de contenidos deba estar situado en un segundo plano en la planificación de un curso en particular. La posición que se le ha dado en el presente trabajo responde al propósito de estudiar algunos aspectos que tradicionalmente han recibido menos atención por parte de la didáctica del Inglés para Fines Específicos que otros que han sido tratados con mayor interés, como es el caso de la terminología.

5 Se consideran 'actos de tipo afectivo' aquellos actos que no son de tipo memorístico, ni reproducen algo adquirido mediante el aprendizaje, ni incluyen la solución de una actividad de tipo intelectual, sino que muestran los «intereses, actitudes, conceptuaciones, valores y tendencias emotivas» del sujeto que los realiza (Krathwohl, Bloom y Masia 1964:21).
} 
valores que son identificados típicamente como vigentes en el contexto profesional relevante. También podemos justificar establecer este tipo de objetivos a largo plazo cuando existen divergencias entre el discurso académico de un campo de especialización y las prácticas discursivas que se llevan a cabo en el ejercicio de la profesión (v. Candlin, Bhatia y Jensen 2002). Con el fin de presentar una descripción más detallada, a continuación vamos a presentar los objetivos que se relacionan con contenidos de tipo actitudinal, de acuerdo con el repertorio de objetivos educacionales de la Taxonomía de Bloom.

\subsubsection{Taxonomía de objetivos de la educación: ámbito de la afectividad}

Uno de los primeros obstáculos con el que se encontraron Bloom y sus colaboradores para establecer una clasificación de objetivos del ámbito afectivo fue que el criterio de complejidad utilizado para organizar las categorías del ámbito cognoscitivo no era tan claro y convincente como principio clasificador en este ámbito, por lo que tuvieron que decantarse por otro criterio más apropiado. El criterio elegido fue el grado de internalización que representa cada uno de los objetivos, que se distribuyen a lo largo de la tabla en orden ascendente, desde la percepción consciente implicada en el primero de los objetivos, hasta la internalización total que conlleva la última categoría.

Otra de las dificultades con las que se toparon estos investigadores es lo que describen como «la labor de corrosión provocada en el significado y esencia de los objetivos afectivos como consecuencia de la mayor trascendencia conferida a los cognoscitivos» (Krathwohl, Bloom y Masia 1964:29). Podemos señalar que, a pesar del tiempo transcurrido desde la elaboración de esta taxonomía, esta afirmación aún continúa teniendo vigencia, al menos en el entorno educativo al que nos estamos refiriendo en este trabajo, donde el énfasis puesto en los objetivos relacionados casi exclusivamente con el aprendizaje de conocimientos de tipo lingüístico produce una ausencia absoluta de otras dimensiones igualmente relevantes y necesarias para alcanzar el nivel experto.

Por último debemos mencionar, asimismo, la dificultad añadida de que los resultados del aprendizaje de actitudes y valores sólo se puedan obtener a largo plazo y no de forma inmediata, tal como sospechan Bloom y sus colaboradores:

Un elemento determinado de información o una habilidad específica se adquieren con gran rapidez y su aplicación es inmediata en los exámenes de tipo cognoscitivo. Las aptitudes más complejas pueden aprenderse durante un 
curso de un semestre o de un año. Por el contrario, se admite generalmente que los intereses, actitudes y características personales van desarrollándose muy lentamente y sólo pueden captarse por medio de las técnicas de evaluación tras haber transcurrido largos periodos de tiempo, posiblemente años enteros. (Krathwohl, Bloom y Masia 1964:34) $^{6}$

En este orden de cosas, la clasificación de objetivos educacionales del ámbito afectivo fue abordada como una propuesta tentativa (y no definitiva) para ofrecer un repertorio de objetivos educacionales completo en cuanto a los diferentes ámbitos de la taxonomía (a excepción del ámbito psicomotor, que no llegó a ser desarrollado debido a su presencia marginal en los objetivos de la mayoría de los cursos), así como para reflejar adecuadamente en la planificación de los cursos «las diferencias entre la solución de problemas y las actitudes, entre el pensamiento y el sentimiento y entre el acto y el pensamiento o la sensación» (Krathwohl, Bloom y Masia 1964:22).

Con respecto a la relación entre unas clases de objetivos y otras, debemos tener en cuenta que ningún objetivo educacional se encuentra totalmente al margen de los factores integrantes de las demás clases, por lo que los ámbitos establecidos «representan evidentemente unos elementos de insistencia y, en ciertos casos, de preferencia por ciertos tipos de objetivos» (Krathwohl, Bloom y Masia 1964:23), pero nunca de exclusión de los demás.

En la Tabla 11 presentamos en forma resumida la clasificación de objetivos educacionales del ámbito de la afectividad de la Taxonomía de Bloom. Tal como sucede en la clasificación referente al ámbito del conocimiento, las categorías aparecen ordenadas de menor a mayor grado de internalización. En este caso, la taxonomía consta de cinco categorías que van, desde la denominada 'recepción', relativa a la atención hacia un fenómeno, hasta la categoría denominada 'caracterización por un valor o un conjunto de valores', que se refiere a la conducta que el aprendiz muestra de forma generalizada, incluyendo su perspectiva sobre las cosas y el mundo, así como los valores, opiniones, actitudes y creencias que ha internalizado y que tienen gran influencia en las decisiones que toma.

Al igual que hicimos en el caso de la clasificación de objetivos educacionales de tipo cognoscitivo, vamos a describir de forma detallada en los subsiguientes apartados qué es lo que caracteriza cada una de estas categorías y, en su caso, cuál es la subclasificación ulterior en que se dividen.

\footnotetext{
${ }^{6}$ No obstante, Krathwohl, Bloom y Masia (1964:34) reconocen que la investigación sobre esa cuestión es insuficiente.
} 


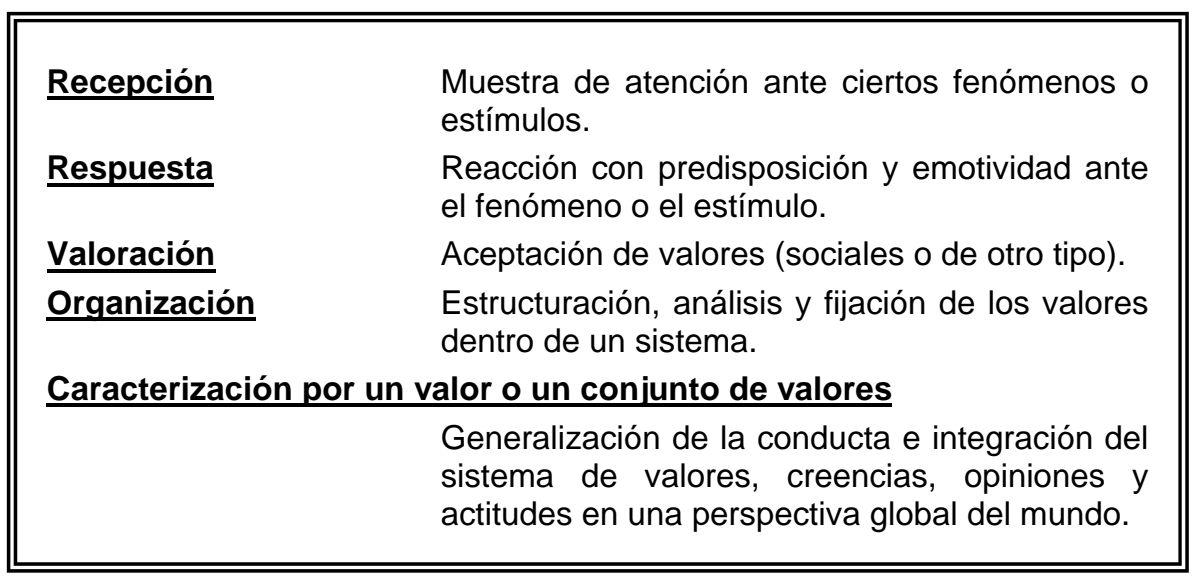

Tabla 11. Taxonomía de los Objetivos de la Educación: ámbito de la afectividad (adaptada de Krathwohl, Bloom y Masia 1964)

\subsubsection{Recepción}

La categoría que aparece en primer lugar, la recepción, se refiere al papel de la consciencia en relación con los fenómenos que se presentan ante el aprendiz. Vamos a comenzar por describir estos objetivos a partir de la clasificación y uso terminológico de Bloom y sus colaboradores, para relacionarlos a continuación con la consciencia tal como la hemos tratado con anterioridad en relación con el aprendizaje del inglés como lengua extranjera (v. 3.2).

Los objetivos educacionales relacionados con la recepción se dividen a su vez en tres subclases con el fin de poner de relieve tres niveles distintos de la atención. No obstante, aunque se haya establecido esta división, los tres niveles se distribuyen como una constante que se extiende, desde una posición en la que el aprendiz se muestra totalmente pasivo, hasta otra posición en la que el propio aprendiz dirige su atención hacia el fenómeno, si bien de modo semi-inconsciente. Los niveles o subclases de esta categoría son:

- La conciencia. Aunque esta subclase constituye prácticamente una actitud de tipo cognoscitivo, la razón por la que se encuentra en esta tabla es porque lo que nos interesa aquí no es la memorización o el recuerdo, sino que el alumno «tenga cierta conciencia de algo cuando se le brinda una oportunidad para ello» (Krathwohl, Bloom y Masia 1964:122). Por otra parte, el alumno puede tener conciencia de algo «sin que se produzca una diversificación o reconocimiento específicos de las características peculiares del objeto», de modo que es posible 
que éste «no sea capaz de expresar oralmente los factores del estímulo que provocan el conocimiento» (Krathwohl, Bloom y Masia 1964:122).

- La predisposición a la recepción. En este segundo nivel de la recepción, aún nos encontramos dentro de las denominadas 'reacciones cognoscitivas' (Krathwohl, Bloom y Masia 1964). Se produce una actitud de neutralidad o de juicio diferido con respecto del estímulo, tal como sucede en el nivel anterior, pero ahora se identifica una «actitud de cierto deseo de tolerancia frente a un estímulo dado» (Krathwohl, Bloom y Masia 1964:131).

- La atención controlada o selectiva. El estímulo es captado aquí de forma individualizada en un nivel consciente o, en ciertos casos, semi-consciente. Se diversifican los aspectos de un estímulo, cuya percepción destaca con claridad sobre los estímulos restantes, es decir, se da un «control de la atención, de tal modo que la fijamos sobre el estímulo preferido, dejando al margen otros rivales que podrían interferir su atención» (Krathwohl, Bloom y Masia 1964:138-139). En este nivel puede que el alumno no conozca los términos o símbolos técnicos que se utilizan para definir el estímulo o para darlo a conocer a los demás.

Desde la perspectiva de la didáctica general, la cuestión de la consciencia constituye una variable fundamental, que afecta tanto al ámbito cognoscitivo como al afectivo. Sin embargo, estos investigadores le atribuyen una función diferente para cada uno. Mientras que consideran que «las actividades cognoscitivas poseen un elevado nivel consciente en todas las etapas», sugieren que «la consciencia va desarrollándose lentamente en el ámbito afectivo para alcanzar un alto grado de concreción y perder después en intensidad al entrar en función el proceso de internalización» (Krathwohl, Bloom y Masia 1964:122).

Por lo que respecta al papel de la consciencia en esta primera categoría del ámbito de la afectividad, nos topamos de nuevo con ciertos problemas causados por la falta de precisión de los términos 'consciousness' y 'awareness', similares a los que ya aludimos al tratar esta cuestión desde la perspectiva del aprendizaje del inglés como lengua extranjera (v. 3.2). De acuerdo con la clasificación que utilizamos en esa ocasión, podemos señalar que la clasificación recogida en la Taxonomía de Bloom de tres niveles de objetivos y contenidos relacionados con la recepción corresponde, a grandes rasgos, a la clasificación de los componentes principales del sistema humano de atención, de acuerdo con Tomlin y Villa (1994). Podemos establecer esta correspondencia del siguiente modo: 
1. el nivel más bajo, que Tomlin y Villa identifican como 'alerta' y definen como el estado general de disposición para tratar con los estímulos que se presentan, se corresponde con la 'conciencia' de la Taxonomía de Bloom

2. la 'orientación', que consiste en la asignación específica de la atención a un estímulo en particular, es interpretada en la Taxonomía de Bloom como el nivel de 'predisposición a la recepción'

3. la 'detección' o 'atención focal' (Schmidt 1994:17), definida como el proceso de selección de una información en particular, se corresponde con la 'atención controlada' o 'selectiva'

Así pues, podemos decir que los tres niveles establecidos en la Taxonomía de Bloom buscan facilitar el establecimiento de objetivos educacionales que se correspondan con los tres niveles de atención detectados en el comportamiento humano. En este sentido, recordamos de nuevo que en la concepción de Schmidt (1994), la atención y el control no son sino dos aspectos diferentes del mismo proceso desde un punto de vista teórico, estando la atención centrada en el procesamiento del input, y el control en el procesamiento del output.

En esta categoría inicial de objetivos educacionales del ámbito denominado de la afectividad, únicamente nos estamos refiriendo a los diferentes niveles de atención sobre lo que queremos considerar input en el curso, y no sobre el control de la producción comunicativa del aprendiz. Se trata de un input en el que no son los aspectos formales o funcionales del sistema lingüístico los que nos llevarán a la consideración de que una muestra específica de lenguaje en uso constituye un input apropiado para tratar los contenidos relacionados con los objetivos de esta categoría, sino más bien aquellos aspectos que se relacionen con los valores y actitudes sobre los que queremos llamar la atención del aprendiz, tales como rasgos típicos o relevantes de una cultura determinada, los valores de la relación social entre los participantes de un texto, etc. En general, nos referimos a rasgos socio-semióticos que tienen que ver con las características asociadas típicamente con el contexto de situación del texto.

No obstante, existe un aspecto igualmente relevante en relación con la recepción en la resolución de problemas al realizar tareas de traducción. Nos referimos al modo centrado en el aprendiz que vamos a utilizar para tratar la detección de problemas en la producción práctica de TTs.

Según esta perspectiva, vamos a considerar únicamente los problemas que son detectados como tales por el propio aprendiz, con el fin de evitar una aproximación exhaustiva que se proponga agotar de forma extensiva el potencial de 
problemas que puede presentar la traducción de un texto determinado. Creemos que no es útil adoptar un enfoque exhaustivo sobre la tarea de traducción por varias razones. El potencial puede ser ciertamente amplio, la manifestación explícita de este potencial (los problemas reales que son detectados por los propios aprendices) presenta un cierto grado de variación de un grupo a otro de aprendices, de tal modo que tal manifestación no es exactamente la misma al realizar la misma tarea con diferentes grupos de aprendices y, por último, los objetivos educacionales de tipo actitudinal cuya consecución se pretende facilitar mediante la realización de la tarea de traducción sólo pueden ser alcanzados si el aprendiz aprende a focalizar su atención en la información relevante.

Como hemos podido comprobar de forma práctica, al emprender la realización de tareas de traducción, los aprendices tienden a fijar su atención de forma aleatoria en unos aspectos del texto que llaman su atención más que otros, y que se corresponden típicamente con palabras que desconocen. Ésta es una etapa previa a conseguir que la focalización llegue a ser lo suficientemente selectiva como para que el aprendiz logre fijar su atención en los aspectos que son más relevantes en relación con la tarea y el objetivo propuestos. A modo de ilustración de estos aspectos más relevantes, podemos mencionar aquellos casos en los que el aprendiz detecta problemas en un texto. Estos problemas pueden estar producidos por incoherencias en la macroestructura textual, por la relación social establecida entre el autor y el receptor en el TO, por las manifestaciones de tal relación mediante las expresiones de tratamiento utilizadas, o incluso por las diferencias interculturales existentes en el tratamiento (y en los modos de expresión de ese tratamiento) disponibles en las dos lenguas respectivamente. Se trata de aspectos que están relacionados con la comunicación en el contexto de situación relevante y que en las tareas de traducción se prestan a ser abordados de forma contrastiva. Este contraste se manifiesta como modos de comunicación paralelos en diferentes culturas mediante sistemas lingüísticos que disponen de recursos diferentes $\mathrm{y}$, por la parte que corresponde a los objetivos actitudinales, como modos de comunicación de grupos sociales que cuentan con unos valores, opiniones, actitudes y creencias determinados, cuyo significado únicamente se puede establecer en función del contexto de situación en que se realiza la comunicación (Matthiessen 2001).

\subsubsection{Respuesta}

Siguiendo el orden correlativo de la Tabla 11, la siguiente categoría es la respuesta. En este nivel el alumno ya se encuentra en posesión de una atención 
activa, es decir, se incorpora en cierta medida al fenómeno estudiado, por lo que las reacciones de esta categoría son distintas de la mera recepción, como en el nivel anterior. Se establecen aquí tres niveles graduales:

- La aceptación de la respuesta, que representa el primer nivel de respuesta activa una vez que el alumno ya ha concentrado su atención. En esta fase se habla de 'sumisión voluntaria' porque es el alumno quien lleva a cabo la respuesta pero no llega a asumir totalmente aun la necesidad de hacerlo. Este nivel es muy importante para la educación porque, en general, se considera que «para que sea realmente eficaz, todo esfuerzo docente presupone siempre un alto grado de buena voluntad por parte del alumno» (Krathwohl, Bloom y Masia 1964:146). No obstante, y aunque sean necesarios para alcanzar las actitudes de categorías superiores, no podemos esperar repercusiones a largo plazo debidas a la consecución de los objetivos relacionados con este nivel ya que «las actitudes que se van imbuyendo en el alumno dentro de este nivel podrán no llegar a internalizarse en mayor grado nunca ni a caer bajo un mayor control del propio alumno» (Krathwohl, Bloom y Masia 1964:145).

- La predisposición a la respuesta. Las reacciones que se producen en este nivel tienen ya las características de elecciones libres. Son de suma importancia para el desarrollo educativo en general, pero se convierten en fundamentales en un enfoque de aprendizaje autónomo porque se refieren a la predisposición del alumno en cuanto a su capacidad para realizar actividades de forma voluntaria. Estos objetivos se relacionan con lo que Krashen (1981) denomina 'motivación integradora' y que se refiere, como ya hemos visto, a la implicación del aprendiz en el aprendizaje. De acuerdo con Bloom y sus colaboradores, el medio fundamental para alcanzar los objetivos sociales incluidos en este nivel es que el profesor elabore «un clima que facilite la emisión de la conducta en el seno de la situación social» (Krathwohl, Bloom y Masia 1964:151).

- La satisfacción en la respuesta. En este nivel, el comportamiento del aprendiz se ve acompañado de una sensación de satisfacción, es decir, de una respuesta emotiva que puede ser de deleite, placer o entusiasmo. Destacan en este punto las dificultades encontradas por los investigadores para situar esta categoría en la jerarquía de la tabla. La inclusión arbitraria en este lugar del esquema responde al razonamiento de que es en este punto donde se desarrolla con mayor frecuencia, aunque no de forma exclusiva, y «por constituir uno de los factores constitutivos de los objetivos característicos de esta fase de la constante» (Krathwohl, Bloom y Masia 1964:159). 


\subsubsection{Valoración}

La valoración se refiere de modo general al valor que puede ostentar un fenómeno, un objeto o una actitud. El concepto de valor se puede referir tanto al «proceso de tasación efectuado por el propio individuo», como a un «proceso social que ha ido aceptándose poco a poco hasta convertirse en un módulo general» (Krathwohl, Bloom y Masia 1964:168). En este segundo caso, se trata de un proceso que hemos situado previamente en el contexto social del lenguaje (v. 4.3.3) y cuya relevancia en este trabajo se refiere específicamente a los valores vigentes en el contexto social de la comunicación especializada (v. 5.1).

Por otra parte, la conducta en esta categoría tiene ya las características de una opinión o una actitud. El aprendiz ostenta sus opiniones o su actitud en todos los casos que para él tienen un valor, por lo que los dos aspectos que mejor resumen esta categoría son la persistencia y el equilibrio en las respuestas del alumno con respecto a un mismo valor. Esta categoría está dividida en tres niveles:

- La aceptación de un valor. El aprendiz se halla en posesión de una opinión en el sentido de que se limita a aceptar un valor determinado. Es decir, en esta posición las opiniones no se encuentran arraigadas definitivamente, por lo cual es más posible que se produzca una rectificación en este nivel que en los niveles superiores. No obstante, podemos afirmar que «el valor se ha internalizado en grado suficiente para constituir una eficaz fuerza de control de la conducta» (Krathwohl, Bloom y Masia 1964:170), por lo cual las opiniones y actitudes mostradas son respuestas estables.

- La preferencia por un valor. Este nivel intermedio es incluido aquí debido a que existen ciertos objetivos que se encuentran, en cuanto a su grado de internalización, a caballo entre la simple aceptación de un valor y la entrega o el sentimiento de convicción, dentro de lo que constituiría la aceptación corriente de estos términos en una materia cualquiera (v. Krathwohl, Bloom y Masia 1964:174). En esta posición, el individuo muestra una marcada preferencia por un valor en particular en detrimento de otros.

- La entrega. Las actitudes mostradas en este nivel se pueden definir como de 'convicción' o de 'certeza sin sombra de duda', incluyendo una actitud de fidelidad por una causa, una posición determinada o un grupo social. Se puede decir que el individuo que muestra una actitud semejante a éstas está en posesión de un valor, el cual le lleva a promover constantemente el objeto valorado y cuanto representa, de modo que tiene «una auténtica motivación para dar rienda suelta a sus convicciones» (Krathwohl, Bloom y Masia 1964:180). 


\subsubsection{Organización}

Con esta categoría denominada 'organización', se describe un nivel en el que el sistema de valores se encuentra en una fase de elaboración progresiva, incorporando nuevos valores a los ya adoptados previamente o en sustitución de éstos, lo cual le lleva a estar sometido a constantes cambios.

Estos cambios se producen con mayor facilidad cuando el alumno es un niño que cuando se trata de un adulto, ya que la estructuración se hace más rígida con el paso del tiempo de modo que «el adulto se halla menos predispuesto a aceptar un valor más o menos incompatible con los que ya posee» (Krathwohl, Bloom y Masia 1964:185). En este sentido, a las dificultades ya mencionadas para la didáctica en relación con la necesidad de planificar los objetivos de este tipo a largo plazo, se suma aquí el problema añadido de enfrentarnos en la didáctica del Inglés para Fines Específicos con aprendices que, al no tratarse de niños, pueden tener valores organizados con una estructura firme y, por consiguiente, más difícil de cambiar.

Se distinguen en esta categoría de objetivos dos niveles diferentes, que representan los dos aspectos necesarios para definir las fases iniciales de la elaboración de un sistema de valores. Se trata de los siguientes:

- La conceptualización de un valor. En este nivel aparecen los factores de abstracción o conceptualización que son necesarios para que el individuo pueda comprobar las relaciones del nuevo valor con los que ya posee previamente o con los que vaya incorporando progresivamente. Esta conceptualización de los valores puede ser verbal o no verbal. Siempre es de tipo abstracto y, en ese sentido, de carácter simbólico, si bien no es necesario que se trate de símbolos verbales. Por otra parte, para que se produzca la conceptualización, es necesario que se lleven a cabo dos procesos, uno de abstracción y otro de generalización. Mediante la abstracción se ponen de relieve los rasgos que caracterizan un concepto en particular, mientras que la generalización resulta de la aplicación del concepto a una serie de datos más extensa que la de procedencia. Por consiguiente, el concepto representa «un conocimiento que no se percibe directamente a través de los sentidos, sino que más bien es el resultado de la manipulación de las impresiones sensoriales bajo una forma abstracta» (Krathwohl, Bloom y Masia 1964:187). Se incluyen aquí objetivos que son necesarios para la conceptualización de un valor, suministrando una base para su evaluación y para comprobar sus interrelaciones con otros valores, aunque esos mismos objetivos sean susceptibles de ser interpretados como 
objetivos de tipo cognoscitivo que han de someterse a un proceso de evaluación ${ }^{7}$.

- La organización de un sistema de valores. Los objetivos de este nivel exigen al alumno la presencia de un conjunto de valores y la estructuración de todos ellos. Esta estructuración será, idealmente, armónica y bien equilibrada, ya que el fin primordial de estos objetivos es que sea el propio alumno quien elabore su filosofía de vida. No obstante, en realidad el sistema de valores va sufriendo cambios de forma regular, por lo que su equilibrio es más bien de tipo dinámico. Además de la localización de conceptos dentro de una estructura de valores, en este nivel se puede incluir también la conducta relativa a los objetivos que se relacionan con aquellos casos en los que la organización de valores puede conducir a su sintetización en un único valor o en un conjunto de valores de orden superior.

\title{
6.1.2.5 Caracterización por un valor o un conjunto de valores
}

En esta última categoría en el orden creciente de internalización nos encontramos con unas conductas y actitudes descritas así:

\begin{abstract}
Los valores poseen ya un lugar dentro de la jerarquía valorativa del individuo, se han estructurado en un sistema de equilibrio interno, ejercen sobre la conducta del individuo un control suficiente para que se haya acostumbrado ya a una conducta específica y, finalmente, su comportamiento ya no provoca en él ninguna emoción o afecto, a excepción de los casos en que sobre él pende algún peligro. (Krathwohl, Bloom y Masia 1964:197)
\end{abstract}

No es frecuente la inclusión de objetivos de este tipo en la planificación docente porque, por lo general, la educación formal no suele llegar a este nivel de formación, sino que este tipo de caracterización se produce más bien a través del paso de los años y la adquisición de experiencia:

La madurez y la integración personal esenciales para este nivel no se logran sino bastantes años después de que el individuo ha completado su educación formal. El tiempo y la experiencia han de entreverarse en el aprendizaje afectivo y cognoscitivo para que el individuo se halle capacitado para

\footnotetext{
7 Bloom y sus colaboradores señalan que un objetivo expresado como iniciación en la elaboración de juicios sobre la responsabilidad de la sociedad en la conservación de los recursos humanos y materiales' puede ser interpretado como un objetivo de tipo cognoscitivo o bien de tipo afectivo ya que, por una parte «parece basarse en la evaluación comparativa de diversos valores para determinar la responsabilidad de la sociedad», pero «también podría significar que el profesor haga lo posible para que el alumno vaya internalizándose un valor conexionado con la salvaguardia de dichos recursos hasta lograr conceptualizarlo» (Krathwohl, Bloom y Masia 1964:187).
} 
contestar preguntas tan cruciales como: «QQuién soy yo?»y «¿Qué significo yo?» (Krathwohl, Bloom y Masia 1964:197-198)

En esta categoría pueden diferenciarse dos niveles diferentes en cuanto al grado de internalización de los valores que se denominan, respectivamente, 'perspectiva generalizada' y 'caracterización'.

- La perspectiva generalizada. Proporciona el equilibrio interno al sistema de valores en cada momento particular. Consiste en una respuesta de tipo selectivo y muchas veces se define como una predisposición a la actuación dentro de unas normas fijas. Constituye una respuesta integral a todo un conjunto de objetos o situaciones relacionados entre sí. Asimismo, «con frecuencia constituye una visión inconsciente que orienta la acción sin previa intervención de la conciencia» (Krathwohl, Bloom y Masia 1964:198). Esta perspectiva generalizada se interpreta como un complejo criterio por defecto que guía las pautas de actuación, de tal modo que el individuo puede actuar de modo eficiente sin necesidad de decidir o reflexionar a cada paso y en cada momento en qué valores se basa para actuar de un modo determinado:

Una norma de orientación que facilita al individuo el control y la estructuración del complejo mundo que lo rodea y su acción consecuente y efectiva dentro de él. Este proceso de orientación llega a coordinar toda una serie de actitudes, valores y creencias. Por su medio, podrá un extraño pronosticar y comprender las reacciones del individuo. (Krathwohl, Bloom y Masia 1964:199)

Los objetivos incluidos en el nivel de la perspectiva generalizada se refieren a actos que se encuentran ya desprovistos de toda carga afectiva en la vida diaria, por lo que se podría poner en duda su pertenencia a este ámbito. No obstante, la afectividad suele mostrarse en los momentos de peligro o de contradicción y, además, los objetivos de este tipo representan la culminación de «una larga práctica presidida por el mundo de la afectividad» (Krathwohl, Bloom y Masia 1964:199). Por otra parte, el desarrollo de estos objetivos es lento, ya que viene a representar la culminación de todo el proceso de asimilación de las pautas de actuación. Desde esta perspectiva, se trata de objetivos que generalmente se encuentran «fuera del alcance de un solo profesor, de un curso y hasta de un centro escolar, todos los cuales corrientemente se darán por satisfechos si consiguen cierto progreso a lo largo de un semestre o un año» (Krathwohl, Bloom y Masia 1964:200). No obstante, las perspectivas generalizadas de los alumnos tienen suma importancia en todo el proceso de enseñanza-aprendizaje porque ejercen una influencia (que puede resultar tanto beneficiosa como perjudicial) sobre cómo se va a producir el aprendizaje en general: 
Estas perspectivas generalizadas condicionan en buena medida las características de la solución de un problema, determinan la relativa importancia que el individuo concede a sus diversos elementos $\mathrm{y}$, finalmente, son los factores determinantes de la fidelidad con que el sujeto se aferra a su primitiva interpretación del problema (dando origen, por consiguiente, a su resistencia a salir del callejón sin salida en que se ha metido). Las actitudes que comprenden, aun cuando no forman parte propiamente del ámbito cognoscitivo, condicionarán en buena medida el modo de aplicar lo aprendido en el campo cognoscitivo a la solución de problemas. Si el alumno no es capaz de integrarse ciertos objetivos que se hallan comprometidos en este nivel, aunque logre al propio tiempo los objetivos cognoscitivos, su capacidad para incorporarse las actitudes cognoscitivas quedará imperfecta, se reducirá a un frío academicismo; en definitiva, será de mucho menos valor para su vida que en el caso contrario. (Krathwohl, Bloom y Masia 1964:199)

- La caracterización. Constituye el nivel más alto del proceso de internalización y sus objetivos se relacionan con «la interpretación personal del universo, con la filosofía individual de la vida, con la Weltanshauung de cada individuo, es decir, con un sistema de valores que se proponen como meta cuanto nos es conocido o cuanto es cognoscible» (Krathwohl, Bloom y Masia 1964:203). En este nivel se hace más énfasis que en el anterior en el equilibrio interno que posee el conjunto de actitudes, opiniones o ideales y se describe como el nivel de caracterización apelando a que todos los objetivos se encuentran interrelacionados de tal modo que llegan a caracterizar prácticamente por completo al individuo. En este nivel podemos decir que la actuación del individuo muestra una total coherencia con respecto de su escala o sistema de valores.

A lo largo de las dos obras de referencia en las que Bloom y sus colaboradores presentan y describen las taxonomías de objetivos de la educación para el ámbito del conocimiento y para el de la afectividad, hemos podido establecer cuáles son las implicaciones de cada objetivo educacional en particular. De este modo, podemos tratar con un mayor nivel de precisión qué aspectos debemos tener en cuenta cuando consideramos el establecimiento de un objetivo educacional, en especial cuando se trata de objetivos poco definidos o simplemente ausentes de las planificaciones docentes, como sucede frecuentemente con los objetivos de tipo actitudinal.

No obstante, para poder establecer la funcionalidad didáctica de las tareas de traducción como método de evaluación para el aprendizaje, debemos tratar también los aspectos relativos a la evaluación de estos objetivos. Para ello, vamos a delimitar qué tipos de evaluación nos resultan más relevantes en relación con la utilización de tareas de traducción en la enseñanza y el aprendizaje del Inglés para Fines Específicos. 


\subsection{Evaluación: referencias, funciones y tipos}

$\mathrm{Al}$ aspecto general de la evaluación que hemos tratado hasta este momento, qué vamos a evaluar, debemos sumar los criterios o referencias que vamos a emplear para poder valorar la información recogida (cómo vamos a evaluar), así como los propósitos que perseguimos con la evaluación (para qué vamos a evaluar). Por consiguiente, vamos a comenzar por establecer los distintos tipos de criterios o referencias que podemos utilizar, así como las diferentes funciones que la evaluación puede cumplir, para distinguir posteriormente entre dos tipos de evaluación, denominados respectivamente 'evaluación sumativa' y 'evaluación formativa'.

\subsubsection{Referencias o criterios de evaluación}

Cuando hablamos de referencias o criterios de evaluación, nos podemos estar referiendo tanto a los objetivos de la evaluación (cuando evaluamos el grado de consecución del objetivo), como a los criterios que se emplean para evaluar (cuando decidimos de acuerdo con qué criterio vamos a valorar la información recogida). Desde esta segunda perspectiva, Herrera García y Rodríguez Conde (2001) señalan que, además de los objetivos que esperamos alcanzar con la evaluación, es necesario establecer los criterios que se van a utilizar para evaluar el aprendizaje. En otras palabras, debemos especificar en relación con qué vamos a llevar a cabo la evaluación, cuál va a ser nuestro punto de referencia para establecer una escala de valores que nos permita evaluar los datos recogidos.

Estas autoras describen tres tipos de referencia que podemos utilizar para establecer nuestro baremo de evaluación del aprendizaje, la referencia externa, la referencia en el grupo y la referencia individual.

\subsubsection{La referencia externa}

Podemos tomar, como ejemplo de punto de referencia externa, los propios objetivos que hemos establecido para la enseñanza. A este tipo de evaluación que se basa en una referencia externa para establecer los criterios que se consideran relevantes para una valoración determinada se le denomina 'evaluación criterial'. En 
el caso de la evaluación de traducciones con una finalidad formativa, aún hoy en día es muy habitual la utilización de criterios confusos o indebidamente implícitos que tienden más bien a mostrar dónde considera el evaluador que las traducciones son fallidas, que su valor o su éxito como texto en una situación comunicativa.

Por otra parte, podemos nombrar el Marco de Referencia Europeo como ejemplo ilustrativo de referencia externa unificada, en cuanto que este marco de referencia constituye un modelo que se está implantando en el ámbito de la Unión Europea con el propósito de poder comparar el nivel de competencia comunicativa en diferentes lenguas mediante criterios equiparables entre ellas. Teniendo esto en cuenta, toda la evaluación del aprendizaje de lenguas extranjeras que se lleva a cabo en el Espacio Europeo de Educación Superior debería estar convergiendo hacia la aplicación de estos criterios para fortalecer y hacer efectiva la libre circulación de los estudiantes y trabajadores en Europa.

\subsubsection{La referencia en el grupo}

Cuando se utiliza este tipo de referencia o criterio, se evalúa a cada aprendiz en relación con el rendimiento del grupo. Este tipo de evaluación se denomina 'evaluación normativa'. Como ya hemos indicado en otros trabajos anteriores (Elorza 2001; 2002), cuando utilizamos tareas de traducción en el aula, lo que hacemos los profesores es (tratar de) gestionar la diversidad textual producida a partir de un único TO, por lo que es posible identificar algunos comportamientos textuales como tendencias del grupo. A partir de ese reconocimiento podemos identificar también qué casos se alejan más o menos de la tendencia general.

Independientemente del valor que queramos asignar a este tipo de referencia en relación con la evaluación de la actuación de un aprendiz en particular u otro, lo cierto es que, cuando trabajamos con tareas que conllevan la manipulación, reformulación o reestructuración de información textual, este tipo de referencia nos proporciona información fiable acerca de la casuística de dificultades o problemas que tenderán a surgir con otros grupos análogos de aprendices que lleven a cabo tareas de traducción con el mismo TO. Por esta razón, la consideración atenta del rendimiento del grupo no sólo nos puede llevar a extraer conclusiones acerca del aprendizaje global del grupo, sino que invita además a una reflexión más general acerca de la propia metodología, de los objetivos establecidos, o del rendimiento de los materiales utilizados. 


\subsubsection{La referencia individual}

Utilizamos un criterio individual cuando el aprendiz es evaluado en relación consigo mismo, es decir, en relación con sus propios progresos o su desarrollo personal, por lo que a este tipo de evaluación se le denomina 'evaluación personalizada'. La referencia individual tiene una importancia fundamental cuando se utilizan enfoques amplios del proceso de enseñanza-aprendizaje, como el concepto de 'aprendizaje durante toda la vida' (life-long learning), el cual actualmente constituye uno de los pilares en los que el Consejo de Europa apoya su proyecto de desarrollo en favor de la igualdad de oportunidades para todos los ciudadanos de la Unión Europea.

La referencia individual subyace también en la idea que ha dado origen al futuro Pasaporte Lingüístico Europeo (European Language Portfolio) que, junto con la referencia externa desarrollada mediante el establecimiento de niveles comunicativos equiparables para todas las lenguas de la Unión, servirá para reflejar el estado de conocimientos lingüísticos de cada ciudadano de la Unión Europea en un futuro próximo, junto con el denominado 'Suplemento Europeo al Título' que se va a comenzar a utilizar en los próximos años en el entorno de la educación superior $^{8}$.

Con estos instrumentos a los que nos hemos referido, el Consejo de Europa espera fomentar de forma efectiva la movilidad de los estudiantes y trabajadores europeos en todo el territorio de la Unión. Sin embargo, a pesar de las evidentes ventajas que supone la posibilidad de que utilicemos unos criterios homogéneos con el resto de países de la Unión Europea para la referencia externa y la referencia individual, no existen actualmente directrices explícitas de convergencia en cuanto a los objetivos educacionales de la enseñanza de lenguas extranjeras en el entorno de la educación superior en Europa, ni tampoco está prevista ningún tipo de convergencia dentro del propio sistema universitario español ${ }^{9}$.

Así las cosas, cabe señalar que el repertorio de funciones didácticas de la traducción no se va a encontrar con ningún tipo de restricción coyuntural que afecte a su potencial para el presente trabajo. Esto significa que podemos establecer en un nivel teórico si un objetivo educacional puede ser alcanzado o no mediante las

\footnotetext{
${ }^{8}$ Véase el «Real Decreto 1044/2003, de 1 de agosto, por el que se establece el procedimiento para la expedición por las universidades del Suplemento Europeo al Título».

${ }^{9}$ Al menos según las previsiones de Pedro Chacón, ex-Director General de Universidades del Ministerio de Educación, Ciencia y Deportes, en respuesta a una pregunta formulada por mí durante el curso «Educación superior en Europa: desde la Declaración de Bolonia hasta la Cumbre de Berlín» (XV Cursos Europeos y XXII Cursos de Verano en San Sebastián; Universidad del País Vasco, 14 y 15 de julio de 2003).
} 
tareas de traducción de entre todos los objetivos descritos en la Taxonomía de Bloom, sin eliminar ninguno previamente por razones de tipo coyuntural. En cualquier caso, como quiera que la función didáctica de las tareas de traducción que más nos interesa aquí es la de método de evaluación para el aprendizaje, es el momento de explicar con mayor detalle a qué función de la evaluación nos estamos refiriendo en particular.

\subsubsection{Funciones de la evaluación}

Si bien habitualmente cuando se habla de evaluación en el ámbito académico tendemos a pensar en las pruebas dirigidas a la calificación de los conocimientos de los estudiantes, existen otras funciones que hacen que las pruebas de evaluación nos proporcionen información valiosa para el propio aprendizaje. De hecho, son estas otras funciones las que ofrecen mayor interés para nuestro trabajo, puesto que dotan a la evaluación de una perspectiva menos limitada, tal como señalan Rea-Dickins y Germaine: «while evaluation may be seen as a 'means' analysis (it is intended to serve the learning process), student assessment has a much more limited perspective with a focus on the 'ends' of learning in terms of what the learner has achieved at particular points» (Rea-Dickins y Germaine 1992:5).

Al definir el repertorio de posibles funciones didácticas de la traducción en el Capítulo 2, incluimos la clasificación utilizada por Morales Vallejo (1995a) para detallar qué funciones específicas puede cumplir la evaluación: comprobar la consecución de objetivos, informar sobre el aprendizaje, orientar, motivar y contribuir al aprendizaje, clarificar los objetivos, y proporcionar datos necesarios para la investigación educativa. Como ya señalamos entonces (v. 2.4.4.1), nuestro interés se centra en este trabajo en los procedimientos de evaluación formativa, entendidos como actividades de aprendizaje utilizadas por el profesor para obtener datos con los que tomar decisiones relativas al curso. Señalamos también que cuando queremos que las actividades de aprendizaje cumplan esta finalidad formativa, necesitamos contar con un procedimiento de recogida de datos, así como con una referencia o criterio explícito de corrección, lo que, en el caso de que las actividades elegidas sean tareas de traducción, es imprescindible puesto que la equivalencia traslativa no es suficientemente evidente per se al comparar el TT con su correspondiente TO.

Por otra parte, existe una relación entre las distintas funciones que puede llevar a cabo la evaluación y el tipo de prueba que se debe utilizar en cada caso 
como instrumento de recogida de la información. Los instrumentos de recogida pueden sufrir grandes variaciones en función de la materia que se trate en el curso, por lo que vamos a tratar esta cuestión en relación con la didáctica especial de las lenguas extranjeras.

\subsubsection{Recogida de datos y tipos de evaluación}

Para el ámbito de la didáctica de las lenguas extranjeras, Rea-Dickins y Germaine (1992) distinguen varios tipos de instrumentos de recogida de información en forma de pruebas o exámenes, que varían de acuerdo con la finalidad que se persigue con la evaluación, así como con el tipo de referencias o criterios utilizados en cada caso.

\subsubsection{Pruebas de clasificación}

Se utilizan pruebas de clasificación cuando lo que queremos es categorizar a los aprendices con alguna finalidad en particular. Por ejemplo, utilizamos una 'prueba de nivel' (placement test) cuando es necesario ubicar a un alumno con otros de su mismo nivel, lo cual sucede típicamente al principio de un curso. Se trata además de un tipo de prueba de suma importancia cuando el grupo tiene conocimientos muy heterogéneos, tan habituales en los cursos de Inglés para Fines Específicos.

Por otra parte, la finalidad de la evaluación puede responder a otro tipo de objetivos. Cuando necesitamos realizar un proceso de selección de entre todos los aspirantes a formar parte de un curso, entonces utilizaremos un instrumento de recogida de información que nos permita clasificar a los aspirantes de acuerdo con el criterio que utilicemos. En estos casos, el instrumento recibe el nombre de 'prueba de selección' (selection or screening test).

No obstante, dado que para poder clasificar a los alumnos en cualquiera de estos casos necesitamos en numerosas ocasiones que el contenido de la prueba esté basado en algún tipo de manual o de programa, podemos decir que las pruebas de clasificación pueden compartir también algunas características con las 'pruebas de progreso' (achievement or attaintment tests), que son herramientas de tipo pedagógico de recogida de datos sin utilidad para la clasificación, por lo que serán descritas más adelante. Cuando, por el contrario, la prueba no se relaciona con ningún programa en particular, sino con niveles de competencia externos (como sucede, por ejemplo, si la prueba se basa en los niveles de competencia 
comunicativa definidos por el Consejo de Europa), entonces se trata de 'pruebas de competencia' (proficiency tests). Según Rea-Dickins y Germaine (1992:47), las pruebas de competencia deben ser realizadas al final del curso pero deben ser administradas al margen del curso, sin integrarse en la situación de enseñanzaaprendizaje.

En general, podemos decir que todos estos tipos de pruebas de clasificación son utilizados en la periferia del desarrollo del programa, bien al principio o bien al final, y esto es lo que hace que su valor pedagógico sea muy escaso o nulo, a excepción del valor diagnóstico que tienen las pruebas de nivel realizadas al principio del curso. De acuerdo con el repertorio de instrumentos de recogida de información utilizado por Cunningham (1998), los instrumentos utilizados preferentemente para llevar a cabo las pruebas de nivel y las de selección suelen ser de tipo objetivo (objective tests) por su rapidez de corrección. No obstante, las pruebas de competencia suelen incluir además otros tipos de instrumento, tales como preguntas de respuesta abierta en las que el aprendiz debe elaborar una respuesta (constructed response items). Estas pruebas abiertas pueden ser de diversos tipos (short answer items, essay tests, extended response questions, etc.).

Teniendo todo esto en cuenta, y a la vista del enfoque que seguimos en este trabajo, podemos afirmar que las actividades de traducción no tienen funcionalidad potencial como pruebas de clasificación de conocimientos en la didáctica especial de las lenguas para fines específicos.

\subsubsection{Pruebas pedagógicas}

Utilizamos este tipo de instrumentos de recogida de datos cuando la información que queremos obtener mediante la prueba va a ser utilizada con una finalidad didáctica.

Para que el instrumento de recogida de información que hemos elegido nos pueda proporcionar información útil para tomar algún tipo de decisión pedagógica, lo que necesitamos es que la prueba nos aporte información de tipo descriptivo relacionada con los objetivos y contenidos específicos del curso. Según Rea-Dickins y Germaine (1992), en estos casos utilizamos lo que denominan 'pruebas de progreso' (achievement or attaintment tests). Si estas pruebas se diseñan con el fin de evaluar algún aspecto específico del programa, entonces pueden tener además una dimensión diagnóstica.

Dentro de este tipo de pruebas, se incluyen no sólo instrumentos objetivos de recogida de información (objective tests) o de respuesta abierta (constructed 
response items), como en el caso de las pruebas de clasificación, sino otro tipo de instrumentos que, aunque no muestran valor clasificatorio, tienen valor pedagógico.

De acuerdo con Cunningham (1998), cuando el objetivo de la evaluación es pedagógico, se puede utilizar también lo que este autor denomina métodos de evaluación alternativos (alternative assessment), que describe como un enfoque de evaluación donde se enfatiza la distinción entre los métodos convencionales de evaluación y otros que, simplemente, no son convencionales pero que pueden ser igualmente válidos para alcanzar el objetivo que persigue la evaluación. Cunningham incluye las denominadas 'pruebas de actuación' (performance tests) como un instrumento válido para un enfoque pedagógico de la evaluación, interpretando la evaluación basada en la actuación de este modo: «the terms performace tests and performance assessment generally refer to an authentic, alternative form of assessment in which students are assessed directly by having them perform high level, real-world tasks, often in a group setting» (Cunningham 1998:121). En el presente trabajo, las actividades de traducción son consideradas pruebas de la actuación de los aprendices del tipo descrito por Cunningham, tal como veremos más adelante en relación con su funcionalidad como método de evaluación para el aprendizaje.

De acuerdo con el uso que vamos a dar a la información obtenida mediante las pruebas de evaluación y con la finalidad que persigue la realización de la misma, Rea-Dickins y Germaine (1992:46) distinguen diferentes tipos de evaluación en el ámbito de la didáctica de las lenguas extranjeras, como se puede observar en la Figura 6.

Según estos autores, dado que el uso que queremos dar a la información obtenida influye en el tipo de prueba que debemos utilizar, para poder decidir qué tipo de prueba será el más apropiado en un caso particular debemos comenzar por establecer cuál será la finalidad de la información que vamos a obtener. Esta finalidad puede ser didáctica, con repercusiones en el proceso de enseñanza y aprendizaje, o bien estar dirigida a otros usos diferentes, tales como certificar los conocimientos del alumno. En el primero de los casos, decimos que la finalidad de las pruebas es formativa, mientras que en el segundo, la finalidad de las pruebas se considera sumativa.

De todos modos, Cunningham llama la atención sobre la importancia de no olvidar que la función principal de llevar a cabo la evaluación es el poder utilizar los resultados para tomar decisiones, hasta tal punto que «if no decisions are to be made, no assessment should be conducted» (Cunningham 1998:45). Son, por 
consiguiente, las decisiones que tomamos las que son esencialmente sumativas (por ejemplo, emitir un certificado acreditativo o no hacerlo) o formativas (por ejemplo, dedicar una clase extra a tratar un contenido que no ha sido suficientemente aprendido), si bien habitualmente se utilizan estos apelativos para referirse a los dos tipos de evaluación que vamos a considerar a continuación.

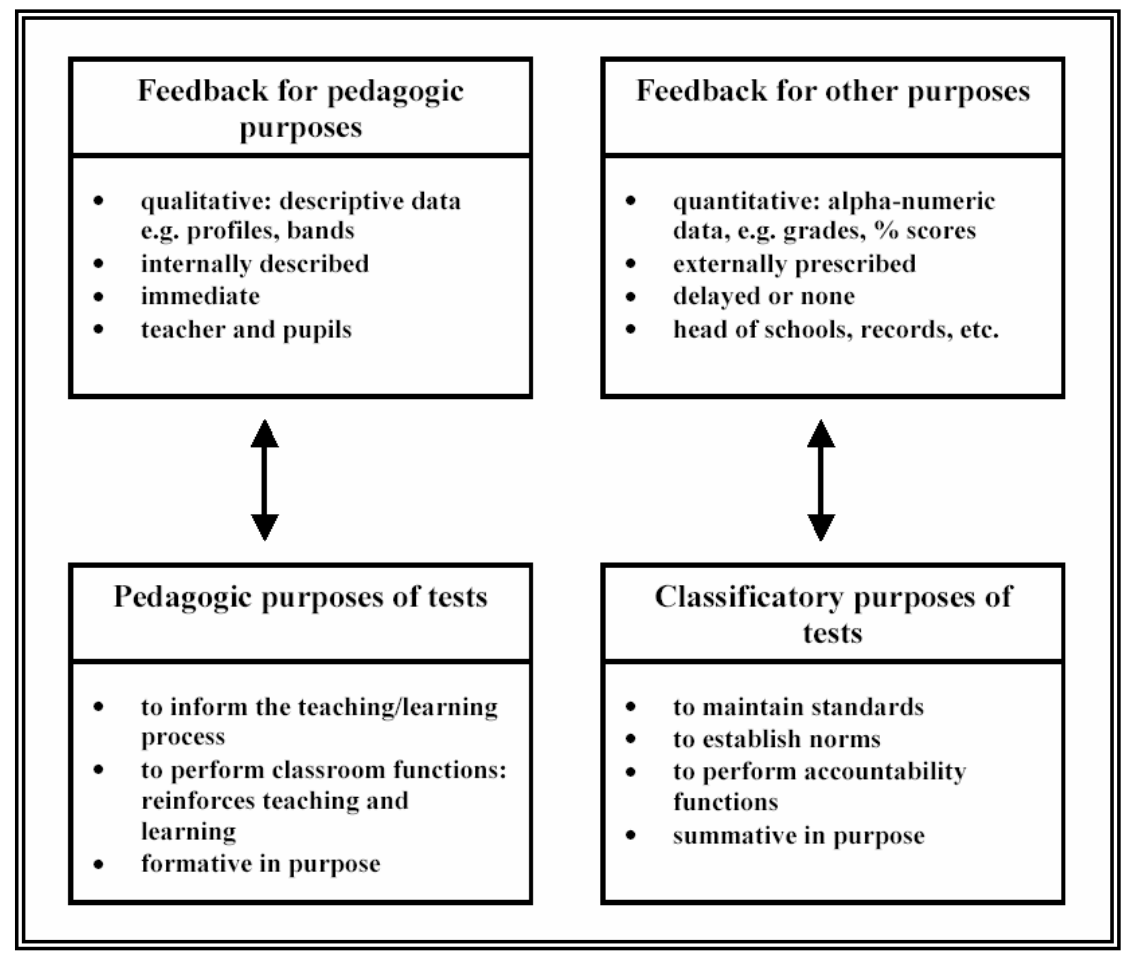

Figura 6. Tipos de feedback y objetivos de la evaluación (Rea-Dickins 1989)

A continuación vamos a detallar cuáles son las características más representativas de la evaluación sumativa y de la evaluación formativa.

\subsubsection{Evaluación sumativa}

La función esencial de la evaluación sumativa es certificar el nivel de conocimientos del alumno y, por tanto, se suele utilizar para comunicar los resultados finales de un proceso o de una parte de un proceso de enseñanzaaprendizaje. Algunos ejemplos de decisiones sumativas son «the assessments used 
for assigning grades, the determination of whether a student is to be promoted or retained, or whether a student is to be accepted or rejected in an educational program» (Cunningham 1998:45).

Así pues, dado el carácter certificativo de este tipo de evaluación, los métodos que se suelen utilizar para la recogida de datos suelen ser formales y rigurosos y la información que proporcionan es de tipo cuantitativo, obtenida mediante la aplicación de escalas de valor cuyo resultado son datos porcentuales o (alfa)numéricos.

Por otra parte, este tipo de evaluación suele conllevar consecuencias importantes, ya que el éxito o el fracaso en la prueba suelen tener algún tipo de repercusiones en la trayectoria vital del alumno. Las Pruebas de Selectividad al finalizar la educación secundaria o las Pruebas de Acceso a la Universidad son ejemplos de ello. Como se trata de un tipo de evaluación en el que los datos obtenidos son calificados, las pruebas que se llevan a cabo con el fin de recoger información suelen producir tensión en los sujetos que se someten a ellas.

Por lo que se refiere a los objetivos de nuestro trabajo, la evaluación sumativa no tiene demasiada utilidad en relación con la cuestión que estamos tratando, ya que probablemente la única situación posible para que la tarea de traducción tenga relevancia como prueba, o parte de una prueba, de evaluación sumativa en el ámbito del Inglés para Fines Específicos es en aquellos casos en los que la destreza de traducir esté incluida como uno de los objetivos y de los contenidos del curso. Aun cuando esta situación es posible, nuestro interés se centra más bien en aquellos casos en que la tarea de traducción se relaciona con el aprendizaje del alumno, más que con la certificación de sus conocimientos. Por esta razón, nuestra atención se dirige con mayor interés a la evaluación de tipo formativo, que describiremos a continuación.

\subsubsection{Evaluación formativa}

Al contrario que la evaluación sumativa, la evaluación formativa no persigue certificar el nivel del alumno, sino más bien proporcionar información, fundamentalmente al profesor y al aprendiz, con el fin de mejorar la enseñanza (en cuanto que puede constituir una fuente de información para el profesor acerca de la marcha del curso) y el aprendizaje (en cuanto que la información que proporciona se puede utilizar para facilitar el aprendizaje). Esto hace, por una parte, que los métodos que se utilizan para llevar a cabo este tipo de evaluación no sean necesariamente tan formales como los requeridos para la evaluación sumativa y, por 
otra, que la información obtenida sea de tipo descriptivo. Además, las decisiones que se toman como consecuencia de la evaluación pueden afectar a todo el grupo (por ejemplo, introduciendo modificaciones en la marcha del curso), pero también a cada individuo de forma separada (por ejemplo, haciéndole volver sobre algún aspecto de los contenidos del curso en el que no ha profundizado lo suficiente), tal como describe Cunningham:

\begin{abstract}
Formative evaluation can have an individual or group focus. For individuals, the emphasis is usually on the acquisition of diagnostic information to be used for remediation or academic acceleration. Formative evaluation can focus on the entire class or some portion of it. This sort of evaluation may include decisions about the rate that content is presented or whether there is a need to repeat what has already been taught. (Cunningham 1998:45)
\end{abstract}

Dado que la evaluación formativa no se lleva a cabo con la finalidad de calificar al aprendiz, este tipo de pruebas no produce la misma tensión en los alumnos, por lo que tiene una utilidad efectiva reconocida como instrumento de reflexión acerca del propio aprendizaje. Teniendo en cuenta sus características, en este tipo de evaluación es posible utilizar una variada gama de herramientas. Entre otros instrumentos de recogida de información, queremos destacar la utilización de pruebas específicas destinadas a la autoevaluación de la actuación, que proporcionan a los aprendices una base para la reflexión. En este tipo de pruebas, los aprendices deben suministrar información acerca de su propia actuación. Si bien las autoevaluaciones suelen ser utilizadas con el fin de que el propio aprendiz pueda valorar su aprendizaje, también es posible utilizar la información suministrada como base para la reflexión. En este sentido, la evaluación formativa tiene una evidente utilidad en un enfoque que, como el que seguimos en este trabajo, se centra en el desarrollo y la utilización de estrategias asociadas al aprendizaje autónomo.

A su vez, como podemos utilizar instrumentos basados en la actuación de los aprendices, este tipo de evaluación se asocia con un enfoque centrado en el papel activo del aprendiz. De acuerdo con Herrera García y Rodríguez Conde (2001), este papel activo constituye una de las características que debe incluir el proceso de evaluación del curso y supone un elemento de mejora del proceso de evaluación frente a otros que no incluyen esta perspectiva. Este y otros elementos de mejora del proceso de evaluación han sido presentados por estas autoras en una tabla que reproducimos a continuación, donde se puede observar claramente cómo la utilización de procedimientos de evaluación formativa supone una mejora con respecto a la utilización exclusiva de procedimientos de evaluación sumativa. 


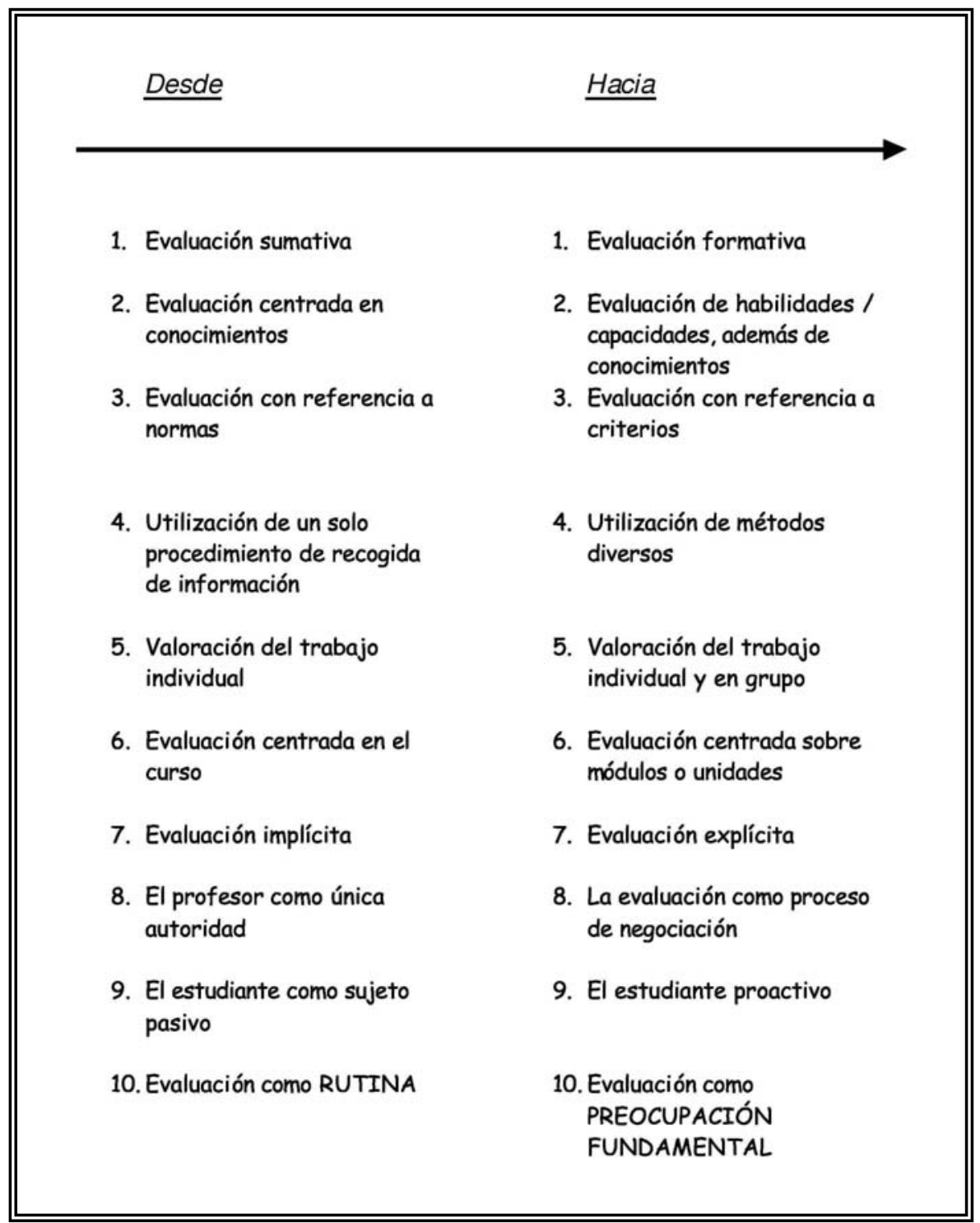

Tabla 12. Modos de mejora del proceso de evaluación (Herrera García y Rodríguez Conde 2001)

En esta tabla podemos observar cómo el papel activo del estudiante, la utilización de instrumentos de evaluación formativa, la evaluación de habilidades y capacidades, o la explicitación de los criterios utilizados al evaluar suponen mejoras del proceso de evaluación en su conjunto. Creemos que estas mejoras son aplicables en términos generales a cualquier ámbito de la didáctica, por lo que asumimos su 
validez para la didáctica especial de lenguas extranjeras y, por extensión, para la didáctica del Inglés para Fines Específicos. Aun sin olvidar que debemos tener en cuenta la conjunción de todos los factores involucrados en el proceso de evaluación, nuestro interés al analizar la funcionalidad didáctica de la traducción como medio de facilitación del aprendizaje se centrará especialmente en esos aspectos particulares. Para poder tratar esto de forma pormenorizada, a continuación vamos a comenzar por describir cómo se procede a evaluar la traducción de un modo pedagógico en el ámbito de los Estudios de Traducción, con la finalidad de establecer qué problemas se asocian típicamente con la evaluación de las traducciones y, lo que es más importante, qué tipo de soluciones se plantean para paliar dichos problemas. Una vez hecho esto, pasaremos a centrarnos en algunos procedimientos específicos de evaluación formativa que pueden ser utilizados cuando son las tareas de traducción las que se utilizan como un medio de facilitación del aprendizaje.

\subsection{Traducción y evaluación}

Dado que en esta sección vamos a considerar, además de su potencial funcionalidad como actividad de aprendizaje, la posible utilidad de la traducción como instrumento de recogida de datos para la evaluación, podemos comenzar señalando que la traducción, al igual que la elaboración de resúmenes y otras tareas complejas, presenta ciertos inconvenientes cuando es utilizada como un instrumento para la recogida de información. Estos inconvenientes, tanto de tipo teórico (por ejemplo, en cuanto al establecimiento de criterios) como de tipo práctico (por ejemplo, en cuanto a la laboriosidad en el análisis de los resultados), probablemente son responsables en buena medida de la escasa utilización de la traducción como método de recogida de datos en la evaluación sumativa fuera del ámbito de los Estudios de Traducción.

De acuerdo con la tipología didáctica de la traducción que proponíamos en el Capítulo 2, cuando la traducción es utilizada como un procedimiento de evaluación lo que hacemos es recoger datos que nos permitan valorar el aprendizaje de los contenidos del curso o la consecución de los objetivos de la enseñanza. Así, para calificar el aprendizaje y poder certificar el nivel del aprendiz (en el caso de una evaluación sumativa) aplicamos un criterio previamente establecido, de modo 
que el análisis crítico de la información recogida nos lleve a clasificar los datos obtenidos de acuerdo con un baremo.

\subsubsection{La evaluación de las traducciones}

La evaluación de las traducciones ha sido un tema de preocupación y de interés en el ámbito de los Estudios de Traducción, por lo que para poder tratar debidamente los aspectos más relevantes relacionados con la traducción como instrumento de evaluación debemos acudir, en primer lugar, a los planteamientos desarrollados en el entorno de la traductología y de la didáctica de la traducción, donde nos encontramos con la descripción que hace Lee-Jahnke de la situación general de la traductología acerca de esta cuestión:

L'évaluation en traduction est un thème à la mode au point même de susciter actuellement des enquêtes internationales via Internet [...], de nombreux colloques et des articles de revues spécialisées (The Translator 2000). Pourquoi? Parce que, d'une part, les critères d'évaluation ne sont pas aussi clairs qu'on le souhaiterait et que, d'autre part, notre profession, dont la notoriété s'accroît, est en quête d'une assise forte en ce domaine. En effet, la traductologie ne peut être respectée à sa juste valeur que si elle est en mesure de fournir des «produits» de qualité. (Lee-Jahnke 2001:259)

En el entorno de la didáctica de la traducción, Martínez Melis y Hurtado Albir (2001) señalan con mayor precisión cuáles son los aspectos que han recibido mayor interés de los investigadores hasta el momento al considerar la evaluación de las traducciones:

In the context of translation teaching, reflection has basically focussed on the search for correcting and rating scales (Delisle 1993; Hurtado 1995), on how errors in translation operate (Nord, 1996; Kussmaul 1995; Pym 1993; Gouadec 1981 and 1989) and on the notion of the translation problem, which is closely linked to that of translation error (Nord 1988; Presas 1996). (Martínez Melis y Hurtado Albir 2001:274-275)

Tanto los aspectos relacionados con los criterios de evaluación y los baremos de calificación, la noción de problema traslativo, así como la relatividad del concepto de error de traducción, son aspectos pertinentes para tratar la evaluación de las traducciones en todos los casos, es decir, con independencia de que la evaluación se lleve a cabo con el fin de formar traductores profesionales o con otros fines distintos, como el que nos ocupa en este trabajo, y también con independencia de que la evaluación sea sumativa o formativa, a excepción de las 
condiciones de validez de la traducción como prueba de evaluación, tal como veremos más adelante.

Por otra parte, de acuerdo con Waddington (2001), los trabajos del ámbito de la traductología que se han ocupado de la evaluación de la calidad de las traducciones han sido principalmente descriptivos y teóricos, siendo excepcionales los trabajos empíricos, y se han concentrado específicamente en uno o varios de los siguientes aspectos:

- Establishing the criteria for a «good translation» (Darbelnet 1977, Newmark 1991);

- The nature of translation errors:

- Defining the nature of translation errors as opposed to language errors (House 1981, Nord 1993, Kussmaul 1995, Gouadec 1989);

- Drawing up a catalogue of possible translation errors (Gouadec 1981);

- Establishing the relative, as opposed to absolute, nature of translation errors (Williams 89, Gouadec 89, Pym 92, Kussmaul 95) [sic];

- The need to assess quality not only at the linguistic but also the pragmatic level (Sager 1989, Williams 1989, Hewson 1995, Kussmaul 1995, Nord 1996, Hatim \& Mason 1997);

- Basing quality assessment on text linguistic analysis (House 1981, Larose 1989);

- Establishing various textual levels on a hierarchical basis and linking the importance of mistakes to these levels (Dancette 1989, Larose 1989);

- Assessment based on the psycholinguistic theory of «scenes and frames» (Dancette 1989 and 1992, Bensoussan \& Rosenhouse 1994, Snell-Hornby 1995).

(Waddington 2001:311-312)

Podemos generalizar diciendo que el objetivo común de estos trabajos es doble ya que, por un lado, se parte de la preocupación por establecer cuáles son los parámetros necesarios para la evaluación (bien desde un enfoque inclusivo, que intenta abarcar todos los aspectos involucrados, o bien desde un enfoque exclusivo, que intenta establecer cuáles, de entre los posibles, son los parámetros relevantes para la evaluación), mientras que, por otro lado, los esfuerzos se encaminan a establecer criterios que sean objetivos y transparentes, incluyendo la cuestión de establecer qué es un error de traducción y qué no lo es.

Dada la cantidad de variables implícitas en la evaluación de las traducciones, no es sorprendente que los aspectos particulares que están recibiendo el interés de la investigación en el ámbito de los Estudios de Traducción sean tan diversos como Waddington señala. No obstante, dado que en nuestro trabajo la consideración de los aspectos concernientes a la evaluación de las traducciones está guiada por la cuestión del potencial de la traducción como herramienta de 
evaluación para el aprendizaje, no todos los aspectos investigados tienen la misma relevancia para nuestro objetivo, máxime si tenemos en cuenta que los fines de la evaluación tal como es investigada en los Estudios de Traducción no tienen por qué coincidir exactamente con los planteados en nuestro trabajo, ni con los límites de la didáctica tampoco.

Dentro del ámbito de la didáctica de la traducción, es conveniente recordar que la traducción es considerada en los Estudios de Traducción como un instrumento de evaluación del aprendizaje de la competencia traductora, y que esta competencia traductora es lo que se suele identificar en ese ámbito como el objetivo educacional por defecto cuya consecución es evaluada mediante la traducción: «the object of evaluation (what is being evaluated) ultimately takes us back to the competencies required in order to carry out a good translation» (Martínez Melis y Hurtado Albir 2001:275). Sin embargo, en el entorno de la didáctica de las lenguas para fines específicos estamos considerando como objetivo educacional por defecto la competencia comunicativa en la lengua extranjera desde una perspectiva global de la comunicación en el entorno profesional.

Ahora bien, tomando como referencia la 'relación de posibles ingredientes de la competencia traductora' elaborada por Zabalbeascoa (1999), que ya reprodujimos anteriormente (v. 2.4.1), podemos concluir que una buena parte de los conocimientos y destrezas necesarios para tener una buena competencia traductora son igualmente necesarios para comunicarse de forma eficaz en cualquier entorno profesional, tales como un conocimiento (o sensibilidad especial) de la naturaleza de los fenómenos lingüísticos y comunicativos y de las diferencias que pueden existir entre las lenguas y las culturas (así como la subjetividad de sus perspectivas), el dominio de una amplia gama de recursos retóricos, una buena formación académica e intelectual y la experiencia de haber leído una gran variedad de tipos de textos en más de una lengua, y un cierto nivel de inteligencia y capacidad de razonamiento lógico e inferencial, junto con una memoria que permita aprovechar al máximo todas las experiencias, así como una gran capacidad de análisis (Zabalbeascoa 1999:36-37).

La cuestión es que, si tomamos la traducción como un modo de mediación intercultural dentro de un modelo comprehensivo de comunicación, podemos identificar conocimientos, destrezas, o estrategias que son comunes a muchas actividades diferentes relacionadas con la comunicación mediante textos. Es en este sentido como podemos decidir qué resultados de la investigación acerca de la evaluación de las traducciones pueden contribuir a establecer la funcionalidad 
didáctica de este tipo de actividades en el entorno de la didáctica de las lenguas extranjeras y de la didáctica de las lenguas para fines específicos.

En última instancia, además de los diferentes énfasis y descripciones de algunas subcompetencias asociadas con la competencia traductora y/o con la competencia comunicativa, la investigación sobre la evaluación de las traducciones que más interés presenta para nuestro trabajo es aquella que se ocupa de cuestiones que afectan, más que a la evaluación sumativa mediante la traducción, a la evaluación formativa (incluyendo los procedimientos de autoevaluación), es decir, a la dimensión de la evaluación como una actividad de aprendizaje.

En este sentido, por lo que concierne al ámbito de la traducción especializada, nos resulta interesante el trabajo de Bowker (2001), que se inscribe dentro de las propuestas relacionadas con la mejora de las referencias o criterios de evaluación de las traducciones. El interés de este trabajo para nuestro enfoque reside en que Bowker señala la urgencia que exige la resolución de la carencia de criterios fiables no sólo cuando se realiza una evaluación sumativa, sino también cuando se desea llevar a cabo una evaluación formativa:

[In the past] many translations were assessed in a relative vacuum -a situation that is particularly untenable in a translation classroom, where trainers are responsible not only for grading students' work, but perhaps more importantly for providing useful feedback. (Bowker 2001:345)

La solución que aporta Bowker para paliar este problema se relaciona con la utilización de muestras auténticas suficientemente representativas de la lengua de especialidad que puedan aportar evidencias acerca del uso real de la lengua en el contexto de situación relevante:

\footnotetext{
Given that translation evaluation entails making judgements about appropriate language use, it should not rely on intuition, anecdotal evidence or small samples; rather, such studies require empirical analyses of larger bodies of authentic text, as found in the corpus-based approach. (Bowker 2001:346)
}

Para esta autora, un corpus representativo de textos relevantes es útil para poder comparar traducciones de acuerdo con diferentes niveles de comparación: «a specially designed Evaluation Corpus can act as a benchmark against which translator trainers can compare student translation on a number of different levels» (Bowker 2001:345). La presuposición subyacente en la que se basa Bowker para utilizar el corpus de textos como referencia externa para la evaluación de las traducciones es que, al tratarse de datos objetivos y no de información intuitiva extraída del acervo personal del profesor, los textos constituyen una fuente de 
feedback más convincente y fiable que cuando el profesor utiliza como referencia únicamente sus conocimientos e intuición personales:

By having access to a wide range of authentic and suitable texts, the trainer can verify or correct the students' choices, both conceptual and linguistic, and can provide more constructive feedback based on the evidence (or indeed, on the lack of evidence) in the corpus. Moreover, students benefit more from, and are more receptive to, this type of concrete and objective feedback because they can see for themselves that it is based on corpus evidence and not merely on the subjective opinions or incomplete understanding of the trainer. (Bowker 2001:345-346)

Con la elaboración de este corpus especial para la evaluación, Bowker pretende desarrollar una metodología general, que puede ser también utilizada de forma complementaria a otros métodos, y que permite a los profesores evitar la utilización de criterios de evaluación de tipo intuitivo. Y lo que es más, la utilización del corpus como fuente de información permite también establecer una escala de valores en cuanto a la importancia relativa de los errores de las traducciones producidas por los aprendices: «a [...] general methodology that translator trainers can adopt in order to equip themselves with the information they need in order to be able to make sound decisions with regard to the seriousness of the errors they encounter» (Bowker 2001:346).

El planteamiento de Bowker parte del supuesto de que lo que produce la subjetividad en la evaluación de las traducciones es la no utilización de una fuente de información fiable en los casos en que el profesor no puede ser considerado como tal. Este caso, frecuente según Bowker en el ámbito de los Estudios de Traducción, es identificado también como una situación habitual en el entorno del Inglés para Fines Específicos, donde los profesores encargados de los cursos no suelen ser expertos del campo de especialización. Por este motivo, el supuesto de Bowker es asimismo relevante para el entorno didáctico considerado aquí, si bien en el caso del Inglés para Fines Específicos (a diferencia de lo que suele suceder en los Estudios de Traducción) los aprendices tienen con frecuencia mayores conocimientos especializados que los profesores de lenguas para fines específicos (Giménez 1996).

Para la evaluación de las traducciones producidas por los estudiantes, Bowker utiliza como criterio de referencia la lengua del corpus de textos especializados confeccionado ad hoc por ella misma. Así, su propuesta para mejorar la fiabilidad de la referencia utilizada consiste en adoptar un modelo de evaluación con una referencia de tipo criterial (v. 6.2.1.1) en el que, al utilizar una muestra 
suficiente de textos especializados auténticos como referencia acerca de qué es normal y qué no lo es, el resultado de la evaluación contribuye al aprendizaje del alumno al constituir un feedback preciso y objetivo (Bowker 2001:347). La comparación del uso de la lengua en los textos producidos por los estudiantes con el propio comportamiento de la lengua presente en el corpus nos indica que el criterio utilizado para evaluar las traducciones consiste en las normas de uso de la lengua de especialización, extraídas a partir de la presencia y ausencia de elementos lingüísticos en el corpus.

No obstante, el procedimiento utilizado por Bowker, basado en el análisis comparativo entre el resultado de la actuación del aprendiz y el corpus electrónico de textos especializados de referencia, proporciona únicamente información relativa a la aparición (o ausencia) y frecuencia relativa de elementos lingüísticos de rango menor a la oración (palabras, colocaciones, etc.), de acuerdo con los resultados obtenidos mediante un programa de concordancias, WordSmith Tools en este caso. Este procedimiento permite al profesor y al alumno, por tanto, averiguar si el elemento sobre el que desea realizar la búsqueda está presente en el corpus, con qué frecuencia y en qué situaciones contextuales y co-textuales aparece. De acuerdo con los resultados obtenidos, se establece la pauta o norma de utilización del elemento en cuestión en la lengua especializada del corpus.

Esta propuesta ofrece evidentes ventajas en cuanto a la objetividad del tipo de evidencia discursiva que es capaz de proporcionar a los profesores de traducción. No obstante, creemos que constituye un feedback limitado para la evaluación formativa. La utilización de un corpus como referencia externa puede proporcionar evidencias acerca de la presencia y frecuencia relativa de ciertos tipos de elementos. Pero creemos que, a menos que estemos considerando un corpus suficientemente grande, los resultados constituirán una caracterización simplificada del tipo textual, por lo que debemos aceptar con cautela las generalizaciones acerca del uso lingüístico de los elementos analizados. En este sentido, se trata de un feedback necesario pero probablemente no suficiente en cuanto a su fiabilidad como representación típica de un tipo de discurso.

Por otra parte, aunque con la utilización del corpus podamos comprobar y quizá elaborar explicaciones acerca del uso de la lengua de especialización, éste no nos puede proporcionar información acerca de la actuación del aprendiz. Es decir, el procedimiento propuesto por Bowker utiliza la norma de uso de la lengua de especialización como criterio de calidad de la actuación del aprendiz. Identifica, por tanto, la actuación del aprendiz con una actuación que aspira a ajustarse a la norma 
de uso establecida mediante el corpus textual, con lo cual deja fuera de consideración cualquier aproximación a la actuación del aprendiz que se base en el control consciente por parte de éste de la actividad de traducir y de la producción del TT.

Desde nuestra perspectiva, creemos que es conveniente desligar las normas socioculturales de uso del lenguaje, que son convenciones establecidas en una dimensión supraindividual, con la actuación real del aprendiz. Así, no creemos que un texto sea única ni fundamentalmente el resultado de normas socioculturales de ningún tipo, sino más bien el resultado de un propósito y un deseo controlados individualmente por el autor que produce el texto, que es quien toma las decisiones relativas a qué elementos componen el texto y cómo se relacionan entre sí, incluyendo la utilización de cualquier clase de comportamiento convencional. Creemos que no debemos dar por sentado que el autor del texto desea hacer un uso convencional del lenguaje en todo momento. En este sentido, el texto no tiene por qué ser un reflejo fiel de un repertorio de normas socioculturales, a pesar de que el corpus pueda informarnos acerca del uso convencional del léxico utilizado en los textos analizados, así como de otros tipos de información.

Así pues, podemos decir como conclusión que la utilización de un corpus como referencia externa en la evaluación de las traducciones es útil para proporcionar feedback objetivo sobre el uso de elementos léxicos, de estructuras sintácticas, o de otros tipos de información textual y contextual, pero no sobre aspectos relacionados con la actuación de los aprendices en las traducciones elaboradas por ellos.

Bowker utiliza la información obtenida al analizar el corpus para establecer la gravedad de los errores presentes en las traducciones realizadas por los aprendices. Desde su perspectiva, los errores de traducción son errores en cuanto a un uso que no corresponde con la norma convencional extraída del lenguaje del corpus. Desde un enfoque cognitivo sobre la traducción, no podemos identificar todos los errores de traducción como errores relacionados con el uso convencional del lenguaje. Necesitamos una gradación del error que tenga que ver con el control ejercido sobre el TT, como producto que ha traspasado el umbral de finalización, aunque esa gradación se refiera a una tipología de errores que incluya también aquellos derivados de un uso no convencional del lenguaje de acuerdo con un contexto particular. El tipo de feedback que necesitamos, por consiguiente, deberá incluir también información sobre la actuación específica del aprendiz, de tal modo que sea no sólo preciso y objetivo, sino también significativo para el aprendiz. 
Además de utilizar un criterio externo de evaluación que sea objetivo, como el corpus que propone Bowker, existen otras posibilidades para establecer criterios fiables de evaluación.

Gerzymisch-Arbogast (2001) parte del supuesto de que la subjetividad es inevitable al llevar a cabo la evaluación de las traducciones, puesto que es inherente al evaluador. A partir de este planteamiento esta autora propone, como medida para controlar la subjetividad, hacer explícitos los parámetros de evaluación que estamos utilizando, así como la relación jerárquica existente entre ellos. En esto, su planteamiento es consistente desde el punto de vista de la didáctica general, puesto que un modo de evitar la utilización de criterios internos y subjetivos consiste, precisamente, en hacer que éstos sean explícitos y que el estudiante los conozca de antemano.

Para esta autora, la interrelación de parámetros que aplicamos en la evaluación de las traducciones depende en gran medida del propósito del TT:

Translation evaluation will always contain a «subjective» element because evaluators have different preferences and make different judgements. However, these need to be made transparent as the evaluator's individual ranking of equivalence parameters according to their assumed or projected relevance in the target text. Such ranking judgements will largely depend on the purpose of the target text. (Gerzymisch-Arbogast 2001)

De acuerdo con este planteamiento, la relación jerárquica de los parámetros de evaluación no es fija, sino que adopta una configuración específica en función del tipo de texto de que se trate. Esto es consistente con una perspectiva cognitiva sobre la interacción entre el lector y el texto, en cuanto que las expectativas que tenemos sobre un texto están condicionadas (al menos en parte) por el tipo textual con el que lo asociamos.

El tipo textual constituye una representación que aglutina todo lo que se considera un patrón habitual en los textos que asociamos con ese tipo en cuestión, lo que podemos esperar encontrar y no encontrar típicamente, es decir, lo que consideramos normal en la representación verbal del evento comunicativo de que se trate. La generalización de patrones en forma de clase textual supone una estrategia para procesar de manera económica la información que nos encontramos de modo que, al asignar las expectativas asociadas con un tipo textual a un texto en particular, activamos un modelo de procesamiento relevante para esa situación. Como señala Smith (1978:124), «the specific questions a particular reader might ask at a particular time depend on what is read and the reasons for reading it». Algunos investigadores manifiestan que este tipo de procesamiento selectivo también es 
relevante para la traducción. Ibrahim, por ejemplo, señala que «different text types and different reasons for translating call for different strategies» (Ibrahim 1994:151). En el caso de la evaluación de las traducciones, este planteamiento implica el propósito de valorar la actuación del aprendiz en cuanto a las estrategias empleadas para producir el texto. O, dicho de otro modo, en una evaluación cuyos parámetros tienen una relevancia relativa de acuerdo con el tipo textual, subyace el planteamiento de que el aprendiz se ha basado en el tipo textual para tomar (parte de) las decisiones que le han llevado a producir el texto en particular que vamos a evaluar.

Este planteamiento, en el que la relación jerárquica de los parámetros que forman el criterio de la evaluación no es fija para todos los casos, es consistente también con la perspectiva funcionalista sobre la traducción, en cuanto que es la función del TT la que marca o guía la actuación del traductor, tal como señala Nord:

The overall frame of reference for the translator should not be the original and
its function, as equivalence-based translation theory would have it, but the
function (or set of functions) the target text is to achieve in the target culture.
The intended target function or 'translation scopos' is primarily determined by
the addressees of the translation [...] and sets the standard for any decision the
translator is to take in the course of the translation process. (Nord 1992:39)

Por otra parte, los parámetros de evaluación de la traducción que suelen proponer los investigadores no suelen ser susceptibles de proporcionar datos de tipo cuantitativo, de tal forma que la aplicación de los parámetros analíticos organizados de forma jerárquica suele constituir un método cualitativo de análisis. Esto es así debido a que los parámetros utilizados son de tipo descriptivo y se relacionan con aspectos lingüísticos y pragmáticos, ya que se basan en los elementos que constituyen y regulan la traducción (en un sentido muy restrictivo, esto suele incluir un repertorio de procedimientos traslativos y algunos aspectos contrastivos de los sistemas lingüísticos del par involucrado en la traducción), o bien la comunicación (en un sentido amplio que suele abarcar los parámetros que se consideran relevantes para la mediación intercultural en general, incluyendo los anteriores).

En el modelo de análisis textual desarrollado por Nord (1991) para la formación de traductores profesionales, los parámetros que constituyen la referencia para el análisis crítico de la traducción se relacionan jerárquicamente entre sí de acuerdo con un patrón analítico y son los mismos que se utilizan como patrón de toma de decisiones para la producción del TT.

En el modelo de Nord se sigue un procedimiento de traducción que comienza por establecer la función comunicativa del texto a partir del análisis del 
conjunto específico de factores que presenta la situación comunicativa en la que se utiliza el texto. Este análisis de factores extratextuales se lleva a cabo antes de la propia lectura y traducción del texto, de tal forma que el aprendiz pueda elaborar ciertas expectativas acerca de las características intratextuales del TO, con el fin de percibir el efecto textual por contraste entre sus expectativas y lo que la lectura del texto le presenta realmente:

The extratextual factors are analysed before reading the text, simply by observing the situation in which the text is used. In this way, the recipient builds up a certain expectation as to the intratextual characteristics of the text, but it is only when, through reading, he contrasts this expectation with the actual features of the text that he experiences the particular effect the text has on him. The last question (to what effect?) therefore refers to a global or holistic concept, which comprises the interdependence or interplay of extratextual and intratextual factors. (Nord 1992:43)

El modelo de Nord es un modelo de tipo descriptivo en el que sólo el establecimiento del efecto textual implica una valoración al comparar las expectativas creadas con las características textuales. Utilizado como un procedimiento de evaluación, este modelo sirve para hacer explícitos los criterios en los que se ha basado el aprendiz para tomar las decisiones que le han llevado a producir un TT con unas características determinadas. En este sentido, el procedimiento de Nord puede ser utilizado como un constructo pedagógico que constituya un instrumento donde se pueda recoger la información referente a los problemas detectados por el aprendiz al llevar a cabo la traducción, así como el modo como ha llegado a resolver tales problemas y las razones que le han impulsado a hacerlo así.

Por otra parte, la conveniencia de hacer explícitos los parámetros de evaluación que se van a utilizar al valorar la actuación de los aprendices conlleva la introducción y aplicación de dichos parámetros en la propia metodología del curso, con el fin de que el alumno sea capaz de comprenderlos y asimilarlos mediante actividades de evaluación formativa y, en última instancia, para aprender a producir mejores traducciones, tal como explica Chesterman:

In real life, most translation assessment is pedagogical. It is carried out by teachers or professionals, and is applied to translations produced by translation trainees or language students (or perhaps other professionals). It typically takes place as part of translator training, and [...] its main purpose is not descriptive but evaluative. Its aim is either accreditation (that is, to certify whether the translator in question has reached a predetermined standard) or prescription (to provide feedback that will enable the translator to improve the quality of future translations). For accreditation, translations are done in a test 
situation; for prescription, they are done in a learning situation. (Chesterman 1997:138)

Así, los parámetros que se tienen en consideración en la evaluación de las traducciones se suelen utilizar como pautas que guían el procedimiento de traducción en la metodología del curso. Aquí, dada la complejidad de la traducción, House sugiere utilizar una metodología interrogativa que, como ya hemos visto, es apropiada para tratar objetivos de tipo actitudinal:

In view of the complexity of any type of translation activity, we would suggest that any (native or foreign language) source text should be analyzed, discussed, translated, and evaluated either in the class plenum on in small groups so that all students derive the maximum benefit out of the reflections about linguistic/pragmatic choices and their relative adequacy at every step of the translation activities. (House 1981:232)

Por lo que se refiere al baremo de valoración, ya hemos señalado que estos parámetros tienen un carácter descriptivo, puesto que son utilizados para analizar el TO, el TT, así como la situación comunicativa del TO y la del TT. Esto significa que, si queremos utilizarlos para evaluar la calidad de las traducciones, necesitamos incorporar algún tipo de baremo que establezca qué se considera una actuación positiva y qué una actuación negativa o mejorable.

Dollerup (1994) utiliza un sistema de feedback que incluye la utilización del siguiente baremo:

a) an excellent translation,

b) the minor inaccuracy where the original meaning is preserved in the target language,

c) a distortion, but no more so that the meaning of the original can be grasped,

d) an incomprehensible rendering. It may confuse, but will rarely lead astray,

e) a self-contradictory rendering which is misunderstood,

f) a rendering which reads fluently and makes perfect sense in the source language but distorts the meaning of the original.

(Dollerup 1994:123)

Según esta autora, la valoración de las traducciones es también el resultado de la importancia relativa de los errores que se detectan o de la calidad global del texto producido:

Most freshman students's [sic] translations are easily bracketed as (b) to (d)s, that is, as muddled and confused renditions, which are either understandable to the (imaginary) target audience (b-c), or at the very least by the teacher (d).

Type $\mathrm{f}$ is the gravest error which can be commited in translation. However, it is doubtful whether it can be stamped out. The best one can do is 
presumably to call attention to it in classroom settings and hope to make students better at avoiding it in professional work.

Even within these categories, there are variations in importance: a distortion involving only a word [sic] will usually (but not invariably) be less serious than the one [sic] affecting one sentence, and so on. (Dollerup 1994:123)

El baremo utilizado por Dollerup se basa, al menos en parte, en el hecho de que el par de lenguas involucrado (inglés y danés) presenta unas características específicas que influyen en el modo de concebir la traducción:

English and Danish are closely related Indo-European languages which have basic syntactical points in common. They also share numerous words both from Indo-European origin [...] and from Danish introduced by Danish settlers in England in the 8th to the 11th centuries [...]. These linguistic facts affect translation as well as views on translation: in many cases an interlinear translation between Danish and English will make sense, although the actual wording may jar. (Dollerup 1994:122)

En cualquier caso, su importancia para nuestro trabajo no se basa en la escala de gradación que utiliza ni el par de lenguas involucrado, sino en los criterios en los que se sustenta para establecer la gravedad de los errores o la importancia relativa de éstos.

Dollerup utiliza un criterio mixto de valoración. Tiene en cuenta la fidelidad del TT al TO como un criterio general que interpreta, en el caso de ese par de lenguas en particular, como una fidelidad esencialmente semántica: «communication, translation, especially between closely related languages, must be a close semantic approximation to the source text, or, to put it in traditional terms: it must have a high degree of fidelity» (Dollerup 1994:122). Además de este criterio, valora la calidad textual del TT (utilizando calificativos para el TT como 'selfcontradictory' o 'incomprehensible', que no se refieren a la relación entre el TT y el TO), la veracidad de la información del TT (en el último grado de la escala, la información textual no corresponde en cuanto al contenido proposicional con la del original y esta falta de veracidad es considerada el error más grave posible) y el alcance del error en cuestión. Este último criterio es abordado por Dollerup de un modo un tanto confuso en relación con la perspectiva que declara adoptar sobre la traducción como actividad comunicativa de tipo social (Dollerup 1994:122), por lo que nos vamos a detener brevemente en él.

En la escala de Dollerup, se asocia la gravedad de los errores con la cantidad de elementos que se ven afectados en cuanto a su extensión en el texto, de tal modo que si se detecta un error que afecta a una única palabra, se considera más 
leve que si afecta a toda una oración. Es cierto que Dollerup matiza que esto puede no ocurrir siempre, pero no explica de qué depende que esto sea así o no.

Desde una perspectiva holística del texto, el alcance o la importancia relativa de una palabra en un texto depende de múltiples factores que tienen que ver, entre otras cosas, con su frecuencia de aparición y con la posición relativa que ocupa con respecto de los demás elementos del co-texto, así como del contexto de situación (por ejemplo, podemos esperar razonablemente que un error en el modo de tratamiento empleado con el lector será más llamativo que un error al utilizar un nombre inapropiado para un elemento que aparece en el texto de modo marginal).

Por consiguiente, para poder establecer qué tipo de alcance tendrá un error que afecta a una palabra o a otro tipo de elemento textual, debemos establecer necesariamente cuál es el peso relativo de dicho elemento en el texto, cuál es su función tanto desde una perspectiva local como global. Si esto es así, ¿debemos suponer, como tienden a hacer algunos aprendices, que los errores que afectan a elementos no verbales tienen menor importancia que los que afectan a elementos léxicos?, ¿cómo podemos establecer la importancia de cualquier otro factor que se puede ver afectado por la utilización errónea de una única palabra? (por ejemplo, ¿cómo evaluar la importancia de un 'vosotros' en un océano textual de 'ustedes' ?).

Para arrojar luz sobre esta cuestión, Waddington (1999) se ha basado en un método desarrollado por Van Leuven para describir los cambios que se pueden detectar en traducciones literarias narrativas con respecto de sus correspondientes TOs. Este investigador ha descubierto que los datos parecen indicar «que no existe forzosamente una relación consistente entre la calidad global de la traducción y el número de errores detectados al micronivel», por lo que concluye sugiriendo que, más que el error en sí, lo importante parece ser «el efecto que tiene el error sobre el resto de la traducción» (Waddington 1999:259). Esta sugerencia es consistente con un enfoque sobre el efecto textual como un elemento analítico valorativo, más que meramente descriptivo.

Creemos que la asociación que Dollerup establece entre la levedad o gravedad de los errores y la cantidad de elementos lingüísticos afectados se debe a que esta evaluación pretende paliar el problema de los profesores «confronted with large numbers of foreign language errors in translation classes, notably in the beginning [sic]», en lo que denomina «the existence of a large interface, an overlapping area, between foreign language learning and translation» (Dollerup 1994:121). 
Si bien para Dollerup el denominado solapamiento supone un problema para los cursos de traducción, ya que impide concentrarse en la tarea de traducir, nosotros nos planteamos aprovechar este supuesto solapamiento en beneficio del aprendizaje de la lengua extranjera. Desde esta perspectiva, nos parece que es necesario proceder con suma cautela al establecer una asociación directa de tipo cuantitativo entre las unidades lingüísticas de tipo discreto donde se identifica un error y la gravedad de éste, en cuanto a las posibles implicaciones de tal asociación para las presuposiciones de los aprendices acerca del funcionamiento del lenguaje. En especial, nos preocupa que los aprendices tiendan a identificar los posibles errores o problemas que deben resolver únicamente con el nivel léxico de las palabras y no con otros niveles y rangos superiores.

Aun con estas salvedades, el sistema de feedback que emplea Dollerup constituye un tipo de análisis cualitativo de las traducciones producidas por los aprendices que puede ser utilizado como un procedimiento de evaluación formativa no sólo para la enseñanza y el aprendizaje de la traducción, sino también de las lenguas extranjeras y, por lo que concierne a este trabajo, del Inglés para Fines Específicos. Este sistema de feedback consiste en entregar al aprendiz el TT evaluado (es decir, modificado por el profesor mediante la aplicación de los criterios y del baremo de evaluación) para que éste lo analice críticamente a la vista de las puntualizaciones del profesor. Aunque no utilicemos exactamente el mismo baremo que Dollerup, dado que el mismo dependerá de los objetivos del curso, creemos que este sistema tiene una amplia utilidad para desarrollar y practicar estrategias de tipo metacognitivo, puesto que constituye para el aprendiz una herramienta de reflexión sobre su propia actuación, y también para tratar contenidos de tipo actitudinal, puesto que supone la explicitación de los valores que se emplean para decidir acerca de la calidad del texto producido.

En el campo de la investigación sobre los procesos cognitivos involucrados en la traducción, Laukkanen (1996) se plantea la importancia de los factores afectivos en los procesos de traducción, analizando la evaluación de las traducciones desde la perspectiva de la formulación de opiniones críticas durante el proceso de traducción. Nos referimos a opiniones expresadas por un sujeto con respecto de las características que tiene un TO en particular, que debe tener su correspondiente TT (de acuerdo con el propósito del sujeto en cuestión) y, en general, valoraciones positivas o negativas referentes a los factores involucrados en el proceso. Este trabajo, aun cuando no se inscriba directamente en la investigación sobre la didáctica de la traducción, es relevante para establecer si es posible alcanzar 
o ayudar a alcanzar (algunos de) los objetivos del ámbito afectivo mediante la utilización de un sistema de feedback como el de Dollerup, por lo que vamos a centrarnos en su contribución a esta cuestión.

Laukkanen (1996) realiza un experimento en el que analiza la actuación de una traductora profesional al realizar una tarea rutinaria y la compara con la actuación de la misma traductora al realizar una tarea no rutinaria. Ambas tareas consisten en la traducción de un texto. Se mantienen invariables tanto el par de lenguas asociado como la dirección del par en que se realiza la traducción, establecidos ambos de acuerdo con lo que representa la situación más familiar para la persona que realiza el experimento. La variable que se compara es la familiaridad (o no) con el tipo de texto utilizado para llevar a cabo cada tarea en relación con los procesos involucrados en cada caso y el método consiste en el análisis de las semejanzas y las diferencias de actuación del sujeto en la realización de las dos tareas. Este análisis se realiza sobre los datos obtenidos mediante el registro sonoro (y posterior transcripción) de la verbalización que el sujeto hace de la realización de la tarea, es decir, mediante la recogida de TAPs (Think-aloud Protocols). Los aspectos que reciben mayor atención en el experimento son «the affective features revealed by the evaluative utterances as well as their relations to the subject's translation processes and products» (Laukkanen 1996:258), dado que las expectativas previas apuntan a que las aserciones evaluativas del sujeto podrían revelar diferencias de tipo afectivo entre los procesos de las dos tareas y a que estas diferencias, a su vez, podrían servir para explicar algunas de las diferencias cualitativas que se dan entre ambos productos. De hecho, ésa es la tesis final que plantea Laukkanen tras el análisis de los datos obtenidos con el experimento: «evaluative utterances occurring in the protocols may reflect such attitudinal and affective factors that could be correlated wih qualitative differences in translators' performance» (Laukkanen 1996:258).

Así, el experimento de Laukkanen pone de manifiesto que existen diferencias de tipo cuantitativo en el número de aserciones evaluativas expresadas por el sujeto, con una cantidad de opiniones críticas mayor en la tarea rutinaria (la realizada con el tipo de texto considerado familiar), pero no se dan diferencias significativas de tipo cualitativo, es decir, las opiniones críticas formuladas en ambos casos son cualitativamente semejantes pero cuantitativamente más numerosas en el caso de la tarea rutinaria. Los resultados de este experimento tienen una validez asociada principalmente con la identificación de parámetros relevantes en la utilización del método de TAPs (v. Laukkanen 1996:260), por lo que este 
experimento revela que no existen diferencias significativas en cuanto a la clase de aserciones evaluativas expresadas en relación con la familiaridad de la tarea de traducción cuando se utilizan los TAPs como sistema de recogida de datos, sino que, cuando la tarea se lleva a cabo con un tipo de texto que es familiar para el sujeto, las aserciones evaluativas expresadas por él son únicamente más numerosas. La cuestión que más nos interesa aquí es ¿qué repercusiones puede tener esto para la utilización de la traducción con fines didácticos?

Por lo que concierne a los intereses específicos de nuestra tesis, no sólo los resultados sino el planteamiento general de Laukkanen nos permitirán esclarecer algunos puntos en particular.

En primer lugar, el experimento de Laukkanen contribuye a apoyar la hipótesis de que las tareas de traducción son pruebas útiles para recoger datos acerca de las actitudes y opiniones del sujeto que las realiza. Esto significa que, al menos potencialmente, las tareas de traducción tienen una utilidad específica en su didáctica como medio de facilitación del aprendizaje de contenidos de tipo actitudinal. Esta investigadora nos sugiere que, cuando es utilizada con el propósito de analizar las actitudes, los intereses o los valores del sujeto que realiza la tarea, la traducción puede tener capacidad como prueba indirecta de recogida de información de las actitudes y opiniones críticas de los aprendices. Según señala Waddington (1999:268), las pruebas indirectas intentan «medir competencias que subyacen a la destreza que queremos medir», si bien este tipo de pruebas tiene la desventaja de que «a veces resulta difícil apreciar la conexión entre el contenido de la prueba» (producir un TT a partir de un TO) y la competencia que se quiere medir o 'competencia criterial' (en nuestro caso, saber interpretar el contexto de situación asociado típicamente al tipo de texto especializado que se ha traducido, por ejemplo). Por el contrario, en una prueba directa lo que se quiere evaluar es precisamente la destreza que se pide ejecutar en la propia prueba, por lo que se utiliza la traducción como prueba directa cuando se quiere evaluar la competencia traductora del sujeto, lo cual no es nuestro caso.

No obstante, las tareas de traducción no son suficientes por sí mismas como pruebas indirectas de recogida de información de tipo cognitivo o actitudinal. El resultado final de la tarea (el TT) no es una evidencia suficientemente elocuente o inteligible en sí, ya que ofrece únicamente los resultados de un proceso en el que intervienen característicamente la resolución de los problemas identificados como tales al realizar la tarea (problemas traslativos o de otra índole), así como las decisiones que han sido necesarias para llevar a cabo la tarea. 
Desde la perspectiva de los aspectos relacionados con el ámbito afectivo, el texto elaborado por el sujeto como resultado final de la tarea presenta unas características configuradas de acuerdo con las decisiones adoptadas por él mismo (bien consciente o bien inconscientemente) que no constituyen una formulación explícita de sus actitudes, valores o intereses. Por esta razón, el TT, si bien asociado a tales actitudes, intereses o valores (en cuanto que, en cierto modo es el resultado de una actuación guiada por ellos), no es suficiente como fuente de información acerca de los mismos. Es necesario, por consiguiente, utilizar algún tipo de herramienta subsidiaria que permita recoger información referente a la propia realización de la tarea para relacionarla con el resultado de la misma.

Con la finalidad de recoger la información referente al proceso de la traducción, en el trabajo de Laukkanen (1996) se ha utilizado una herramienta propia de la metodología de la investigación experimental sobre los procesos de tipo cognitivo. El inconveniente para nosotros es que esta herramienta no es adecuada para los fines didácticos propuestos aquí, debido a su incapacidad para recoger de forma conveniente los datos procedentes de la verbalización de la realización de la tarea de cada uno de los alumnos cuando esta tarea se realiza en el aula.

No nos referimos sólo a la complejidad técnica que supone recoger simultáneamente los datos de un grupo numeroso de alumnos o a los medios necesarios para ello, sino que también debemos contar con la influencia del grupo en la inhibición o en la desviación de las verbalizaciones, así como considerar la atención desproporcionada que probablemente recibiría la aplicación de tal procedimiento. Digamos que la utilización de este método de recogida de datos no nos resulta fácilmente compatible con la aplicación de un método interrogativo para tratar en el aula los aspectos relacionados con los valores, actitudes u opiniones de los aprendices en el entorno descrito en este trabajo. Esta suposición se basa en que el tiempo y los medios que deben ser empleados para obtener la información son excesivos como para que la aplicación sea eficiente en este entorno (lo cual no significa que este método de recogida de datos no sea apropiado en otras condiciones, de tal modo que pueda ser utilizado para la evaluación formativa mediante el método de estudio de casos, por ejemplo).

En este sentido, creemos que resulta más útil o más aplicable una herramienta de recogida de información apropiada para la clase de metodología y de objetivo educacional planteados y, preferiblemente, de tipo escrito.

Morales Vallejo (1995c) señala que, cuando queremos recoger información acerca de actitudes, valores o intereses, los tipos de prueba preferibles son los 
sistemas cerrados, tales como las denominadas 'escalas' o los 'cuestionarios', ya que en ellos es más fácil codificar e interpretar las respuestas, en contraposición con lo que sucede con las pruebas de respuesta abierta. Volveremos sobre esta cuestión más adelante, para tratarla de forma más precisa en relación con la traducción como método de evaluación formativa para el aprendizaje del Inglés para Fines Específicos.

En la clasificación utilizada por Laukkanen para identificar los diferentes tipos de opiniones críticas expresadas por el sujeto, se establece una distinción muy interesante para nuestra tesis. Esta investigadora identifica los casos relevantes como «utterances that contained an [explicit] evaluation of anything that was somehow connected with the assignment»(Laukkanen 1996:263). No obstante, aislar los casos pertinentes evitando al mismo tiempo una complejidad excesiva para el tipo de estudio propuesto se revela como una tarea compleja, debido a la presencia de casos cuya pertinencia es confusa, por lo que Laukkanen se ve en la necesidad de establecer una distinción entre lo que denomina 'clear evaluations' y 'neutral opinions':

\begin{abstract}
Of course virtually everything that a person says can be considered in some sense evaluative, but in order to avoid excessive complexity in the analysis in the present study, only the 'clear' evaluations where the subject expressed likes or dislikes, acceptance or rejection -i.e. said that something was good or bad, fluent or clumsy, difficult or easy, interesting or boring, etc.- were included in the analysis. In addition to this, certain 'neutral' opinions uttered by the subject, even though they could not be directly categorized as either positive or negative, were regarded as evaluations. (Examples of neutral evaluations included in the analysis are «well this is indeed typical text» [sic] or «this text really addresses people directly»). (Laukkanen 1996:263) (énfasis original)
\end{abstract}

Esta distinción entre evaluaciones y opiniones neutras refleja al menos dos tipos de comportamiento analítico en el sujeto del experimento: por una parte, el análisis describe lo que el sujeto ve, mientras que por otra, el análisis revela lo que el sujeto evalúa (es decir, describe emitiendo un juicio de valor) y los términos (más bien positivos o más bien negativos) de dicha valoración. Al poner de manifiesto lo que el sujeto ve y valora en el TO, en el TT, o bien en otros aspectos relacionados con la situación que son considerados pertinentes por el propio sujeto (puesto que es quien los saca a colación), el análisis efectuado constituye un método indirecto para hacer explícitos algunos aspectos más o menos puntuales del estado de conocimientos, actitudes y valores del sujeto. 
Podemos concluir, por tanto, que es potencialmente posible obtener información referente al estado de conocimientos, actitudes y valores de los aprendices mediante un método indirecto de recogida de información similar al utilizado por Laukkanen, aunque no tenga que ser necesariamente el aplicado por la investigación experimental.

Desde la perspectiva de la didáctica, la importancia de acceder a este tipo de información radica en que esto permite al profesor poder someterla a evaluación. Es decir, el profesor puede, de este modo, valorar los datos críticamente y sopesarlos en relación con el contexto especializado de situación comunicativa que es relevante en el contexto educativo de que se trate.

Tal como ya hemos señalado, Cunningham (1998:45) sugiere que el objetivo de la evaluación formativa del estado de conocimientos, actitudes y valores de los alumnos debe permitir, en última instancia, que podamos tomar decisiones justificadas que afectarán de un modo u otro a las características o al desarrollo del curso (por ejemplo, establecer qué contenidos son más relevantes para alcanzar el nivel de competencia o de capacidad deseado en relación con la actuación experta). La información obtenida mediante este procedimiento debe poder ser utilizada como base para la enseñanza y el aprendizaje. Si es éste el caso, la distinción entre aserciones descriptivas y aserciones evaluativas es relevante para identificar diferentes tipos de datos, puesto que podemos suponer razonablemente que las opiniones neutras o aserciones descriptivas ponen de relieve presuposiciones del sujeto relacionadas con sus conocimientos experienciales del mundo, mientras que las evaluaciones propiamente dichas o aserciones evaluativas contendrán información relacionada específicamente con las actitudes y los valores del sujeto.

En las secciones posteriores, especificaremos con mayor detalle las características de una herramienta de recogida de información de este tipo pero antes, en el apartado que introducimos a continuación, vamos a tratar otra cuestión más general relacionada con la traducción como un instrumento de recogida de información: las condiciones de validez de la traducción cuando es utilizada como prueba de evaluación.

\subsubsection{Las condiciones de validez de la traducción como prueba de evaluación}

De acuerdo con Cunningham (1998), podemos establecer una distinción entre la validez de las pruebas de tipo objetivo y los métodos alternativos de 
evaluación, que incluyen las pruebas de actuación (así como el uso de los denominados 'portafolios', que trataremos más adelante).

No obstante, para poder establecer la validez de la traducción con la finalidad formativa que estamos investigando, debemos tratar en primer lugar otro tipo de distinción que ya hemos mencionado previamente (v. 6.3.1), aunque sin detenernos en profundidad. Nos referimos a las diferencias existentes entre las 'pruebas directas' de evaluación y las denominadas 'pruebas indirectas'.

Cunningham (1998:140) considera que una prueba es directa cuando la interpretación de sus resultados no se basa en inferencias. Por ejemplo, en la prueba práctica para obtener el carnet de conducir en España se pide al candidato que conduzca por entre el tráfico haciendo cierta cantidad de maniobras con el objetivo de medir su capacidad para conducir en situaciones reales. El objetivo de una prueba directa es evaluar la destreza que se pide ejecutar en la propia prueba, por lo que se identifica la actuación puntual con el propio constructo que se mide (Waddington 1999:268). Así pues, la traducción se utiliza claramente como prueba directa cuando el objetivo de la evaluación es averiguar el estado de conocimientos de la competencia traductora de los aprendices.

Por el contrario, las pruebas indirectas son descritas como «indicators of a student's status in relation to the construct being measured» (Cunningham 1998:127). Lo que se intenta medir con este tipo de pruebas son competencias o comportamientos subyacentes asociados a la propia destreza. En este caso, el inconveniente que se presenta con respecto a su validez consiste en las dificultades para establecer la conexión entre el contenido de la prueba y la competencia que se quiere medir (Waddington 1999). Así pues, si queremos analizar la funcionalidad de la traducción como prueba de evaluación de otras competencias, capacidades o habilidades que las asociadas con la competencia traductora, debemos definir en primer lugar la conexión entre las actividades o items de la prueba de traducción y el constructo de medición.

Otro problema añadido consiste en que, cuando consideramos la traducción como un instrumento de evaluación formativa para facilitar la adquisición de conocimientos de tipo actitudinal, por una parte estamos tomando la traducción como una prueba de actuación mientras que, por otra, decimos que se trata de una prueba indirecta de evaluación. Dado que las pruebas de actuación se suelen considerar pruebas directas, por las razones apuntadas más atrás, a continuación vamos a tratar de establecer cuáles son las condiciones necesarias para evitar caer en esta contradicción. Así pues, para poder resolver los problemas que hemos 
planteado, vamos a comenzar por definir a qué nos referimos cuando hablamos de un constructo de medición.

Utilizamos la denominación 'constructo de medición' como un término genérico que designa una clase de comportamientos, que son los atributos que se evalúan, y cuya totalidad se denomina 'dominio de observables', de acuerdo con la descripción de Cunningham:

\begin{abstract}
A construct is defined by all the behaviors that are associated with it. The totality of these behaviors is called the domain of observables. For tests, the domain of observables would include all of the possible items that could be included and not just the actual items that appear on a particular test or measuring instrument. The goal of good test construction is to ensure that the items on a test are representative of the entire domain. When this occurs, it is legitimate to claim that the score of the test represents an estimate of the quantification of a construct on the basis of item responses. (Cunningham 1998:11)
\end{abstract}

Desde esta perspectiva, la cuestión que se plantea en primer lugar es en qué condiciones puede la traducción ser considerada una prueba válida en relación con el constructo de medición.

Según Cunningham, la validez con el constructo no es relevante cuando nos referimos a las pruebas de actuación, dado que se trata de pruebas directas de evaluación: se considera que la competencia del sujeto es directamente observable en su actuación en la prueba. Por consiguiente, podemos concluir que, en el caso de la traducción, la validez en relación al constructo no es relevante cuando el objetivo de la evaluación es la medición de la competencia traductora. Pero la cuestión no es tan obvia cuando lo que queremos medir no es la competencia traductora, sino otros tipos de conocimientos, capacidades o habilidades.

Cuando la traducción es una prueba de actuación pero además constituye una prueba de evaluación indirecta, como es el caso que estamos considerando aquí, de lo que estamos hablando es de una prueba compuesta por más de un instrumento de recogida de información, cuyos objetivos específicos no son comunes a todos ellos. Estamos hablando, por consiguiente, de una prueba que se lleva a cabo a partir de una serie de instrucciones que conllevan no sólo la producción de un texto (el TT). Además de ésta, se pide también la producción de algún tipo de resultado documental donde el aprendiz pueda suministrar información referente al proceso que ha seguido para producir el texto, al que nos hemos referido como 'constructo pedagógico' y cuyas funciones principales asignadas son que el aprendiz pueda verbalizar su actuación al traducir y que, a la larga, pueda llegar a realizar la tarea 
ejerciendo un control consciente sobre el proceso de toma de decisiones involucrado en la misma.

Así pues, la traducción constituye una prueba indirecta en relación con el objetivo de la evaluación sólo en cuanto que producción del TT, mientras que podemos considerar que se trata de una prueba directa en cuanto que verbalización de la reflexión consciente recogida mediante el instrumento que utilicemos para tal fin.

Desde esta perspectiva dual, la validez de la traducción en relación con el constructo de medición se identifica, cuando no queremos evaluar la competencia traductora, con la validez del instrumento adicional de recogida que utilicemos aparte del propio TT. En tanto en cuanto dicho instrumento constituya una prueba de actuación podemos considerar que, como prueba directa, su validez con respecto al constructo de medición no es relevante, como sucede por ejemplo si pedimos al aprendiz que exprese verbalmente todos sus pensamientos al llevar a cabo la traducción y recogemos esa verbalización mediante una herramienta apropiada para tal fin.

En el supuesto que nos ocupa en este trabajo, una vez que hemos procedido a la recogida de información, el análisis de los datos obtenidos nos puede llevar a distinguir, como hace Laukkanen (1996), entre aserciones descriptivas y aserciones evaluativas que nos permitan identificar diferentes tipos de información referente al estado de conocimientos, actitudes y valores del sujeto.

En cualquier caso, la validez con respecto del constructo de medición no es lo único que debemos considerar en relación con esta cuestión. Cunningham menciona dos posiciones confrontadas en relación con la validez necesaria cuando utilizamos pruebas de actuación (performance tests):

\footnotetext{
When interest in the use of performance tests was increasing in the early 1990 s, there were two distinctly different points of view regarding validity. The more conservative of the two emphasized the importance of maintaining high standards of validity for performance tests. The second perspective placed less importance on the need for these assessments to meet the same tchnical standards as other tests. (Cunningham 1998:139)
}

Desde la perspectiva menos conservadora de estas dos, este autor apunta la falta de relevancia de la validez de las pruebas de actuación en relación con el constructo de medición, dada su condición de pruebas directas. Existen dos tipos más de validez que debemos considerar para llegar a una conclusión global. Se trata de la validez con respecto de los contenidos de la prueba, así como la validez en relación con el criterio adoptado. Las pruebas de actuación no suelen tener validez 
en cuanto a los contenidos porque «the lengthy responses required on performance tests permit the inclusion of only a small number of items» (Cunningham 1998:139). No obstante, este autor defiende la utilización de estas pruebas «against charges of poor content validity by an emphasis on the directness of their assessment instructional objectives» (Cunningham 1998:139). En cuanto a la validez en relación al criterio, Cunningham (1998:139) señala su irrelevancia para las pruebas de actuación, ya que «the instructional goals they address are intended to be ends in themselves. They are the criterion and this characteristic obviates the need for concern abouth whether performance tasks meet the criterion».

Por último, queremos enfatizar que las consideraciones y conclusiones que acabamos de exponer se limitan a la evaluación formativa y a la traducción como una prueba de tipo pedagógico y no clasificatorio, que son las condiciones específicas que nos permiten llegar a concluir que, cuando la traducción es utilizada como prueba de evaluación de otro tipo de conocimientos, capacidades, destrezas o habilidades que no son la propia competencia traductora, entonces es necesario utilizar un instrumento adicional de recogida de datos que tenga las características de una prueba de actuación directa. Para otros casos diferentes, deberemos considerar la cuestión con otros criterios más estrictos, tal como señala Cunningham:

\begin{abstract}
When performance assessments are used for instructional purposes and decisions have low stakes, strict adherence to the conventional rules of test construction is not critically important. Likewise, there is less need to ensure acceptable reliability and validity. As long as students derive an educational benefit from the experience and instruction is enhanced, the use of performace tasks is easily justified instructionally. Of course, when performance assessments are used to make high stakes decisions, they should meet the same criteria as conventional tests. (Cunningham 1998:138-139) ${ }^{10}$
\end{abstract}

A continuación vamos a tratar la traducción como prueba de evaluación en relación con el entorno relevante en este trabajo.

\footnotetext{
${ }^{10}$ Para un tratamiento más conservador de la validación de la traducción como instrumento de evaluación, véase el trabajo de Ghonsooly (1993). En relación con la traducción como prueba de evaluación sumativa, véase Farahzad (1992). Para un acercamiento mucho más completo que el desarrollado aquí en relación con las pruebas de traducción para la formación de traductores profesionales, véase Waddington (1999).
} 


\subsubsection{La traducción como evaluación en la enseñanza y el aprendizaje del Inglés para Fines Específicos}

Ya hemos señalado anteriormente que no existe un consenso en el ámbito de la enseñanza del Inglés para Fines Específicos acerca de las ventajas o desventajas de la traducción como instrumento para evaluar el aprendizaje de la lengua inglesa. Las razones que nos han impulsado a emprender este trabajo son, justamente, la confusión que existe en este entorno acerca del papel que tiene la traducción en la didáctica para fines específicos y la carencia de un tratamiento sistemático sobre esta cuestión.

Por otra parte, con el tipo de coyuntura con que se desarrolla la docencia de lenguas para fines específicos en el entorno universitario español, las planificaciones de cursos de Inglés para Fines Específicos no suelen prever que estos tengan una duración muy dilatada en el tiempo. Considerando esta circunstancia, vamos a comenzar por tratar un aspecto que es de suma importancia como criterio de elección de unos objetivos docentes u otros y que nos resulta muy interesante en relación con la utilización de textos en el aprendizaje de lenguas extranjeras. Esto, en última instancia, nos ayudará a situar con mayor rigor qué ventajas e inconvenientes presenta la utilización de tareas de traducción en este entorno educativo. El aspecto al que nos referimos es la distinción señalada por Bloom y sus colaboradores entre «los objetivos que constituyen unas metas que hemos de proponernos directamente y aquellos otros que son considerados como subproductos de otros objetivos» (Krathwohl, Bloom y Masia 1964:35), y que estos autores describen así:

Durante largo tiempo, se ha venido admitiendo que, si un alumno lograba aprender los objetivos docentes de un curso, lograba al propio tiempo adquirir los objetivos de la solución de problemas como consecuencia de dicho aprendizaje. De este modo, la responsabilidad del profesor se ceñía a brindar al alumno las necesarias experiencias de aprendizaje para desarrollar en ellas la instrucción, destinándose los exámenes a una valoración de los progresos del alumno hacia los objetivos de la instrucción. [...] Apenas tiene ya partidarios en la actualidad esta tesis que afirma el desarrollo «automático» de los procesos mentales superiores. No obstante, persiste todavía la creencia de que, si se desarrollan los objetivos cognoscitivos, se desarrollarán también de un modo recíproco las actitudes afectivas correspondientes. Los trabajos de investigación, resumidos por Jacob (1957), ponen en tela de juicio la veracidad de esta hipótesis. Esas investigaciones parecen indicar que se desarrollan las actitudes afectivas cuando se brindan al alumno las adecuadas experiencias de aprendizaje, al igual que, aproximadamente, ocurre con las actitudes cognoscitivas, las cuales se van adquiriendo a través de unas experiencias de aprendizaje apropiadas. (Krathwohl, Bloom y Masia 1964:35) 
En el entorno didáctico que estamos tratando en este trabajo, está comúnmente aceptada la suposición de que para ser un buen profesional (para alcanzar el 'nivel experto') es necesario saber comunicarse de forma eficaz y adecuada. No obstante, sabemos que los aprendices tienden a equiparar la idea de 'comunicación eficaz y adecuada' con la idea de 'hablar correctamente', en el sentido de producir emisiones lingüísticas carentes de incorrecciones principalmente en cuanto a la aplicación de reglas gramaticales, es decir, hablar con corrección desde un punto de vista formal.

Por otra parte, cabe suponer razonablemente que estos valores, actitudes y opiniones que los aprendices tienen acerca del lenguaje en general, del tipo descrito por Muñoz Martín (1995), condicionan de algún modo su propio aprendizaje de la lengua extranjera, tal como explica Kohonen:

\begin{abstract}
Language learning $[\ldots]$ involves a number of important student properties that are educationally valuable learning goals in their own right. Students come to our classes with their personal properties and beliefs and assumptions of language learning which they have acquired as part of their learning biographies in their families and school. These features evolve, one way or another, in connection with the affective, social and cognitive processes of language learning. They impinge indirectly on the student's observable language performance. (Kohonen 2000:1)
\end{abstract}

Cabe admitir que la extensa experiencia que poseen los aprendices como hablantes de su lengua materna les permite comunicarse de forma eficaz y adecuada en su primera lengua, aun sin ser conscientes de los factores que contribuyen a que se desenvuelvan con éxito en situaciones comunicativas muy variadas. No obstante, creemos que sus actitudes hacia la lengua y su aprendizaje tienen una relevancia diferente en el caso del aprendizaje de una segunda lengua o de una lengua extranjera.

Lograr comunicarse en una lengua extranjera con éxito conlleva no sólo enfrentarse con una gran variedad de problemas asociados a la comunicación (ambigüedad, etc.), sino además ser capaz de resolver estos problemas de forma automática o inconsciente, de tal modo que el mayor esfuerzo no se emplee en estrategias encaminadas al mantenimiento de la comunicación, sino en estrategias dirigidas a controlar la situación. Cuando el aprendiz se enfrenta con algún problema al comunicarse en una lengua extranjera, en ocasiones estos problemas producen un bloqueo que hace que la comunicación se interrumpa.

Desde la perspectiva de aplicación de estrategias comunicativas (v. 3.3.4), esto significa que, cuando el aprendiz no es capaz de resolver el problema que se le 
presenta, opta por utilizar una estrategia de reducción que le puede llevar a suspender la comunicación. Si se trata de la realización de una actividad de traducción, tiende a dejar en el texto algunos huecos en blanco, o bien inserta en él fragmentos sin traducir copiados directamente del TO. En este caso, consideramos que el umbral de finalización de la producción del texto es establecido prematuramente: el aprendiz, simplemente, abandona la tarea antes de finalizarla.

De modo general, podemos decir que el desarrollo de la competencia estratégica incide en que el aprendiz logre alcanzar con éxito o sin él, o con mayor o menor rapidez, un estado en el que es capaz de controlar una variada gama de situaciones cuando se comunica en la lengua extranjera. En el caso del aprendizaje del Inglés para Fines Específicos, esta gama de situaciones corresponde con las que se desarrollan habitualmente en el entorno profesional, sean éstas identificadas como típicas de un entorno particular (tales como seguir un determinado protocolo de comunicación de instrucciones entre un controlador aéreo y un piloto para llevar a cabo un aterrizaje), o comunes a situaciones comunicativas habituales en muchos entornos diferentes (por ejemplo, hacer las presentaciones entre compañeros de trabajo que no se conocen).

La cuestión del tipo de problemas que el aprendiz debe ser capaz de resolver al finalizar el curso es relevante al determinar qué metodología puede resultar más adecuada y qué tipo de actividades de aprendizaje se incluirán en la planificación docente. En este caso concreto, nuestro interés específico se refiere a las actividades de aprendizaje que permitan a los aprendices alcanzar los objetivos educacionales de tipo actitudinal. Si, como señalan Krathwohl y sus colaboradores, no se produce un desarrollo automático de los procesos mentales superiores, ni podemos confiar tampoco en que, si se desarrollan los objetivos cognoscitivos, se desarrollen también las actitudes afectivas correspondientes, entonces parece oportuno incluir actividades que sean adecuadas para brindar las experiencias de aprendizaje necesarias (Krathwohl, Bloom y Masia 1964:35). Desde la perspectiva que hemos abordado en este trabajo, estamos hablando principalmente de experiencias que sean adecuadas para desarrollar una actitudes afectivas que correspondan con un concepto de lenguaje capaz de dar cuenta de la comunicación lingüística tal como sucede en el mundo real, y específicamente de la comunicación tal como se produce en los entornos profesionales asociados típicamente con el campo de especialización de los aprendices.

En este sentido, en este trabajo pretendemos clarificar la cuestión sobre si las actividades de traducción pueden constituir experiencias de aprendizaje 
adecuadas o no. Para poder responder adecuadamente, en este punto es conveniente reformular esta pregunta hacia la cuestión de si las actividades de traducción pueden contribuir a dotar a los aprendices con la capacidad de resolver problemas comunicativos a los que puede que nunca se hayan enfrentado. Debemos señalar que los problemas a los que nos estamos refiriendo son problemas en los que están involucrados procesos mentales de orden superior, y que tienen soluciones complejas.

Desde un enfoque constructivista, podemos plantear el tratamiento de problemas que precisan la utilización de niveles superiores de pensamiento aunque los aprendices aún no dominen algunas destrezas de niveles inferiores. Por consiguiente, podemos suponer que no existe este tipo de inconveniente para tratar estos problemas con aprendices cuya competencia comunicativa en lengua inglesa no haya adquirido aún un nivel muy avanzado, sino que, por el contrario, puede ofrecer ventajas en cuanto a la motivación de los aprendices. Este enfoque es posible en tanto en cuanto utilicemos el tratamiento de dichos problemas como actividades de aprendizaje. No obstante, es conveniente marcar la diferencia existente entre los objetivos que pretendemos lograr mediante la realización de estas actividades y los objetivos relacionados con el aprendizaje de contenidos, incluyendo las explicaciones necesarias acerca de utilizar la evaluación con una finalidad formativa y no sumativa, para que los aprendices puedan ver claramente cuáles son nuestros propósitos al adoptar un enfoque constructivista como el que describe Cunningham:

\begin{abstract}
Constructivists believe that the acquisition of high level thinking skills is not dependent on the mastery of lower level skills and knowledge and therefore does not need to be delayed until they have been acquired. At the same time, they believe that asking students to solve higher level problems can motivate them to learn the underlying skills and knowledge needed to solve the problem. From this perspective, a high level discussion of a crisis in the Middle East should not be put off until students have gained a proper knowledge of the history and geography of the area. Instead, the initiation of the discussion might motivate students to learn more about history and geography. The constructivists philosophy [sic] is incompatible with high stakes accountability systems and objective testing in general. (Cunningham 1998:126)
\end{abstract}

A continuación vamos a describir con más detalle qué queremos decir cuando hablamos de problemas relacionados con procesos mentales de orden superior. Para ello, nos vamos a basar en el sistema de gradación de la dificultad de los problemas a los que nos podemos enfrentar que presenta Greene (1975:23-24), y que mostramos en la Tabla 13. 
Nivel 1: La persona ya conoce la solución (por ejemplo, que París es la capital de Francia)

Nivel 2: La persona conoce ya las reglas para tener la solución (por ejemplo, la fórmula para hacer grandes divisiones)

Nivel 3: La persona aprende respuestas correctas durante la tarea (por ejemplo, encontrar el camino a través de un laberinto)

Nivel 4: La persona tiene que seleccionar y evaluar operaciones para tener una solución (por ejemplo, hacer un crucigrama)

Nivel 5: La persona tiene que reformular el problema y/o crear algún método desusado de solución (por ejemplo, inventar un nuevo tipo de limpiador de parabrisas)

Nivel 6: La persona tiene que darse cuenta de que existe un problema (por ejemplo, Newton se dio cuenta de que la caída de la manzana necesitaba una explicación)

Tabla 13. Niveles de dificultad de resolución de problemas en orden creciente (Greene 1975:23-24)

Greene propone un modelo para graduar la dificultad de resolución de los problemas de acuerdo con los niveles de 'pensamiento viejo', aquel que implica la reavivación de operaciones mentales previas, o de 'pensamiento nuevo', aquel que precisa la reestructuración de la experiencia- que es necesario en cada caso. Según este criterio, se establecen seis niveles distintos, que aparecen en orden creciente de dificultad en la Tabla 13.

De acuerdo con estos niveles, el tipo de problemas a los que nos estamos refiriendo se pueden clasificar como problemas de cuarto, quinto y sexto nivel. Son problemas para los que el aprendiz debe elaborar una solución no aprendida, lo cual a veces requiere la reformulación del propio problema. No obstante, se trata en primera instancia de problemas en tanto en cuanto han sido identificados como un problema por los propios aprendices, de forma que no son ni identificados ni tratados por todos los aprendices de igual modo.

La eficacia en la comunicación implica todos estos niveles. Se considera que una persona ejerce un control eficaz sobre lo que dice e interpreta en la 
comunicación cuando resuelve problemas de estos niveles de complejidad de forma apropiada y eficiente para la comunicación. Obviamente no sólo de los niveles superiores, sino también de los niveles menos complejos. Pero nos preocupan especialmente los tres últimos niveles de dificultad porque poder elaborar soluciones para problemas comunicativos correspondientes a estos niveles justamente es lo que nos permite comunicarnos con éxito.

Según este planteamiento, si queremos evaluar la capacidad de los aprendices para comunicarse en situaciones relevantes, debemos averiguar si son capaces de resolver problemas correspondientes también a los tres niveles de dificultad superior, y no sólo a los niveles más bajos. La evaluación de la competencia en el reconocimiento de léxico o en la aplicación de reglas gramaticales corresponde con los niveles más bajos de la tabla. Por el contrario, la evaluación de la competencia estratégica y de la competencia discursiva suele implicar la resolución de problemas de los niveles de mayor dificultad de la tabla.

A continuación, vamos a analizar el constructo pedagógico que asociamos a las actividades de traducción con el fin de relacionar de un modo práctico este tipo de actividades con la funcionalidad didáctica específica de evaluar el aprendizaje.

Aunque el concepto de evaluación tiene una doble vertiente, como procedimiento de evaluación del aprendizaje y como medio de evaluación para el aprendizaje, nuestro interés en este trabajo recae en esta última función didáctica, por lo que los dos apartados siguientes se refieren específicamente a dos aspectos asociados con esta función didáctica formativa. Ambos aspectos persiguen de diferente modo el objetivo de hacer más visible, tanto para el profesor como para los propios aprendices, la competencia lingüística relevante de los aprendices, de acuerdo con lo que Kohonen (2000) denomina «visible and invisible outcomes in language learning», y que explica de este modo:

\footnotetext{
Developing learning autonomy in language teaching raises the question of what we actually mean by language learning outcomes. We customarily tend to think that the outcome is the learner's comunicative competence which can be measured using various performance or proficiency tests. While the skillsoriented tests measure the student's language performance and thus make it visible, they miss, however, a number of significant learning outcomes that do not lend themselves directly to quantitative testing. A great deal of relevant language competence easily remains invisible both to the teacher and to the student. (Kohonen 2000:1)
}

De acuerdo con Kohonen, los resultados invisibles del aprendizaje (invisible learning outcomes) incluyen propiedades esenciales para el desarrollo de la competencia lingüística y la motivación, tales como: 
1. commitment for and ownership of one's language learning

2. tolerance of ambiguity and uncertainty in communicative situations

3. and learning in general [sic]

4. willingness to take risks in order to cope with communicative tasks and situations

5. understanding of oneself as a language learner and a language user in terms of the beliefs about language use and one's role as a learner

6. understanding of one's cultural identity and what it means to become an intercultural speaker

7. skills and attitudes for socially responsible learning and language use

8. plurilingualism, involving a reflective awareness and appreciation of languages and language learning, as well as assuming respect for and appreciation of cultural diversity and otherness

9. learning skills and strategies necessary for continuous, independent language learning

10. a reflective basic orientation to language learning, with abilities for selfassessment

(Kohonen 2000:1)

El constructo pedagógico que presentamos a continuación se compone de dos mecanismos diseñados para hacer más visibles algunos aspectos del aprendizaje del Inglés para Fines Específicos como instrumentos de recogida de datos utilizados al realizar las actividades de traducción. Kohonen interpreta esta visibilidad como un modo mediante el cual «language teachers can facilitate their students to become aware of the wide range of goals and learning outcomes connected with the language learning enterprise» (Kohonen 2001:12).

Según Kohonen, en muchos casos este tipo de aspectos del aprendizaje sólo se puede inferir indirectamente a partir de los datos lingüísticos que los profesores obtienen de las actividades realizadas por los aprendices, de modo que, «unless we pay explicit attention to them, they remain inaccesible to the student for conscious monitoring and to the teacher for pedagogical intervention» (Kohonen 2000:1). En este sentido, creemos que la traducción es una actividad de aprendizaje con funcionalidad didáctica potencial para lograr hacer visibles algunos de estos aspectos del aprendizaje, ya que los parámetros que se utilizan para evaluar las traducciones deben ser hechos transparentes, y por lo tanto, visibles, tal como señala Gerzymisch-Arbogast (2001).

Por consiguiente, al hacer visibles los criterios contrastivos de comparación entre sistemas lingüísticos y los criterios descriptivos y valorativos de los textos, las actividades de traducción pueden facilitar la visibilidad de aspectos relacionados con la comparación entre sistemas socio-semióticos, incluyendo la descripción de conjuntos de valores asociados a una comunidad en particular, así como la descripción de características asociadas a la creación de significado en el discurso que se asocia con un contexto de uso en particular. Según esto, este tipo de actividad 
tiene efectivamente una funcionalidad potencial como actividad de aprendizaje para alcanzar objetivos educacionales de tipo actitudinal. No obstante, dado que es necesario definir en qué términos es posible que esta funcionalidad sea explotada de forma práctica, vamos a mostrar, a modo de ejemplo ilustrativo, de qué modo se puede llevar esto a cabo.

A continuación vamos a tratar las actividades de traducción desde la perspectiva de dos tipos de herramienta de recogida de datos que se utilizan en conjunción o a partir de la propia producción del TT. En el primer caso, el instrumento que vamos a describir consiste en un cuestionario abierto de autoevaluación al que hemos denominado 'informe de la traducción' y que el aprendiz lleva a cabo durante la producción del TT. En segundo lugar, trataremos otro instrumento, que hemos denominado 'repertorio de variaciones entre el TT y el TO', que el profesor aplica como método de análisis del TT en relación con el TO y también en relación con su condición de texto.

El primero de estos instrumentos de recogida de datos está diseñado con la finalidad de elevar el nivel de consciencia de los aprendices sobre los factores involucrados en la comunicación, en la traducción y en la producción de textos, si bien al mismo tiempo es una fuente de información para la intervención pedagógica del profesor, mientras que el segundo de ellos responde a la necesidad de establecer un marco de análisis de estas cuestiones y es utilizado en la intervención pedagógica.

\subsubsection{La traducción especializada como autoevaluación}

Vamos a comenzar a tratar esta cuestión describiendo dos tipos de procedimientos de autoevaluación, denominados 'cuestionarios' y 'portafolios'.

Tanto desde la perspectiva de la evaluación de la metodología (evaluation) como de la evaluación del aprendizaje (assessment), la utilización de cuestionarios de autoevaluación tiene la función de estructurar las observaciones que se realizan desde un enfoque centrado en los participantes (Murdoch 2000:55). Por su parte, la utilización de 'portafolios', es decir, carpetas o dossieres en los que se van archivando sistemáticamente las actividades de aprendizaje realizadas y que muestran los logros de los aprendices (Cunningham 1998:143), es más bien considerada una herramienta de evaluación mediante la cual el profesor puede valorar el aprendizaje, lo que Murdoch (2000:55) describe como «a teacher-driven assessment tool». La utilización de portafolios suele tener la función de estructurar las observaciones de acuerdo con un enfoque centrado en el profesor. El constructo 
pedagógico que presentamos a continuación aspira a cumplir ambas funciones, puesto que se compone de cuestionarios de autoevaluación que se van organizando en un portafolios a lo largo del curso. De hecho, pensamos que elaborar un portafolios donde el aprendiz y el profesor puedan observar la evolución en el tipo de reflexiones realizadas por el aprendiz a lo largo del tiempo es necesario cuando se proyecta alcanzar objetivos a largo plazo, como es el caso de los objetivos de tipo actitudinal.

Como cuestionario de autoevaluación, este constructo está pensado con el fin de facilitar la reflexión a los aprendices. No obstante, la producción sucesiva de informes permite también la creación de un portafolios que el profesor puede utilizar como fuente de datos para comprobar la evolución en los aspectos más relevantes para los objetivos establecidos.

La función asignada al constructo que proponemos como herramienta adicional a la actividad de traducir es, por tanto, doble. Por una parte, debe cumplir la función de inducir a los aprendices a la práctica reflexiva. Al mismo tiempo, debe cumplir la función de hacer visibles para el profesor las reflexiones de los aprendices acerca de las estrategias utilizadas en la resolución de los problemas textuales y traslativos detectados, y los valores, opiniones y creencias acerca de la comunicación en general, especialmente de la comunicación tal como se produce en el entorno profesional relevante. Es justamente la visibilidad de las reflexiones de los aprendices la que permitirá al profesor la intervención pedagógica, tal como recomienda Kohonen (2001). Lograr esta visibilidad es el requisito mínimo que las actividades de traducción deben cumplir para que podamos plantear una potencial funcionalidad como método de evaluación para el aprendizaje.

Por otra parte, la visibilidad de las reflexiones de los aprendices se produce mediante un proceso descriptivo que no persigue, como sucede con los TAPs utilizados en la investigación experimental de los procesos de traducción, hacer visible lo que sucede internamente en el sujeto, sino hacer visibles las reflexiones del aprendiz que se hacen conscientes mediante la descripción narrativa. En realidad, el constructo busca, más que hacer visible algo que permanecía oculto, provocar la toma de decisión consciente en relación con los problemas textuales y de traducción detectados por el propio aprendiz.

En nuestro enfoque, la toma consciente de decisiones sobre el proceso de producción textual es un paso necesario para poder ejercer un control efectivo sobre la propia producción y, por extensión, sobre las intervenciones que hace el aprendiz al comunicarse. 
El concepto operativo más relevante al tratar este constructo pedagógico de autoevaluación es el de 'narración' del proceso. Desde la concepción del Marco de Referencia Europeo, esta narración forma parte de la 'biografía del aprendizaje', en la que se incluye «information on linguistic and cultural experiences gained in and outside formal educational contexts» (Little y Simpson 2003:3).

De acuerdo con Little y Simpson (2003:4), la mayoría de modelos de biografía desarrollados para aprendices adultos promueven la narración reflexiva sin ningún tipo de enfoque en especial. No obstante, la biografía del aprendizaje del Inglés para Fines Específicos difiere de la presentada en el Marco de Referencia Europeo en que las experiencias interculturales descritas reflexivamente siguen un enfoque específico sobre la comunicación especializada en un entorno profesional en particular, que también se relaciona con los objetivos establecidos en el curso.

En pro de la usabilidad de este constructo (v. 5.2.3.1), tanto para el profesor como para los aprendices, el informe debe seguir el 'principio de transparencia', tal como lo define Kohonen (2001:2): «the principle of transparence means that information must be clearly formulated and explicit, available and clearly comprehensible to users». En este caso, dado que el destinatario del constructo es el profesor y, en ocasiones, el resto de aprendices del grupo también, la explicitación y la claridad de comprensión deben ser las suficientes para todos esos destinatarios.

Por otra parte, para que la elaboración del informe pueda cumplir su objetivo de elevar el nivel de consciencia y de reflexión de los aprendices, es necesario que definamos la relación existente entre el informe emitido, el TO y el TT como una relación de coherencia, que Kohonen (2001:2) define del siguiente modo: «coherence implies that the description is free from internal contradictions and requires a harmonious relationship among the components», lo cual en nuestro caso significa que no deben existir inconsistencias ni contradicciones entre las afirmaciones y descripciones que se hacen en el informe y las características presentes en el texto creado a partir del proceso de traducción del $\mathrm{TO}^{11}$. En este sentido, este informe constituye una prueba directa fiable de recogida de datos únicamente cuando se da esta relación de coherencia entre sus contenidos y los resultados observables en el TT, por lo que la relación de coherencia entre ambas actividades es un prerrequisito de que la prueba pedagógica es suficientemente

\footnotetext{
11 Kohonen se refiere a los diferentes componentes de los sistemas educativos y no a los elementos que componen la actividad de traducción de la que estamos hablando aquí. No obstante, creemos que es igualmente aplicable su interpretación de la relación de coherencia al caso que estamos tratando.
} 
fiable (es decir, que representa suficientemente los argumentos, reflexiones y decisiones desarrollados por el aprendiz en la realización de la actividad).

Así, la elaboración del informe y la producción del TT son consideradas como un único proceso productivo y no como dos procesos paralelos e independientes. En este proceso, la elaboración del informe sirve de ayuda para tomar decisiones frente a los problemas que el aprendiz reconoce como tales en la traducción y para explicar a otros por qué el TT tiene las características determinadas que ha elegido $\mathrm{y}$, en última instancia, defender las opciones que ha identificado como mejores del repertorio escrutado de opciones posibles.

Somos conscientes de algunos de los problemas con los que nos enfrentamos al utilizar constructos como el informe en las actividades de traducción. Uno de estos problemas, probablemente el más preocupante puesto que puede afectar a la validez de la utilización del informe como prueba de actuación, afecta a la aplicación práctica del constructo y es descrito por Parkinson del siguiente modo:

The [...] problem began to crystallise for me when an IALS student wrote about her translation course at home: 'we do all this text analysis, we fill in the tables from Newmark, but then we don't use it. We just translate the text without using this, in the way we always have done'. I have since found that such perceptions are common, at least with reference to the few overseas courses about which I have been able to inquire. The smugness which this engendered lasted for only a few weeks, to be replaced by the sudden thought that other students might be telling their teachers at home exactly the same thing about my course! To be sure, I believed that my colleagues and I had integrated text analysis and translation as a seamless whole, and that we used (or, more usually, helped participants to use) ideas from the former in the latter, but memories of some of my own recent translation classes suggested that this reference back was rarer and less systematic that I might like to admit. (Parkinson 1995:80)

Nuestro constructo no tiene la función específica de mejorar la calidad de las traducciones producidas por los estudiantes, por lo que no es necesario plantearse la validez de éste en cuanto a su incidencia en la producción textual. Teniendo esto en cuenta, podemos decir que las objeciones planteadas por Parkinson afectan a la utilización de constructos de este tipo cuando el objetivo es la competencia traductora, pero no necesariamente en otros casos. Dado que los objetivos que hemos establecido son actitudinales, y la consecución de éstos suele ser a largo plazo, no aspiramos a que en un curso corto sea posible extraer datos de los TTs relacionados con la mejora de la calidad de la traducción pero, de todos modos, si éste fuera el caso, la mejora de la calidad de las traducciones sólo podría 
ser interpretada como un efecto colateral aleatorio, puesto que no se ha identificado previamente como un objetivo de la enseñanza ni de la evaluación, ni tampoco como un contenido del curso.

No obstante es habitual que, partiendo de una concepción de la evaluación de las traducciones en términos absolutos de corrección, se interprete que la única función posible del constructo sea su incidencia en la calidad de las traducciones. Como ya hemos señalado más atrás, el tipo de validez de la prueba de actuación denominada 'informe' afecta más bien a la coherencia interna de éste con el TT. En este sentido, es posible observar directamente cuándo no hay un paralelismo entre la reflexión, según se describe en el informe, y la acción, según se observan sus resultados en el TT. En esos casos se pueden detectar inconsistencias o incoherencias entre la descripción y valoración en el informe y los elementos presentes o ausentes en el TT, al menos entre lo que el aprendiz dice que es la mejor solución a un problema (información que aparece en el informe) y lo que podemos ver en el TT (si efectivamente ha utilizado la solución descrita en el informe o no lo ha hecho). Así pues, no podemos probar que este constructo en particular tenga funcionalidad didáctica cuando el objetivo es mejorar las estrategias traslativas de los aprendices, si bien, aunque sería muy interesante investigar sobre esta cuestión, esto queda fuera de los límites de esta investigación.

En cuanto al tipo de constructo que hemos elegido en relación con el enfoque metodológico adoptado, podemos señalar que la utilización de un instrumento de recogida de datos en forma de cuestionario de autoevaluación no sólo es consistente con un enfoque centrado en la promoción de la autonomía en el aprendizaje sino que es justamente uno de los pilares del aprendizaje autónomo (Harris 1997:12).

No obstante, del mismo modo que hemos distinguido diferentes tipos de evaluación, podemos hablar de dos tipos diferentes de autoevaluación, según lo que se persiga sea una evaluación sumativa del aprendizaje, o bien una evaluación formativa.

En relación con el desarrollo de la autoevaluación en el Pasaporte Lingüístico Europeo o European Language Portfolio, Little y Simpson (2003) se refieren a los cuestionarios de autoevaluación como el procedimiento habitual de obtención de datos en ambos casos. No obstante, estos autores establecen una distinción (relevante aquí) entre los cuestionarios utilizados para la evaluación sumativa, y aquellos utilizados para la evaluación formativa: 
The self-assessment grid in the language passport provides an overview of L2 proficiency that can be updated at regular intervals, for example, at the end of a school year or a university semester, or after a period of residence abroad. It thus serves a summative function similar to an end-of-year or end-of-course examination. The goal-setting and self-assessment checklists in the language biography, on the other hand, serve a formative function, since they are designed to accompany learning from day to day, week to week and month to month. (Little y Simpson 2003:29)

Puesto que el objetivo que perseguimos con la evaluación no es valorar la competencia comunicativa de los aprendices, no podemos utilizar ninguna tabla de autoevaluación (self-assessment grid) con descriptores funcionales comunicativos, como se suele hacer con los que definen cada uno de los niveles del Marco de Referencia. La segunda opción mencionada por Little y Simpson sí es, por el contrario, utilizable para los fines formativos que persigue nuestra evaluación.

El diseño del informe de autoevaluación que adjuntamos en el Anexo F, a modo de ilustración del enfoque que estamos siguiendo en este trabajo, sigue un formato de cuestionario o formulario con preguntas de respuesta abierta y también de respuesta cerrada. La razón para proceder así es que estamos de acuerdo con Kohonen cuando afirma que es positivo comenzar a tratar las estrategias metacognitivas planteando preguntas concretas: «like with any new skill, it seems a good idea to teach reflection by giving students concrete questions to begin with» (Kohonen 2001:13).

La utilización del cuestionario es consistente con los fines que le hemos asignado puesto que, según Morales Vallejo (1995c), se trata de un instrumento adecuado para evaluar objetivos de tipo actitudinal. Si bien este especialista del campo de la didáctica general señala que son preferibles los cuestionarios cerrados frente a los de preguntas abiertas, en cuanto a su sencillez para codificar e interpretar las respuestas, otros especialistas del campo de la didáctica de las lenguas extranjeras sugieren que, al menos en relación con la biografía del aprendizaje, se puede mantener una posición «against the idea of self-assessment based on checklists and in favour of some flexible means of self-profiling» (Little y Simpson 2003:5). Para ilustrar qué aspecto tienen estos formularios, más flexibles que los que se componen de preguntas de respuesta cerrada, reproducimos un cuestionario que sigue un modelo de pregunta abierta en el Anexo G. Este cuestionario ha sido desarrollado para aprendices de nivel universitario de acuerdo con el Marco de Referencia Europeo, con el fin de que reflexionen acerca de las diferencias culturales comparando otras culturas con la suya propia. 
En nuestro cuestionario, utilizamos preguntas con opciones cerradas para aquellos aspectos sobre los que queremos dirigir el posicionamiento en la reflexión, en casos como cuál es el alcance del problema que el aprendiz trata de resolver, por ejemplo, mientras que utilizamos preguntas de respuesta abierta en aquellos casos donde queremos que el aprendiz elabore la reflexión consciente de forma individual, describiendo con sus propias palabras cuál es el problema.

La colección de todos estos informes da como resultado un dossier o portafolios donde el aprendiz recoge las reflexiones sobre los distintos textos que va traduciendo, que se van complementando con los análisis del resultado de la actividad de traducir, que se llevan a cabo utilizando el segundo instrumento de recogida de datos. En este sentido, el portafolios está diseñado con la finalidad de dar la oportunidad al aprendiz de recopilar sus reflexiones a lo largo del tiempo y, de este modo, permitirle compararlas con las de otros aprendices y las del profesor, defenderlas, modificarlas, analizarlas, y todo aquello que tenga utilidad, no sólo para alcanzar los objetivos específicos que se persiguen, sino en general para mejorar la metacognición:

The portfolio should not be a static presentation of what a student has done. Students need to be encouraged and supported in thinking about what they have accomplished, how and why they used a particular strategy, and most importantly how they feel about this process. Students should not view their assignments as merely something to complete, which doesn't really involve them. Written self-reflection can force a student to take ownership of what they have done. It is not enough for the portfolio to provide an opportunity for the student to record their self reflection. Self reflection also needs to be encouraged and nurtured. This might require modelling by the teacher. The teacher should demonstrate his or her own self reflection in the class being taught, to increase the likelihood that students will be self reflective. (Cunningham 1998:145)

El procedimiento de recogida de datos que hemos presentado en este apartado se ha utilizado hasta el momento de forma práctica en cursos de Inglés para Fines Específicos del siguiente modo. Al finalizar la primera traducción que realizan los aprendices en el curso, se les pide que procedan a realizar el informe de acuerdo con el cuestionario. El orden inicial que seguimos para introducir este instrumento de recogida de datos responde a esta secuencia con el fin de que el proceso de reflexión se active de forma consciente y diferenciada sin causar interferencias en el proceso de traducción.

No obstante, una vez que este procedimiento se ha puesto en marcha por primera vez, en las sucesivas actividades de traducción el informe se realiza al tiempo que la propia producción del TT, de tal modo que la actividad no se da por 
concluida hasta que tanto el informe como el TT se consideran finalizados por el aprendiz.

Por otra parte, puesto que este instrumento se utiliza de forma intuitiva y sus resultados sirven de fuente de datos para la intervención pedagógica del profesor, la utilización del cuestionario sucede secuencialmente antes que la aplicación del segundo instrumento de recogida de datos que utilizamos en nuestro constructo pedagógico, el repertorio de variaciones de efecto entre el TT y el TO.

Una vez ha finalizado la actividad de traducir, disponemos de datos procedentes de dos fuentes distintas: el TT y el informe elaborado sobre la traducción. Es en este momento cuando se procede a analizar el TT en relación con sus características textuales y con las características del TO. Es también el momento en que el repertorio cumple su función didáctica. Así, vamos a describir a continuación con mayor detalle las características más sobresalientes de este segundo instrumento de recogida de información asociado a las actividades de traducción y a la funcionalidad didáctica de ésta.

\subsubsection{La traducción especializada como evaluación formativa}

Al igual que el procedimiento de recogida de información que hemos descrito en el apartado anterior, consistente en la elaboración de informes sobre las traducciones y su recopilación sucesiva en dossieres o portafolios, el segundo instrumento que presentamos en este trabajo persigue la visibilidad. En un sentido general, lo que queremos lograr es hacer explícitos y conscientes algunos de los aspectos relacionados con el aprendizaje del Inglés para Fines Específicos y de la comunicación especializada en un entorno profesional que es culturalmente diferente al entorno habitual de los aprendices, tanto en lo relativo a la especialización profesional como a sus características socioculturales.

Con este segundo instrumento, el 'repertorio de variaciones de efecto entre el TT y el TO', lo que perseguimos específicamente es presentar y enseñar a presentar resultados de un proceso de análisis comparativo, de tal modo que las conclusiones de tal análisis sean visibles para el aprendiz.

Este instrumento utilizado en nuestro constructo pedagógico se aplica mediante un procedimiento que consiste en el análisis de las variaciones que se pueden identificar entre los efectos de un TT y los efectos del TO. El análisis comparativo se lleva a cabo mediante la aplicación del repertorio de variaciones de efecto, que actúa como criterio o referencia para la comparación textual. 
Puesto que el énfasis del análisis se centra en las variaciones que se detectan entre textos, el concepto operativo más relevante para describir este instrumento del constructo es la 'percepción de discrepancias' entre textos. Estas discrepancias se pueden producir en una dimensión intertextual pero también en una dimensión intratextual. Es decir, al analizar los textos, no sólo podemos identificar discrepancias entre elementos, recursos o estrategias utilizados en cada uno de los textos, discrepancias que podríamos denominar 'translémicas', según la concepción de Rabadán (1991b), sino que también es posible identificar discrepancias que podríamos denominar 'internas', ya que afectan únicamente a uno de los textos. Este tipo de discrepancias tiene que ver con los mecanismos de regulación del propio texto y con el mayor o menor éxito de los elementos específicos que se han elegido para lograr un efecto particular.

En cuanto a la relación temporal entre la aplicación de este instrumento y el descrito anteriormente, el análisis del TT en relación con el TO ocurre secuencialmente en segundo lugar y, en general, es llevado a cabo por el profesor. Los resultados de este análisis se llevan a un espacio de discusión para ser utilizados como actividad de aprendizaje mediante un método interrogativo. Podemos señalar, además, que este instrumento de recogida de datos constituye una herramienta de evaluación formativa porque no es un baremo cuantitativo de calificación, sino que se utiliza como un método de evaluación cualitativa de la traducción producida por el aprendiz en relación con el TO.

Como constructo de intervención pedagógica, a esta herramienta le podemos asignar potencialmente algunas funciones didácticas específicas. De acuerdo con las cinco funciones principales que Morales Vallejo (1995a) distingue para la evaluación, este constructo está diseñado con la finalidad general de orientar, motivar y contribuir al aprendizaje. En este sentido, la aplicación del repertorio como baremo analítico pretende facilitar el aprendizaje, mediante la identificación de discrepancias que pueden constituir errores pero también representar únicamente diferentes opciones comunicativas, y también busca ocupar un espacio en las actividades dedicado a la consolidación de lo aprendido, sin olvidar su funcionalidad potencial como condicionante del aprendizaje, puesto que muestra un modo específico de argumentación analítica.

Por último, hay otro aspecto relevante que se refiere al modo como este constructo actúa en el aprendizaje. Murdoch afirma que, para que la práctica reflexiva pueda ser empleada en la evaluación formativa con éxito, es necesario tratar con suma atención el establecimiento de un marco de identificación de 
problemas, que define del siguiente modo: «problem setting is a process in which, interactively, we name the things to which we will attend and frame the context in which we will attend to them» (Murdoch 2000:55). A este respecto, el segundo instrumento de nuestro constructo pedagógico responde a la necesidad de establecer un marco de análisis para la intervención pedagógica, tal como vamos a explicar a continuación.

El constructo pedagógico que estamos describiendo está diseñado con una finalidad funcional específica: inducir en los aprendices la reflexión metacognitiva acerca de su propia actuación al traducir, y de las razones a las que obedece tal actuación.

El procedimiento que se ha seguido hasta el momento en la utilización práctica del repertorio que hemos diseñado comprende una progresión en su uso en el aula. Al principio el profesor utiliza este repertorio como un baremo para mostrar de forma práctica el análisis constrastivo llevado a cabo por él entre el TT producido por alguno de los aprendices y el TO, de modo que se suscite la discusión sobre las (o algunas de las) soluciones aportadas en los TTs por el grupo de la clase. Más adelante, además del profesor, son los propios aprendices quienes lo van utilizando progresivamente, al principio para analizar textos que han sido traducidos por sus compañeros, y más tarde para analizar su propia actuación. En última instancia, la presuposición subyacente es que el análisis contrastivo entre ambos textos, y el propio análisis textual del TT, ayuda a los aprendices a tomar decisiones en cuanto a los elementos específicos que compondrán los TTs que están produciendo. Así, cuando el profesor comienza a utilizar el baremo, analiza uno o dos de los textos producidos por los aprendices, comparándolos con su correspondiente TO. De este modo, muestra de forma práctica el análisis que lleva a cabo y comenta los aspectos más relevantes de acuerdo con los objetivos establecidos y, al mostrar cómo reflexiona él mismo, va modelando la reflexión de los estudiantes, tal como sugiere Cunningham (1998:145).

Con respecto al establecimiento de un marco de análisis donde podamos identificar qué es un problema y qué no lo es, queremos poner énfasis en que, dado que convergen tantos niveles y rangos susceptibles de análisis, y teniendo asimismo en cuenta el hecho de que los conocimientos y la experiencia del profesor y de los aprendices no son comparables, cuando exponemos en el aula el análisis de un texto es extremadamente importante utilizar algún tipo de herramienta que permita hacer visible lo que el profesor y lo que cada aprendiz está viendo en cada momento. Es decir, se hace necesario encontrar un punto de encuentro de todas las perspectivas 
que convergen sobre el texto que permita al profesor y al aprendiz comprender qué está viendo el analista y, por tanto, cómo está interpretando lo que sucede en el TT o en el TO, o en la comparación entre ambos textos. El baremo que presentamos en la sección siguiente, como ejemplo ilustrativo de qué tipo de parámetros puede componer un repertorio semejante, es utilizado con esta finalidad esencial y supone, por consiguiente, un instrumento pedagógico de visualización de la interpretación del profesor y de los aprendices del análisis textual.

Hemos diseñado una herramienta que, al igual que el instrumento de recogida de datos que presentamos en primer lugar, contribuye a hacer visibles algunos aspectos del aprendizaje del Inglés para Fines Específicos que con una metodología diferente no sería posible tratar. En este sentido, el repertorio no es un baremo de certificación de conocimientos o competencias (no serviría como baremo de evaluación sumativa a menos que se introdujeran modificaciones), sino que se utiliza como una herramienta de tipo descriptivo y no sólo de tipo valorativo.

Dado que el tiempo que solemos dedicar a la consecución de los objetivos educacionales del curso mediante este instrumento no suele ser muy amplio en un curso de Inglés para Fines Específicos, la mayor utilidad del baremo no estriba en su exhaustividad, sino en que nos permite visualizar los aspectos relevantes para el aprendizaje. Por consiguiente, a pesar de que el baremo permite ser utilizado con exhaustividad para describir los efectos o las variaciones de efectos entre textos, hasta el momento únicamente se ha utilizado para tratar los aspectos que el profesor ha considerado relevantes para la consecución de algún objetivo educacional en particular, así como aquellos aspectos que se revelan como los más relevantes para los propios aprendices a través de sus preguntas, argumentos o comentarios en las sesiones de discusión desarrolladas en clase.

\subsection{Análisis didáctico de la traducción: un repertorio de variaciones entre los efectos textuales del TT y los del TO}

A continuación se presenta una recopilación de efectos que se refieren a la información suministrada en el TT y que son percibidos, analizados y descritos, bien al describir y evaluar el TT en comparación con el TO, o bien al describir y evaluar el TT, de acuerdo con los criterios de textualidad establecidos por De Beaugrande y Dressler (1981), así como con el repertorio de preguntas desarrollado por Nord (1991). 
Esta recopilación se ha ido elaborando a partir de análisis de textos producidos por aprendices de Inglés para Fines Específicos al traducir textos especializados como actividades de aprendizaje y sigue un proceso de revisión constante. Por esta razón, el repertorio que presentamos no se debe interpretar como un listado exhaustivo ni completo de posibles variaciones de efecto entre textos relacionados intertextualmente mediante la traducción, sino únicamente como el estado actual de variaciones que han sido detectadas y clasificadas de acuerdo con la finalidad didáctica del repertorio.

Los efectos textuales que presentamos a continuación tienen denominaciones que se refieren generalmente al tipo de variación que representan con respecto de los efectos textuales que se perciben en el TO, pero también incluyen descripciones que afectan a discrepancias que se detectan únicamente en uno de los textos, habitualmente en el TT, puesto que el que se utiliza como modelo es el TO. El alcance de esas variaciones, en cuanto a su importancia o repercusión para el lector del texto donde se detecta la discrepancia, no es el mismo para todos los casos que se recogen en el repertorio, dado que no es posible establecer el impacto de la variación sobre el efecto del texto en los lectores en el grado de generalización del repertorio, sino que es en el análisis de cada caso concreto donde podremos establecer cuál es la repercusión de la variación en cuestión. Tal como veremos a continuación, hemos clasificado las discrepancias que incluimos en el repertorio de acuerdo con el nivel textual en el que se han detectado, estableciendo una separación general entre un nivel macrotextual (v. 6.4.1) y un nivel microtextual (v. 6.4.2). Como quiera que se han detectado casos que se han manifestado en diferentes ocasiones en distintos niveles, se ha optado por incluir estos casos en un apartado independiente (v. 6.4.3).

\subsubsection{Variaciones de efecto que afectan al nivel macrotextual}

Las discrepancias en los efectos textuales que recogemos en este primer apartado consisten en variaciones que afectan al efecto que el TT produce en sus lectores en cuanto al nivel macrotextual. Se trata de un nivel en el que podemos indentificar efectos que se relacionan con mecanismos que funcionan en los rangos superiores del texto o que presentan una distribución textual amplia, tales como la cohesión léxica, la progresión temática, la macroestructura y la superestructura del texto, el estilo y el tono, incluyendo efectos asociados con lo que se ha identificado 
como una frecuencia excesiva de ciertas estructuras sintácticas o con anomalías en la coherencia temporal en el nivel proposicional (v. 5.2.1.2) ${ }^{12}$.

Se incluyen igualmente en este apartado efectos que tienen que ver con factores de tipo extratextual. También nos referimos a casos donde el efecto producido es anómalo o inesperado, hasta tal punto que los elementos discordantes canalizan la atención del lector de tal modo que el recuerdo de la discrepancia mantiene su vigencia a lo largo de todo el texto o de buena parte de él, es decir, causan un gran impacto sobre el lector.

Los mecanismos utilizados para poner de manifiesto la relación que se establece entre el autor del texto y el lector prospectivo son un ejemplo de recursos que afectan a este tipo de efectos, por ejemplo cuando a lo largo del texto se va tuteando y tratando de usted al lector aleatoriamente. También podemos incluir en este caso los mecanismos de edición que se han utilizado para estructurar visualmente el texto en diferentes secciones y apartados, tales como títulos, subtítulos, tamaño de los tipos utilizados o ubicación de ilustraciones.

\subsubsection{Cohesión léxica (CL)}

La cohesión léxica se refiere a un tipo de variación relativa a las repeticiones léxicas que se suceden en el texto para referirse a la misma entidad una y otra vez a lo largo de éste. Se pueden dar diferentes casos, incluyendo aquellos relacionados con lo que se suele llamar 'repetición elegante', que consiste en evitar repetir la misma expresión en el texto para referirse a una misma entidad, de modo que se van alternando distintas formas de expresión con el fin de que el estilo del texto no sea repetitivo (Cook 1989:19). Los mecanismos específicos que se utilizan para establecer cadenas léxicas en el texto varían entre unos autores y otros, por lo que aquí mantenemos una posición abierta acerca de qué casos podemos clasificar dentro de esta denominación. En líneas generales, interpretamos la cohesión léxica como aquel tipo de cohesión que se produce «among items that are presumably related within the lexicon of the language as well as the text at hand» (De Beaugrande 1997:260).

\footnotetext{
12 'Frecuencia excesiva' se refiere aquí a que la frecuencia de aparición de una determinada estructura sintáctica llama la atención del lector, es percibida especialmente como algo llamativo o no natural. Aquí se recoge específicamente este parámetro en relación con el uso de estructuras sintácticas pasivas.
} 
Ejemplo:

TO con una cadena léxica resaltada (fragmento):

A force of attraction exists between every body in the universe. It has been investigated by many scientists including Galileo and Newton. This gravitational force depends on the mass of the bodies involved. Normally it is very small but when one of the bodies is a planet, like the earth, the force is considerable. Everything on or near the surface of the earth is attracted by the mass of the earth. The greater the mass, the greater is the earth's force of attraction on it. We call this force of attraction gravity.

(English for Mechanical Engineering, J. B. Allen y H. G. Widdowson, 1984:36)

TT con su correspondiente cadena léxica resaltada (fragmento de una traducción realizada por un estudiante de Ingeniería Técnica Industrial):

Una fuerza de atracción existe en todos los cuerpos del universo. Esto ha sido investigado por algunos científicos incluyendo Galileo y Newton. Esta fuerza gravitacional depende de las masas de los cuerpos implicados. Normalmente es muy pequeña pero cuando uno de los cuerpos es un planeta como la Tierra, la fuerza es considerable. Toda cosa sobre o cerca de la superficie de la Tierra es atraída por la masa terrestre. [hueco en blanco] llamamos a esta fuerza de atracción gravitación.

En el ejemplo que reproducimos, la cadena léxica resultante en el TT tiene dos elementos menos que la cadena del TO. El elemento que aparece en segundo lugar en la cadena del TO («It» en la línea 1) no ha sido interpretado en la versión en español como un elemento integrante de dicha cadena, sino que su referente en el TT es toda la oración anterior en conjunto (lo que se investiga no es la fuerza de atracción, sino su existencia en todos los cuerpos del universo). La ausencia del otro elemento mencionado («it» en la línea 3) no es chocante, puesto que en español no se suelen utilizar los pronombres con función de sujeto a menos que exista ambigüedad, y en este caso no la hay.

Estas dos variaciones tienen diferente efecto sobre el lector. En el primer caso, podemos decir que el traductor hace una interpretación errónea del referente del pronombre «It». «Force of attraction» no es sólo el sujeto de la primera oración, sino que continúa siéndolo también en las oraciones posteriores («This gravitational force depends on ...»y «(Normally) it is very small ...»), por lo que podemos afirmar que en las cuatro primeras oraciones, el tema corresponde con el sujeto de la oración. Se trata, por tanto, de un sujeto tematizado (Brown y Yule 1983). Así, podemos afirmar que el TT presenta una relación cohesiva diferente de la del TO y, en ese sentido, esta variación supone un error en la traducción. Por el contrario, la ausencia del otro elemento descrito es lo que esperamos en ese caso en el texto en 
español, por lo que, aquí, la variación no supone ningún tipo de error, simplemente es un reflejo de que ambos textos utilizan lenguas con mecanismos diferentes. En la oración «Normalmente es muy pequeña ...» sabemos que el tema continúa siendo la fuerza de atracción porque es la única entidad que concuerda en género y número con el adjetivo «pequeña», de modo que sólo se trata de una muestra de que la tematización se construye de un modo diferente a la del TO.

\subsubsection{Recursos de edición (ED)}

Con este tipo de variación se indica que se han utilizado en la edición del TT recursos diferentes a los del TO, de tal modo que el efecto visual del TT es diferente.

Se consideran variaciones de edición aquellos casos en los que en el TT no aparecen ilustraciones, diagramas, títulos, subtítulos u otros elementos que afectan al efecto visual del texto, incluyendo la disposición del texto en espacios limitados como columnas o viñetas.

En casos extremos, esta variación puede afectar a las condiciones de verdad de la información, por lo que el analista también puede clasificar la discrepancia detectada como 'información falsa' (v. 6.4.3.4). Cuando esto sucede, la variación es identificada como un error de la traducción y no únicamente como un cambio de efecto. Podemos encontrar casos de este tipo de variación cuando advertimos discrepancias dentro del propio TT entre lo que dice la información verbal (por ejemplo, «... como podemos ver en la figura 4 ...») y lo que dice la información no verbal (aunque se alude a ella, la figura 4 no aparece en el TT).

\subsubsection{Estructuras textuales (EST)}

Este tipo de variación se refiere a la estructura textual desde una perspectiva global. La estructura afectada puede ser la macroestructura del texto o bien la superestructura (v. 5.2.4.1). En el ejemplo que recogemos a continuación, el TT presenta una estructura lineal, a pesar de que el TO presenta una estructura hipertextual (reticular). En este caso, la variación detectada afecta a la propia funcionalidad del texto. En el TT el lector no puede acceder a la información suministrada en el folleto (Bio-security advice leaflet) puesto que, para hacerlo, debe utilizar un hiperenlace que en el TT no aparece. 
Ejemplo:

TO con estructura hipertextual (fragmento):

\section{Bio-security Advice for Farmers}

It is imperative that all involved in the livestock industry continue to take all possible precautions to ensure that animal disease is not spread from farm to farm, to this end Cambridgeshire Trading standards have produced an advice leaflet on bio security measure for keepers of livestock. Please click here to download a copy of the Bio-security advice leaflet.

(URL:<http://www.camcnty.gov.uk/sub/footmouth/index.htm>)

TT sin estructura hipertextual (fragmento de una traducción realizada por una estudiante de Ciencias Ambientales):

\section{INFORME DE BIO-SEGURIDAD PARA GRANJEROS}

Es imprescindible que todos los implicados en la industria del ganado sigan tomando todas las posibles precauciones para asegurar que la enfermedad animal no sea propagada de granja a granja, con este propósito, las normas Comerciales del Condado de Cambridge han creado un folleto informe sobre la medida de bio-seguridad para guardas de ganado. Por favor cliquee aquí para bajarse una copia del folleto informe de Bio-Seguridad.

\subsubsection{Relaciones interpersonales (INT)}

Este tipo de variación significa que la relación interpersonal establecida en el TT entre el autor y el lector no es adecuada para la situación del TT o no corresponde con la que se establece en el TO. En algunos casos, como el del primer ejemplo que mostramos, la variación no implica necesariamente un error de traducción, dado que el autor del TT puede querer deliberadamente utilizar un estilo o tono diferente del que aparece en el TO.

Puesto que las relaciones interpersonales se establecen de un modo particular en cada cultura, a menudo estas diferencias culturales justifican diferencias de estilo, incluso en tipos de discurso donde típicamente se establecen relaciones entre miembros de diferentes culturas, como es el caso de la correspondencia comercial. No obstante, el estilo del texto responde también al propio estilo personal del autor, por lo que las diferencias de estilo pueden deberse simplemente a diferencias de tipo personal. En los dos ejemplos que mostramos a continuación, podemos observar cómo en un mismo tipo de texto (se trata de dos manuales universitarios estadounidenses) aparecen estilos muy diferentes. 
En el primer texto, que se puede consultar con mayor detalle en el Anexo E, los autores utilizan en general un estilo indirecto, si bien a partir del segundo párrafo establecen una relación de proximidad con el lector mediante la utilización de un pronombre de primera persona del plural («we»). En el primer ejemplo reproducimos un único caso donde se puede observar cómo en el TO se utiliza un estilo indirecto, mientras que en el TT el traductor ha optado por utilizar una forma directa. A pesar de que podemos detectar una variación entre ambos textos, el ejemplo presentado no constituye un error de traducción, ya que se trata de un caso que no es contradictorio con el tratamiento que el autor hace del lector a lo largo del texto.

Por el contrario, el segundo caso que presentamos constituye un ejemplo donde se puede advertir un tratamiento del lector en el TT que no es adecuado, porque no representa la relación que se establece en el TO entre el autor y el lector, ni tampoco responde a necesidades del TT, como el tipo de texto o las costumbres culturales. En este caso, la variación sí es identificada como un error de la traducción, puesto que no se encuentran razones que la justifiquen suficientemente.

Ejemplo:

TO con tono indirecto e impersonal (correspondiente al Anexo E):

$[\ldots]$ if the motion of a body is to be determined $[\ldots]$

TT con tono directo y personal (fragmento de una traducción realizada por un estudiante de Ingeniería Técnica Industrial):

[...] si queremos determinar el movimiento de un cuerpo [...]

Ejemplo:

TO con tono directo entre el autor y el lector (fragmento):

To the Student

I hope you will learn calculus from this book. On this page I will admit that I even hope for more. If you find that the explanations are clear, and also the purpose is clear - that means you see not only equations but ideas. Then the book was worth writing, and the course is a success.

(Calculus, G. Strang, 1991:xv)

TT con un tono directo no adecuado para el tipo de lector del TT (fragmento de una traducción realizada por un estudiante de Ingeniería Técnica Industrial):

PARA EL ESTUDIANTE 
Yo espero que usted aprenderá el cálculo de este libro. En esta página que tengo la esperanza de aún más. Si usted encuentra que las explicaciones son claras, y también el propósito está claro - eso significa que usted no sólo ve ecuaciones, sino ideas. Entonces el libro ha valido la pena escribirlo y el curso es un éxito.

\subsubsection{Uso excesivo de estructuras pasivas (PAS)}

Este tipo de variación se refiere a la repetición de un tipo de estructura sintáctica. De acuerdo con Brown y Yule (1983), la repetición sintáctica puede ser utilizada como un mecanismo de cohesión textual. Esta variación entre el TT y el TO significa que se ha creado un efecto en el TT mediante una presencia excesiva de estructuras pasivas que afecta al tono o al estilo del texto. Debemos entender aquí por 'presencia excesiva' una utilización acumulativa de estructuras pasivas en el TT que resulta llamativa al lector.

En cuanto al uso, la utilización profusa de estructuras pasivas se suele considerar característica de los textos no ficcionales, especialmente de los textos científicos y técnicos tanto en inglés como en español. Pero esta estructura no guarda una relación de uno a uno entre ambas lenguas, lo que significa que la estructura sintáctica pasiva supone potencialmente una fuente de variación entre ambas lenguas, dadas las diferencias existentes ya en sus respectivos sistemas sintácticos. Ésta es la razón primordial por la que esta estructura en particular está presente en el repertorio, dada su relevancia para la traducción de textos no ficcionales de inglés a español y los tipos de variaciones que potencialmente origina.

Si comparamos los respectivos repertorios del inglés y del español en relación con esta estructura, encontramos dos fuentes potenciales de variación entre ellos, producidas por una distribución de estructuras diferente en cada lengua.

En el primer caso, para una estructura pasiva en inglés como la del ejemplo, el español dispone de dos estructuras:

Ejemplo:

After the second ad, on a Wednesday, the flat was sold on the following Sunday.

(The Guardian, April 13, 2002)

Estructura posible 1 (estructura pasiva):

[...] el piso fue vendido al domingo siguiente. 
Estructura posible 2 (estructura pasiva refleja):

[...] el piso se vendió al domingo siguiente.

El hecho de que los repertorios sintácticos del inglés y del español no guarden una relación de uno a uno en cuanto a estructuras pasivas como las de los ejemplos anteriores implica diferencias potenciales de frecuencia y distribución de su uso entre las dos lenguas. En particular, la aparición de estructuras pasivas en un texto en español sin alternancia con estructuras pasivas reflejas suele ser llamativa desde el punto de vista del tono o del estilo del texto. Por consiguiente, cuando el TT presenta una acumulación excesiva de estructuras pasivas nos encontramos con una variación de tipo estilístico, como se puede observar en el ejemplo siguiente:

Ejemplo:

[TO correspondiente al primer párrafo del Anexo E]

TT con las estructuras pasivas resaltadas (fragmento de una traducción realizada por un estudiante de Ingeniería Técnica Industrial):

Un paso importante en cualquier análisis de ingeniería es describir precisamente lo que está siendo estudiado. En mecánica, si el movimiento de un cuerpo está siendo determinado, normalmente el primer paso es definir un cuerpo libre e identificar todas las fuerzas ejercidas sobre él por otros cuerpos. La segunda ley de Newton del movimiento es aplicada entonces. En termodinámica el término sistema es usado para identificar el tema de análisis. Una vez el sistema es definido y las interacciones relevantes con otros sistemas están identificadas, una o más leyes físicas o relaciones $\underline{\text { son }}$ aplicadas.

El segundo caso de variación potencial consiste en que para una estructura pasiva en inglés como cualquiera de las dos de abajo, el sistema sintáctico del español no cuenta con ninguna estructura pasiva que se pueda considerar equivalente desde el punto de vista estructural.

Ejemplo:

The flat was said to be furnished.

(Student Experiences)

Ejemplo:

I was bought a pair of DKNY trousers for Christmas (75 per cent polyester, 25 per cent viscose) which say dry clean only on the label.

(The Observer, January 6, 2002) 
Habitualmente en estos casos los textos en español suelen presentar estructuras con verbo activo en las que no se menciona quién es el sujeto, como sucede en el siguiente ejemplo.

Ejemplo:

Me dieron unos 280 mil pesos que, con todos los impuestos, al final se quedaron en 230 .

(Reproducido en Diario de la Sociedad Civil, 4 de junio de 2001)

La falta de equivalencia de este tipo de estructura pasiva entre el sistema sintáctico del inglés y del español hace que las variaciones producidas en los TTs de los aprendices afecten no sólo al estilo o al tono del texto, sino también a la tematización, como sucede en el ejemplo que presentamos a continuación, en el que el aprendiz no establece ninguna distinción entre las dos estructuras resaltadas.

Ejemplo:

TO con una estructura pasiva y otra activa resaltadas (fragmento tomado del Anexo E):

Two basic kinds of systems are distinguished in this book. These are referred to, respectively, as closed systems and control volumes. A closed system refers to a fixed quantity of matter, whereas a control volume is a region of space through which mass may flow.

TT con las estructuras correspondientes resaltadas (fragmento de una traducción realizada por un estudiante de Ingeniería Técnica Industrial):

Dos clases básicas de sistemas son distinguidas en este libro. Se refieren respectivamente, a sistemas cerrados y control de volúmenes. Un sistema cerrado se refiere a una cantidad fija de materia, mientras un control de volumen es una region del espacio a través de la cual la masa debe fluir.

\subsubsection{Esquema temporal (T)}

Esta variación se refiere a la consistencia en el uso de los tiempos verbales del texto. De acuerdo con Brown y Yule (1983), la consistencia temporal es uno de los mecanismos que se utilizan para la cohesión textual. Distinguimos dos tipos de variación temporal. El esquema utilizado para expresar el tiempo en el que transcurren las acciones puede presentar diferencias con el que se utiliza en el TO (en este caso se trata de una variación intertemporal del efecto). Pero también puede ser anómalo en cuanto a las relaciones temporales de las acciones que aparecen en 
el propio TT (en este caso se trata de una variación intratemporal del efecto). En el ejemplo que presentamos a continuación, se puede observar una variación de tipo intertemporal puesto que, aunque la secuencia temporal que aparece en el TT es posible en cuanto a la relación establecida entre los diferentes tiempos verbales utilizados, ésta no se corresponde con la del TO.

Ejemplo:

TO con la estructura temporal resaltada (fragmento tomado del Anexo E):

Systems can be studied from a macroscopic or a microscopic point of view. The macroscopic approach to thermodynamics is concerned with the gross or overall behavior This is sometimes called classical thermodynamics.

Ejemplo:

TT con una estructura temporal diferente a la del TO (fragmento de una traducción realizada por una estudiante de Ingeniería Industrial):

Los sistemas pueden ser estudiados desde un punto de vista macroscópico o microscópico. El enfoque macroscópico de la termodinámica está interesado en la conducta grave o global. Esto será llamado algún día termodinámica clásica.

\subsubsection{Variaciones de efecto que afectan al nivel microtextual}

En este apartado recogemos las variaciones de efecto que se refieren a aspectos relacionados con los niveles y rangos inferiores del texto. Aquí aparecen efectos asociados al grupo nominal y al grupo verbal, cuyo alcance no va más allá del rango de la oración.

\subsubsection{Tratamiento de entidades (ENT)}

Con este tipo de variación se identifica un tratamiento diferente en el TT de uno o varios conceptos o entidades del TO. La variación de efecto puede suceder por 'fragmentación', cuando una entidad es tratada como varias, pero también por 'fusión conceptual' cuando varias entidades son tratadas como un solo concepto. A continuación mostramos un ejemplo de variación por fragmentación conceptual en el que la entidad «any engineering analysis» del TO es interpretada por el traductor como dos entidades diferentes, «un análisis» y «una ingeniería». 
Ejemplo:

TO con una entidad resaltada (fragmento correspondiente al Anexo E):

An important step in any engineering analysis is to describe precisely what is being studied.

TT con fragmentación de la entidad resaltada (fragmento de una traducción realizada por un estudiante de Ingeniería Técnica Industrial):

Un importante paso en un análisis de una ingeniería es describir con precisión lo que está siendo estudiado.

\subsubsection{Especificidad (ESP)}

Mediante este tipo de variación identificamos aquellos casos en los que una o varias entidades del TT presentan un nivel de especificidad diferente del que tenía su correspondiente entidad en el TO. Al tratarse de una variación referente a la selección léxica que ha hecho el traductor, este tipo está relacionado con la variación que afecta a la cohesión léxica (v. 6.4.1.1). No obstante, dado que estamos tratando las variaciones que se pueden delimitar dentro del nivel microtextual, nuestro interés por los casos recogidos aquí se centran en el repertorio de opciones léxicas disponibles y elegidas para expresar la entidad en cuestión, y no en su contribución a la cohesión léxica del texto. Por consiguiente, se recogen aquí aquellos casos relacionados con la utilización de palabras que se pueden considerar con un grado de especificidad diferente de las utilizadas pero relacionadas semánticamente con las que esperábamos. Las relaciones semánticas a las que nos referimos incluyen las que se establecen mediante la hiponimia, la relación 'partetodo' o meronimia, la sinonimia, la antonimia, las colocaciones o incluso la lexicalización expresada mediante el género (una jarro y una jarra, por ejemplo) o el número (como la relación existente entre un banco de sardinas y una única sardina).

En el primero de los ejemplos que presentamos, la traductora ha elegido la palabra «ver» como traducción de «watch». No obstante, podemos inferir por la información co-textual que el objetivo al que se refiere el texto, además de simplificar, no consiste en «ver los vectores», sino en vigilarlos o controlarlos para que se pueda mantener la estabilidad. Al clasificar esta variación como relativa a la especificidad de la entidad, estamos asumiendo que hay una relación léxica de hiperonimia entre «ver»y «vigilar» en la que «ver» es un hiperónimo de «vigilar». En el segundo ejemplo, la variación de efecto detectada se refiere a que la entidad 
afectada aparece en el TT en singular, mientras que la entidad del TO aparece en plural.

Ejemplo:

TO en el que resaltamos la entidad afectada (fragmento correspondiente al Anexo D):

The goal is always to simplify and to watch the eigenvectors -especially when they are exponentials.

TT en el que se utiliza un hiperónimo para la entidad afectada (fragmento de una traducción realizada por una estudiante de Ingeniería Industrial):

El objetivo es siempre simplificar y ver los vectores -especialmente cuando son exponenciales.

Ejemplo:

TO en el que se resalta la entidad afectada (fragmento correspondiente al Anexo E):

It is essential for the boundary to be delineated carefully before proceeding with any thermodynamic analysis. However, since the same physical phenomena often can be analyzed in terms of alternative choices in the system, boundary, and surroundings, the choice of a particular boundary defining a particular system is governed by the convenience it allows in the subsequent analysis.

TT en el que la entidad resaltada aparece en singular (fragmento de una traducción realizada por un estudiante de Ingeniería Técnica Industrial):

Es esencial para el límite ser delineado con cuidado antes de proceder con ningún análisis termodinámico. Sin embargo, ya que a menudo el mismo fenómeno físico puede ser analizado en periodos de selección alternativa de los límites del sistema y alrededores, la selección de un límite particular definiendo un sistema particular es gobernado por la conveniencia permitida en los análisis posteriores.

\subsubsection{Cambio de función (FUN)}

En términos generales, este tipo de variación afecta a las relaciones establecidas entre los modificadores del grupo nominal (v. 5.2.4.1). No obstante, debemos distinguir dos tipos posibles de relación.

En el esquema de premodificación, a la izquierda del núcleo, los modificadores se acumulan secuencialmente y su orden responde al tipo de 
modificación que ejercen sobre el núcleo. En este esquema no se utilizan preposiciones u otros mecanismos que hagan explícitas las relaciones que se establecen entre los elementos premodificadores y el núcleo del grupo, a excepción del uso de guiones para indicar que un elemento modifica a otro modificador y no al núcleo. Por esta razón, podemos afirmar que en el esquema de premodificación del grupo nominal las relaciones que se establecen entre los modificadores y el núcleo son de naturaleza implícita. Por el contrario, en el esquema de postmodificación que se desarrolla a la derecha del núcleo, las relaciones que se establecen entre los modificadores y el núcleo, y entre los propios modificadores, aparecen marcadas mediante preposiciones, por lo que podemos afirmar que las relaciones que se establecen en el esquema de postmodificación son de naturaleza explícita. Desde esta perspectiva, es conveniente diferenciar entre las variaciones que afectan a las relaciones de tipo implícito del esquema de premodificación y las variaciones que se refieren a las relaciones explícitas del esquema de postmodificación. En este repertorio, vamos a tratar las variaciones que afectan a la premodificación como variaciones de cambio de función (FUN), a las que dedicamos este apartado, mientras que las variaciones relativas a la postmodificación serán tratadas más adelante como variaciones relativas a las preposiciones (PRP).

La construcción del grupo nominal en español no sigue el esquema de premodificación y de postmodificación con la misma agilidad y capacidad expansiva premodificadora que en la lengua inglesa. De acuerdo con Halliday (1998), la capacidad expansiva del grupo nominal en el discurso científico inglés moderno sucede de diversos modos y es prácticamente infinita. Pero lo que es más relevante desde una perspectiva didáctica es que la naturaleza implícita de las relaciones que se establecen dificulta a los aprendices la identificación de qué relación conceptual se trata.

Como ya señalamos anteriormente, la posición relativa que ocupan unos elementos modificadores respecto de los otros elementos del grupo es pertinente desde el punto de vista semántico (Halliday y Hasan 1976). Además, esta estructuración se da simultáneamente a la representación del mundo experiencial mediante una subdivisión funcional de los modificadores. Así, podemos decir que las variaciones que afectan a las relaciones funcionales establecidas entre los diferentes elementos modificadores suponen variaciones semánticas con respecto al TO y se describen típicamente como cambios de función en los que un elemento, que en grupo nominal del TO ejercía la función de modificador, pasa a ejercer en el TT la función de núcleo y viceversa. 
Cabe suponer que la tendencia a incurrir en este tipo de variación se manifestará preferentemente en aquellos casos en los que el grupo nominal presenta una gran acumulación de elementos en la premodificación. Sin embargo la experiencia nos muestra que, en realidad, esta variación sucede con tanta frecuencia cuando la premodificación está compuesta por un único elemento como cuando se compone de varios modificadores.

Ejemplo:

TO con un grupo nominal resaltado (fragmento):

The system boundary is a mathematical entity that is established for the convenience of the analysis.

(The Thermodynamic System, 2001. URL:

http://www.me.ttu.edu/joradn/courses/thermo/Time/Time.htm\#ancho r144093)

TT 1 con un cambio de función en el grupo nominal resaltado, cuyo núcleo ahora es «sistema» (fragmento de una traducción realizada por un estudiante de Ingeniería Técnica Industrial):

El sistema límite es una entidad que es establecida por la conveniencia del análisis.

TT 2 con una versión diferente del mismo cambio de función que en TT1 (fragmento de una traducción realizada por otro estudiante de Ingeniería Técnica Industrial):

El sistema limitado es una entidad matemática que está establecida por la conveniencia del análisis.

Ejemplo:

TO con un grupo nominal resaltado cuyo núcleo es «heats» (fragmento correspondiente al Anexo E):

[...] the microscopic approach is instrumental in developing certain property data, for example, ideal gas specific heats [...]

TT con el correspondiente grupo nominal resaltado cuyo núcleo ahora es «gas» (fragmento de una traducción realizada por un estudiante de Ingeniería Técnica Industrial):

[...] el enfoque microscópico es instrumental en cuanto al desarrollo con seguridad datos propios, por ejemplo, un gas ideal específico caliente [...] 


\subsubsection{Grupo verbal (GV)}

Este tipo de variación se refiere a cambios en el grupo verbal de una oración. El grupo verbal es interpretado, siguiendo a Halliday y Hasan (1976) como una relación lógico-semántica (conjuntiva) entre dos grupos nominales dentro de la misma estructura oracional.

Siguiendo a Halliday (1998:196), podemos establecer una diferencia de efecto entre las variaciones que suceden en el grupo nominal y aquellas que se dan dentro del grupo verbal. Dado que la expansión del grupo verbal es de tipo gramatical (y no léxico, como sucede en el grupo nominal), las variaciones de efecto descritas de este modo tienen que ver con el tiempo, modo y aspecto de los verbos utilizados para asociar grupos nominales en el texto. No se trata de una variación cualitativamente diferente a la que hemos denominado 'esquema temporal' (v. 6.4.1.6) pero, a diferencia de ésta, que es interpretada en su dimensión macrotextual como la relación establecida entre secuencias o cadenas de grupos verbales utilizados para relacionar los diferentes acontecimientos que se narran, la variación de efecto descrita aquí afecta localmente a la relación entre dos grupos nominales.

En el ejemplo que presentamos, el grupo verbal del TO expresa una acción pasada y terminada formada por el pretérito perfecto (present perfect) del verbo 'move', mientras que en el TT la acción no se refiere al pasado y además expresa obligación mediante la perífrasis 'tener que + infinitivo (moverse)'.

Ejemplo:

TO con el grupo verbal resaltado (fragmento correspondiente al Anexo D):

The terms $a u$ and $A u$ have moved to the left side of the equation, leaving space on the right side for $f(t)$.

TT en el que el grupo verbal afectado presenta una perífrasis que expresa obligación (fragmento de una traducción realizada por una estudiante de Ingeniería Industrial):

Los términos au y Au tienen que moverse al lado izquierdo de la ecuación, dejando el espacio de la derecha para $\mathrm{f}(\mathrm{t})$.

\subsubsection{Ortografía y concordancia local (ORT)}

Este tipo de variación se refiere a los cambios de efecto que se aprecian cuando la escritura de una palabra, la ortografía, o la concordancia de género y 
número entre elementos relacionados localmente en el texto no corresponden con la norma lingüística de la variedad de lengua utilizada en el TT. Estas variaciones se refieren, por tanto, a la aplicación que ha hecho el traductor de las reglas gramaticales de la lengua del TT.

Ejemplo:

TO con dos casos resaltados (fragmento):

A thermodynamic system is defined as the material and electric charge contained within a specified, closed surface, which is called the system boundary.

(The Thermodynamic System, 2001. URL:

http://www.me.ttu.edu/joradn/courses/thermo/Time/Time.htm\#ancho $\underline{\mathrm{r} 144093})$

TT con un caso de falta de concordancia de número y otro de falta de concordancia de género (fragmento de una traducción realizada por un estudiante de Ingeniería Técnica Industrial):

Un sistema termodinámico se define en cuanto a la materia y la carga eléctrica contenida en una superficie cerrada específica, el cual es llamado sistema límite.

\subsubsection{Preposiciones (PRP)}

En este tipo de variación se recogen aquellos casos en los que las relaciones explícitas marcadas por preposiciones del esquema de postmodificación del grupo nominal se ven afectadas. Estas variaciones de efecto se pueden referir a un cambio de función entre dos modificadores, o también entre un modificador y el núcleo. Este cambio de función es similar al descrito para el esquema de premodificación. En el primer ejemplo que presentamos más abajo, se puede observar un cambio de función en el modificador «analysis», que pasa a ser núcleo del grupo nominal en el TT como «análisis», y el núcleo «subject», que en el TT aparece como el modificador «objeto».

No obstante, las variaciones de esta clase también se pueden referir a cambios en la naturaleza de la relación marcada mediante la preposición, aunque no se haya producido un cambio de función entre los elementos afectados. Esto es lo que sucede en el segundo ejemplo que presentamos. Aquí, la relación que en el TO se establece en dos ocasiones mediante la preposición «along with» aparece tratada en el TT de un modo diferente. El traductor ha elegido en el primer caso la locución 
preposicional «a lo largo de» para marcar la relación entre el núcleo «espacio» y el modificador «tiempo». Sin embargo, en el segundo grupo nominal resaltado la traductora ha introducido más variaciones que en el anterior. El núcleo del grupo nominal, que en el TO era «slopes», ha cambiado de función puesto que la traductora ha interpretado que se trata de un verbo y la relación establecida mediante la preposición ha pasado a establecerse mediante el adverbio «dentro» y la preposición «con». Estas variaciones de efecto son tan acusadas, que la funcionalidad del texto se ve afectada, puesto que la información no es comprensible.

Ejemplo:

TO con un grupo nominal resaltado (fragmento correspondiente al Anexo E):

In thermodynamics the term system is used to identify the subject of the analysis.

TT con el grupo nominal correspondiente resaltado (fragmento de una traducción realizada por un estudiante de Ingeniería Técnica Industrial):

En termodinámica el término sistema se usa para identificar el análisis del objeto.

Ejemplo:

TO con dos grupos nominales resaltados (fragmento correspondiente al Anexo D):

Then we admit space along with time, and slopes along with velocities, balancing the rate of change $\partial u / \partial t$ with the gradient $\partial u / \partial x$.

TT con las variaciones correspondientes a los dos grupos resaltadas (fragmento de una traducción realizada por una estudiante de Ingeniería Industrial):

Entonces nosotros admitimos el espacio a lo largo del tiempo, e inclinándose dentro con velocidades, se equipara la velocidad de cambio $\overline{\partial u / \partial t \text { con el }}$ gradiente $\partial u / \partial x$.

\subsubsection{Variaciones de efecto que pueden afectar al nivel macrotextual o al nivel microtextual}

Este tercer apartado ha sido concebido a modo de miscelánea. El análisis clasificatorio de las variaciones detectadas nos ha llevado en unos casos a situar las variaciones en el nivel macrotextual y, en otros, en el nivel microtextual. No 
obstante, ha aparecido también una cierta cantidad de efectos que no han podido ser asignados en todos los casos a un grupo en particular, por lo que los incluimos aquí.

\subsubsection{Información absurda o incomprensible (ABS)}

En este tipo de variación la información que presenta el texto es intrínsecamente absurda o incomprensible debido a las relaciones que se han establecido entre las entidades, o bien porque los elementos lingüísticos elegidos son fallidos de algún modo que afecta a la construcción del significado. En el primer ejemplo que presentamos, la variación afecta al nivel microtextual en cuanto a la frecuencia y distribución de aparición de la entidad afectada (una referencia bibliográfica en este caso). No obstante, esta variación afecta a la funcionalidad del texto en cuanto que no es posible acceder a la fuente de referencia citada a partir de la información que aparece en el TT. Se trata, por tanto, de un error de la traducción y no de un simple cambio de efecto. La variación que se puede observar en el segundo ejemplo que presentamos tiene un alcance mayor, puesto que afecta a la totalidad del fragmento presentado (en realidad, a todo el TT). Se trata de un caso extremo donde la información del texto es incomprensible, puesto que no hay suficiente cohesión ni coherencia.

Ejemplo:

TO en el que una referencia bibliográfica aparece resaltada (fragmento):

For more hints about literature searching, see the following:

371.3 GAS

GASH: Effective literature searching for students

(How to Find out in Environmental Engineering, R. McLeod, 1995.

URL: http://www.hw.ac.uk/libWWW/howto/environ.html)

TT con la referencia bibliográfica traducida de un modo absurdo (fragmento de una traducción realizada por un estudiante de Ciencias Ambientales):

[For more hints about literature searching, see the following:

371.3 GAS]

Incisión: Literatura eficaz buscada para estudiantes

Ejemplo:

[TO correspondiente al primer párrafo del Anexo E] 
TT incomprensible (fragmento de una traducción realizada por una estudiante de Ingeniería Técnica Industrial):

Un Paso importante en algún análisis de Ingeniería, es a describir exastamente que serán estudiada en mecanica, si el motivo de un cuerpo es para determinar, normalmente el primer paso, es para definir un paso libre e Identificar todas las fuerzas empleada en él por otros cuerpos. Segundo ley de Newton es cuando aplicó de movimientos. en termodinamica, la ley del sistema está usada para identificar la sujección de los analisis. una vez el sistema esté definida y la interacciones relacionado con otro sistemas, será identificada, una o más leyes física o serán relaciones aplicadas.

\subsubsection{Conexión lógica (CON)}

Esta variación de efecto se refiere a las relaciones lógicas utilizadas en el texto para asociar unas proposiciones con otras. Estas relaciones pueden establecerse entre proposiciones que aparecen dentro de la misma oración o bien que abarcan varias oraciones, por lo que el alcance de la variación del efecto creado puede ser en unos casos local, mientras que en otros tendrá una dimensión macrotextual. Las variaciones de este tipo afectan típicamente al uso que se hace en el texto de los conectores lógicos, en cuanto que marcadores explícitos de las relaciones lógicas establecidas en el nivel proposicional. En el ejemplo que presentamos a continuación, podemos ver en el TO un nexo conjuntivo de tipo causal al principio del segundo párrafo, que es utilizado para marcar explícitamente la relación lógica existente entre la proposición de la oración donde éste se encuentra, «we end with nonlinear partial differential equations» y las tres oraciones anteriores, «Then we admit ... and catches the other waves». No obstante, en el TT esta relación lógica no aparece marcada de forma explícita.

Ejemplo:

TO con un nexo conjuntivo interoracional resaltado que marca explícitamente una relación lógica entre proposiciones (fragmento correspondiente al Anexo D):

This chapter takes the next steps toward that goal. 1t introduces the time $t$ and velocities $d u / d t$ and accelerations $d^{2} u / d t^{2}$. The unknown $u$, a scalar or a vector, evolves in time from its initial state $u_{0}$ at $t=0$. We start with no space variables, studying ordinary differential equations. Their solution, analytical and later numerical, comes first. Then we admit space along with time, and slopes along with velocities, balancing the rate of change $\partial u / \partial t$ with the gradient $\partial u / \partial x$. There is conservation of mass or momentum or energy. This balance equation allows waves to travel in space-time, and when it is nonlinear those waves can break -producing a shock that travels at 
supersonic speed and catches the other waves.

Thus we end with nonlinear partial differential equations. Those are more difficult than linear waves and linear responses, where the frequencies and the harmonics are completely dominant. [...]

TT donde no se marca explícitamente la relación lógica (fragmento de una traducción realizada por un estudiante de Ingeniería Industrial):

Este capítulo muestra los pasos siguientes para llegar a ese fin. Presenta el tiempo t y las velocidades du/dt y las aceleraciones $\mathrm{d}^{2} \mathrm{u} / \mathrm{dt}^{2}$. La incógnita $\mathrm{u}$, un escalar o un vector, evoluciona en el tiempo desde su estado inicial $\mathrm{U}_{0}$ en $\mathrm{t}=0$. empezaremos $\sin$ variables espaciales, estudiando las ecuaciones diferenciales ordinarias. Su solución, analítica y después numérica, viene primero. Luego enfrentaremos el espacio a lo largo del tiempo y las pendientes con las velocidades, equilibrando el porcentaje del cambio du/dt con el gradiente $\mathrm{du} / \mathrm{dx}$. Tendremos conservación de masa o momento o energía. La ecuación de balance permite a las ondas viajar a través del espacio-tiempo, y cuando es no lineal dichas ondas pueden romperse, produciendo un golpe que viaja a velocidad supersónica y captura a las otras ondas.

Terminaremos con las ecuaciones diferenciales parciales no lineales. Estas son más difíciles que las ondas lineales y las respuestas lineales, donde las frecuencias y los armónicos son completamente dominantes.

\subsubsection{Estrategias de correferencia (COR)}

En este tipo de variación, el tratamiento de una entidad a lo largo del texto se ve afectado. Puede que la secuencia donde aparece la entidad no abarque más de una oración, en cuyo caso esta variación tendrá un alcance microtextual, pero también es posible que la secuencia se extienda a lo largo de uno o varios párrafos. La variación en el uso de las diferentes estrategias de correferencia puede detectarse a partir de diferencias entre el TT y el TO en el tratamiento de la entidad. No obstante, también hablamos de variación en la correferencia cuando detectamos usos inapropiados o extraños de artículos, deícticos y demás correferentes en el TT, que influyen negativamente en la construcción del significado relativo a la entidad afectada.

Ejemplo:

TO con una secuencia resaltada (fragmento correspondiente al Anexo D):

The mathematics in this book springs from two sources: calculus and linear algebra. Those are both at the service of applied mathematics, and they are called on constantly. 
TT con una variación en la secuencia a partir de un antecedente diferente al del TO (fragmento de una traducción realizada por una estudiante de Ingeniería Industrial):

Las matemáticas en este libro provienen de dos fuentes: cálculo y álgebra lineal. Ellas están ambas al servicio de las matemáticas aplicadas, y son consideradas constantemente.

Ejemplo:

TO con una secuencia resaltada (fragmento):

Pickers seeking seasonal work are registered on a database and allocated work according to grower demands. Those who return year after year generally have a good relationship with a grower, who will expect these pickers to be back the following season.

(Jobs for the picking, T. Robbins, 2001. URL: http://sydney.citysearch.com.au/feature/344/)

TT1 en el que la secuencia correspondiente aparece resaltada (fragmento de una traducción realizada por un estudiante de Ciencias Ambientales):

Los recolectores que buscan trabajo estacional, se registran en una base de datos y se les asigna el trabajo según la demanda de los fruticultores. Aquellos que repiten año tras año, generalmente mantienen una buena relación con un fruticultor que cuenta con la vuelta de estos recolectores, la próxima temporada.

TT2 en el que aparece una variación de número en el último elemento de la secuencia (fragmento de una traducción realizada por una estudiante de Ciencias Ambientales):

Los recolectores que buscan un trabajo estacional están registrados en una base de datos y el trabajo se asigna de acuerdo a las demandas de los cultivadores. Quienes regresan año tras año tienen, por lo general, una buena relación con un cultivador, quien esperara que este recolector vuelva la próxima estación.

\subsubsection{Información falsa (F)}

Traduttore, traditore: este tipo de variación describe aquellos casos en los que se considera que la información que aparece en el TT es falsa en relación con las condiciones de verdad del TO. Como ya vimos anteriormente (v. 6.3.1), para autores como Dollerup (1994) esta variación (interpretada por esta autora únicamente en relación con el contenido proposicional del texto) supone el error más grave que se puede cometer al traducir. En el primero de los ejemplos que 
presentamos, la introducción de información falsa sucede en un nivel microtextual, puesto que su distribución no sobrepasa los límites de la oración. No obstante, esta variación afecta a la definición de uno de los términos clave utilizados en el manual, lo cual tendrá repercusiones en la aplicación de este término a lo largo de todo el texto (por no mencionar su efecto negativo en el aprendizaje sobre los sistemas termodinámicos de los lectores del TT). En el segundo ejemplo, se puede observar que la traductora introduce información falsa en varias ocasiones a lo largo del TT. Las variaciones detectadas se refieren en este caso a diferentes tipos de información textual y esto llega a producir en el analista una falta de confianza en la información textual en su conjunto.

Ejemplo:

TO con una parte de una definición resaltada (fragmento):

A control volume is defined to be a system that has fixed size and shape but is free to have matter cross its boundaries.

(The Thermodynamic System, 2001. URL:

http://www.me.ttu.edu/joradn/courses/thermo/Time/Time.htm\#ancho $\underline{\mathrm{r} 144093)}$

TT con una variación en la definición (fragmento de una traducción realizada por un estudiante de Ingeniería Técnica Industrial):

Un volumen de control es definido como un sistema que ha cambiado de tamaño y forma pero es libre de tener materia que cruza sus límites.

Ejemplo:

TO con diferentes datos resaltados (fragmento):

Marie Fontana, Employment National's business manager for Shepparton and Echuca, has the big job of recruiting pickers for the region's growers. Her Harvest Labour Office works closely with the NVFA. Last season the office placed about 3500 people, with more than 90 per cent from outside the Shepparton region, many of these backpackers.

(Jobs for the picking, T. Robbins, 2001. URL: http://sydney.citysearch.com.au/feature/344/)

TT en el que los datos resaltados han variado (fragmento de una traducción realizada por una estudiante de Ciencias Ambientales):

Marie Fontana, eficiente directora del Instituto de Empleo Nacional para Shepparton y Echuca, tiene el gran trabajo de contratar recolectores para los agricultores regionales. Su oficina del Sindicato de recolección trabaja conjuntamente con la Asociación de Recolectores de fruta de Victoria del Norte (NVFA). La pasada temporada la oficina coloco alrededor de 35000 personas, mas del 90 por ciento de las afueras de la región de Shepparton, 
muchos de estos porteadores.

\subsubsection{Estrategias de puntuación (PUN)}

Esta variación se refiere a la utilización de los recursos de puntuación disponibles, tales como comas, puntos, etc., destinados a estructurar las palabras marcando visualmente las estructuras sintácticas en que aparecen organizadas. Utilizamos este tipo de variación para indicar que los recursos utilizados en el TT hacen que la organización de las palabras favorezca una construcción del significado diferente de la utilizada en el TO. En el ejemplo que presentamos, se puede observar cómo la ausencia de puntuación para separar la información en dos estructuras oracionales diferentes hace que la agrupación de las palabras sea confusa, de modo que no podemos saber, sin utilizar otro tipo de información, si el complemento de lugar «en la sección 1.5.» corresponde a la acción «se expuso» o a «podemos repasar».

Ejemplo:

TO con una secuencia de dos oraciones (fragmento correspondiente al Anexo D):

A start was made on ordinary differential equations in Section 1.5. We can review in three lines what was done: $[\ldots]$

TT con una única oración (fragmento de una traducción realizada por un estudiante de Ingeniería Industrial):

Se expuso una forma de inicio con ecuaciones diferenciales ordinarias en la sección 1.5. podemos repasar en tres líneas que se hizo: [...]

\subsubsection{6 "Algo suena mal” (SM)}

En este tipo de variación los elementos afectados no se ajustan al uso normal de la lengua meta (el castellano en nuestro repertorio) en esa situación, bien porque la asociación de palabras es extraña o bien por otras razones. Desde un punto de vista intuitivo, al leer el texto tenemos la sensación de que 'algo suena mal'. Este parámetro representa en el repertorio aquellos efectos textuales que se relacionan con el uso convencional del lenguaje. Está formulado de modo negativo porque, 
desde una perspectiva intuitiva sobre el uso convencional, es fácil reconocer cuándo el texto presenta algún elemento (o asociación de elementos) que no corresponde con el uso convencional en ese contexto particular, más que lo contrario. Creemos que la formulación de este parámetro de forma intuitiva es la idónea en cuanto a su usabilidad para los aprendices, como punto de partida para llevar a cabo un análisis más profundo con el fin de establecer con mayor precisión qué es lo que ocurre.

En general, es frecuente que en un análisis preliminar de un TT se marquen variaciones de este tipo que posteriormente podrán ser descritas o identificadas como variaciones de un tipo diferente, más específico. En el ejemplo que presentamos a continuación podemos ver marcados cuatro casos en los que fácilmente se percibe que algo no suena bien. Sin embargo, será necesario un análisis mucho más detallado para identificar qué tipos de variación se dan en cada uno de los casos.

Ejemplo:

[TO correspondiente al Anexo E]

TT en el que se han resaltado las secuencias que suenan mal (fragmento de una traducción realizada por un estudiante de Ingeniería Técnica Industrial):

El sistema es lo que nosotros queremos estudiar. Debe ser tan simple como un cuerpo libre o tan complicado como un refinamiento químico completo. Nosotros debemos querer estudiar una cantidad de materia contenida dentro de un tanque cerrado rígido-amurallado, o debemos considerar algo tal como una tubería de gas a través de la cual fluye la materia.

\subsubsection{Recursos tipográficos (TIP)}

Este tipo de variaciónse refiere a aquellos casos en los que el TT no presenta la utilización de los recursos tipográficos del TO, u otros similares, para marcar visualmente aquellos elementos textuales que en el TO aparecen resaltados. A diferencia de la variación relativa a los recursos de edición empleados, interpretamos aquí que la finalidad de resaltar un elemento léxico del texto mediante un recurso tipográfico puede responder a un enfoque microtextual, puesto que el elemento en cuestión se hace más visible que el resto de los elementos presentes en su co-texto inmediato. No obstante, podemos considerar asimismo la utilización que se hace a lo largo de todo el texto de un recurso tipográfico en particular (la cursiva, por ejemplo). En este caso, nuestras consideraciones corresponderán a una perspectiva macrotextual. 
Ejemplo:

TO con dos términos en cursiva resaltados (fragmento correspondiente al Anexo E):

An important step in any engineering analysis is to describe precisely what is being studied. In mechanics, if the motion of a body is to be determined, normally the first step is to define a free body and identify all the forces exerted on it by other bodies. Newton's second law of motion is then applied. In thermodynamics the term system is used to identify the subject of the analysis. Once the system is defined and the relevant interactions with other systems are identified, one or more physical laws or relations are applied.

TT en el que no se utiliza la cursiva ni ningún otro recurso tipográfico para resaltar la información (fragmento realizado por una estudiante de Ingeniería Industrial):

Una importante etapa en cualquier análisis de ingeniería es describir previamente lo que se está estudiando. En mecánica, si se determina el movimiento de un cuerpo, normalmente el primer paso es definir un cuerpo libre e identificar todas las fuerzas sobre él por otros cuerpos. Después se aplica la segunda ley de Newton para el movimiento. En termodinámica el sistema térmico es utilizado para identificar el objeto de análisis. Una vez definido el sistema y definidas las interacciones relevantes con otros sistemas se aplican una o más leyes físicas o relaciones.

A continuación, en la Tabla 14 se recoge la relación de los parámetros de variación que hemos descrito, de acuerdo con su potencial alcance textual:

\begin{tabular}{|c|c|c|c|c|c|}
\hline \multicolumn{2}{|c|}{ ALCANCE GLOBAL } & \multicolumn{2}{|c|}{$\begin{array}{l}\text { ALCANCE GLOBAL, } \\
\text { LOCAL O MEDIO }\end{array}$} & \multicolumn{2}{|c|}{ ALCANCE LOCAL } \\
\hline CL & $\begin{array}{l}\text { Cohesión } \\
\text { léxica }\end{array}$ & ABS & $\begin{array}{l}\text { Información } \\
\text { absurda o } \\
\text { incomprensible }\end{array}$ & ENT & $\begin{array}{l}\text { Tratamiento } \\
\text { de entidades }\end{array}$ \\
\hline ED & $\begin{array}{l}\text { Recursos de } \\
\text { edición }\end{array}$ & CON & $\begin{array}{l}\text { Conexión } \\
\text { lógica }\end{array}$ & ESP & Especificidad \\
\hline EST & $\begin{array}{l}\text { Estructuras } \\
\text { textuales }\end{array}$ & COR & $\begin{array}{l}\text { Estrategias de } \\
\text { correferencia }\end{array}$ & FUN & $\begin{array}{l}\text { Cambio de } \\
\text { función }\end{array}$ \\
\hline INT & $\begin{array}{l}\text { Relaciones } \\
\text { interpersonales }\end{array}$ & $\mathbf{F}$ & $\begin{array}{l}\text { Información } \\
\text { falsa }\end{array}$ & GV & Grupo verbal \\
\hline
\end{tabular}




\begin{tabular}{|c|c|c|c|c|c|}
\hline PAS & $\begin{array}{l}\text { Uso excesivo } \\
\text { de estructuras } \\
\text { pasivas }\end{array}$ & PUN & $\begin{array}{l}\text { Estrategias de } \\
\text { puntuación }\end{array}$ & ORT & $\begin{array}{l}\text { Ortografía y } \\
\text { concordancia } \\
\text { local }\end{array}$ \\
\hline \multirow[t]{2}{*}{$\mathbf{T}$} & $\begin{array}{l}\text { Esquema } \\
\text { temporal }\end{array}$ & SM & $\begin{array}{l}\text { "Algo suena } \\
\text { mal" }\end{array}$ & PRP & Preposiciones \\
\hline & & TIP & $\begin{array}{l}\text { Recursos } \\
\text { tipográficos }\end{array}$ & & \\
\hline
\end{tabular}

Tabla 14. Repertorio de variaciones de efecto entre el TT y el TO (versión revisada de Elorza 1999; 2001; 2002)

No queremos concluir esta sección dedicada a este instrumento de recogida de datos, que hemos descrito con el fin de presentar un modo de dar visibilidad al análisis textual de las traducciones, sin comentar brevemente tres aspectos puntuales que afectan a la clasificación de las variaciones detectadas así como a la utilización del repertorio con fines evaluativos.

En primer lugar, queremos indicar que, dado que el repertorio es susceptible de ser aplicado de diferentes modos en diferentes momentos y por diferentes personas, es posible clasificar una misma discrepancia como diferentes casos de variación. Podemos aducir dos razones diferentes que explican este aspecto.

Por una parte, debemos señalar que el repertorio responde a la clasificación interpretativa del analista. No se trata de un repertorio excluyente en el que la clasificación de un ítem como perteneciente a una clase excluye automáticamente las opciones de pertenecer a otra clase diferente. La aplicación de este repertorio con fines didácticos admite la visión subjetiva del analista. No olvidemos que su función primordial no es clasificatoria, sino que lo que persigue es hacer visible la mirada del analista, bien sea el profesor, bien sea el alumno. Se trata, en este sentido, de una herramienta para contar o explicar lo que vemos en el texto.

Por otra parte, las clases establecidas en el repertorio no son clases cerradas debido a que el lenguaje crea el significado de forma multimodal, como explica Matthiessen (2001). Esto significa que el texto, como objeto complejo de lenguaje en uso, consta de multitud de elementos y niveles que actúan simultáneamente, de tal forma que, si tomamos una palabra del mismo (como caso típico de elemento discreto identificado por los aprendices), podemos analizarla de diferentes modos de acuerdo con el nivel de construcción del significado que estemos considerando en 
ese momento preciso (por ejemplo, como un conjunto de letras o de sílabas, como parte central de un sintagma, como forma de expresión de un significado, como participante en la correferencia de una entidad del texto, etc.). La clasificación que hacemos de una discrepancia detectada depende, por tanto, no sólo de la visión subjetiva del analista, sino que esta visión subjetiva es producto igualmente del cúmulo de posibilidades reales de analizar los elementos textuales, que son susceptibles de ser analizados desde diferentes perspectivas.

En segundo lugar, no es posible establecer de antemano cuándo una variación de efecto supone un error de traducción o cuándo se trata de una discrepancia, quizá necesaria para lograr el efecto textual deseado. Esta distinción es importante puesto que la definición de problema de traducción y la definición de error de traducción no son equiparables. Podemos simplemente generalizar aquí diciendo que es sólo posteriormente a la detección de la discrepancia cuando podemos aplicar un baremo que nos permita asignarle un valor positivo o negativo y, por tanto, que nos permita establecer cuándo, además de una discrepancia, se ha producido también un error.

En tercer lugar, la finalidad de este instrumento de recogida de datos no es expresamente poner de manifiesto las actitudes, opiniones y valores del aprendiz en relación con el contexto de la situación comunicativa del TO y del TT, por lo que no debe ser contemplado como un instrumento diseñado con la finalidad de facilitar la consecución de objetivos de tipo actitudinal en particular. Como ya hemos señalado, es el primer instrumento que hemos presentado, el informe, donde podemos visualizar las reflexiones de los aprendices con relación a las actitudes, opiniones y valores que muestran con respecto a la situación comunicativa y a la actividad que están realizando. En este sentido, no se debe olvidar que la finalidad de este segundo constructo tiene que ver con la intervención pedagógica. Teniendo en cuenta la cantidad de factores involucrados en la comunicación mediante la mediación intercultural, esta intervención puede ser necesaria o aconsejable en aspectos muy variados, por lo cual el repertorio refleja muchas de las posibilidades (pero no necesariamente todas) que el profesor puede querer explotar. Aunque no lo hemos señalado explícitamente, sí que hemos identificado en la práctica una variación de efecto que suele dar pie con facilidad para tratar cuestiones relacionadas con los valores vigentes en los contextos de situación de los textos. Nos referimos a la variación relativa a la relación social de los participantes, que hemos denominado 'relaciones interpersonales' (v. 6.4.1.4), si bien con frecuencia 
otros tipos de variaciones también permiten que la discusión del aula se dirija a tratar cuestiones relacionadas con contenidos de tipo actitudinal ${ }^{13}$.

Para finalizar este extenso capítulo, queremos recordar que hemos comenzado por tratar el concepto de evaluación desde una perspectiva general, para pasar a continuación a plantear que lo que evaluamos depende directamente de lo que queremos que nuestros alumnos aprendan y, por consiguiente, de lo que vamos a enseñarles. Aquí hemos introducido la clasificación propuesta por Bloom y sus colaboradores para tratar los objetivos que podemos establecer en un curso y los contenidos que podemos incluir en él $\mathrm{y}$, por tanto, qué conocimientos pueden adquirir nuestros aprendices y qué objetivos puede perseguir la evaluación. Nos hemos limitado a describir de modo general los objetivos de tipo cognoscitivo (v. 6.1.1) y los de tipo actitudinal (v. 6.1.2), dejando fuera la clasificación de objetivos psicomotores por falta de relevancia para nuestra investigación. De esta taxonomía, hemos identificado los objetivos de tipo actitudinal como aquellos objetivos educacionales sobre los que considerar específicamente la funcionalidad didáctica de las actividades de traducción en el entorno del Inglés para Fines Específicos.

Posteriormente (v. 6.2) hemos tratado las referencias o criterios que podemos utilizar para evaluar, así como las diferentes funciones que puede cumplir la evaluación y los tipos de evaluación y modos de recogida de datos que tenemos disponibles. Hemos establecido qué diferencias básicas existen entre la evaluación que persigue una finalidad sumativa o certificadora de competencias y conocimientos, y la evaluación que se utiliza con una finalidad formativa, es decir, como un instrumento de intervención pedagógica, así como qué tipos de instrumentos de recogida de datos son más adecuados en cada caso.

Seguidamente (v. 6.3) hemos tratado la evaluación de las traducciones desde la perspectiva de los Estudios de Traducción, donde más estudios y análisis hemos encontrado sobre esta cuestión. Aquí hemos resumido algunos trabajos que

\footnotetext{
${ }^{13}$ Una traducción como la del ejemplo presentado en 6.4.1.4, «Yo espero que usted aprenderá el cálculo de este libro», nos da pie en el aula para tratar cuestiones relativas a la distancia social establecida entre los participantes y, por extensión, a los valores sociales vigentes en diferentes culturas. Habitualmente esto se lleva a cabo mediante la confrontación de diferentes versiones de los propios alumnos. En el ejemplo citado, otros alumnos habían presentado versiones diferentes en el tratamiento del receptor como «Espero que aprendas cálculo de este libro» o también «Yo espero que tú aprendas cálculo de este libro». Al confrontar las distintas versiones, el alumno se ve obligado a reflexionar acerca de las razones que pueden justificar su elección, y también a seguir otros argumentos diferentes al suyo.
} 
presentan aspectos de interés en relación con los fines que persigue nuestro trabajo, concluyendo además que la traducción es una actividad que precisa de instrumentos o constructos elaborados expresamente para poder ser evaluada. También hemos analizado cuáles son las condiciones mínimas de validez de la traducción como método de evaluación para el aprendizaje, concluyendo que la traducción es una prueba de actuación indirecta, que precisa de instrumentos adicionales de recogida de información cuando el objetivo de la evaluación no es la competencia traductora. Así pues, hemos establecido al menos un caso en el que la traducción tiene una finalidad didáctica válida desde una perspectiva teórica.

Para ilustrar de qué modo se pueden utilizar constructos pedagógicos funcionales para tratar contenidos de tipo actitudinal en relación con las actividades de traducción, hemos presentado dos instrumentos de recogida de datos adicionales a la actividad de traducir que han sido utilizados de forma práctica en cursos de Inglés para Fines Específicos, y que hemos denominado respectivamente el 'informe de la traducción' y el 'repertorio de variaciones entre el TT y el TO'. Hemos mostrado cómo, desde una perspectiva teórica, es posible asignar funcionalidad didáctica a las actividades de traducción como método de evaluación para el aprendizaje, de acuerdo con el planteamiento desarrollado a lo largo de este trabajo.

Sólo nos queda señalar que, dado que el objetivo principal que nos proponíamos alcanzar con esta investigación era precisamente establecer si era posible corroborar o no en un nivel teórico la funcionalidad didáctica de las actividades de traducción al menos en un caso (para el entorno definido y con los objetivos educacionales establecidos), podemos concluir que, al menos cuando se cumplen las condiciones descritas, no existen discrepancias teóricas para refutar una funcionalidad didáctica de la traducción como medio de facilitación del aprendizaje en el entorno de la didáctica del Inglés para Fines Específicos.

No obstante, a lo largo de esta investigación hemos podido extraer diferentes conclusiones relacionadas con otros de los muchos aspectos que hemos tratado, y creemos que estas conclusiones pueden tener relevancia para tratar investigaciones posteriores que se centren en esta cuestión. Con el fin de dar cuenta de una forma más sistemática de las conclusiones relevantes a las que hemos llegado como resultado general de este trabajo, vamos a presentarlas de forma pormenorizada, aunque brevemente, en el siguiente y último capítulo. 


\section{Sobre la funcionalidad de la traducción para la didáctica del Inglés para Fines Específicos y otras conclusiones}

\subsection{Introducción}

En este último capítulo queremos presentar, a modo de síntesis, las conclusiones más relevantes a las que hemos llegado a lo largo de esta investigación, que están relacionadas con aspectos diversos y puntuales de los que hemos tratado en los capítulos anteriores.

Hemos agrupado nuestras conclusiones alrededor de cuatro aspectos generales que se refieren a cuatro bloques temáticos.

En primer lugar, vamos a presentar nuestras conclusiones acerca de ciertos límites que podemos imponer, desde una perspectiva teórica, al establecimiento de objetivos educacionales en función de la distinción metodológica entre el Inglés general y el Inglés para Fines Específicos (v. 7.1). Posteriormente (v. 7.2), vamos a centrarnos en varios aspectos relativos a las expectativas razonables que podemos formarnos sobre la eficacia de la metodología que vamos a utilizar a partir de la homogeneidad del grupo, la eficiencia de la enseñanza y el nivel de precisión del aprendizaje, y la integración entre el aprendizaje autónomo y los objetivos de tipo actitudinal. A continuación (v. 7.3), nuestra atención se va a trasladar a la relación entre la traducción, la competencia de lectura de los aprendices y la metacognición, para pasar a tratar los límites funcionales de la traducción como actividad de aprendizaje (v. 7.4). Finalmente, vamos a presentar nuestras conclusiones sobre la 
traducción especializada como método de evaluación formativa y de autoevaluación (v. 7.5).

\subsection{Límites del establecimiento de objetivos educacionales en relación con la distinción entre Inglés General e Inglés para Fines Específicos}

De acuerdo con las características que hemos asociado típicamente a la enseñanza del Inglés para Fines Específicos (v. 2.2), y basándonos en la concepción de lengua para fines específicos utilizada por Widdowson (1983), podemos señalar que lo que habitualmente se denomina 'Inglés para Fines Específicos', por oposición al denominado 'Inglés General', no es ni más ni menos específico que éste ni en cuanto a la lengua utilizada ni en cuanto a los propósitos que persiguen los hablantes en la comunicación en cada caso. No obstante, sí podemos establecer diferencias entre ambos tipos en cuanto a la relevancia y a la pertinencia de algunos objetivos educacionales.

Recordemos que Widdowson (1983) puntualiza que la consecución de los objetivos de los cursos de Inglés para Fines Específicos suele tener una funcionalidad inmediata, mientras que en los cursos de Inglés General la aplicabilidad de los logros obtenidos es únicamente prospectiva. Esto lleva a este lingüista a establecer una distinción entre objetivos educacionales del curso (objectives) y metas que se esperan haber alcanzado cuando éste haya finalizado (aims). Desde esta perspectiva, podemos concluir que la distinción entre Inglés General e Inglés para Fines Específicos es pertinente cuando nos proponemos analizar la funcionalidad didáctica de la traducción en relación con un objetivo educacional en particular. Puesto que los objetivos que han recibido mayor interés en nuestra investigación son los de tipo actitudinal, a continuación vamos a tratar con mayor detalle esta distinción en relación con este tipo de objetivos.

\subsubsection{Diferencias en la relevancia de los objetivos educacionales de tipo actitudinal}

Desde una perspectiva general sobre el aprendiz, podemos hablar de conjuntos de valores vigentes comunes en cuanto a la generalización de la conducta y la integración de los sistemas de valores, creencias, opiniones y actitudes en una 
perspectiva global del mundo que posee previamente el aprendiz, independientemente de que éste siga un curso de Inglés General o uno de Inglés para Fines Específicos, y que afectan a su conceptualización acerca del funcionamiento del lenguaje, así como a sus expectativas acerca del propio aprendizaje de la lengua. No obstante, por otra parte podemos identificar valores asociados típicamente a un entorno profesional en particular que tienen relevancia en función de que se trate de un proyecto de enseñanza-aprendizaje de Inglés General o Inglés para Fines Específicos. Esto significa que podemos identificar objetivos actitudinales que son relevantes para un curso de Inglés para Fines Específicos, pero que serán irrelevantes para un curso de Inglés General.

Es muy interesante señalar que estas diferencias en la relevancia de los objetivos en cuanto al tipo de inglés que se enseña no se dan en relación con los objetivos de tipo cognoscitivo, puesto que los conocimientos de tipo cognoscitivo no dependen del contexto situacional donde se utiliza el lenguaje en la comunicación. En este sentido debemos manifestar que, dado que nuestra investigación se refiere a la utilidad de las actividades de traducción en relación con la consecución de objetivos de tipo actitudinal en el entorno de la didáctica del Inglés para Fines Específicos, la validez de nuestras conclusiones con respecto de la utilidad de la traducción se limita a la didáctica de lenguas para fines específicos. No podemos hacer estas conclusiones extensivas a cualquier ámbito de la didáctica especial de las lenguas extranjeras ya que, para llevar a cabo una investigación que aspirase a alcanzar este tipo de validez, sería necesario que ésta versara sobre la funcionalidad de las actividades de traducción en relación con la consecución de objetivos de tipo cognoscitivo, es decir, en relación con la consecución de objetivos educacionales para los que la distinción entre Inglés General e Inglés para Fines Específicos no fuera pertinente.

Por lo tanto podemos afirmar que, aun cuando se demuestre que las actividades de traducción tienen una funcionalidad didáctica para alcanzar objetivos actitudinales en la enseñanza del Inglés para Fines Específicos, quedará aún por demostrar su funcionalidad para alcanzar objetivos cognoscitivos en ese mismo entorno, así como su funcionalidad didáctica para la consecución de objetivos educacionales propios de la enseñanza del Inglés General. Y lo que es más, puesto que la relevancia de los objetivos de tipo actitudinal depende de los valores vigentes en la comunidad profesional que estemos considerando, podemos afirmar que, incluso dentro del entorno del Inglés para Fines Específicos, la adecuación en la relación que se establece entre las actividades de traducción y los objetivos 
actitudinales considerados será únicamente generalizable a otros entornos culturales donde esos mismos valores asociados a los objetivos actitudinales estén también vigentes.

\subsection{Expectativas sobre la eficacia de la metodología}

Además de las condiciones mínimas necesarias en las que se deben desarrollar los argumentos para justificar la funcionalidad didáctica (o su carencia) y de los límites que podemos establecer para la validez de los resultados y conclusiones a los que lleguemos, queremos presentar nuestras conclusiones sobre tres aspectos que tienen que ver con las expectativas que podemos formarnos acerca de la metodología que adoptemos para el curso de Inglés para Fines Específicos, basándonos en algunas de las características de este entorno educativo que son identificables en un nivel teórico y que se refieren a la homogeneidad del grupo, al nivel de precisión exigido al aprendizaje y a la relación entre los objetivos de tipo actitudinal y el aprendizaje autónomo.

\subsubsection{Homogeneidad del grupo}

Hemos establecido una diferencia entre el Inglés para Fines Específicos y el Inglés General en relación con la homogeneidad del grupo basándonos en que, a diferencia de lo que sucede en la enseñanza del Inglés General, la homogeneidad del grupo en el caso del Inglés para Fines Específicos se sitúa en el punto de llegada, pero no en el punto de partida (v. 2.2).

La situación de heterogeneidad en el punto de partida del aprendizaje tiene repercusiones para las investigaciones experimentales acerca de la eficacia de la metodología utilizada en los cursos de Inglés para Fines Específicos, como veremos a continuación.

Si el grupo de aprendices de un curso de Inglés para Fines Específicos no es homogéneo en cuanto a los conocimientos que éstos muestran al comenzar el curso, no será posible determinar cuál es el aprendizaje efectivo logrado, en términos de la distancia recorrida por los aprendices, desde sus conocimientos iniciales hasta los conocimientos adquiridos al final del curso. Esta situación afecta gravemente la posibilidad de investigar sobre la eficacia de la metodología utilizada, de tal modo que, para que sea posible la investigación sobre el grado de eficacia que podemos 
esperar razonablemente de una metodología en particular, será necesario que los estudios llevados a cabo se realicen sobre grupos de aprendices de Inglés para Fines Específicos que sean homogéneos en el punto de partida del curso. El hecho de que los grupos de tipo homogéneo no se den con frecuencia en condiciones normales dificulta enormemente las posibilidades de la investigación educativa en este ámbito. Sin embargo, debemos señalar la urgencia de que se lleven a cabo este tipo de investigaciones ya que, hasta que no contemos con resultados objetivos, las conclusiones extraídas acerca de la eficacia de la metodología utilizada en un caso particular no dejan de ser intuiciones elaboradas mediante una experiencia subjetiva y, por consiguiente, con una validez muy limitada, puesto que están elaboradas a partir de datos que no pueden ser replicados experimentalmente.

\subsubsection{Eficiencia de la enseñanza y nivel de precisión del aprendizaje}

Otro aspecto a considerar en relación con la eficiacia de la metodología que se utiliza en el curso de Inglés para Fines Específicos tiene que ver con el nivel de precisión requerido al aprendizaje (Bloom et al. 1956:48).

En el caso que nos ocupa, uno de los inconvenientes apuntados para no utilizar la traducción como actividad de aprendizaje tiene que ver con la creencia de que se trata de una actividad que demanda más tiempo y esfuerzo al profesor que otras actividades que tienen la (supuesta) misma funcionalidad, es decir, se considera una actividad de aprendizaje poco eficiente desde el punto de vista del tiempo que se debe emplear en su enseñanza.

En este sentido, debemos recordar que el número de objetivos educacionales que podemos incluir en un proyecto es limitado, dependiendo en gran medida del tiempo de duración del curso. Debemos tener en cuenta, además, la corta duración y/o la presencia testimonial en el plan docente general que suelen tener los cursos de Inglés para Fines Específicos en los planes de estudios científicos y técnicos en la universidad española. En este orden de cosas, podemos afirmar que el nivel de precisión demandado al aprendizaje y la cantidad de objetivos establecidos en función del tiempo disponible adquieren una importancia extrema.

Es posible que, si a la complejidad con que nos enfrentamos cuando consideramos la traducción como un tipo de mediación intercultural, le sumamos una noción de rentabilidad centrada en la consecución a corto plazo de los objetivos propuestos, la lógica nos aconseje desechar la utilización de actividades de 
traducción. No obstante, podemos presentar aquí dos objeciones. En primer lugar, existen objetivos que simplemente no pueden ser alcanzados a corto plazo, y el caso de los objetivos de tipo actitudinal es uno de ellos. En segundo lugar, es posible utilizar actividades de traducción demandando un bajo nivel de precisión en aquellos aspectos relativos a la traducción que puedan exigir al aprendiz un esfuerzo poco eficiente aun a pesar de que puedan ser eficaces.

La explotación didáctica de actividades de traducción requiere la utilización de algún tipo de constructo pedagógico, puesto que la equivalencia entre dos textos no se manifiesta espontáneamente de forma objetiva, sino que está sujeta a la interpretación. Por esta razón, cabe pensar que la utilización de este constructo ralentice o haga menos próxima la consecución del objetivo educacional planteado, ya que la propia presentación y utilización del constructo precisará un tiempo de enseñanza.

En este sentido, el constructo pedagógico que presentamos en este trabajo puede ilustrar cómo podemos mitigar las consecuencias de este inconveniente, ya que presenta dos características que suponen una ventaja para solventar o atenuar este problema. Estas características has sido denominadas respectivamente 'versatilidad', puesto que el constructo se basa en un repertorio que hemos identificado como versátil, y 'usabilidad', puesto que se ha buscado la facilidad de aplicación del constructo para sus usuarios, tanto para los estudiantes como para los profesores. La introducción de parámetros intuitivos de valoración, como por ejemplo el que en nuestro repertorio hemos denominado 'algo suena mal', se justifica en pro de la usabilidad del constructo de acuerdo con el tipo de estudiantes con el que se ha utilizado.

Por otra parte podemos establecer, de acuerdo con Rodríguez Espinar (1999), un nivel de valoración de los contenidos seleccionados para la planificación docente, diferenciando entre los conocimientos que se consideran básicos, los conocimientos complementarios y los conocimientos optativos. En este caso, la funcionalidad de las actividades de traducción dependerá de la correlación que se establezca entre el valor asignado a los contenidos de tipo actitudinal que se desee que los estudiantes adquieran, y la presencia asignada al desarrollo de este tipo de actividades, incluyendo la presentación y aplicación del constructo.

En un sentido amplio, aunque utilicemos un único concepto de traducción en la didáctica del Inglés para Fines Específicos y en la didáctica de la traducción para la formación de futuros traductores, es posible establecer diferencias entre un entorno educativo y otro. Estas diferencias no se refieren únicamente al repertorio 
específico de objetivos educacionales relevantes en cada caso, como ya señalamos en relación con el Inglés General, sino también a la valoración relativa asignada a los contenidos (que puede variar aun cuando los contenidos fueran los mismos) y también al nivel de precisión exigido en cada caso al grupo.

Si, como afirma Rodríguez Espinar (1999), sólo considerando la interacción entre objetivos, contenidos y grupo podemos establecer estrategias metodológicas que sean adecuadas para cada ocasión (y, por tanto, potencialmente eficaces), entonces podemos esperar razonablemente que la eficacia de las estrategias varíe en función de los cambios que se produzcan en la terna al considerar diferentes entornos educativos. No obstante, esto en ningún caso justifica que la concepción fenomenológica o la idealización utilizada de la traducción y del lenguaje deban variar en función del entorno educativo que se considera en cada caso, ya que no se ha identificado ninguna relación de dependencia de los conceptos de traducción y de lenguaje con el tipo de entorno educativo.

\subsubsection{Aprendizaje autónomo, objetivos actitudinales y traducción}

En el Capítulo 3 planteamos la hipótesis de que podemos elaborar expectativas razonables sobre la eficacia de una metodología a partir de consideraciones de tipo cuantitativo (cuanto mayor sea el número de factores considerado, mayores serán nuestras expectativas de que la planificación del curso es eficaz para alcanzar los objetivos propuestos) y de tipo cualitativo (cuanto más pertinente sea la integración de los factores pedagógicos que dependen directamente de la situación de enseñanza-aprendizaje, mayores serán nuestras expectativas sobre la eficacia de la metodología adoptada).

Desde la perspectiva teórica de la didáctica general, podemos elaborar ciertas expectativas sobre la eficacia de la metodología adoptada en un curso en cuanto a su relación con los objetivos educacionales para los que se ha elegido dicha metodología. En relación con los objetivos de este trabajo, las expectativas que más nos interesan son aquellas que tienen que ver con la metodología del aprendizaje autónomo, con la consecución de objetivos de tipo actitudinal y también con la utilización de actividades de traducción. En cuanto a la relación entre métodos y objetivos, vamos a comenzar refiriéndonos a los dos aspectos mencionados en primer lugar. 
Por lo que se refiere al aprendizaje autónomo, De la Cruz (1999) señala que éste conlleva la utilización de métodos de aprendizaje individual en los que el profesor actúa como supervisor del trabajo del aprendiz, por lo que las ventajas de este enfoque metodológico se reconocen únicamente para la consecución de objetivos relacionados con la adquisición de conocimiento de tipo declarativo o factual (De la Cruz 1999), aquellos que Bloom y sus colaboradores (Bloom et al. 1956) sitúan en el nivel menos complejo de la taxonomía de objetivos cognoscitivos (v. Tabla 10).

¿Podemos concluir entonces que no existe una integración adecuada entre la metodología del aprendizaje autónomo y la consecución de objetivos actitudinales y procedimentales?

Para responder suficientemente, vamos a comenzar por referirnos a dos dimensiones de aprendizaje: el 'aprendizaje a corto plazo', que representa los logros que podemos esperar a partir de la planificación de un curso, y el 'aprendizaje a largo plazo', que se refiere a los logros que podemos esperar a partir de una visión global de todo el periodo de aprendizaje, para finalizar situando la cuestión en relación con la situación de aprendizaje que hemos definido en este trabajo.

Podemos comenzar señalando que la afirmación de De la Cruz (1999) que hemos mencionado se refiere al primer caso. Esta especialista en didáctica enumera y describe aquellos métodos docentes tradicionales que son más utilizados por los profesores universitarios, distinguiendo entre la lección magistral, la tutoría, la supervisión de investigación, los grupos de discusión, la enseñanza en laboratorio, las prácticas, el aprendizaje autónomo y el seminario. De todo este repertorio de métodos, De la Cruz (1999) identifica únicamente la lección magistral, la tutoría, los grupos de discusión y el seminario como métodos adecuados para la consecución de objetivos actitudinales. Estos métodos son compatibles (exceptuando quizá la lección magistral) con la utilización de una metodología interrogativa para alcanzar objetivos actitudinales, tal como hemos visto que Rodríguez Espinar (1999) propone.

En relación con el aprendizaje a largo plazo hay que señalar que, cuando hablamos de aprendizaje autónomo, no lo hacemos en el sentido anterior, como un plan de acción que sigue unos pasos bien definidos en cuanto a las actividades de aprendizaje específicas que se van a utilizar, el modo de presentarlas y realizarlas y el papel del profesor y del alumno. El aprendizaje autónomo se define desde esta perspectiva como una meta a largo plazo, como la situación final a lo largo de todo 
el continuo de enseñanza-aprendizaje, desde la posición inicial de dependencia del alumno con respecto del profesor, hasta la situación de independencia.

Por lo que se refiere a los objetivos de tipo actitudinal, podemos concluir que, siguiendo a De la Cruz (1999), no debemos albergar expectativas de eficacia sobre la utilización de un método de aprendizaje autónomo compuesto de actividades que se realizan de forma independiente del profesor. En este nivel de generalización, esta conclusión no tiene repercusiones muy importantes para la utilización de actividades de traducción, puesto que no es frecuente la realización de traducciones de forma totalmente independiente del profesor en el entorno definido. Sin embargo, queremos llamar la atención de las repercusiones de esta conclusión para la pujante didáctica de hibridación, basada en las tecnologías de la información y la comunicación (con denominaciones varias como 'e-Learning', 'TechnologyEnhanced Learning', 'Computer-Assisted Learning', etc.), puesto que la utilización de métodos de aprendizaje autónomo tiene gran peso en la planificación de cursos basados en estas tecnologías.

La adecuación en la integración de objetivos actitudinales y aprendizaje autónomo tiene mayor interés cuando es estudiada desde la perspectiva del aprendizaje a largo plazo, puesto que, como hemos visto, este tipo de objetivos sólo pueden ser alcanzados tras largos periodos de tiempo, superiores a un curso de seis meses (Krathwohl, Bloom y Masia 1964:34).

A la vista de la taxonomía de objetivos de tipo actitudinal (v. Tabla 11), que sigue un orden de complejidad creciente, podemos concluir que la integración entre la metodología empleada en cada etapa del aprendizaje y los objetivos de tipo actitudinal sólo nos podrá llevar a forjarnos expectativas razonables de eficacia si se establece un orden de complejidad creciente en la secuenciación de objetivos actitudinales a lo largo de todos los cursos. De este modo, podremos evaluar la generalización de la conducta y la integración del sistema de valores en la última etapa del aprendizaje, que corresponde con el final de la trayectoria hacia la autonomía e independencia del aprendiz con respecto del profesor.

Por lo que se refiere a la situación relevante de enseñanza-aprendizaje que hemos definido en este trabajo, a corto plazo nos interesan los aspectos relativos a la planificación docente de un curso de Inglés para Fines Específicos. Aquí, debemos recordar que el supuesto que nosotros hemos estudiado en esta investigación se refiere únicamente a un aspecto puntual de los cursos, así que debemos precisar que la utilización de las actividades de traducción como método de evaluación para el aprendizaje de contenidos actitudinales no puede constituir el total de la 
planificación de ningún curso, ya que es necesario incluir contenidos y objetivos de otros tipos.

Por su parte, el dominio a largo plazo está definido por la trayectoria del aprendizaje a lo largo de toda la carrera universitaria. Aquí podemos concluir que, al depender de un método interrogativo de aprendizaje, la utilización de actividades de traducción será más eficaz para alcanzar objetivos de tipo actitudinal en las etapas iniciales del aprendizaje. Siguiendo la secuenciación de la Taxonomía de Bloom, podemos precisar nuestras conclusiones hasta el punto de proponer que podemos esperar razonablemente que las actividades de traducción, diseñadas y llevadas a cabo de acuerdo con los supuestos en los que nos hemos basado y que hemos descrito a lo largo de este trabajo, serán eficaces para alcanzar objetivos actitudinales relativos a la 'recepción' (atención hacia ciertos fenómenos), 'respuesta' (reacción ante el fenómeno en cuestión) y 'valoración' (aceptación de valores sociales o de otro tipo).

\subsection{Traducción, competencia de lectura y metacognición: like a rabbit facing a snake, like a rabbit eating a carrot}

Considerando que las actividades de traducción conllevan la lectura, interpretación y comprensión de textos, podemos analizar la funcionalidad potencial de este tipo de actividades en relación con la competencia de lectura de los aprendices.

Hemos visto que lo que diferencia desde una perspectiva metacognitiva a los buenos lectores de los sujetos con una competencia de lectura pobre es «the focus and directionality of self-reflection during reading» (Fischer y Mandl 1982:347). Podemos suponer razonablemente que uno de los aspectos relevantes que contribuyen a la heterogeneidad del grupo de aprendices tiene que ver con las diferencias existentes entre unos aprendices y otros en cuanto a su competencia de lectura. Podemos suponer también que, si aplicamos una metodología basada en gran medida en actividades que conllevan la lectura de textos, los problemas derivados de una lectura poco eficiente podrían limitar el aprendizaje esperado (o incluso hacer que éste no se llegue a producir). El razonamiento subyacente es que los esfuerzos de los malos lectores no se dirigirán en la dirección adecuada, de tal modo que, según Fischer y Mandl, estos aprendices se bloquearán, comportándose «like a rabbit facing a snake» (Fischer y Mandl 1982:347). Así, se concentrarán de 
tal forma en su propia condición invariable y en la tarea pendiente, que su capacidad de regulación (y por tanto, de control) estará totalmente absorbida por el esfuerzo. En el caso de la competencia de lectura, la condición invariable a la que aluden estos autores se refiere a «one's individual strengths or weaknesses in reading skill or domain-specific prior knowledge» (Fischer y Mandl 1982:347).

La utilización de un constructo pedagógico como el que hemos desarrollado para las actividades de traducción permite al profesor conocer, mediante la información recogida a través de los informes elaborados por los aprendices, en qué aspectos concretos se concentra la reflexión del aprendiz y de qué modo lo hace.

En las instrucciones que recibe el aprendiz para llevar a cabo la actividad de traducción, se le pide que describa y comente los problemas detectados al llevar a cabo la traducción, así como las soluciones utilizadas para cada problema, justificando las razones en las que se ha basado para optar por esa solución. Seguir estas instrucciones implica elaborar por escrito las reflexiones que el aprendiz considera más importantes en relación con la realización de la actividad propuesta.

Es conveniente detenernos a tratar dos cuestiones relevantes en este momento. En primer lugar, las objeciones que en numerosas ocasiones se suelen plantear en la investigación de la traducción como proceso en relación con la dudosa capacidad de los métodos de obtención de datos acerca de los procesos mentales, así como con la propia naturaleza de los datos obtenidos, no tienen validez aquí. El objetivo que se persigue en este caso no es investigar acerca de los procesos mentales de los aprendices, sino más bien obtener información acerca de su capacidad metacognitiva. Aquí, la conciencia (awareness) no es un obstáculo para acceder a los procesos inconscientes del sujeto, sino que la información que nos va a resultar de utilidad para el aprendizaje consiste, justamente, en las reflexiones conscientes que el aprendiz elabora por escrito acerca de lo que él mismo interpreta como problemas que debe resolver.

En segundo lugar, además de la obtención de este tipo de información, que el profesor necesita para poder hacerse una idea de los conocimientos, procesos y actitudes de los aprendices con respecto a la actividad de traducción, la propia realización de la actividad es utilizada por el profesor para provocar la reflexión en el aprendiz. Es sobre todo en este sentido en el que podemos decir que la actividad de traducción constituye una actividad de facilitación del aprendizaje ya que, a partir de la reflexión provocada en el aprendiz, podemos establecer qué puntos específicos es preciso tratar en la discusión en clase. 
Podemos ilustrar y corroborar estas conclusiones presentando algunos ejemplos del tipo de información que podemos obtener mediante la elaboración de un informe sobre la traducción. Lo que nos interesa especialmente en este punto son las diferencias de tipo metacognitivo que se pueden observar entre ambos aprendices. La información que se incluye aquí corresponde a la instrucción 'explica brevemente en qué ha consistido el problema'.

APRENDIZ 1 [Problema 1; Informe 3; ETSII_02_03]:

Existe una palabra en el texto: "boundary", que es definida en el diccionario como frontera, límite, barrera o comienzo o fin de un cuerpo, zona..., y al desconocer la asignatura la traduje indistintamente.

APRENDIZ 1 [Problema 2; Informe 3; ETSII_02_03]:

Con la expresión "volume control" había dificultades para traducirla ya que la traducción literal y aparentemente lógica no sonaba bien.

APRENDIZ 2 [Problema 1; Informe 4; ETSII_02_03]:

La traducción literal de la expresión "As for mass, length, and time" no es utilizada en el castellano.

Para traducir esta expresión he barajado las siguientes expresiones:

-"Al igual que ocurre con la masa, la longitud y el tiempo"

-"Como en la masa, longitud y el tiempo"

-"Así como en la masa, longitud y tiempo"

Como ya he dicho antes la segunda opción la he descartado porque no suena bien. La primera y la tercera de las opciones podrían ser válidas indistintamente, sin embargo yo me he quedado con la tercera porque me parece que con ella estamos haciendo una buena comparación para hacer ver al lector que la definición del concepto de temperatura tampoco es sencillo, como ocurre con otros parámetros como son la masa, la longitud y el tiempo.

APRENDIZ 2 [Problema 2; Informe 4; ETSII_02_03]:

El problema consiste en la traducción de la condicional y los tiempos de los verbos que habría que utilizar en ella.

Las diferentes posibilidades son:

"Si los bloques se pusieran en contacto y se aislaran de su entorno, interaccionarían en un camino que puede ser descrito como interacción térmica (o de calor)".

"Si los bloques se ponen en contacto y se aislan de su entorno 
interaccionan en un camino que puede describirse como interacción térmica (o de calor)".

Aunque lo habitual para una frase condicional sería poner un tiempo de futuro, yo he escogido la segunda opción porque pienso que el trasladar esta frase a un tiempo presente facilita la comprensión y el receptor la asimila más rápidamente.

El APRENDIZ 1 centra la escueta reflexión del primer problema en sus propias limitaciones de conocimiento de termodinámica. En el segundo problema que describe, las dificultades que detecta en relación con sus insuficientes conocimientos del tema tratado le bloquean hasta tal punto que se muestra incapaz de encontrar una solución, tal como se puede ver en la descripción más detallada que se incluye en el mismo informe:

APRENDIZ 1 [Problema 2; Informe 3; ETSII_02_03]:

¿Qué es lo que pasa? Que existen dificultades para darle la traducción correcta a la expresión volume control

¿Por qué es un problema? Porque la traducción literal por volumen controlado no es la mas adecuada en el texto

¿Qué diferentes posibilidades tengo? Control de volumen, volumen controlado o volumen de control

¿Cuál de ellas elijo? Al consultar con la profesora y comprobarlo en distintos libros de termodinámica lo traducimos por volumen de control

¿Por qué elijo esa opción? Porque es su traducción en termodinámica

No obstante, podemos observar cómo, a diferencia del APRENDIZ 1, el APRENDIZ 2 presenta reflexiones más desarrolladas que incluyen el punto de vista del lector de su TT.

Desde esta perspectiva, podríamos decir que el modo en que ambos aprendices se enfrentan a la tarea corresponde con las diferencias entre buenos y malos lectores descritas por Fischer y Mandl. En este caso, podemos decir que el APRENDIZ 1 aborda la actividad de traducir comportándose «like a rabbit facing a snake» (Fischer y Mandl 1982:347), mientras que el comportamiento del APRENDIZ 2 se podría describir, siguiendo en la misma línea metafórica, como «like a rabbit eating a carrot».

Por otra parte, podemos elaborar algunas generalizaciones a partir de los datos que hemos obtenido mediante los informes. Ambos aprendices, como usuarios 
del lenguaje, descartan opciones de traducción que previamente han considerado porque la expresión lingüística no les suena bien. Por esta razón, decidimos incorporar al repertorio de valoración el parámetro denominado 'algo suena mal'. A continuación incluimos fragmentos de varios informes donde se utiliza este tipo de argumentación:

APRENDIZ 3 [Problema 2; Informe 1; CAA_02_03]:

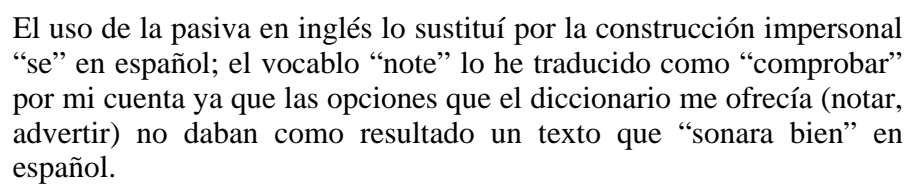

APRENDIZ 3 [Problema 3; Informe 1; CAA_02_03]:

El texto traducido de forma literal daba un resultado que "sonaba mal" en español. Una vez entendido lo que el texto quiere decir, realicé las modificaciones oportunas para que "sonara bien" eliminando la traducción de "boundaries" en el texto traducido. Esto es porque "estar fuera de los límites de una zona" suena pero y además tiene el mismo sentido, o al menos muy parecido que "estar fuera de una zona".

APRENDIZ 4 [Problema 1; Informe 3; CAA_02_03]:

El problema es que todas estas seis primeras oraciones comienzan en el TO con los verbos en infinitivo y con el pronombre you; esto traducido literalmente al castellano no "suena bien".

El informe es una herramienta que nos ha permitido recoger información acerca de los procesos de reflexión de los aprendices, que hemos incorporado a la metodología del curso con el fin de alcanzar nuestro objetivo educacional. En reflexiones poco profundas o escasamente desarrolladas, 'algo suena mal' es un criterio muy eficaz desde el punto de vista de la usabilidad del constructo, ya que su mayor ventaja es que constituye un cajón de sastre que precisa una descripción más detallada. Es decir, a partir de que una expresión lingüística es etiquetada por el aprendiz como 'algo suena mal', sabemos que es necesario dar un paso más para ahondar en la naturaleza de esa variación de efecto. Así que, más que profundamente informativo, se trata de un parámetro que responde a una clasificación intuitiva de problemas lingüísticos que la gente utiliza.

Por otra parte, podemos observar cómo el APRENDIZ 2, al tratar el Problema 2, elige una de las opciones que ha considerado pertinentes porque esa opción «facilita la comprensión y el receptor la asimila más rápidamente». Podemos interpretar aquí un deseo por parte del aprendiz de transformar la información para 
presentar una representación más usable. Tras varios años utilizando este constructo, estamos en situación de afirmar que esta necesidad de hacer el texto más comprensible es frecuente en los informes elaborados por los aprendices (como también lo es la descripción de que una expresión lingüística suena mal). Estos resultados son consistentes con lo que Chesterman (1993:4) describe como uno de los universales del comportamiento en la traducción (v. 3.3.3).

A la vista del tipo de datos que podemos obtener mediante la elaboración de informes, podemos concluir que la utilización de un constructo pedagógico como el que hemos presentado en este trabajo hace que la actividad de traducir tenga una utilidad para poner de manifiesto problemas asociados a la competencia de lectura de los aprendices equiparable a la de otras actividades que conllevan la lectura, interpretación y comprensión de textos.

\subsection{Pautas para aclarar los límites difusos de la funcionalidad didáctica de la traducción}

Cuando la traducción ha sido tratada por la didáctica de las lenguas extranjeras en relación con su utilidad para contribuir al aprendizaje de la lengua, su funcionalidad ha sido generalmente contemplada en su calidad de actividad de aprendizaje de conocimientos de tipo gramatical.

Una concepción de la enseñanza de las lenguas extranjeras centrada particularmente en el desarrollo de la competencia gramatical conlleva un énfasis en el establecimiento de objetivos educacionales relacionados con la adquisición de «knowledge of vocabulary and rules of word formation, pronunciation/spelling and sentence formation» (Cummings y Swain 1986:168). De acuerdo con la categorización del dominio del conocimiento establecida en la Taxonomía de Bloom, podemos identificar el conocimiento del léxico y la morfosintaxis de una lengua con la clase de conocimientos que corresponde con el nivel menos complejo de la taxonomía de objetivos de tipo cognoscitivo (v. Tabla 10), en una coyuntura de aprendizaje en que, tras la acumulación en la mente de ciertos datos, la adquisición de los conocimientos implica que el estudiante puede recordarlos (Bloom et al. 1956:73). La funcionalidad de la traducción sólo se puede establecer en este contexto respondiendo la pregunta ¿es útil la traducción para la enseñanza del léxico y de la morfosintaxis de la lengua? 
Análogamente, a partir de una concepción de la competencia lingüística diferente a ésta, la pregunta que debemos formular variará, siendo necesario que precisemos cuáles son los objetivos de la enseñanza antes de poder responder acerca de la utilidad de la traducción.

Creemos que el rechazo o la falta de aceptación de la traducción para la didáctica especial de las lenguas extranjeras implica un temor tácito a que la respuesta sea negativa. Pero este temor, perfectamente comprensible a falta de pruebas concluyentes en un sentido o en otro, en ningún caso debe ser utilizado como una justificación suficiente para descartar a priori la funcionalidad potencial de la traducción. En todo caso, esta incertidumbre debe ser asumida activamente como un indicio de la necesidad (y quizá de la urgencia) de desarrollar investigaciones que puedan arrojar luz sobre esta cuestión.

Por otra parte, en un campo de la didáctica como el de la enseñanza del inglés, dominado por la perspectiva de los países anglófonos, quizás la cuestión de la funcionalidad de la traducción no se contempla como algo urgente ni siquiera necesario. No es fácil vislumbrar ningún tipo de funcionalidad didáctica para la traducción en un modelo, como el de Krashen (1981), centrado en la adquisición de la lengua y donde el aprendizaje se lleva a cabo principalmente mediante cursos de inmersión lingüística. Estos modelos, donde la exposición a la lengua extranjera y las oportunidades de comunicación real son continuas, no son comparables con la situación de enseñanza y aprendizaje de la lengua inglesa que se da en la mayoría de países no anglófonos, incluyendo España. Quizá estas diferencias de perspectiva puedan contribuir a explicar que, ante la ausencia de indicaciones claras de la didáctica, el uso de la traducción en el aula de lengua inglesa en España, más que el secreto mejor guardado, sea un secreto a voces.

No hemos encontrado trabajos concluyentes acerca de la funcionalidad didáctica de la traducción como actividad de aprendizaje de la competencia gramatical ni de otros tipos de competencia en el entorno de la didáctica de la lengua inglesa, lo cual nos sugiere que aún queda mucha investigación por llevar a cabo en relación con esta cuestión. De todos modos, a partir de las directrices que hemos seguido en nuestra investigación, creemos que es necesario establecer dos prerrequisitos que deben ser tomados como condiciones necesarias para poder contestar suficientemente la pregunta que hemos formulado más atrás.

En primer lugar, sólo es posible establecer la funcionalidad didáctica de la traducción de forma relativa y no en términos absolutos. Este requisito tiene una implicación directa en el desarrollo argumentativo de esta cuestión, así como en la 
generalización de los resultados que se obtengan, de tal modo que sólo será posible establecer el potencial de la traducción para una función didáctica determinada en relación con el concepto de traducción y con el concepto de enseñanza de la lengua inglesa que se adopten. De este modo, la funcionalidad didáctica de la traducción queda supeditada en el nivel teórico a la descripción específica del marco conceptual utilizado.

El segundo requisito se refiere a la adecuación entre los objetivos educacionales considerados y las actividades de traducción. Para explicar esta conclusión, vamos a partir del supuesto hipotético de que la traducción no tiene una funcionalidad potencial para enseñar inglés. Parece razonable suponer que, en tal caso, esta falta de funcionalidad puede no ser achacable a la propia actividad de traducir, sino a la relación que se da entre la ejercitación práctica de la actividad y el objetivo educacional que pretendemos alcanzar mediante esa actividad.

Tomemos como caso hipotético el aprendizaje de léxico, como el objetivo educacional considerado, y la funcionalidad didáctica de la traducción, y pensemos en la relación entre la actividad de traducir y el objetivo educacional. Aunque a la vista de las consideraciones hechas en este trabajo no parece existir una relación directa entre la realización de actividades de traducción y el aprendizaje de léxico, esto sólo nos puede llevar a pensar que puede que estas actividades no tengan funcionalidad como medio de facilitación del aprendizaje de léxico (es decir, en relación con el aprendizaje de léxico como un objetivo educacional del curso), pero no a concluir que la funcionalidad didáctica es nula o poco probable para cualquier tipo de objetivo educacional. Por ejemplo, habiendo definido el aprendizaje de léxico como un objetivo educacional del curso, es posible establecer una relación entre este objetivo y las actividades de traducción con la función de pruebas clasificatorias de evaluación sumativa, tal como proponen Sánchez Manzano y Alonso (1999).

En este sentido, para poder establecer la funcionalidad didáctica potencial de la traducción en los términos adecuados, debemos tener en cuenta los aspectos involucrados en relación con unos conceptos específicos de traducción, de uso del lenguaje y de enseñanza y aprendizaje de la lengua (como hemos hecho a lo largo de este trabajo), y con las características específicas del objetivo educacional establecido (como hemos hecho antes en relación con los objetivos de tipo actitudinal), así como de la función didáctica particular que queramos considerar para las actividades de traducción, la cual en este trabajo consiste en una función 
didáctica compleja, en cuanto que comparte funciones de evaluación con funciones de actividad de aprendizaje.

\subsection{Conclusiones sobre la traducción especializada como método de evaluación formativa y de autoevaluación para la consecución de objetivos actitudinales}

Siguiendo las pautas que acabamos de recoger, podemos concluir diciendo que, en el trabajo que presentamos en estas páginas, hemos establecido una perspectiva comprehensiva acerca del lenguaje, de la traducción y de la comunicación especializada, además de describir nuestro enfoque general sobre la didáctica del Inglés para Fines Específicos. Sobre estos parámetros, hemos analizado desde una perspectiva teórica la funcionalidad didáctica de la traducción como un método de evaluación para el aprendizaje, en relación con la consecución de objetivos de tipo actitudinal.

Hemos ilustrado con ejemplos reales un modo que nos permite lograr de forma efectiva que las reflexiones de los aprendices, necesarias para poder intervenir pedagógicamente en su sistema de valores relacionado con el contexto de situación relevante para la comunicación especializada, sean plasmadas en un instrumento adicional de recogida de información.

Hemos potenciado, de este modo, el desarrollo de estrategias metacognitivas para poder tratar los contenidos relacionados con los objetivos actitudinales más bajos de la Taxonomía de Bloom. Si nos atenemos a lo que sugieren estos investigadores, la consciencia tiene un papel fundamental en las clases de objetivos actitudinales menos complejos, puesto que «la consciencia va desarrollándose lentamente en el ámbito afectivo para alcanzar un alto grado de concreción y perder después en intensidad al entrar en función el proceso de internalización» (Krathwohl, Bloom y Masia 1964:122), por lo que podemos decir que, desde una perspectiva teórica, las actividades de traducción tienen una potencial funcionalidad didáctica.

No obstante, nuestra investigación no se ha ocupado de la funcionalidad potencial de las actividades de traducción para alcanzar otros objetivos ni para adoptar otras funciones, por lo que nuestras conclusiones no pueden ser generalizables a otros casos que los objetivos actitudinales y la función didáctica compleja que hemos considerado nuestro objeto de investigación en este trabajo. 
Partiendo de un estado de confusión acerca de la funcionalidad de la traducción para la didáctica del Inglés para Fines Específicos, como caso particular de didáctica especial de las lenguas extranjeras, hemos basado nuestra investigación en los marcos teóricos pertenecientes a las tres disciplinas que, de diversos modos, se vienen a reunir en la encrucijada interdisciplinar de la enseñanza y el aprendizaje de una lengua. Nuestros esfuerzos, por tanto, se han limitado en esta investigación a buscar y relacionar teorías que pudieran aportarnos razones para apoyar o refutar la utilidad de las actividades de traducción para la función específica asignada. Basándonos en esas teorías, así como en los indicios de nuestra experiencia práctica del aula, hemos podido diseñar, describir y mostrar un constructo pedagógico que ilustra de un modo plausible que la función asignada a la traducción puede tener utilidad para la consecución de objetivos actitudinales de nivel bajo. En este sentido, el paso siguiente que se debe dar para obtener resultados con mayor potencial de aplicación en investigaciones posteriores se debe dirigir hacia una comprobación experimental de la eficacia de las actividades de traducción para la consecución de objetivos actitudinales de bajo nivel, o bien hacia el establecimiento del potencial de la funcionalidad didáctica de la traducción para otros objetivos, así como para otras funciones didácticas. 


\section{Referencias}




\section{Índice general de referencias}

ALBENTOSA HERNÁNDEZ, J. I. (1998) “Géneros periodísticos anglosajones. Características de género y registro en las secciones de internacional y de cultura de 'The Guardian Weekly' " En DOWNING, A., MOYA, A. J. y ALBENTOSA, J. I. (coords.) Patterns in Discourse and Text. Ensayos de análisis del discurso en lengua inglesa. Cuenca: Universidad de Castilla-La Mancha, 1998, p. 79-107.

ALCARAZ, E. y MOODY, B. (1978) Small World 3. Alcoy: Marfil, 1978.

ALDERSON, J. Ch. (1984) "Reading in a foreign language: a reading problem or a language problem?” En ALDERSON, J. Ch. y URQUHART, A. H. (eds.) Reading in a Foreign Language. Nueva York: Longman, 1984, p. 1-24.

ALDERSON, J. Ch. y URQUHART, A. H. (1984a) "Postcript on Alderson" En ALDERSON, J. Ch. y URQUHART, A. H. (eds.) Reading in a Foreign Language. Nueva York: Longman, 1984, p.25-27.

(1984b) "Postcript on Steffensen and Joag-Dev" En ALDERSON, J. Ch. y URQUHART, A. H. (eds.) Reading in a Foreign Language. Nueva York: Longman, 1984, p. 62-64.

ALONSO, P. (1995) "Summary Writing and Summary Evaluation: A Method Based on Semantic Discourse Analysis". Estudios Ingleses de la Universidad Complutense. 3 (1995), p. 151-171.

ALONSO, P. et al. (eds.) (2002) Models of Discourse Analysis. Salamanca: Universidad de Salamanca, 2002.

ÁLVAREZ DE MON, I. (1993) "La interacción Emisor-Destinatario en el texto técnico escrito" En RUIZ DE MENDOZA, F. J. y CUNCHILLOS, C. (eds.) Actas del XV Congreso de AEDEAN. Logroño: Colegio Universitario de La Rioja, 1993, p. 713-719. 
ÁLVAREZ DE MON, I. y LERCHUNDI, M. A. (1992) "The role of vocabulary in an ESP reading course" En BARRUECO, S., SÁNCHEZ, M. J. y SIERRA, L. (eds.) Actas de las I Jornadas Internacionales de Inglés Académico, Técnico y Profesional: Investigación y Enseñanza. Alcalá de Henares: Universidad de Alcalá de Henares, 1992, p. 136-138.

ÁlVAREZ RODRÍGUEZ, R., CORCHADO, M. T. y ONCINS, J. L. (1992) "La traducción consecutiva/simultánea como práctica contrastiva en la enseñanza para fines generales y específicos” En FERNÁNDEZ NISTAL, P. (coord.) Estudios de Traducción. Primer curso superior de traducción: inglés/español. Valladolid: Universidad de Valladolid, 1992, p. 71-77.

ARAUZ, P. (1992) "Errores frecuentes en la traducción" En BARRUECO, S., SÁNCHEZ, M. J. y SIERRA, L. (eds.) Actas de las I Jornadas Internacionales de Inglés Académico, Técnico y Profesional: Investigación y Enseñanza. Alcalá de Henares: Universidad de Alcalá de Henares, 1992, p. 179-183.

BAKER, M. (1996) "Professing Translation". The European English Messenger. 5.1 (1996), p. 42-44.

BARNES, B. (1985) Sobre ciencia. Trad. J. Faci Lacasta. Barcelona: Labor, 1987. Trad. de About Science. Oxford: Basil Blackwell, 1985.

BARRUECO, S., SÁNCHEZ, M. J. y SIERRA, L. (eds.) (1992) Actas de las I Jornadas Internacionales de Inglés Académico, Técnico y Profesional: Investigación y Enseñanza. Alcalá de Henares: Universidad de Alcalá de Henares, 1992.

BARRUECO, S., HERNÁNDEZ, E. y SIERRA, L. (eds.) (1999) Lenguas para Fines Específicos VI. Investigación y enseñanza. Alcalá de Henares: Universidad de Alcalá, 1999.

BARTLETT, F. C. (1932) Recordar: estudio de psicología experimental y social. Trad. P Soto y C. Del Barrio. Madrid: Alianza Editorial, 1995. Trad. de Remembering: An Experimental and Social Study. Cambridge: Cambridge University Press, 1932.

BEAUGRANDE, R. A. De (1978) Factors in a Theory of Poetic Translating. Assen: Van Gorcum y Amsterdam: Rodopi, 1978. (1980a) Text, Discourse and Process. Norwood: Ablex, 1980.

(1980b) "Toward a Semiotic Theory of Literary Translating" En WILSS, W. (ed.) Semiotik und Übersetzen. Tubinga: Gunter Narr, 1980, p. 23-42. (1984) Text Production. Norwood: Ablex, 1984. 
(1994) "Cognition, Communication, Translation, Instruction: The Geopolitics of Discourse" En BEAUGRANDE, R. A. De, SUNNAQ, A. y HELIEL, M. H. (eds.) Language, Discourse and Translation in the West and Middle East. Amsterdam: John Benjamins, 1994, p. 1-22.

(1997) New Foundations for a Science of Text and Discourse: Cognition, Communication and the Freedom of Access to Knowledge and Society. Norwood: Ablex, 1997.

(1998) "Translation and Semantics in Theory and Practice". International $\begin{array}{lllll}\text { Journal of } & \text { Translation. } & 20 & \text { agosto }\end{array}$ <http://beaugrande.bizland.com/TranslationSemantics.htm> (2000a) Text linguistics at the millennium: Corpus data and missing links. $2000 . \quad 7 \quad$ abril 2002 <http://beaugrande.bizland.com/Textmillennium1.htm >

(2000b) Translation in the University: Prospects for the New Millennium. United Arab Emirates University Technical Report 2000-2. 2000. 7 abril $2002<$ http://beaugrande.bizland.com/NEWTITLES.htm>

(2002) "Cognition and Technology in Education: Knowledge and Information - Language and Discourse". Miscelánea: A Journal of English and American Studies. 25 (2002), p. 11-52.

BEAUGRANDE, R. A. De y DRESSLER, W. U. (1981) Introduction to Text Linguistics. Nueva York: Longman, 1981.

_- (1997) Introducción a la lingüística del texto. Versión española de S. Bonilla, Barcelona: Ariel, 1997.

BELL, R. (1991) Translation and Translating: Theory and Practice. Essex: Longman, 1991.

BELTRÁN LLERA, J. A. (1999) “Aprender en la universidad" En RUIZ CARRASCOSA, J. (coord.) Aprender y enseñar en la universidad. Iniciación a la docencia universitaria. Jaén: Universidad de Jaén, 1999, p. $9-42$.

BLANCO PRIETO, F. (1996) La evaluación en la educación secundaria. Salamanca: Amarú, 1996.

BLOOM, B. S., et al. (1956) Taxonomía de los objetivos de la educación: clasificación de las metas educativas. Tomo I: ámbito del conocimiento. Trad. I. Acarreta. Alcoy: Marfil, 1975. Trad. de Taxonomy of Educational Objectives: The Classification of Educational Goals. Handbook I: Cognitive Domain. Nueva York: David McKay, 1956. 
BOBROW, D. G. y WINOGRAD, T. (1977) "An overview of KRL, a knowledge representation language”. Cognitive Science. 1 (1977), p. 3-46.

BÖRSCH, S. (1986) "Introspective Methods in Research on Interlingual and Intercultural Communication” En HOUSE, J. y BLUM-KULKA, S. (eds.) Interlingual and Intercultural Communication. Discourse and Cognition in Translation and Second Language Acquisition Studies. Tubinga: Gunter Narr, 1986, p. 195-209.

BONILLA, S. (1997) "Estudio preliminar" En BEAUGRANDE, R. A. De y DRESSLER, W. U. Introducción a la lingüística del texto. Versión española de S. BONILLA, Barcelona: Ariel, 1997, p. 7-25.

BOURHIS, R. Y. et al. (1975) "Social consequences of accommodating one's style of speech: A cross-national investigation". International Journal of the Sociology of Language. 6.5 (1975), p. 5-71.

BOWKER, L. (2001) "Towards a Methodology for a Corpus-Based Approach to Translation Evaluation”. Meta. 46.2 (2001), p. 345-364. 2001. 12 mayo 2004 〈http://www.erudit.org/revue/meta/2001/v46/n2/002135ar.pdf $>$

BRANSFORD, J. D. y JOHNSON, M. K. (1972) "Contextual Prerequisites for Understanding: Some Investigations of Comprehension and Recall". Journal of Verbal Learning and Verbal Behavior. 11 (1972), p. 717-726.

BRENES GARCÍA, A. M. y LAUTERBORN, W. (2002) La comunicación informal en los negocios, Madrid: Arco Libros, 2002.

BRISLIN, R. W. (ed.) (1976) Translation: Approaches and Research. Nueva York: Gardner Press, 1976.

BROECK, R. van den (1992) “Translation Theory Revisited”. Target. 4.1 (1992), p. 111-120.

BROWN, G. (1990) "Cultural values: the interpretation of discourse". ELT Journal. 44.1 (1990), p. 11-17.

BROWN, G. y YULE, G. (1983) Discourse Analysis. Cambridge: Cambridge University Press, 1983.

BÜHLER, H. (1987) "Language and Translation: Translating and Interpreting as a Profession”. Annual Review of Applied Linguistics 1986. 7 (1987), p. 105119.

CABRÉ, M. T. (1993) La terminología. Teoría, metodología, aplicaciones. Barcelona: Antártida/Empuries, 1993. 
CANALE, M. y SWAIN, M. (1980) "Theoretical Bases of Communicative Approaches to Second Language Teaching and Testing". Applied Linguistics. 1 (1980), p. 1-47.

CANDLIN, Ch. N., BHATIA, V. y JENSEN, Ch. H. (2002) "Must the Worlds Collide? Professional and Academic Discourses in the Study and Practice of Law” En CORTESE, G. y RILEY, P. (eds.) Domain-specific English: Textual Practices Across Communities and Classrooms, Berna: Peter Lang, 2002, p. 101-114.

CAPOTE, T. (1949) A Tree of Night and Other Stories. Harmondsworth: Penguin, 1978.

CARDELLE-ELAWAR, M. (1995) "Effects of Metacognitive Instruction on Low Achievers in Mathematics Problems". Teaching and Teacher Education. 11.1 (1995), p. 81-95.

CARRELL, P. L. y EISTERHOLD, J. C. (1983) "Schema Theory and ESL Reading Pedagogy”. TESOL Quarterly. 17.4 (1983), p. 553-573.

CENCILLO, L. (1988) Interacción y conocimiento. I Discurso, lenguaje y procesos cognitivos. Salamanca: Amarú, 1998.

THE CENTER FOR UNIVERSAL DESIGN (1997) Principles of Universal $\begin{array}{lllll}\text { Design. } & 1997 . & 27 & \text { marzo } & \end{array}$ <http://www.design.ncsu.edu/cud/univ design/ud.htm>

CHAFE, W. L. (ed.) (1979) The Pear Stories: Cognitive, Cultural and Linguistic Aspects of Narrative Production. Norwood, N. J.: Ablex, 1979.

CHARTERIS-BLACK, J. y MUSOLFF, A. (2003) “'Battered Hero' or 'Innocent Victim'?: A Comparative Study of Metaphors for Euro Trading in British and German Financial Reporting”. English for Specific Purposes. 22.2 (2003), p. 153-176.

CHAUDRON, C. (1985) "Intake: On models and methods for discovering learners' processing of input”. Studies in Second Language Acquisition. 7 (1985), p. $1-14$.

CHESTERMAN, A. (1993) "From 'Is' to 'Ought': Laws, Norms and Strategies in Translation Studies". Target. 5.1 (1993), p. 1-20.

(1997) Memes of Translation. The Spread of Ideas in Translation Theory. Amsterdam: John Benjamins, 1997.

CHRISTIE, F. (1998) "Science and apprenticeship: The pedagogic discourse" En MARTIN, J. R. y VEEL, R. (eds.) Reading Science. Critical and 
Functional Perspectives on Discourses of Science. Londres: Routledge, 1998, p. 152-177.

COMMON European Framework of Reference for Languages: Learning, Teaching, Assessment. Estrasburgo: Council of Europe, 2001. 2001. 23 mayo 2004. $\langle$ http://culture2.coe.int/portfolio/documents/0521803136txt.pdf $>$

CONDE, J. L. (1996) El segundo amo del lenguaje. Madrid: Escuela de Letras, 1996.

CONSEJO Escolar del Estado. Informe sobre el Estado y Situación del Sistema Educativo Español. Curso 1997/98. 23 agosto 2001. <http://www.mec.es/cesces/indexd.htm>

CONSEJO de Universidades (1994) Memoria de Actividades Junio 1991 - Julio 1993. Madrid: Secretaría General del Consejo de Universidades, 1994.

COOK, G. (1989) Discourse. Oxford: Oxford University Press, 1989. (1997) "Schemas". ELT Journal. 51.1 (1997), p. 86.

COOPER, M. (1984) "Linguistic competence of practised and unpractised nonnative readers of English" En ALDERSON, J. Ch. y URQUHART, A. H. (eds.) Reading in a Foreign Language. Nueva York: Longman, 1984, p. 122-135.

CORDER, S. P. (1981) Error Analysis and Interlanguage. Oxford: Oxford University Press, 1981.

CORTESE, G. (1988) “Cognition, metacognition, translation” En GLASS, E. et al. (eds.) Metamorfosi. Traduzione/Tradizioni. Atti del IX Congresso AIA (Associazione Italiana di Anglistica), Pescara 25/26 October 1986, Pescara: Edizioni Clua, 1988, p. 190-197.

CORTESE, G. y RILEY, P (eds.) (2002) Domain-specific English: Textual Practices Across Communities and Classrooms. Berna: Peter Lang, 2002.

COTS, J. M. (1994) "Un enfoque socio-pragmático en la enseñanza de una lengua extranjera”. Signos. Teoría y Práctica de la Educación. 11 (1994), p. 46-51.

COUNCIL for Cultural Co-Operation (1989) Conference Language learning in Europe: the challenge of diversity (Final conference of the modern languages Project No. 12). Strasbourg, 22-25 March 1988. Report. Estrasburgo: Consejo de Europa, 1989.

(1996) Modern Languages: Learning, Teaching, Assessment. A Common European Framework of reference. 1996. 15 octubre 2001. <http://culture.coe.fr/lang/eng/eedu2.4c.htm> 
CRANNY-FRANCIS, A. (1998) "The 'science' of science fiction: A sociocultural analysis” En MARTIN, J. R. y VEEL, R. (eds.) Reading Science. Critical and Functional Perspectives on Discourses of Science. Londres: Routledge, 1998, p. 63-80.

CROMBIE, W. (1985) Process and relation in discourse and language learning. Oxford: Oxford University Press, 1985.

CRUZ, A. De la (1999) "Taller: Formación del profesorado universitario en metodología docente” En Ruiz Carrascosa, J. (coord.) Aprender y enseñar en la universidad. Iniciación a la docencia universitaria. Jaén: Universidad de Jaén, 1999, p. 43-120.

- (2001) Elaboración del Proyecto Docente. Curso dentro del ciclo de Actividades de Formación y Perfeccionamiento del Profesorado Universitario (19-20 de febrero, Universidad de Salamanca).

CUMMINS, J. y SWAIN, M. (1986) Bilingualism in Education, Essex: Longman, 1986.

CUNNINGHAM, G. K. (1998) Assessment in the Classroom: Constructing and Interpreting Texts. Londres: Falmer Press, 1998.

DAHLGREN, M. y PÉREZ PAZ, M. F. (1993) "Problemática actual de la Enseñanza de Idiomas para Fines Específicos ante la Masificación de Aulas" En Barrueco, S. et al. (eds.) Actas de las II Jornadas de Lenguas para Fines Específicos. Alcalá de Henares: Universidad de Alcalá de Henares, 1993, p. 335-343.

DAMASIO, A. R. y DAMASIO, H. (1992) "Brain and language". Scientific American. 267 (1992), p. 88-95.

DAVIES, A. (1993) "Speculation and Empiricism in Applied Linguistics". Edinburgh Working Papers in Applied Linguistics. 4 (1993), p. 14-25.

DIJK, T. A. Van (1977) Text and Context: Explorations in the Semantics and Pragmatics of Discourse. Nueva York: Longman, 1997.

(1978) La ciencia del texto. Trad. S. Hunzinger, Barcelona: Paidós, 1983. Trad. de Tekstwetenschap: Een interdisciplinaire inleiding. Utrecht: Het Spectrum, 1978.

DIJK, T. A. Van y KINTSCH, W. (1983) Strategies of discourse comprehension. Nueva York: Academic Press, 1983.

DIXON, P. y BORTOLUSSI, M. (2001) “Text Is Not Communication: A Challenge to a Common Assumption". Discourse Processes. 31.1 (2001), p. 1-25. 
DOLLERUP, C. (1994) "Systematic Feedback in Teaching Translation" En DOLLERUP, C. y LINDEGAARD, A. (eds.) Teaching Translation and Interpreting 2: Insights, aims, visions. Amsterdam: John Benjamins, 1994, p. 121-132.

DUBIN, F., ESKEY, D. E. y GRABE, W. (1986) Teaching second language reading for academic purposes. Reading, Massachusetts: Addison-Wesley, 1986.

DUDA, R. y RILEY, P. (eds.) (1990) Learning Styles. Presses Universitaires de Nancy, 1990.

DUDLEY-EVANS, T. (ed.) (1987) Genre Analysis and ESP, ELR Journal 1. Birmingham: English Language Research, University of Birmingham, 1987.

(1994) "Genre analysis: an approach to text analysis for ESP" En COULTHARD, M. (ed.) Advances in Written Text Analysis. Londres: Routledge, 1994, p. 219-228.

(1999) "The Integration of Genre Analysis and Corpus-based Research in English for Science and Technology'. Presentación en el 'LSP Forum'99' (17-19 de septiembre de 1999, Charles University, Praga), según el informe de Les KIRKHAM 1999 para el TESOL Arabia Special Interest Group on $\begin{array}{lllll}\text { Business } & \text { English. } & \text { 1999. } 4 & \text { abril }\end{array}$ <http://imtcsamba.hct.ac.ae/tesol_bizeng_esp/swales.htm>

DUDLEY-EVANS, T. y ST. JOHN, M. J. (1998) Developments in ESP: A multidisciplinary approach. Cambridge: Cambridge University Press, 1998.

EK, J. A. Van (1980) “The «threshold level» in a unit/credit system” En TRIM, J. L. M. et al. Systems Development in Adult Language Learning. Oxford: Pergamon Press, 1980, p. 89-128.

ELORZA, I. (1999) Apuntes de traducción técnica. Salamanca: Revide, 1999. (2000) "Textos técnicos: de los conocimientos previos al conocimiento compartido en la enseñanza de ESP” En RUIZ, J. M., SHEERIN, P. H. y ESTÉBANEZ, C. (eds.) Estudios de Metodología de la Lengua Inglesa. Valladolid: Universidad de Valladolid-Centro Buendía, 2000, p. 109-118. (2001) "Effect Variations within the TT-ST pair: A Proposal for Scientific and Technical Translation Assessment in the Classroom" En CHABÁS, J., CASES, M y GASER, R. (coords.) Proceedings. First International Conference on Specialized Translation. Barcelona, March 2-4, 2000. Barcelona: Universitat Pompeu Fabra, 2001, p. 126-127. 
(2002) "Assessing Translation in Domain-specific Learning Environments:

A Study of Textual Variation" En CORTESE, G. y RILEY, P. (eds.) Domain-specific English: Textual Practices Across Communities and Classrooms. Berna: Peter Lang, 2002, p. 295-321.

(2003a) Apuntes de traducción funcional de textos no ficcionales: teoría.

Material suplementario de la asignatura «Textos técnicos mediante las TIC (inglés-español)».

(2003b) "La interfaz lenguaje-cognición: mecanismos de construcción del significado y lagunas de conocimiento especializado en los aprendices de traducción” En MUÑOZ MARTíN, R. (ed.) I AIETI: Actas del Congreso Internacional de la Asociación Ibérica de Estudios de Traducción e Interpretación, 12-14 de febrero de 2003. Vol. II. Granada: AIETI, 2003, p. 3-17.

(2003c) "La elección de las unidades analíticas del texto: problemas y soluciones posibles". Vigo International Journal of Applied Linguistics VIAL, Número 0 (2003), p. 25-42.

ESCOBAR, M. (1999) "La Correspondencia Comercial en Inglés y el Enfoque de su Traducción” En BARRUECO, S, HERNÁNDEZ, E. y SIERRA, L. (eds.) Lenguas para Fines Específicos VI. Investigación y enseñanza. Alcalá de Henares: Universidad de Alcalá, 1999, p. 417-421.

ESCRIBANO GONZÁLEZ, A. (1998) Aprender a enseñar. Fundamentos de Didáctica General. Cuenca: Ediciones de la Universidad de Castilla-La Mancha, 1998.

EUROPEAN CENTRE FOR MODERN LANGUAGES. Medium-Term Programme of Activities 2000-2002. $23 \quad$ agosto 2001. 〈http://www.ecml.at/documents/medium\%20term_english_web.pdf>

EVEN-ZOHAR, I. (1990) "The Textemic Status of Signs in Translation”. Poetics Today. $11.1 \quad$ (1990), $\quad$ p. 247-251. 12 agosto 2002. <http://www.tau.ac.il/ itamarez/ps/>

FARAHZAD, , F. (1992) "Testing achievement in translation classes" En DOLLERUP, C. \& LODDEGAARD, A. (eds.) Teaching Translation and Interpreting. Training, Talent and Experience. Amsterdam: John Benjamins, 1992, p. 271-278.

FAERCH, C. y KASPER, G. (1986) “One Learner - Two Languages: Investigating Types of Interlanguage Knowledge” En HOUSE, J. y BLUM-KULKA, S. (eds.) Interlingual and Intercultural Communication. Discourse and 
Cognition in Translation and Second Language Acquisition Studies. Tubinga: Gunter Narr, 1986, p. 211-227.

FERNÁNDEZ TOLEDO, P. (2000) Conocimiento previo, esquemas de género y comprensión lectora en inglés como lengua extranjera. Murcia: Universidad de Murcia, 2000.

FERNÁNDEZ VERNET, E. (1995) “1950-1985: La Escuela Soviética de Traducción (I)”. Sendebar, 6 (1995), p. 53-71.

FISCHER, P. M. y MANDL, H. (1982) "Metacognitive Regulation of Text Processing: Aspects and Problems Concerning the Relation between SelfStatements and Actual Performance" En FLAMMER, A. y KINTSCH, W. (eds.) Discourse Processing. Holanda: North-Holland Publishing Company, 1982, p. 339-351.

FLORES GARCÍA, A. (1999) "Lenguajes Específicos y Traducción Especializada" En BARRUECO, S., HERNÁNDEZ, E. y SIERRA, L. (eds.) Lenguas para Fines Específicos VI. Investigación y enseñanza. Alcalá de Henares: Universidad de Alcalá, 1999, p. 173-178.

FOSTER, P. (1999) “Task-based learning and pedagogy”. ELT Journal 53.1 (1999), p. 69-70.

FUENTE GARCÍA, J. M. (1992) Legislación universitaria. Madrid: Civitas, 1992.

FULLER, G. (1998) "Cultivating science: Negotiating discourse in the popular texts of Stephen Jay Gould" En MARTIN, J. R. y VEEL, R. (eds.) Reading Science. Critical and Functional Perspectives on Discourses of Science. Londres: Routledge, 1998, p. 35-62.

GALLARDO SAN SALVADOR, N. (1999) "Enseñanza de la traducción técnica: la formación de traductores no especialistas" En GIL DE CARRASCO, A. y HICKEY, L. (eds.) Aproximaciones a la traducción. Madrid: Instituto Cervantes, 1999, p. 63-83.

GARCÍA IZQUIERDO, I. (2000) "The Concept of Text Type and Its Relevance to Translator Training”. Target. 12.2 (2000), p. 283-295.

GARCÍA MAYO, M. P. (2000) English for Specific Purposes: Discourse Analysis and Course Design. Bilbao: Universidad del País Vasco, 2000.

GARCÍA REINA, S., MARTÍN DE LEÓN, C. y WITTE, H. (1996) "Nota de las traductoras". En REISS, K. y VERMEER, H. J. (1991) Fundamentos para una teoría funcional de la traducción. Trad. S. García Reina y C. Martín de León, Madrid: Akal, 1996, p. 9-10. 
GARCÍA-BELTRÁN, A. et al. (1998) “Análisis del perfil de conocimientos de alumnos de nuevo ingreso en la Escuela Técnica Superior de Ingenieros Industriales de la Universidad Politécnica de Madrid". Enseñanza. 16 (1998), p. 23-39.

GENTZLER, E. (1993) Contemporary Translation Theories. Londres: Routledge, 1993.

GERLOFF, P. (1986) "Second Language Learner's Reports on the Interpretive Process: Talk-aloud Protocols of Translation" En HOUSE, J. y BLUMKULKA, S. (eds.) Interlingual and Intercultural Communication. Discourse and Cognition in Translation and Second Language Acquisition Studies. Tubinga: Gunter Narr, 1986, p. 243-262.

GERZYMISCH-ARBOGAST, H. (2001) "Equivalence Parameters and Evaluation”. Meta. 46.2 (2001), p. 227-242. 2001. 25 mayo 2004. <http://www.erudit.org/revue/meta/2001/v46/n2/002886ar.pdf>

GHADESSY, M. (1994) "Key concepts in ELT: Register". ELT Journal. 48.3 $\begin{array}{llllll}\text { (1994), } & \text { p. } & \text { 287-289. } & 7 & \text { marzo } & 2002 .\end{array}$ <http:www.oup.co.uk//eltj/hdb/Volume 48/Issue 03/>

GHONSOOLY, B. (1993) "Development and Validation of a Translation Test". Edinburgh Papers in Applied Linguistics. 4 (1993), p. 54-62.

GIMÉNEZ, J. C. (1996) "Process Assessment in ESP: Input, Throughput and Output”. English for Specific Purposes. 15.3 (1996), p. 233-241.

GIRARD, D. y TRIM, J. (comps. y eds.) (1988) Project No. 12: Learning and teaching modern languages for communication. Final report of the Project Group (Activities 1982-87). Estrasburgo: Consejo de Europa, 1998.

GIVÓN, T. (1999) "The functional approach to grammar" En FERNÁNDEZ GONZÁLEZ, J. et al. (eds.) Lingüística para el Siglo XXI. Vol. I. Salamanca: Universidad de Salamanca, 1999, p. 21-48.

GONZÁLEZ, J. M. (2002) "In Search of Synergy: Agents Involved and their Contribution" En CORTESE, G. y RILEY, P. (eds.) Domain-specific English: Textual Practices Across Communities and Classrooms. Berna: Peter Lang, 2002, p. 345-365.

GONZÁleZ POZUETA, A. y ÁLVAREZ GONZÁLEZ, J. A. (1992) “ESP: Análisis de Necesidades” En Barrueco, S., SÁNCHEZ, M. J., y SIERRA, L. (eds.) Actas de las I Jornadas Internacionales de Inglés Académico, Técnico y Profesional: Investigación y Enseñanza. Alcalá de Henares: Universidad de Alcalá de Henares, 1992, p. 42-54. 
GOTTI, M. (1996) "Il linguaggio della divulgazione: problematiche di traduzione intralinguistica” En CORTESE, G. (ed.) Tradurre i linguaggi settoriali. Turín: Edizioni Cortina, 1996.

GREENE, J. (1975) Pensamiento y lenguaje. Trad. R. Carrasco Ruiz. México: CECSA, 1979. Trad. de Thinking and Language. Londres: Methuen, 1975. (1986) Language Understanding: A Cognitive Approach, Milton Keynes: Open University Press.

GRICE, P. (1975) "Logic and Conversation" En COLE, P. y MORGAN, J. L. (eds.) Syntax and Semantics Vol. 3: Speech Acts. Nueva York: Academic Press, 1975.

GUTIÉRREZ ALMARZA, G. y BELTRÁN LLAVADOR, F. (1996) "Critical Praxis of the English Language: its Pedagogy as Cultural Action". Atlantis. 18.1-2 (1996), p. 176-194.

GUTT, E. A. (1989) “Translation and Relevance”. Working Papers in Linguistics. 1 (1989), p. 75-94.

(1990) "A Theoretical Account of Translation -Without a Translation Theory”. Target. 2.2 (1990), p. 135-164.

(1991) Translation and Relevance: Cognition and Context. Oxford: Blackwell, 1991.

(1996) "Implicit Information in Literary Translation: A RelevanceTheoretic Perspective". Target. 8.2 (1996), p.239-256.

HAGHIGHI, M. (1994) "Supra-lingual aspects of literary translation" En DOLLERUP, C. y LINDEGAARD, A. (eds.) Teaching Translation and Interpreting 2: Insights, aims, visions. Amsterdam: John Benjamins, 1994, p. 47-50.

HALLIDAY, M. A. K. (1978) Language as Social Semiotic. Londres: Edward Arnold, 1978.

(1998) "Things and relations: Regrammaticising experience as technical knowledge" En MARTIN, J. R. y VEEL, R. (eds.) Reading Science. Critical and Functional Perspectives on Discourses of Science. Londres: Routledge, 1998, p. 185-235.

HALLIDAY, M. A. K. y HASAN, R. (1976) Cohesion in English. Nueva York: Longman, 1976.

HARMER, J. (1983) The Practice of English Language Teaching. Essex: Longman, 1983. 
HARRIS, M. (1997) "Self-assessment of language learning in formal settings". ELT Journal. 51.1 (1997), p. 12-20.

HARTLEY, A. y PARIS, C. (2001) “Translation, controlled languages, generation" En STEINER, E. y YALLOP, C. (eds.) Exploring Translation and Multilingual Production: Beyond Content. Berlín: Mouton de Gruyter, 2001, p. 307-325.

HATIM, B. y MASON, I. (1990) Discourse and the Translator. Nueva York: Longman, 1990.

HERNÁNDEZ HERNÁNDEZ, M. A. (2000) “An Interview with Michael Halliday: The Man and the Linguist". Revista Canaria de Estudios Ingleses. 40 (2000), p. 233-243.

HERRERA GARCÍA, E. y RODRÍGUEZ CONDE, M. J. (2001) Estrategias de Evaluación de los Alumnos. Curso del ciclo de Actividades de Formación y Perfeccionamiento del Profesorado Universitario (12-14 de septiembre, Universidad de Salamanca).

HERVEY, S. y HIGGINS, I (1992) Thinking Translation. A Course in Translation Method: French to English. Londres: Routledge, 1992.

HEWINGS, M. y HEWINGS, A. (2002) “"It is Interesting to Note that ...": A Comparative Study of Anticipatory 'It' in Student and Published Writing”. English for Specific Purposes. 21.4 (2002), p. 367-383.

HEWSON, L. y MARTIN, J. (1991) Redefining Translation. The Variational Approach. Londres: Routledge, 1991.

HOLMES, J. S. (1988) Translated! Papers on literary translation and Translation Studies. Amsterdam: Rodopi, 1988.

HOUSE, J. (1981) A Model for Translation Quality Assessment. Tubinga: Gunter Narr, 1981.

_ (2001) "Pragmatics and translation" En FERNÁNDEZ, P. y BRAVO, J. M. (eds.) Pathways of Translation Studies. Valladolid: Centro Buendía, Universidad de Valladolid, 2001, p. 57-77.

HURTADO ALBIR, A. (Dir.) (1999) Enseñar a traducir. Metodología en la formación de traductores e intérpretes. Teoría y fichas prácticas. Madrid: Edelsa, 1999.

HUTCHINSON, T. y WATERS, A. (1987) English for Specific Purposes. A Learning-centered Approach. Cambridge: Cambridge University Press, 1987. 
HYDE, J. (1999) “"Lo demás es literatura” - Predicción y adversitividad en textos argumentativos en inglés y español” En FERNÁNDEZ GONZÁLEZ, J. et al. (eds.) Lingüística para el Siglo XXI. Vol. II. Salamanca: Universidad de Salamanca, 1999, p. 935-941.

HYMES, D. (1972) “On Communicative Competence” En GUMPERZ, J. J. y HYMES, D. (eds.) Directions in Sociolinguistics. The Ethnography of Communication. Nueva York: Holt, Rinehart \& Winston, 1972.

IBRAHIM, H. (1994) “Translation Assessment: A Case for a Spectral Model” En DOLLERUP, C. y LINDEGAARD, A. (eds.) Teaching Translation and Interpreting 2: Insights, aims, visions. Amsterdam: John Benjamins, 1994, p. 151-156.

IDIAZABAL, I. (ed.) (1991) Adquisición del lenguaje en niños bilingües y monolingües. Hizkuntz Jabekuntza Haur Elebidun eta Elebakarretan. San Sebastián: Universidad del País Vasco, 1991.

IGLESIAS IGLESIAS, N. (1999) "El español comercial en la enseñanza del español como lengua extranjera” En FERNÁNDEZ GONZÁLEZ, J. et al. (eds.) Lingüística para el Siglo XXI. Vol. II. Salamanca: Universidad de Salamanca, 1999, p. 943-951.

JÄÄSKELAINEN, R. y TIRKKONEN-CONDIT, S. (1999) “Automatised Processes in Professional vs. Non-Professional Translation: A Think-Aloud Protocol Study" En TIRKKONEN-CONDIT, S. (ed.) Empirical Research in Translation and Intercultural Studies. Tubinga: Gunter Narr, 1999, p. 89-109.

JACOBS, G. M. y FARRELL, Th. S. C. (2001) "Paradigm Shift: Understanding and Implementing Change in Second Language Education”. TESL-EJ 5.1 (2001), p. :A-1. 25 julio 2001. <http:www.zait.unibremen.de/wwwgast/tesl_ej/ej17/a1.html>

JAMES, K. (1984) "Mr. Sulaiman, the buttoning of cauliflowers and How I Learnt to Love the Abstract" En JAMES, G. (ed.) The ESP Classroom. Methodology, Materials, Expectations. Exeter: University of Exeter, 1984, p. 58-68.

JOHNSTONE, R. (1989) Communicative Interaction: A Guide for Language Teachers, Londres: CILT, 1989.

JONES, S. (1993) "Cognitive Learning Styles: Does Awareness Help? A Review of Selected Literature”. Language Awareness. 2.4 (1993), p. 195-207. 
JUST, M. A. y CARPENTER, P. A. (1987) The psychology of reading and language comprehension. Boston: Allyn and Bacon, 1987.

KEMELMAN, H. (1967) The Nine Mile Walk. The Nicky Welt Stories of Harry Kemelman. Nueva York: Putnam, 1967.

KERN, R. G. (1994) "The Role of Mental Translation in Second Language Reading”. Studies in Second Language Acquisition. 16.4 (1994), p. 441461.

KINDELÁN ECHEVARRÍA, M. P. (1998-1999) "How to Incorporate Strategy Training into the Foreign Language Curriculum". Revista de Lenguas para Fines Específicos. 5-6 (1998-1999), p. 325-354.

KLEIN, W. (1986) Second Language Acquisition. Cambridge: Cambridge University Press, 1986.

KOHONEN, V. (2000) Student reflection in portfolio assessment: making language learning more visible. 2000. 21 abril 2004. <http://www.uta.fi/laitokset/ok1/tokl/projektit/eks/pdf/babylonia100.pdf $>$

(2001) Developing the European language portfolio as a pedagogical instrument for advancing student autonomy. 2001. 21 abril 2004 <http://www.uta.fi/laitokset/ok1/tokl/projektit/eks/pdf/kohonen2001.pdf $>$

KRASHEN, S. D. (1977) "El modelo del monitor y la actuación de los adultos en las lenguas segundas". Trad. de "The Monitor Model for adult second language performance" En Burt, M., Dulay, H. y Finocchiaro, M. (eds.) Viewpoints on English as a Second Language, Nueva York: Reyes, 1977. En MUÑOZ LICERAS, J. (comp.) La adquisición de las lenguas extranjeras. Madrid: Visor, 1992.

(1981) Second Language Acquisition and Second Language Learning, Oxford: Pergamon Press. 17 noviembre 2003. <http://www.sdkrashen.com/SL Acquisition and Learning/>

KRATHWOHL, D.R., BLOOM, B.S., y MASIA, B.B. (1964) Taxonomía de los objetivos de la educación: clasificación de las metas educativas. Tomo II: Ámbito de la afectividad. Trad. I. Acarreta. Alcoy: Marfil, 1975. Trad. de Taxonomy of Educational Objectives: The Classification of Educational Goals. Handbook II: Affective Domain. Nueva York: David McKay, 1964.

KRINGS, H. P. (1986) "Translation Problems and Translation Strategies of Advanced German Learners of French (L2)" En HOUSE, J. y BLUM- 
KULKA, S. (eds.) Interlingual and Intercultural Communication. Discourse and Cognition in Translation and Second Language Acquisition Studies. Tubinga: Gunter Narr, 1986, p. 263-276.

(1995) “Übersetzen und Dolmetschen” En BAUSCH, K.-R. et al. (eds.) Handbuch Fremdsprachenunterricht. Tubinga y Basilea: Francke, 1995, p. 325-332.

KRISTEVA, J. (1981) Semiotica I. Trad. J. M. Arancibia. Madrid: Fundamentos, 1981.

KUHN, Th. S. (1962) La estructura de las revoluciones científicas. Trad. A. Contín. México: Fondo de Cultura Económica, 1995. Trad. de The Structure of Scientific Revolutions, Chicago: University of Chicago Press, 1962.

LANKAMP, R. E. (1988) A Study on the Effect of Terminology on L2 Reading Comprehension. Should Specialist Terms in Medical Texts be Avoided? Amsterdam: Rodopi, 1988.

LAUKKANEN, J. (1996) "Affective and Attitudinal Factors in Translation Processes". Target. 8.2 (1996), p. 257-274.

LAVANDERA, B. R. (1990) Curso de Lingüística para el Análisis del Discurso. Buenos Aires: Centro Editor de América Latina, 1990.

LEE-JAHNKE, H. (2001) “Aspects pédagogiques de l'évaluation en traduction". Meta. 46.2 (2001), p. 258-271. 2001. 15 mayo 2004. <http://www.erudit.org/revue/meta/2001/v46/n2/003447ar.pdf>

LEMKE, J. (1998) "Multiplying meaning: Visual and verbal semiotics in scientific text" En MARTIN, J. R. y VEEL, R. (eds.) Reading Science. Critical and Functional Perspectives on Discourses of Science. Londres: Routledge, 1998, p. 87-113.

LERAT, P. (1997) Las lenguas especializadas. Barcelona: Ariel, 1997.

LEUVEN-ZWART, K. M. Van (1991) "Translation and Translation Studies:

Discord or Unity?" En TIRKKONEN-CONDIT, S. (ed.) Empirical Research in Translation and Intercultural Studies. Tubinga: Gunter Narr, 1991, p. 35-44.

LEVINE, A., FERENZ, O. y REVES, Th. (2000) "EFL Academic Reading and Modern Technology: How Can We Turn Our Students into Independent Critical Readers?" TESL-EJ. 4.4 (2000), p. A-1. 2000. 24 julio 2001 <http:www.zait.uni-bremen.de/wwwgast/tesl_ej/ej16/a1.html> 
LITTLE, D. y SIMPSON, B. (2003) European Language Portfolio. The Intercultural Component and Learning How to Learn. 2003. 22 abril 2004. <http://culture2.coe.int/portfolio//documents/Templates.pdf>

LÖRSCHER, W. (1991) Translation Performance, Translation Process, and Translation Strategies. A Psycholinguistic Investigation. Tubinga: Gunter Narr, 1991.

LOUHIALA-SALMINEN, L. (2002) “The Fly's Perspective: Discourse in the Daily Routine of a Business Manager". English for Specific Purposes. 21.3 (2002), p. 211-231.

LOZANO MARTÍNEZ, J. (1998) "Proyectos integrados de aprendizaje como respuesta educativa a la diversidad”. Enseñanza. 16 (1998), p. 231-248.

McCARTHY, M. (1991) Discourse analysis for language teachers. Cambridge: Cambridge University Press, 1991.

MALMKJAER, K. (1993) “Underpinning Translation Theory”. Target. 5.2 (1993), p. $133-148$.

MARCO de referencia europeo para el aprendizaje, la enseñanza y la evaluación de lenguas. Alcalá de Henares: Instituto Cervantes, 2002. 2002. 2 febrero 2004 $<$ http://cvc.cervantes.es/obref/marco $>$.

MARCOS MARÍN, F. y SÁNCHEZ LOBATO, J. (1991) Lingüística Aplicada. Madrid: Síntesis, 1991.

MARMARIDOU, A. S. S. (1996) "Directionality in Translation Processes and Practices". Target. 8.1 (1996), p. 49-73.

MARTIN, J. R. (1998) "Discourses of Science: Recontextualisation, genesis, intertextuality and hegemony" En MARTIN, J. R. y VEEL, R. (eds.) Reading Science. Critical and Functional Perspectives on Discourses of Science. Londres: Routledge, 1998, p. 3-14.

MARTIN, J. R. y VEEL, R. (eds.) (1998) Reading Science. Critical and Functional Perspectives on Discourses of Science. Londres: Routledge, 1998.

MARTÍN DE LEÓN, C. (2003) “¿Barreras culturales o modelos mentales? La metáfora del TRASLADO en los estudios de traducción” En MUÑOZ MARTÍN, R. (ed.) I AIETI: Actas del Congreso Internacional de la Asociación Ibérica de Estudios de Traducción e Interpretación, 12-14 de febrero de 2003. Vol. II. Granada: AIETI, 2003, p. 79-99.

MARTÍN MARTÍN, P. (2002) "A Genre Analysis of English and Spanish Research Paper Abstracts in Experimental Social Sciences". English for Specific Purposes. 22.1 (2002), p. 25-43. 
MARTÍN MIGUEL, F. (1998) La Gramática de Halliday desde la filosofía de la ciencia. Almería: Universidad de Almería, 1998.

MARTÍNEZ ALFARO, M. J. (1996) "Intertextuality: Origins and Development of the Concept". Atlantis. 18.1-2 (1996), p. 268-285.

MARTÍNEZ MELIS, N. y HURTADO ALBIR, A. (2001) "Assessment in Translation Students: Research Needs”. Meta. 46.2 (2001), p. 272-287. 2001. 25 mayo 2004. <http://www.erudit.org/revue/meta/2001/v46/n2/003624ar.pdf >

MATTHIESSEN, Ch. M. I. M. (2001) "The environments of translation" En STEINER, E. y YALLOP, C. (eds.) Exploring Translation and Multilingual Production: Beyond Content. Berlín: Mouton de Gruyter, 2001, p. 41-124.

MAYORAL ASENSIO, R. (1999) "Aspectos curriculares de la enseñanza de la traducción e interpretación en España" En GIL DE CARRASCO, A. y HICKEY, L. (eds.) Aproximaciones a la traducción. Madrid: Instituto Cervantes, 1999, p. 51-62.

MEIX IZQUIERDO, F. (1993) La dialéctica del significado lingüístico. Salamanca: Universidad de Salamanca, 1993.

MINSKY, M. (1975) “A framework for representing knowledge” En WINSTON, P. H. (ed.) The Psychology of Computer Vision. Nueva York: McGraw-Hill, 1975, p. 211-277.

MITCHELL, D. C., CUETOS, F. y ZAGAR, D. (1990) "Reading in different languages: is there a universal mechanism for parsing sentences?" En BALOTA, D. A., FLORES D'ARCAIS, G. B. y RAYNER, K. (eds.) Comprehension Processes in Reading. Hillsdale: Lawrence Erlbaum Associates, 1990, p. 285-302.

MOLINER, M. (1987) Diccionario de uso del español. Madrid: Gredos, 1987.

MONTAÑES BRUNET, E. y BOSCH ABARCA, E. (1992) "Testing in ESP: Some wh-questions” En BARRUECO, S. SÁNCHEZ, M. J. y SIERRA, L. (eds.) Actas de las I Jornadas Internacionales de Inglés Académico, Técnico y Profesional: Investigación y Enseñanza. Alcalá de Henares: Universidad de Alcalá de Henares, 1992, p. 156-161.

MOORE, T. (2002) "Knowledge and Agency: A Study of "Metaphenomenal Discourse' in Textbooks from Three Disciplines". English for Specific Purposes. 21.4 (2002), p. 347-366. 
MORALES VALLEJO, P. (1995a) La evaluación académica: conceptos y planteamientos básicos. Bilbao: Universidad de Deusto, 1995.

(1995b) Los objetivos didácticos. Bilbao: Universidad de Deusto, 1995.

(1995c) Tipos de pruebas: los exámenes orales y las preguntas de respuesta abierta. Bilbao: Universidad de Deusto, 1995.

MORAN, Ch. (1999) "Illusion and Reality in English Language Teaching" En ALONSO, P. et al. (eds.) Teaching and Research in English Language and Linguistics. León: Celarayn, 1999.

MORAN, M. J. y SHAPIRO, H. N. (1992) Fundamentals of Engineering Thermodynamics. Nueva York: John Wiley \& Sons, 1992.

MORENO, A. I. (2003) "Matching Theoretical Descriptions of Discourse and Practical Applications to Teaching: The Case of Causal Metatext". English for Specific Purposes. 22.3 (2003), p. 265-295.

MORENO MORENO, P. y RODRÍGUEZ MEDEROS, C. (1992) "La correspondencia profesional en inglés” En BARRUECO, S. SÁNCHEZ, M. J. y SIERRA, L. (eds.) Actas de las I Jornadas Internacionales de Inglés Académico, Técnico y Profesional: Investigación y Enseñanza. Alcalá de Henares: Universidad de Alcalá de Henares, 1992, p. 146-148.

MUDERSBACH, K. y GERZYMISCH-ARBOGAST, H. (1989) "Isotopy and Translation". Translator and Interpreter Training and Foreign Language Pedagogy Strategy. Nueva York: State University of New York at Binghamton, 1989, p. 147-170.

MUNDAY, J. (2001) Introducing Translation Studies: Theories and Applications. Londres: Routledge, 2001.

MUÑOZ MARTÍN, R. (1995) Lingüística para traducir. Barcelona: Teide, 1995.

MURDOCH, G. (2000) "Introducing a teacher-supportive evaluation system". ELT Journal. 54.1 (2000), p. 54-64.

MYERS, G. A. (1992) "Textbooks and the Sociology of Scientific Knowledge". English for Specific Purposes. 11.1 (1992), p. 3-17.

New Electronics on Campus 11.1 (2000), Horton Kirby: Findlay Publications.

NEWMARK, P. (1987) Manual de traducción. Trad. V. Moya, Madrid: Cátedra, 1992. Trad. de A Textbook of Translation. Hertfordshire: Prentice Hall, 1987.

NORD, Ch. (1991) Text Analysis in Translation. Amsterdam: Rodopi, 1991.

(1992) "Text analysis in translation training" En DOLLERUP, C. y LODDEGAARD, A. (eds.) Teaching Translation and Interpreting. 
Training, Talent and Experience. Amsterdam: John Benjamins, 1992, p. 39-48.

(1997) Translating as a Purposeful Activity. Manchester: St. Jerome, 1997.

NUNAN, D. (1995) “Closing the Gap Between Learning and Instruction”. TESOL Quarterly. 29.1 (1995), p. 133-158.

(1996) "Learner Strategy Training in the Classroom: An Action Research Study". TESOL Journal. 6.1 (1996), p. 35-41.

NUTTALL, Ch. (1982) Teaching Reading Skills in a Foreign Language. Londres: Heinemann, 1982.

O’MALlEY, J. M. y CHAMOT, A. U. (1990) Learning Strategies in Second Language Acquisition. Cambridge: Cambridge University Press, 1990.

ORTNER, B. (1998) Alternative Methoden im Fremdsprachenunterricht. Lerntheoretischer Hintergrund und prakstische Umsetzung. Ismaning: Max Hueber, 1998.

PAJARES INFANTE, E. y ROMERO ARMENTIA, F. (1992) "En defensa del ESP” En BARRUECO, S. SÁNCHEZ, M. J. y SIERRA, L. (eds.) Actas de las I Jornadas Internacionales de Inglés Académico, Técnico y Profesional: Investigación y Enseñanza. Alcalá de Henares: Universidad de Alcalá de Henares, 1992, p. 129-135.

PARIKBAHT, (1985) "Strategic Competence and Language Proficiency". Applied Linguistics. 6.2 (1985), p. 132-146.

PARKINSON, B. (1995) "Research to inform advanced FL courses involving translation: An immodest proposal”. Edinburgh Working Papers in Applied Linguistics. 6 (1995), p. 78-82.

PEÑA, S. y HERNÁNDEZ GUERRERO, M. J. (1994) Traductología. Málaga: Universidad de Málaga, 1994.

PÉREZ GONZÁlEZ, L. (1999) "Traducción de Documentos Auténticos en la Enseñanza de Francés Empresarial” En BARRUECO, S. HERNÁNDEZ, E. y SIERRA, L. (eds.) Lenguas para Fines Específicos VI. Investigación y enseñanza. Alcalá de Henares: Universidad de Alcalá, 1999, p. 515-520.

PINTO DA SILVA, C. (1992) "Strategic Competence and its Role in the ESP Classroom” En BARRUECO, S. SÁNCHEZ, M. J. y SIERRA, L. (eds.) Actas de las I Jornadas Internacionales de Inglés Académico, Técnico y Profesional: Investigación y Enseñanza. Alcalá de Henares: Universidad de Alcalá de Henares, 1992, p. 12-16. 
PINTO DOS SANTOS, V. B. M. (2002) "Genre Analysis of Business Letters of Negotiation”. English for Specific Purposes. 21.2 (2002), p. 167-199.

POYATOS, F. (ed.) (1997) Nonverbal Communication and Translation: New Perspectives and Challenges in Literature, Interpretation and the Media. Amsterdam: John Benjamins, 1997.

PRIGOGINE, I. (1996) El fin de las certidumbres. Trad. P. Jacomet, Madrid: Taurus, 1997. Trad. de La fin des certitudes. París: Odile Jacob, 1996.

PRITCHARD, R. (1990) "The effects of cultural schemata on reading processing strategies". Reading Research Quarterly. 25.4 (1990), p. 273-295.

QUINTANILLA, M. A. (1989) Tecnología: un enfoque filosófico. Madrid: Fundesco, 1989.

RABADÁN, R. (1991a) Equivalencia y traducción. Problemática de la equivalencia translémica inglés-español. León: Universidad de León, 1991. (1991b) "The Unit of Translation Revisited". Translation Theory and Practice. Nueva York: State University of New York at Binghamton, 1991, p. 38-48.

REA-DICKINS, P. y GERMAINE, K. (1992) Evaluation. Oxford: Oxford University Press, 1992.

REASON, J. (1984) "Lapses in attention in everyday life" En PARASURAMAN, R. y DAVIES, D. (eds.) Varieties of Attention. Orlando: Academic Press, 1984, p. 515-549.

REBER, A. (1989) "Implicit learning and tacit knowledge". Journal of Experimental Psychology: General. 118 (1989), p. 219-235.

_ (1992) "The cognitive unconscious: An evolutionary perspective". Consciousness and Cognition. 1 (1992), p. 93-133.

REDDY, M. (1979) "The conduit metaphor. A case of frame conflict in our language about language" En ORTONY, A. (ed.) Metaphor and Thought. Cambridge: Cambridge University Press, 1979, p. 284-324.

REISS, K. y VERMEER, H. J. (1991) Fundamentos para una teoría funcional de la traducción. Trad. S. García Reina y C. Martín de León. Madrid: Akal, 1996. Trad. de Grundlegung einer allgemeine Translationstheorie. Tubinga: Niemeyer, 1991.

REVILLA VICENTE, R. (1995) Revisión histórica del Inglés para Fines Específicos. Teoría y praxis: la correspondencia comercial. Tesis Doctoral. Universidad de Salamanca, 1995. 
—_ (2003) Revisión histórica del Inglés para Fines Específicos. Teoría y praxis: la correspondencia comercial. Salamanca: Universidad de Salamanca, 2003.

REY, J. (2000) "La traduction des textes scientifiques: Structure textuelle et processus cognitifs". Target. 12.1 (2000), p. 63-82.

REYES, G. (1990) La pragmática lingüística. Barcelona: Montesinos, 1990.

RICHARDS, J. C., PLATT, J. y PLATT, H. (1992) Longman Dictionary of Language Teaching \& Applied Linguistics. Essex: Longman, 1992.

RICHTERICH, R. (1980) "Definition of language needs and types of adults" En TRIM, J. L. M. et al. Systems Development in Adult Language Learning. Oxford: Pergamon Press, 1980, p. 29-88.

ROBINSON, P. (1991) ESP Today: A Practitioner's Guide. Hertfordshire: Prentice Hall, 1991.

RODRÍGUEZ ESPINAR, S. (1999) "La planificación de la docencia universitaria" En RUIZ CARRASCOSA, J. (coord.) Aprender y enseñar en la universidad. Iniciación a la docencia universitaria. Jaén: Universidad de Jaén, 1999, p. 121-141.

RUMELHART, D. E. y ORTONY, A. (1977) "Representation of knowledge" En ANDERSON, R. J., SPIRO, R. J. y MONTAGUE, W. E. (eds.) Schooling and the Acquisition of Knowledge. Hillsdale: Lawrence Erlbaum Associates, 1977, p. 99-135.

RUTHERFORD, W. E. (1987) Second Language Grammar: Learning and Teaching. Essex: Longman, 1987.

RYLE, G. (1949) The Concept of Mind. Harmondsworth, Middlesex: Penguin, 1963.

SAGER, J. C. (1990) Curso práctico sobre el procesamiento de la terminología. Trad. L. Chumillas Moya, Madrid: Fundación Germán Sánchez Ruipérez, 1993. Trad. A Practical Course in Terminology Processing. Amsterdam: John Benjamins, 1990.

(2001) "Posibilidades de investigación de la terminología" En FERNÁNDEZ, P. y BRAVO, J. M. (eds.) Pathways of Translation Studies. Valladolid: Centro Buendía, Universidad de Valladolid, 2001, p. 127-146.

SALABERRI RAMIRO, S. (1999) El discurso del profesor en el aula y su relación con las tareas de aprendizaje. Almería: Universidad de Almería, 1999.

SALAGER-MEYER, F., ALCARAZ ARIZA, M. A. y ZAMBRANO, N. (2003)

"The Scimitar, the Dagger and the Glove: Intercultural Differences in the 
Rhetoric of Criticism in Spanish, French and English Medical Discourse (1930-1995) ". English for Specific Purposes. 22.3 (2003), p. 223-247.

SAMRAJ, B. (2002) "Introductions in Research Articles: Variations across Disciplines” English for Specific Purposes. 21.1 (2002), p. 1-17.

SÁNCHEZ, A. (2001) "Investigación y análisis mediante corpus lingüísticos: el poder de atracción de las palabras" En FERNÁNDEZ, P. y BRAVO, J. M. (eds.) Pathways of Translation Studies. Valladolid: Centro Buendía, Universidad de Valladolid, 2001, p. 11-45.

SÁNCHEZ MANZANO, M. J. (1999) El conocimiento léxico y su aprendizaje en el inglés como lengua extranjera: aplicación del Pathfinder como método de análisis. Tesis Doctoral. Universidad de Salamanca, 1999.

SÁNCHEZ MANZANO, M. J. y ALONSO, P. (1999) "Metodología para la apreciación del aprendizaje en la traducción”. Estudios de Filología Moderna. 1999, p. 287-298.

SÁNCHEZ MIGUEL, E. (1993) Los textos expositivos. Estrategias para mejorar su comprensión. Madrid: Aula XXI / Santillana, 1993.

SANFORD, A. J. y GARROD, S. C. (1981) Understanding Written Language. Explorations of Comprehension Beyond the Sentence. Chichester: John Wiley \& Sons, 1981.

SANTIAGO GUERVÓS, J. De (1999) "Sobre lenguas especiales" En FERNÁNDEZ GONZÁLEZ, J. et al. (eds.) Lingüística para el Siglo XXI. Vol. II. Salamanca: Universidad de Salamanca, 1999, p. 1483-1489.

SANTOYO, J. C. (1983) “A propósito del término «translema»" En Actas I Congreso Nacional de Lingüística Aplicada. Tema: tendencias actuales en las aplicaciones de la lingüística. Murcia: Universidad de Murcia, 1983, p. 255-265.

SCHANK, R. C. y ABELSON, R. P. (1977) Guiones, planes, metas y entendimiento: un estudio de las estructuras del conocimiento humano. Trad. E. Gilboy y J. Zanón. Barcelona: Paidós, 1987. Trad. de Scripts, Plans, Goals and Understanding: An Enquiry into Knowledge Structures. Hillsdale: Lawrence Erlbaum Associates, 1977.

SCHEUER, J. (2001) "Recontextualization and communicative styles in job interviews". Discourse Studies. 3.2 (2001), p. 223-248.

SCHMIDT, R. (1992) "Psychological mechanisms underlying second language fluency”. Studies in Second Language Acquisition. 14 (1992), p. 357-385. 
_ (1994) "Deconstructing consciousness in search of useful definitions for applied linguistics”. AILA Review. 11 (1994), p. 11-26.

SCHMIDT, S. J. (1973) Teoría del texto. Problemas de una lingüística de la comunicación verbal. Trad. de M. L. Arriola y S. Crass. Madrid: Cátedra, 1977. Trad. de Texttheorie, Munich: Wilhelm Fink, 1973.

SEARLE, J. R. (1969) Speech acts. An essay in the philosophy of language. Nueva York: Cambridge University Press, 1969.

SEVILLA, J. M. (1996) "Involuntary rehearsal of second language at the elementary level: do elementary school children experience the din in the head?". System. 24.1 (1996), p. 101-105.

SHANNON, C. E. (1948) "A Mathematical Theory of Communication". The Bell System Technical Journal. 27 (1948), p. 379-423, p. 623-656. Reimpresión con correcciones 1998. 25 abril 2003. <http://cm.belllabs.com $/ \mathrm{cm} / \mathrm{ms} /$ what $/$ shannondy/paper.html>

SINCLAIR, B. (1995) Activate Your English: Pre-Intermediate Coursebook. Cambridge: Cambridge University Press, 1995.

(1999) "Recent publications on autonomy in language learning". ELT Journal. 53.4 (1999), p. 309-329.

SINCLAIR, J. McH. (1994) "Trust the Text” En COULTHARD, M. (ed.) Advances in Written Text Analysis. Londres: Routledge, 1994, p. 12-25.

SLAOUTI, D. (1999) "The World Wide Web for Academic Purposes: Old Study Skills for New? " En BARRUECO, S. HERNÁNDEZ, E. y SIERRA, L. (eds.) Lenguas para Fines Específicos VI. Investigación y enseñanza. Alcalá de Henares: Universidad de Alcalá, 1999, p. 47-54.

SMITH, F. (1978) Reading. Cambridge: Cambridge University Press, 1978.

SOLER, V. (2002) "Analysing Adjectives in Scientific Discourse: An Exploratory Study with Educational Applications for Spanish Speakers at Advanced University Level”. English for Specific Purposes. 21.2 (2002), p. 145-165.

SPERBER, D. y WILSON, D. (1986) Relevance: Communication and Cognition. Oxford: Blackwell, 1986.

STEFFENSEN, M. S. y JOAG-DEV, Ch. (1984) "Cultural knowledge and reading" En ALDERSON, J. Ch. y URQUHART, A. H. (eds.) Reading in a Foreign Language. Nueva York: Longman, 1984, p. 48-61.

STEINER, G. (1975) After Babel: Aspects of language and translation. Assen: Van Gorcum, 1975. 
- (1992) After Babel: Aspects of language and translation. $2^{\mathrm{a}}$ ed. Oxford: Oxford University Press, 1992.

STERN, H. H. (1983) Fundamental Concepts of Language Teaching. Oxford: Oxford University Press, 1983.

STRANG, G. (1986) Introduction to Applied Mathematics. Wellesley: WellesleyCambridge Press, 1986.

STRANG, G. (1991) Calculus. Wellesley: Wellesley-Cambridge Press, 1991.

STREVENS, P. (1988) "ESP after twenty years: A re-appraisal" En Tickoo, M. (ed.) ESP: State of the Art. Singapur: SEAMEO Regional Language Centre, 1988., p. 35-49.

STUDY Group on Education and Training. Study Group on Education and Training Report. Accomplishing Europe Through Education and Training. DG XXIIEducation, Training and Youth, Comisión Europea. 26 agosto 2001. <http://europa.eu.int/comm/education/reflex/en/homeen.html>

SUlLIVAN, P. y GIRGINER, H. (2002) "The Use of Discourse Analysis to Enhance ESP Teacher Knowledge: An Example Using Aviation English”. English for Specific Purposes. 21.4 (2002), p. 397-404.

SWALES, J. (1981) Aspects of Article Introductions. Birmingham: The University of Aston Language Studies Unit, 1981.

(1984) "Thoughts on, in and outside the classroom" En JAMES, G. (ed.) The ESP Classroom. Methodology, Materials, Expectations. Exeter: University of Exeter, 1984, p. 7-16.

(1986) "A genre-Based Approach to Language Across the Curriculum" En TICKOO, M. L. (ed.) Language Across the Curriculum. Singapur: SEAMEO Regional Language Centre, 1986, p. 10-22.

_ (1988) Episodes in ESP. A source and reference book on the development of English for Science and Technology. Hertfordshire: Prentice Hall, 1988.

(1990) Genre Analysis. English in academic and research settings. Cambridge: Cambridge University Press, 1990.

(2001) "Issues of Genre: Purposes, Parodies and Pedagogies" En MORENO, A. I. y COLWELL, V. (eds.) Perspectivas Recientes sobre el Discurso. Recent Perspectives on Discourse. León: AESLA y Universidad de León, 2001, p. 11-25.

TARONE, E. et al. (1988) "On the Use of the Passive in Two Astrophysics Journal Papers” En SWALES, J. (1988) Episodes in ESP. A source and reference 
book on the development of English for Science and Technology. Hertfordshire: Prentice Hall, 1988, p. 191-205.

TIRKKONEN-CONDIT, S. (ed.) (1991) Empirical Research in Translation and Intercultural Studies. Tubinga: Gunter Narr, 1991.

_ (1992) "A theoretical Account of Translation -Without Translation Theory?”. Target. 4.2 (1992), p. 237-245.

TOLCHINSKY, L. et al. (2000) "Posicionamiento temático y personal en el desarrollo de textos expositivos". Comunicación presentada en el XVIII Congreso Nacional de AESLA, Barcelona; mayo de 2000. 25 marzo 2002. $\langle$ http://www.ub.es/ice/recerca/grerli/docs/6.pdf $>$

TOMLIN, R. S. y VILLA, V. (1994) "Attention in Cognitive Science and Second Language Acquisition”. Studies in Second Language Acquistion. 16 (1994), p. 183-203.

TORRE, E. (1994) Teoría de la traducción literaria. Madrid: Síntesis, 1994.

TOURY, G. (1980) In Search of a Theory of Translation. Tel Aviv: The Porter Institute for Poetics and Semiotics, 1980.

(1991) "Experimentation in Translation Studies: Achievements, Prospects and Some Pitfalls" En TIRKKONEN-CONDIT, S. (ed.) Empirical Research in Translation and Intercultural Studies. Tubinga: Gunter Narr, 1991, p. 45-66.

(1995) "The Nature and Role of Norms in Translation" En TOURY, G. Descriptive Translation Studies and Beyond. Amsterdam: John Benjamins, 1995, p. 53-69. 12 agosto 2002. <http://www.tau.ac.il/ toury/works/gtnorms.htm>.

TRAGANT, E. (2000) "Some Aspects of the Metacognitive Knowledge of Students of English: An Empirical Study" En PÉREZ GUERRA, J. (ed.) AEDEAN Select Papers in Language, Literature and Culture. Proceedings of the $17^{\text {th }}$ International Conference. Vigo: Universidade de Vigo, 2000, p. 213-219.

TRIM, J.L.M. (1998) Modern Languages Project: Language Policies for a Multilingual and Multicultural Europe. Commentary on Recommendation No. $R$ (98) 6 of the Committee of Ministers to Member States concerning Modern Languages (Documento CC-LANG (98) 18), Estrasburgo: Council for Cultural Co-operation, Consejo de Europa, 1998. 25 agosto 2001. <http://culture.coe.fr/AEL2001EYL/pdf/acclang9818.pdf>

TUDOR, I. (1987) “Using translation in ESP”. ELT Journal. 41.4 (1987), p. 268273. 
UNDERWOOD, M. (2002) The Shannon-Weaver Model. 2002. 2 junio 2003 <http://www.cultsock.ndirect.co.uk/MUHome/cshtml/index.html>

UPTON, Th. A. (1997) "First and Second Language Use in Reading Comprehension Strategies of Japanese ESL Students". TESL-EJ. 3.1 (1997), p. A-3. 1997. 25 julio 2001. <http:www.zait.unibremen.de/wwwgast/tesl ej/ej09/a3.html>

VALERO GARCÉS, C. (1992) "El papel de la traducción en el diseño de un syllabus de ESP” En BARRUECO, S. SÁNCHEZ, M. J. y SIERRA, L. (eds.) Actas de las I Jornadas Internacionales de Inglés Académico, Técnico y Profesional: Investigación y Enseñanza. Alcalá de Henares: Universidad de Alcalá de Henares, 1992, p. 184-188.

VARANTOLA, K. (1986) "Special Language and General Language: Linguistic and Didactic Aspects". ALSED-LSP Newsletter. 9.2 (1986), p. 10-20.

VEEL, R. (1998) "The greening of school science: Ecogenesis in secondary classrooms" En MARTIN, J. R. y VEEL, R. (eds.) Reading Science. Critical and Functional Perspectives on Discourses of Science. Londres: Routledge, 1998, p. 114-151.

VEGA, M. A. (1994) Textos clásicos de teoría de la traducción. Madrid: Cátedra, 1994.

VEGA ENCABO, J. (1996) Epistemología de las técnicas. El problema del saber práctico y el conocimiento técnico. Tesis Doctoral. Universidad de Salamanca, 1996.

VICTORI, M. (2000) “A selected and annotated bibliography on autonomy in language learning". Links \& Letters. 7 (2000), p. 183-200.

WADDINGTON, Ch. (1999) Estudio comparativo de diferentes métodos de traducción general (Inglés-Español). Madrid: Universidad Pontificia de Comillas, 1999.

(2001) "Different Methods of Evaluating Student Translations: The Question of Validity”. Meta. 46.2 (2001), p. 311-325. 2001. 27 mayo 2004. <http://www.erudit.org/revue/meta/2001/v46/n2/004583ar.pdf>

WHITE, M. (2003) "Metaphor and Economics: The Case of Growth". English for Specific Purposes. 22.2 (2003), p. 131-151.

WHITE, P. R. R. (1998) "Extended reality, proto-nouns and the vernacular: Distinguishing the technological from the scientific" En MARTIN, J. R. y VEEL, R. (eds.) Reading Science. Critical and Functional Perspectives on Discourses of Science. Londres: Routledge, 1998, p. 266-296. 
WIDDOWSON, H. G. (1979) Explorations in Applied Linguistics. Oxford: Oxford University Press, 1979.

(1983) Learning Purpose and Language Use. Oxford: Oxford University Press, 1983.

WILSS, W. (1982) The Science of Translation. Problems and Methods. Tubinga: Gunter Narr, 1982.

YOUNG, C. E. (2003) “College's Students Reactions to Accents of L2 Learners of Spanish and English" En SAYAHI, L. (ed.) Selected Proceedings of the First Workshop on Spanish Sociolinguistics. Somerville: Cascadilla Proceedings Project, 2003, p. 107-111. 5 marzo 2004. <http://lingref.com>

ZABALBEASCOA, P. (1999) "La didáctica de la traducción: desarrollo de la competencia traductora” En GIL DE CARRASCO, A. y HICKEY, L. (eds.) Aproximaciones a la traducción. Madrid: Instituto Cervantes, 1999, p. 3150.

ZARO, J. J. (2001) La traducción como procedimiento en la enseñanza de lenguas extranjeras: Estado de la cuestión. 2001. 24 julio 2002. $<$ http://averroes.cec.junta-andalucia.es/ eeooii/actas99$\underline{00 / \text { traduccion.htm }>}$

ZIMAN, J. M. (1968) El conocimiento público. Un ensayo sobre la dimensión social de la ciencia. Trad. J. J. Utrilla. México: Fondo de Cultura Económica, 1972. Trad. de Public Knowledge: The Social Dimension of Science. Cambridge: Cambridge University Press, 1968.

ZLATEVA, P. (ed.) (1993) Translation as Social Action. Russian and Bulgarian Perspectives. Londres: Routledge, 1993.

ZOHREVANDI, Z. (1994) "Translation as a Resource: Teaching English as a Foreign Language" En BEAUGRANDE, R. A. De, SUNNAQ, A. y HELIEL, M. H. (eds.) Language, Discourse and Translation in the West and Middle East. Amsterdam: John Benjamins, 1994, p. 181-187. 
Anexos 


\section{Anexo A}

\section{Engineering Graduates}

National Power PLC is a leading integrated energy company. Soon to be re-branded as npower, a dynamic new company with generation, co-generation and renewables, retail. operations and engineering interests, we are set to take the industry by storm.

As an equal opportunities employer, National

Producing electricity in the current hugely competitive climate requires innovative Power welcomes

Producing electricity in the cur

applications from

graduate opportunities and would be very interested to hear from:

men and women

including ethnic

minorities and

- Mechanical engineers

- Electrical engineers

people with

Chemical engineers

- Materials scientists

disabilities.

- IT graduates with an engineering background

National Power runs IEE, I Mech Eng and BCS accredited training schemes and we are committed to developing our staff to meet their full potential.

If you would like to find out more or to apply, please telephone the

National Power Graduate Recruitment Line on 0800834921.

Alternatively, you can e-mail us on nationalpoweretmpw.co.uk

Please quote reference number: 5475 in all correspondence.

(New Electronics on Campus 11.1 (2000), p. 49) 


\section{Anexo B}

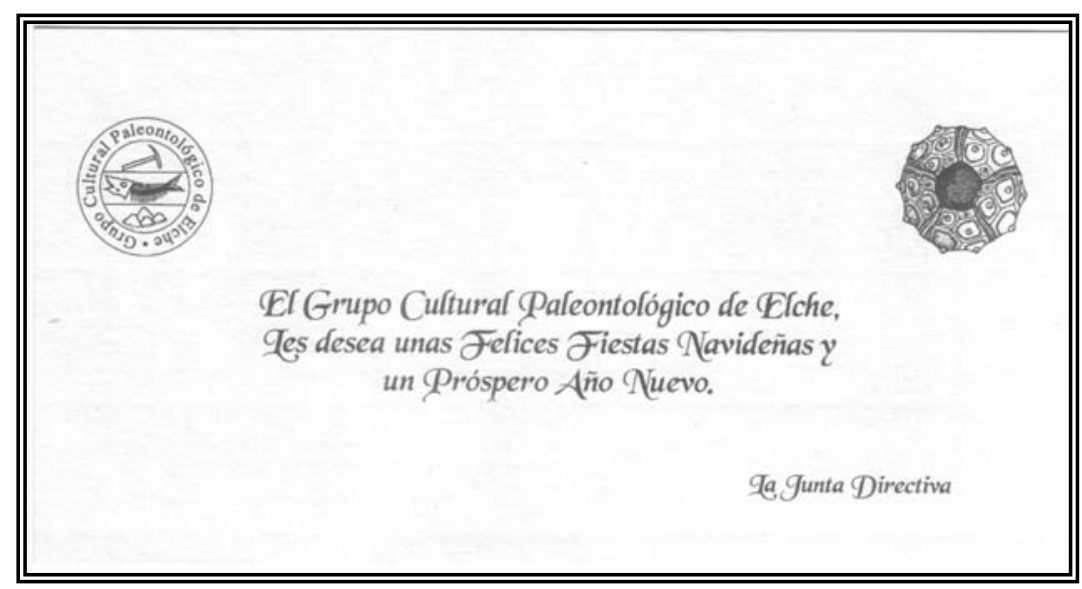

(Grupo Cultural Paleontológico de Elche 2001) 


\section{Anexo C}

\section{Termodinámica Técnica}

Asignatura Obligatoria de 2 o Curso. Mecánica. 6 créditos.

Profesor: Juan Ramón Muñoz Rico (rico@gugu.usal.es)

La Termodinámica es una parte de la Física que, basada en unos principios fundamentales, estudia las transformaciones energéticas de las sustancias, en general, y de la forma en que aquellas pueden predecirse con ayuda de sus propiedades físicas.

ACCIÓN:

La asignatura de Termodinámica Técnica es eficaz en aquellos alumnos que sienten curiosidad por conocer razonadamente la motivación de los más simples fenómenos físicos que suceden a su alrededor, haciendo especial hincapié en aquellos en los que intervienen decisivamente los factores calor y temperatura, pero sin olvidarse de cualesquiera otros, ya que todos están regidos por las mismas leyes físicas. Por incluirse esta asignatura en un Plan de Estudios de Ingeniería, los alumnos conocerán cómo los Ingenieros aplican dichas leyes para preveer y poyectar sistemas con los que obtener algún tipo de beneficio como pudiera ser la obtención de trabajo, frío, calor, dinero, etc.

COMPOSICIÓN CUANTITATIVA:

1. Conceptos introductorios. Definiciones.

2. Energía y Primer Principio.

3. Propiedades Termodinámicas.

4. Primer Principio para volúmenes de control.

5. Segundo Principio.

6. Entropía.

7. Análisis Exergético. 


\section{INDICACIONES:}

La asignatura de Termodinámica Técnica está especialmente indicada en aquellos alumnos que, cursando la especialidad Mecánica, y teniendo una buena y sólida base de Física y Matemáticas, se hayan matriculado en el segundo curso de la Titulación de Ingeniero Técnico Industrial, Especialidad Mecánica, sea cual fuere su intensificación.

POSOLOGíA:

Váyase a clase. Escúchese al profesor y razónese con él mentalmente. Pregúntesele, si no se le entiende. Al volver a casa, medítese sobre lo escuchado breves instantes. Léanse en los libros de texto propuestos en la bibliografía los capítulos relacionados con lo expuesto en clase e inténtese hacer los problemas de fin de capítulo que se relacionan con lo que el profesor haya explicado. Todo ello en pequeñas dosis y de una forma continuada.

CONTRAINDICACIONES:

La asignatura Termodinámica Técnica está especialmente contraindicada en aquellos alumnos que aún tienen problemas con las Matemáticas o la Física y en los que piensan que la definición de estudiar es sentarse delante de los apuntes para, tras un breve periodo de tiempo repitiendo lo que en ellos está escrito, ser capaces de recitar lo mismo con un cierto grado de aproximación. Está, asimismo, contraindicado tomar apuntes en clase (entendiendo por apuntes lo que creo que le he oído decir al profesor y me ha dado tiempo de copiar), dado que todo lo que el profesor diga estará mejor expresado con toda seguridad en los libros de texto propuestos en la bibiografía. Además, el profesor indicará siempre en qué libro de texto se encuentra mejor escrito, bajo su punto de vista, lo que en cada momento se esté diciendo.

También está contraindicado especialmente en todos aquellos alumnos que sufran del pensamiento enfermizo de que los Proyectos o Estudios Técnicos se redactan exclusivamente aplicando normas. Estos alumnos deben considerar la posibilidad de no necesitar pasar por la Universidad para la consecución de sus propósitos.

Se contraindica especialmente, también, en aquellos alumnos que piensan enfermizamente que todo razonamiento humano se puede sustituir por un buen programa de ordenador que sólo ellos conocen, incluso la Termodinámica Técnica. Esta exposición de ignorancia, atrevida como todas 
ellas, supone un altísimo desprecio hacia un gran colectivo de Profesores e Investigadores de todo el mundo. La experiencia demuestra que se trata de una manifestación esquizofrénica que siempre conduce a resultados altamente erróneos, ya que no se tendrá nunca seguridad acerca de lo que se está haciendo y el alumno será incapaz de apercibirse de las más mínimos errores cometidos, pudiendo dar lugar a la aceptación como válidos de resultados altamente absurdos.

Por último, se contraindica en aquellos individuos que piensan que la asignatura tiene un nivel superior al de un Plan de Estudios de Primer Ciclo. Al comparar el contenido de la asignatura Termodinámica Técnica impartida en la ETSII de la Universidad de Salamanca con los contenidos de asignaturas similares impartidas en otras Escuelas de otras Universidades de todo el mundo se observa una coincidencia prácticamente total, lo que evidencia su error.

PRECAUCIONES:

En alumnos con especial adversión a los razonamientos lógicos o abstractos y a la simplicidad del pensamiento humano puede causar odio profundo a la Ingeniería, prurito, rash, vómitos, diarreas, dolores abdominales y en las articulaciones y cefaleas, seguido todo ello de fobias y deseos atentatorios contra las instalaciones, en primer lugar, y los profesores, después. De observarse alguno de estos síntomas, comprobar si se cumplen estrictamente las condiciones enumeradas en las indicaciones. Si se cumpliesen y el individuo no se encontrase tampoco en ninguno de los grupos a los que se alude en las contraindicaciones, acudir rápida y pacíficamente a hablar con el profesor para tratar de descubrir la causa de dichas extrañas sensaciones.

EFECTOS SECUNDARIOS:

No se han descrito a las dosis recomendadas. Sólo en aquellos casos de atracón previo al examen se han descrito reacciones adversas de muy diversa índole, entre las que se pueden citar las ya anteriormente enumeradas. Por otro lado, en alumnos que han seguido la posología indicada se observan dos fenómenos, por naturaleza buenos, que son: En primer lugar, el alumno percibe una cierta sensación de dominio en Ingeniería, que se acentúa cuando empieza a conocer las múltiples aplicaciones de los conceptos que ha aprendido. En segundo lugar, el ya descrito por Sócrates en su ya conocida sentencia «sólo sé que no sé nada»; es decir, el 
descubrimiento del límite del propio conocimiento. Estos alumnos suelen encontrar en la asignatura Termodinámica Técnica un alto grado de satisfacción, y pueden, incluso, llegar a solicitar al profesor su tutela para la realización de algún trabajo de fin de carrera, para lo que éste último nunca ha puesto ni pondrá ninguna dificultad, más bien al contrario, ya que esto le satisface sobremanera (hay que recordar que el Profesor pertenece a esa especie de los que les gusta enseñar lo poquito que sabe). No hay duda de que estos alumnos son los que mejores puestos de trabajo consiguen una vez terminada su carrera.

ADVERTENCIAS:

Esta asignatura contiene una alta dosis de razonamiento matemático abstracto, requiriendo solidez mental para la comprensión de determinados conceptos físicos, por lo que existe la posibilidad de hacer razonamientos altamente erróneos en aquellos alumnos que aún no hayan superado las asignaturas relacionadas con dichas materias.

INTOXICACIÓN Y SU TRATAMIENTO:

La sobredosis se presenta en aquellos alumnos que, desviando su atención durante el curso hacia otros mucho más importantes menesteres, desean, en aproximadamente quince días, hacer penetrar en su cabeza las ideas que no lo han hecho durante cuatro meses, lo cual es materialmente imposible. La sintomatología por sobredosis incluye excitabilidad, pérdida súbita de la conversación, depresión, desánimo, abandono de novias/os y, sobre todo, culpabilización del profesor. Ante esta sintomatología no existe ningún tratamiento efectivo, salvo que el alumno en cuestión, si no está en sexta convocatoria, se presente al examen por si cuela y, de no colar, que será lo más seguro, vuelva a matricularse cuando se encuentre en condiciones óptimas de seguir la asignatura.

PRESENTACIÓN:

La asignatura Termodinámica Técnica se presenta en la ETSII de la Universidad de Salamanca contenida en seis créditos, es decir, cuatro horas semanales en el primer cuatrimestre distribuidas en dos horas teóricas y otras dos prácticas. Dado el interés que para los Ingenieros tiene la resolución de problemas, no se garantiza el exquisito cumplimiento de esta distribución, dedicándose más tiempo a la resolución de problemas del tipo de los que se ponen en los exámenes, con el objeto de facilitar al máximo a los alumnos la obtención de buenos resultados. La evaluación se realiza mediante 
un examen escrito (oral, para quien así lo prefiera) en el que habitualmente se vienen planteando veinte cuestiones tipo Test y tres o cuatro problemas, y cuya valoración y criterio se exponen en el transcurso de la primera clase de la asignatura ( si no se asiste a esta clase, es posible que se lo escuche al Profesor a lo largo del curso, pero si no va a asistir regularmente, haga un favor a la humanidad: no diga que no se dijo). Tanto el contenido de la asignatura como los exámenes de la misma se encuentran disponibles en la siguiente bilbiografía:

ÇENGEL, Y. A. y BOLES, M. A., Termodinámica. Ed. Mc Graw Hill, 1996 (Dos volúmenes).

ÇENGEL, Y. A. y BOLES, M. A., Solutions Manual to Accompany, Thermodynamics, and Engineering Approach. Ed. Mc Graw Hill, 1994.

JONES, J. B. y DUGAN, R. E., Ingeniería Termodinámica. Ed. PrenticeHall Hispanoamericana, S. A., 1997.

JONES, J. B. y DUGAN, R. E., Solutions Manual. Engineering Thermodynamics. Ed. Prentice-Hall Hispanoamericana, S. A., 1996.

LEVENSPIEL, O., Fundamentos de Termodinámica. Ed. Prentice-Hall Hispanoamericana, S. A., 1997.

MORAN, M. J. y SHAPIRO, H. N., Fundamentals of Engineering Thermodynamics. Ed. John Wiley \& Sons, Inc., 1992.

MORAN, M. J. y SHAPIRO, H. N., Fundamentals of Engineering Thermodynamics, Instructor's Manual to Accompany. Ed. John Wiley \& Sons, Inc., 1991.

MORAN, M. J. y SHAPIRO, H. N., Fundamentos de Termodinámica Técnica. Ed. Reverté, 1994 (Dos volúmenes).

MUÑOZ, J. R., Tests de Termodinámica Técnica. Comercial Studio, S. A., 1994.

MUÑOZ, J. R., Apuntes de Termodinámica Técnica. Revide, S. A., 1994.

SALA LIZARRAGA, J. M. Cogeneración. Servicio Editorial, Universidad del País Vasco, 1994.

WARK, K., Termodinámica. Ed. Reverté, 1988. 
Algunos de estos libros incluyen software. No encontrará los disquetes si los busca en los ejemplares depositados en la Biblioteca del Centro. Si Ud. desea retirarlos en préstamo, puede hacerlo solicitándolo a la persona encargada del préstamo en la Biblioteca.

RECOMENDACIONES:

Dado que la evolución mundial y la tendencia prácticamente generalizada a la utilización de, por un lado, un idioma común, y, por otro, herramientas informáticas, se recomienda encarecidamente a los alumnos que vayan a cursar la asignatura Termodinámica Técnica, se matriculen de asignaturas que les sirvan para aprender Inglés y defenderse con dignidad en una conversación técnica y para manejar, o al menos quitarse el miedo de los ordenadores.

Tanto el dominio del Inglés como el conocimiento y la utilización de ordenadores simplifica notablemente el trabajo relacionado con la Termodinámica Técnica.

En caso de no poder matricularse de tales asignaturas por causas ajenas a su voluntad, se recomienda al alumno que busque el medio de aprender sobre estos dos temas.

Por otro lado, y dado que en el contenido no se incluye ninguna lección de Ortografía, se ruega encarecidamente a los alumnos que eviten a los profesores de esta Escuela que, dadas las circunstancias, en ningún caso les examinarán de dicho tema, el berrinche de tener que despedirse de ellos después de haberles tenido que aprobar con exámenes en los que se hayan escrito faltas de ortografía.

(Escuela Técnica Superior de Ingeniería Industrial 2000/2001: Guía Académica, 2000:163-166) 


\section{Anexo D}

\section{ORDINARY DIFFERENTIAL EQUATIONS 6.1}

The mathematics in this book springs from two sources: calculus and linear algebra. Those are both at the service of applied mathematics, and they are called on constantly. When the unknown is a vector we need linear algebra. That is sufficient for a discrete problem, provided the system is linear. A problem in which $u$ varies continuously, in space or time or both, needs calculus. If the law involves derivatives $d u / d x$ or $d u / d t$, we have passed from matrix equations to differential equations. Algebra organizes our ideas about the dependent variables $u_{1}, \ldots, u_{n}$, while calculus deals with the independent variables $x$ or $y$ or $t$. When both complications are present we have a system of differential equations -possibly partial differential equations and possibly nonlinear. That may not be the ultimate in generality or in difficulty, but within applied mathematics it is pretty close.

This chapter takes the next steps toward that goal. It introduces the time $t$ and velocities $d u / d t$ and accelerations $d^{2} u / d t^{2}$. The unknown $u$, a scalar or a vector, evolves in time from its initial state $v_{0}$ at $t=0$. We start with no space variables, studying ordinary differential equations. Their solution, analytical and later numerical, comes first. Then we admit space along with time, and slopes along with velocities, balancing the rate of change $\partial u / \partial t$ with the gradient $\partial u / \partial x$. There is conservation of mass or momentum or energy. This balance equation allows waves to travel in space-time, and when it is nonlinear those waves can break -producing a shock that travels at supersonic speed and catches the other waves.

Thus we end with nonlinear partial differential equations. Those are more difficult than linear waves and linear responses, where the frequencies and the harmonics are completely dominant. The Laplace transform (in time) joins the Fourier transform (in 
space) to convert constant-coefficient equations back to linear algebra. Those transforms apply also to finite difference equations, where the crucial problems are stability and accuracy. The goal is always to simplify and to watch the eigenvectors especially when they are exponentials.

A start was made on ordinary differential equations in Section 1.5. We can review in three lines what was done:

\begin{tabular}{|c|c|c|c|}
\hline 1st order equations: & $u^{\prime}-a u=0$ & leads to & $u=e^{a t} u_{0}$ \\
\hline 2nd order equations: & $u^{\prime \prime}+p u^{\prime}+q u=0$ & leads to & $u=c_{1} e^{\lambda l t}+c_{2} e^{\lambda 2 t}$ \\
\hline 1st order systems: & $u^{\prime}-A u=0$ & leads to & $u=e^{A t} U_{0}=\partial c_{i} e^{\lambda_{i t} t} x_{i}$ \\
\hline
\end{tabular}

All those problems are linear, with constant coefficients and zero right hand sides. They are the most basic equations, but certainly not the only ones. Therefore we begin to allow time-dependent coefficients $\boldsymbol{a}(\boldsymbol{t})$ on the left side, forcing terms $\boldsymbol{f}(\boldsymbol{t})$ on the right side, and nonlinear equations.

A few words about notation. The symbol $\boldsymbol{u}^{\prime}$ is a shorthand for $\boldsymbol{d u} / \boldsymbol{d t}$. Some authors would write $\boldsymbol{d} \boldsymbol{y} / \boldsymbol{d} \boldsymbol{x}$, but the whole point is the distinction between time and space (and between initial conditions and boundary conditions). Other authors write $\dot{u}$, but in my classroom the dot looks like ambient dust. The matrix exponential $\boldsymbol{e}^{\boldsymbol{A t}}$ is new, it could have appeared earlier but did not. The terms $\boldsymbol{a u}$ and $\boldsymbol{A} \boldsymbol{u}$ have moved to the left side of the equation, leaving space on the right side for $\boldsymbol{f}(\boldsymbol{t})$. You recognize that the constants $\boldsymbol{c}_{\boldsymbol{1}}, \boldsymbol{c}_{\boldsymbol{2}}$ in a second-order equation and $\boldsymbol{c}_{\boldsymbol{1}}, \ldots, \boldsymbol{c}_{\boldsymbol{n}}$ in a first-order system are adjusted to match the initial conditions. Higher-order equations and second-order systems are also important but we cannot do everything.

(Introduction To Applied Mathematics, G. Strang, 1986:471-472) 


\section{Anexo E}

\subsection{THERMODYNAMIC SYSTEMS}

An important step in any engineering analysis is to describe precisely what is being studied. In mechanics, if the motion of a body is to be determined, normally the first step is to define a free body and identify all the forces exerted on it by other bodies. Newton's second law of motion is then applied. In thermodynamics the term system is used to identify the subject of the analysis. Once the system is defined and the relevant interactions with other systems are identified, one or more physical laws or relations are applied.

The system is whatever we want to study. It may be as simple as a free body or as complex as an entire chemical refinery. We may want to study a quantity of matter contained within a closed, rigid-walled tank, or we may want to consider something such as a gas pipeline through which matter flows. Even a vacuum, which is devoid of matter, may be the focus of interest. The composition of matter inside the system may be fixed or may be changing through chemical or nuclear reactions. The shape or volume of the system being analyzed is not necessarily constant, as when a gas in a cylinder is compressed by a piston or a balloon is inflated.

Everything external to the system is considered to be part of the system's surroundings. The system is distinguished from its surroundings by a specified boundary, which may be at rest or in motion. You will see that the interactions between a system and its surroundings, which take place across the boundary, play an important part in engineering thermodynamics. It is essential for the boundary to be delineated carefully before proceeding with any thermodynamic analysis. However, since the same physical phenomena often can be analyzed in terms of alternative choices in 
the system, boundary, and surroundings, the choice of a particular boundary defining a particular system is governed by the convenience it allows in the subsequent analysis.

\subsubsection{Types of Systems}

Two basic kinds of systems are distinguished in this book. These are referred to, respectively, as closed systems and control volumes. A closed system refers to a fixed quantity of matter, whereas a control volume is a region of space through which mass may flow.

A closed system is defined when a particular quantity of matter is under study. A closed system always contains the same matter. There can be no transfer of mass across its boundary. A special type of closed system that does not interact in any way with its surroundings is called an isolated system.

Figure 1.1 shows a gas in a piston-cylinder assembly. Let us consider the gas to be a closed system. The boundary lies just inside the piston and cylinder walls, as shown by the dashed lines on the figure. If the cylinder were placed over a flame, the gas would expand, raising the piston. The portion of the boundary between the gas and the piston moves with the piston. No mass would cross this or any other part of the boundary.

In subsequent sections of this book, thermodynamic analyses are made of devices such as turbines and pumps through which mass flows. These analyses can be conducted in principle by studying a particular quantity of matter, a closed system, as it passes through the device. In most cases it is simpler to think instead in terms of a given region of space through which mass flows. With this approach, a region within a prescribed boundary is studied. The region is called a control volume. Mass may cross the boundary of a control volume.

A schematic diagram of an engine is shown in Fig. 1.2. The dashed line defines a control volume that surrounds the engine. Observe that air, fuel, and exhaust gases cross the boundary.

The term control mass is sometimes used in place of closed system, and the term open system is used interchangeably with control volume. When the terms control mass and control volume are used, the system boundary is often referred to as a control surface. 


\subsubsection{Macroscopic and Microscopic Views of Thermodynamics}

Systems can be studied from a macroscopic or a microscopic point of view. The macroscopic approach to thermodynamics is concerned with the gross or overall behavior This is sometimes called classical thermodynamics. No model of the structure of matter at the molecular, atomic, and subatomic levels is directly used in classical thermodynamics. Although the behavior of systems is affected by molecular structure, classical thermodynamics allows important aspects of system behavior to be evaluated from observations of the overall system.

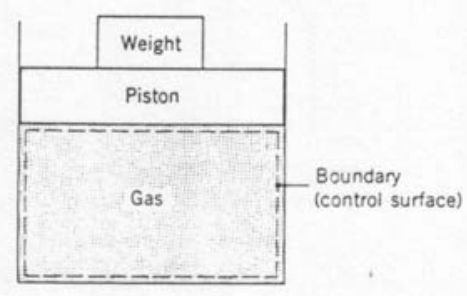

Figure 1.1 Example of a closed system (control mass). A gas in a pistoncylinder assembly.

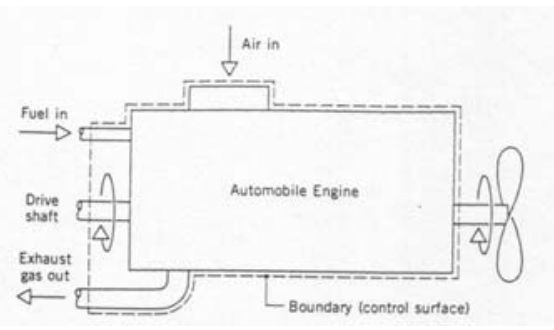

Figure 1.2 Example of a control volume (open system). An automobile engine.

The microscopic approach to thermodynamics, known as statistical thermodynamics, is concerned directly with the structure of matter. The objective of statistical thermodynamics is to characterize by statistical means the average behavior of the particles making up a system of interest and relate this information to the observed macroscopic behavior of the system.

For applications involving lasers, plasmas, high-speed gas flows, chemical kinetics, very low temperatures (cryogenics), and others, the methods of statistical thermodynamics are essential. Moreover, the microscopic approach is instrumental in developing certain property data, for example, ideal gas specific heats (Sec. 
3.5.1). For the great majority of engineering applications, however, classical thermodynamics not only provides a considerably more direct approach for analysis and design but also requires far fewer mathematical complications. For these reasons the macroscopic viewpoint is the one adopted in this book. When it serves to promote understanding, however, concepts are interpreted from the microscopic point of view. Finally, we note that relativity effects are not significant for the systems under consideration in this book.

(Fundamentals of Engineering Thermodynamics, M. J. Moran y H. N.

Shapiro, 1992:2-4) 


\section{Anexo F}

\section{Formulario de Identificación de Problemas}

PROBLEMAN ….... .

¿ Se trata de un PROBLEMA DE COMPRENSIÓN ?

¿ Se trata de un PROBLEMA DE PRODUCCIÓN ?

\section{LOCALIZACIÓN Y ALCANCE DEL PROBLEMA}

El problema empieza en la línea y termina en la línea

El problema empieza con la palabra y termina con la palabra

¿ Se trata de un PROBLEMA DE ALCANCE LOCAL ?

¿ Se trata de un PROBLEMA DE ALCANCE GLOBAL ?

¿Se trata de un PROBLEMA DE ALCANCE MEDIO ?

\section{Origen del problema}

¿ Se trata de un PROBLEMA DEL TEXTO ?

¿ Se trata de una DIFICULTAD DEL TRADUCTOR ? 


\section{Descripción del problema}

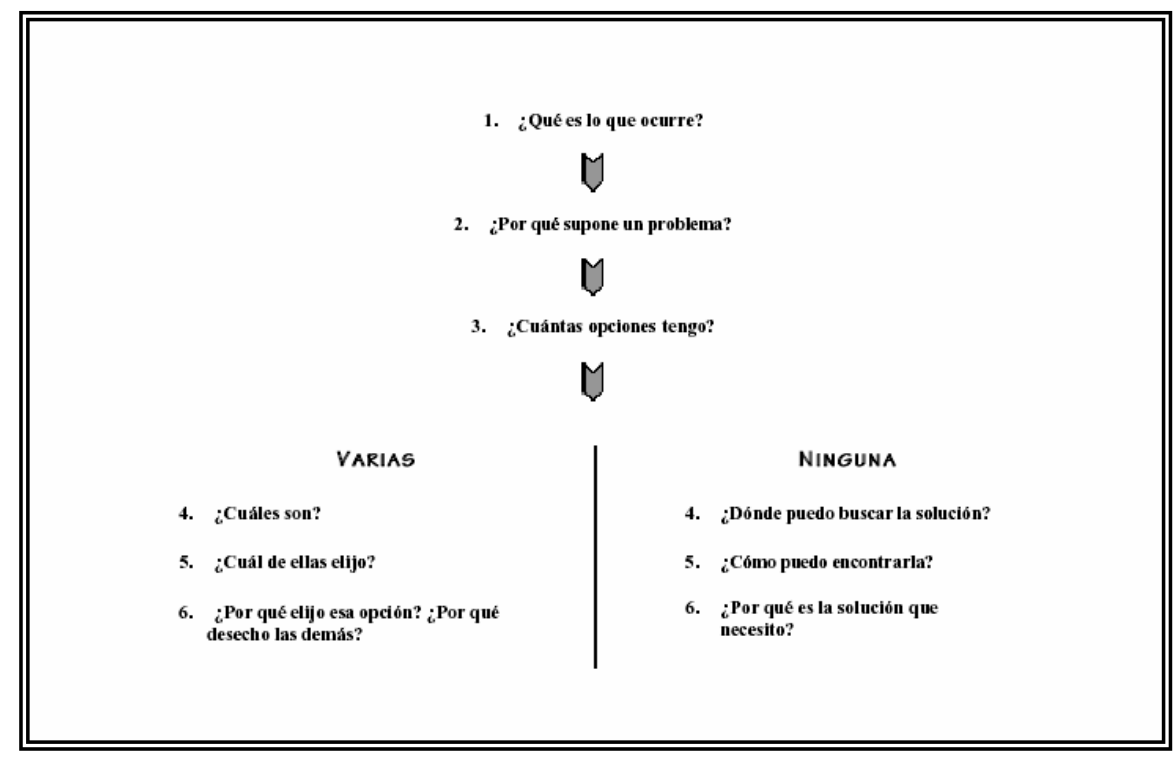

Factor (o factores) principal(es) involucrado(s) en el problema

¿ Receptor?

¿ Conocimiento Compartido / Información Nueva ?

¿ Tema?

¿ Orden de la información ?

¿ Razón, propósito o función ?

¿ Palabras?

¿ Estructuras sintácticas?

$¿$ Elementos no verbales?

¿ Tono ?

¿Efecto ?

(Apuntes de traducción funcional de textos no ficcionales:

teoría, I. Elorza, 2003a, pp. 67-68) 


\section{Anexo G}

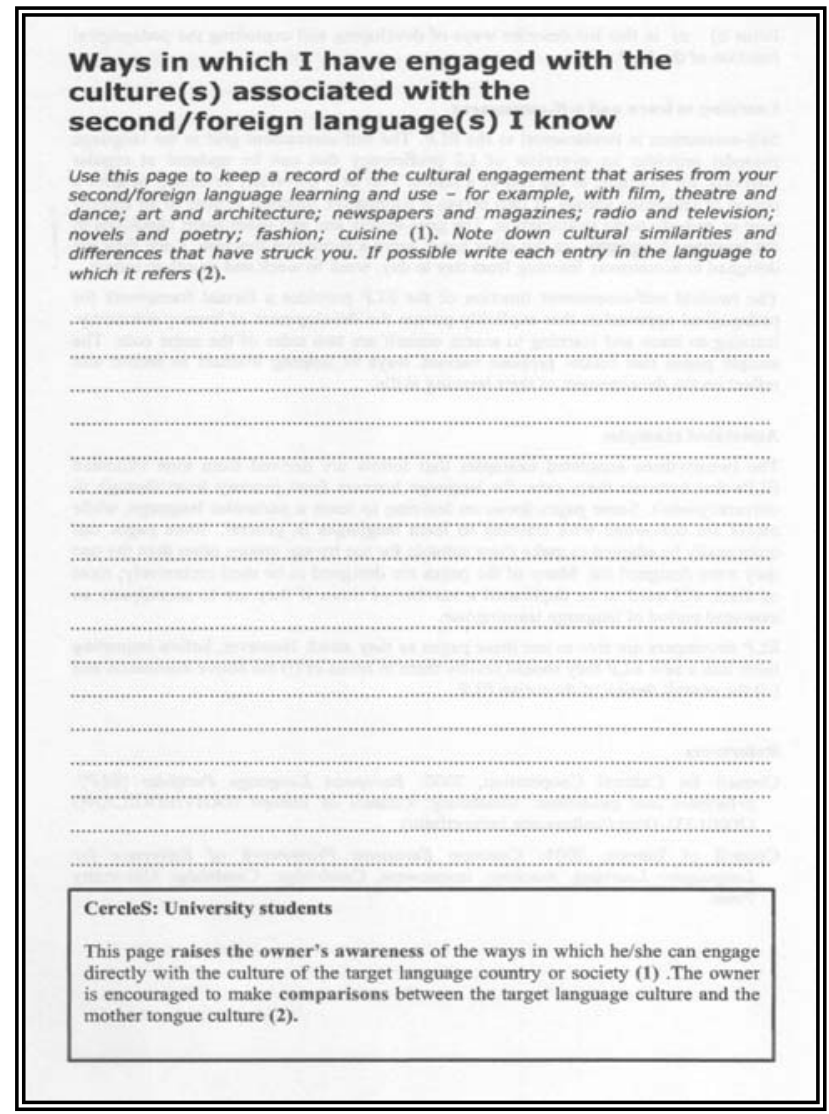

(European Language Portfolio. The Intercultural Component and Learning How to Learn, D. Little y B. Simpson, 2003:24) 